HNF-EP-0918

Revision 1

\title{
Solid Waste Integrated Forecast Technical (SWIFT) Report: FY1997 to FY2070, Revision 1
}

\author{
O. J. Valero
}

RUST Federal Services of Hanford Inc.

K. J. Templeton

Pacific Northwest National Laboratory

J. Morgan

Battelle Seattle Research Center

Date Published

January 1997

Prepared for the U.S. Department of Energy

Assistant Secretary for Environmental Management 


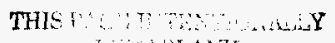
LEN DLANK 
LFGAL DISCLAMER

This report was prepared as an account of work sponsored by an agency of the United States Government.' Neither the United States Government nor any egency thereof, nor any of their employees, nor any of their contractors, subcontractors of their employees, makes any warranty, oxpress or implied. or assumes any legel liability or responsibility for the accuracy, completeness, of eny third party's use of the reaults of such use of any information, apparatus, product, or process disclosed, or represents that its uso would not infringo privately owned rights. Reference herein to any specific comrnercied product, process, or pervice by trade neme, trademak, menufacturer, or otherwise, does not necessarily constitute or imply ite endoreement, recommendation, or favoring by the United States Government or any agency thereof or its contractors or subcontrectors. The views and opinions of authors expressed herein do not necessarily state or reflect those of the United States Government or any agency thereof.

This report has been reproduced from the best available copy. Available in paper copy and microfiche.

Available to the U.S. Department of Energy and its contrectors from

U.S. Depertment of Energy

Office of Scientific and Technical Information (OST)

P.O. Box 62

Oak Ridge, TN 37831

(615) 576-8401

Avalibble to the public from the U.S. Depertment of Commerce National Technical Information Service (NTIS)

$\mathbf{5 2 8 5}$ Port Royal Roed

Springtield, VA 22161

(703) 487-4650

Printed in the United Stetcen of Americe

DISCLM-1.CHP (8-95) 


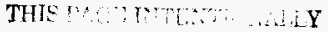
h... : ULivh 


\section{RELEASE AUTHORIZATION}

Document

Number:

Document

Title:

Release Date:

$1 / 7 / 97$
HNF-EP-0918, Rev. 1

Solid Waste Integrated Forecast Technical (SWIFT)

Report: FY 1997 to FY 2070

This document was reviewed following the procedures described in WHC-CM-3-4 and is:

\section{APPROVED FOR PUBLIC RELEASE}

WHC Information Release Administration Specialist:

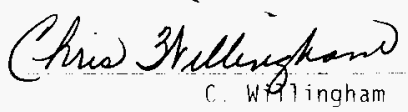

$1 / 7 / 97$ 


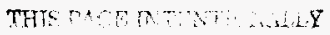

1 Livi: 


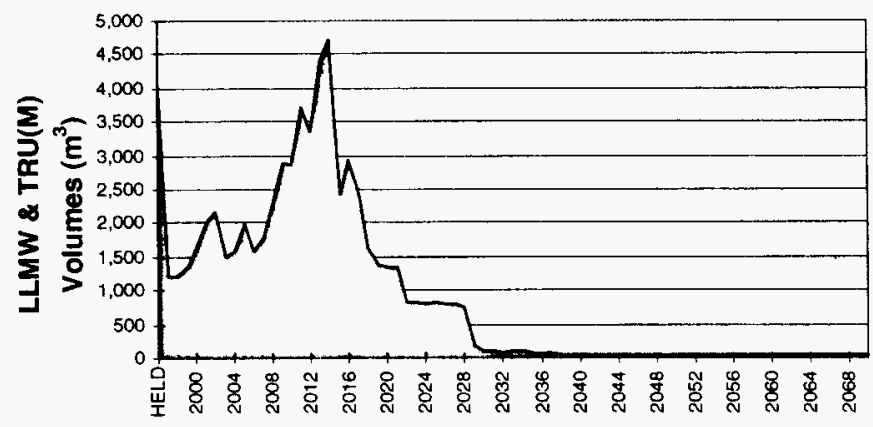

SWIFT Report: FY1997 to FY2070, rev. 1

\section{Solid Waste \\ Integrated Forecast Technical (SWIFT) \\ Report:}

FY1997 to FY2070, Revision 1

(Formerly WHC-EP-0918) 


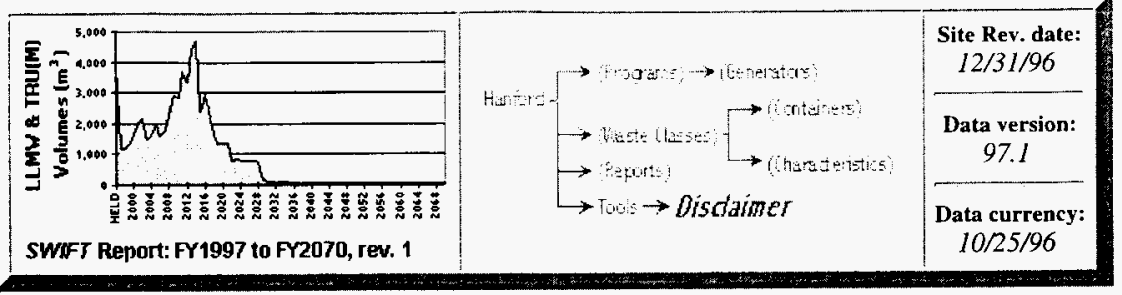

\section{Legal Disclaimer}

This report was prepared as an account of work sponsored by an agency of the United States Government. Neither the United States Government nor any agency thereof, nor any of their employees, nor any of their contractors, subcontractors, or their employees, makes any warranty, express or implied, or assumes any legal liability or responsibility for the accuracy, completeness, or any third party's use or the results of such use of any information, apparatus, product, or process disclosed, or represents that its use would not infringe privately owned rights. Reference herein to any specific commercial product, process, or service by trade name, trademark, manufacturer, or otherwise, does not necessarily constitute or imply its endorsement, recommendation, or favoring by the United States Government or any agency thereof or its contractors or subcontractors. The views and opinions of authors expressed herein do not necessarily state or reflect those of the United States Government or any agency thereof.

\section{Release Authorization}

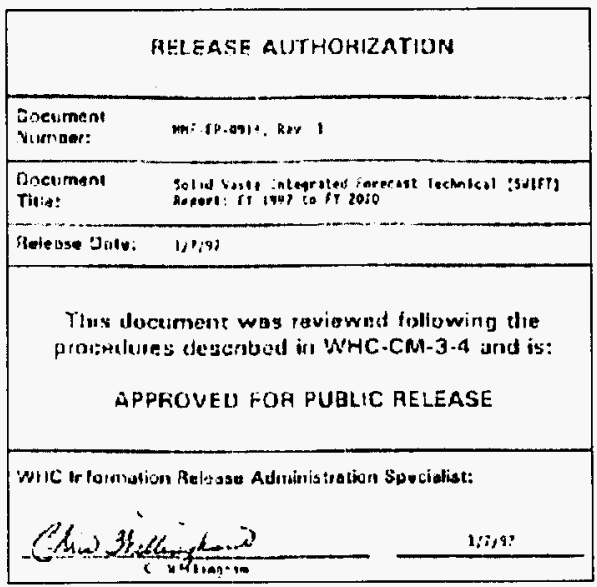




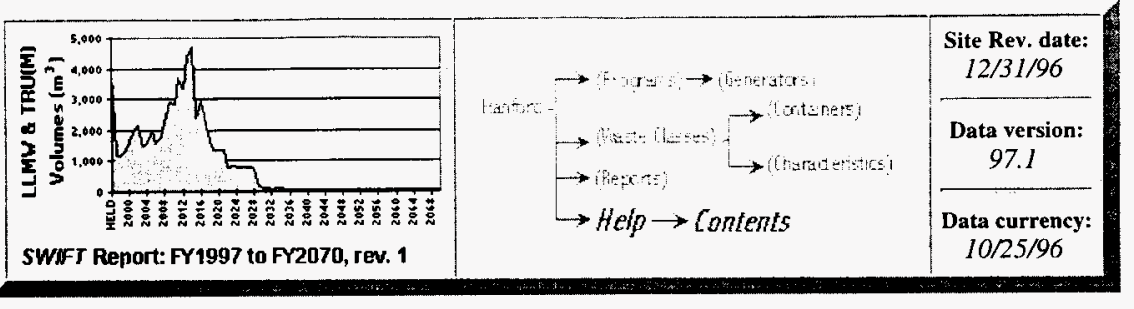

\title{
Contents
}

\section{Welcome}

\section{Analytical Services}

222S Analytical Laboratory

6266 Waste Sampling \& Characterization Facility

\section{EM-40 (Environmental Restoration)}

Surplus Facilities

\section{Facility Transitions}

\author{
202A PUREX Operations \\ 225B B Plant \\ 2345Z Plutonium Finishing Plant \\ 303K Fuels Fabrication Transition \\ 309 PRTR Vault Waste (Ion Exchange Mod) \\ 324 Building \\ 327 Building \\ 335 Sodium Test Facility \\ FFTF Transition Project \\ Waste Encapsulation/Storage Facility
}

Landlord (EM-60)

Liquid Effluent

300 Area/Treated Effluent Disposal Facilities C018H-200 Area Effluent Treatment Facility

\section{Non Programmatic}

300 Area Facilities Non-Transition 400 Area Facilities Non-Transition 
B Plant Non-Transition

PFP Non-Transition

PUREX Non-Transition

REDOX Non-Transition

Site Support Non-Transition

Stored Equipment

T Plant Non-Transition

U Plant Non-Transition

\section{Offsite}

Ames Laboratory-Ames, Iowa Argonne National Laboratory-East

Bates Accelerator-Massachusetts

Battelle Columbus Laboratories

Bettis Atomic Power-Laboratory

Bettis Atomic Power-Shipyards

Brookhaven National Laboratory

Fermi National Accelerator Laboratory

General Atomics

Knolis Atomic Power-Laboratory

Knolls Atomic Power-Shipyards

Lawrence Berkeley Laboratory

Paducah Energy Systems

Pearl Harbor Naval Shipyards

Portsmouth Energy Systems

Portsmouth Naval Shipyards

Princeton Plasma Physics Lab

Puget Sound Naval Shipyards

Rockwell-Canoga Park

Rocky Flats

Stanford Linear Accelerator Center

University of California-Davis

University of Utah

PNNL

Pacific Northwest National Laboratories

\section{RCRA Monitoring}

Well Drilling

\section{Solid Waste}

218E/W Low Level Burial Grounds 221T/2706T T-Plant Operations

224T TRU Storage \& Assay Facility 
Central Waste Complex

W026-Waste Receiving And Processing (WRAP1)

\title{
Spent Nuclear Fuel
}

100K K-Basin Operations

K-Basin Fuel Sampling Project

\section{TWRS}

Cross-Site Transfer System

DST Retrieval Systems (10 tanks)

High Level Vitrification Project

Low Level Vitrification Project

SST Long Length Equipment

SST Retrieval (149 tanks)

SST/DST Tank Farm Operations

Tank Farm Restoration

Tank Farm Ventilation Upgrade

W343 DST Retrieval (17 Tanks)

\section{Waste Classes}

\author{
CH_LLMW \\ RH_LLMW \\ CH_TRU(M) Waste \\ RH_TRU(M) Waste \\ GTC III Waste \\ LLW \\ Hazardous Waste (HAZ)
}

Waste Class Container Summary

CH_LLMW Containers

RH_LLMW Containers

CH_TRU(M) Waste Containers

RH_TRU(M) Waste Containers

GTC. III Waste Containers

LLW Containers

HAZ Waste Containers

\section{Waste Class Characteristics Summary}

CH_LLMW Characteristics

RH_LLMW Characteristics

CH_TRU(M) Waste Characteristics

RH_TRU(M) Waste Characteristics

GTC. III Waste Characteristics

LLW Characteristics 
HAZ Waste Characteristics

\section{Reports}

LLMW and TRU(M) Solid Waste Generators: by Volume

LLMW and TRU(M) Solid Waste Generators: by Program and Volume

FY97 Waste Generator List by Hanford Program Area

\section{Tools}

Data Requests

Feedback Form

Glossary

Help

Web Site Map

PROGRAMS:

Analytical Services · EM-40 - Landlord · Facility Transitions - Liquid Effluent · NP · Offsite - PNNL - RCRA · Solid Waste - SNF · TWRS

CHARACTERISTICS:

CH_LLMW $\cdot$ RH_LLMW $\cdot$ CH_TRU(M) $\cdot$ RH_TRU(M) . GTC III $\cdot$ LLW $\cdot$ HAZ

\section{CONTAINERS:}

CH_LLMW $\cdot$ RH_LLMW $\cdot$ CH_TRU(M) . RH_TRU(M) - GTC III $\cdot$ LLW $\cdot$ HAZ

\section{WASTE Classes:}

CH_LLMW $\cdot$ RH_LLMW $\cdot$ CH_TRU(M) $\cdot$ RH_TRU(M) $\cdot$ GTC III $\cdot$ LLW $\cdot$ HAZ

Home - Contents - Web Site Map - Glossary · Help - Reports - Data Requests - Feedback Form

NOTICE: This page is provided subject to our disclaimer. Contact: Oscar Valero at (509) 373-4752.

HNF-EP-0918 rev. 1 Approved for public release; distribution is unlimited. 
'Mग!ลNวAO วI!S

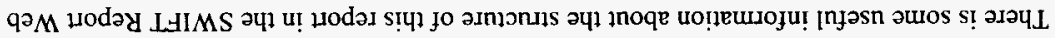

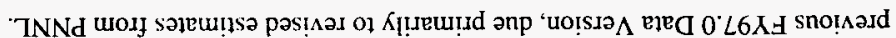

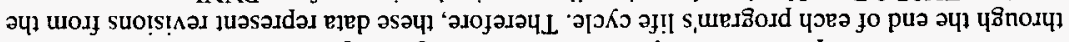

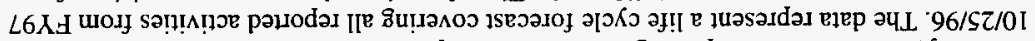

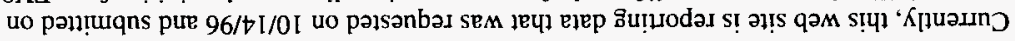

pəp!no.d osje

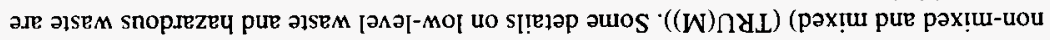

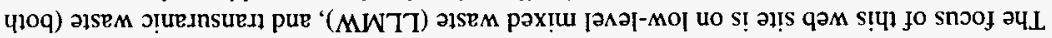

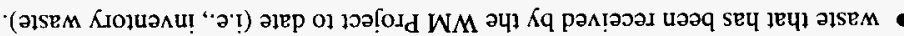
pue

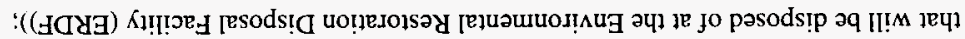

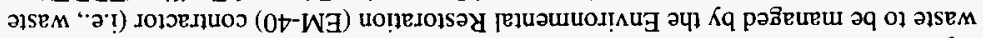

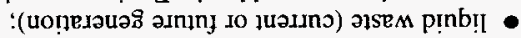

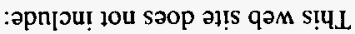

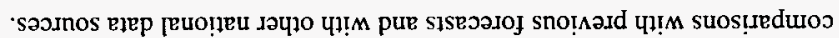

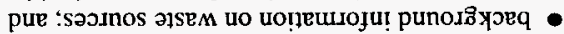

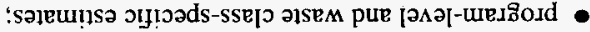

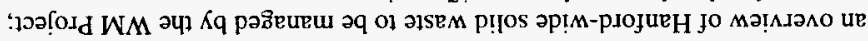

:səpnjou!

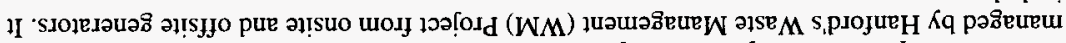

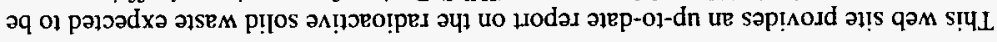

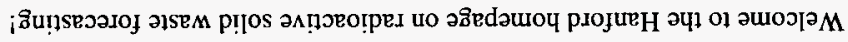

$\operatorname{auov\rho \mu M~}$

\section{UO!S!̣AY '0 LOZXH 01 L66LXH :1.IOdaY (LHIMS)

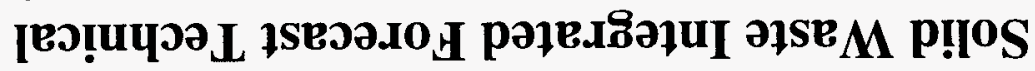

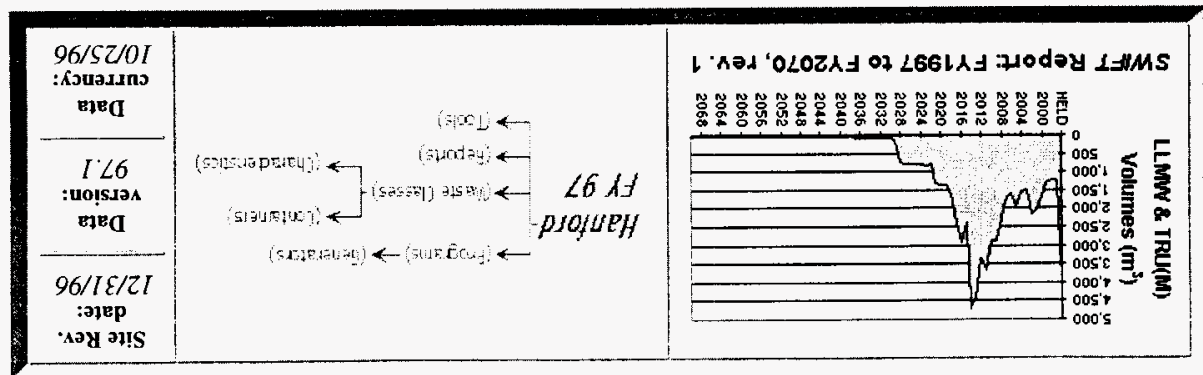




\section{Contents}

» Hanford Highlights

"Annual Waste Class Volumes

„Summary Table

"Forecast Accuracy

»Comparison to Previous Baseline(s)
» Comparison to National Data Calls

» Identified But Unforecasted Activities

» Forecast Background

"Other Forecast Data

\section{Hanford Highlights}

- A total of $67,630 \mathrm{~m}^{3}$ of LLMW and TRU(M) waste is expected at Hanford's WM Project over the life cycle of the site (2070).

- This forecast shows a $50 \mathrm{~m}^{3}$ increase from the FY97.0 forecast of $67,580 \mathrm{~m}^{3}$, due primarily to revisions in waste estimates from PNNL.

- Based on ranges provided by the various programs, this estimate could fluctuate between $37,680 \mathrm{~m}^{3}$ and $108,280 \mathrm{~m}^{3}$.

- The total waste volume is comprised of $59,660 \mathrm{~m}^{3}$ of LLMW and 7,970 $\mathrm{m}^{3}$ of TRU(M) waste.

- TWRS is the major waste-generating program, generating $74 \%\left(50,120 \mathrm{~m}^{3}\right)$ of the waste volume.

Waste Class Distribution

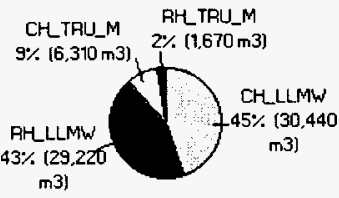

Total $=67,630 \mathrm{m3}$

\section{Physical Waste Form Distribution}

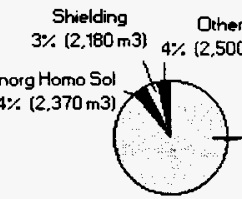

Tolal $=67.630 \mathrm{~m} 3$

\section{Program Distribution}

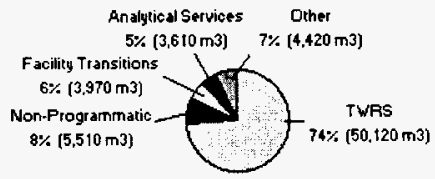

Total $=67.630 \mathrm{~m}^{3}$

\section{Hazardous Constituent Distribution}

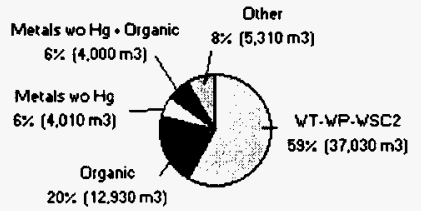

Total $=63.290 \mathrm{m3}$

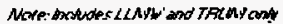




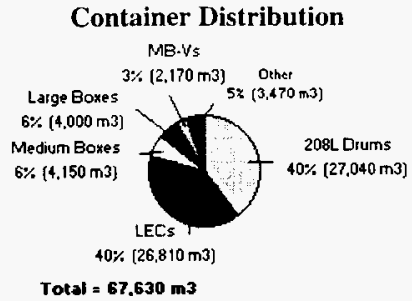

Sum of totals may not add due to rounding: numbers over $10 \mathrm{~m}^{3}$ are rounded to the nearest $10 \mathrm{~m}^{3}$, numbers less than $10 \mathrm{~m}^{3}$ are rounded to integers, non-zero numbers less than 1 are rounded to $I$.

\section{Annual Waste Class Volumes}

(If the full width of the report does not display, either print Landscape or reduce the image to 80 percent.)

\begin{tabular}{|c|c|c|c|c|c|c|c|c|c|c|c|c|c|}
\hline $\begin{array}{l}\text { LLMN E TRU(M) } \\
\text { Vaste Summarg: } \\
\text { Waste Class }\end{array}$ & HELD & 1997 & 1998 & 1999 & 2000 & 2001 & 2002 & 2003 & 2004 & 2005 & 2006 & $\begin{array}{l}2007- \\
2070 \\
\end{array}$ & Tored \\
\hline CH LLMW & 4,000 & 540 & 450 & 480 & 660 & 610 & 680 & 720 & 690 & 580 & 520 & 20,490 & $52+10$ \\
\hline BH LLMW & 0 & 150 & 140 & 200 & 220 & 780 & 840 & 270 & 770 & 1.280 & 970 & 23.610 & $2 \times 220$ \\
\hline CH TRUMM] & 0 & 450 & 510 & 640 & 730 & 450 & 460 & 310 & 90 & 110 & 80 & 2.460 & 6.310 \\
\hline RH TRU(M) & 0 & 80 & 110 & 20 & 20 & 170 & 180 & 180 & 20 & 20 & 20 & 850 & 1,67 \\
\hline serropor & $1,0 \%$ & 8.220 & 1,230 & 1,570 & 1.650 & 2,220 & 2700 & 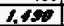 & 1,570 & $z, \infty$ & $\operatorname{lsc}$ & 47,18 & 67.650 \\
\hline LLW & 220 & 6.050 & 5.030 & 4.600 & 6,330 & 5,650 & 6,740 & 5,370 & 5,020 & 2,880 & 2,830 & 101,810 & AEZSFA \\
\hline HAZ & 0 & 50 & 40 & 50 & 40 & 40 & 40 & 40 & 40 & 40 & 40 & 2,320 & 2770 \\
\hline Tord & 1,220 & 7.250 & 6,230 & 530 & 3000 & 7,720 & 2,356 & 6,97 & abs & 4,320 & $\cos \theta$ & $\overline{A F f, 35 \theta}$ & $22 Z, 3+6$ \\
\hline
\end{tabular}

Sum of lotals may not add due to rounding: numbers over $10 \mathrm{~m}^{3}$ are rounded to the nearest $10 \mathrm{~m}^{3}$, numbers less than $10 \mathrm{~m}^{3}$ are rounded to integers, non-zero numbers less than 1 are rounded to 1.

The majority of waste is forecast for the period 1997 through 2030, during which time many generators expect to complete their waste-generating activities. The general increase in waste from 2008 to the peak in 2014 is largely a result of tank retrieval and cleanout activities within the TWRS program.

The large amount of HELD waste (shown at the left side of the chart) arises from the Stored Equipment generator. This represents waste that exists, but for which no shipping schedule has been developed.

Minimum and maximum estimates for the waste track fairly consistently with the baseline waste estimates. For 2014 - the peak year in baseline waste generation, the baseline estimate is $4,720 \mathrm{~m}^{3}$, with a maximum estimate of $6,800 \mathrm{~m}^{3}$ and a minimum estimate of $2,510 \mathrm{~m}^{3}$. 


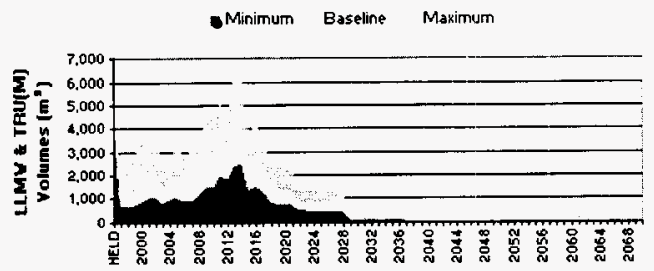

\section{Summary Table (LLMW and TRU(M) waste volumes in $\mathbf{~ m}^{3}$ )}

\begin{tabular}{|c|c|c|c|c|c|c|}
\hline $\begin{array}{l}\text { LLMY \& TRU(M) Summarg: } \\
\text { Program }\end{array}$ & CH_LLMV| & FH_LLMV & CH_TRU(M] & RH_TRU(M)] & Subtotal & PCT \\
\hline TWRS & 18,260 & 29040 & 1,360 & 1450 & 50,120 & $74 \%$ \\
\hline Non-Programmatic & +190 & of & 1,320 & o & 5.510 & $8 \%$ \\
\hline Faciliky Transitions & 770 & 70 & 3,110 & 10 & 3,970 & $6 \%$ \\
\hline Analytical Services. & 3,600 & 0 & 20 & 0 & 3.610 & $5 \%$ \\
\hline Liquid Effluent & 2,540 & 0 & 0 & 0 & 2,540 & $4 \%$ \\
\hline PNNH & .490 & 50 & 240 & 110 & 900 & $1 \%$ \\
\hline Solid W aste & 310 & 60 & 0 & 30 & 400 & $1 \%$ \\
\hline EM-40 & 10 & 0 & 230 & 0 & 240 & $<1 \%$ \\
\hline affsite & 200 & 5 & 2 & 0 & 210 & $<1 \%$ \\
\hline Spent Nuclest Fuel & 5 & 0 & 20 & 60 & 80 & $51 \%$ \\
\hline ACPA Monitoring & 60 & o & 0 & 0 & 60 & $\times 1 \%$ \\
\hline Tard & $38+10$ & 20,270 & G.7\% & 4,57 & 67,650 & $99 \%$ \\
\hline PCT & $45 \%$ & $43 \%$ & $9 \%$ & $2 \%$ & $100 \%$ & \\
\hline
\end{tabular}

Sum of totals may not add due to rounding: numbers over $10 \mathrm{~m}^{3}$ are rounded to the nearest $10 \mathrm{~m}^{3}$, numbers less than $10 \mathrm{~m}^{3}$ are rounded to integers, non-zero numbers less than $I$ are rounded to 1.

\section{Forecast Accuracy}

- The overall trend in the forecast accuracy has improved significantly in recent years. In the first three years of the forecast (1990-1992), an average of only about $45 \%$ of forecasted waste was actually received but in the last four years the average has been approximately $100 \%$.

- The FY 1993 and FY 1994 receipt data include backlog wastes from Tank Farms resulting in more waste being received than was forecasted since these wastes weren't included in the forecasts for these years.

- Waste from offsite generators has been excluded from the comparison because the forecasts are technical in nature and don't reflect the changing political environment typically affecting receipts from offsite. 


\section{Actual Receipts versus Previous Year's Forecast Volumes for Onsite LLW, LLMW, and TRU(h) Waste Volumes \\ [Forecast data represent only the first yeat of the previous year's forecast]}

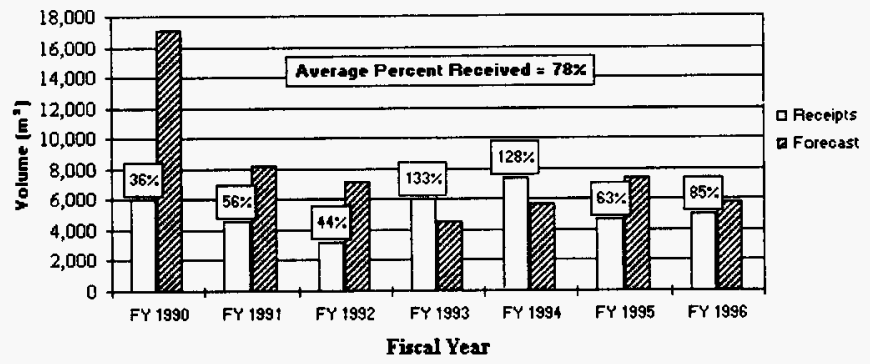

\section{Comparison to Previous Baseline(s)}

This forecast of $67,630 \mathrm{~m}^{3}$ shows a $50 \mathrm{~m}^{3}$ increase from the 97.0 forecast of $67,580 \mathrm{~m}^{3}$, as shown in the following table:

\begin{tabular}{|c|c|c|c|}
\hline $\begin{array}{l}\text { LLMW \& TRU(M) Comparison: } \\
\text { Waste Class }\end{array}$ & $\begin{array}{l}\text { FY97.1 } \\
\text { Forecast } \\
\left(\mathrm{m}^{3}\right)\end{array}$ & $\begin{array}{l}\text { FY97.0 } \\
\text { Forecast } \\
\left(\mathrm{m}^{3}\right)\end{array}$ & $\begin{array}{l}\text { FYa6 } \\
\text { Forecast } \\
\left(\mathrm{m}^{3}\right)\end{array}$ \\
\hline CH_LLMN & 30,440 & 30,410 & 73,040 \\
\hline RH_LLMN & 29,220 & 29,220 & 4,040 \\
\hline $\mathrm{CH}$ TRU(M) & 6,310 & 6,270 & 9,830 \\
\hline RH TRU(M) & 1,570 & 1,700 & 13,350 \\
\hline LLWN GTCIII & 0 & 0 & 640 \\
\hline Subtotaf & 67,630 & 67,580 & to0900 \\
\hline LLW & 152,540 & 152,380 & 353,160 \\
\hline LLW GTCIII & 0 & 0 & 350 \\
\hline $\mathrm{HAZ}$ & 2.770 & 2,770 & 33,830 \\
\hline Totgl & 222,950 & 222,740 & 408,240 \\
\hline
\end{tabular}

Sum of totals may not add due to rounding: numbers over $10 \mathrm{~m}^{3}$ are rounded to the nearest $10 \mathrm{~m}^{3}$, numbers less than $10 \mathrm{~m}^{3}$ are rounded to integers, non-zero numbers less than $I$ are rounded to 1 .

The increase arises from the PNNL program estimate due to a revision to the programmatic baseline for the transition of PNNL Building 327. The revision is based on better planning since a defined path forward is now available.

The largest source of reduction between FY97.0 and FY96 Forecasts arises from the TWRS program estimate, although almost all programs reported estimate reductions.

The reduction in the TWRS forecast estimate primarily stems from a revision to the programmatic baseline for the disposition of the long-length equipment. The new baseline assumes that only long-length equipment retrieved prior to 2003 will be managed by the Waste Management Project prior to disposal at the WIPP; the remaining long-length equipment will be disposed onsite in a similar manner 
as the underground tanks. Decontamination is expected to occur so that most of the equipment will not be considered transuranic waste.

\begin{tabular}{|c|c|c|c|c|}
\hline $\begin{array}{l}\text { Summary of Forecast } \\
\text { Changes: } \\
\text { Yaste Generator }\end{array}$ & Yaste Class & $\begin{array}{c}\text { FY97.1 } \\
\text { Forecast } \\
\text { (m') }\end{array}$ & $\begin{array}{c}\text { FY97.0 } \\
\text { Forecas } \\
\text { t(ms) }\end{array}$ & $\begin{array}{c}\text { Fr97.1 } \\
\text { Increase } \\
\text { [Deciease) }\end{array}$ \\
\hline \multicolumn{5}{|l|}{ Offsite } \\
\hline \multirow[t]{3}{*}{ Battelle Columbus Laboratory } & CH_LLMWI & 8 & 6 & 2 \\
\hline & $O H \angle k^{\prime} \mid$ & $142^{2}$ & $\mu_{2}^{2}$ & $a$ \\
\hline & $C 1 \angle \mathrm{W}$ & 50 & sm & $a$ \\
\hline \multirow[t]{2}{*}{ Faducah Energy Systems } & CH_LMW I & 23 & 0 & 23 \\
\hline & CHIL" & 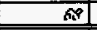 & G9 & $?$ \\
\hline \multirow[t]{2}{*}{ Portsmouth Energy Systems } & $\Delta H /(k)$ & & 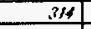 & arts \\
\hline & $O H \backslash L W \|{ }^{\prime}$ & $\pi / 4$ & & .714 \\
\hline \multicolumn{5}{|l|}{ Facilite Transitions } \\
\hline \multirow[t]{7}{*}{324 Building (PNNL) } & CH_LLMW III & 20 & 20. & 0 \\
\hline & CH TRUM & 4 & 4 & 0 \\
\hline & $\mathrm{RH}$ TPU & 7 & 5 & 2 \\
\hline & RH TRUM & 5 & 5 & 0 \\
\hline & 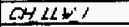 & 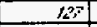 & 28 & $a$ \\
\hline & $O H \angle W^{\prime}$ & 10.8 & sas & $a$ \\
\hline & FOA $112 \div$ & $\sin$ & $\mathscr{M}$ & 0 \\
\hline \multirow[t]{9}{*}{327 Building (PNNL) } & CHLLMW I & 2 & 1 & 1. \\
\hline & CH LLMW III & 1 & & 1 \\
\hline & $\mathrm{CH}$ TRU & 56 & 2 & 53 \\
\hline & $\mathrm{CH}$ TRUMM & 1 & & 1 \\
\hline & RH TRU & & 17 & (17) \\
\hline & RH TRUM & & 15 & 115 \\
\hline & $O H U w^{\prime}$ & 198 & $2 / 1,8$ & $C S$ \\
\hline & OALW" & 22 & & 22 \\
\hline & 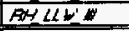 & .7 & & .9 \\
\hline \multirow[t]{2}{*}{ 303K Fuels F abrication Transition } & RHLLMW I & 70 & 66 & 4 \\
\hline & $O H\left(\| x^{\prime}\right)$ & 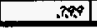 & ath & 19.7 \\
\hline
\end{tabular}

\section{Comparison to National Data Calls}

The Waste Management Program's forecast data is reported to several national data calls throughout a given fiscal year. Although these data calls draw from the same baseline (i.e., the Solid Waste Forecast Database), the reported data can sometimes appear different due to the specific data requirements of the particular national data call. The following table displays the "differences" in data reported to several national data calls in fiscal year 1996.

The FY97.0 Solid Waste Forecast (SWF) data is consistent with the $9 / 96$ Multi-Year Work Plan (MYWP) primarily because these two data calls were integrated this year to eliminate duplicative efforts on the part of waste generators. However, 97.1 is the most current baseline, revised in 10/96 to reflect new programmatic assumptions.

The Baseline Inventory Report (BIR), Rev.3 of 4/96 reports only TRU(M) waste to the Waste Isolation Pilot Plant; therefore, LLW and LLMW waste levels are excluded from this national data call. In addition, offsite waste is also excluded. Finally, this report includes an interim update (dated 3/96) to the TWRS' program RH_TRU waste.

The Baseline Environmental Management Report (BEMR) differs from all data calls because it reports after-processing disposal volumes while other national 
data calls require before-processing volumes.

Finally, all reports based on FY95 and FY96 estimates fail to include the most recent programmatic assumptions, and therefore differ from the FY97 Solid Waste Forecast and the 9/96 MYWP.

\begin{tabular}{|l|r|r|r|r|r|r|r|}
\hline & $\begin{array}{r}\text { SWF } \\
\text { FY97.1 }\end{array}$ & $\begin{array}{r}\text { SWF } \\
\text { FY97.0 }\end{array}$ & $\begin{array}{r}\text { MYWP } \\
9 / 96\end{array}$ & $\begin{array}{r}\text { BIR, Rev 3 } \\
\text { 4/96 }\end{array}$ & $\begin{array}{r}\text { SWF } \\
\text { FY96 }\end{array}$ & $\begin{array}{r}\text { BEMR } \\
\text { I/96 }\end{array}$ & $\begin{array}{r}\text { MYPP } \\
9 / 95\end{array}$ \\
\hline LLW & $\mathbf{1 5 2 , 5 4 0}$ & 152,380 & 152,380 & NA & 353,510 & 359,730 & $1.516,850$ \\
\hline LLMW & $\mathbf{5 9 , 6 6 0}$ & 59,630 & 59,630 & NA & 77,720 & 104,790 & 131,670 \\
\hline CH_TRU(M) & $\mathbf{6 , 3 1 0}$ & $\mathbf{6 , 2 6 0}$ & 6,260 & 9,640 & 9,830 & 10,330 & 9,830 \\
\hline RH_TRU(M) & 1,670 & 1,700 & 1,700 & 3,470 & 13,350 & 15,900 & 13,350 \\
\hline
\end{tabular}

\section{Identified But Unforecasted Activities}

Several Hanford Site activities have been identified that are not included in the forecasts of any of the reporting waste generators. This is often the case for future facilities or missions for which a responsible program has not been determined. The following lists several activities or waste that will be generated; but for which forecast data is not included in the current report.

\section{GTC III waste from PNNL:}

This waste currently exists, however, a defined path forward for the waste is undetermined. PNNL did not include this waste of approximately $530 \mathrm{~m}^{3}$ in their forecast since management by the Waste Management Project may not be the selected option for disposition.

\section{Post-2001 LLMW and LLW from RCRA Monitoring:}

Due to transition of program responsibility, waste generated by RCRA Monitoring after 2001 has not been included in the current forecast. However, since monitoring of Hanford's groundwater will continue during the life cycle of the site (through 2070), it is certain that this waste will be generated and will require management over the full life cycle of the site.

\section{RH_TRU(M) Waste from Surplus Facilities:}

Approximately $360 \mathrm{~m}^{3}$ of RH_TRU(M) waste is known to exist in the 618 Burial Grounds; however, this waste has not been forecasted by Surplus Facilities because only sites that have been characterized are included in their forecast. Although the 618 Burial Grounds have not been adequately characterized for inclusion in the forecast, this waste does exist and will be managed by the Waste Management Project.

\section{D\&D of future facilities and the Tank Farms:}

D\&D volume estimates have not been provided for any facilities that are not on the Surplus Facilities List. Therefore, D\&D waste from facilities such as the High Level Vitrification Plant, the PUREX tunnels, and the tank farms are not included in this baseline despite the fact that this waste will be generated in the future. 
As programmatic responsibilities and DOE Complex-wide issues are resolved, forecasts for these waste generating activities will be better defined and included in future baselines.

\section{Forecast Background}

Since 1989 , a waste volume forecast has been collected annually from onsite and offsite generators planning to ship waste to the Hanford WM Project's Central Waste Complex (CWC). The waste is generated from ongoing operations and maintenance, deactivation, decontamination and decommissioning (D\&D), and environmental restoration (ER) activities. The generators provide details about:

- the amount of waste to be generated each year,

- the containers that will be used to ship the waste, and

- the specific waste characteristics of the waste.

The focus of this web site is on low-level mixed waste (LLMW) and transuranic waste - both non-mixed and mixed - (TRU(M)). However some details on low-level waste (LLW) and hazardous waste are also included. It should be noted that hazardous waste is only included for those generators who plan to have the WM Project manage their waste. Other sources of hazardous waste are not included.

This document is intended to be used as a reference for short- and long-term planning of Rust Federal Services of Hanford (RFSH) WM TSD activities over the next several decades.

Facility planners can use this document to:

- determine the timing of key waste management activities,

- evaluate alternative treatment strategies, and

- plan storage and disposal capacities.

\section{Other Forecast Data}

\section{- Low Level Waste}

o A total of $152,540 \mathrm{~m}^{3}$ of LLW is expected to be shipped to the Central Waste Complex over the life cycle of the site (2070).

- This forecast shows a $57 \%$ decrease from the FY96 forecast of $353,160 \mathrm{~m}^{3}$ due primarily to reductions in estimates from the Offsite, PNNL, and RCRA programs.

o This forecast also is a $160 \mathrm{~m}^{3}$ increase from the FY 97.0 forecast of $152,380 \mathrm{~m}^{3}$ due to adjustments in the forecast for $303 \mathrm{~K}$ Fuels Fabrication Transition waste generator.

\section{- Hazardous Waste}

- A total of $2,770 \mathrm{~m}^{3}$ of hazardous waste is expected to be shipped to the Central Waste Complex over the life cycle of the site (2070). This does NOT include hazardous waste that is shipped directly offsite by generators. 


\section{PROGRAMS:}

Analytical Services - EM-40 · Facility Transitions - Landlord - Liquid Effluent - NP · Offsite · PNNL - RCRA - Solid Waste - SNF - TWRS

CHARACTERISTICS:

CH_LLMW $\cdot$ RH_LLMW $\cdot$ CH_TRU(M) $\cdot$ RH_TRU(M) . GTC III $\cdot$ LLW $\cdot$ HAZ

\section{CONTAINERS:}

CH LLMW - RH LLMW - CH TRU(M) RH_TRU(M) $\cdot$ GTC III $\cdot$ LLW $\cdot$ HAZ

\section{WASTE CLASSES:}

CH_LLMW $\cdot$ RH_LLMW $\cdot$ CH_TRU(M) $\cdot$ RH_TRU(M) $\cdot$ GTC III $\cdot$ LLW $\cdot$ HAZ

Home $\cdot$ Contents - Web Site Map · Glossary · Help · Reports · Data Requests · Feedback Form

NOTICE: This page is provided subject to our disclaimer. Contact: Oscar Valero at (509) 373-4752.

HNF-EP-0918 rev. 1 Approved for public release; distribution is unlimited. 
THE PAGT MTHNTGNALY Li:H ISLANK 


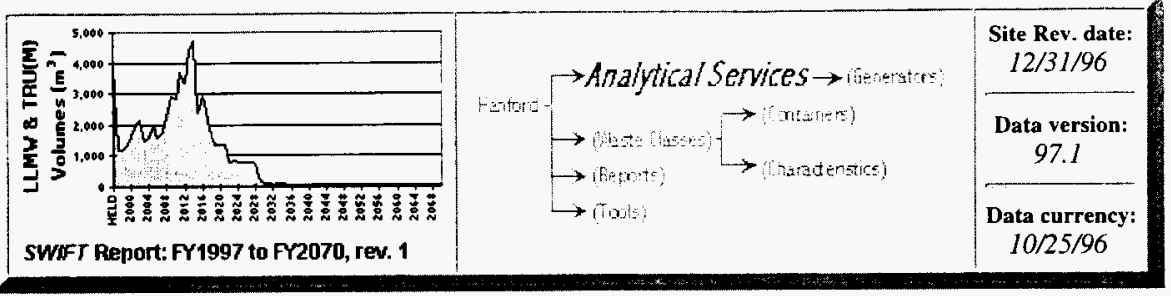

\section{Analytical Services}

\section{Contents}

" Highlights

"Annual Waste Class Volumes

»Summary Table

"Comparison to Previous Baseline(s)
》Background

》Forecast Assumptions and Comments

»Other Analytical Services Forecast Data

\section{Highlights}

- The forecast life cycle for Analytical Services ends in 2070.

- The life cycle total of LLMW and TRU(M) waste for Analytical Services is $3,610 \mathrm{~m}^{3}$, or $5 \%$ of the Hanford total.

- This forecast shows a $51 \%$ increase from the FY96 forecast of $2,390 \mathrm{~m}^{3}$, due mainly to the increase of CH_LLMW from the 222-S Analytical Laboratories.

- $\mathrm{CH} \_$LLMW is the primary waste class generated, representing $99 \%\left(3,600 \mathrm{~m}^{3}\right)$ of the waste.

- Nearly all (98\%) of the waste is projected to be contained in 208 liter drums.

- The physical waste forms for this program are mostly debris: metal, organic, inorganic, plastic/rubber, and heterogeneous. Homogeneous organic waste ( $20 \%$ by volume) and organic lab packs are the only other forms $(1 \%)$.

- All of the waste from this program will contain hazardous constituents. Nearly all of the waste (93\%) contains a mixture of metals without mercury, organics, and state regulated waste. The remaining volume is composed of metals with mercury (3\%), PCBs (3\%), and other hazardous constituents $(1 \%)$. 


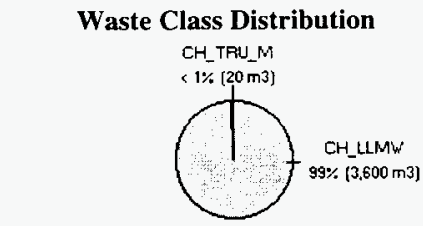

Total $=3.610 \mathrm{~m} 3$

\section{Generator Distribution}

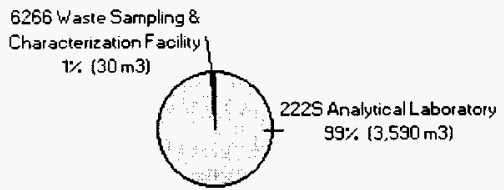

$\operatorname{Tot}=3,610 \mathrm{m3}$

Physical Waste Form Distribution

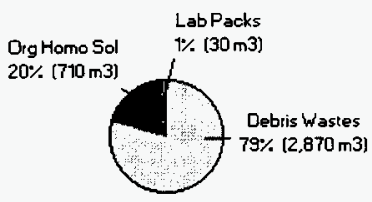

Hazardous Constituent Distribution

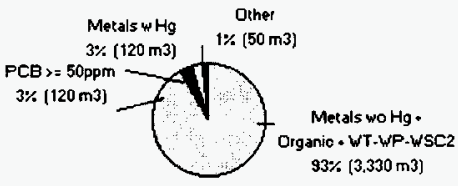

Total $=3,610 \mathrm{m3}$

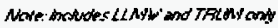

Total $=3,610 \mathrm{~m} 3$

\section{Container Distribution}

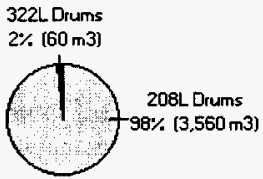

Total $=\mathbf{3 , 6 1 0 ~} \mathrm{m} 3$

Sum of totals may not add due to rounding: numbers over $10 \mathrm{~m}^{3}$ are rounded to the nearest $10 \mathrm{~m}^{3}$, numbers less than $10 \mathrm{~m}^{3}$ are rounded to integers, non-zero numbers less than $I$ are rounded to 1 .

\section{Annual Waste Class Volumes}

Analytical Services waste will be generated from 1997 to the end of life cycle in 2070 . The annual generation of waste is constant at about $50 \mathrm{~m}^{3}$ per year between 1997 and 2032, and at about $40 \mathrm{~m}^{3}$ per year between 2033 and 2070 .

\section{Annual Baseline Volumes}




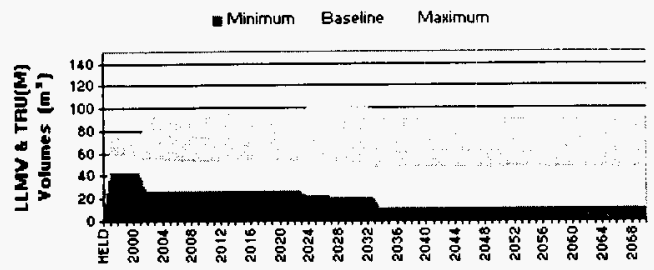

\section{Annual Baseline by Waste Class}

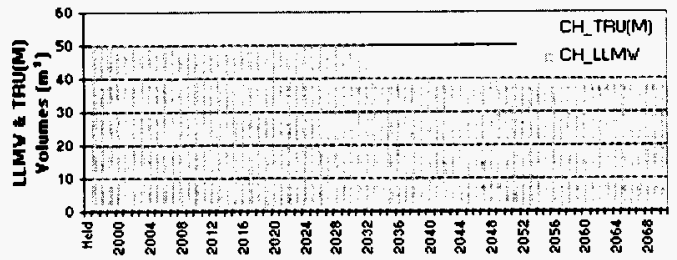

\section{Summary Table (Volumes in $\mathbf{m}^{\mathbf{3}}$ )}

\begin{tabular}{|c|c|c|c|c|}
\hline $\begin{array}{l}\text { Analytical Services Summary: } \\
\text { Generator }\end{array}$ & CH_LLMW & CH_TRU(M) & Subtotal & PCT \\
\hline 2225 Analytical Labor atory & 3,570 & 20 & 3,590 & $99 \%$ \\
\hline 6266 Waste Sampling Characterization Facillty & 30 & 0 & 30 & $1 \%$ \\
\hline 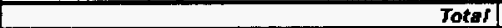 & 3,600 & 20 & 3,670 & $100 \%$ \\
\hline PCT & $99 \%$ & $1 \%$ & anes: & \\
\hline
\end{tabular}

Sum of totals may not add due to rounding: numbers over $10 \mathrm{~m}^{3}$ are rounded to the nearest $10 \mathrm{~m}^{3}$, numbers less than $10 \mathrm{~m}^{3}$ are rounded to integers, non-zero numbers less than I are rounded to 1.

\section{Comparison to Previous Baseline(s)}

The 97.1 LLMW and TRU(M) waste forecast for $222 \mathrm{~S}$ Analytical Services of $3,610 \mathrm{~m}^{3}$ shows a $51 \%$ increase from the FY96 forecast of $2,390 \mathrm{~m}^{3}$. The main reason for this increase is the $56 \%$ increase in CH_LLMW from the Analytical Laboratories due to an increase in tank farm analysis.

\section{Comparison to Previous Baseline(s) by Waste Class}

The 1996 physical waste form forecast included inorganic waste and soil/gravel (5\% of the volume total) that are not forecast for 1997.

Hazardous constituents for the current forecast shows $93 \%$ of the volume as metals without mercury, organic, and state regulated wastes mixed together. The 1996 forecast showed these wastes separately: $37 \%$ by volume was organic, $27 \%$ was state regulated, and metals without mercury was $18 \%$. In addition, corrosive constituents are not forecast for 1997 , whereas 20 
cubic meters were expected last year.

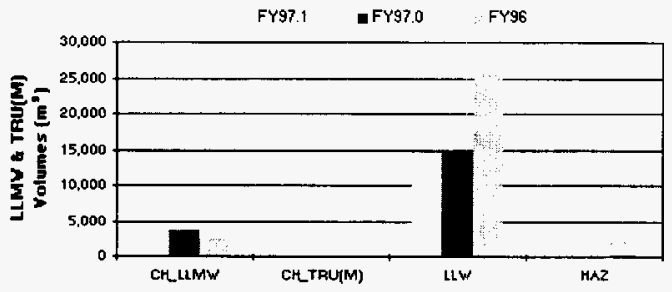

\begin{tabular}{|c|c|c|c|}
\hline $\begin{array}{l}\text { Anahytical Services Comparison: } \\
\text { Waste Class }\end{array}$ & $\begin{array}{c}\text { FY97.1 } \\
\text { Forecast } \\
\left(\mathrm{m}^{3}\right)\end{array}$ & $\begin{array}{c}\text { FY97.0 } \\
\text { Forecest } \\
\left(\mathrm{m}^{3}\right)\end{array}$ & $\begin{array}{l}\text { FY96 } \\
\text { Forecast } \\
\text { (m) }\end{array}$ \\
\hline $\mathrm{CH} L L M M$ & 3,600 & 3,600 & 2,370 \\
\hline $\mathrm{CH}$ TRU(M) & 20 & 20 & 20 \\
\hline Subtotal & 3,670 & 3,610 & 2,390 \\
\hline LLW & 14,640 & 14,640 & 25,710 \\
\hline $\mathrm{HAZ}$ & 120 & 120 & 2,280 \\
\hline Total & 18,370 & 18,370 & 30,370 \\
\hline
\end{tabular}

Sum of totals may not add due to rounding: numbers over $10 \mathrm{~m}^{3}$ are rounded to the nearest $10 \mathrm{~m}^{3}$, numbers less than $10 \mathrm{~m}^{3}$ are rounded to integers, non-zero numbers less than 1 are rounded to 1.

\section{Background}

Analytical Services provides analytical field support and process development services to other Site programs using onsite and offsite analytical laboratories. Analytical Services also provides field sampling, field screening, mobile laboratories, and data deliverables.

There are 2 generators included in the Analytical Services program: the 222-S Laboratory (RFSH_ANALYT_LAB) and the 6266 Waste Sampling and Characterization Facility (RFSH_WSCF).

Solid waste will be generated from laboratory analyses of Double-Shell and Single-Shell Tank waste samples, Hanford Site sample retums and laboratory standards, and organic chemicals or supplies used in support of analytical testing. Main forms of waste include metal, organic, and plastic/rubber debris.

\section{Forecast Assumptions and Comments}

This forecast was prepared with the assumption that the laboratory will remain active until 2070. Estimates are based on current operation history and expected generation rates. The minimum and maximum range for this waste is $38 \%$ and $189 \%$ of the baseline.

\section{Other Forecast Data}

\section{- Low Level Waste}

O A total of $14,640 \mathrm{~m}^{3}$ of LLW is expected from Analytical Services until 2070. 
- This forecast shows a decrease of $43 \%$ in LLW from the FY96 forecast of $25,710 \mathrm{~m}^{3}$, primarily due to the level of funding and mission changes within the Analytical Laboratory.

- Of the LLW sent by this program, 75\% by volume will be in MB-V boxes. 208 liter drums will handle $24 \%$, and $1 \%$ will be in 322 liter drums.

- The physical forms of the LLW are primarily various kinds of debris; $8 \%$ by volume will be soil/gravel.

\section{- Hazardous Waste}

- $120 \mathrm{~m}^{3}$ of hazardous waste is expected to be sent to the CWC.

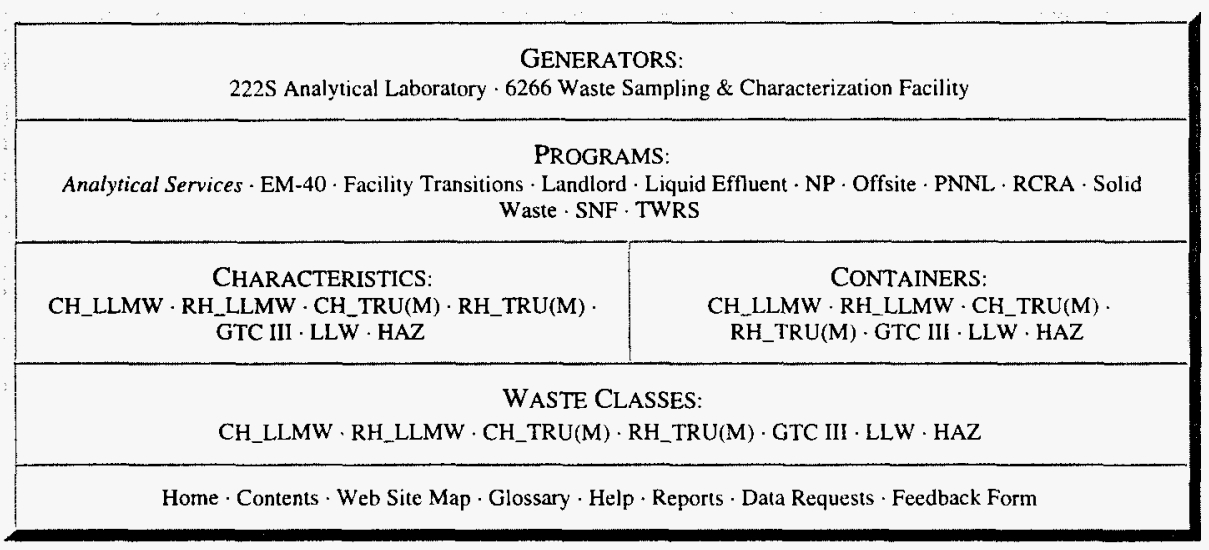

NOTICE: This page is provided subject to our disclaimer, Contact: Oscar Valero at (509) 373-4752.

HNF-EP-0918 rev. 1 Approved for public release; distribution is unlimited. 


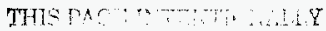

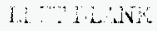




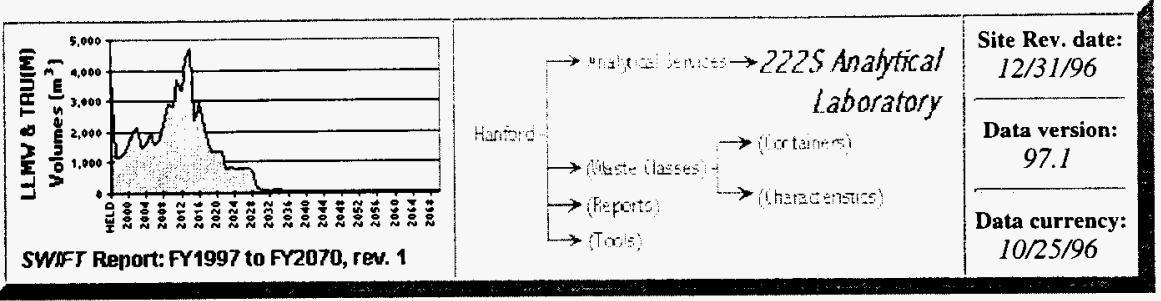

\section{Analytical Services - 222S Analytical Laboratory}

\section{Contents}

» Highlights

»Annual Volumes

„Comparison to Previous Baseline(s)

» Background
" Forecast Assumptions and Comments

»Other 222S Analytical Laboratory Forecast Data

»Detailed Forecast Data

\section{Highlights}

- The forecast life cycle for 222-S Laboratory (RFSH_ANALYT_LAB) ends in 2070.

- The 222-S Laboratory contributes $3,590 \mathrm{~m}^{3}$ of LLMW and TRU(M) waste.

- This forecast shows a $55 \%$ increase from the FY96 forecast of $2,320 \mathrm{~m}^{3}$, due mainly to the increase of CH_LLMW.

- $\mathrm{CH} \_$LLMW is the primary waste class generated, representing $99 \%\left(3,570 \mathrm{~m}^{3}\right)$ of the waste.

- Almost $98 \%$ of this generator's LLMW and TRU(M) waste will be in 208 liter drums, and the rest will use 322 liter drums.

- The physical forms of this mixed and TRU(M) waste are various kinds of debris. Only $20 \%$ by volume is a different form: organic solids.

- A mixture of metals without mercury, organics, and state regulated waste account for nearly all (94\%) of the LLMW and TRU(M) waste. Also, metals with mercury and PCBs each account for $3 \%$. 


\section{Waste Class Distribution}

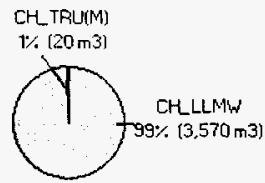

$T o t a l=3.590 \mathrm{~m} 3$

Physical Waste Form Distribution Org Homo Sol
$20 \%(710 \mathrm{~m} 3)$

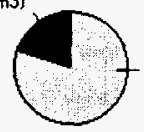

Total $=\mathbf{3 , 5 9 0 ~} \mathrm{m3}$

\section{Hazardous Constituent Distribution}

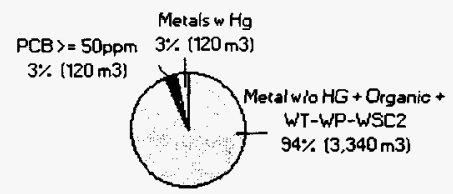

Total $=3.590 \mathrm{m3}$

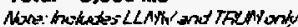

\section{Container Distribution}

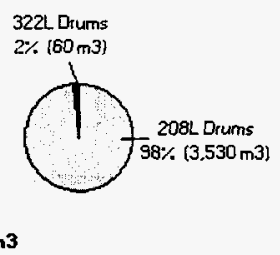

Sum of totals may not add due to rounding: numbers over $10 \mathrm{~m}^{3}$ are rounded to the nearest $10 \mathrm{~m}^{3}$, numbers less than $10 \mathrm{~m}^{3}$ are rounded to integers, non-zero numbers less than $I$ are rounded to $I$.

\section{Annual Volumes}

\section{Annual Baseline Volumes}




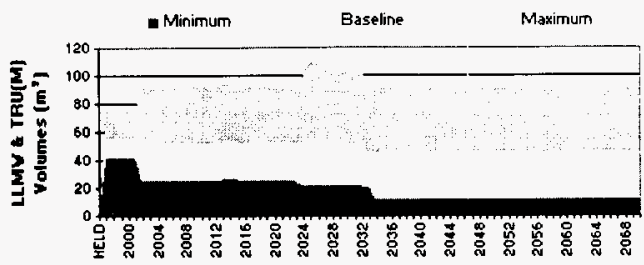

Annual Baseline by Waste Class

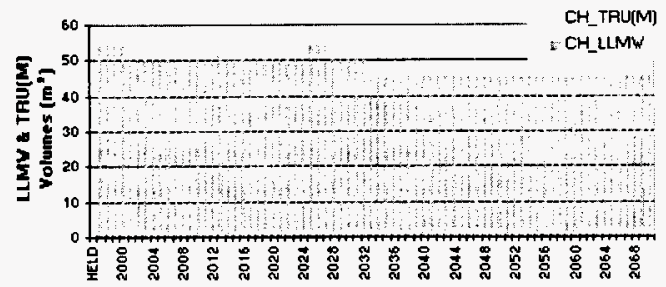

\section{Comparison to Previous Baseline(s)}

The FY97.1 LLMW and TRU(M) forecast for 222-S Laboratory of 3,590 $\mathrm{m}^{3}$ shows a $55 \%$ increase from the FY 96 forecast of $2,320 \mathrm{~m}^{3}$, due to an increase in tank farm analysis.

The 1996 physical waste form forecast included inorganic waste and soil/gravel ( $5 \%$ of the volume total) that are not forecast for 1997.

Hazardous constituents for the current forecast shows $94 \%$ of the volume as metals without mercury, organics, and state regulated wastes mixed together. The 1996 forecast showed these wastes separately: $39 \%$ by volume was organic, $28 \%$ was state regulated, and metals without mercury was $19 \%$. In addition, corrosive constituents are not forecast for 1997, whereas 20 cubic meters were expected last year.

\section{Comparison to Previous Baseline(s) by Waste Class}

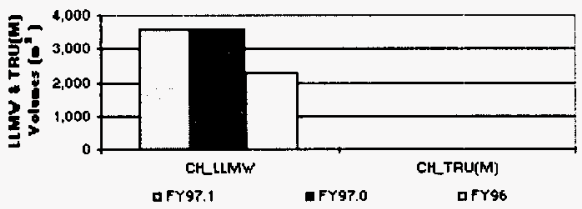




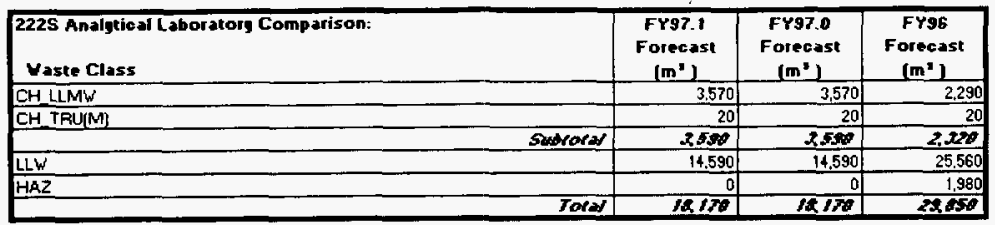

Sum of totals may not add due to rounding: numbers over $10 \mathrm{~m}^{3}$ are rounded to the nearest $10 \mathrm{~m}^{3}$, numbers less than $10 \mathrm{~m}^{3}$ are rounded to integers, non-zero numbers less than 1 are rounded $t o l$.

\section{Background}

The mission of 222-S Laboratory is to support all Hanford clean-up activities. Approximately 60 to $70 \%$ of the laboratory workload is in support of tank farms; hence, the laboratory carries the same waste codes as tank farms.

Solid waste will be generated from laboratory analyses of Double-Shell and Single-Shell Tank waste samples and construction activities. Main forms of waste include metal, organic, and plastic/rubber debris.

\section{Forecast Assumptions and Comments}

This forecast was prepared with the assumption that the laboratory will remain active until 2070. Estimates are based on current operation history and expected generation rates. The minimum and maximum range for this waste is $38 \%$ and $189 \%$ of the baseline.

\section{Other Forecast Data}

\section{- Low Level Waste}

- A total of $14,590 \mathrm{~m}^{3}$ of LLW is expected from 222-S Laboratory until 2070.

- This forecast shows a decrease of $43 \%$ from the FY96 forecast of $25,560 \mathrm{~m}^{3}$, primarily due to the level of funding and mission changes within the laboratory.

- $76 \%$ of the LLW will be sent using MB-V boxes, $23 \%$ using 208 liter drums, and $1 \%$ using 322 liter drums.

- The physical forms of the LLW are various kinds of debris. Only $8 \%$ by volume is a different form: soil and soil/gravel.

\section{- Hazardous Waste}

- No hazardous waste is expected from 222-S Laboratory for management by the CWC. 


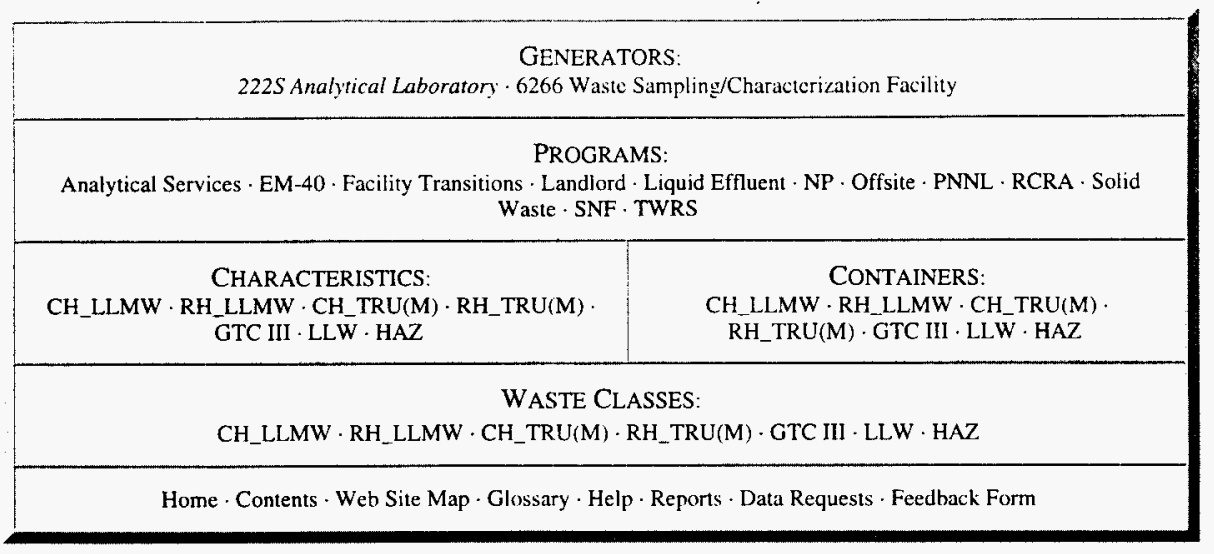

NOTICE: This page is provided subject to our disclaimer. Contact: Oscar Valero at (509) 373-4752.

HNF-EP-0918 rev. 1 Approved for public release; distribution is unlimited. 
THE PAOE TTE

1.... : EAva 


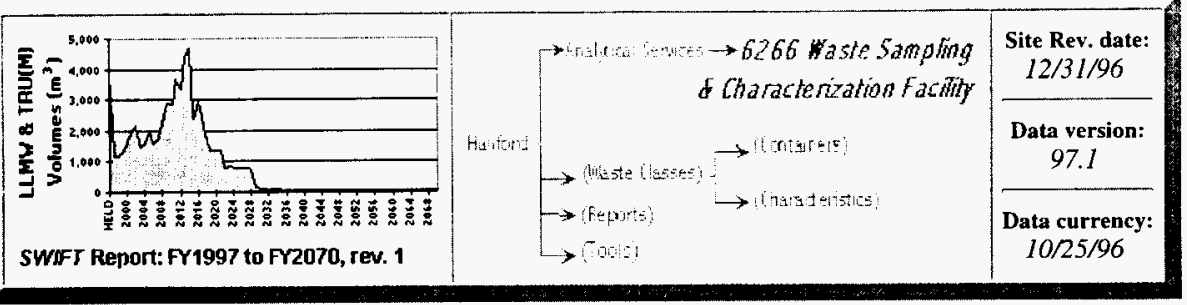

\section{Analytical Services - 6266 Waste Sampling \& Characterization Facility}

\section{Contents}
» Highlights
» Forecast Assumptions and Comments
» Annual Volumes
» Other Waste Sampling \& Characterization Forecast Data
»Comparison to Previous
Baseline(s)
» Detailed Forecast Data
» Background

\section{Highlights}

- The forecast life cycle for the Waste Sampling and Characterization Facility (RFSH_WSCF) ends in 2025

- This facility contributes $30 \mathrm{~m}^{3}(1 \%)$ of Analytical Services' LLMW forecast.

- This forecast shows a $63 \%$ decrease from the FY96 forecast of $80 \mathrm{~m}^{3}$, due mostly to more careful considerations for reduction and consolidation of the waste.

- $100 \%$ of the expected containers will be 208 liter drums.

- The physical waste form for this generator's LLMW is $100 \%$ organic lab packs.

- Organic, state regulated waste make up $80 \%$ of the LLMW, and the other $20 \%$ is ignitable, organic, state regulated waste mixed together. 


\section{Waste Class Distribution}

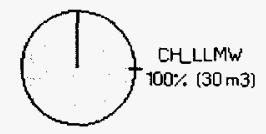

Total $=30 \mathrm{m3}$

Physical Waste Form Distribution

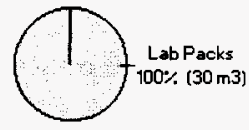

Total $=30 \mathrm{m3}$

\section{Hazardous Constituent Distribution}

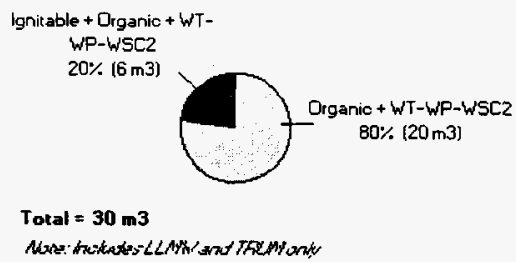

Ignitable + Drganic + WT -

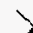

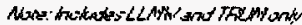

\section{Container Distribution}

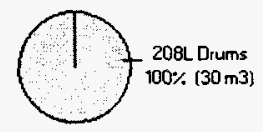

Total $=\mathbf{3 0 ~} \mathbf{m} 3$

Sum of totals may not add due to rounding: numbers over $10 \mathrm{~m}^{3}$ are rounded to the nearest $10 \mathrm{~m}^{3}$, numbers less than $10 \mathrm{~m}^{3}$ are rounded to integers, non-zero numbers less than I are rounded to $I$.

\section{Annual Volumes}

Annual Baseline Volumes 


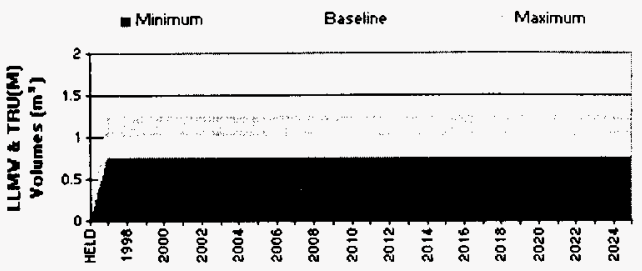

\section{Annual Baseline by Waste Class}

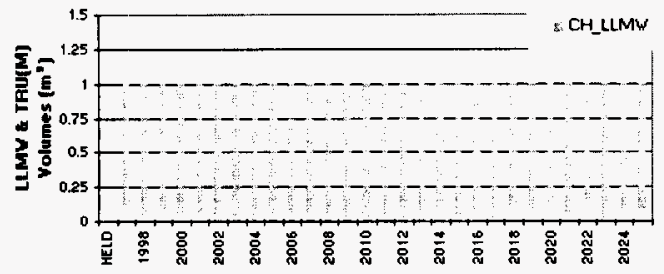

\section{Comparison to Previous Baseline(s)}

The FY97.1 forecast of $30 \mathrm{~m}^{3}$ for the Waste Sampling and Characterization Facility is a $63 \%$ decrease from the FY96 forecast of $80 \mathrm{~m}^{3}$. This estimate is based on more careful considerations for reduction and consolidation of the waste and using current operation history and expected generation rates.

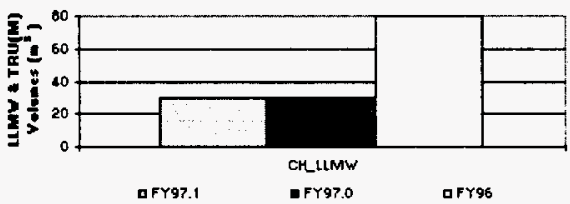

\begin{tabular}{|c|c|c|c|}
\hline $\begin{array}{l}\text { 6266 Yaste Sampling } * \text { Characterization Facility Comparison: } \\
\text { Yaste Class }\end{array}$ & $\begin{array}{l}\text { FY97.1 } \\
\text { Foreeast } \\
\left(\mathbf{m}^{3}\right)\end{array}$ & $\begin{array}{c}\text { FY97.0 } \\
\text { Foreeast } \\
\left(\mathrm{m}^{\circ}\right)\end{array}$ & $\begin{array}{l}\text { FY96 } \\
\text { Forecast } \\
\left(\mathrm{m}^{2}\right)\end{array}$ \\
\hline CH LLMW & 30 & 30 & 80 \\
\hline Suprofy & 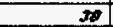 & $\pi$ & $\infty$ \\
\hline LLW & 60 & 60 & 150 \\
\hline HAZ & 120 & 120 & 300 \\
\hline Tord & $2 \theta 0$ & $2 \theta$ & 528 \\
\hline
\end{tabular}

Sum of totals may not add due to rounding: numbers over $10 \mathrm{~m}^{3}$ are rounded to the nearest $10 \mathrm{~m}^{3}$, numbers less than $10 \mathrm{~m}^{3}$ are rounded to integers, non-zero numbers less than 1 are rounded to 1 .

\section{Background}


The mission of the Waste Sampling and Characterization Facility is to analyze low-leve! radioactive and non-radioactive samples that may originate from any location on the Hanford Site, and will include items such as liquid grab samples, air filters, purified water samples, and samples from wells. The waste is generated from processes/excess sample, reagents/chemicals, filters and laboratory support equipment.

Waste consists of organic chemicals, or supplies used in support of analytical testing.

\section{Forecast Assumptions and Comments}

This forecast was prepared with the assumption of more careful considerations for reduction and consolidation of the waste and using current operation history and expected generation rates. The minimum and maximum range for this waste is $75 \%$ and $125 \%$ of the baseline.

\section{Other Forecast Data}

\section{- Low Level Waste}

- A total of $60 \mathrm{~m}^{3}$ of LLW is expected from Waste Sampling and Characterization Facility until 2070.

- This forecast shows a decrease of $60 \%$ from the FY96 forecast of $150 \mathrm{~m}^{3}$.

- All of the LLW is to be shipped in 208 liter drums.

- The physical forms of this LLW are various kinds of debris similar to the mixed waste: plastic/rubber, inorganic, and metal.

\section{- Hazardous Waste}

- A total of $120 \mathrm{~m}^{3}$ of hazardous waste was reported by Waste Sampling and Characterization Facility for management by the CWC.

\begin{tabular}{|c|c|}
\hline \multicolumn{2}{|c|}{$\begin{array}{l}\text { GENERATORS: } \\
\text { 222S Analytical Laboratory · } 6266 \text { Waste Sampling/Characterization Facility }\end{array}$} \\
\hline \multicolumn{2}{|c|}{$\begin{array}{l}\text { PROGRAMS: } \\
\text { Analytical Services } \cdot \text { EM-40 } \cdot \text { Facility Transitions } \cdot \text { Landlord } \cdot \text { Liquid Effluent } \cdot \text { NP } \cdot \text { Offsite } \cdot \text { PNNL } \cdot \text { RCRA } \cdot \text { Solid } \\
\text { Waste } \cdot \text { SNF } \cdot \text { TWRS }\end{array}$} \\
\hline $\begin{array}{l}\text { CHARACTERISTICS: } \\
\mathrm{CH}_{-} L L M W \cdot \mathrm{RH} \_L L M W \cdot \text { CH_TRU(M) } \\
\text { GTC III } \cdot \text { LLW_TRU(M) } \cdot \text { HAZ }\end{array}$ & $\begin{array}{l}\text { CONTAINERS: } \\
\text { CH_LLMW } \cdot \text { RH_LLMW } \cdot \text { CH_TRU(M) } \\
\text { RH_TRU(M) } \cdot \text { GTC III } \cdot \text { LLW } \cdot \text { HAZ }\end{array}$ \\
\hline \multicolumn{2}{|c|}{$\begin{array}{l}\text { WASTE CLASSES: } \\
\text { CH_LLMW } \cdot \text { RH_LLMW } \cdot \text { CH_TRU(M) } \cdot \text { RH_TRU(M) } \cdot \text { GTC III } \cdot \text { LLW } \cdot \text { HAZ }\end{array}$} \\
\hline
\end{tabular}

NOTICE: This page is provided subject to our disclaimer. Contact: Oscar Valero at (509) 373-4752.

HNF-EP-0918 rev. 1 Approved for public release; distribution is unlimited. 


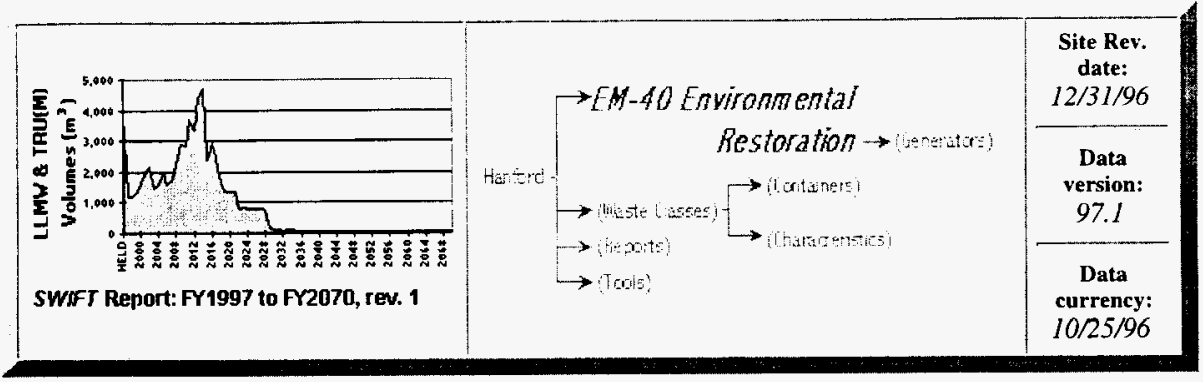

\section{EM-40 Environmental Restoration (ER)}

\section{Contents}
» Highlights
»Background
»Annual Waste Class Volumes
» Forecast Assumptions and Comments
»Summary Table
» Other EM-40 Environmental Restoration Forecast
»Comparison to Previous Baseline(s) Data
» Detailed Forecast Data

\section{Highlights}

- The solid waste forecast life cycle for Surplus Facilities (BHI_SURPLS_FAC), and thus the Environmental Restoration program, ends in 2001 ; however, the program will continue operating after 2001.

- The life cycle total of LLMW and TRU(M) waste for ER is $240 \mathrm{~m}^{3}$, or $<1 \%$ of the Hanford total.

- This forecast shows an $88 \%$ decrease from the FY96 forecast of $1,980 \mathrm{~m}^{3}$, due to revised estimates of the number and types of ER projects occurring, as well as changes in the final destinations of some waste.

- $\mathrm{CH} \_$TRU(M) waste is the primary waste class generated, representing $96 \%$, or $230 \mathrm{~m}^{3}$, of the Environmental Restoration waste volume.

- All of the waste in this program is generated by Surplus Facilities.

- $100 \%$ of this volume will be sent in 208 liter drums.

- Debris constitutes nearly all of this waste's physical form (94\%), but $4 \%$ is organic solids.

- 99\% of the LLMW and TRU(M) waste hazardous constituents are to be metals without mercury. Ignitable and organic waste compose the other $1 \%$ of the volume. 
Waste Class Distribution

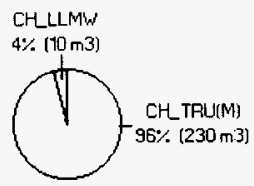

Tolal $=240 \mathrm{m3}$

Physical Waste Form Distribution

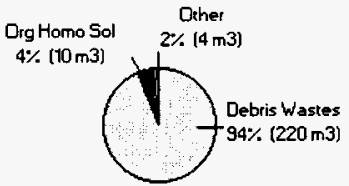

Total $=240 \mathrm{~m} 3$

\section{Generator Distributions}

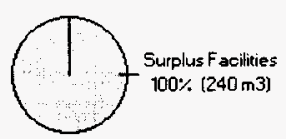

Total $=240 \mathrm{m3}$
Diher

$1 \%(2 \mathrm{~m} 3)$

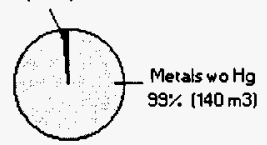

Total $=140 \mathrm{m3}$

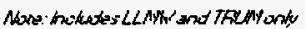

\section{Container Distribution}

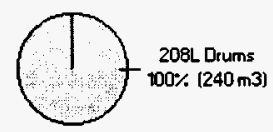

Totel $=240 \mathrm{~m} 3$

Sum of totals may not add due to rounding: numbers over $10 \mathrm{~m}^{3}$ are rounded to the nearest $10 \mathrm{~m}^{3}$, numbers less than $10 \mathrm{~m}^{3}$ are rounded to integers, non-zero numbers less than 1 are rounded to $I$.

\section{Annual Waste Class Volumes}

Surplus Facilities waste will be generated from 1997 to the end of life-cycle in 2001 . The major amount of waste will be shipped in 1998 and 1999.

\section{Annual Baseline Volumes}


a Minimum Baseline Maximum

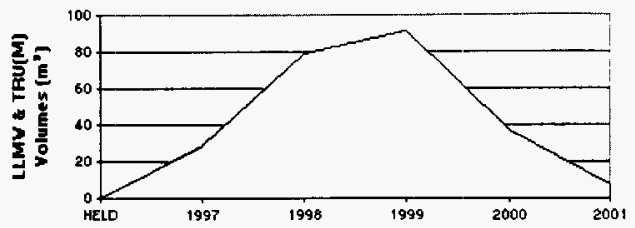

Annual Baseline by Waste Class

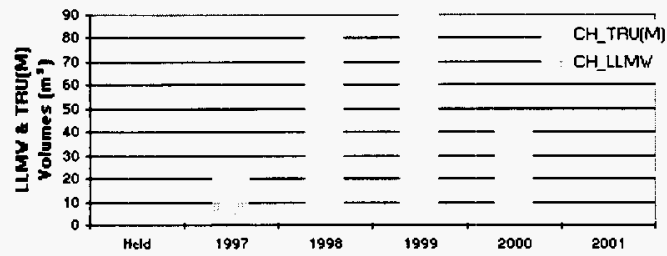

\section{Summary Table (Volumes in $\mathbf{m}^{3}$ )}

\begin{tabular}{|l|r|r|r|r|}
\hline $\begin{array}{l}\text { EM-40 (Envir onmental Restoration) Surnmary: } \\
\text { Generator }\end{array}$ & & & \\
\hline Surplus Facilities & CH_LLMw & CH_TRU(M) & Subtotor & PCT \\
\hline & 10 & 230 & 240 & $100 \%$ \\
\hline & 10 & 230 & 240 & \\
\hline
\end{tabular}

Sum of totals may not add due to rounding: numbers over $10 \mathrm{~m}^{3}$ are rounded to the nearest $10 \mathrm{~m}^{3}$, numbers less than $10 \mathrm{~m}^{3}$ are rounded to integers, non-zero numbers less than 1 are rounded to 1 .

\section{Comparison to Previous Baseline(s)}

The FY97.1 forecast for Surplus Facilities of $240 \mathrm{~m}^{3}$ shows an $88 \%$ decrease from the FY96 forecast of $1,980 \mathrm{~m}^{3}$. This reduction is due to a big change in the amount of waste forecast for ERDF. Some projects considered in the previous forecasts have been eliminated or consolidated with other projects; projects which had previously forecast for a later life cycle have already started.

The TRU(M) waste is reduced $88 \%$ between the FY96 and FY97.1 forecasts, from $1,880 \mathrm{~m}^{3}$ of RH_TRU(M) and CH_TRU(M) in FY96 to just $230 \mathrm{~m}^{3} \mathrm{CH}_{-}$TRU(M) in FY97. One reason for this reduction is that past forecasts were based on estimating facility size without clear knowledge of the waste mixture. The FY97 forecast includes only sites that have been characterized, resulting in less forecast volume and higher forecast accuracy. As a result, sites such as the 618 Burial Grounds are not included in the present forecast.

Compared to the 1996 forecast, the percentage of metal debris has risen from $16 \%$ to $94 \%$ for 
this year. In addition, the Other category has nearly disappeared, falling from $42 \%$ to $2 \%$ this year. The amounts of organic, plastic/rubber, and heterogeneous debris make up much less of the whole as well.

The difference between hazardous constituents forecast in 1996 and 1997 is that only $40 \%$ of the volume was metals without mercury. State regulated waste also composed $40 \%$ of the waste, but it is not reported this year. Corrosive waste is also not reported this year, when in 1996 less than one cubic meter was forecast.

\section{Comparison to Previous Baseline(s) by Waste Class}

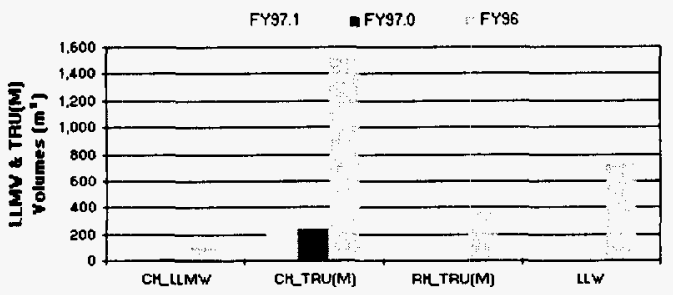

\begin{tabular}{|c|c|c|c|}
\hline $\begin{array}{l}\text { EM-40 Comparison: } \\
\text { Weste Class }\end{array}$ & $\begin{array}{c}\text { FYg7.1 } \\
\text { For ecast } \\
\left(\mathrm{m}^{3}\right)\end{array}$ & $\begin{array}{l}\text { FY97.0 } \\
\text { forecast } \\
\left(\mathrm{m}^{3}\right)\end{array}$ & $\begin{array}{c}\text { Fygs } \\
\text { Forecest } \\
\text { (m) }\end{array}$ \\
\hline $\mathrm{CH}$ LLMWN & 10 & 10 & 100 \\
\hline $\mathrm{CH}$ TRU(M) & 230 & 230 & 1,520 \\
\hline RH TRU(M) & 0 & 0 & 360 \\
\hline Subtotal & 240 & 240 & 1,980 \\
\hline LLW & 0 & 0 & 710 \\
\hline Total & 240 & 240 & 2,690 \\
\hline
\end{tabular}

Sum of totals may not add due to rounding: numbers over $10 \mathrm{~m}^{3}$ are rounded to the nearest $10 \mathrm{~m}^{3}$, numbers less than $10 \mathrm{~m}^{3}$ are rounded to integers, non-zero numbers less than 1 are rounded to 1 .

\section{Background}

The mission of Surplus Facilities is to perform clean-up activities to preserve, protect, or restore the Hanford Site to allow other beneficial uses. The Remedial Action summary Subproject includes the management, identification, assessment, and remediation of the Hanford Site past-practice waste sites that have been inactive since March 1, 1987. Also included are the identification and completion of interim stabilization actions to mitigate the potential for the expansion of contaminated zones and disposition of non-radioactive underground storage tanks and certain Resource Conservation and Recovery Act of 1976 (RCRA) facilities. D\&D includes the surveillance and maintenance of facilities awaiting decommissioning as well as the D\&D of facilities, abatement of asbestos, and compliance with all applicable regulations.

The Environmental Restoration Disposal Facilities Summary Subproject (ERDF) includes the planning, construction, and operation of all storage and disposal facilities required for the success of the ER project. The major piece of work scope is a final disposal facility that will receive and isolate low-level radioactive waste, hazardous waste, or a combination thereof 
(LLMW), generated by remediation of the Hanford Site past-practice waste sites.

Waste consists primarily of soil samples.

\section{Forecast Assumptions and Comments}

The waste identified in this forecast is primarily from those projects and facilities currently under the Decontamination and Decommissions Subproject. No forecast was submitted for waste generated under CERCLA or RCRA past practices clean-up activities. The facilities in this forecast are identified in the "Surplus Facilities Surveillance \& Maintenance Plan - FY96" and "Facility Transition Work Scope - 9/95" (BHI00369). This plan assumes that transfer facilities have had major contamination removed prior to transition. Only a small amount of facility LLMW debris is anticipated each fiscal year. Since waste has not been identified, characterization cannot be completed and any forecast would be inaccurate.

Most facilities under the ER program are not fully characterized. A general building characterization is not sufficient to forecast solid waste quantities, physical waste forms, percentage of hazardous constituents or the levels of radionuclides. Characterization is normally done just prior to decommissioning.

Although CERCLA wastes and RCRA Past Practice wastes are not included in this forecast, there is a possibility that many of the current facilities may be reclassified as CERCLA sites. This will reduce the amount of forecast waste substantially because it will be deposited in the ERDF unless it contains an untreatable Land Disposal Restricted material.

This forecast also assumes that some waste reduction techniques such as waste recycling, volume reduction, or waste minimization are performed - which would decrease the shipment volumes.

The plan for final disposal of the reactors has not yet officially changed, and one-piece transportation and disposal in the ERDF is still planned. In waste forecasting, it was assumed that each reactor will take 4 years to decommission, with $15 \%$ of the total waste volume to be deposited in the first year, $50 \%$ in the second year, $25 \%$ in the third year, and $10 \%$ in the fourth year.

The minimum and maximum ranges for this waste are both $100 \%$ of the baseline, indicating that there are minimal fluctuations expected from the baseline forecast.

\section{Other Forecast Data}

\section{- Low Level Waste}

- No low level waste is expected from Environmental Restoration for management by the CWC.

o This is a $100 \%$ decrease from the FY 96 forecast of $710 \mathrm{~m}^{3}$.

\section{- Hazardous Waste}

- No hazardous waste is expected from Environmental Restoration for management by the CWC. 
GENERATORS:

Surplus Facilities

\section{PROGRAMS}

Analytical Services - EM-40 - Facility Transitions - Landlord - Liquid Effluent - NP - Offsite - PNNL - RCRA - Solid Waste $\cdot$ SNF - TWRS

CHARACTERISTICS:

CH_LLMW $\cdot$ RH_LLMW $\cdot$ CH_TRU(M) $\cdot$ RH_TRU(M) $\cdot$ GTC III $\cdot$ LLW $\cdot$ HAZ

\section{CONTAINERS:}

CH_LLMW $\cdot$ RH_LLMW $\cdot$ CH_TRU(M) RH_TRU(M) - GTC III - LLW · HAZ

\section{WASTE CLASSES:}

CH_LLMW $\cdot$ RH_LLMW $\cdot \mathrm{CH}_{-}$TRU(M) $\cdot \mathrm{RH}_{-}$TRU(M) $\cdot$ GTC III $\cdot$ LLW $\cdot$ HAZ

Home - Contents - Web Site Map · Glossary · Help · Reports - Data Requests · Fcedback Form

NOTICE: This page is provided subject to our disclaimer. Contact: Oscar Valero at (509) 373-4752.

HNF-EP-0918 rev. 1 Approved for public release; distribution is unlimited. 


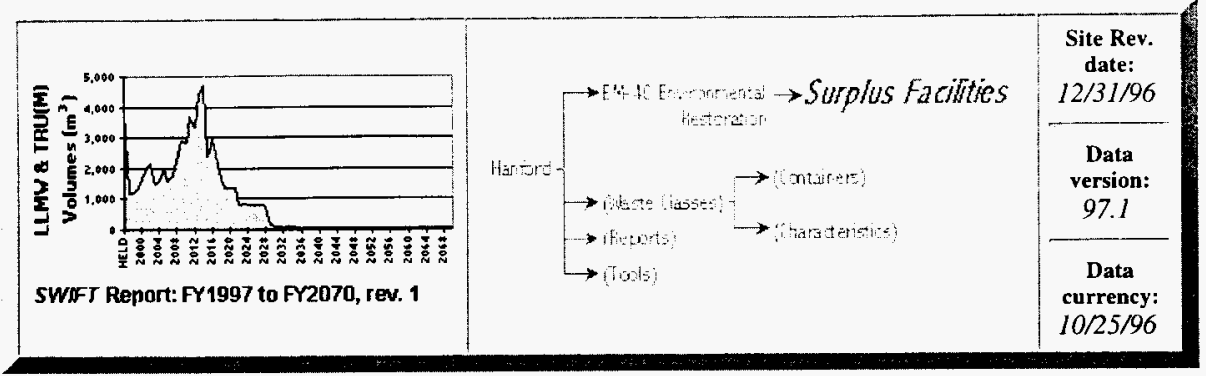

\section{EM-40 (Environmental Restoration) - Surplus Facilities}

Because Surplus Facilities is the only generator within the EM-40 (ER) program that will ship waste to the $\mathrm{CWC}$, waste information for this generator is identical to that found on the program page.

\begin{tabular}{|c|c|}
\hline \multicolumn{2}{|c|}{$\begin{array}{l}\text { GENERATORS: } \\
\text { Surplus Facilities }\end{array}$} \\
\hline \multicolumn{2}{|c|}{$\begin{array}{l}\text { PROGRAMS: } \\
\text { Analytical Services } \cdot \text { EM-40 } \cdot \text { Facility Transitions } \cdot \text { Landlord } \cdot \text { Liquid Effluent } \cdot \text { NP } \cdot \text { Offsite } \cdot \text { PNNL } \cdot \text { RCRA } \cdot \text { Solid } \\
\text { Waste } \cdot \text { SNF } \cdot \text { TWRS }\end{array}$} \\
\hline $\begin{array}{l}\text { CHARACTERISTICS: } \\
\mathrm{CH}_{-} \mathrm{LLMW} \cdot \mathrm{RH} \text { _LLMW } \cdot \mathrm{CH} \text { _TRU(M) } \cdot \mathrm{RH}+\mathrm{TRU}(\mathrm{M}) \\
\text { GTC III } \cdot \mathrm{LLW} \cdot \mathrm{HAZ}\end{array}$ & $\begin{array}{l}\text { CONTAINERS: } \\
\text { CH_LLMW } \cdot \text { RH_LLMW } \cdot \text { CH_TRU(M) } \\
\text { RH_TRU(M) } \cdot \text { GTC III } \cdot \text { LLW } \cdot \text { HAZ }\end{array}$ \\
\hline \multicolumn{2}{|c|}{$\begin{array}{l}\text { WASTE CLASSES: } \\
\text { CH_LLMW } \cdot \text { RH_LLMW } \cdot \text { CH_TRU(M) } \cdot \text { RH_TRU(M) } \cdot \text { GTC III } \cdot \text { LLW } \cdot \text { HAZ }\end{array}$} \\
\hline Home - Contents - Web Site Map - Glossary $\cdot$ H & rts - Data Requests - Feedback Form \\
\hline
\end{tabular}

NOTICE: This page is provided subject to our disclaimer. Contact: Oscar Valero at (509) 373-4752.

HNF-EP-0918 rev. 1 Approved for public release; distribution is unlimited. 
THIS $, \ldots, \ldots$

$$
\text { B. L N }
$$




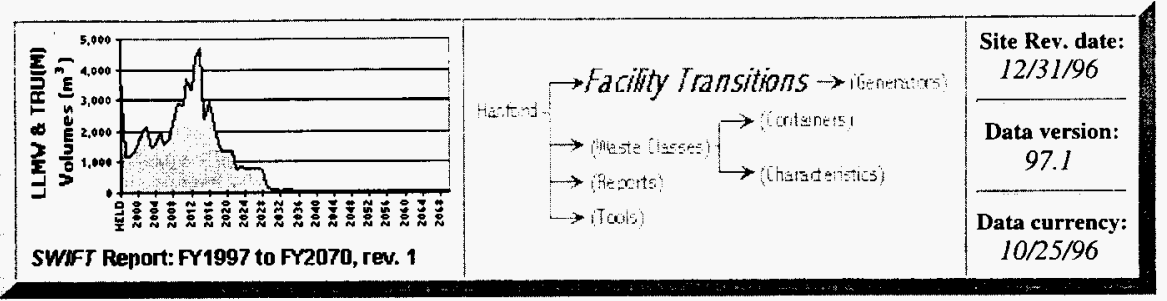

\section{Facility Transitions}

\section{Contents}

$\gg$ Highlights

»Annual Waste Class Volumes

» Summary Table

»Comparison to Previous Baseline(s)
"Background

» Forecast Assumptions and Comments

»Other Facility Transitions Forecast Data

\section{Highlights}

- The forecast life cycle for the Facility Transitions program ends in 2034.

- The life cycle total of LLMW and TRU(M) waste from Facility Transitions is $3,970 \mathrm{~m}^{3}$, or $6 \%$ of the Hanford total.

- This forecast shows a $65 \%$ decrease from the FY96 forecast of $11,370 \mathrm{~m}^{3}$, due primarily to revised estimates by the Plutonium Finishing Plant and B Plant.

- A $100 \mathrm{~m}^{3}$ increase is observed from the FY97.0 value of $3,870 \mathrm{~m}^{3}$ due to the transfer of 324 and 327 Buildings to this program.

- $\mathrm{CH}_{-}$TRU(M) waste is the primary waste class generated, representing $78 \%,\left(3,110 \mathrm{~m}^{3}\right)$ of the Facility Transitions waste volume.

- The Plutonium Finishing Plant is the major source of waste, generating $95 \%,\left(3,760 \mathrm{~m}^{3}\right)$ of the waste volume.

- 208 liter drums will hold $88 \%$ of the waste, and SWBs will contain $11 \%$ of the waste, while other container types are responsible for small volumes $(<1 \%)$.

- This program's mixed waste physical waste forms are very diverse. Nearly $87 \%$ is expected to be debris of some kind, while inorganic solids and special wastes make up more than $10 \%$.

- Most of the hazardous constituent volume will be metals without mercury $(65 \%)$. Ignitable waste will be $13 \%$ of the volume, corrosive waste will be $9 \%$, and organic waste will be $7 \%$. State regulated waste accounts for $3 \%$ of the volume, and $4 \%$ will be other hazardous constituents. 
Waste Class Distribution

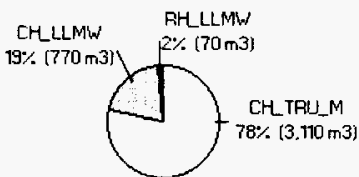

Total $=3,970 \mathrm{m3}$

\section{Physical Waste Form Distribution}

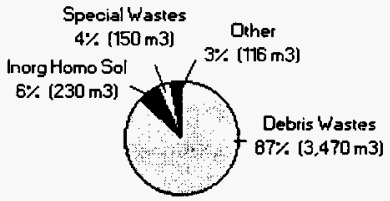

Total $=3,970 \mathrm{~m} 3$

\section{Generator Distributions}

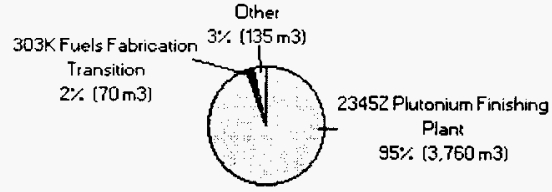

Total $=3,970 \mathrm{~m} 3$

\section{Hazardous Constituent Distribution}

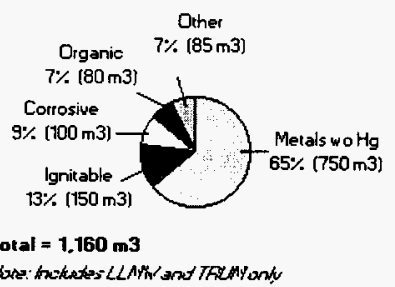

\section{Container Distribution}

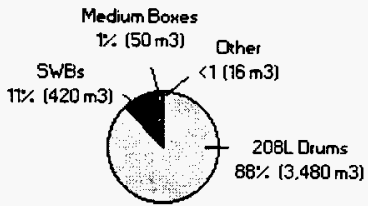

Total $=3,970 \mathrm{~m} 3$

Sum of totals may not add due to rounding: numbers over $10 \mathrm{~m}^{3}$ are rounded to the nearest $10 \mathrm{~m}^{3}$, numbers less than $10 \mathrm{~m}^{3}$ are rounded to integers, non-zero numbers less than 1 are rounded to 1 .

\section{Annual Waste Class Volumes}

Facility Transitions waste will be generated from 1997 to the end of life cycle in 2034.

\section{Annual Baseline Volumes}




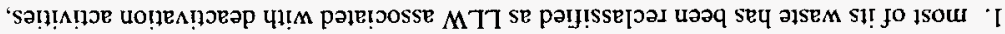

:əsneว29

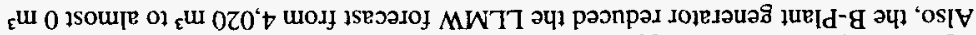

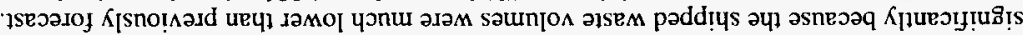

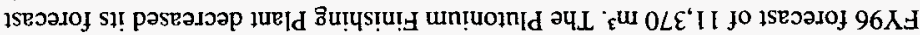

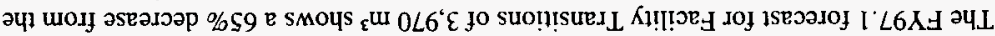

(s)วu!̣วeg sno!̣axd 01 uos!̣edwo

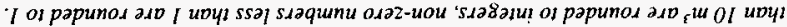

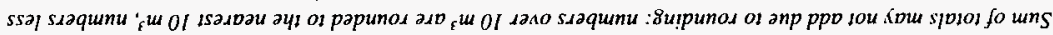

\begin{tabular}{|c|c|c|c|c|c|c|}
\hline & $.2028 \mathrm{H}$ & WD & F2820 & $+\infty$ & $\because 281$ & 128 \\
\hline 7001 & $0 \angle 6 E$ & 06 & OLLE & $\overline{02}$ & $0 \angle L$ & 18201 \\
\hline$\% 0$ & $b$ & 0 & 0 & D & b & 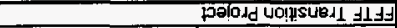 \\
\hline$\overline{\mathbf{Z 0}}$ & $b$ & 0 & 0 & 0 & 1 & 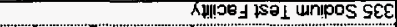 \\
\hline$\% 0$ & 1 & 0 & li & 0 & 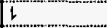 & 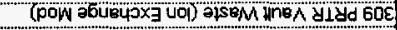 \\
\hline 80 & $\bar{z}$ & 0 & 0 & 0 & $z$ & Weld GGSZZ \\
\hline$\% 0$ & $0 t$ & 0 & 0 & 0 & Ob & 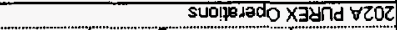 \\
\hline$\because 1$ & $0 \varepsilon$ & 0 & 0 & 0 & $0 \varepsilon$ & XYilje $\mathrm{g}$ a \\
\hline$\%$ & 00 & 01 & $t$ & 0 & $0 z$ & бU़िing $\nabla Z \varepsilon^{-}$TNNd \\
\hline$\% 2$ & 09 & 0 & 09 & 0 & $D$ & 5U!p|ing $\angle Z \varepsilon-7 N N$ d \\
\hline 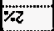 & 02 & 0 & 0 & 02 & 0 & 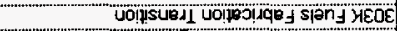 \\
\hline$\% 96$ & $09 \angle \varepsilon$ & 0 & 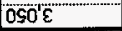 & 0 & $0 \mathrm{LL}$ & 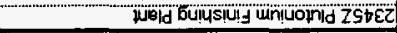 \\
\hline 13d & IFjouqns & (w)mal Ha & (w)חнг-но & AWт7'H4 & ANTT" HO & 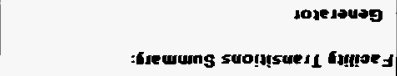 \\
\hline
\end{tabular}

( ${ }_{\varepsilon}$ w u!̣ saunjo $\Lambda$ )

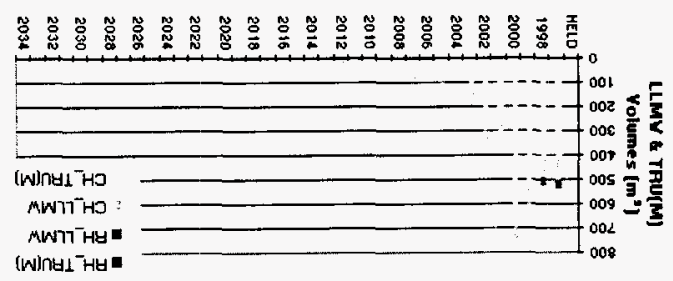

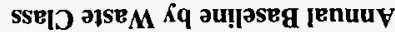

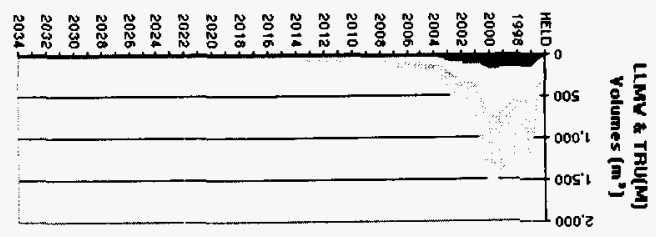

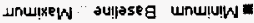


and

2. the FY96 forecast significantly overestimated waste volumes.

The FY97.1 forecast volume is an $100 \mathrm{~m}^{3}$ increase over the FY 97.0 forecast due to the transfer of 324 and 327 Buildings to the program.

The only striking change in physical waste forms is that inorganic salt waste composed $7 \%$ of the LLMW volume last year, whereas that form is currently negligible.

\section{Comparison to Previous Baseline(s) by Waste Class}

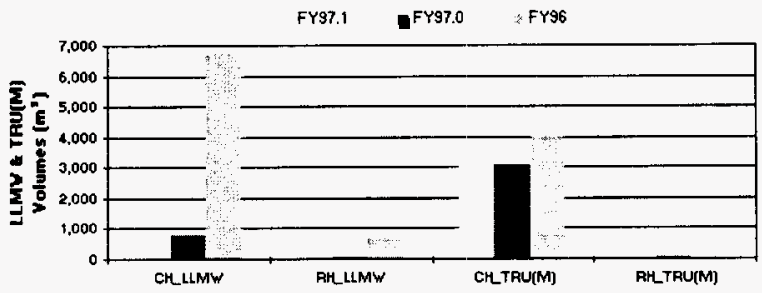

\begin{tabular}{|c|c|c|c|}
\hline $\begin{array}{l}\text { Facility Trensitions Comparison: } \\
\text { Waste Class }\end{array}$ & $\begin{array}{l}\text { FY97.1 } \\
\text { Forecast } \\
\left(\mathrm{m}^{3}\right)\end{array}$ & $\begin{array}{l}\text { FY97.0 } \\
\text { Forecast } \\
\left(m^{2}\right)\end{array}$ & $\begin{array}{c}\text { FYg6 } \\
\text { Forecast } \\
\left(\mathrm{m}^{3}\right)\end{array}$ \\
\hline $\mathrm{CH} L L M M N$ & 770 & 750 & 6,710 \\
\hline RH_LLMNN & 70 & 70 & 660 \\
\hline $\mathrm{CH}$ TRU(M) & 3,110 & 3,050 & 4,010 \\
\hline RH TRU(M) & 10 & 0 & 0 \\
\hline Subtots & 3,970 & 3,870 & 11,370 \\
\hline LLW & 6.470 & 5,410 & 9600 \\
\hline $\mathrm{HAZ}$ & 10 & 10 & 950 \\
\hline Total & 10,450 & 2,290 & 21,920 \\
\hline
\end{tabular}

Sum of totals may not add due to rounding: numbers over $10 \mathrm{~m}^{3}$ are rounded to the nearest $10 \mathrm{~m}^{3}$, numbers less than $10 \mathrm{~m}^{3}$ are rounded to integers, non-zero numbers less than I are rounded to $I$.

\section{Background}

The Facility Transitions mission is to manage the deactivation activities of those facilities that are no longer in the operational phase. As stored material and wastes are removed, the facilities will be deactivated and transferred to the D\&D program. The forecast life cycle for waste generated by Facility Transitions extends to 2034. The types of waste generated within this program can be operational/maintenance waste, deactivation waste, and surveillance \& maintenance waste. Generation of surveillance \& maintenance waste is expected to be minimal, since the planning baseline for each facility assumes that-upon completion of deactivation-the facility will be immediately transferred to the EM-40 contractor for D\&D.

Two generators that reported waste volumes in FY96 but not in FY97 are Legacy Facilities Transition and Large 105DR Sodium Fire Facility. These facilities are no longer generating solid waste. 


\section{Forecast Assumptions and Comments}

The Facility Transitions waste volume forecast assumes no slip in the schedule for some sites to transition to Surveillance and Maintenance phase. Specifically, the Plutonium Finishing Plant will be cleaned out and the facility turned over to D\&D by 2034.

The minimum and maximum range for this waste is $28 \%$ and $244 \%$ of the baseline, indicating a high degree of uncertainty for the baseline forecast.

\section{Other Forecast Data}

\section{- Low Level Waste}

- A total of $6,470 \mathrm{~m}^{3}$ of LLW is expected from Facility Transitions until 2034.

- This forecast shows a $32 \%$ reduction from the FY96 forecast of $9,600 \mathrm{~m}^{3}$ and a $20 \%$ increase from the FY97 forecast of $5,410 \mathrm{~m}^{3}$.

- LLW will be shipped in five different container types: $45 \%$ of the volume is contained in 208 liter drums, $24 \%$ in MB-IV boxes, $20 \%$ in MB-V boxes, $10 \%$ in Medium boxes, and $1 \%$ in others.

- LLW physical forms are basically all debris $(96 \%)$.

\section{- Hazardous Waste}

- A total of $10 \mathrm{~m}^{3}$ of hazardous waste is expected from Facility Transitions for management by the CWC.

GENERATORS:

202A PUREX Operations - 225B B Plant - 2345Z Plutonium Finishing Plant - 303K Fuels Fabrication Transition · 309 PRTR Vault Waste (Ion Exchange Mod) - 324 Building · 327 Building - 335 Sodium Test Facility · FFTF Transition Project - Waste Encapsulation/Storage Facility

PROGRAMS:

Analytical Services - EM-40 - Facility Transitions - Landlord - Liquid Effluent - NP · Offsite - PNNL - RCRA - Solid Waste $\cdot$ SNF $\cdot$ TWRS

\begin{tabular}{|c|c|}
\hline $\begin{array}{c}\text { CHARACTERISTICS: } \\
\text { CH_LLMW } \cdot \text { RH_LLMW } \cdot \text { CH_TRU(M) } \\
\text { GTC III } \cdot \text { LLW_TRU(M) } \cdot \text { HAZ }\end{array}$ & $\begin{array}{c}\text { CONTAINERS: } \\
\text { CH_LLMW } \cdot \text { RH_LLMW } \cdot \text { CH_TRU(M) } \\
\text { RH_TRU(M) } \cdot \text { GTC III } \cdot \text { LLW } \cdot \text { HAZ }\end{array}$ \\
\hline \multicolumn{2}{|c|}{$\begin{array}{c}\text { WASTE ClaASSES: } \\
\text { CH_LLMW } \cdot \text { RH LLMW } \cdot \text { CH_TRU(M) } \cdot \text { RH_TRU(M) } \cdot \text { GTC III } \cdot \text { LLW } \cdot \text { HAZ }\end{array}$} \\
\hline
\end{tabular}

NOTICE: This page is provided subject to our disclaimer. Contact: Oscar Valero at (509) 373-4752.

HNF-EP-0918 rev. 1 Approved for public release; distribution is unlimited. 


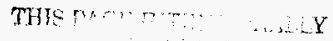

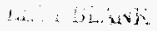




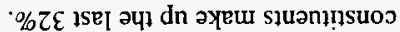

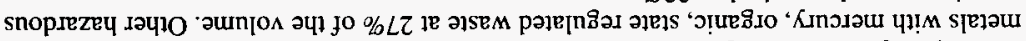

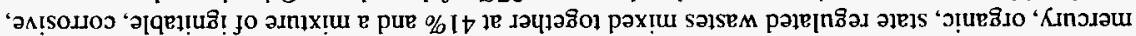

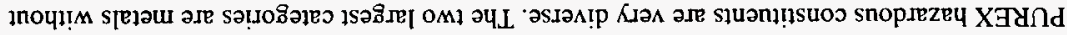

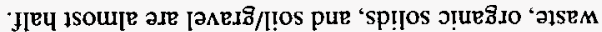

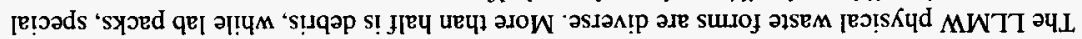

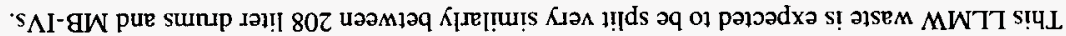

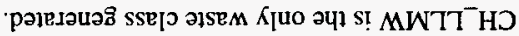

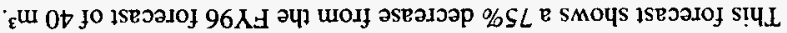
' [e10101

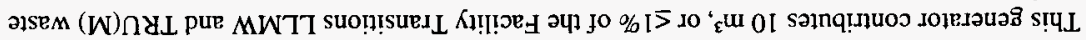

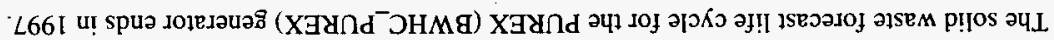

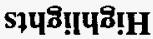

punoเôxวeg «

Ried iserjo primerod «

cle sluวuسo pue suo!̣dunss $\forall$ 1seวa.o

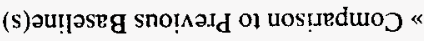
sounjo $\Lambda$ [enuu $\forall \ll$ งเบชี!กษิ์!H «

sานวนน0ว

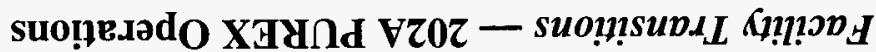

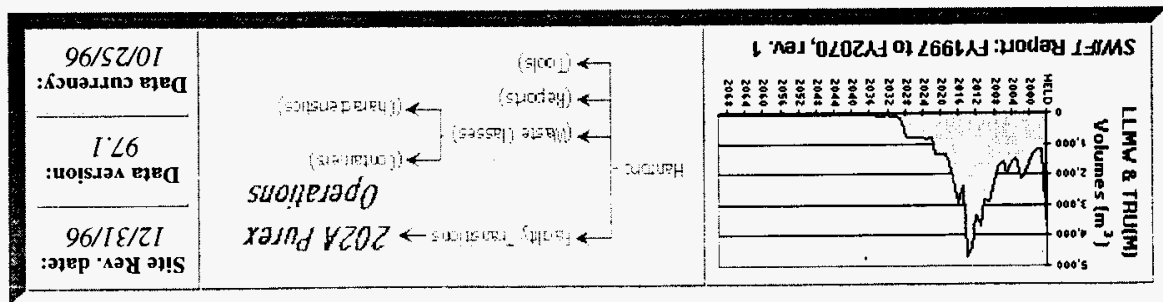




\section{Waste Class Distribution}

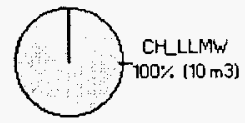

Total $=10 \mathrm{~m} 3$

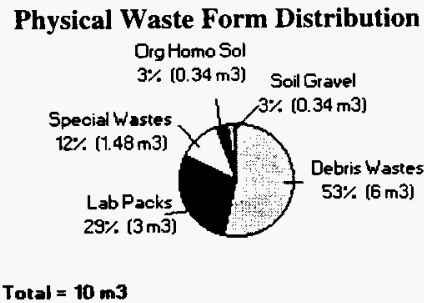

Physical Waste Form Distribution

Org Homo Sol

Soil Gravel

Total $=10 \mathrm{~m} 3$

\section{Hazardous Constituent Distribution}

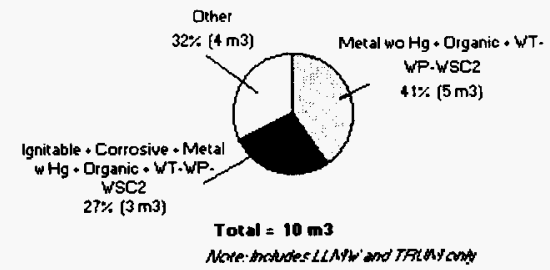

\section{Container Distribution}

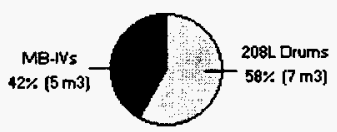

Total $=10 \mathrm{m3}$

Sum of totals may not add due to rounding: numbers over $10 \mathrm{~m}^{3}$ are rounded to the nearest $10 \mathrm{~m}^{3}$, numbers less than $10 \mathrm{~m}^{3}$ are rounded to integers, non-zero numbers less than 1 are rounded to 1 .

\section{Annual Volumes}

\section{Annual Baseline Volumes}

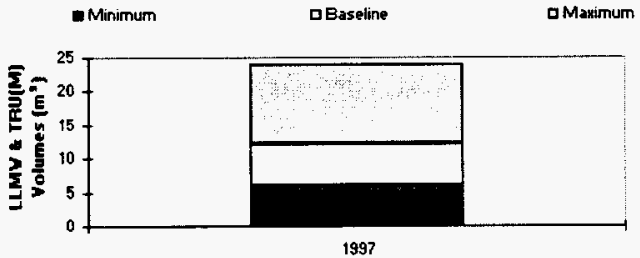




\section{Annual Baseline by Waste Class}

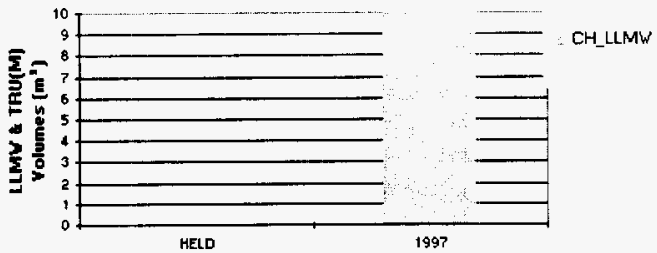

\section{Comparison to Previous Baseline(s)}

The FY97 forecast for PUREX of $10 \mathrm{~m}^{3}$ shows a $75 \%$ decrease from the FY 96 forecast of 40 $\mathrm{m}^{3}$. There is also no TRU(M) waste expected from PUREX in FY 97 compared to about $10 \mathrm{~m}^{3}$ of CH_TRU(M) forecasted in FY96. These forecast reductions are due to the completion of deactivation activities in 1997. Last year's forecast included waste to be generated in FY96-97; whereas only FY97 is included in the current forecast.

\section{Comparison to Previous Baseline(s) by Waste Class}

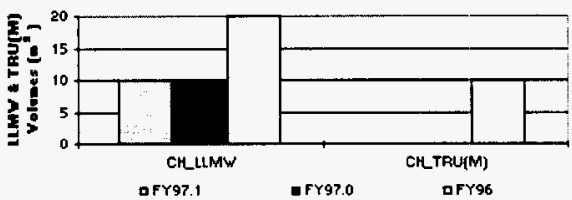

\begin{tabular}{|c|c|c|c|}
\hline $\begin{array}{l}\text { 202A PUREX Operations Comparison: } \\
\text { Yaste Class }\end{array}$ & $\begin{array}{c}\text { FY97.1 } \\
\text { Forecast } \\
\text { (m²) }\end{array}$ & $\begin{array}{c}\text { Fr97.0 } \\
\text { Forecast } \\
\left(\mathbf{m}^{2}\right)\end{array}$ & $\begin{array}{l}\text { FY96 } \\
\text { Forecast } \\
\text { (m²] }\end{array}$ \\
\hline CH_LLMW & 10 & 10 & 20 \\
\hline CH TRU'(M) & 0 & 0 & 10 \\
\hline suprory & $\omega$ & $1 \theta$ & 10 \\
\hline$L L W$ & 390 & 390 & 580 \\
\hline HAZ & 4 & 4 & 9 \\
\hline Toral & 10 & 110 & 650 \\
\hline
\end{tabular}

Sum of totals may not add due to rounding: numbers over $10 \mathrm{~m}^{3}$ are rounded to the nearest $10 \mathrm{~m}^{3}$, numbers less than $10 \mathrm{~m}^{3}$ are rounded to integers, non-zero numbers less than 1 are rounded to 1 .

\section{Background}

PUREX is currently undergoing deactivation, expected to be completed in October 1997.

Solid waste is generated from zone reduction, routine operations, maintenance activities, and housekeeping associated with the deactivation efforts.

\section{Forecast Assumptions and Comments}


Assumptions used in preparing this forecast are that PUREX will not generate or ship solid waste to the CWC after FY97; that PUREX waste volume may increase with deactivation efforts; and that solid waste characteristics, constituents, and container types currently described in the PUREX/Waste Management (formerly PUREX/Solid Waste) Interface Control Document will remain unchanged.

The minimum and maximum range for this waste volume is $50 \%$ and $200 \%$ of the baseline. The minimum percentage is based on uncertainty of waste volume generated from the PUREX deactivation efforts and the exact schedule in which waste will actually be generated. The maximum percentage is based on uncertainty about actual waste volumes that could be generated due to deactivation activities and zone reduction.

\section{Other Forecast Data}

\section{- Low Level Waste}

- A total of $390 \mathrm{~m}^{3}$ of LLW is expected from PUREX until 1997.

- This forecast shows a 34\% reduction from the FY96 forecast of $590 \mathrm{~m}^{3}$.

- MB-V boxes will account for 54\% of the LLW, while 208 liter drums and Medium boxes will account for similar volumes of the rest of the waste ( $24 \%$ and $22 \%$ respectively).

- Essentially all of the LLW will be in the physical form of debris: soil and soil/gravel and lab packs represent only a single percent of the volume.

\section{- Hazardous Waste}

- About $4 \mathrm{~m}^{3}$ of hazardous waste is expected from PUREX for management by the CWC.

\section{GENERATORS:}

202A PUREX Operations · 225B B Plant - 2345Z Plutonium Finishing Plant - 303K Fuels Fabrication Transition - 309 PRTR Vault Waste (Ion Exchange Mod) · 324 Building · 327 Building · 335 Sodium Test Facility · FFTF Transition Project - Waste Encapsulation/Storage Facility

PROGRAMS:

Analytical Services - EM-40 - Facility Transitions · Landlord · Liquid Effluent $\cdot$ NP $\cdot$ Offsite $\cdot$ PNNL $\cdot$ RCRA $\cdot$ Solid Waste - SNF - TWRS

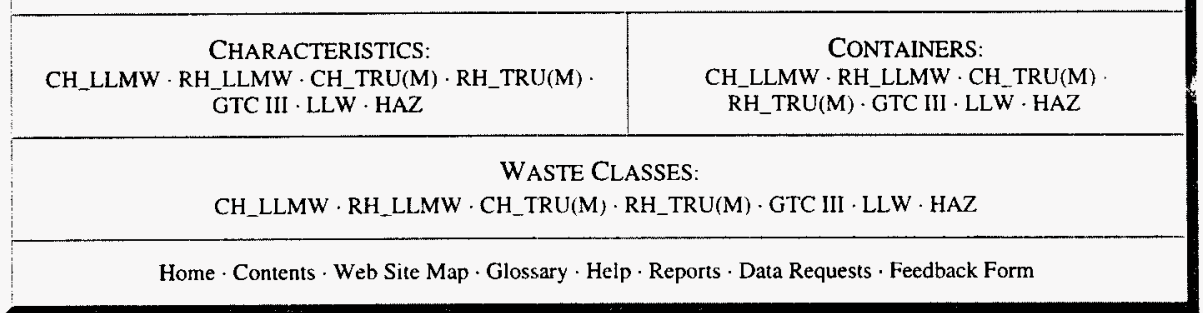

NOTICE: This page is provided subject to our disclaimer. Contact: Oscar Valero at (509) 373-4752.

HNF-EP-0918 rev. 1 Approved for public release; distribution is unlimited. 


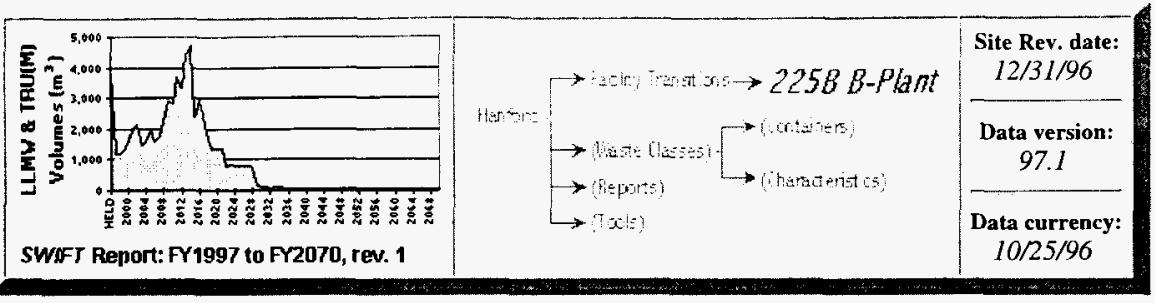

\section{Facility Transitions - 225B B Plant}

\section{Contents}

" Highlights

» Annual Volumes

" Comparison to Previous Baseline(s)

"Background
" Forecast Assumptions and Comments

"Other 225B B Plant Forecast Data

"Detailed Forecast Data

\section{Highlights}

- The solid waste forecast life cycle for the B Plant generator ends in 1998.

- B Plant contributes $2 \mathrm{~m}^{3}(<1 \%)$ of Facility Transitions' LLMW forecast.

- This forecast shows almost a $100 \%$ decrease from the FY96 forecast of $4,020 \mathrm{~m}^{3}$, based on reclassification of some estimated waste to LLW.

- $\mathrm{CH}$ _LLMW is the only waste class generated.

- The 208 liter drum is to contain all of this generator's LLMW.

- The physical waste forms from B Plant are $60 \%$ inorganic solids, while organic solids, debris, and special wastes account for $15 \%, 15 \%$, and $10 \%$ respectively.

- The LLMW hazardous constituents evenly divide the volume: corrosive, ignitable, state regulated wastes, organic, and metals without mercury; each compose $20 \%$ of the total volume. 


\section{Waste Class Distribution}

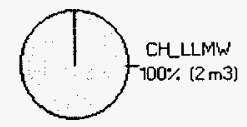

Total $=2 \mathbf{m} 3$

Physical Waste Form Distribution

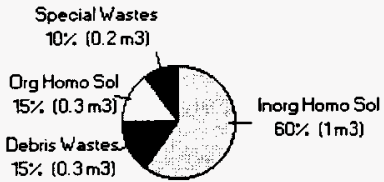

Total $=2 \mathrm{~m} 3$

\section{Hazardous Constituent Distribution}

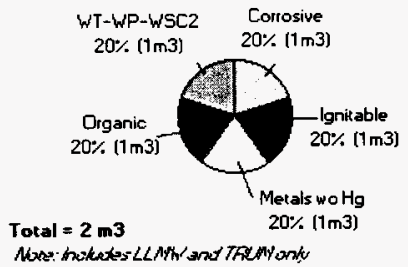

\section{Container Distribution}

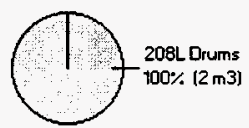

Total $=2 \mathrm{m3}$

Sum of totals may not add due to rounding: numbers over $10 \mathrm{~m}^{3}$ are rounded to the nearest $10 \mathrm{~m}^{\mathrm{s}}$, numbers less than $10 \mathrm{~m}^{3}$ are rounded to integers, non-zero numbers less than 1 are rounded to 1 .

\section{Annual Volumes}

\section{Annual Baseline Volumes}




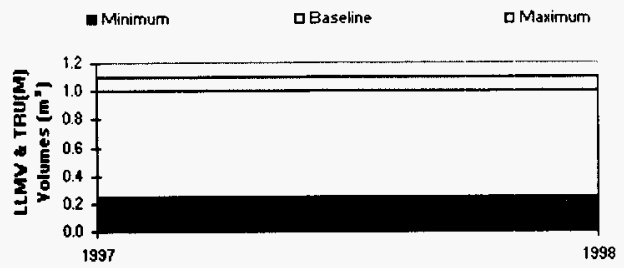

\section{Annual Baseline by Waste Class}

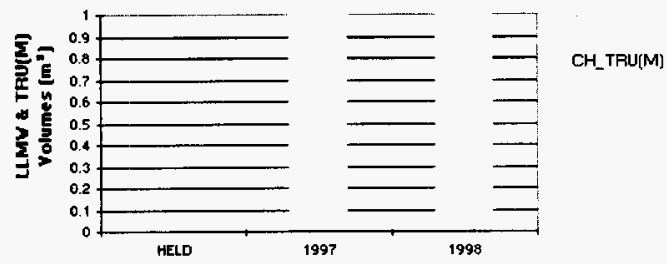

\section{Comparison to Previous Baseline(s)}

The FY97 forecast for B Plant of $2 \mathrm{~m}^{3}$ shows a $100 \%$ decrease from the FY 96 forecast of $4,020 \mathrm{~m}^{3}$. This is because:

- some of the waste has been reclassified as LLW associated with deactivation activities, - the FY96 forecast significantly overestimated waste volume.

The FY96 forecast for B Plant included the Waste Encapsulation/Storage Facility (WESF). In FY97, WESF waste is reported separately, reducing the B Plant waste volume by at least $7 \%$.

\section{Comparison to Previous Baseline(s) by Waste Class}

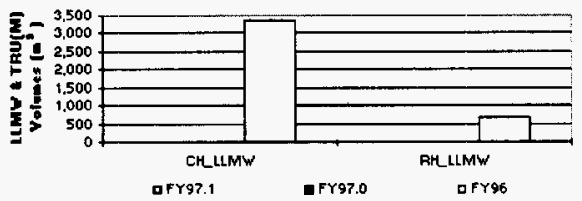

\begin{tabular}{|c|c|c|c|}
\hline $\begin{array}{l}225 B \text { B Plant Comparison: } \\
\text { Yaste Class }\end{array}$ & $\begin{array}{c}\text { FY97_1 } \\
\text { Foreesst } \\
\left(\mathrm{m}^{3}\right)\end{array}$ & $\begin{array}{c}\text { FY97.0 } \\
\text { Forecast } \\
\text { (m') }\end{array}$ & $\begin{array}{c}\text { FY96 } \\
\text { Forecast } \\
\text { (m') }\end{array}$ \\
\hline CH LLMW & 2 & 2 & 3,360 \\
\hline RH_LLMW & 0 & o & 660 \\
\hline sodrores & 2 & 2 & 1,028 \\
\hline LLW & 270 & 270 & 0 \\
\hline Tores & $2 m$ & 270 & 1,020 \\
\hline
\end{tabular}

Sum of totals may' not add due to rounding: numbers over $10 \mathrm{~m}^{3}$ are rounded to the nearest $10 \mathrm{~m}^{3}$, numbers less 
than $10 \mathrm{~m}^{3}$ are rounded to integers, non-zero numbers less than 1 are rounded to 1.

\section{Background}

The current mission of B Plant is to transition the facility to a safe configuration for transfer to the ERC team for long term surveillance and maintenance activities. Wastes generated during this process are from the reduction/removal of hazards within the facility. The waste will include minor decontamination waste and system deactivation waste. Large portions of the waste will be from contamination control and personal protective equipment. Some chemical/product disposal will occur.

\section{Forecast Assumptions and Comments}

The main assumption for the B Plant forecast is that the facility will complete its deactivation mission by the end of FY98.

The minimum and maximum range for this waste is $25 \%$ and $110 \%$ of the baseline.

\section{Other Forecast Data}

- Low Level Waste

- A total of $270 \mathrm{~m}^{3}$ of LLW is expected from B Plant until 1998.

o FY96 forecast of LLW was $0 \mathrm{~m}^{3}$.

- MB-V boxes will contain two-thirds of this LLW. Medium boxes will contain more than one-quarter of the waste, and some will arrive in 208 liter drums as well.

o Four physical waste forms are reported for LLW: debris ( $89 \%$ by volume), soil and soil/gravel $(7 \%)$, inorganic solids (2\%), and organic solids $(2 \%)$.

\section{- Hazardous Waste}

- No hazardous waste is expected from B Plant for management by the CWC. 


\section{GENERATORS}

202A PUREX Operations - 225B B Plant $\cdot 2345 \mathrm{Z}$ Plutonium Finishing Plant - 303K Fuels Fabrication Transition $\cdot 309$

PRTR Vault Waste (Ion Exchange Mod) · 324 Building · 327 Building · 335 Sodium Test Facility · FFTF Transition

Project - Waste Encapsulation/Storage Facility

\section{PROGRAMS:}

Anaiytical Services - EM-40 - Facility Transitions - Landlord - Liquid Effuent - NP · Offsite - PNNL - RCRA - Solid Waste - SNF - TWRS

\begin{tabular}{|c|c|}
\hline $\begin{array}{c}\text { CHARACTERISTICS: } \\
\text { CH_LLMW } \cdot \text { RH_LLMW } \cdot \text { CH_TRU(M) } \cdot \text { RH_TRU(M) } \\
\text { GTC III } \cdot \text { LLW } \cdot \text { HAZ }\end{array}$ & $\begin{array}{c}\text { CONTAINERS: } \\
\text { CH_LLMW } \cdot \text { RH_LLMW } \cdot \text { CH_TRU(M) } \\
\text { RH_TRU(M) } \cdot \text { GTC III } \cdot \text { LLW } \cdot \text { HAZ }\end{array}$ \\
\hline CH_LLMW $\cdot$ RH_LLMW $\cdot$ CH_TRU(M) $/$ RH_TRU(M) $)$ GTC III $\cdot$ LLW $\cdot$ HAZ \\
\hline Home $\cdot$ Contents $\cdot$ Web Site Map $\cdot$ Glossary $\cdot$ Help $\cdot$ Reports $\cdot$ Data Requests $\cdot$ Feedback Form
\end{tabular}

NOTICE: This page is provided subject to our disclaimer. Contact: Oscar Valero at (509) 373-4752.

HNF-EP-0918 rev. 1 Approved for public release; distribution is unlimited. 
THL:" A... DSL NS 


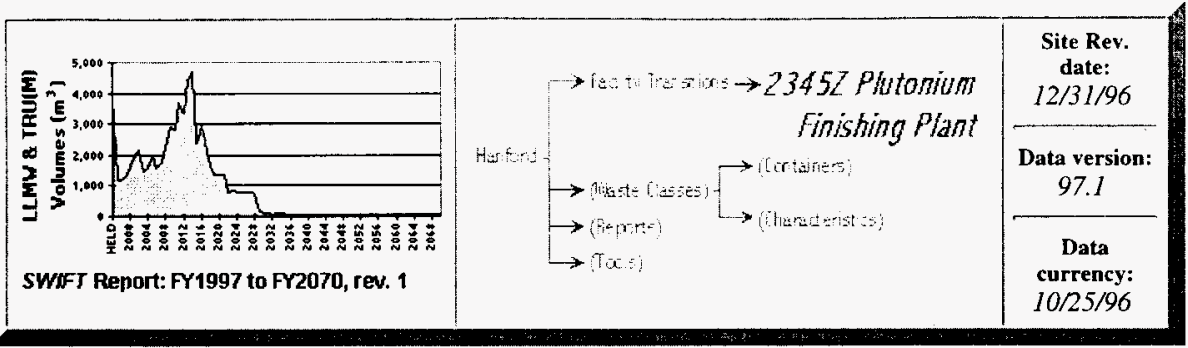

\section{Facility Transitions - 2345Z Plutonium Finishing Plant}

\section{Contents}
» Highlights
"Forecast Assumptions and Comments
»Annual Volumes
» Other 2345Z Plutonium Finishing Plant Forecast
»Comparison to Previous Baseline(s)
Data
»Background
»Detailed Forecast Data

\section{Highlights}

- The forecast life cycle for the Plutonium Finishing Plant (BWHC_PFP) generator ends in 2034.

- This generator contributes $3,760 \mathrm{~m}^{3}$, or $95 \%$ of the Facilities Transition LLMW and TRU(M) waste total.

- This forecast shows a $48 \%$ decrease from the FY96 forecast of $7,270 \mathrm{~m}^{3}$.

- $\mathrm{CH}_{-}$TRU(M) is the primary waste class generated, representing $81 \%$, or $3,050 \mathrm{~m}^{3}$ of the Plutonium Finishing Plant waste volume.

- Roughly $89 \%$ of the LLMW and TRU(M) waste volume is projected to be shipped in 208 liter drums, and the rest of the waste in SWBs.

- Debris accounts for $89 \%$ of this LLMW and TRU(M) waste. Inorganic waste, lab packs, and special wastes account for the remaining $11 \%$.

- Metals without mercury is the most common hazardous constituent ( $64 \%$ by volume). Other constituents are ignitable (14\%), corrosive $(9 \%)$, organic $(7 \%)$, and PCBs and state regulated waste $(6 \%)$. 


\section{Waste Class Distribution}

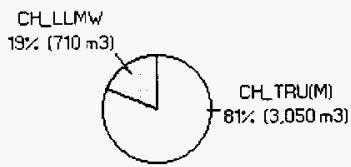

Total $=3,760 \mathrm{m3}$

\section{Physical Waste Form Distribution}

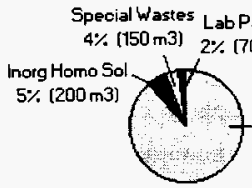

Total $=3,760 \mathrm{~m} 3$

\section{Hazardous Constituent Distribution}

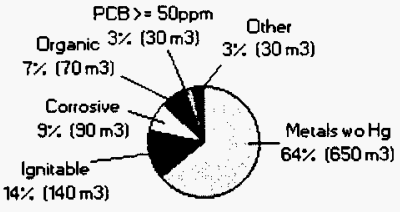

Total $=1,010 \mathrm{m3}$

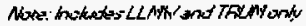

\section{Container Distribution}

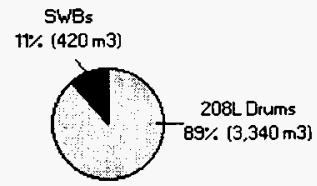

Total $=3,760 \mathrm{m3}$

Sum of totals may not add due to rounding: numbers over $10 \mathrm{~m}^{3}$ are rounded to the nearest $10 \mathrm{~m}^{3}$, numbers less than $10 \mathrm{~m}^{3}$ are rounded to integers, non-zero numbers less than 1 are rounded to 1 .

\section{Annual Volumes}

\section{Annual Baseline Volumes}




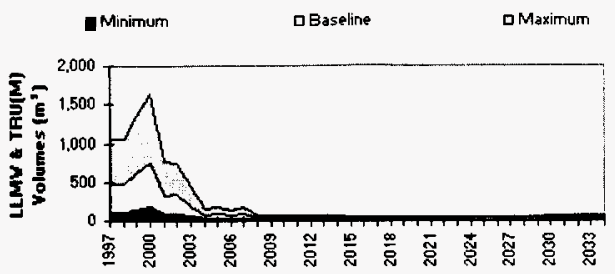

\section{Annual Baseline by Waste Class}

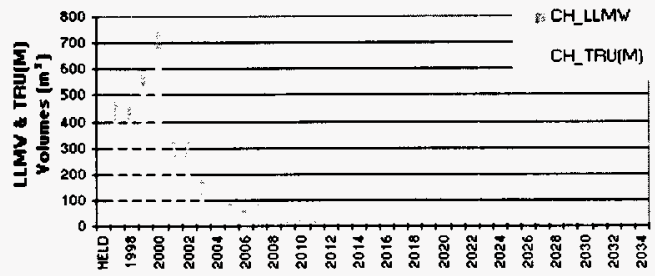

\section{Comparison to Previous Baseline(s)}

The FY 97 forecast for Plutonium Finishing Plant of $3,760 \mathrm{~m}^{3}$ shows a $48 \%$ decrease from the FY96 forecast of $7,270 \mathrm{~m}^{3}$, primarily because the CH_LLMW and CH_TRU(M) shipped volumes were so much lower than previously forecast. Additionally, some reduction in CH_LLMW is due to the change of paint type, from paint that was a mixture of regulated metals and solvents to a paint that is regulated for only one type of hazard. Other reasons for the volume reduction are the cancellation, delay, and acceleration of a number of projects within this facility.

\section{Comparison to Previous Baseline(s) by Waste Class}

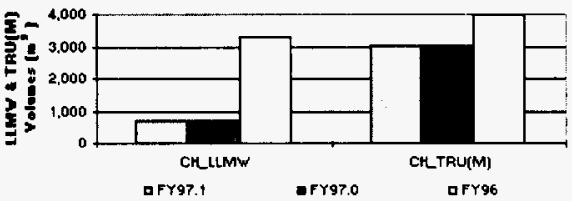

\begin{tabular}{|c|c|c|c|}
\hline $\begin{array}{l}23452 \text { Plutonium Finishing Plant Comparison: } \\
\text { Vaste Class }\end{array}$ & $\begin{array}{c}\text { Frs7.1 } \\
\text { Forecast } \\
\left(m^{2}\right)\end{array}$ & $\begin{array}{c}\text { FY97.0 } \\
\text { Forecast } \\
\text { (m') }\end{array}$ & $\begin{array}{c}\text { FY96 } \\
\text { Forecast } \\
\text { (m) }\end{array}$ \\
\hline CH LLMW & 710 & 710 & 3,280 \\
\hline CH_TRU[M] & 3.050 & 3.050 & 4.000 \\
\hline stoptoros & $\pi 760$ & 3,700 & $7.27 \theta$ \\
\hline LLW & 3.880 & 3,880 & 8,370 \\
\hline $\mathrm{HAZ}$ & 0 & 0 & 900 \\
\hline Tord & 7,650 & 7,650 & 16510 \\
\hline
\end{tabular}


Sum of totals may not add due to rounding: numbers over $10 \mathrm{~m}^{3}$ are rounded to the nearest $10 \mathrm{~m}^{3}$, numbers less than $10 \mathrm{~m}^{3}$ are rounded to integers, non-zero numbers less than 1 are rounded to $l$.

\section{Background}

The Plutonium Finishing Plant consists of 14 facilities that generate solid waste. The waste is generated through surveillance and maintenance, decontamination, and stabilization activities. Most of the stabilization and deactivation will be completed by 2007 .

\section{Forecast Assumptions and Comments}

The assumption method used in providing this forecast is the comparison of data with SWITS resulting in the lowering of LLMW and TRU(M) waste.

The minimum and maximum range for this waste volume is $27 \%$ and $242 \%$ of the baseline. The minimum percentage is based on clean-out activities not taking place and what is assumed to be a reasonable number. The maximum percentage is based on perceived variations in waste generating estimates. These percentages indicate a low degree of confidence in the forecast and a waste shipment that probably will be higher than the baseline volume.

\section{Other Forecast Data}

\section{- Low Level Waste}

- A total of $3,880 \mathrm{~m}^{3}$ of LLW is expected from Plutonium Finishing Plant until 2034.

- This forecast shows a $54 \%$ decrease from the FY96 forecast of $8,370 \mathrm{~m}^{3}$.

o The containers for the LLW will be 208 liter drums ( $60 \%$ ), MB-IV boxes (39\%), and MB-V boxes (1\%)

- $100 \%$ of the PFP's LLW is debris in physical waste form; yet, the majority of the volume is the plastic/rubber variety of debris.

\section{- Hazardous Waste}

- No hazardous waste is expected from Plutonium Finishing Plant for management by the CWC. 


\section{GENERATORS:}

202A PUREX Operations - 225B B Plant $\cdot 2345 Z$ Plutonium Finishing Plant - 303K Fuels Fabrication Transition · 309 PRTR Vault Waste (Ion Exchange Mod) - 324 Building · 327 Building · 335 Sodium Test Facility · FFTF Transition Project - Waste Encapsulation/Storage Facility

\section{PROGRAMS}

Analytical Services $\cdot$ EM-40 - Facility Transitions · Landlord - Liquid Effluent $\cdot$ NP $\cdot$ Offsite $\cdot$ PNNL $\cdot$ RCRA $\cdot$ Solid Waste $\cdot$ SNF - TWRS

CHARACTERISTICS:
CH_LLMW $\cdot$ RH_LLMW $\cdot$ CH_TRU(M) $\cdot$ RH_TRU(M)
GTC III $\cdot$ LLW - HAZ

\section{WASTE CLASSES:}

CH_LLMW $\cdot$ RH_LLMW $\cdot$ CH_TRU(M) $\cdot$ RH_TRU(M) $\cdot$ GTC III $\cdot$ LLW $\cdot$ HAZ
CONTAINERS:

CH_LLMW $\cdot$ RH_LLMW $\cdot$ CH_TRU(M) . RH_TRU(M) $\cdot$ GTC III $\cdot$ LLW $\cdot$ HAZ

Home - Contents - Web Site Map - Glossary · Help · Reports · Data Requests · Feedback Form

NOTICE: This page is provided subject to our disclaimer. Contact: Oscar Valero at (509) 373-4752.

HNF-EP-0918 rev. 1 Approved for public release; distribution is unlimited. 


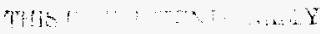
1.. . is thvi 


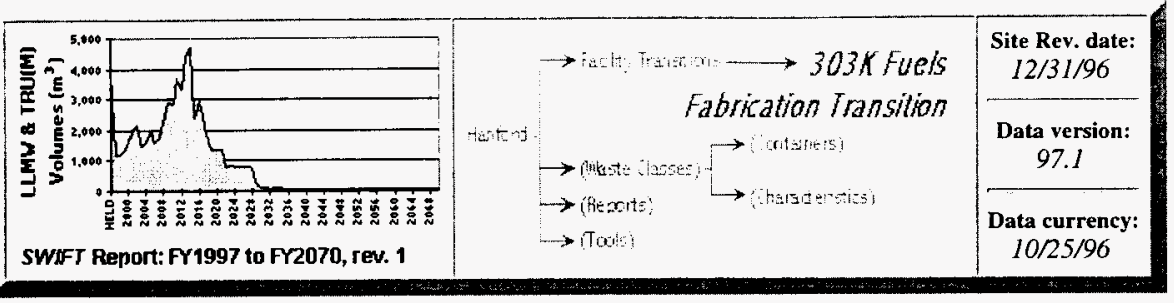

\section{Facility Transitions - 303K Fuels Fabrication Transition}

\section{Contents}
» Highlights
»Forecast Assumptions and Comments
» Annual Volumes
» Other 303K Fuels Fabrication Transition Forecast
Data
» Comparison to Previous Baseline(s)
»Detailed Forecast Data
» Background

\section{Highlights}

- The forecast life cycle for the Fuels Fabrication Transition (BWHC_FUEL_TRANS) generator ends in 1998.

- This generator contributes $70 \mathrm{~m}^{3}$, or $2 \%$ of the Facilities Transition LLMW total.

- The FY97.1 forecast shows a $250 \%$ increase from the FY96 forecast of $20 \mathrm{~m}^{3}$.

- RH_LLMW is the only waste class generated.

- This generator will send RH_LLMW in Medium boxes (76\%), Small boxes (14\%), and 208 liter drums (10\%).

- The only physical waste form is debris: $90 \%$ contaminated metal and $10 \%$ inorganic nonmetal.

- $100 \%$ of the LLMW is expected to have metals without mercury. 


\section{Waste Class Distribution}

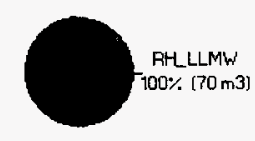

Total $=70 \mathrm{m3}$

\section{Physical Waste Form Distribution Hazardous Constituent Distribution}
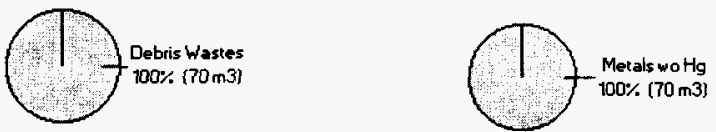

Total $=70 \mathrm{~m} 3$

Total $=70 \mathrm{m3}$

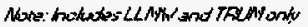

\section{Container Distribution}

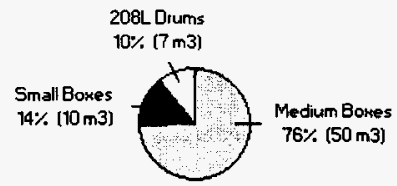

$$
\text { Total }=70 \mathrm{~m} 3
$$

Sum of totals may not add due to rounding: numbers over $10 \mathrm{~m}^{3}$ are rounded to the nearest $10 \mathrm{~m}^{3}$, numbers less than $10 \mathrm{~m}^{3}$ are rounded to integers, non-zero numbers less than 1 are rounded to 1 .

\section{Annual Volumes}

\section{Annual Baseline Volumes}




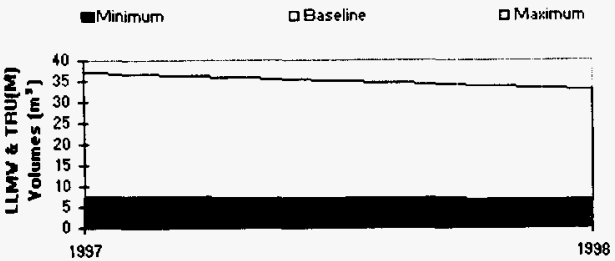

\section{Annual Baseline by Waste Class}

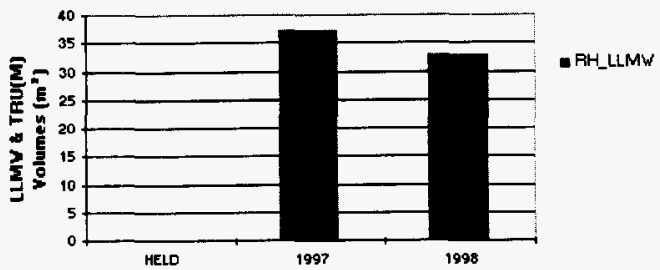

\section{Comparison to Previous Baseline(s)}

The FY97 forecast for 303 Fuels Fabrication Transition of $70 \mathrm{~m}^{3}$ shows a $250 \%$ increase from the FY96 forecast of $20 \mathrm{~m}^{3}$, primarily because the facility will be generating much more mixed waste due to changes in work scope. The FY97.1 forecast shows an $4 \mathrm{~m}^{3}$ increase in RH_LLMW that is not significant when the volumes are rounded.

The 1996 forecast expected only Other waste forms, but this year debris is the only expected form.

Hazardous constituents forecast last year were all in the 'other' category; however, only metals without mercury constituents are expected in this year's forecast.

\section{Comparison to Previous Baseline(s) by Waste Class}

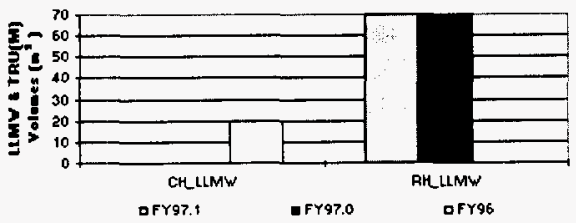




\begin{tabular}{|c|c|c|c|}
\hline $\begin{array}{l}\text { 303K Fuels Fabrication Transition Comparison: } \\
\text { Yaste Class }\end{array}$ & $\begin{array}{c}\text { FY97.1 } \\
\text { Forecast } \\
\text { (m.'] }\end{array}$ & $\begin{array}{l}\text { FY97.0 } \\
\text { Forecast } \\
\left(\mathbf{m}^{2}\right)\end{array}$ & $\begin{array}{l}\text { FY96 } \\
\text { Forecast } \\
\text { (m') }\end{array}$ \\
\hline CH LLMW & 0 & 0 & 20 \\
\hline PH LLMW & 70 & 70 & 0 \\
\hline Sublofer & $7 \theta$ & 78 & $2 \theta$ \\
\hline LLW & 400 & 260 & 250 \\
\hline HAZ & D & 0 & 2 \\
\hline Fory & 170 & 320 & 278 \\
\hline
\end{tabular}

Sum of totals may not add due to rounding: numbers over $10 \mathrm{~m}^{3}$ are rounded to the nearest $10 \mathrm{~m}^{3}$, numbers less than $10 \mathrm{~m}^{3}$ are rounded to integers, non-zero numbers less than 1 are rounded to $\mathrm{l}$.

\section{Background}

The mission for Fuels Fabrication Transition is to gain knowledge and provide training on the facility deactivation process. The LLMW is generated from facility clean-up.

\section{Forecast Assumptions and Comments}

The main assumption for the Fuels Fabrication Transition forecast is the continued RCRA clean-up activities in the $313 \mathrm{~S}$ Sludge Recovery Area.

The minimum and maximum range for this waste volume is $20 \%$ and $100 \%$ of the baseline. These percentages are based on the uncertainties in the planned deactivation work schedules and the anticipated shipping schedule.

\section{Other Forecast Data}

- ow Level Waste

- A total of $400 \mathrm{~m}^{3}$ of LLW is expected from Fuel Fabrication Transition until 1998.

- The FY97.1 shows a $54 \%$ increase from the FY97 forecast.

- The FY 97.0 forecast of $260 \mathrm{~m}^{3}$ is nearly identical to the FY96 forecast of $250 \mathrm{~m}^{3}$.

- $92 \%$ of the waste will be shipped in Medium boxes; only $8 \%$ of the LLW will be shipped in 208 liter drums.

o All of the LLW is to be debris: $92 \%$ contaminated metal and $8 \%$ inorganic nonmetal.

\section{- Hazardous Waste}

- No hazardous waste is expected from Fuel Fabrication for management by the CWC. 


\section{GENERATORS:}

202A PUREX Operations - 225B B Plant - 2345Z Plutonium Finishing Plant - 303K Fuels Fabrication Transition 309

PRTR Vault Waste (Ion Exchange Mod) 324 Building · 327 Building $\cdot 335$ Sodium Test Facility · FFTF Transition

Project - Waste Encapsulation/Storage Facility

\section{PROGRAMS}

Analytical Services · EM-40 · Facility Transitions · Landlord - Liquid Effluent · NP · Offsite · PNNL - RCRA · Solid Waste $\cdot$ SNF $\cdot$ TWRS

CHARACTERISTICS:
CH_LLMW $\cdot$ RH_LLMW $\cdot$ CH_TRU(M) $\cdot$ RH_TRU(M)
GTC III $\cdot$ LLW $\cdot$ HAZ

\section{WASTE CLASSES:}

CH_LLMW $\cdot$ RH_LLMW $\cdot$ CH_TRU(M) $\cdot$ RH_TRU(M) $\cdot$ GTC III $\cdot$ LLW $\cdot$ HAZ

Home $\cdot$ Contents $\cdot$ Web Site Map · Glossary $\cdot$ Help $\cdot$ Reports · Data Requests · Feedback Form

NOTICE: This page is provided subject to our disclaimer. Contact: Oscar Valero at (509) 373-4752.

HNF-EP-0918 rev. 1 Approved for public release; distribution is unlimited. 


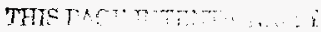

I.i. ans 


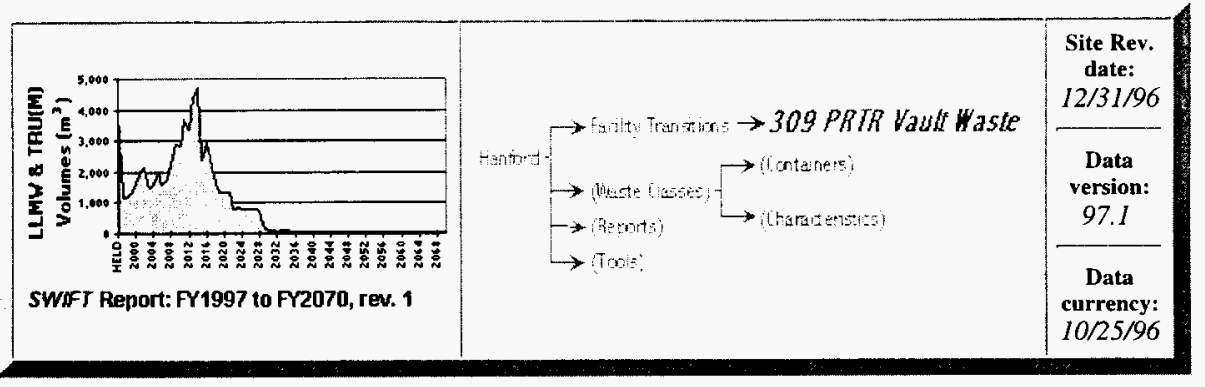

\section{Facility Transitions - 309 PRTR Vault Waste (Ion Exchange Mod)}

\section{Contents}

" Highlights

» Annual Volumes

"Comparison to Previous Baseline(s)

» Background
》Forecast Assumptions and Comments

» Other 309 PRTR Vault Waste Forecast Data

»Detailed Forecast Data

\section{Highlights}

- The forecast life cycle for the 309 PRTR Vault Waste (BWHC_PRTR) generator ends in 1998.

- This generator contributes $1 \mathrm{~m}^{3}$, or $<1 \%$ of the Facility Transitions LLMW and TRU(M) waste total.

- $\mathrm{CH}_{-}$TRU(M) waste and $\mathrm{CH}$ _LLMW are the two waste classes generated.

- The 208 liter drum is the only container reported for this LLMW and TRU(M) waste.

- Except for 5\% special waste, all of the LLMW and TRU(M) waste is in the physical form of debris. The debris varies from metal, plastic/rubber, organic, and inorganic nonmetal.

- The LLMW hazardous constituents will be split equally between organic waste (54\% by volume) and metals without mercury $(46 \%)$. 


\section{Waste Class Distribution}

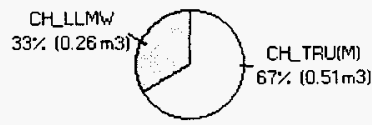

Total $=0.77 \mathrm{m3}$

Physical Waste Form Distribution

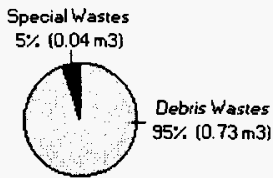

Total $=0.77 \mathrm{m3}$

\section{Hazardous Constituent Distribution}

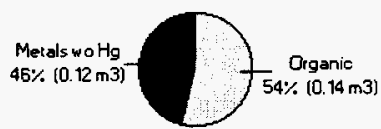

Toxal $=0.26 \mathrm{m3}$

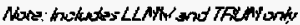

Container Distribution

Sum of totals may not add due to rounding: numbers over $10 \mathrm{~m}^{3}$ are rounded to the nearest $10 \mathrm{~m}^{3}$, numbers less than $10 \mathrm{~m}^{3}$ are rounded to integers, non-zero numbers less than 1 are rounded to 1 .

\section{Annual Volumes}

\section{Annual Baseline Volumes}




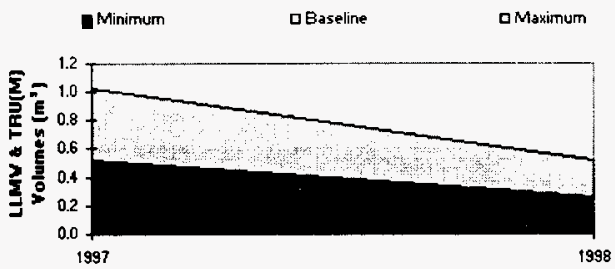

\section{Annual Baseline by Waste Class}

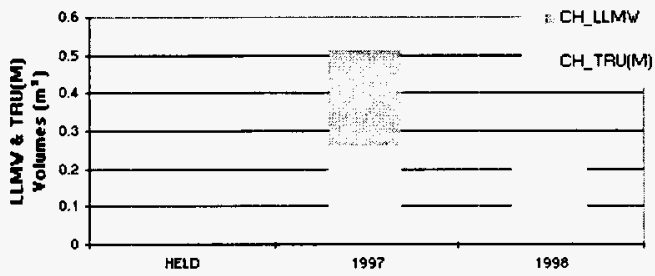

\section{Comparison to Previous Baseline(s)}

FY97 is the first year this generator provided a forecast. In previous forecasts, this generator was included in the Fast Flux Test Facility (BWHC_FFTF) forecast.

\section{Comparison to Previous Baseline(s) by Waste Class}

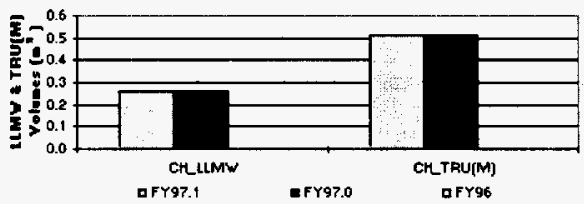

\begin{tabular}{|c|c|c|c|}
\hline $\begin{array}{l}309 \text { PRTR Yault Vaste (lon Eachange Mod] Comparison: } \\
\text { Vaste Class }\end{array}$ & $\begin{array}{l}\text { FY97.1 } \\
\text { Forecast } \\
\left(\mathrm{m}^{3}\right)\end{array}$ & $\begin{array}{l}\text { FY97.0 } \\
\text { Forecast } \\
\left(m^{3}\right)\end{array}$ & $\begin{array}{c}\text { FY96 } \\
\text { Forecast } \\
\left(m^{2}\right)\end{array}$ \\
\hline CH LLMW & $\mathbf{0 . 3}$ & 0.3 & 0 \\
\hline $\mathrm{CH}$ TRU(M) & 0.5 & 0.5 & 0 \\
\hline suprorer & $2=$ & Qt & $\theta$ \\
\hline$L L W$ & 70 & 70 & 0 \\
\hline HAZ & 1 & 1 & 0 \\
\hline Fotol & $\boldsymbol{X}$ & 70 & $\theta$ \\
\hline
\end{tabular}

Sum of totals may not add due to rounding: numbers over $10 \mathrm{~m}^{3}$ are rounded to the nearest $10 \mathrm{~m}^{3}$, numbers less than $10 \mathrm{~m}^{3}$ are rounded to integers, non-zero numbers less than $I$ are rounded to 1 .

\section{Background}

During facility transition to ERC, the 309 PRTR waste is generated in meeting turnover 
requirements.

\section{Forecast Assumptions and Comments}

The assumptions for this forecast are based on the current planning and scheduling of the facility transition to ERC and is expected on funding availability.

The minimum and maximum range for this waste volume is $100 \%$ and $200 \%$ of the baseline. The minimum percentage is based on an estimation of the confidence in the facility's ability to meet schedule. The maximum percentage is based on accelerating the work schedule.

\section{Other Forecast Data}

- Low Level Waste

- A total of $70 \mathrm{~m}^{3}$ of LLW is expected from PRTR until 1998.

- No comparison is possible with FY96 data, since this generator was previously combined with other generators.

- $78 \%$ of the LLW is expected in 208 liter drums, $20 \%$ in Medium boxes and $2 \%$ in Other drums.

- Slightly more than half of the physical LLW form will be soil and soil/gravel (56\%), while the rest will be debris (contaminated metal, inorganic nonmetal, plastic/rubber, and organic solids).

\section{- Hazardous Waste}

- Less than $1 \mathrm{~m}^{3}$ of hazardous waste is expected from 309 PRTR Vault Waste for management by the CWC.

GENERATORS:

202A PUREX Operations · 225B B Plant - 2345Z Plutonium Finishing Plant · 303K Fuels Fabrication Transition · 309

PRTR Vault Waste (Ion Exchange Mod) 324 Building · 327 Building · 335 Sodium Test Facility · FFTF Transition Project - Waste Encapsulation/Storage Facility

PROGRAMS:

Analytical Services - EM-40 - Facility Transitions - Landlord - Liquid Effluent - NP · Offsite - PNNL - RCRA - Solid Waste · SNF . TWRS

\begin{tabular}{|c|c|}
\hline $\begin{array}{c}\text { CHARACTERISTICS: } \\
\text { CH_LLMW } \cdot \text { RH_LLMW } \cdot \text { CH_TRU(M) } \\
\text { GTC III } \cdot \text { LLW_TRU(M) } \cdot \text { HAZ }\end{array}$ & CONTAINERS: \\
\hline
\end{tabular}

WASTE CLASSES:

CH_LLMW $\cdot$ RH_LLMW $\cdot$ CH_TRU(M) $\cdot$ RH_TRU(M) $\cdot$ GTC III $\cdot$ LLW $\cdot$ HAZ

Home - Contents - Web Site Map - Glossary - Help - Reports - Data Requests - Feedback Form

NOTICE: This page is provided subject to our disclaimer. Contact: Oscar Valero at (509) 373-4752.

HNF-EP-0918 rev. 1 Approved for public release; distribution is unlimited. 
THIS PAC MTS MAL 


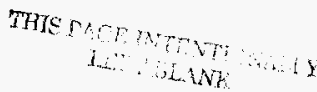




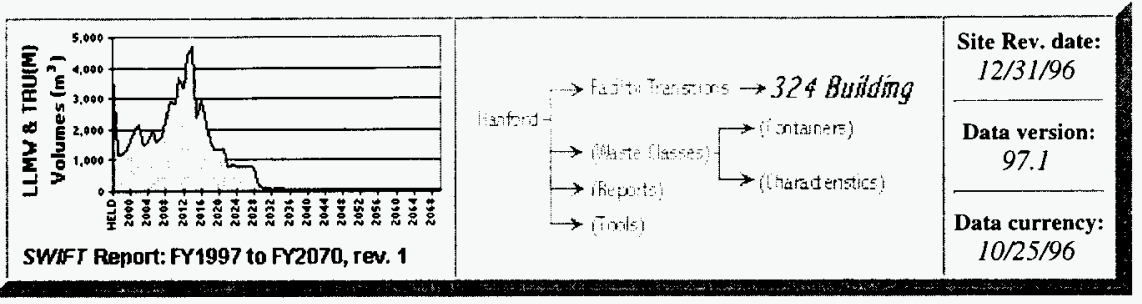

\section{Facility Transitions - 324 Building}

\section{Contents}
» Highlights
" Forecast Assumptions and Comments
»Annual Volumes
» Other 324 Building Forecast Data
„Comparison to Previous Baseline(s)
»Detailed Forecast Data
»Background

\section{Highlights}

- 324 Building contributes $40 \mathrm{~m}^{3}$ (1\%) of Facility Transition's solid waste forecast.

- The end of life cycle for the 324 Building is 2001 .

- $\mathrm{CH} \_$LLMW is the primary waste class generated, representing $54 \%$ of the waste $\left(20 \mathrm{~m}^{3}\right)$.

- Containers for this facility's LLMW and TRU(M) waste are projected to be only 208 liter drums.

- The physical LLMW and TRU(M) waste forms are $56 \%$ debris, and $44 \%$ as lab packs.

- Metals without mercury account for $70 \%$ of the hazardous constituents. Organic, state regulated, and corrosive metals without mercury constituents each make up $10 \%$ of the volume.

\section{Waste Class Distribution}

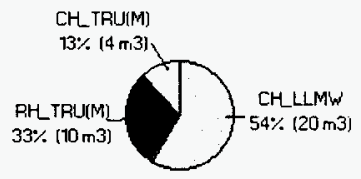

Total $=30 \mathrm{m3}$ 
Physical Waste Form Distribution

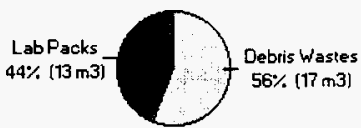

Total $=\mathbf{3 0} \mathrm{m} 3$

\section{Hazardous Constituent Distribution}

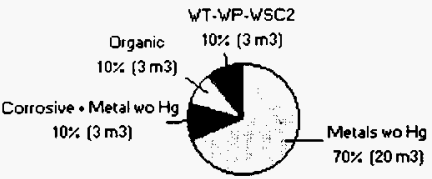

Total $=\mathbf{3 0} \mathbf{m} 3$

More AndederLIIYW' and TALM

\section{Container Distribution}

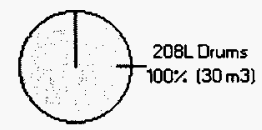

Total $=\mathbf{3 0} \mathrm{m} 3$

Sum of totals may not add due to rounding: numbers over $10 \mathrm{~m}^{3}$ are rounded to the nearest $10 \mathrm{~m}^{3}$, numbers less than $10 \mathrm{~m}^{3}$ are rounded to integers, non-zero numbers less than 1 are rounded to 1.

\section{Annual Volumes}

\section{Annual Baseline Volumes}

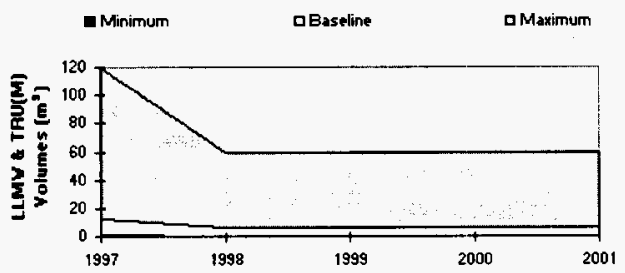

Annual Baseline by Waste Class 


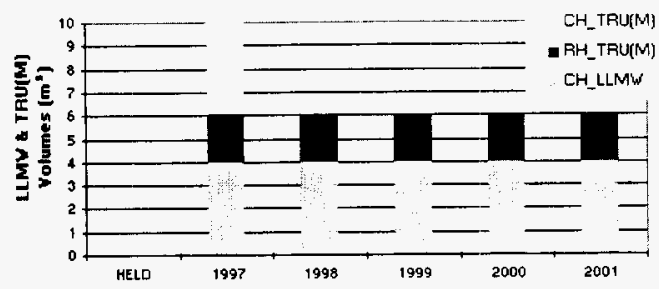

\section{Comparison to Previous Baseline(s)}

This generator was previously reported as a part of the overall forecast for PNNL. Now as pan of Facility Transitions, the estimates have been updated as per the best currently available data.

\section{Comparison to Previous Baseline(s) by Waste Class}

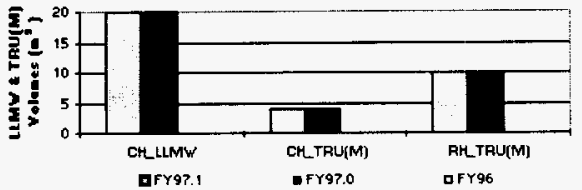

\begin{tabular}{|c|c|c|c|}
\hline $\begin{array}{l}324 \text { Building (PNWL) Comparison: } \\
\text { Yaste Class }\end{array}$ & $\begin{array}{c}\text { FY97.1 } \\
\text { Foreeast } \\
\text { [m"] }\end{array}$ & $\begin{array}{l}\text { Fr97.0 } \\
\text { Forecast } \\
\text { (m) }\end{array}$ & $\begin{array}{c}\text { Frgs } \\
\text { Forecast } \\
\text { (m) }\end{array}$ \\
\hline CH LLMW & 20 & 20 & 0 \\
\hline CH_TRU(M) & 4 & 4 & 0 \\
\hline RH TAU(M) & 10 & 10 & 0 \\
\hline solpord & 10 & 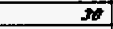 & e \\
\hline$L L W$ & 690 & 690 & 0 \\
\hline Ford & 730 & 720 & $\theta$ \\
\hline
\end{tabular}

Sum of totals may not add due to rounding: numbers over $10 \mathrm{~m}^{3}$ are rounded to the nearest $10 \mathrm{~m}^{3}$, numbers less than $10 \mathrm{~m}^{3}$ are rounded to integers, non-zero numbers less than 1 are rounded to 1 .

\section{Background}

The 324 Building supported research operations and is now in transition.

Waste generated includes debris, miscellaneous PPE, contamination control equipment, and various wastes generated during facility operations and hot cell clean-out.

\section{Forecast Assumptions and Comments}

The 324 Building was transferred to the M\&I contractor as of $11 / 1 / 96$.

Waste will be generated from hot cell clean-out and each waste class could contain up to the category limit. 
Confidence in these estimates is "one step above a guess" based on the limited data available. Any use of the data should take this into account.

Annual minimum and maximum ranges for the waste are $10 \%$ and $1,000 \%$ respectively. This large range is necessary to account for the lack of sufficient data to provide a good estimate.

\section{Other Forecast Data}

- Low Level Waste

- A total of $690 \mathrm{~m}^{3}$ of $\mathrm{LLW}$ is expected from the 324 Building.

- No comparison with FY96 data is possible, since this generator was previously combined with other generators.

o The majority (76\%) of the waste will be in MB-V boxes, and 208 liter drums will hold the remaining $24 \%$.

- The only physical LLW forms projected are heterogeneous debris ( $88 \%$ by volume) and concrete shielding (12\%).

\section{- Hazardous Waste}

- No hazardous waste is expected from 324 Building for management by the CWC.

\section{GENERATORS:}

202A JREX Operations - 225B B Plant - 2345Z Plutonium Finishing Plant - 303K Fuels Fabrication Transition - 309

PRTK Vault Waste (Ion Exchange Mod) · 324 Building · 327 Building · 335 Sodium Test Facility - FFTF Transition

Project - Waste Encapsulation/Storage Facility

\section{P'ROGRAMS:}

Analytical Services - EM-40 - Facility Transitions - Landlord - Liquid Effluent $\cdot$ NP $\cdot$ Offsite $\cdot$ PNNL $\cdot$ RCRA $\cdot$ Solid Waste - SNF - TWRS

\begin{tabular}{|c|c|}
\hline 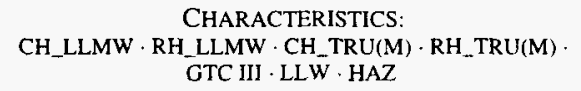 & $\begin{array}{l}\text { CONTAINERS: } \\
\text { CH_LLMW } \cdot \text { RH_LLMW } \cdot \text { CH_TRU(M) } \\
\text { RH_TRU(M) } \cdot \text { GTC III } \cdot \text { LLWW } \cdot \text { HAZ }\end{array}$ \\
\hline $\begin{array}{r}\text { WASTE C } \\
\mathrm{CH} \text { LLMW } \cdot \mathrm{RH} \_L L M W \cdot \mathrm{CH} \text {-TRU(M) }\end{array}$ & $\mathrm{U}(\mathrm{M}) \cdot \mathrm{GTC}$ III $\cdot \mathrm{LLW} \cdot \mathrm{HAZ}$ \\
\hline
\end{tabular}

NOTICE: This page is provided subject to our disclaimer. Contact: Oscar Valero at (509) 373-4752.

HNF-EP-0918 rev. 1 Approved for public release; distribution is unlimited. 


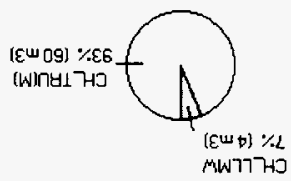

uo!̣nq!Jıs!d SSEID aıse $M$

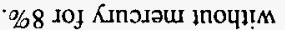

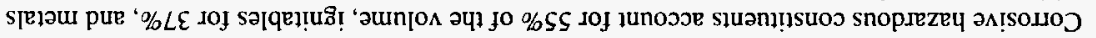

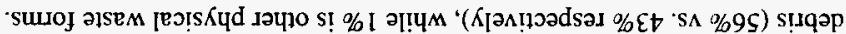

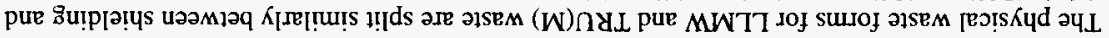

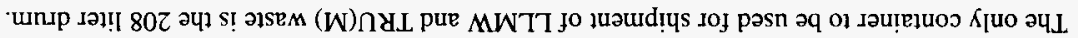

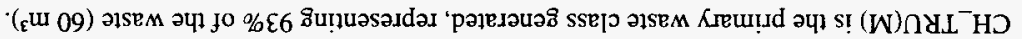

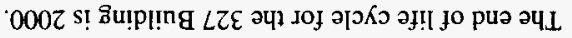

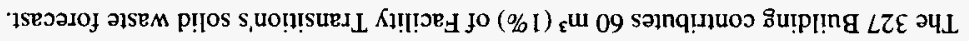

งมนริ!!บธี!ก

RIE 1SeวaIO

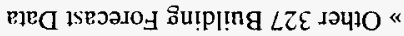
s]นวuน⿰冫 pue suo!̣dunss $\forall$ 1seวองо

\begin{abstract}
punoso̊xoeg «
uosurduoว «

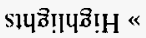

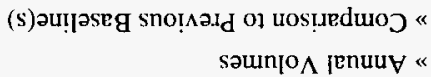

squวฺนoว

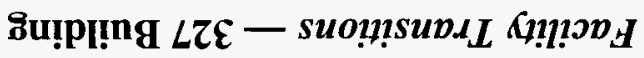

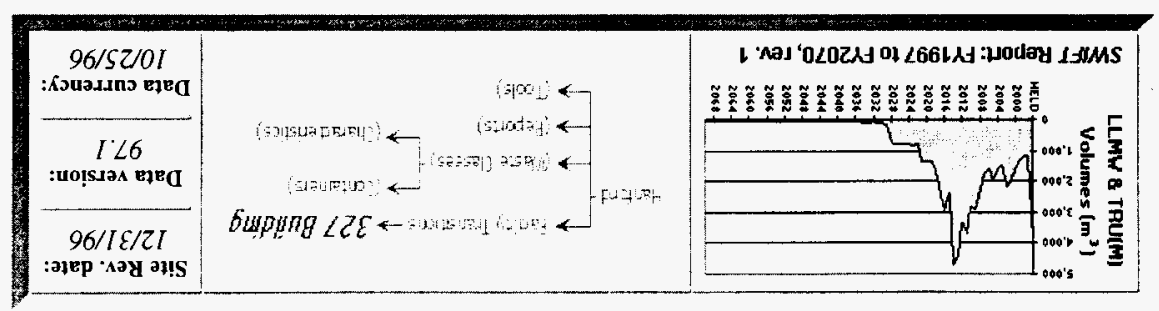




\section{Physical Waste Form Distribution}

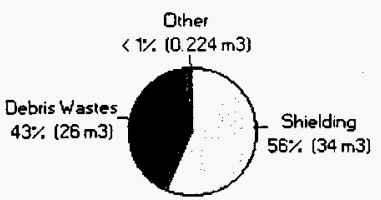

Total $=60 \mathrm{~m} 3$

\section{Hazardous Constituent Distribution}

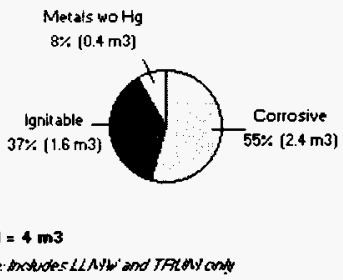

\section{Container Distribution}

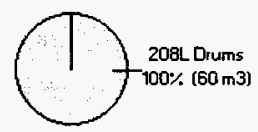

Total $=60 \mathrm{m3}$

Sum of totals may not add due to rounding: numbers over $10 \mathrm{~m}^{3}$ are rounded to the nearest $10 \mathrm{~m}^{3}$, numbers less than $10 \mathrm{~m}^{3}$ are rounded to integers, non-zero numbers less than 1 are rounded to $\mathrm{I}$.

\section{Annual Volumes}

\section{Annual Baseline Volumes}

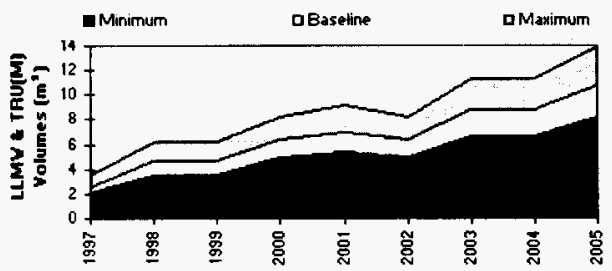

\section{Annual Baseline by Waste Class}




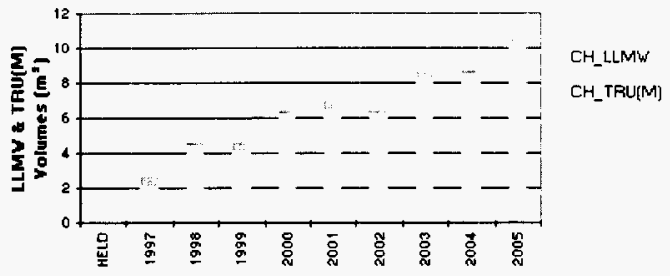

\section{Comparison to Previous Baseline(s)}

This generator was previously reported as a generator for PNNL. FY97.1 accounts for a $20 \mathrm{~m}^{3}$ increase of LLMW and TRU(M) waste and reclassification of RH _TRU(M) waste to CH_TRU(M) waste due to better estimates.

\section{Comparison to Previous Baseline(s) by Waste Class}

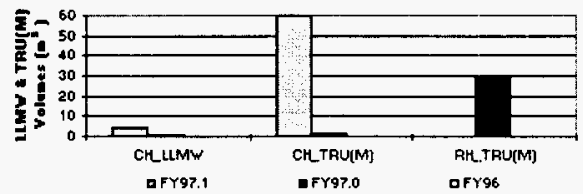

\begin{tabular}{|c|c|c|c|}
\hline $\begin{array}{l}327 \text { Building (PNNL) Comparison: } \\
\text { Yaste Class }\end{array}$ & $\begin{array}{c}\text { FY97.1 } \\
\text { Forecast } \\
\left(m^{2}\right)\end{array}$ & $\begin{array}{c}\text { FY97.0 } \\
\text { Forecast } \\
\left(m^{2}\right)\end{array}$ & $\begin{array}{c}\text { FY96 } \\
\text { Forecast } \\
\left(\mathrm{m}^{3}\right)\end{array}$ \\
\hline $\mathrm{CH}$ LLMW' & 4 & 1 & 0 \\
\hline $\mathrm{CH}$ TRU(M) & 60 & 2 & D \\
\hline $\mathrm{RH}$ TRU(M) & 0 & 30 & 0 \\
\hline suchard & $\theta$ & 10 & $\theta$ \\
\hline$\underline{L L W}$ & 220 & 210 & 0 \\
\hline Toret & 200 & 259 & $a$ \\
\hline
\end{tabular}

Sum of totals may not add due to rounding: numbers over $10 \mathrm{~m}^{3}$ are rounded to the nearest $10 \mathrm{~m}^{3}$, numbers less than $10 \mathrm{~m}^{3}$ are rounded to integers, non-zero numbers less than $I$ are rounded to 1 .

\section{Background}

The 327 Building is now in transition.

\section{Forecast Assumptions and Comments}

The 327 Building was transferred to the M\&I contractor as of $11 / 1 / 96$.

No minimum and maximum ranges were provided by this generator. In this case, the assumption is made that minimum and maximum ranges for the waste are $100 \%$ and $100 \%$ respectively.

\section{Other Forecast Data}




\section{- Low Level Waste}

- A total of $220 \mathrm{~m}^{3}$ of LLW is expected from the 327 Building.

- No comparison with FY96 data is possible, since this generator was previously combined with other generators. This FY 97.1 volume is a $10 \mathrm{~m}^{3}$ increase from the FY 97.0 volume.

- MB- $V$ boxes and 208 liter drums will contain $60 \%$ and $40 \%$ of the LLW, respectively.

- All of the LLW's physical form is expected to be debris (plastic/rubber, organic, contaminated metal, and heterogeneous), except for less than one cubic meter of shielding.

\section{- Hazardous Waste}

- No hazardous waste is expected from 327 Building for management by the CWC.

\section{GENERATORS:}

202A PUREX Operations · 225B B Plant - 2345Z Plutonium Finishing Plant - 303K Fuels Fabrication Transition - 309

PRTR Vault Waste (Ion Exchange Mod) $\cdot 324$ Building $\cdot 327$ Building $\cdot 335$ Sodium Test Facility · FFTF Transition Project - Waste Encapsulation/Storage Facility

PROGRAMS:

Analytical Services - EM-40 - Facility Transitions - Landlord - Liquid Effluent - NP · Offsite - PNNL - RCRA - Solid Waste - SNF - TWRS

\begin{tabular}{|c|c|}
\hline $\begin{array}{l}\text { CHARACTERISTICS: } \\
\text { CH_LLMW } \cdot \text { RH_LLMW } \cdot \text { CH_TRU(M) } \cdot \text { RH_TRU }(M) \cdot \\
\text { GTC III } \cdot \text { LLW } \cdot \text { HAZ }\end{array}$ & $\begin{array}{l}\text { CONTAINERS: } \\
\text { CH_LLMW } \cdot \text { RH_LLMW } \cdot \text { CH_TRU(M) } \\
\text { RH_TRU(M) } \cdot \text { GTC III } \cdot \text { LLW } \cdot \text { HAZ }\end{array}$ \\
\hline \multicolumn{2}{|c|}{$\begin{array}{l}\text { WASTE CLASSES: } \\
\text { WH }\end{array}$} \\
\hline
\end{tabular}

NOTICE: This page is provided subject to cur disclaimer. Contact: Oscar Valero at (509) 373-4752.

HNF-EP-0918 rev. 1 Approved for public release; distribution is unlimited. 


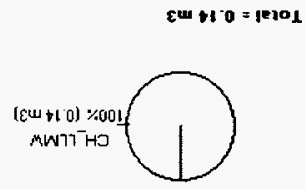

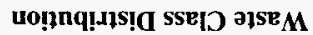

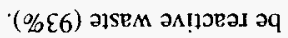

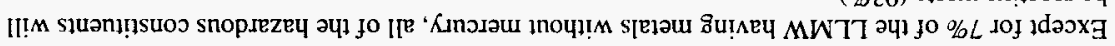

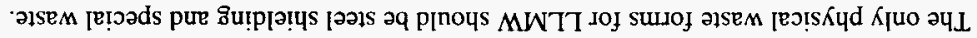

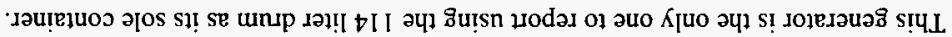

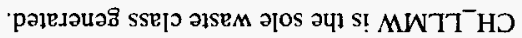

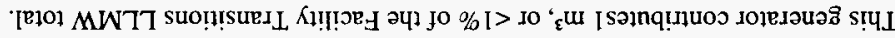

$666 \mathrm{I} \mathrm{UI}$

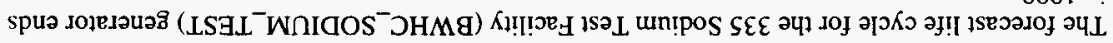
งฺบชิ!กบำ!H

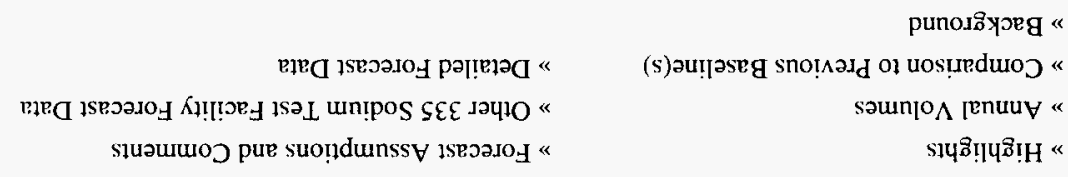
Sานวฺนоว К‼!

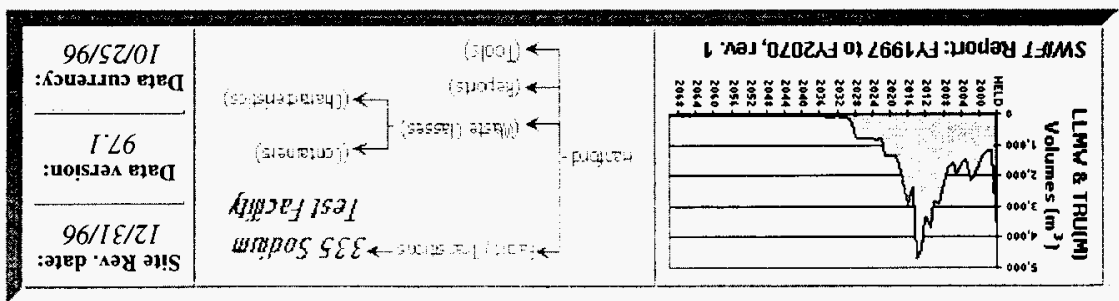




\section{Physical Waste Form Distribution}

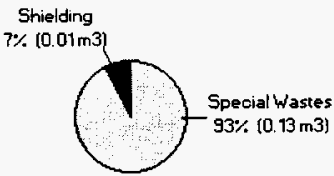

Total $=0.14 \mathrm{m3}$

\section{Hazardous Constituent Distribution}

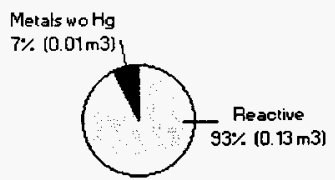

Total $=0.14 \mathrm{m3}$

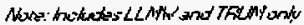

\section{Container Distribution}

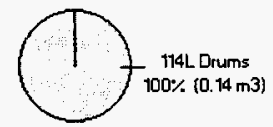

Total $=0.14 \mathrm{m3}$

Sum of totals may not add due to rounding: numbers over $10 \mathrm{~m}^{3}$ are rounded to the nearest $10 \mathrm{~m}^{3}$, numbers less than $10 \mathrm{~m}^{3}$ are rounded to integers, non-zero numbers less than 1 are rounded to 1.

\section{Annual Volumes}

\section{Annual Baseline Volumes}

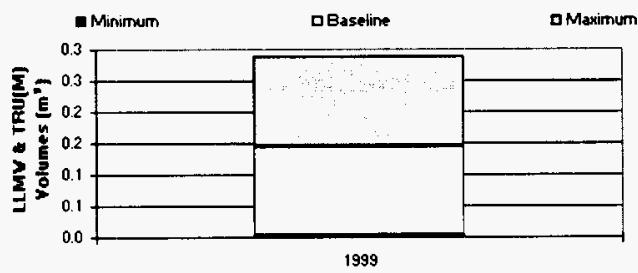

Annual Baseline by Waste Class 


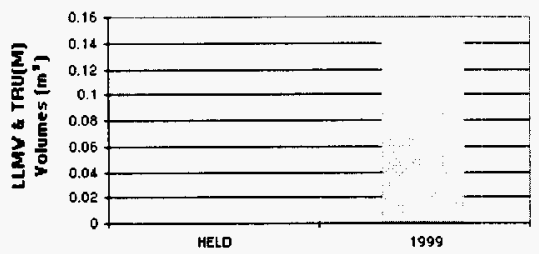

CH_LIMW

\section{Comparison to Previous Baseline(s)}

FY97 is the first year this generator provided a forecast. In previous forecasts, 335 Sodium Test Facility was included in the Fast Flux Test Facility (BWHC_FFTF) forecast.

\section{Comparison to Previous Baseline(s) by Waste Class}

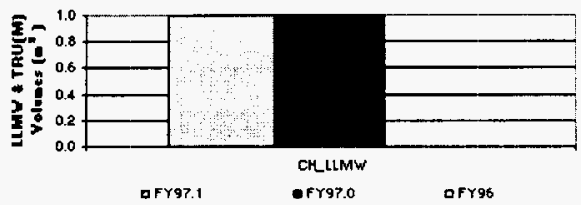

\begin{tabular}{|c|c|c|c|}
\hline $\begin{array}{l}335 \text { Sodium Test Facility Comparison: } \\
\text { Yaste Class }\end{array}$ & $\begin{array}{c}\text { FY97.1 } \\
\text { Forecast } \\
\text { (m') }\end{array}$ & $\begin{array}{l}\text { FY97.0 } \\
\text { Forecast } \\
{\left[\mathbf{m}^{2}\right]}\end{array}$ & $\begin{array}{l}\text { FY96 } \\
\text { Forecast } \\
\text { (m') }\end{array}$ \\
\hline CH_LLMW & 1 & 1 & 0 \\
\hline suprors & I & 1 & $a$ \\
\hline LLW & 1 & 1 & 0 \\
\hline $\mathrm{HAZ}$ & 9 & 9 & 0 \\
\hline Ford & 10 & 10 & $\theta$ \\
\hline
\end{tabular}

Sum of totals may not add due to rounding: numbers over $10 \mathrm{~m}^{3}$ are rounded to the nearest $10 \mathrm{~m}^{3}$, numbers less than $10 \mathrm{~m}^{3}$ are rounded to integers, non-zero numbers less than 1 are rounded to $\mathrm{I}$.

\section{Background}

The mission for 335 Sodium Test Facility is to dismantle retired sodium test loops. The solid waste generated is from the small amount of material that cannot be recycled, scrapped, or shipped to a treatment center.

The work at 335 Sodium Test Facility is to remove the insulation and wiring from the sodium test systems, and to cut the sodium-wetted and sodium-filled piping.

\section{Forecast Assumptions and Comments}

The minimum and maximum range for this waste volume is $1 \%$ and $200 \%$ of the baseline. The minimum percentage, representing zero waste, would arise if the facility could clean or transfer all sodium-wetted materials. The maximum percentage is based on there being more material than anticipated that could not be sent to a landfill. 


\section{Other Forecast Data}

- Low Level Waste

- A total of $1 \mathrm{~m}^{3}$ of LLW is expected from the 335 Sodium Test Facility.

- $100 \%$ of the LLW is to be shipped in Other drums.

- This LLW's physical form should be: mostly lead shielding and some steel shielding.

\section{- Hazardous Waste}

- A total of $9 \mathrm{~m}^{3}$ of hazardous waste is expected from the 335 Sodium Test Facility for management by the CWC.

\section{GENERATORS:}

202A PUREX Operations · 225B B Plant · 2345Z Plutonium Finishing Plant - 303K Fuels Fabrication Transition - 309

PRTR Vault Waste (Ion Exchange Mod) $\cdot 324$ Building $\cdot 327$ Building $\cdot 335$ Sodium Test Facility · FFTF Transition

Project - Waste Encapsulation/Storage Facility

\section{PROGRAMS:}

Analytical Services · EM-40 - Facility Transitions - Landlord · Liquid Effluent $\cdot$ NP · Offsite $\cdot$ PNNL $\cdot$ RCRA $\cdot$ Solid Waste $\cdot$ SNF $\cdot$ TWRS

\begin{tabular}{|c|c|}
\hline $\begin{array}{l}\text { CHARACTERISTICS: } \\
\text { CH_LLMW } \cdot \text { RH_LLMW } \cdot \text { CH_TRU(M) } \cdot \text { RH_TRU(M) } \\
\text { GTC III } \cdot \text { LLW } \cdot \text { HAZ }\end{array}$ & $\begin{array}{l}\text { CONTAINERS: } \\
\text { CH_LLMW } \cdot \text { RH_LLMW } \cdot \text { CH_TRU(M) } \\
\text { RH_TRU(M) } \cdot \text { GTC III } \cdot \mathrm{LLW} \cdot \mathrm{HAZ}\end{array}$ \\
\hline \multicolumn{2}{|c|}{$\begin{array}{l}\text { WASTE CLASSES: } \\
\text { CH_LLMW } \cdot \text { RH_LLMW } \cdot \text { CH_TRU(M) } \cdot \text { RH_TRU(M) } \cdot \text { GTC III } \cdot \text { LLW } \cdot \text { HAZ }\end{array}$} \\
\hline
\end{tabular}

NOTICE: This page is provided subject to cur disclaimer. Contact: Oscar Valero at (509) 373-4752.

HNF-EP-0918 rev. 1 Approved for public release; distribution is unlimited. 


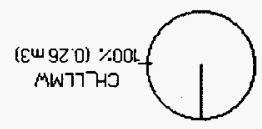

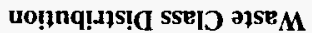

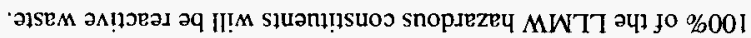
'วิ5อM [ए!

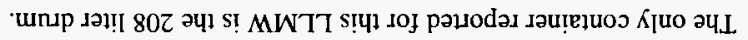

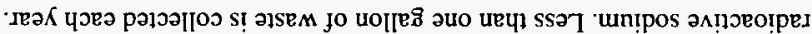

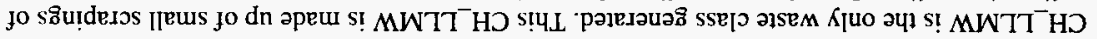

'uotyeunoju! uo!̣ez!rioerey

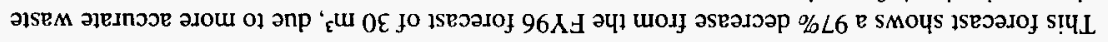

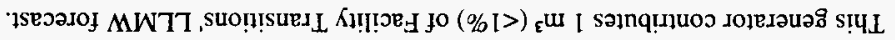

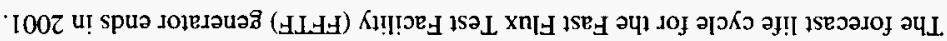

\section{ราบรี!!บริ!H}

punolôxวreg «

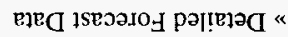

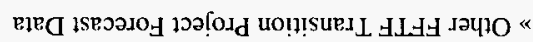

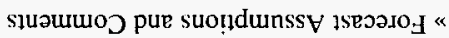

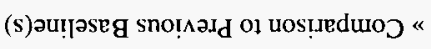
səun $0 \Lambda$ [enuu $\forall \ll$

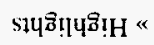

ราบวาน⿰习

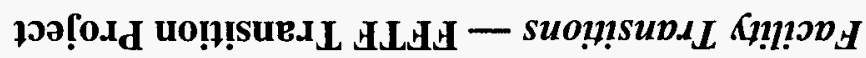

\begin{tabular}{|c|c|c|c|}
\hline $\begin{array}{c}\text { 96/SZ/OI } \\
\text { :Souasuns eqEa }\end{array}$ & $300 \div$ & & 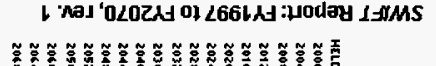 \\
\hline $\begin{array}{c}l \angle 6 \\
: \text { uo!̣san вjed }\end{array}$ & Walou (a) & p.9. & $-000^{\circ} 2 \frac{5}{30}$ \\
\hline $\begin{array}{c}96 / I \mathcal{E} / Z I \\
: \text { әрер } \cdot \text { Аәу әи!S }\end{array}$ & UOUISUEII $J 1 J 4 \leftarrow$ & & 寻蒙 \\
\hline
\end{tabular}


Physical Waste Form Distribution

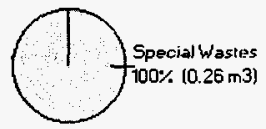

Total $=0.26 \mathrm{m3}$

\section{Hazardous Constituent Distribution}

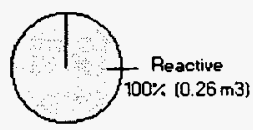

Total $=0.26 \mathrm{m3}$

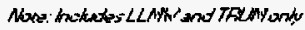

\section{Container Distribution}

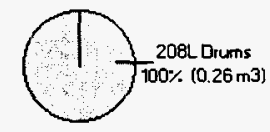

$$
\text { Total }=0.26 \mathrm{m3}
$$

Sum of totals may not add due to rounding: numbers over $10 \mathrm{~m}^{3}$ are rounded to the nearest $10 \mathrm{~m}^{3}$, numbers less than $10 \mathrm{~m}^{3}$ are rounded to integers, non-zero numbers less than I are rounded to $I$.

\section{Annual Volumes}

\section{Annual Baseline Volumes}

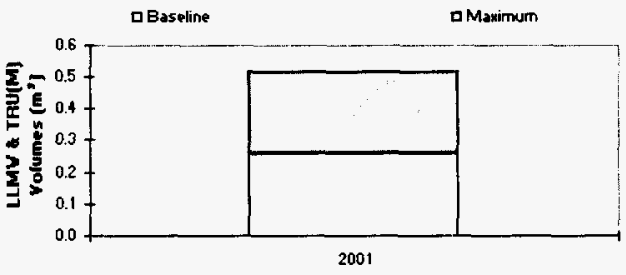

Annual Baseline by Waste Class 


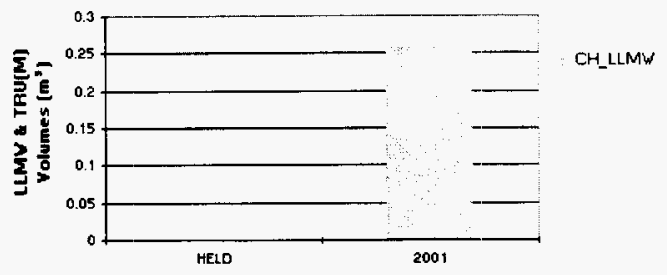

\section{Comparison to Previous Baseline(s)}

The FY97 forecast for FFTF of $1 \mathrm{~m}^{3}$ shows a $97 \%$ decrease from the FY96 forecast of $30 \mathrm{~m}^{3}$, primarily due to more accurate information on waste characterization.

The FY96 forecast for FFTF included 5 facilities: FFTF, 309 Facility, Legacy, 308 Facility, and 335 Sodium Test Facility. For the FY97 forecast, FFTF includes only 2 facilities: FFTF and 308 Facility. The other facilities either report separately or have been taken out of the forecast since they no longer generate solid waste.

The physical waste forms projected in 1996 included 4 cubic meters of debris (heterogeneous, metal, plastic/rubber, and organic) along with Other forms, but only special waste is forecast this year.

\section{Comparison to Previous Baseline(s) by Waste Class}

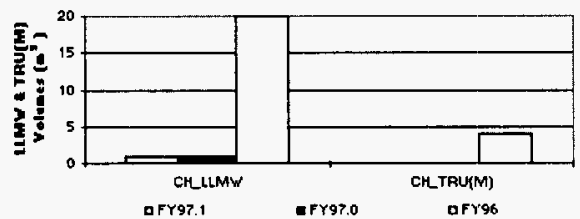

\begin{tabular}{|c|c|c|c|}
\hline $\begin{array}{l}\text { FFTF Transition Projeet Comparison: } \\
\text { Vaste Class }\end{array}$ & $\begin{array}{c}\text { FY97.1 } \\
\text { Forecast } \\
\text { (m) }\end{array}$ & $\begin{array}{l}\text { FYg7.d } \\
\text { Forecast } \\
\text { (m') }\end{array}$ & $\begin{array}{c}\text { FYg6 } \\
\text { Foreeast } \\
\left(\mathrm{m}^{\prime \prime}\right)\end{array}$ \\
\hline CH_LLMW & 1 & 1 & 20 \\
\hline CH TRU(M) & 0 & 0 & 4 \\
\hline sroveres & $\boldsymbol{r}$ & 1 & 50 \\
\hline LLW & 80 & 80 & 390 \\
\hline $\mathrm{HAZ}$ & 0 & $a$ & 40 \\
\hline ford & $a \theta$ & $m$ & $\operatorname{sis} \theta$ \\
\hline
\end{tabular}

Sum of totals may not add due to rounding: numbers over $10 \mathrm{~m}^{3}$ are rounded to the nearest $10 \mathrm{~m}^{3}$, numbers less than $10 \mathrm{~m}^{3}$ are rounded to integers, non-zero numbers less than $I$ are rounded to 1.

\section{Background}

Currently, FFTF's transition to the Surveillance and Maintenance Phase is being reviewed by the Department of Energy. Almost the entire waste volume forecast from FFTF is LLW generated during maintenance and decontamination activities, processing and disassembling 
irradiated reactor core components, and washing the FFTF fuel assemblies in the IEM cell.

\section{Forecast Assumptions and Comments}

The main assumption for the FFTF forecast is that the facility will continue on to Surveillance and Maintenance Phase by 2001.

Liquid and solid sodium is not included in this forecast.

The minimum and maximum range for this waste is $100 \%$ and $200 \%$ of the baseline.

\section{Other Forecast Data}

\section{- Low Level Waste}

- A total of $80 \mathrm{~m}^{3}$ of LLW is expected from FFTF until 2001.

- This forecast shows a $79 \%$ decrease from the FY 96 forecast of $390 \mathrm{~m}^{3}$.

- Waste will be split between other drums (41\%) and 208 liter drums (37\%), besides the $24 \%$ in MB-V boxes.

- The physical waste forms for LLW include $3 \%$ (by volume) organic particulates and $97 \%$ debris (organic, metal/activated metal and heterogeneous).

\section{- Hazardous Waste}

- No hazardous waste is expected from FFTF for management by the CWC.

\section{GENERATORS:}

202A PUREX Operations - 225B B Plant - 23452 Plutonium Finishing Plant $\cdot 303 \mathrm{~K}$ Fuels Fabrication Transition $\cdot 309$

PRTR Vault Waste (Ion Exchange Mod) 324 Building · 327 Building · 335 Sodium Test Facility · FFTF Transition Project - Waste Encapsulation/Storage Facility

PROGRAMS:

Analytical Services · EM-40 - Facility Transitions - Landlord - Liquid Effluent · NP · Offsite · PNNL · RCRA - Solid Waste $\cdot$ SNF $\cdot$ TWRS

\begin{tabular}{|c|c|}
\hline $\begin{array}{c}\text { CHARACTERISTICS: } \\
\text { CH_LLMW } \cdot \text { RH_LLMW } \cdot \text { CH_TRU(M) } \cdot \text { RH_TRU(M) } \\
\text { GTC III } \cdot \text { LLW } \cdot \text { HAZ }\end{array}$ & $\begin{array}{c}\text { CONTAINERS: } \\
\text { CH_LLMW } \cdot \text { RH_LLMW } \cdot \text { CH_TRU(M) } \\
\text { RH_TRU(M) } \cdot \text { GTC III } \cdot \text { LLW } \cdot \text { HAZ }\end{array}$ \\
\hline
\end{tabular}

Home - Contents - Wcb Sitc Map - Glossary · Help - Reports - Data Requests - Fecdback Form

NOTICE: This page is provided subject to our disclaimer. Contact: Oscar Valero at (509) 373-4752.

HNF-EP-0918 rev. 1 Approved for public release; distribution is unlimited. 


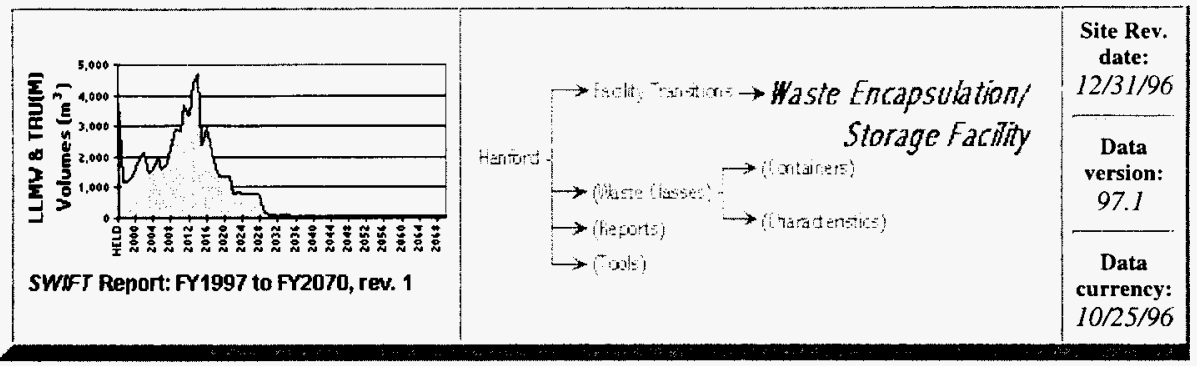

\section{Facility Transitions - Waste Encapsulation/Storage Facility}

\section{Contents}

» Highlights

» Annual Volumes

" Comparison to Previous

Baseline(s)

" Background
" Forecast Assumptions and Comments

» Other Waste Encapsulation/Storage Facility Forecast

Data

»Detailed Forecast Data

\section{Highlights}

- The forecast life cycle for the Waste Encapsulation/Storage Facility (BWHC_WESF) generator ends in 2025 .

- This generator contributes $30 \mathrm{~m}^{3}$, or $<1 \%$ of the Facility Transitions LLMW total.

- CH_LLMW is the sole waste class generated.

- The only reported LLMW container to be used is the 208 liter drum.

- Physical waste forms vary from $10 \%$ special waste, $13 \%$ organic solids, $13 \%$ debris, to $64 \%$ inorganic solids.

- The LLMW hazardous constituents will be evenly divided. State regulated, ignitable, and corrosive wastes each represent $25 \%$ of the volume. Metals without mercury and organic constituents account for $18 \%$ and $7 \%$, respectively. 


\section{Waste Class Distribution}

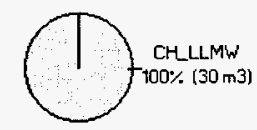

Toral $=\mathbf{3 0 ~} \mathbf{m} \mathbf{3}$

\section{Physical Waste Form Distribution}

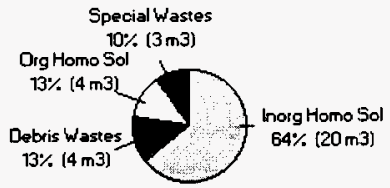

Total $=30 \mathrm{m3}$

\section{Hazardous Constituent Distribution}

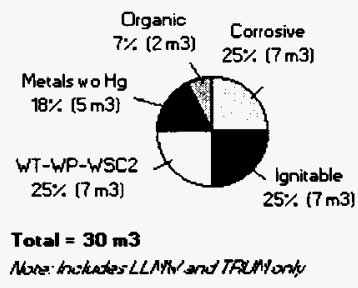

\section{Container Distribution}

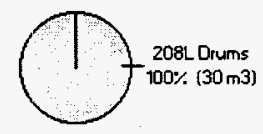

Total $=30 \mathrm{~m} 3$

Sum of totals may not add due to rounding: numbers over $10 \mathrm{~m}^{3}$ are rounded to the nearest $10 \mathrm{~m}^{3}$, numbers less than $10 \mathrm{~m}^{3}$ are rounded to integers, non-zero numbers less than 1 are rounded to 1 .

\section{Annual Volumes}

\section{Annual Baseline Volumes}




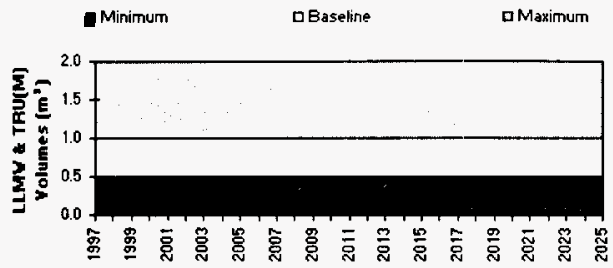

\section{Annual Baseline by Waste Class}

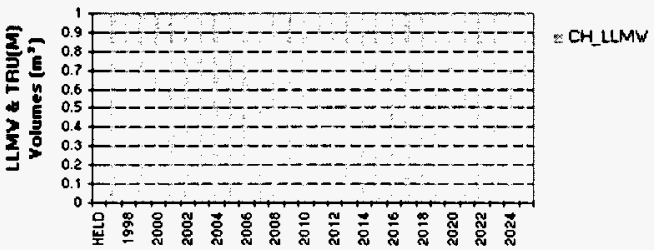

\section{Comparison to Previous Baseline(s)}

FY97 is the first year this generator provided a forecast. In previous forecasts Waste Encapsulation/Storage Facility was included in the B Plant generator (BWHC_B_PLANT) forecast.

\section{Comparison to Previous Baseline(s) by Waste Class}

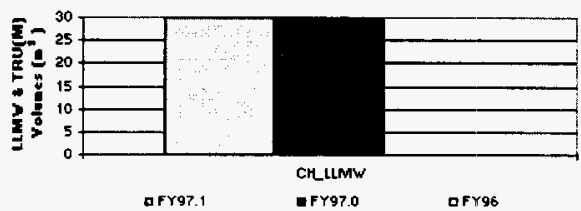

\begin{tabular}{|c|c|c|c|}
\hline $\begin{array}{l}\text { Waste EncapsulationtStorage Facility Comparison: } \\
\text { Vaste Class }\end{array}$ & $\begin{array}{c}\text { FYg7.1 } \\
\text { Forecast } \\
\left(\mathrm{m}^{3}\right)\end{array}$ & $\begin{array}{c}\text { FY97.0 } \\
\text { Forecast } \\
\text { (m') }\end{array}$ & $\begin{array}{l}\text { FY96 } \\
\text { Forecast } \\
\text { [m'] }\end{array}$ \\
\hline CH_LLMW & 30 & 30 & 0 \\
\hline Solrord & $\pi$ & $\boldsymbol{N}$ & 0 \\
\hline LLW & 460 & 460 & 0 \\
\hline Tord & $\$ P$ & $\$ \infty$ & $\theta$ \\
\hline
\end{tabular}

Sum of totals may not add due to rounding: numbers over $10 \mathrm{~m}^{3}$ are rounded to the nearest $10 \mathrm{~m}^{3}$, numbers less than $10 \mathrm{~m}^{3}$ are rounded to integers, non-zero numbers less than $I$ are rounded to 1 .

\section{Background}

The mission for Waste Encapsulation/Storage Facility is the continued safe and efficient 
storage of cesium and strontium capsules until final disposition has been determined. Waste generated from this facility is associated with entry into radiological areas, radiological decontamination, etc.

\section{Forecast Assumptions and Comments}

This forecast assumes that waste generation remains constant over the life cycle, and that waste currently being accumulated in B Cell will be packaged and stored in B Plant Cell 4 and will not be shipped to the burial grounds in the foreseeable future. Also, strontium and cesium capsules are not included in this forecast.

The minimum and maximum range for this waste volume is $50 \%$ and $200 \%$ of the baseline. Since this is the first year Waste Encapsulation/Storage Facility waste has been identified separately from B Plant, there is a high degree of uncertainty associated with the forecast quantities. Although best estimates place generation at about $10 \%$ of the combined total, it is thought it could vary by a factor of 2 in either direction.

\section{Other Forecast Data}

\section{- Low Level Waste}

- $460 \mathrm{~m}^{3}$ of LLW is expected from Waste Encapsulation/Storage Facility.

- There are no details available for the FY96 forecast.

- This waste will be sent in mostly MB-V boxes (61\%), 22\% in Medium boxes, and 17\% in 208 liter drums.

- The physical LLW form will vary from $4 \%$ (by volume) inorganic and organic solids, to some soil and soil/gravel, to five kinds of debris (90\%).

\section{- Hazardous Waste}

- No hazardous waste is expected from Waste Encapsulation/Storage Facility for management by the CWC. 


\section{GENERATORS:}

202A PUREX Operations - 225B B Plant - 2345Z Plutonium Finishing Plant - 303K Fuels Fabrication Transition - 309

PRTR Vault Waste (Ion Exchange Mod) · 324 Building · 327 Building · 335 Sodium Test Facility · FFTF Transition Project · Waste Encapsulation/Storage Facility

\section{PROGRAMS:}

Analytical Services - EM-40 - Facility Transitions - Landlord - Liquid Effluent · NP · Offsite - PNNL - RCRA - Solid Waste $\cdot$ SNF $\cdot$ TWRS

CHARACTERISTICS:
CH_LLMW $\cdot$ RH_LLMW $\cdot$ CH_TRU(M) $\cdot$ RH_TRU(M)
GTC III $\cdot$ LLW $\cdot$ HAZ

WASTE CLASSES:

CH_LLMW $\cdot$ RH_LLMW $\cdot$ CH_TRU(M) $\cdot$ RH_TRU(M) $\cdot$ GTC III $\cdot$ LLW $\cdot$ HAZ

Home · Contents · Web Site Map · Glossary · Help · Reports · Data Requests · Feedback Form

NOTICE: This page is provided subject to our disclaimer. Contact: Oscar Valero at (509) 373-4752.

HNF-EP-0918 rev. 1 Approved for public release; distribution is unlimited. 
THE rae 


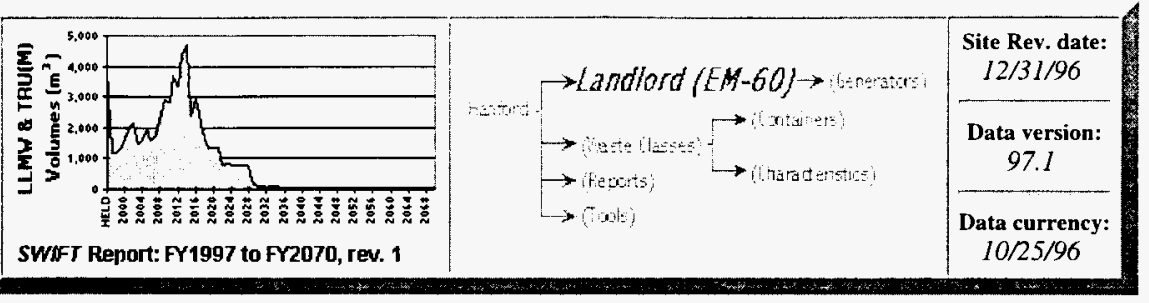

\section{Landlord (EM-60)}

The Landlord program did not provide a forecast in FY97 nor for the 97.1 revision for the following reasons:

- As with previous forecasts, the program does not expect to generate LLMW, TRU(M) waste, or LLW.

- Hazardous waste generated by the program will be managed directly by the program and will not utilize the Waste Management Project. This is a change from previous years.

PROGRAMS:

Analytical Services - EM-40 - Facility Transitions · Landlord - Liquid Effluent $\cdot$ NP · Offsite $\cdot$ PNNL $\cdot$ RCRA $\cdot$ Solid Waste $\cdot$ SNF $\cdot$ TWRS

\begin{tabular}{|c|c|}
\hline $\begin{array}{l}\text { CHARACTERISTICS: } \\
\text { CH_LLMW } \cdot \text { RH_LLMW } \cdot \text { CH_TRU(M) } \cdot \text { RH_TRU(M) } \\
\text { GTC III } \cdot \text { LLW } \cdot \mathbf{H A Z}\end{array}$ & $\begin{array}{c}\text { CONTAINERS: } \\
\text { CH_LLMW } \cdot \text { RH_LLMW } \cdot \text { CH_TRU(M) } \\
\text { RH_TRU(M) } \cdot \text { GTC III } \cdot \text { LLW } \cdot \text { HAZ }\end{array}$ \\
\hline \multicolumn{2}{|c|}{ WASTE CLASSES: } \\
\hline
\end{tabular}

NOTICE: This page is provided subject to our disclaimer. Contact: Oscar Valero at (509) 373-4752.

HNF-EP-0918 rev. 1 Approved for public release; distribution is unlimited. 
TH? i. a ivi: 


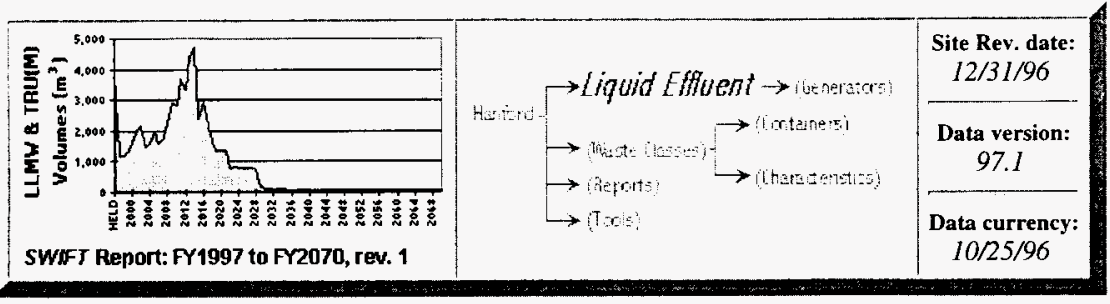

\section{Liquid Effluent}

\section{Contents}

» Highlights

》 Annual Waste Class Volumes

»Summary Table

»Comparison to Previous Baseline(s)
» Background

"Forecast Assumptions and Comments

»Other Liquid Effluent Forecast Data

\section{Highlights}

- The overall life cycle for the Liquid Effluent program ends in 2034.

- A total of $2,540 \mathrm{~m}^{3}$ of LLMW is expected from this generator over the life cycle, or $4 \%$ of the Hanford total.

- This forecast shows a $55 \%$ decrease from the FY96 forecast of $5,620 \mathrm{~m}^{3}$, due to the use of more likely production rates.

- CH_LLMW is the sole waste class generated by the 200 Area Effluent Treatment Facility.

- $100 \%$ of the LLMW from this program is projected to be sent in 208 liter drums.

- The Liquid Effluent program expects to ship five physical forms of LLMW: $79 \%$ inorganic solids, $13 \%$ debris, $5 \%$ organic solids, $2 \%$ special waste, and $1 \%$ lab packs.

- $75 \%$ of the LLMW is metals without mercury. The rest of the volume is a mixture of various hazardous constituents. 
Waste Class Distribution

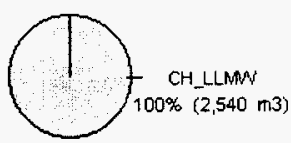

Total $=2,540 \mathrm{~m} 3$

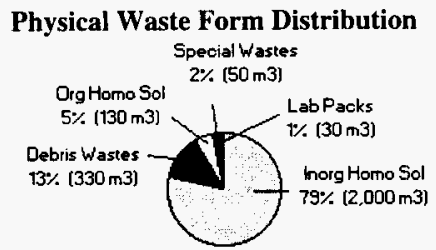

Total $=2,540 \mathrm{~m} 3$

\section{Generator Distribution}

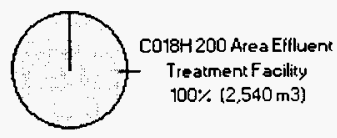

Total $=2,540 \mathrm{m3}$

\section{Hazardous Constituent Distribution}
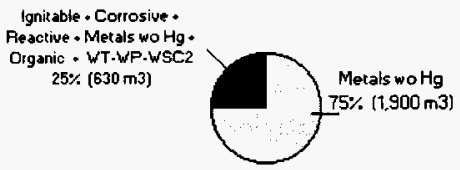

Total $=2,540 \mathrm{m3}$

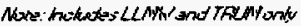

\section{Container Distribution}

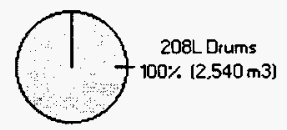

Total $=2.540 \mathrm{~m} 3$

Sum of totals may not add due to rounding: numbers over $10 \mathrm{~m}^{3}$ are rounded to the nearest $10 \mathrm{~m}^{3}$, numbers less than $10 \mathrm{~m}^{3}$ are rounded to integers, non-zero numbers less than 1 are rounded to 1 .

\section{Annual Waste Class Volumes}

Liquid Effluent waste will be generated from 1997 to the end of the life cycle in 2034 . The major amount of waste will be generated from 2011 to 2028, corresponding to the expected treatment of liquid waste from the TWRS program.

\section{Annual Baseline Volumes}




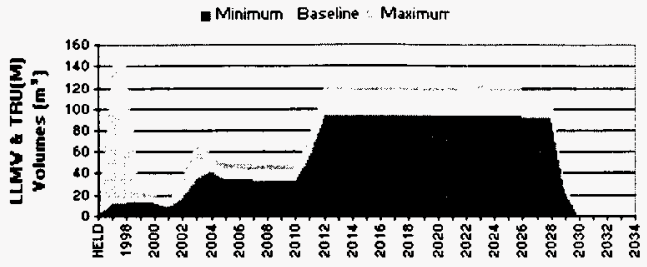

\section{Annual Baseline by Waste Class}

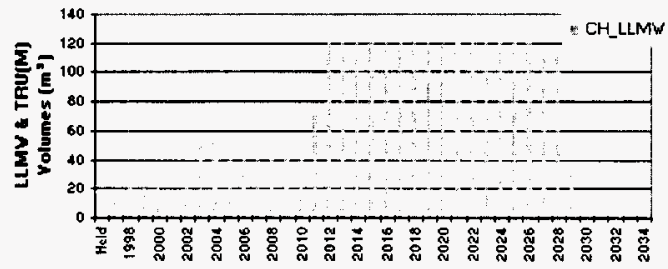

\section{Summary Table (Volumes in $\mathbf{m}^{3}$ )}

\begin{tabular}{|c|c|c|c|}
\hline $\begin{array}{l}\text { Liquid Effluent Summary: } \\
\text { Generator }\end{array}$ & CH_LLMY & Suproty & PCT \\
\hline C018H 200 Area Effluent Treatinent Facility & 2,540 & 2,540 & $100 \%$ \\
\hline Total & 2,540 & 2,540 & mens \\
\hline PCT & $100 \%$ & farest & \\
\hline
\end{tabular}

Sum of totals may not add due to rounding: numbers over $10 \mathrm{~m}^{3}$ are rounded to the nearest $10 \mathrm{~m}^{3}$, numbers less than $10 \mathrm{~m}^{3}$ are rounded to integers, non-zero numbers less than $I$ are rounded to $I$.

\section{Comparison to Previous Baseline(s)}

The FY97 forecast for Liquid Effluent of $2,540 \mathrm{~m}^{3}$ shows a $55 \%$ decrease from the FY96 forecast of $5,620 \mathrm{~m}^{3}$. This reduction is because last year's forecast was based on predictions of production rates. The FY 97 forecast is from a schedule of 26 Liquid Effluents to LERF/ETF.

The 1996 hazardous constituents forecast showed only $1 \%$ of the volume as metals without mercury, whereas the current expectation is for most of the waste to be metals without mercury. While $25 \%$ of the waste is forecast to be mixed constituents, these same constituents were reported as separate last year.

\section{Comparison to Previous Baseline(s) by Waste Class}




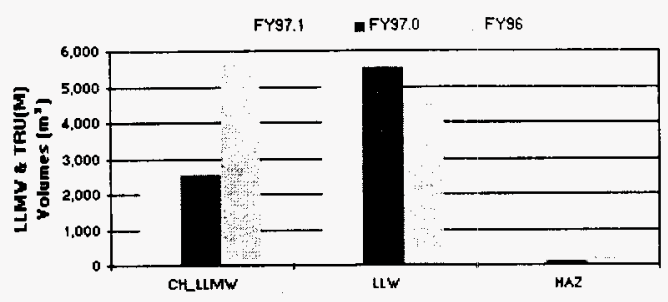

\begin{tabular}{|c|c|c|c|}
\hline $\begin{array}{l}\text { Liquid Effluent Comparison: } \\
\text { Waste Class }\end{array}$ & $\begin{array}{c}\text { Frg7.1 } \\
\text { Forecast } \\
\left(\mathrm{m}^{3}\right)\end{array}$ & $\begin{array}{c}\text { FY97.0 } \\
\text { Forecast } \\
\left(\mathrm{m}^{3}\right)\end{array}$ & $\begin{array}{c}\text { FY96 } \\
\text { Forecast } \\
\text { (m) }\end{array}$ \\
\hline CH LLMMN & 2,540 & 2,540 & 5,620 \\
\hline Subtotal & 2,540 & 2,540 & 5,620 \\
\hline LLWW & 5,490 & 5,490 & 4,480 \\
\hline HAI & 80 & 80 & 190 \\
\hline Tots! & 8710 & 8,110 & 10,290 \\
\hline
\end{tabular}

Sum of totals may not add due to rounding: numbers over $10 \mathrm{~m}^{3}$ are rounded to the nearest $10 \mathrm{~m}^{3}$, numbers less than $10 \mathrm{~m}^{3}$ are rounded to integers, non-zero numbers less than $I$ are rounded to $I$.

\section{Background}

The Liquid Effluent program mission is to eliminate the use of the soil column for liquid effluent treatment, and to manage current and future liquid effluent streams in a safe, responsible, cost-effective, and legally compliant manner. The program generates solid waste during the treatment of liquid effluents from TWRS' 242-A Evaporator and from the 300 Area. The forecast life cycle for generators in this program extends to 2034 .

Two generators reported solid waste in this program: 200 Area Effluent Treatment Facility, and the 300 Area/Treated Effluent Disposal Facilities (which now includes the Waste Neutralization Facility). The latter generator reported only LLW.

\section{Forecast Assumptions and Comments}

The minimum and maximum range for this waste is $79 \%$ and $117 \%$ of the baseline. The minimum percentage assumes that all solid waste from 200-UP-1 groundwater, N-Basin water, and purge water are sent to ERDF. The maximum percentage assumes that all these are sent to Waste Management.

\section{Other Forecast Data}

\section{- Low Level Waste}

- A total of $5,490 \mathrm{~m}^{3}$ of $\mathrm{LLW}$ is expected from all generators in the Liquid Effluent program. 80 $\mathrm{m}^{3}$ is expected from the 200 Area Effluent Treatment Facility, and $5,410 \mathrm{~m}^{3}$ is expected from the 300 Area/Treated Effluent Disposal Facilities.

- This forecast shows a $23 \%$ increase from the FY96 forecast of $4,480 \mathrm{~m}^{3}$.

- LLW will be shipped in Medium boxes ( $98 \%$ of the volume) and in 208 liter drums (2\%). 
- LLW's physical forms are mostly all inorganic salt waste, with $6 \%$ debris, $2 \%$ of organic solids, and less than one percent of soil and soil/gravel.

\section{- Hazardous Waste}

- A total of $80 \mathrm{~m}^{3}$ of hazardous waste is expected from the 200 Area Effluent Treatment Facility for management by the CWC.

GENERATORS:

300 Arearreated Effluent Disposal Facilities · C018H-200 Area Effluent Treatment Facility

\section{PROGRAMS:}

Analytical Services - EM-40 - Facility Transitions - Landlord - Liquid Effluent - NP - Offsite - PNNL - RCRA - Solid Waste $\cdot$ SNF $\cdot$ TWRS

\begin{tabular}{|c|c|}
\hline $\begin{array}{l}\text { CHARACTERISTICS: } \\
\text { CH_LLMW } \cdot \text { RH_LLMW } \cdot \text { CH_TRU(M) } \cdot \text { RH_TRU(M) } \\
\text { GTC III } \cdot \text { LLW } \cdot \text { HAZ }\end{array}$ & $\begin{array}{c}\text { CONTAINERS: } \\
\text { CH_LLMW } \cdot \text { RH_LLMW } \cdot \text { CH_TRU(M) } \\
\text { RH_TRU(M) } \cdot \text { GTC III } \cdot \text { LLW } \cdot \text { HAZ }\end{array}$ \\
\hline \multicolumn{2}{|c|}{ WASTE CLASSES: } \\
\hline
\end{tabular}

NOTICE: This page is provided subject to our disclaimer. Contact: Oscar Valero at (509) 373-4752.

HNF-EP-0918 rev. 1 Approved for public release; distribution is unlimited. 


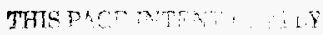

L W M 


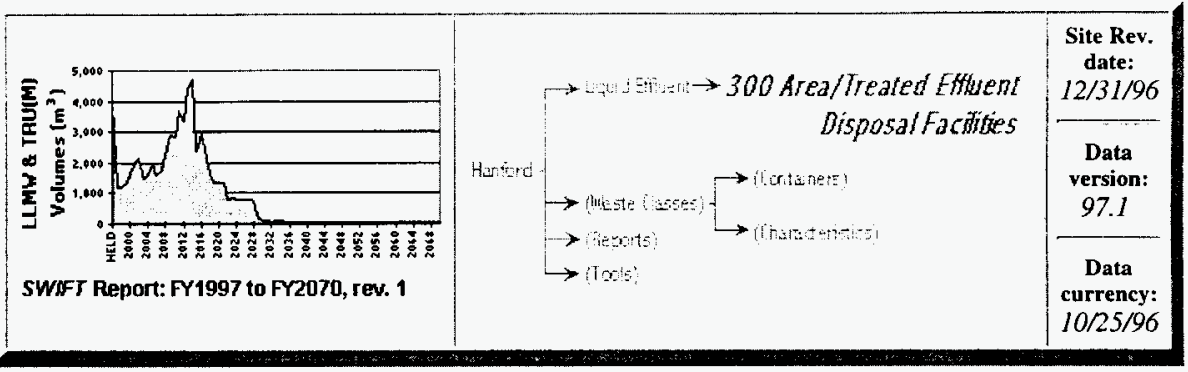

\section{Liquid Effluent - 300 Area/Treated Effluent Disposal Facilities}

\section{Contents}

》 Highlights

» Annual Volumes

»Comparison to Previous Baseline(s)

» Background
》Forecast Assumptions and Comments

»Other 300 Area/Treated Effluent Disposal Forecast Data

》Detailed Forecast Data

\section{Highlights}

- The 300 Area Treated Effluent Disposal Facility (WHC_TEDF) waste volume forecast also includes volumes from Waste Neutralization Facility.

- The overall life cycle for the 300 Area Treated Effluent Disposal Facility ends in 2025.

- No LLMW or TRU(M) waste is expected from these generators.

- Only LLW is expected at a total of $5,410 \mathrm{~m}^{3}$ of LLW for the life cycle of the facility.

\section{Annual LLMW and TRU(M) Waste Volumes}

\section{Annual Baseline Volumes}

No LLMW or TRU(M) waste is expected from 300 Area/Treated Effluent Disposal Facilities.

\section{Annual Baseline by Waste Class}

(Not applicable.)

\section{Comparison to Previous Baseline(s)}

The FY96 forecast included $3 \mathrm{~m}^{3}$ of LLMW from the Waste Neutralization Facility. The FY97 forecast includes only LLW. 


\section{Comparison to Previous Baseline(s) by Waste Class}

\begin{tabular}{|c|c|c|c|}
\hline $\begin{array}{l}\text { 300 AreapTreated Elfluent Disposal F acilities Comparison: } \\
\text { Yaste Class }\end{array}$ & $\begin{array}{l}\text { FY\$7.1 } \\
\text { Forecast } \\
{\left[\mathrm{m}^{3}\right]}\end{array}$ & $\begin{array}{l}\text { FYs7.0 } \\
\text { Forecast } \\
\left(\mathbf{m}^{\circ}\right)\end{array}$ & $\begin{array}{l}\text { FY96 } \\
\text { Forecast } \\
\left(\mathbf{m}^{3}\right)\end{array}$ \\
\hline LLW & 5,410 & 5.410 & 4,360 \\
\hline Tory & $54 / 9$ & $5+10$ & 1.368 \\
\hline
\end{tabular}

Sum of totals may not add due to rounding: numbers over $10 \mathrm{~m}^{3}$ are rounded to the nearest $10 \mathrm{~m}^{3}$, numbers less than $10 \mathrm{~m}^{3}$ are rounded to integers, non-zero numbers less than 1 are rounded to 1 .

\section{Background}

The Waste Neutralization Facility accumulates and provides interim storage for tank waste analysis effluents generated by 300 Area Laboratories. This facility also provides online monitoring of the 300 Area Retention Process Sewer to ensure protection of the environment prior to the effluents being sent to the 300 Area TEDF. The mission of the 300 Area / Treated Effluent Disposal Facilities is to treat and dispose of 300 Area Process Sewer effluent, and to collect and transport 300 Area radioactive liquid waste system discharges to the double-shelled tanks.

\section{Forecast Assumptions and Comments}

The assumptions for this forecast are that the TEDF operating parameters continue unchanged, that the Offsite release criteria applicable to suspect LLW does not change, that the TEDF influent volumes remain unchanged, that the contaminant loading in TEDF influent does not increase markedly, and that the TEDF spent IX resin is LLW.

\section{Other Forecast Data}

\section{- Low Level Waste}

- A total of $5,410 \mathrm{~m}^{3}$ of $\mathrm{LLW}$ is expected from 300 Area Treated Effluent Disposal Facility.

- This forecast shows a $24 \%$ increase over the FY 96 forecast of $4,360 \mathrm{~m}^{3}$. This increase is mainly due to the site receiving indication from DOE_RL that 340 may shut down in less than 2 years, causing TEDF to switch to bulk disposal of sludge.

- LLW will be shipped in Medium boxes (99\%) and in 208 liter drums (1\%).

- Nearly all of the LLW is in the inorganic salt waste physical form. Debris accounts for $6 \%$ of the volume, and organic solids and soil/gravel account for $1 \%$.

\section{- Hazardous Waste}

- No hazardous waste is expected from 300 Area Treated Effluent Disposal Facility for management by the CWC. 


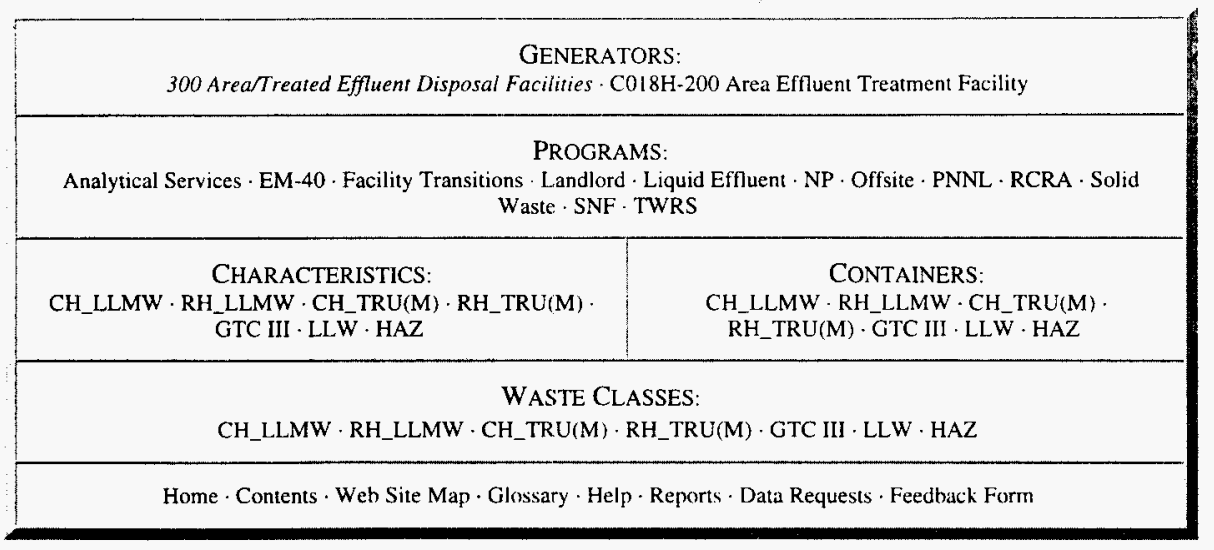

NOTICE: This page is provided subject to our disclaimer. Contact: Oscar Valero at (509) 373-4752.

HNF-EP-0918 rev. 1 Approved for public release; distribution is unlimited. 
THIS $4: \cdots$

L.: : A 


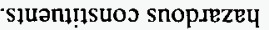

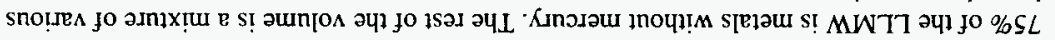

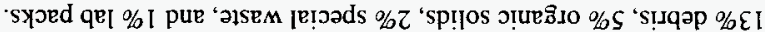

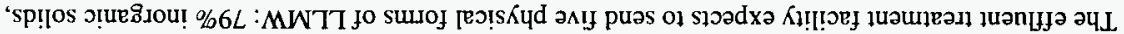

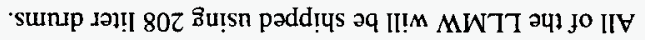

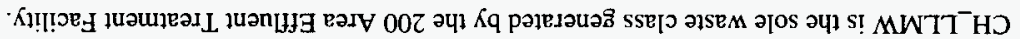

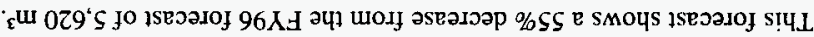

-ue.sold

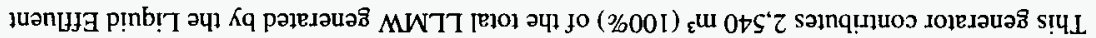

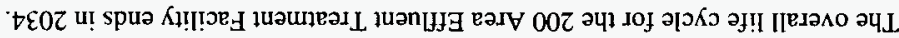

งเบชิ!!บชิ!H

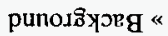

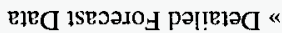

EIEC 1 SEวajo

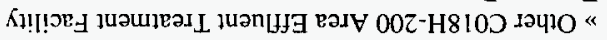

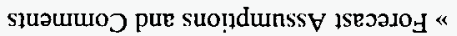

(s)วutןoseg

snoinวid ol uostueduo

səumpo $\Lambda$ [enuu $\forall \ll$

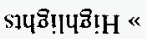

รานวนนกอ

\section{К1!!}

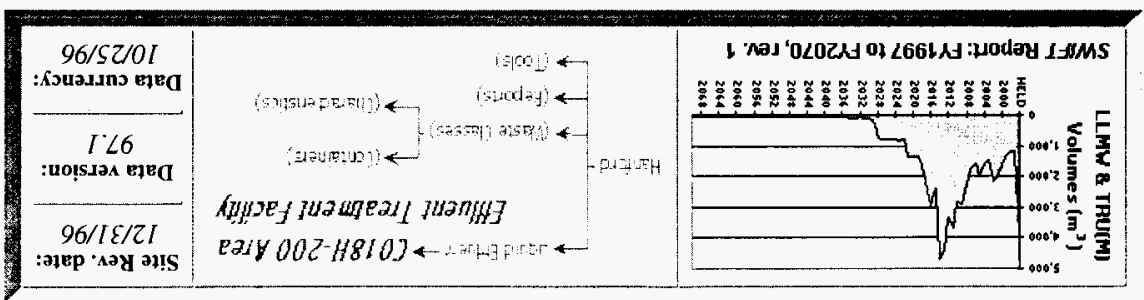




\section{Waste Class Distribution}

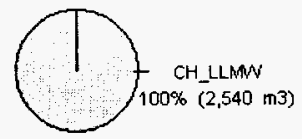

Totel $=2,540 \mathrm{~m} 3$

\section{Physical Waste Form Distribution}

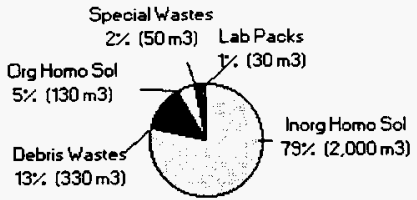

Total $=2.540 \mathrm{m3}$

\section{Hazardous Constituent Distribution}

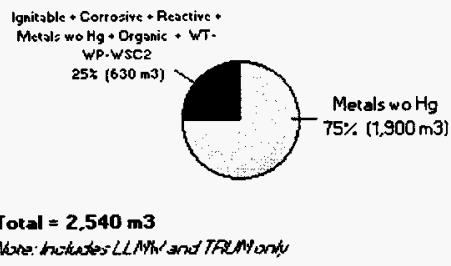

\section{Container Distribution}

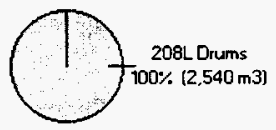

Total $=2,540 \mathrm{m3}$

Sum of totals may not add due to rounding: numbers over $10 \mathrm{~m}^{3}$ are rounded to the nearest $10 \mathrm{~m}^{3}$, numbers less than $10 \mathrm{~m}^{3}$ are rounded to integers, non-zero numbers less than $I$ are rounded to $I$.

\section{Annual Volumes}

\section{Annual Baseline Volumes}




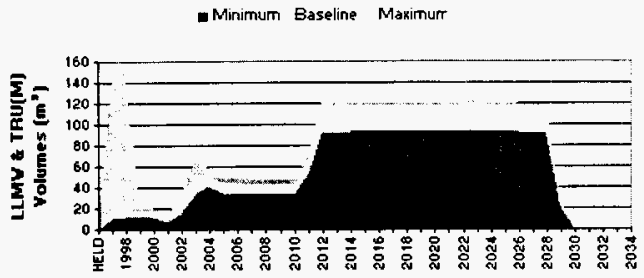

\section{Annual Baseline by Waste Class}

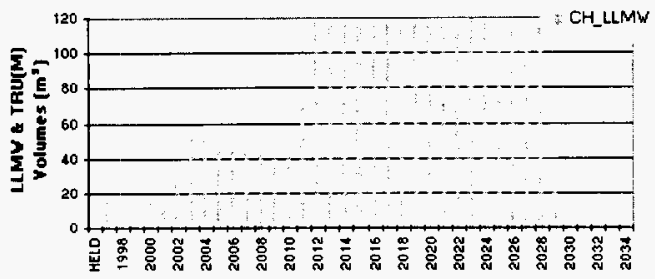

\section{Comparison to Previous Baseline(s)}

The FY97 forecast for 200 Area Effluent Treatment Facility of $2,540 \mathrm{~m}^{3}$ shows a $55 \%$ decrease from the FY 96 forecast of $5,620 \mathrm{~m}^{3}$. This reduction is because last year's forecast was based on predictions of production rates. The FY97 forecast is from a schedule of 26 Liquid Effluents to LERF/ETF.

The 1996 hazardous constituents forecast showed only $1 \%$ of the volume as metals without mercury, whereas the current expectation is for most of the waste to be metals without mercury. While $25 \%$ of the waste is forecast to be mixed constituents, these same constituents were reported as separate last year.

\section{Comparison to Previous Baseline(s) by Waste Class}

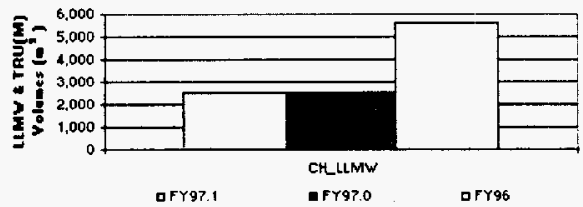




\begin{tabular}{|c|c|c|c|}
\hline $\begin{array}{l}\text { Co18H-200 Area Effluent Treatment Facility Comparison: } \\
\text { Vaste Class }\end{array}$ & $\begin{array}{c}\text { FY97.1 } \\
\text { Forecast } \\
\text { (m") }\end{array}$ & $\begin{array}{c}\text { FY97.0 } \\
\text { Forecast } \\
\text { (m') }\end{array}$ & $\begin{array}{c}\text { FY96 } \\
\text { Forecest } \\
\text { (m') }\end{array}$ \\
\hline $\mathrm{CH} L \mathrm{LLMW}$ & 2,540 & 2,540 & 5,620 \\
\hline suprocal & 2510 & 2,519 & 5628 \\
\hline LLW & 80 & 80 & 0 \\
\hline HAZ & 80 & 80 & 190 \\
\hline Tarey & 2,700 & 2,300 & 5810 \\
\hline
\end{tabular}

Sum of totals may not add due to rounding: numbers over $10 \mathrm{~m}^{3}$ are rounded to the nearest $10 \mathrm{~m}^{3}$, numbers less than $10 \mathrm{~m}^{3}$ are rounded to integers, non-zero numbers less than 1 are rounded to $I$.

\section{Background}

The 200 Area Effluent Treatment Facility is designed to provide effluent treatment and disposal capabilities required to support the continued operation of the 242-A Evaporator and to process the stored evaporator effluents in the Liquid Effluent Retention Facility (LERF). Operations began in 1995 and will continue through 2033.

The mission of 200 Area Effluent Treatment Facility is to treat liquid waste on the Hanford site to a level at which the end product meets the limits within the facility's State Waste Discharge permit for release to the environment.

\section{Forecast Assumptions and Comments}

The minimum and maximum range for this waste is $79 \%$ and $117 \%$ of the baseline. The minimum percentage assumes that all solid waste from $200-\mathrm{UP}-1$ groundwater, N-Basin water, and purge water are sent to ERDF. The maximum percentage assumes that all these are sent 10 SWDD.

\section{Other Forecast Data}

\section{- Low Level Waste}

- $80 \mathrm{~m}^{3}$ of LLW is expected from the 200 Area Effluent Treatment Facility.

- No LLW was indicated in the FY96 forecast.

- 208 liter drums will contain all of this LLW.

- The physical LLW forms are 55\% debris (five different kinds), 35\% organic solids, and $10 \%$ inorganic solids.

\section{- Hazardous Waste}

- A total of $80 \mathrm{~m}^{3}$ of hazardous waste is expected from 200 Area Effluent Treatment Facility for management by the CWC. 


\section{GENERATORS:}

300 Area/Treated Effluent Disposal Facilities · COI8H-200 Area Effluent Treatment Facility

\section{PROGRAMS:}

Analytical Services - EM-40 - Facility Transitions · Landlord - Liquid Effluent - NP · Offsite - PNNL · RCRA - Solid Waste - SNF - TWRS

CHARACTERISTICS:

CH_LLMW $\cdot$ RH_LLMW $\cdot$ CH_TRU(M) $\cdot$ RH_TRU(M) . GTC III $\cdot$ LLW $\cdot$ HAZ

\section{CONTAINERS:}

CH_LLMW $\cdot$ RH_LLMW $\cdot$ CH_TRU(M) RH_TRU(M) $\cdot$ GTC III $\cdot$ LLW $\cdot$ HAZ

WASTE CLASSES:

CH_LLMW $\cdot$ RH_LLMW $\cdot$ CH_TRU(M) $\cdot$ RH_TRU(M) $\cdot$ GTC III $\cdot$ LLW $\cdot$ HAZ

Home - Contents - Web Site Map - Glossary - Help · Reports - Data Requests · Feedback Form

NOTICE: This page is provided subject to our disclaimer. Contact: Oscar Valero at (509) 373-4752.

HNF-EP-0918 rev. 1 Approved for public release; distribution is unlimited. 
THIE $\cdots \cdots, \cdots:$ i. .... 


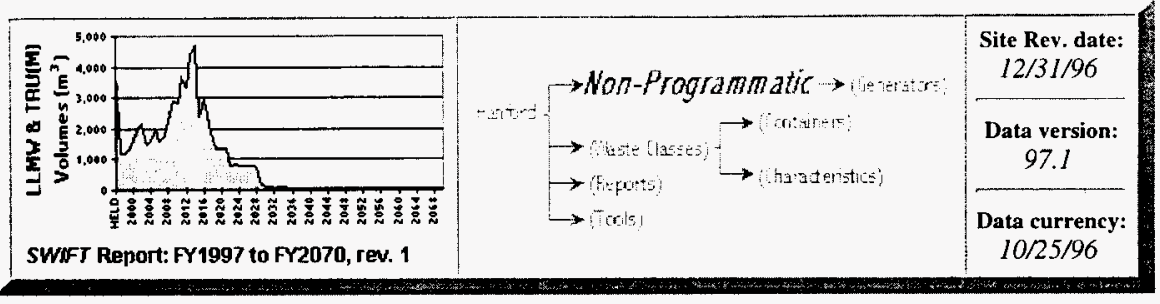

\section{Non-Programmatic}

\section{Contents}

" Highlights

" Annual Waste Class Volumes

»Summary Table

»Comparison to Previous Baseline(s)
"Background

"Forecast Assumptions and Comments

»Other Non-Programmatic Forecast Data

\section{Highlights}

- The forecast life cycle for all non-programmatic generators ends in 2037.

- The life cycle total of LLMW and TRU(M) waste for these generators is $5,510 \mathrm{~m}^{3}$, or $8 \%$ of the Hanford total.

- This forecast shows a $36 \%$ decrease from the FY96 forecast of $8,590 \mathrm{~m}^{3}$, due to a revised estimate for Stored Equipment (formerly Buried Equipment) based on new information.

- $\mathrm{CH}$ _LLMW is the primary waste class generated, representing $76 \%\left(4,190 \mathrm{~m}^{3}\right)$ of the waste volume.

- Stored Equipment is the major source of waste, generating $73 \%\left(4,000 \mathrm{~m}^{3}\right)$ of the waste volume.

- The containers used by this generator include large boxes ( $72 \%$ by volume), 208 liter drums ( $25 \%$ ), and SWBs $(3 \%)$.

- Every generator but one will use 208 liter drums to ship LLMW and TRU(M) waste.

- The physical waste forms reported show $98 \%$ of the LLMW and TRU(M) waste volume to be debris. Lab packs, special waste, organic, and inorganic solids are all included, but account for negligible volumes.

- The Non-Programmatic program forecasts more kinds of hazardous constituents than any other program. Nearly all (91\%) of the LLMW and TRU(M) waste volume is metals without mercury and organic mixed constituents. Metals without mercury represents $5 \%$, and the last $4 \%$ includes many mixed hazardous constituents. 
Waste Class Distribution

CHLTRU_M $24 \%(1,320 \mathrm{~m} 3)$

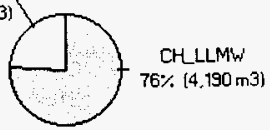

\section{Generator Distribution}

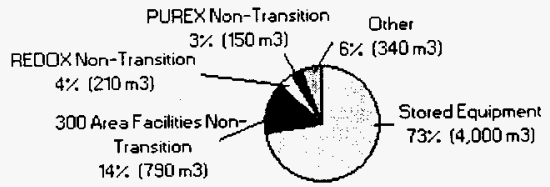

Total $=\mathbf{5 . 5 1 0 ~} \mathrm{m} 3$
Total $=5,510 \mathrm{~m} 3$

Physical Waste Form Distribution

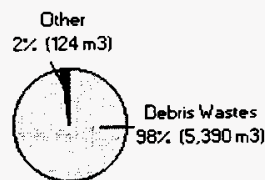

Total $=\mathbf{5 , 5 1 0 ~} \mathrm{m3}$

\section{Hazardous Constituent Distribution}

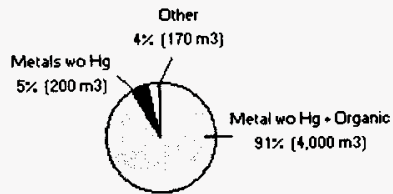

Total $=\$, 370 \mathrm{m3}$

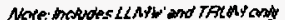

\section{Container Distribution}

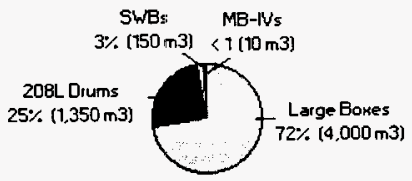

Total $=5,510 \mathrm{m3}$

Sum of totals may not add due to rounding: numbers over $10 \mathrm{~m}^{3}$ are rounded to the nearest $10 \mathrm{~m}^{3}$, numbers less than $10 \mathrm{~m}^{3}$ are rounded to integers, non-zero numbers less than 1 are rounded 101.

\section{Annual Waste Class Volumes}

The majority of waste expected from non-programmatic generators is in the HELD category. This is Stored Equipment waste that currently exists, but for which no shipping schedule has been set. In addition to HELD waste, non-programmatic generators will generate waste intermittently from 2011 through 2037.

\section{Annual Baseline Volumes}




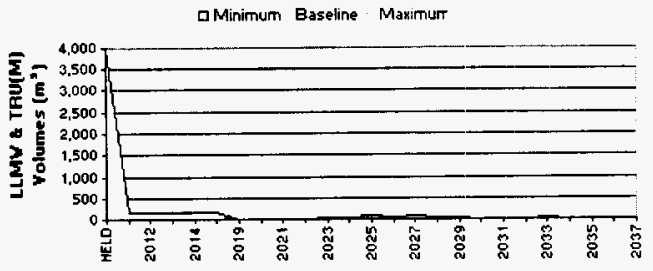

\section{Annual Baseline by Waste Class}

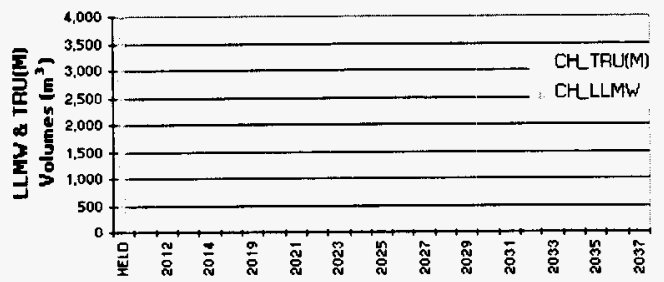

\section{Summary Table (Volumes in $\mathbf{m}^{3}$ )}

\begin{tabular}{|c|c|c|c|c|}
\hline $\begin{array}{l}\text { Non Programmatic Summary: } \\
\text { Generator }\end{array}$ & CH LLMY & CH TRU(M) & soproper & PCT \\
\hline Stored Equipment & 4,000 & 0 & 4,000 & $73 \%$ \\
\hline 300 Area F acilities Non-Transition & 60 & 730 & 790 & $14 \%$ \\
\hline REDOX Non-Transition & 2 & 210 & 210 & 4 \\
\hline PUREX Non-Transition & 50 & 110 & 150 & $3 \%$ \\
\hline PFP Nan-Transition & 80 & 60 & 130 & $2 \%$ \\
\hline 400 Area Facilities Non-Transition & 0 & 70 & 70 & $1 \%$ \\
\hline G Plant Non-Transition & 0 & 60 & 60 & $1 \%$ \\
\hline T Plant Nan-Transition & 0 & 40 & 40 & $1 \%$ \\
\hline Site Support Non-Transition & 0 & 30 & 30 & $1 \%$ \\
\hline U Plant Non-Transition & 3 & 10 & 10 & $0 \%$ \\
\hline Totaf & 4,790 & 1,320 & 5,550 & $100 \%$ \\
\hline $\mathrm{PCT}$ & $76 \%$ & $24 \%$ & $10 x=$ & \\
\hline
\end{tabular}

Sum of totals may not add due to rounding: numbers over $10 \mathrm{~m}^{3}$ are rounded to the nearest $10 \mathrm{~m}^{3}$, numbers less than $10 \mathrm{~m}^{3}$ are rounded to integers, non-zero numbers less than $/$ are rounded to 1.

\section{Comparison to Previous Baseline(s)}

The FY97 forecast shows a decrease from the FY96 forecast of $8,590 \mathrm{~m}^{3}$. This decrease is due to a revised estimate of the amount of waste expected from Stored Equipment, based on new information regarding the location and amount of waste to be managed.

The forecast estimates for other generators within this group are equivalent to the FY96 forecast.

Unlike the 1996 hazardous constituent forecast which showed $80 \%$ of the volume as organic 
waste, the 1997 forecast is mostly organic and metals without mercury waste combined. The 1996 forecast also expected $18 \%$ of the volume to be metals without mercury, which is only $5 \%$ of the volume this year. In essence then, waste is currently expected to have a combined hazardous constituent makeup, whereas the previous forecast showed the constituents well separated.

\section{Comparison to Previous Baseline(s) by Waste Class}

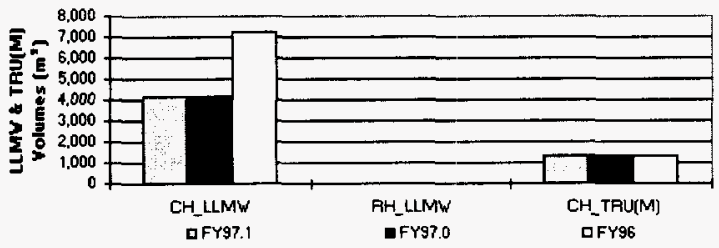

\begin{tabular}{|c|c|c|c|}
\hline $\begin{array}{l}\text { Non-Programmatic Comparison: } \\
\text { Waste Cless }\end{array}$ & $\begin{array}{l}\text { FY97.1 } \\
\text { Forecast } \\
\text { (m) }\end{array}$ & $\begin{array}{l}\text { Fr97.0 } \\
\text { Forecast } \\
\text { (m') }\end{array}$ & $\begin{array}{l}\text { Fy96 } \\
\text { Forecast } \\
\text { (m) }\end{array}$ \\
\hline $\mathrm{CH}$ LLMMV & 4,190 & 4,190 & 7,270 \\
\hline RH_LLMW & 0 & 0 & 0 \\
\hline $\mathrm{CH}$ TRU(M) & 1,320 & 1,320 & 1,320 \\
\hline Subtots & 5,550 & 5570 & 0,594 \\
\hline LLVW & 2,330 & 2,330 & 2,330 \\
\hline $\mathrm{HAZ}$ & $\mathbf{0}$ & 0 & 500 \\
\hline Toter & 7,840 & 7,840 & 11,420 \\
\hline
\end{tabular}

Sum of totals may not add due to rounding: numbers over $10 \mathrm{~m}^{3}$ are rounded to the nearest $10 \mathrm{~m}^{3}$, numbers less than $10 \mathrm{~m}^{3}$ are rounded to integers, non-zero numbers less than I are rounded to $I$.

\section{Background}

Non-programmatic generators include generators not currently within a Hanford program, and generators with uncertainties regarding which program is responsible for their future waste-generating activities ("orphan" facilities).

\section{Forecast Assumptions and Comments}

The volumes reported for most non-Programmatic waste generators are from BEMR estimates from FY96. In particular, "orphan" facility waste volumes were estimated by BEMR through use of a modeling tool that projected future transitional waste volumes for those facilities currently not within the Facility Transitions program.

In addition, the Stored Equipment (formerly Buried Equipment) generator has not completed a forecast since 1992 as no program currently has responsibility for this waste; therefore, waste volumes from the 1992 forecasts have been used as a starting point for this generator, with revisions this year based on new information. One result is that this generator's name has been changed from the FY96 forecast name of Buried Equipment, because it has been determined that the waste is not buried as previously thought, but is stored in $2711-\mathrm{E}$.

In addition, the container, hazardous constituent, physical waste form, radionuclides, handling 
characteristics, and waste class informatior was assumed to be similar to that within the Facility Transition Program. For this generator, the average information from Facility

Transition Program was used.

Minimum and maximum ranges are assumed to be $100 \%$.

\section{Other Forecast Data}

\section{- Low Level Waste}

o A total of $2,330 \mathrm{~m}^{3}$ of LLW is expected from non-programmatic generators.

o This forecast shows no change from the FY96 forecast.

- The physical LLW forms reported shows $96 \%$ of the volume to be debris. Soil and soil/gravel accounts for $3 \%$ of the volume, and fractions of organic solids, inorganic solids, and lab packs are also forecast.

- $45 \%$ of this LLW will be contained in MB-V boxes, $38 \%$ of the volume is to be in 208 liter drums, Medium boxes contain $14 \%$, and other boxes and drums hold the last $3 \%$.

\section{- Hazardous Waste}

- No hazardous waste from non-programmatic generators is expected to be managed by the CWC.

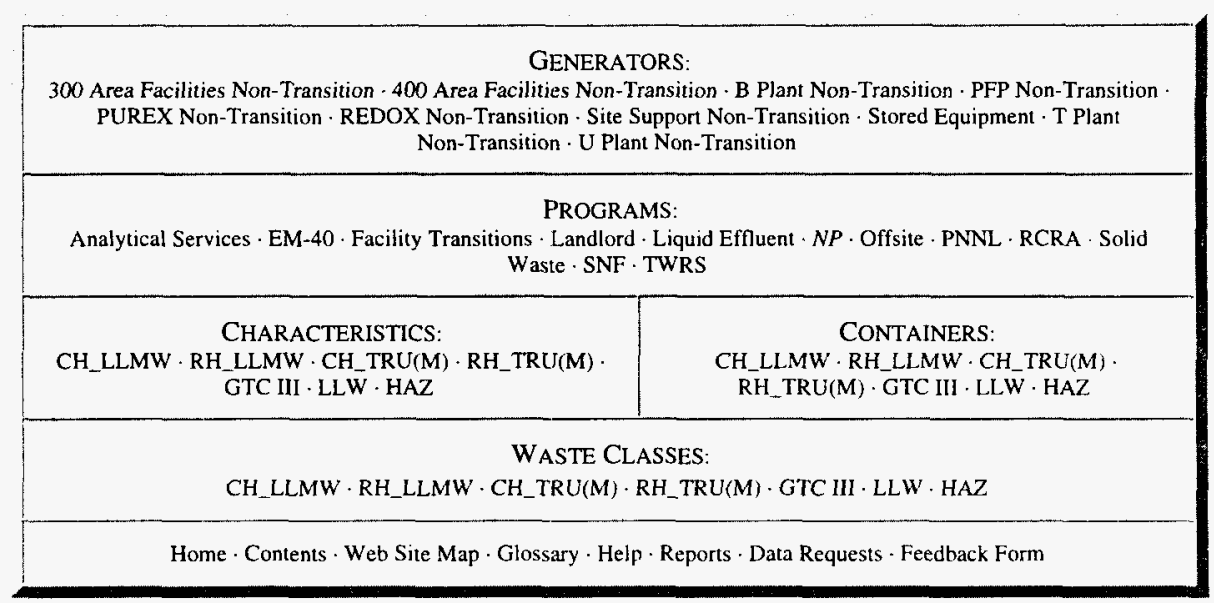

NOTICE: This page is provided subject to our disclaimer. Contact: Oscar Valero at (509) 373-4752.

HNF-EP-0918 rev. I Approved for public release; distribution is unlimited. 
काम 1. ㄱ. 


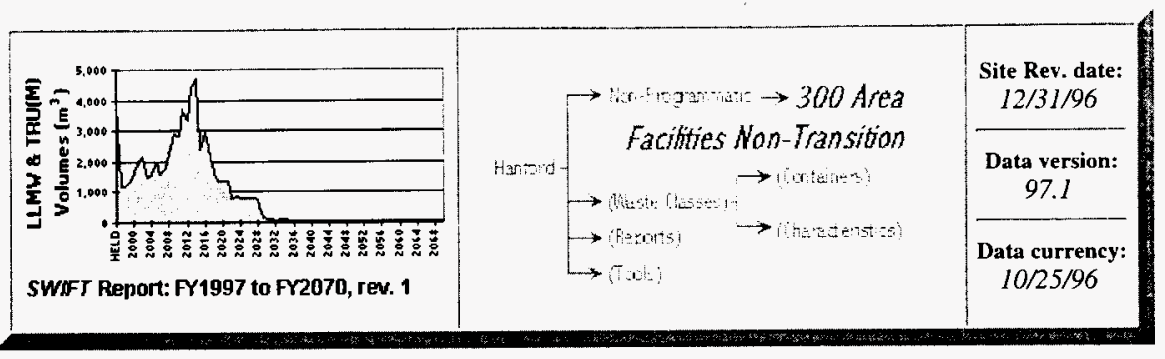

\section{Non-Programmatic - 300 Area Facilities Non-Transition}

\section{Contents}

» Highlights

»Annual Volumes

»Comparison to Previous

Baseline(s)

"Background
》Forecast Assumptions and Comments

» Other 300 Area Facilities Non-Transition Forecast

Data

»Detailed Forecast Data

\section{Highlights}

- 300 Area Facilities - Non-Transition (NP_300) contributes $790 \mathrm{~m}^{3}(14 \%)$ of the non-programmatic generators' LLMW and TRU(M) solid waste forecast.

- The end of life cycle for NP_300 is 2015 .

- $\mathrm{CH}$-TRU(M) is the primary waste class generated, representing $92 \%$ of the waste $\left(730 \mathrm{~m}^{3}\right)$.

- The majority of the containers to be sent are 208 liter drums ( $85 \%$ ), but SWBs account for $15 \%$ by volume.

- Physical LLMW and TRU(M) waste forms are 95\% debris. Lab packs, special wastes, organic solids, inorganic solids, and soil/gravel are expected as well but in fractional volumes.

- This generator expects more hazardous constituent varieties than any other. Metals without mercury composes $61 \%$ of the LLMW and TRU(M) waste volume, while mixed ignitable, corrosive, metals without mercury, organic, state regulated compose $19 \%$, and metals without mercury, organic, state regulated mixed constituents compose $13 \%$. Other hazardous constituents accounts for the last $7 \%$. 


\section{Waste Class Distribution}

CH_LLMN

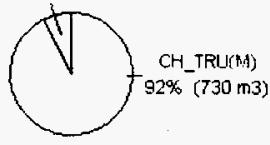

Total $=790 \mathrm{m3}$

\section{Physical Waste Form Distribution}

\section{Hazardous Constituent Distribution}

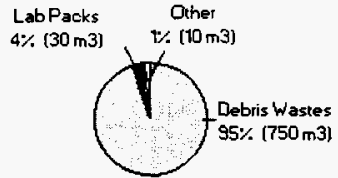

Toral $=790 \mathrm{~m} 3$

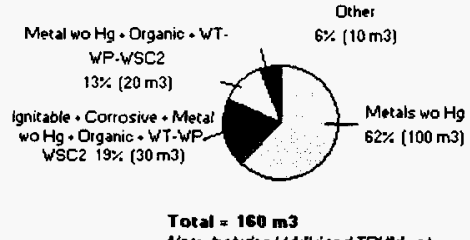

\section{Container Distribution}

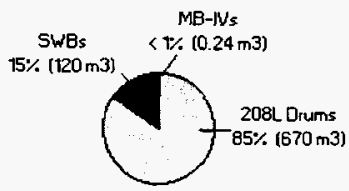

Total $=790 \mathrm{~m} 3$

Sum of totals may not add due to rounding: numbers over $10 \mathrm{~m}^{3}$ are rounded to the nearest $10 \mathrm{~m}^{3}$. numbers less than $10 \mathrm{~m}^{3}$ are rounded to integers, non-zero numbers less than $I$ are rounded to 1 .

\section{Annual Volumes}

\section{Annual Baseline Volumes}




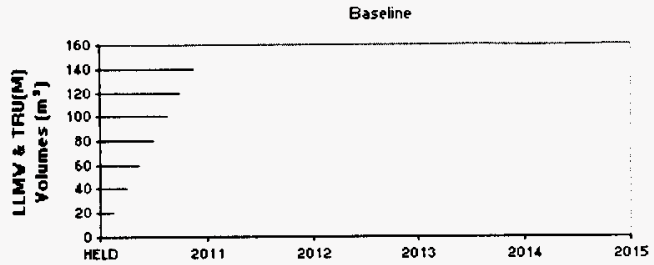

\section{Annual Baseline by Waste Class}

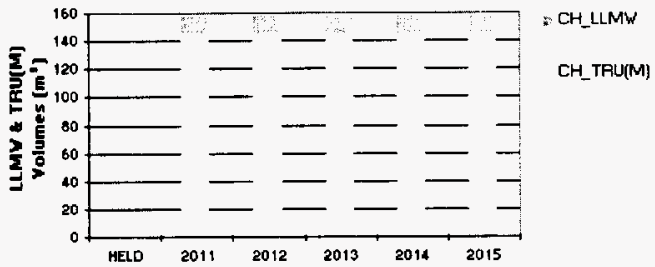

\section{Comparison to Previous Baseline(s)}

The FY97 forecast is equivalent to the FY96 forecast.

\section{Comparison to Previous Baseline(s) by Waste Class}

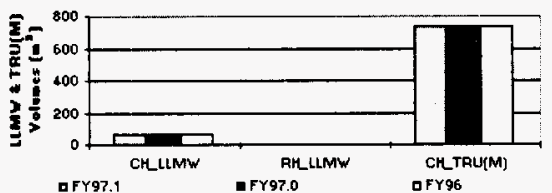

\begin{tabular}{|c|c|c|c|}
\hline $\begin{array}{l}300 \text { Area F acilities Non-Transition Comparison: } \\
\text { Yaste Class }\end{array}$ & $\begin{array}{l}\text { FY97.1 } \\
\text { Forecast } \\
\left(\mathbf{m}^{2}\right]\end{array}$ & $\begin{array}{l}\text { Fr97.0 } \\
\text { Forecest } \\
\left(m^{2}\right)\end{array}$ & $\begin{array}{c}\text { FY96 } \\
\text { Forecast } \\
\text { (m") }\end{array}$ \\
\hline CH_LLMW & 60 & 60 & 60 \\
\hline BH LLIMW & 0 & 0 & 0 \\
\hline CH TRU(M) & 730 & 730 & 730 \\
\hline Stoplofer & $7 x$ & $7 \rightarrow$ & $\pi x$ \\
\hline LLW & 1.420 & 1.420 & 1.420 \\
\hline HAZ & 0 & 0 & 180 \\
\hline rory & 2210 & 2.210 & 2.30 \\
\hline
\end{tabular}

Sum of totals may not add due to rounding: numbers over $10 \mathrm{~m}^{3}$ are rounded to the nearest $10 \mathrm{~m}^{3}$, numbers less than $10 \mathrm{~m}^{3}$ are rounded to integers, non-zero numbers less than $I$ are rounded to $I$.

\section{Background}


This waste generator is a grouping of 32 facilities that are expected to require deactivation in 2011 through 2015 . The deactivation of these facilities has not been included in the planning baseline of any program to date; therefore, the solid waste resulting from deactivation of these facilities has been deemed "non-programmatic."

\section{Forecast Assumptions and Comments}

The volumes reported for this generator are from BEMR estimates from FY96. In particular, waste volumes were estimated by BEMR through use of a modeling tool that projected future transitional waste volumes. In addition, the container, hazardous constituent, physical waste form, radionuclides, handling characteristics, and waste class information was assumed to be similar to that within the Facility Transition Program. For this generator, the average information from Facility Transition Program was used.

Minimum and maximum ranges were not collected for this generator, since forecast volumes were obtained from BEMR model results that did not account for variations in waste generation. In this case, the assumption is made that minimum and maximum ranges for the waste are $100 \%$ and $100 \%$ respectively.

\section{Other Forecast Data}

\section{- Low Level Waste}

- A total of $1,420 \mathrm{~m}^{3}$ of LLW is expected from NP_300.

- This forecast shows no change from the FY96 forecast.

- Physical LLW forms are 95\% debris. Soil/gravel, lab packs, organic solids, inorganic solids, and shielding are expected as well but in fractional volumes.

- Of the containers used for LLW, both MB-V boxes and 208 liter drums share similar volumes: $45 \%$ and $44 \%$ respectively. Medium boxes hold $11 \%$, while a negligible volume will utilize various boxes and drums.

\section{- Hazardous Waste}

o No hazardous waste is expected from NP_300 for management by the CWC. 


\section{GENERATORS:}

300 Area Facilities Non-Transition 400 Area Facilities Non-Transition - B Plant Non-Transition · PFP Non-Transition . PUREX Non-Transition - REDOX Non-Transition - Site Support Non-Transition - Stored Equipment - T Plant Non-Transition - U Plant Non-Transition

PROGRAMS:

Analytical Services $\cdot$ EM-40 - Facility Transitions $\cdot$ Landlord $\cdot$ Liquid Effluent $\cdot$ NP $\cdot$ Offsite $\cdot$ PNNL $\cdot$ RCRA $\cdot$ Solid Waste - SNF - TWRS

CHARACTERISTICS:

CH_LLMW $\cdot$ RH_LLMW $\cdot$ CH_TRU(M) $\cdot$ RH_TRU(M) $\cdot$ GTC III $\cdot$ LLW $\cdot$ HAZ

\section{CONTAINERS:}

CH_LLMW $\cdot$ RH_LLMW $\cdot$ CH_TRU(M) RH_TRU(M) $\cdot$ GTC III $\cdot$ LLW $\cdot$ HAZ

\section{WASTE ClasSES:}

CH_LLMW $\cdot$ RH_LLMW $\cdot$ CH_TRU(M) $\cdot$ RH_TRU(M) $\cdot$ GTC III $\cdot$ LLW $\cdot$ HAZ

Home - Contents - Web Site Map - Glossary · Help - Reports - Data Requests · Feedback Form

NOTICE: This page is provided subject to our disclaimer. Contact: Oscar Valero at (509) 373-4752.

HNF-EP-0918 rev. 1 Approved for public release; distribution is unlimited. 
This: rer tax : 


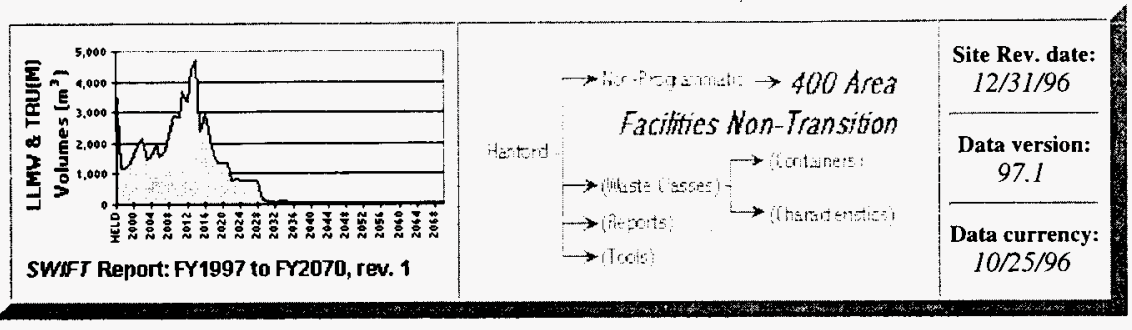

\section{Non-Programmatic - 400 Area Facilities Non-Transition}

\section{Contents}

» Highlights

》Annual Volumes

» Comparison to Previous

Baseline(s)

»Background
》Forecast Assumptions and Comments

»Other 400 Area Facilities Non-Transition Forecast

Data

» Detailed Forecast Data

\section{Highlights}

- 400 Area Facilities - Non-Transition (NP_400) contributes $70 \mathrm{~m}^{3}(1 \%)$ of the non-programmatic generators' LLMW and TRU(M) solid waste forecast.

- The end of life cycle for NP_400 is 2023.

- CH_TRU(M) is the only waste class generated, representing $100 \%$ of the waste $\left(70 \mathrm{~m}^{3}\right)$.

- The great majority of this volume ( $89 \%$ ) will be contained in 208 liter drums, and SWBs will be used also (11\%).

- All of the TRU(M) waste volume is debris (heterogeneous, contaminated metal, plastic/rubber, and organic).

\section{Waste Class Distribution}

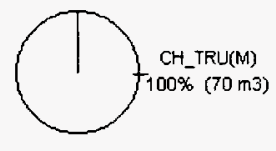

Total $=70 \mathrm{m3}$ 
Physical Waste Form Distribution

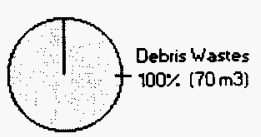

Total $=70 \mathrm{m3}$

\section{Container Distribution}

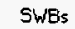

$11 \%(8 \mathrm{~m} 3)$

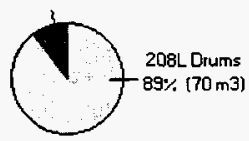

Total $=70 \mathrm{~m} 3$

Sum of totals may not add due to rounding: numbers over $10 \mathrm{~m}^{3}$ are rounded to the nearest $10 \mathrm{~m}^{3}$, numbers less than $10 \mathrm{~m}^{3}$ are rounded to integers, non-zero numbers less than $I$ are rounded to 1.

\section{Annual Volumes}

\section{Annual Baseline Volumes}

Baseline

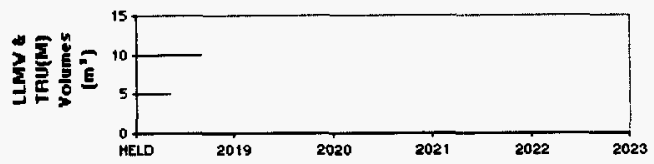

Annual Baseline by Waste Class

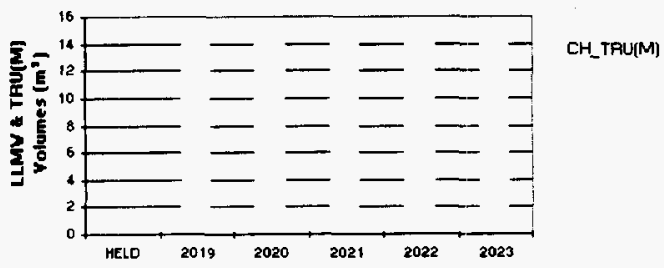

\section{Comparison to Previous Baseline(s)}

The FY97 forecast is equivalent to the FY96 forecast.

Comparison to Previous Baseline(s) by Waste Class 


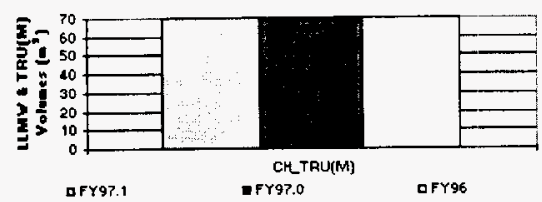

\begin{tabular}{|c|c|c|c|}
\hline $\begin{array}{l}400 \text { Area F acilities Non-Transition Comparison: } \\
\text { Waste Class }\end{array}$ & $\begin{array}{l}\text { FY97_1 } \\
\text { Forecast } \\
\left(\mathrm{m}^{3}\right)\end{array}$ & $\begin{array}{c}\text { FYg7.0 } \\
\text { Forecast } \\
\left(\mathrm{m}^{3}\right) \\
\end{array}$ & $\begin{array}{l}\text { FY96 } \\
\text { Forecast } \\
\left(m^{3}\right)\end{array}$ \\
\hline CHLTRU $(M)$ & 70 & 70 & 70 \\
\hline Sabtoral & 70 & $\overline{70}$ & 77 \\
\hline LLW & 100 & 100 & 100 \\
\hline HAZ & 0 & 0 & 20 \\
\hline Total & 170 & 170 & 190 \\
\hline
\end{tabular}

Sum of totals may not add due to rounding: numbers over $10 \mathrm{~m}^{3}$ are rounded to the nearest $10 \mathrm{~m}^{3}$, numbers less than $10 \mathrm{~m}^{3}$ are rounded to integers, non-zero numbers less than $J$ are rounded to $I$.

\section{Background}

This waste generator is a grouping of facilities at the 400 Area that are expected to require deactivation. The deactivation of these facilities has not been included in the planning baseline of any program to date; therefore, the solid waste resulting from deactivation of these facilities has been deemed "non-programmatic."

\section{Forecast Assumptions and Comments}

The volumes reported for this generator are from BEMR estimates from FY96. In particular, waste volumes were estimated by BEMR through use of a modeling tool that projected future transitional waste volumes. In addition, the container, hazardous constituent, physical waste form, radionuclides, handling characteristics, and waste class information was assumed to be similar to that within the Facility Transition Program. For this generator, the average information from the FFTF Transition Facility was used.

Minimum and maximum ranges were not collected for this generator, since forecast volumes were obtained from BEMR model results that did not account for variations in waste generation. In this case, the assumption is made that minimum and maximum ranges for the waste are $100 \%$ and $100 \%$ respectively.

\section{Other Forecast Data}

\section{- Low Level Waste}

- A total of $100 \mathrm{~m}^{3}$ of LLW is expected from NP_400.

- This forecast shows no change from the FY96 forecast.

- 208 liter drums are forecast to contain $39 \%$ of the LLW volume, Other drums will contain $36 \%$, and one-quarter of the waste will use MB-V boxes.

- This physical LLW form is all debris except for 3 cubic meters of forecast organic particulates. 


\section{- Hazardous Waste}

- No hazardous waste is expected from NP_400 for management by the CWC.

\section{GENERATORS:}

300 Area Facilities Non-Transition - 400 Area Facilities Non-Transition - B Plant Non-Transition - PFP Non-Transition . PUREX Non-Transition - REDOX Non-Transition - Site Support Non-Transition · Stored Equipment - T Plant Non-Transition · U Plant Non-Transition

\section{PROGRAMS:}

Analytical Services · EM-40 - Facility Transitions · Landlord · Liquid Effluent · NP · Offsite · PNNL · RCRA · Solid Waste $\cdot$ SNF $\cdot$ TWRS

\begin{tabular}{|c|c|}
\hline $\begin{array}{l}\text { CHARACTERISTICS: } \\
\mathrm{CH} \text { _LLMW } \cdot \mathrm{RH \_ LLMW} \cdot \mathrm{CH} \text { _TRU(M) } \cdot \mathrm{RH}_{-} \text {TRU(M) } \\
\text { GTC III } \cdot \mathrm{LLW} \cdot \mathrm{HAZ}\end{array}$ & $\begin{array}{c}\text { CONTAINERS: } \\
\text { CH_LLMW } \cdot \text { RH_LLMW } \cdot \text { CH_TRU(M) }^{-} \\
\text {RH_TRU(M) } \cdot \text { GTC III } \cdot \text { LLW } \cdot \text { HAZ }\end{array}$ \\
\hline \multicolumn{2}{|c|}{$\begin{array}{c}\text { WASTE CLASSES: } \\
\text { CH_LLMW } \cdot \text { RH_LLMW } \cdot \mathrm{CH}_{-} \text {TRU(M) } \cdot \text { RH_TRU(M) } \cdot \text { GTC III } \cdot \text { LLW } \cdot \text { HAZ }\end{array}$} \\
\hline
\end{tabular}

NOTICE: This page is provided subject to our disclaimer. Contact: Oscar Valero at (509) 373-4752.

HNF-EP-0918 rev. 1 Approved for public release; distribution is unlimited. 


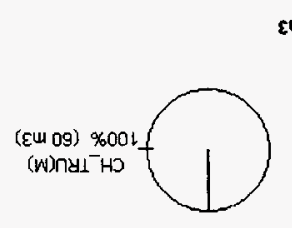

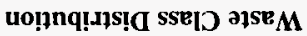

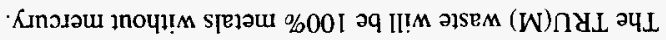

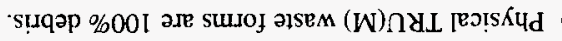
sumsp

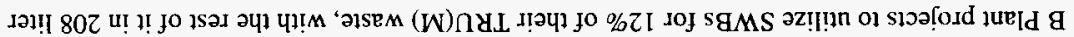

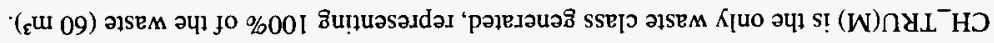

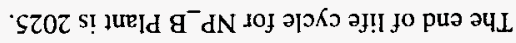

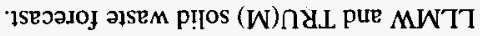
sЈo|e.əuә

\section{ราบธิโ!บชิ!ก}

$$
\text { puno. }
$$

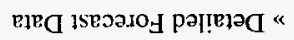

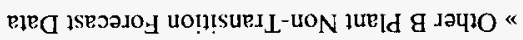

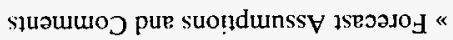

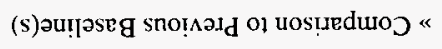
səun!̨o $\Lambda$ [enuu $\forall \ll$

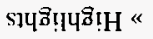

\section{sұนวนแ0อ}

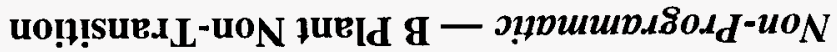

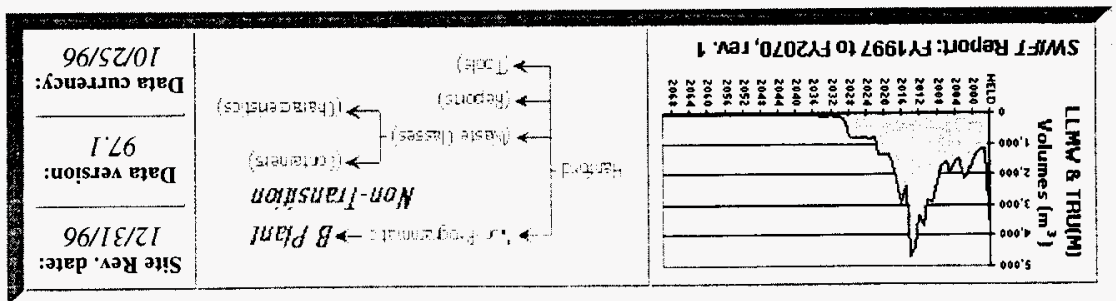


Physical Waste Form Distribution

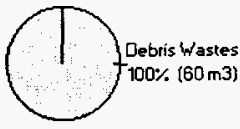

Total $=60 \mathrm{~m} 3$

\section{Hazardous Constituent Distribution}

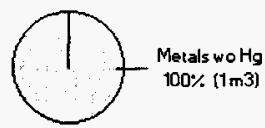

Total $=1 \mathrm{m3}$

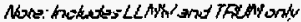

\section{Container Distribution}

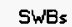

$12 \%(7 \mathrm{~m} 3)$

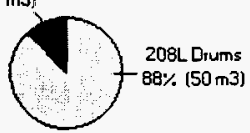

Total $=60 \mathrm{m3}$

Sum of totals may not add due to rounding: numbers over $10 \mathrm{~m}^{3}$ are rounded to the nearest $10 \mathrm{~m}^{3}$, numbers less than $10 \mathrm{~m}^{3}$ are rounded to integers, non-zero numbers less than 1 are rounded to 1.

\section{Annual Volumes}

\section{Annual Baseline Volumes}

Baseline

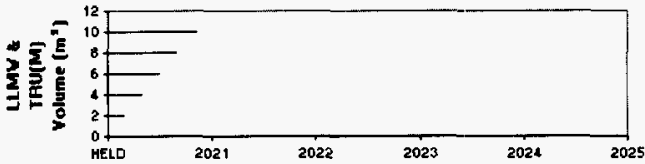

Annual Baseline by Waste Class 


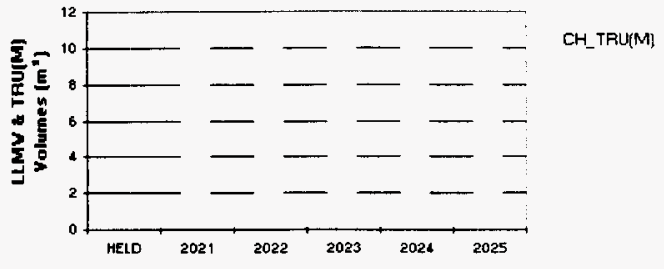

\section{Comparison to Previous Baseline(s)}

The FY97 forecast is equivalent to the FY96 forecast.

\section{Comparison to Previous Baseline(s) by Waste Class}

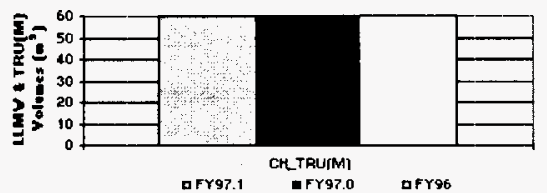

\begin{tabular}{|c|c|c|c|}
\hline $\begin{array}{l}\text { B Plant Non-Transition Comparison: } \\
\text { Waste Class }\end{array}$ & $\begin{array}{c}\text { FY97.1 } \\
\text { Forecast } \\
\left(\mathrm{m}^{3}\right)\end{array}$ & $\begin{array}{c}\text { FY97.0 } \\
\text { Forecast } \\
\left(\mathbf{m}^{3}\right) \\
\end{array}$ & $\begin{array}{c}\text { FY96 } \\
\text { Forecast } \\
\left(\mathrm{m}^{3}\right)\end{array}$ \\
\hline $\mathrm{CH} L \mathrm{TR} \cup(\mathrm{M})$ & 60 & 60 & 60 \\
\hline Subroral & $\mathscr{D O}$ & 60 & 60 \\
\hline LLW & 90 & 90 & 90 \\
\hline$\overline{H A Z}$ & 0 & 0 & 10 \\
\hline Toral & 150 & 150 & 160 \\
\hline
\end{tabular}

Sum of totals may not add due to rounding: numbers over $10 \mathrm{~m}^{3}$ are rounded to the nearest $10 \mathrm{~m}^{3}$, numbers less than $10 \mathrm{~m}^{3}$ are rounded to integers, non-zero numbers less than 1 are rounded to 1.

\section{Background}

This waste generator represents B Plant deactivation. The deactivation has not been included in the planning baseline of any program to date; therefore, the solid waste resulting from this deactivation has been deemed "non-programmatic."

\section{Forecast Assumptions and Comments}

The volumes reported for this generator are from BEMR estimates from FY96. In particular, waste volumes were estimated by BEMR through use of a modeling tool that projected future transitional waste volumes. In addition, the container, hazardous constituent, physical waste form, radionuclides, handling characteristics, and waste class information was assumed to be similar to that within the Facility Transition Program. For this generator, the average information from the B Plant Transition Facility was used.

Minimum and maximum ranges were not collected for this generator, since forecast volumes 
were obtained from BEMR model results that did not account for variations in waste generation. In this case, the assumption is rnade that minimum and maximum ranges for the waste are $100 \%$ and $100 \%$ respectively.

\section{Other Forecast Data}

- Low Level Waste

- A total of $90 \mathrm{~m}^{3}$ of LLW is expected from NP_B Plant.

- This forecast shows no change from the FY96 forecast.

o The LLW will be sent in a variety of containers including boxes ( $37 \%$ by volume), 208 liter drums (13\%), and $50 \%$ in Medium boxes.

- The physical LLW forms are $87 \%$ debris, $6 \%$ soil and soil/gravel, $3 \%$ inorganic solids, $3 \%$ organic solids, and $1 \%$ shielding.

\section{- Hazardous Waste}

- No hazardous waste is expected from NP_B Plant for management by the CWC.

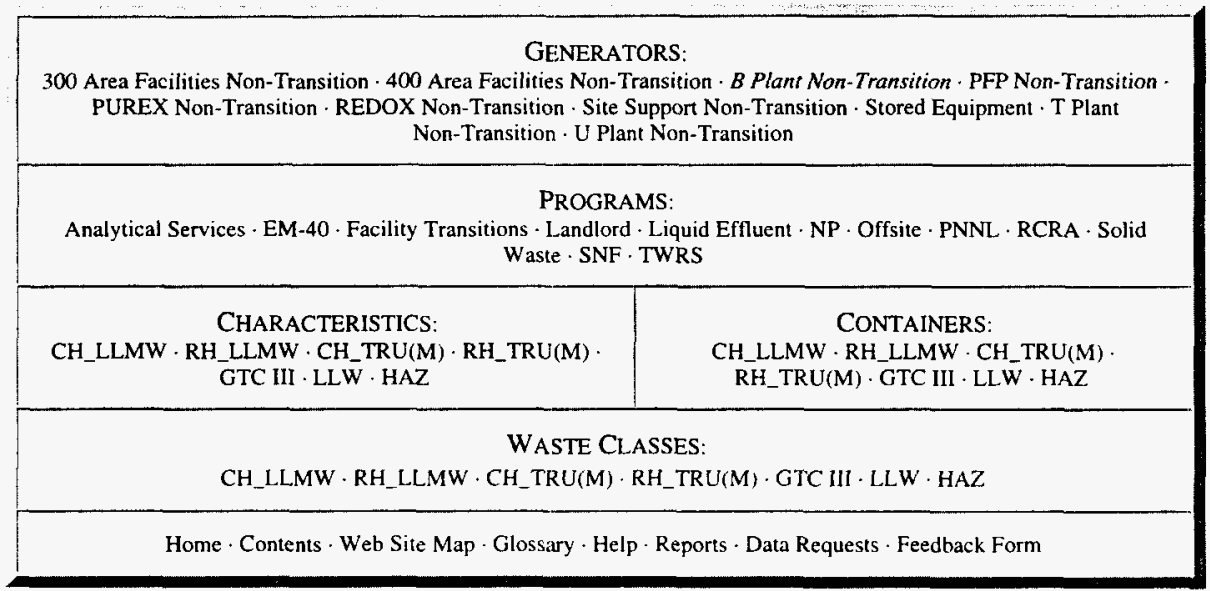

NOTICE: This page is provided subject to our disclaimer. Contact: Oscar Valero at (509) 373-4752.

HNF-EP-0918 rev. 1 Approved for public release; distribution is unlimited. 


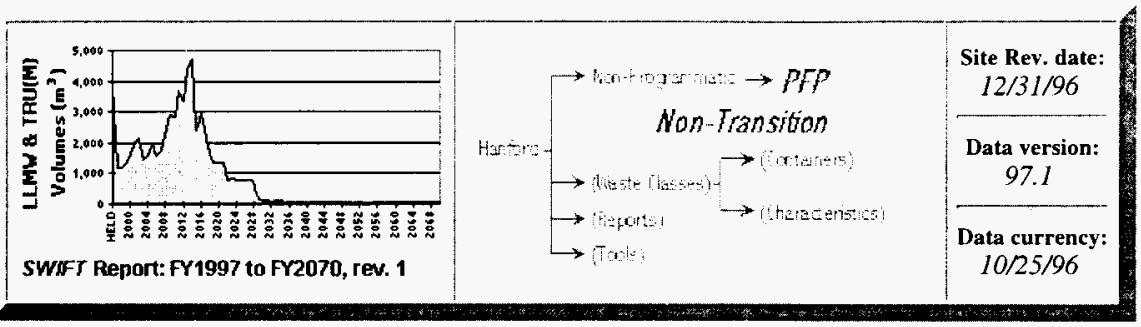

\section{Non-Programmatic — PFP Non-Transition}

\section{Contents}

" Highlights

" Annual Volumes

" Comparison to Previous Baseline(s)

»Background
》 Forecast Assumptions and Comments

»Other PFP Non-Transition Forecast Data

»Detailed Forecast Data

\section{Highlights}

- PFP-Non-Transition (NP_PFP) contributes $130 \mathrm{~m}^{3}(2 \%)$ of the non-programmatic generators' LLMW and TRU(M) solid waste forecast.

- The end of life cycle for NP_PFP is 2037.

- $\mathrm{CH}_{-} \mathrm{LLMW}$ and $\mathrm{CH}$ _TRU(M) are generated in roughly equal proportions.

- SWBs will be used for some CH_TRU(M) waste (7\% of the total volume), and 208 liter drums for the remaining $93 \%$.

- The physical waste forms are mostly debris. In addition, organic lab packs account for $31 \%$ of the volume, and special waste composes $6 \%$.

- LLMW and TRU(M) waste hazardous constituents are mixed ignitable, corrosive, metals without mercury, organic, state regulated ( $42 \%$ by volume), mixed metals without mercury, organic, state regulated $(33 \%)$, metals without mercury $(22 \%)$, and state regulated $(3 \%)$. 


\section{Waste Class Distribution}

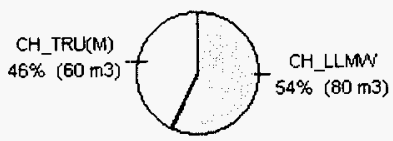

Totel $=130 \mathrm{m3}$

Physical Waste Form Distribution

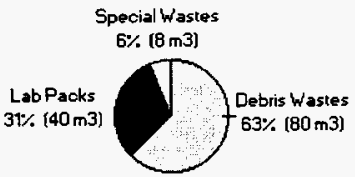

Total $=130 \mathrm{~m} 3$

\section{Hazardous Constituent Distribution}

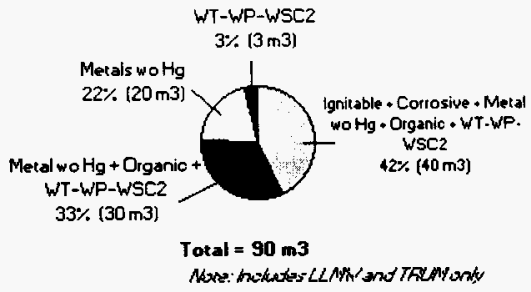

\section{Container Distribution}

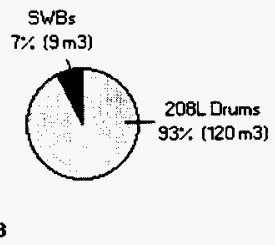

Sum of totals may not add due to rounding: numbers over $10 \mathrm{~m}^{3}$ are rounded to the nearest $10 \mathrm{~m}^{3}$, numbers less than $10 \mathrm{~m}^{3}$ are rounded to integers, non-zero numbers less than 1 are rounded to 1.

\section{Annual Volumes}

\section{Annual Baseline Volumes}


Baseline

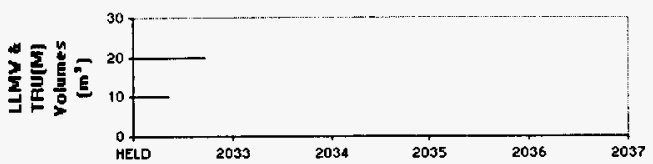

\section{Annual Baseline by Waste Class}

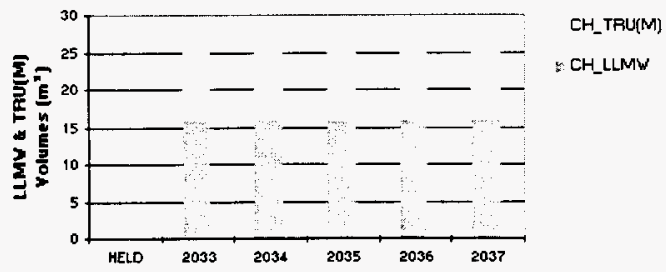

\section{Comparison to Previous Baseline(s)}

The FY97 forecast is equivalent to the FY96 forecast.

\section{Comparison to Previous Baseline(s) by Waste Class}

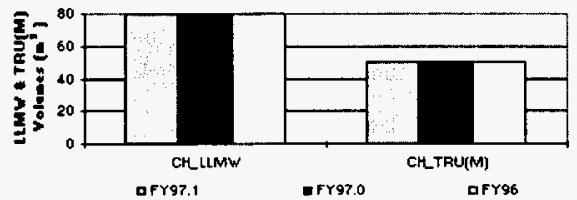

\begin{tabular}{|c|c|c|c|}
\hline $\begin{array}{l}\text { PFP Non-Transition Comparison: } \\
\text { Vaste Class }\end{array}$ & $\begin{array}{l}\text { FY97.1 } \\
\text { Forecast } \\
\text { (m') }\end{array}$ & $\begin{array}{l}\text { Fr97.0 } \\
\text { Forecast } \\
\text { (m'] }\end{array}$ & $\begin{array}{l}\text { FY96 } \\
\text { Forecast } \\
\text { (m') }\end{array}$ \\
\hline CH_LLMW & 80 & 80 & 80 \\
\hline $\mathrm{CH}$ TAU(M) & 50 & 50 & 50 \\
\hline Subraped & 130 & 15 & $\boldsymbol{s}$ \\
\hline LLW & 70 & 70 & 70 \\
\hline HAZ & 0 & 0 & 10 \\
\hline Totor & 20 & $2 \infty$ & 210 \\
\hline
\end{tabular}

Sum of totals may not add due to rounding: numbers over $10 \mathrm{~m}^{3}$ are rounded to the nearest $10 \mathrm{~m}^{3}$, numbers less than $10 \mathrm{~m}^{3}$ are rounded to integers, non-zero numbers less than 1 are rounded to 1.

\section{Background}

This waste generator represents PFP deactivation. The deactivation has not been included in the planning baseline of any program to date; therefore, the solid waste resulting from this 
deactivation has been deemed "non-programmatic."

\section{Forecast Assumptions and Comments}

The volumes reported for this generator are from BEMR estimates from FY96. In particular, waste volumes were estimated by BEMR through use of a modeling tool that projected future transitional waste volumes. In addition, the container, hazardous constituent, physical waste form, radionuclides, handling characteristics, and waste class information was assumed to be similar to that within the Facility Transition Program. For this generator, the average information from the PFP Transition Facility was used.

Minimum and maximum ranges were not collected for this generator, since forecast volumes were obtained from BEMR model results that did not account for variations in waste generation. In this case, the assumption is made that minimum and maximum ranges for the waste are $100 \%$ and $100 \%$ respectively.

\section{Other Forecast Data}

\section{- Low Level Waste}

O A total of $70 \mathrm{~m}^{3}$ of LLW is expected from NP_PFP.

- This forecast shows no change from the FY96 forecast.

- Except for a tiny amount of waste in MB-IV boxes, the containers forecast are 208 liter drums ( $61 \%$ by volume) and MB-V boxes (39\%).

o The physical LLW form from PFP is $98 \%$ debris (by volume). Soil and soil/gravel is also expected for $2 \%$ of the LLW.

\section{- Hazardous Waste}

- No hazardous waste is expected from NP_PFP for management by the CWC.

\section{GENERATORS:}

300 Area Facilities Non-Transition - 400 Area Facilities Non-Transition - B Plant Non-Transition · PFP Non-Transition . PUREX Non-Transition - REDOX Non-Transition - Site Support Non-Transition - Stored Equipment - T Plant Non-Transition . U Plant Non-Transition

PROGRAMS:

Analytical Services - EM-40 - Facility Transitions - Landlord - Liquid Effluent - NP · Offsite - PNNL - RCRA - Solid Waste $\cdot$ SNF $\cdot$ TWRS

\begin{tabular}{|c|c|}
\hline $\begin{array}{c}\text { CHARACTERISTICS: } \\
\text { CH_LLMW } \cdot \text { RH_LLMW } \cdot \text { CH_TRU(M) } \cdot \text { RH_TRU(M) } \\
\text { GTC III } \cdot \text { LLW } \cdot \text { HAZ }\end{array}$ & $\begin{array}{c}\text { CONTAINERS: } \\
\text { CH_LLMW } \cdot \text { RH_LLMW } \cdot \text { CH_TRU(M) } \\
\text { RH_TRU(M) } \cdot \text { GTC III } \cdot \text { LLW } \cdot \text { HAZ }\end{array}$ \\
\hline CH_LLMW $\cdot$ RH_LLMW $\cdot$ CH_TRU(M) $\cdot$ RH_TRU(M) $\cdot$ GTC III $\cdot$ LLW $\cdot$ HAZ \\
\hline Home $\cdot$ Contents $\cdot$ Web Site Map $\cdot$ Glossary $\cdot$ Help $\cdot$ Reports $\cdot$ Data Requests $\cdot$ Feedback Form
\end{tabular}


NOTICE: This page is provided subject to our disclaimer. Contact: Oscar Valero at (509) 373-4752.

HNF-EP-0918 rev. 1 Approved for public release; distribution is unlimited. 


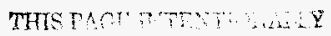

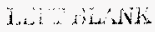




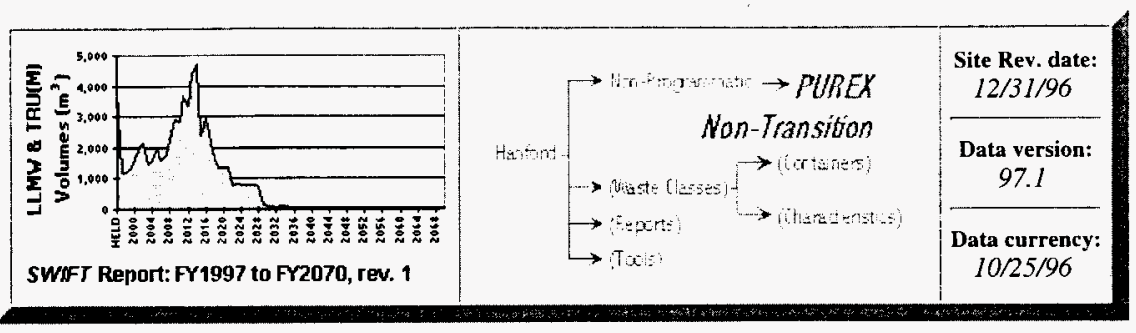

\section{Non-Programmatic - PUREX Non-Transition}

\section{Contents}

" Highlights

» Annual Volumes

"Comparison to Previous Baseline(s)

" Background
»Forecast Assumptions and Comments

" Other PUREX Non-Transition Forecast Data

" Detailed Forecast Data

\section{Highlights}

- PUREX - Non-Transition (NP_PUREX) contributes $150 \mathrm{~m}^{3}$ (3\%) of the non-programmatic generators' LLMW and TRU(M) solid waste forecast.

- The end of life cycle for NP_PUREX is 2027.

- $\mathrm{CH}_{-}$TRU(M) is the primary waste class generated, representing $67 \%$ of the waste $\left(110 \mathrm{~m}^{3}\right)$.

- Nearly all of this waste will be in 208 liter drums, with $7 \%$ in MB-IV boxes.

- Debris accounts for $82 \%$ of the LLMW and TRU(M) waste volume. Other physical waste forms include lab packs (9\%), special waste (7\%), soil/gravel (1\%), and organic solids (2\%).

- LLMW and TRU(M) waste hazardous constituents are metals without mercury (51\% by volume), mixed ignitable, corrosive, metals with mercury, organic, state regulated (17\%), mixed metals without mercury, organic, state regulated (17\%), mixed ignitable, metals with mercury, organic, state regulated $(10 \%)$, and other hazardous contituents $(5 \%)$. 


\section{Waste Class Distribution}

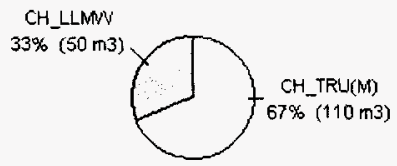

Total $=150 \mathrm{~m}^{3}$

\section{Physical Waste Form Distribution}

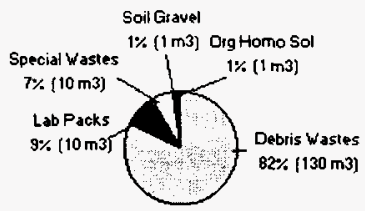

Total $=150 \mathrm{m3}$

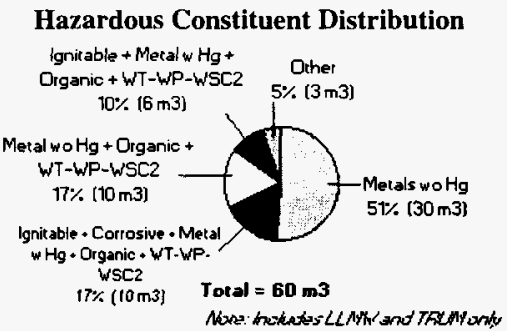

\section{Container Distribution}

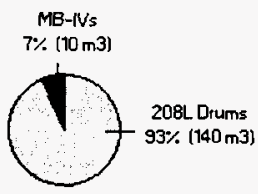

Total $=150 \mathrm{m3}$

Sum of totals may not add due to rounding: numbers over $10 \mathrm{~m}^{3}$ are rounded to the nearest $10 \mathrm{~m}^{3}$, numbers less than $10 \mathrm{~m}^{3}$ are rounded to integers, non-zero numbers less than I are rounded to I.

\section{Annual Volumes}

\section{Annual Baseline Volumes}


Baseline

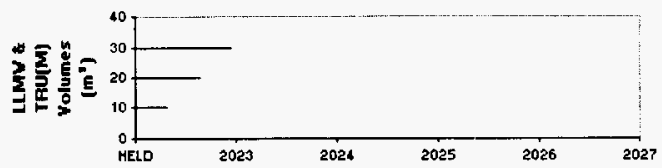

\section{Annual Baseline by Waste Class}

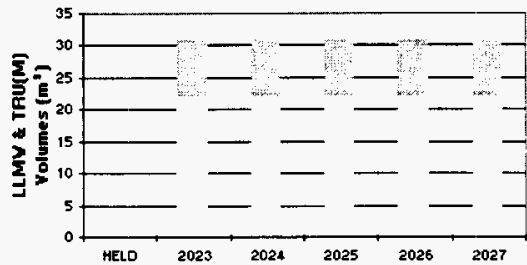

CH_LLMW

CH_TRU(M)

\section{Comparison to Previous Baseline(s)}

The FY97 forecast is equivalent to the FY96 forecast.

\section{Comparison to Previous Baseline(s) by Waste Class}

The apparent increase in the FY97.1 forecast of $\mathrm{CH}$ _LLMW for PUREX is a result of a change in the rounding formula.

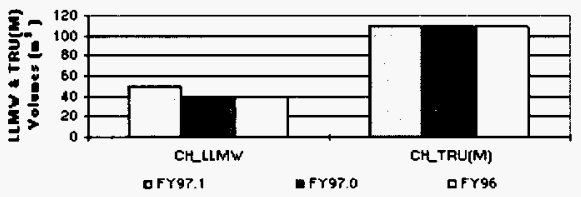

\begin{tabular}{|c|c|c|c|}
\hline $\begin{array}{l}\text { PUREX Won-Transition Comparison: } \\
\text { Waste Class }\end{array}$ & $\begin{array}{c}\text { FY97.1 } \\
\text { Forecest } \\
\left(\mathrm{m}^{3}\right)\end{array}$ & $\begin{array}{c}\text { FY97.0 } \\
\text { Forecast } \\
\left(\mathrm{m}^{3}\right)\end{array}$ & $\begin{array}{c}\text { FY96 } \\
\text { Forecast } \\
\left(\mathrm{m}^{3}\right)\end{array}$ \\
\hline CHLLLMW & 50 & 40 & 40 \\
\hline CH_TRL(M) & 110 & 110 & 110 \\
\hline Subrord & 150 & 150 & 150 \\
\hline LLW & 170 & 170 & 170 \\
\hline HAZ & 0 & 0 & 30 \\
\hline Total & 300 & $x$ & 380 \\
\hline
\end{tabular}

Sum of totals may not add due to rounding: numbers over $10 \mathrm{~m}^{3}$ are rounded to the nearest $10 \mathrm{~m}^{3}$. numbers less than $10 \mathrm{~m}^{3}$ are rounded to integers. non-zero numbers less than $I$ are rounded to 1 .

\section{Background}


This waste generator represents PUREX deactivation. The deactivation has not been included in the planning baseline of any program to date; therefore, the solid waste resulting from this deactivation has been deemed "non-programmatic."

\section{Forecast Assumptions and Comments}

The volumes reported for this generator are from BEMR estimates from FY96. In particular, waste volumes were estimated by BEMR through use of a modeling tool that projected future transitional waste volumes. In addition, the container, hazardous constituent, physical waste form, radionuclides, handling characteristics, and waste class information was assumed to be similar to that within the Facility Transition Program. For this generator, the average information from the PUREX Transition Facility was used.

Minimum and maximum ranges were not collected for this generator, since forecast volumes were obtained from BEMR model results that did not account for variations in waste generation. In this case, the assumption is made that minimum and maximum ranges for the waste are $100 \%$ and $100 \%$ respectively.

\section{Other Forecast Data}

- Low Level Waste

- A total of $170 \mathrm{~m}^{3}$ of LLW is expected from NP_PUREX.

o This forecast shows no change from the FY96 forecast.

- The containers for LLW are MB-V boxes (54\% of the volume), 208 liter drums (24\%), and also Medium boxes (22\%).

- $99 \%$ of the LLW is debris, and the remaining volume is soil/gravel and labpacks.

\section{- Hazardous Waste}

- No hazardous waste is expected from NP_PUREX for management by the CWC. 


\section{GENERATORS:}

300 Area Facilities Non-Transition - 400 Area Facilities Non-Transition · B Plant Non-Transition - PFP Non-Transition PUREX Non-Transition - REDOX Non-Transition. Site Support Non-Transition - Stored Equipment - T Plant Non-Transition · U Plant Non-Transition

\section{PROGRAMS:}

Analytical Services - EM-40 - Facility Transitions - Landlord - Liquid Effluent - NP · Offsite · PNNL - RCRA - Solid Waste - SNF - TWRS

\begin{tabular}{|c|c|}
\hline $\begin{array}{c}\text { CHARACTERISTICS: } \\
\text { CH_LLMW } \cdot \text { RH_LLMW } \cdot \text { CH_TRU(M) }) \text { RH_TRU(M) } \\
\text { GTC III } \cdot \text { LLW } \cdot \text { HAZ }\end{array}$ & $\begin{array}{c}\text { CONTAINERS: } \\
\text { CH_LLMW } \cdot \text { RH_LLMW } \cdot \text { CH_TRU(M) } \\
\text { RH_TRU(M) } \cdot \text { GTC III } \cdot \text { LLW } \cdot \text { HAZ }\end{array}$ \\
\hline CH_LLMW $\cdot$ RH_LLMW $\cdot$ CH_TRU(M) $\cdot$ RH_TRU(M) $\cdot$ GTC IIl $\cdot$ LLW $\cdot$ HAZ \\
\hline Home $\cdot$ Contents $\cdot$ Web Site Map $\cdot$ Glossary $\cdot$ Help $\cdot$ Reports $\cdot$ Data Requests $\cdot$ Feedback Form \\
\hline
\end{tabular}

NOTICE: This page is provided subject to our disclaimer. Contact: Oscar Valero at (509) 373-4752.

HNF-EP-0918 rev. 1 Approved for public release; distribution is unlimited. 


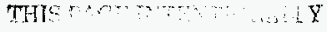




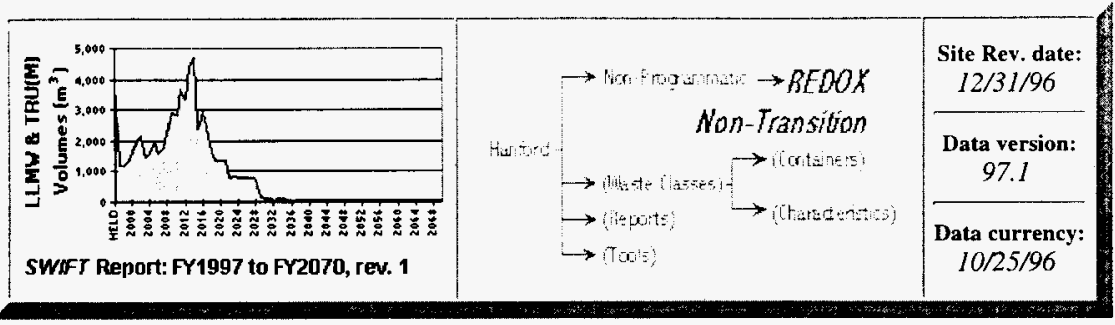

\section{Non-Programmatic - REDOX Non-Transition}

\section{Contents}

» Highlights

» Annual Volumes

»Comparison to Previous Baseline(s)

»Background
》Forecast Assumptions and Comments

» Other REDOX Non-Transition Forecast Data

» Detailed Forecast Data

\section{Highlights}

- REDOX - Non-Transition (NP_REDOX) contributes $210 \mathrm{~m}^{3}(4 \%)$ of the non-programmatic generators' LLMW and TRU(M) solid waste forecast.

- The end of life cycle for NP_REDOX is 2029.

- $\mathrm{CH}_{-}$TRU(M) is the primary waste class generated, representing almost $100 \%$ of the waste (rounded to $210 \mathrm{~m}^{3}$ ).

- Almost $100 \%$ of this volume will be in 208 liter containers.

- Physical waste forms from REDOX are $98 \%$ debris with the remaining $2 \%$ as miscellaneous hazardous constituents.

- LLMW and TRU(M) waste hazardous constituents are nearly all metals without mercury (96\% by volume). The last $4 \%$ includes many other miscellaneous hazardous constituents. 


\section{Waste Class Distribution}

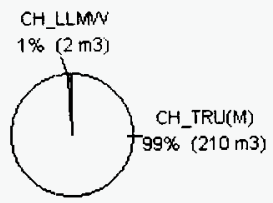

Totel $=210 \mathrm{~m}^{3}$

Physical Waste Form Distribution

Other

$2 \%(4 \mathrm{~m} 3)$

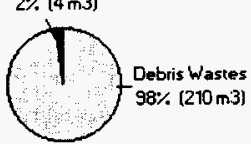

Total $=210 \mathrm{m3}$

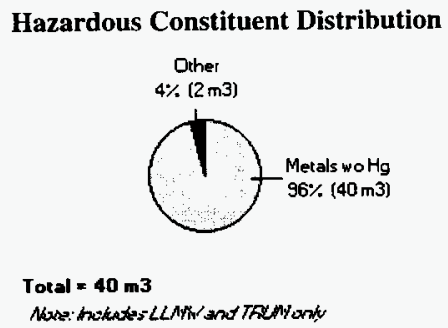

Hazardous Constituent Distribution

$4 \%(2 \mathrm{~m} 3)$

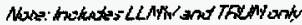

\section{Container Distribution}

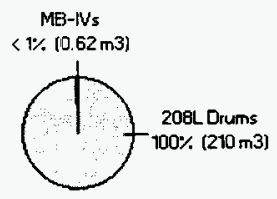

Total $=210 \mathrm{m3}$

Sum of totals may not add due to rounding: numbers over $10 \mathrm{~m}^{3}$ are rounded to the nearest $10 \mathrm{~m}^{3}$, numbers less than $10 \mathrm{~m}^{3}$ are rounded to integers, non-zero numbers less than $I$ are rounded to 1 .

\section{Annual Volumes}

\section{Annual Baseline Volumes}


Baseline

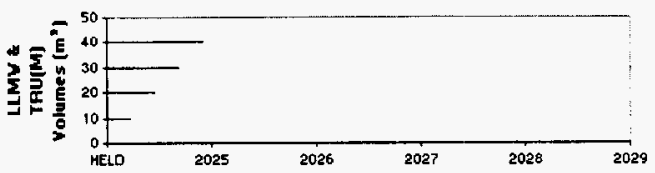

\section{Annual Baseline by Waste Class}

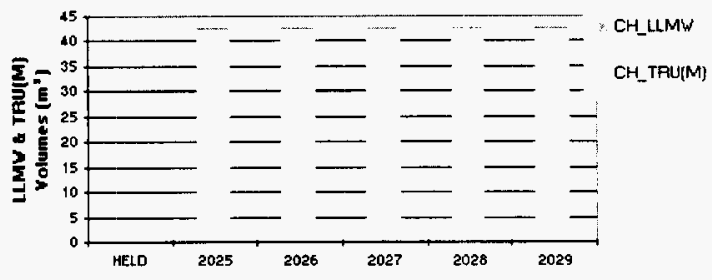

\section{Comparison to Previous Baseline(s)}

The FY97 forecast is equivalent to the FY96 forecast.

\section{Comparison to Previous Baseline(s) by Waste Class}

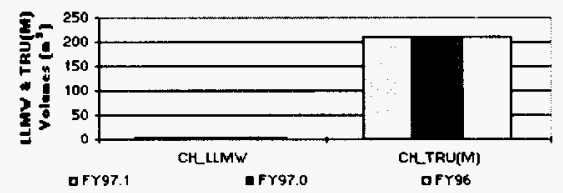

\begin{tabular}{|c|c|c|c|}
\hline $\begin{array}{l}\text { AEDOX Non-Transition Comparison: } \\
\text { Waste Class }\end{array}$ & $\begin{array}{l}\text { FY97.1 } \\
\text { Forecast } \\
{\left[\mathrm{m}^{3}\right]}\end{array}$ & $\begin{array}{l}\text { FY97.0 } \\
\text { Forecast } \\
\left(\mathrm{m}^{3}\right)\end{array}$ & $\begin{array}{l}\text { FY96 } \\
\text { Forecast } \\
\left(\mathrm{m}^{3}\right)\end{array}$ \\
\hline CHLLLMW & & 2 & \\
\hline CH_TRUIM) & 210 & 210 & 210 \\
\hline Serbeard & 210 & 210 & 210 \\
\hline LLW & 300 & 300 & 300 \\
\hline HAZ & 5 & 0 & 40 \\
\hline
\end{tabular}

Sum of totals may not add due to rounding: numbers over $10 \mathrm{~m}^{3}$ are rounded to the nearest $10 \mathrm{~m}^{3}$, numbers less than $10 \mathrm{~m}^{3}$ are rounded to integers, non-zero numbers less than 1 are rounded to $I$.

\section{Background}

This waste generator represents REDOX deactivation. The deactivation has not been included 
in the planning baseline of any program to date; therefore, the solid waste resulting from this deactivation has been deemed "non-programmatic."

\section{Forecast Assumptions and Comments}

The volumes reported for this generator are from BEMR estimates from FY96. In particular, waste volumes were estimated by BEMR through use of a modeling tool that projected future transitional waste volumes. In addition, the container, hazardous constituent, physical waste form, radionuclides, handling characteristics, and waste class information was assumed to be similar to that within the Facility Transition Program. For this generator, the average information from the PUREX Transition Facility was used.

Minimum and maximum ranges were not collected for this generator, since forecast volumes were obtained from BEMR model results that did not account for variations in waste generation. In this case, the assumption is made that minimum and maximum ranges for the waste are $100 \%$ and $100 \%$ respectively.

\section{Other Forecast Data}

\section{- Low Level Waste}

- A total of $300 \mathrm{~m}^{3}$ of LLW is expected from NP_REDOX.

o This forecast shows no change from the FY96 forecast.

- Half of the volume (54\%) will utilize MB-V boxes, while 208 liter drums (24\%) and Medium boxes $(22 \%)$ constitute similar shares of the rest.

- LLW physical forms are $99 \%$ debris. Lab packs and soil and soil/gravel total $1 \%$ of the volume.

\section{- Hazardous Waste}

- No hazardous waste is expected from NP_REDOX for management by the CWC. 


\section{GENERATORS:}

300 Area Facilities Non-Transition 400 Area Facilities Non-Transition - B Plant Non-Transition · PFP Non-Transition · PUREX Non-Transition - REDOX Non-Transition - Site Support Non-Transition - Stored Equipment - T Plant

Non-Transition - U Plant Non-Transition

\section{PROGRAMS:}

Analytical Services - EM-40 - Facility Transitions - Landlord - Liquid Effluent - NP - Offsite · PNNL · RCRA - Solid Waste $\cdot$ SNF . TWRS

\begin{tabular}{|c|c|}
\hline $\begin{array}{l}\text { CHARACTERISTICS: } \\
\text { CH_LLMW } \cdot \text { RH_LLMW } \cdot \text { CH_TRU(M) } \cdot \text { RH_TRU(M) } \\
\text { GTC III } \cdot \text { LLW } \cdot \text { HAZ }\end{array}$ & $\begin{array}{c}\text { CONTAINERS: } \\
\text { CH_LLMW } \cdot \text { RH_LLMW } \cdot \text { CH_TRU(M) } \\
\text { RH_TRU }(\mathrm{M}) \cdot \mathrm{GTC} \text { III } \cdot \text { LLW } \cdot \text { HAZ }\end{array}$ \\
\hline \multicolumn{2}{|c|}{ 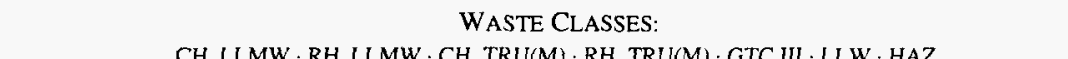 } \\
\hline
\end{tabular}

NOTICE: This page is provided subject to our disclaimer. Contact: Oscar Valero at (509) 373-4752.

HNF-EP-0918 rev. 1 Approved for public release; distribution is unlimited. 
THIS $\cdots+\cdots$ (a) $\quad 2$. 
cW $0 C=\mid B p D \perp$

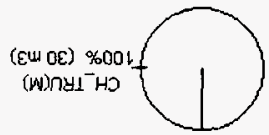

uo!̣nq!-11s!d sselo ว1se $M$

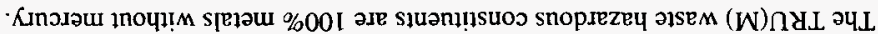

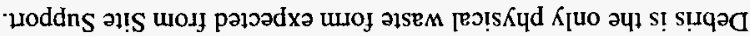

-21SEM

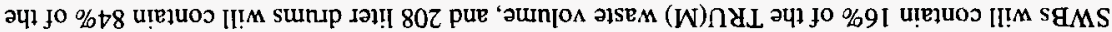

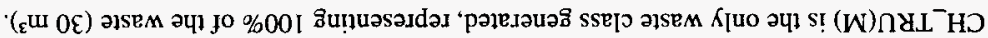

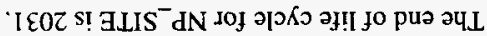

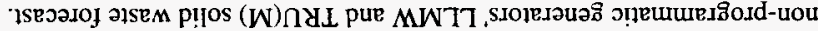

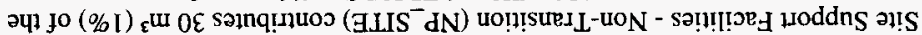

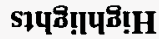

punorôxगeg «

हाएव 1SEวaso ह18 15Eวa.

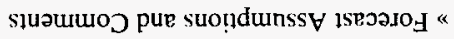

(s)әu!̣วeg snoṭaId ol uos!̣eduoว « soump̣o $\Lambda$ [enuu $\ll$

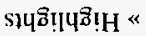

sาuวาน⿰冫

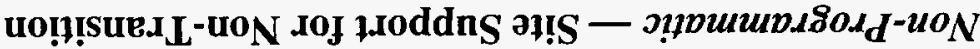

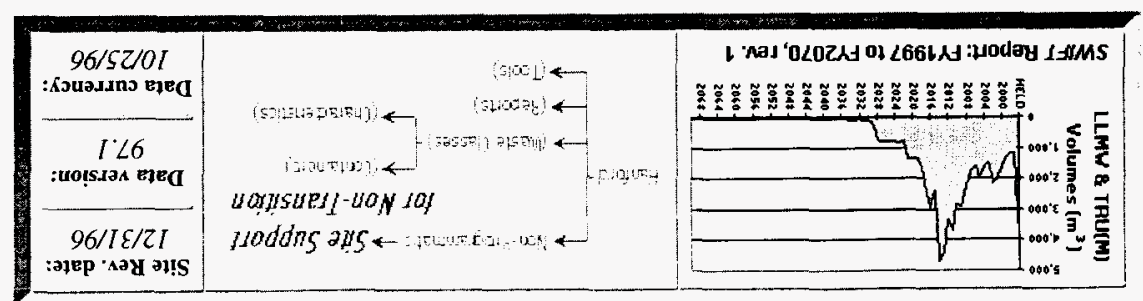


Physical Waste Form Distribution

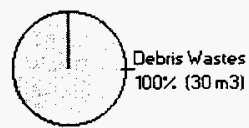

Total $=\mathbf{3 0} \mathbf{m} \mathbf{3}$

\section{Hazardous Constituent Distribution}

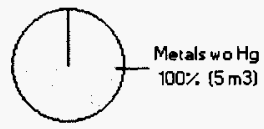

Total = $5 \mathrm{m3}$

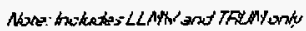

\section{Container Distribution}

Sw'Bs

$16 \%(6 \mathrm{~m} 3)$

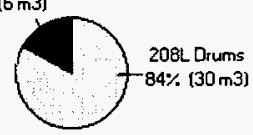

Total $=30 \mathrm{m3}$

Sum of totals may not add due to rounding: numbers over $10 \mathrm{~m}^{3}$ are rounded to the nearest $10 \mathrm{~m}^{3}$, numbers less than $10 \mathrm{~m}^{3}$ are rounded to integers, non-zero numbers less than $I$ are rounded to $I$.

\section{Annual Volumes}

\section{Annual Baseline Volumes}

Baseline

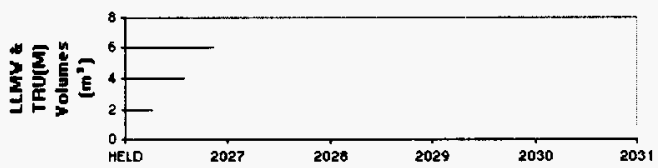

\section{Annual Baseline by Waste Class}

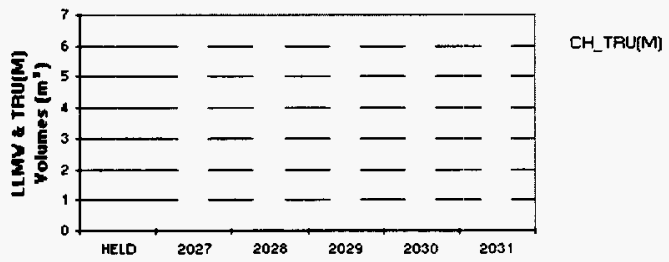




\section{Comparison to Previous Baseline(s)}

The FY97 forecast is equivalent to the FY96 forecast.

\section{Comparison to Previous Baseline(s) by Waste Class}

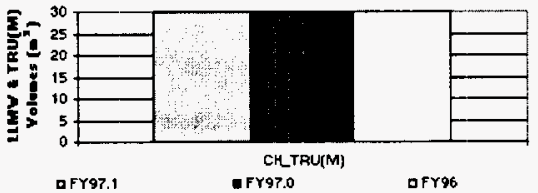

\begin{tabular}{|c|c|c|c|}
\hline $\begin{array}{l}\text { Site Support Mon-Transition Comparison: } \\
\text { Waste Class }\end{array}$ & $\begin{array}{c}\text { FYg7. } \\
\text { Forecast } \\
\left(\mathrm{m}^{3}\right)\end{array}$ & $\begin{array}{c}\text { FY97.0 } \\
\text { Forecast } \\
\left(\mathrm{m}^{3}\right) \\
\end{array}$ & $\begin{array}{c}\text { FY96 } \\
\text { Forecast } \\
\left(\mathrm{m}^{3}\right)\end{array}$ \\
\hline CHLTHU(M) & 30 & 30 & 30 \\
\hline Scebroral & 30 & 30 & 30 \\
\hline LLW & 50 & 50 & 50 \\
\hline $\mathrm{HAZ}$ & 0 & 0 & 180 \\
\hline Tacal & 50 & $\overline{S O}$ & 270 \\
\hline
\end{tabular}

Sum of totals may not add due to rounding: numbers over $10 \mathrm{~m}^{3}$ are rounded to the nearest $10 \mathrm{~m}^{3}$, numbers less than $10 \mathrm{~m}^{3}$ are rounded to integers, non-zero numbers less than 1 are rounded to 1 .

\section{Background}

This waste generator represents deactivation of a group of site support facilities. The deactivation has not been included in the planning baseline of any program to date; therefore, the solid waste resulting from this deactivation has been deemed "non-programmatic."

\section{Forecast Assumptions and Comments}

The volumes reported for this generator are from BEMR estimates from FY96. In particular, waste volumes were estimated by BEMR through use of a modeling tool that projected future transitional waste volumes. In addition, the container, hazardous constituent, physical waste form, radionuclides, handling characteristics, and waste class information was assumed to be similar to that within the Facility Transition Program. For this generator, the average information from the Facility Transition Program was used.

Minimum and maximum ranges were not collected for this generator, since forecast volumes were obtained from BEMR model results that did not account for variations in waste generation. In this case, the assumption is made that minimum and maximum ranges for the waste are $100 \%$ and $100 \%$ respectively.

\section{Other Forecast Data}

- Low Level Waste 
o A total of $50 \mathrm{~m}^{3}$ of LLW is expected from NP_SITE.

- This forecast shows no change from the FY96 forecast.

- Both MB-V boxes and 208 liter drums will contain $44 \%$ of the LLW, leaving $12 \%$ in other boxes and drums.

- LLW physical forms are nearly all (95\%) debris. $4 \%$ of the volume should be soil and soil/gravel, while inorganic solids, organic solids, shielding, and lab packs total $1 \%$.

\section{- Hazardous Waste}

- No hazardous waste is expected from NP_SITE for management by the CWC.

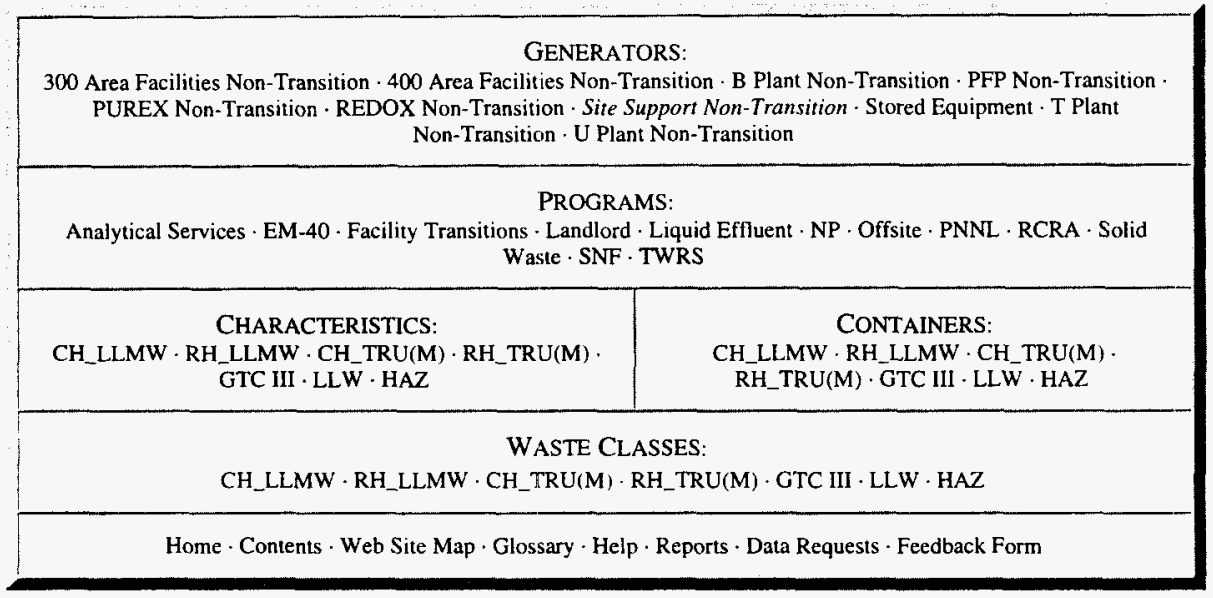

NOTICE: This page is provided subject to our disclaimer. Contact: Oscar Valero at (509) 373-4752.

HNF-EP-0918 rev. 1 Approved for public release; distribution is unlimited. 


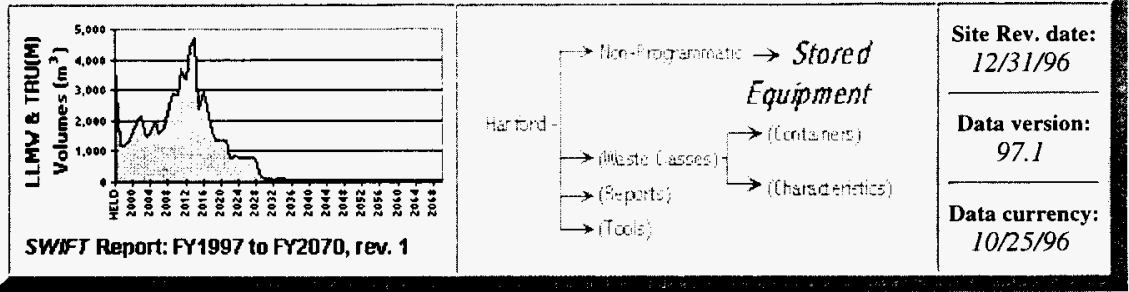

\section{Non-Programmatic - Stored Equipment}

\section{Contents}

" Highlights

"Annual Volumes

"Comparison to Previous Baseline(s)

»Background
» Forecast Assumptions and Comments

»Other Stored Equipment Forecast Data

" Detailed Forecast Data

\section{Highlights}

- Stored Equipment (formerly Buried Equipment) contributes $4,000 \mathrm{~m}^{3}$ (73\%) of the non-programmatic generators' LLMW and TRU(M) solid waste forecast.

- All of Stored Equipment's waste is in the HELD category since a shipping schedule is undetermined due to funding issues.

- CH_LLMW is the only waste class generated, representing $100 \%$ of the waste $\left(4,000 \mathrm{~m}^{3}\right)$.

- All of the LLMW waste will be shipped in Large boxes.

- Contaminated metal debris is the only physical LLMW form

- The LLMW hazardous constituents are $100 \%$ metals without mercury and organic.

\section{Waste Class Distribution}

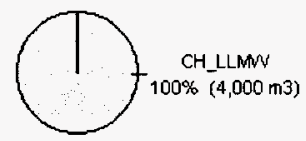

Total $=4,000 \mathrm{m3}$ 
Physical Waste Form Distribution

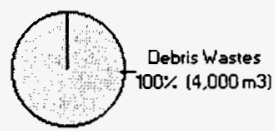

Total $=4,000 \mathrm{~m} 3$

\section{Hazardous Constituent Distribution}

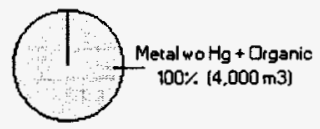

Total $=4.000 \mathrm{~m} 3$

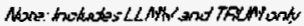

\section{Container Distribution}

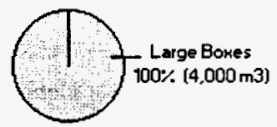

\section{Totel $=4,000 \mathrm{~m} 3$}

Sum of totals may not add due to rounding: numbers over $10 \mathrm{~m}^{3}$ are rounded to the nearest $10 \mathrm{~m}^{3}$, numbers less than $10 \mathrm{~m}^{3}$ are rounded to integers, non-zero numbers less than $I$ are rounded to $I$.

\section{Annual Volumes}

\section{Annual Baseline Volumes}

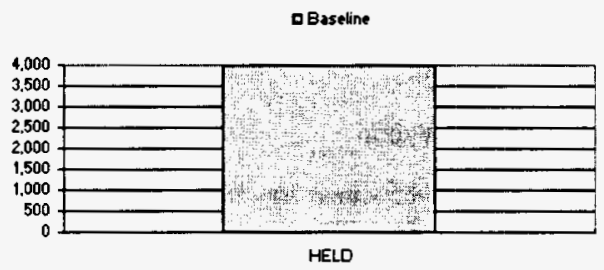

Annual Baseline by Waste Class 


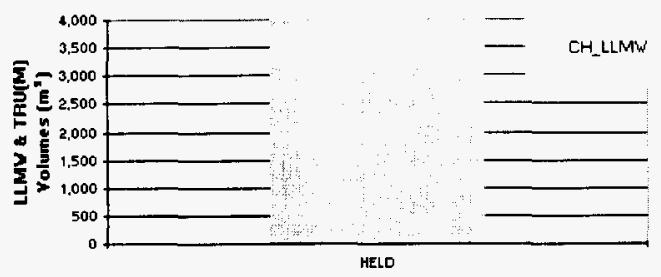

\section{Comparison to Previous Baseline(s)}

The FY97 forecast shows a decrease from the FY96 forecast of $7,080 \mathrm{~m}^{3}$. This decrease is due to a revised estimate based on new information regarding the location and amount of waste to be managed. Some of the previously forecasted equipment has been released for public use; thus, the waste volumes have been revised.

\section{Comparison to Previous Baseline(s) by Waste Class}

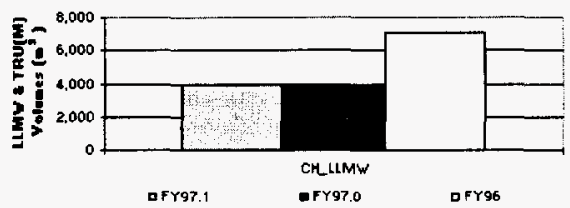

\begin{tabular}{|c|c|c|c|}
\hline $\begin{array}{l}\text { Stored Equipment Comparison: } \\
\text { Uaste Class }\end{array}$ & $\begin{array}{l}\text { FY97.1 } \\
\text { Forecast } \\
\left(\mathrm{m}^{3}\right)\end{array}$ & $\begin{array}{c}\text { FY97.0 } \\
\text { Forecast } \\
\left(\mathrm{m}^{3}\right)\end{array}$ & $\begin{array}{c}\text { FY96 } \\
\text { Forecast } \\
\left(\mathrm{m}^{3}\right)\end{array}$ \\
\hline CHLLLM' $\mathrm{w}^{\prime}$ & 4,000 & 4,000 & 7.080 \\
\hline Sechroied & 4000 & $+0,000$ & 2,050 \\
\hline Tord & 4.000 & 4,000 & 2,000 \\
\hline
\end{tabular}

Sum of totals may not add due to rounding: numbers over $10 \mathrm{~m}^{3}$ are rounded to the nearest $10 \mathrm{~m}^{3}$, numbers less than $10 \mathrm{~m}^{3}$ are rounded to integers, non-zero numbers less than I are rounded to $I$.

\section{Background}

This generator has stored general purpose coded equipment since 1992. The waste includes vehicles and mobile construction units used in tank farms that are classified as contact-handled LLMW.

\section{Forecast Assumptions and Comments}

The Stored Equipment generator has not completed a forecast since 1992, as no program currently has responsibility for this waste; therefore, waste volumes from the 1992 forecasts have been used as a starting point for this generator, with revisions this year based on new information. One result is that this generator's name has been changed from the FY96 forecast name of Buried Equipment, because it has been determined that the waste is not buried as previously thought, but is stored in 2711 -E. Although a path forward has not been determined 
for this equipment, a viable option is management at $\mathrm{CWC}-$ if funding is available.

The general assumption for Stored Equipment is that the material is currently not declared waste. However, if the path forward for this material is determined to be the Waste Management Program, it would be designated as LLMW.

No minimum and maximum ranges were provided by this generator. In this case, the assumption is made that minimum and maximum ranges for the waste are $100 \%$ and $100 \%$ respectively.

\section{Other Forecast Data}

- Low Level Waste

- No LLW is expected from Stored Equipment.

\section{- Hazardous Waste}

o No hazardous waste is expected from Stored Equipment for management by the CWC.

\section{GENERATORS:}

300 Area Facilities Non-Transition - 400 Area Facilities Non-Transition - B Plant Non-Transition - PFP Non-Transition . PUREX Non-Transition - REDOX Non-Transition - Site Support Non-Transition · Stored Equipment - T Plant Non-Transition. U Plant Non-Transition

\section{PROGRAMS:}

Analytical Services - EM-40 - Facility Transitions · Landlord - Liquid Effluent - NP · Offsite - PNNL $\cdot$ RCRA $\cdot$ Solid Waste $\cdot$ SNF $\cdot$ TWRS

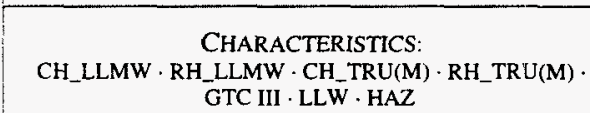

\section{WASTE ClaSSES:}

CH_LLMW $\cdot$ RH_LLMW $\cdot \mathrm{CH}_{-}$TRU(M) $\cdot \mathrm{RH}_{-}$TRU(M) $\cdot$ GTC III $\cdot$ LLW $\cdot$ HAZ
CONTAINERS:

CH_LLMW $\cdot$ RH_LLMW $\cdot$ CH_TRU(M) RH_TRU(M) $\cdot$ GTC III $\cdot$ LLW $\cdot$ HAZ

Home · Contents · Wcb Sile Map · Glossary · Hclp · Reports · Data Requests · Fecdback Form

NOTICE: This page is provided subject to our disclaimer. Contact: Oscar Valero at (509) 373-4752.

HNF-EP-0918 rev. 1 Approved for public release; distribution is unlimited. 


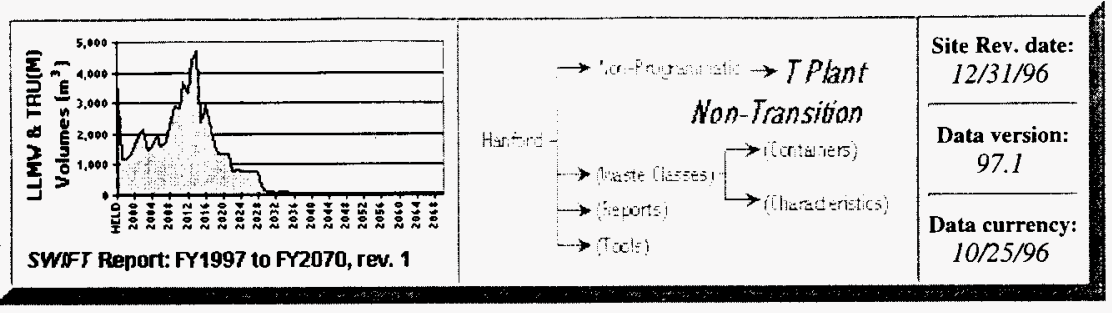

\section{Non-Programmatic - T Plant Non-Transition}

\section{Contents}

» Highlights

»Annual Volumes

»Comparison to Previous Baseline(s)

»Background
» Forecast Assumptions and Comments

»Other T Plant Non-Transition Forecast Data

»Detailed Forecast Data

\section{Highlights}

- T Plant - Non-Transition (NP_T Plant) contributes $40 \mathrm{~m}^{3}(1 \%)$ of the non-programmatic generators' LLMW and TRU(M) solid waste forecast.

- The end of life cycle for NP_T Plant is 2033.

- CH_TRU(M) is the only waste class generated, representing $100 \%$ of the waste $\left(40 \mathrm{~m}^{3}\right)$.

- The only containers expected to be used for this TRU(M) are 208 liter drums.

- $100 \%$ of the TRU(M) waste has the physical form of debris (organic, contaminated metal, and plastic/rubber).

- The TRU(M) waste hazardous constituents are $100 \%$ metals without mercury.

\section{Waste Class Distribution}

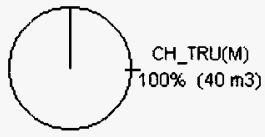

Total $=\mathbf{4 0} \mathbf{m} 3$ 
Physical Waste Form Distribution

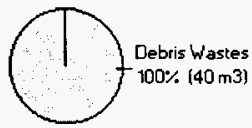

Total $=40 \mathrm{~m} 3$

\section{Hazardous Constituent Distribution}

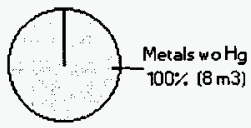

Total $=8 \mathrm{m3}$

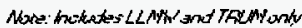

\section{Container Distribution}

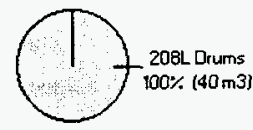

Total $=40 \mathrm{m3}$

Sum of totals may not add due to rounding: numbers over $10 \mathrm{~m}^{3}$ are rounded to the nearest $10 \mathrm{~m}^{3}$, numbers less than $10 \mathrm{~m}^{3}$ are rounded to integers, non-zero numbers less than I are rounded to $l$.

\section{Annual Volumes}

\section{Annual Baseline Volumes}

Baseline

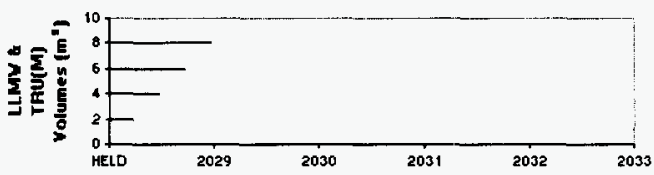

Annual Baseline by Waste Class 


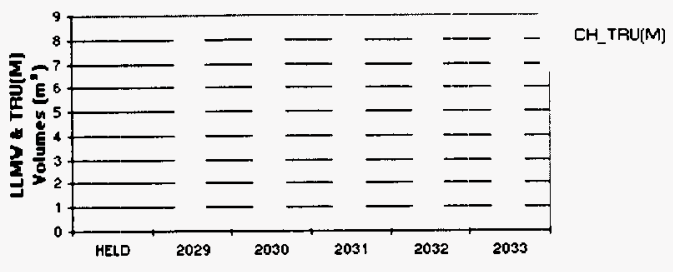

\section{Comparison to Previous Baseline(s)}

The FY97 forecast is equivalent to the FY96 forecast.

\section{Comparison to Previous Baseline(s) by Waste Class}

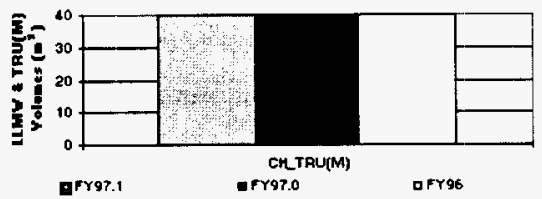

\begin{tabular}{|c|c|c|c|}
\hline $\begin{array}{l}\text { T Plant Non-Transition Comparison: } \\
\text { Veste Class }\end{array}$ & $\begin{array}{c}\text { FY97.1 } \\
\text { Foreeast } \\
\left(m^{3}\right)\end{array}$ & $\begin{array}{c}\text { FY97.0 } \\
\text { Forecast } \\
\text { [m'] }\end{array}$ & $\begin{array}{c}\text { FY96 } \\
\text { Forecast } \\
\text { (m) }\end{array}$ \\
\hline $\mathrm{CH}$ TRU[M] & 40 & 40 & 40 \\
\hline Soprapd & $1 \theta$ & 10 & 10 \\
\hline LLW & 80 & 80 & 80 \\
\hline $\mathrm{HAZ}$ & 0 & 0 & 40 \\
\hline Fars & $\boldsymbol{S P B}$ & 120 & 100 \\
\hline
\end{tabular}

Sum of totals may not add due to rounding: numbers over $10 \mathrm{~m}^{3}$ are rounded to the nearest $10 \mathrm{~m}^{3}$, numbers less than $10 \mathrm{~m}^{3}$ are rounded to integers, non-zero numbers less than 1 are rounded to 1 .

\section{Background}

This waste generator represents $\mathrm{T}$ Plant deactivation. The deactivation has not been included in the planning baseline of any program to date; therefore, the solid waste resulting from this deactivation has been deemed "non-programmatic."

\section{Forecast Assumptions and Comments}

The volumes reported for this generator are from BEMR estimates from FY96. In particular, waste volumes were estimated by BEMR through use of a modeling tool that projected future transitional waste volumes. In addition, the container, hazardous constituent, physical waste form, radionuclides, handling characteristics, and waste class information was assumed to be similar to that within the Facility Transition Program. For this generator, the average information from the PUREX Transition Facility was used.

Minimum and maximum ranges were not collected for this generator, since forecast volumes 
were obtained from BEMR model results that did not account for variations in waste generation. In this case, the assumption is made that minimum and maximum ranges for the waste are $100 \%$ and $100 \%$ respectively.

\section{Other Forecast Data}

- Low Level Waste

- A total of $80 \mathrm{~m}^{3}$ of LLW is expected from NP_T Plant.

- This forecast shows no change from the FY96 forecast.

- LLW should arrive in Medium boxes and 208 liter drums in near equal amounts (22\% and $24 \%$ respectively), but $54 \%$ of the volume should be in MB-V boxes.

- The LLW physical form is essentially all debris (99\%). Soil, soil/gravel and lab packs compose $1 \%$ of the volume.

\section{- Hazardous Waste}

o No hazardous waste is expected from NP_T Plant for management by the CWC.

\begin{tabular}{|c|}
\hline $\begin{array}{l}\text { GENERATORS: } \\
300 \text { Area Facilities Non-Transition - } 400 \text { Area Facilities Non-Transition - B Plant Non-Transition - PFP Non-Transition } \\
\text { PUREX Non-Transition - REDOX Non-Transition - Site Support Non-Transition - Stored Equipment - T Plant } \\
\text { Non-Transition - U Plant Non-Transition }\end{array}$ \\
\hline $\begin{array}{l}\text { PROGRAMS: } \\
\text { Analytical Services } \cdot \text { EM-40 } \cdot \text { Facility Transitions } \cdot \text { Landlord } \cdot \text { Liquid Effluent } \cdot \text { NP } \cdot \text { Offsite } \cdot \text { PNNL } \cdot \text { RCRA } \cdot \text { Solid } \\
\text { Waste } \cdot \text { SNF } \cdot \text { TWRS }\end{array}$ \\
\hline $\begin{array}{l}\text { CHARACTERISTICS: } \\
\text { CH_LLMW } \cdot \text { RH_LLMW } \cdot \text { CH_TRU(M) } \cdot \text { RH_TRU(M) } \\
\text { GTC III } \cdot \text { LLW } \cdot \text { HAZ }\end{array}$ \\
\hline $\begin{array}{l}\text { WASTE CLASSES: } \\
\text { CH_LLMW } \cdot \text { RH_LLMW } \cdot \text { CH_TRU(M) } \cdot \text { RH_TRU(M) } \cdot \text { GTC III } \cdot \text { LLW } \cdot \text { HAZ }\end{array}$ \\
\hline
\end{tabular}

NOTICE: This page is provided subject to our disclaimer. Contact: Oscar Valero at (509) 373-4752

HNF-EP-0918 rev. 1 Approved for public release; distribution is unlimited. 
-sıuวn!̣suos snopiezey

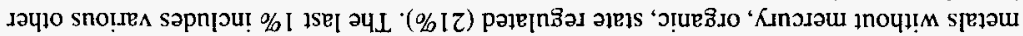

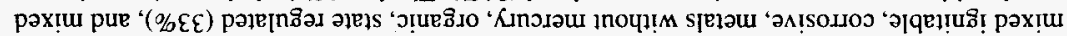

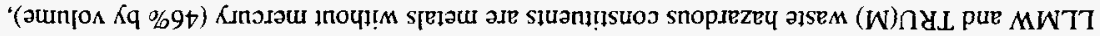

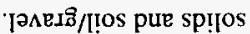

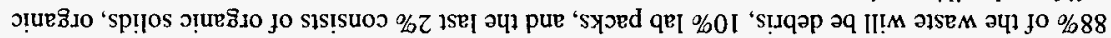

ว1SEM

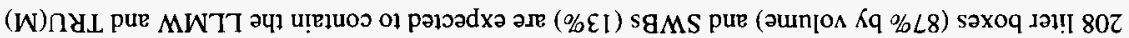

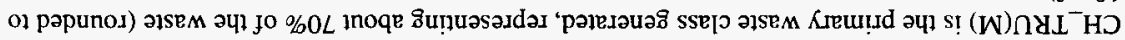

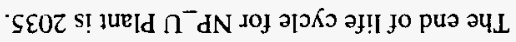

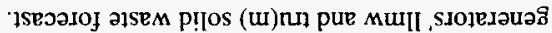

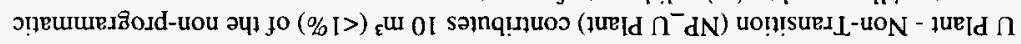

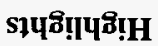

$$
\text { puno.เิมวеย « }
$$

вIR

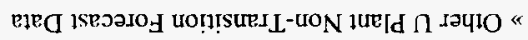

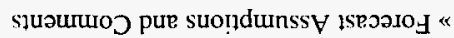

(s)autjaseg sno!nard ol uosịreduoj « sounjo $\Lambda$ jenuu $\forall \ll$

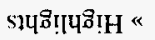

spuว1น0อ

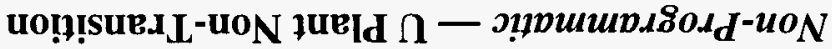

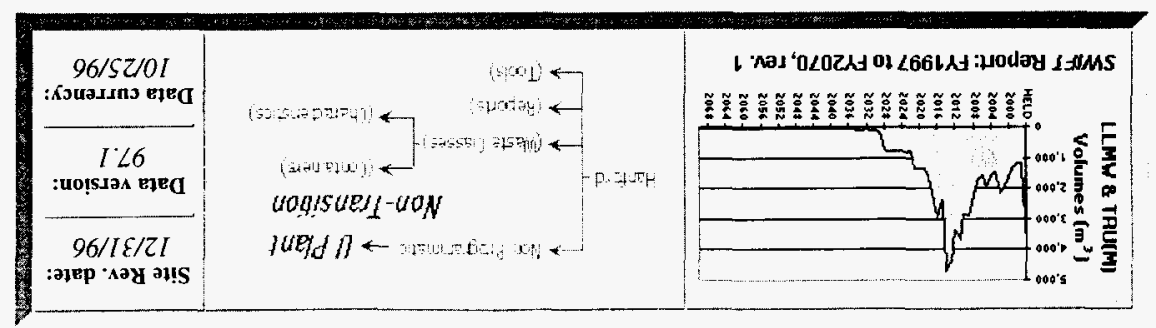




\section{Waste Class Distribution}

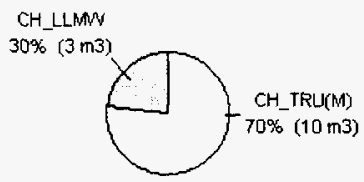

Total $=10 \mathrm{m3}$

\section{Physical Waste Form Distribution Hazardous Constituent Distribution}

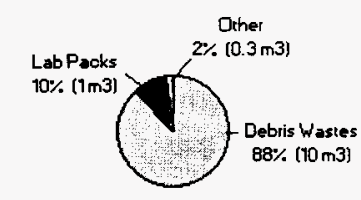

Total $=10 \mathrm{~ms}$

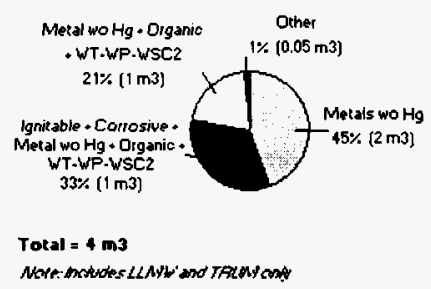

\section{Container Distribution}

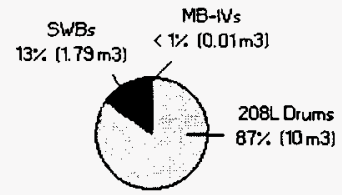

Total $=10 \mathrm{~m} 3$

Sum of totals may not add due to rounding: numbers over $10 \mathrm{~m}^{3}$ are rounded to the nearest $10 \mathrm{~m}^{3}$, numbers less than $10 \mathrm{~m}^{3}$ are rounded to integers, non-zero numbers less than $I$ are rounded to $I$.

\section{Annual Volumes}

\section{Annual Baseline Volumes}


Basetine

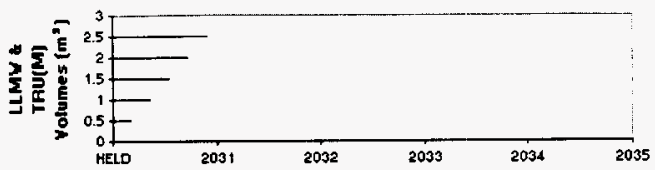

Annual Baseline by Waste Class

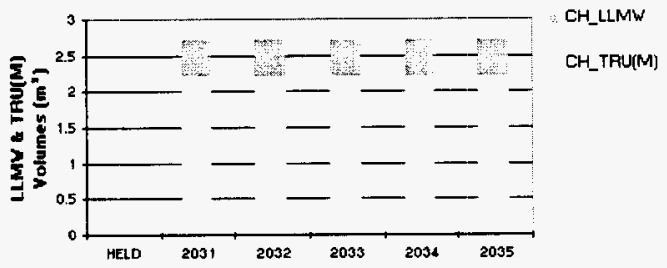

\section{Comparison to Previous Baseline(s)}

The FY97 forecast is equivalent to the FY96 forecast.

\section{Comparison to Previous Baseline(s) by Waste Class}

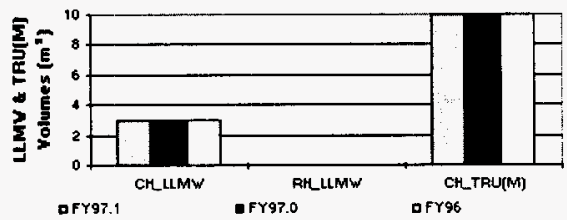

\begin{tabular}{|c|c|c|c|}
\hline $\begin{array}{l}\text { Comparison: } \\
\text { Haste Class }\end{array}$ & $\begin{array}{c}\text { FY97.1 } \\
\text { Forecast } \\
\left(\mathrm{m}^{3}\right)\end{array}$ & $\begin{array}{c}\text { FY97.0 } \\
\text { Forecast } \\
\left(\mathrm{m}^{3}\right)\end{array}$ & $\begin{array}{c}\text { FY96 } \\
\text { Forecast } \\
\left(\mathrm{m}^{3}\right)\end{array}$ \\
\hline CH LLMW & 3 & 3 & 3 \\
\hline $\mathrm{BH}_{\mathbf{L}} \mathrm{LLMW}$ & 0 & $\mathbf{0}$ & 0 \\
\hline $\mathrm{CH}$ TRU(M) & 10 & 10 & 10 \\
\hline Sublocal & 10 & 10 & 10 \\
\hline LLW & 30 & 30 & 30 \\
\hline $\mathrm{HAZ}$ & 0 & D & 5 \\
\hline 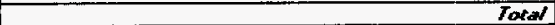 & 50 & 50 & 50 \\
\hline
\end{tabular}

Sum of totals may not add due to rounding: numbers over $10 \mathrm{~m}^{3}$ are rounded to the nearest $10 \mathrm{~m}^{3}$, numbers less than $10 \mathrm{~m}^{3}$ are rounded to integers, non-zero numbers less than 1 are rounded to 1 .

\section{Background}

This waste generator represents U Plant deactivation. The deactivation has not been included 
in the planning baseline of any program to date; therefore, the solid waste resulting from this deactivation has been deemed "non-programmatic."

\section{Forecast Assumptions and Comments}

The volumes reported for this generator are from BEMR estimates from FY96. In particular, waste volumes were estimated by BEMR through use of a modeling tool that projected future transitional waste volumes. In addition, the container, hazardous constituent, physical waste form, radionuclides, handling characteristics, and waste class information was assumed to be similar to that within the Facility Transition Program. For this generator, the average information from the Facility Transition Program was used.

Minimum and maximum ranges were not collected for this generator, since forecast volumes were obtained from BEMR model results that did not account for variations in waste generation. In this case, the assumption is made that minimum and maximum ranges for the waste are $100 \%$ and $100 \%$ respectively.

\section{Other Forecast Data}

\section{- Low Level Waste}

- A total of $30 \mathrm{~m}^{3}$ of LLW is expected from NP_U Plant.

o This forecast shows no change from the FY96 forecast.

- $88 \%$ of the LLW volume will be evenly split between MB-V boxes and 208 liter drums, and other boxes and drums will contain the remaining $12 \%$.

o The physical forms for LLW are debris $(95 \%)$, soil and soil/gravel (4\%), while organic solids, inorganic solids, lab packs, and shielding total to $1 \%$ of the volume.

\section{- Hazardous Waste}

o No hazardous waste is expected from NP_U Plant for management by the CWC. 


\begin{tabular}{|c|}
\hline $\begin{array}{l}\text { GENERATORS: } \\
\text { 300 Area Facilities Non-Transition · } 400 \text { Area Facilities Non-Transition - B Plant Non-Transition · PFP Non-Transition } \\
\text { PUREX Non-Transition · REDOX Non-Transition - Site Support Non-Transition · Stored Equipment - T Plant } \\
\text { Non-Transition - U Plant Non-Transition }\end{array}$ \\
\hline $\begin{array}{l}\text { PROGRAMS: } \\
\text { Analytical Services } \cdot \text { EM-40 } \cdot \text { Facility Transitions } \cdot \text { Landlord } \cdot \text { Liquid Effluent } \cdot \text { NP } \cdot \text { Offsite } \cdot \text { PNNL } \cdot \text { RCRA } \cdot \text { Solid } \\
\text { Waste } \cdot \text { SNF } \cdot \text { TWRS }\end{array}$ \\
\hline $\begin{array}{l}\text { CHARACTERISTICS: } \\
\text { CH_LLMW } \cdot \text { RH_LLMW } \cdot \text { CH_TRU(M) } \cdot \text { RH_TRU(M) } \\
\text { GTC III } \cdot \text { LLW } \cdot \text { HAZ }\end{array}$ \\
\hline $\begin{array}{l}\text { WASTE CLASSES: } \\
\text { CH_LLMW } \cdot \text { RH_LLMW } \cdot \text { CH_TRU(M) } \cdot \text { RH_TRU(M) } \cdot \text { GTC II } \cdot \text { LLW } \cdot \text { HAZ }\end{array}$ \\
\hline
\end{tabular}

NOTICE: This page is provided subject to our disclaimer. Contact: Oscar Valero at (509) 373-4752. HNF-EP-0918 rev. 1 Approved for public release; distribution is unlimited. 
pati: 1 . W 


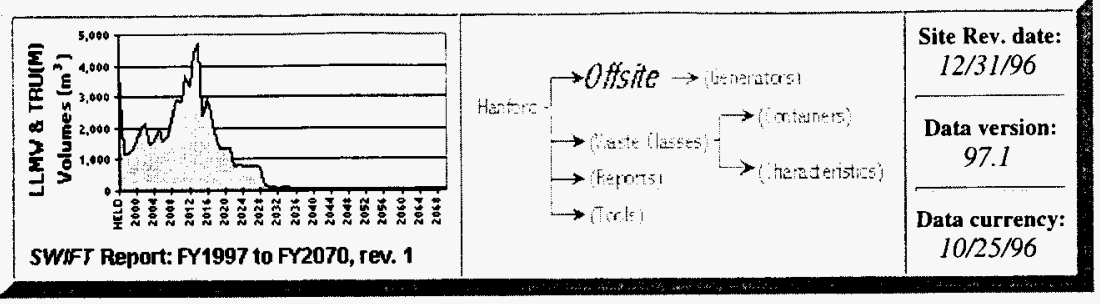

\section{Offsite}

\section{Contents}

》 Highlights

》Annual Waste Class Volumes

» Summary Table

»Comparison to Previous Baseline(s)
" Background

» Forecast Assumptions and Comments

» Other Offsite Forecast Data

\section{Highlights}

- The forecast life cycle for the Offsite program ends in 2070.

- A total of $210 \mathrm{~m}^{3}$ of LLMW and TRU(M) waste is expected from this program over the life cycle. This volume represents less than $1 \%$ of the total LLMW and TRU(M) waste expected at Hanford.

- This forecast shows a $38 \%$ decrease from the FY 96 forecast of $340 \mathrm{~m}^{3}$, primarily due to some generators that do not expect Hanford to be the primary site for waste treatment, while some other generators have shortened their life cycles.

- This forecast shows a $30 \mathrm{~m}^{3}$ increase from the FY97.0 version due to revised estimates from Paducah Energy Systems and Battelle Columbus Laboratory.

- $\mathrm{CH} \_$LLMW is the primary waste class, representing $95 \%$, or $200 \mathrm{~m}^{3}$ of the Offsite waste volume.

- The Princeton Plasma Physics Laboratory generator is expected to generate the most waste in this program, $28 \%$ or $60 \mathrm{~m}^{3}$. The second highest generator is Rockwell-Canoga Park, expected to generate $24 \%$ or $50 \mathrm{~m}^{3}$.

- The Offsite program will be using two main kinds of containers for LLMW and TRU(M) waste volumes: 37\% MB-IV boxes and 33\% 208 liter drums. The remaining waste will be distributed similarly among 322 liter drums (10\%), Small boxes $(10 \%)$, and Other drums $(10 \%)$.

- $50 \%$ of the volume is forecast to have the physical form of debris. Organic solids represent $29 \%$ of the volume, inorganic solids $14 \%$, special waste $5 \%$, and other physical waste forms comprise the remaining $2 \%$.

- The Offsite program forecast 12 different kinds of hazardous constituents. The LLMW and TRU(M) 
waste volume is $32 \%$ metals without mercury, $30 \%$ state regulated, $25 \%$ organic, $5 \%$ metals with mercury, and $4 \%$ ignitable constituents. The other $4 \%$ includes other miscellaneous hazardous constituents.

Waste Class Distribution

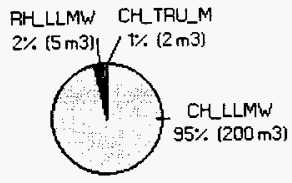

Total $=\mathbf{2 1 0 ~} \mathbf{m} 3$

\section{Generator Distribution}

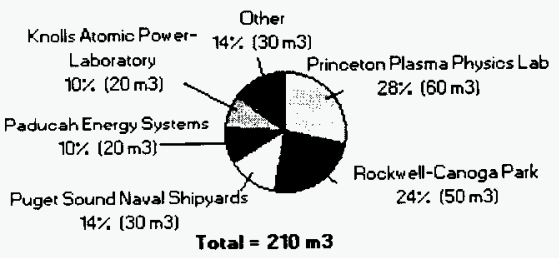

Physical Waste Form Distribution

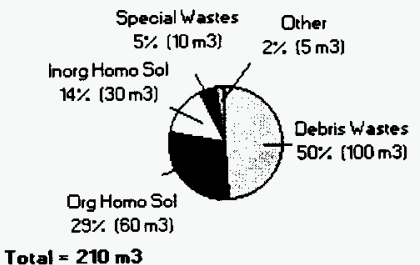

Hazardous Constituent Distribution

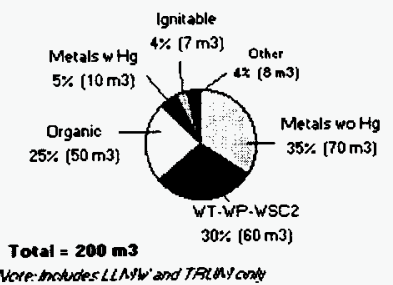

\section{Container Distribution}

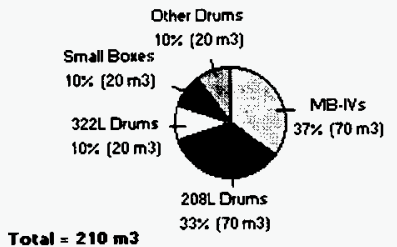

Sum of totals may not add due to rounding: numbers over $10 \mathrm{~m}^{3}$ are rounded to the nearest $10 \mathrm{~m}^{3}$, numbers less than $10 \mathrm{~m}^{3}$ are rounded to integers, non-zero numbers less than 1 are rounded to 1 .

\section{Annual Waste Class Volumes}

Offsite program waste will be generated from 1997 to the end of life cycle in 2070 . The large amount of LLMW forecast is in 1997, corresponding to initial waste shipments from Princeton Plasma Physics Laboratory and Rockwell-Canoga Park.

\section{Annual Baseline Volumes}




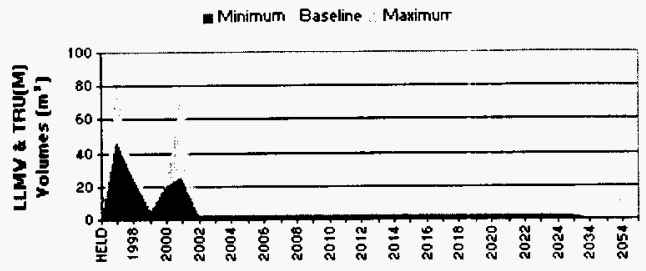

Annual Baseline by Waste Class

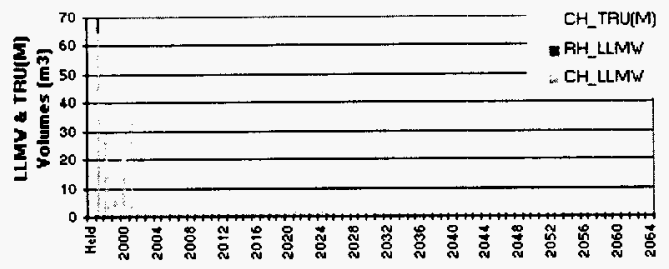

\section{Summary Table (Volumes in $\mathrm{m}^{3}$ )}

\begin{tabular}{|c|c|c|c|c|c|}
\hline $\begin{array}{l}\text { OIfsite Summarg: } \\
\text { Generator }\end{array}$ & CH LLMY & RH LLMY & CH TRULU] & Souprored & PCT \\
\hline Princeton Plasma Physics Lab & 60 & 0 & 0 & 60 & $28 \%$ \\
\hline Rockwell-Canoga Park & 50 & 吾 & o & 50 & $24 \%$ \\
\hline Puget Sound Naval Shipyards. & 30 & 마. & of & 30 & $14 \%$ \\
\hline Paducah Energy Systems & 20 & of & 0 & 20 & $10 \%$ \\
\hline Knolls Atomic Power-Laboratory & 10 & 5 & of & 20 & $10 \%$ \\
\hline Gattelle Columbus Laboratories & 8 & of & 요 & 8 & $4 \%$ \\
\hline General Atomics & 7 & of & 인 & 7 & $3 \%$ \\
\hline University of Utan & 7 & of & of & 7 & $3 \%$ \\
\hline Pearl Harbor Naval Shipyards & 5 & of & of & 5 & $2 \%$ \\
\hline Lawrence Berkeley Labaratory & ㅇ․ & 0 & 1 & 1 & $<1 \%$ \\
\hline Portsmouth Nayel Shipyards & 1 & of & 0 & 1 & $<1 \%$ \\
\hline Ames Laboratory-Ames, lowa & 0 & 0 & -1 & $<1$ & $<1 \%$ \\
\hline Total & 200 & 5 & 2 & 270 & $98 \%$ \\
\hline PCT & $97 \%$ & $2 \%$ & $1 \%$ & lmo: & \\
\hline
\end{tabular}

Sum of rotals may not add due to rounding: numbers over $10 \mathrm{~m}^{3}$ are rounded to the nearest $10 \mathrm{~m}^{3}$, numbers less than $10 \mathrm{~m}^{3}$ are rounded to integers, non-zero numbers less than 1 are rounded to 1.

\section{Comparison to Previous Baseline(s)}

The FY97.1 forecast for Offsite generators of $210 \mathrm{~m}^{3}$ shows a $38 \%$ decrease from the FY96 forecast of $340 \mathrm{~m}^{3}$. This reduction is because four generators do not expect Hanford to be the primary site for treatment, storage, and disposal of LLMW and TRU(M) waste. Additionally, the decrease from the FY96 forecast is that the life cycle end date being reported for a number of generators has been reduced from 2070 to earlier dates. The 2070 estimate for last year was 
based on the Hanford life cycle end date. This year, the generators have corrected this estimate by providing their own specifically scheduled end dates. The FY97.1 shows a $30 \mathrm{~m}^{3}$ increase from the FY97.0 volume of $180 \mathrm{~m}^{3}$ due to revised estimates from Paducah Energy systems and Battelle Columbus Laboratory.

The differences between the 1996 hazardous constituents forecast and this year's forecast are as follows: Metals without mercury composed $50 \%$ of the volume in 1996, but is currently down to $35 \%$, while both state regulated and organic constituents have increased from single digit percents to around $25 \%$ of the volume; also, the amount of 'other' constituents has fallen.

\section{Comparison to Previous Baseline(s) by Waste Class}

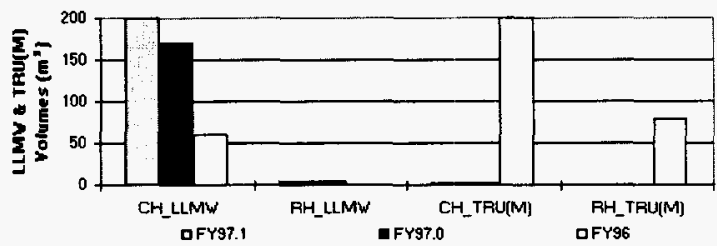

\begin{tabular}{|c|c|c|c|}
\hline $\begin{array}{l}\text { Orraite Comperison: } \\
\text { Waste Class }\end{array}$ & $\begin{array}{l}\text { FY97.1 } \\
\text { Forecast } \\
\left(\mathrm{m}^{3}\right)\end{array}$ & $\begin{array}{l}\text { FY97.0 } \\
\text { Forecast } \\
\left(\mathrm{m}^{3}\right)\end{array}$ & $\begin{array}{c}\text { Frgs } \\
\text { Forecest } \\
\left(\mathrm{m}^{3}\right)\end{array}$ \\
\hline $\mathrm{CH}$ LLLMN & 200 & 170 & 60 \\
\hline RH_LLMN & 5 & 5 & 0 \\
\hline $\mathrm{CH}$ TRU(M) & 2 & 2 & 200 \\
\hline RH TRU(M) & 0 & 0 & 80 \\
\hline Subtotal & 210 & 180 & 340 \\
\hline LLWN & 46,500 & 46,500 & 170,830 \\
\hline Total & 46710 & 46,680 & 175,170 \\
\hline
\end{tabular}

Sum of totals may not add due to rounding: numbers over $10 \mathrm{~m}^{3}$ are rounded to the nearest $10 \mathrm{~m}^{3}$, numbers less than $10 \mathrm{~m}^{3}$ are rounded to integers, non-zero numbers less than $/$ are rounded to 1.

\section{Background}

The missions for Offsite program include general maintenance and operations, environmental restoration, D\&D, and research and development. There are 23 generators within the Offsite program. Most of these generators expect very little to no LLMW and TRU(M) waste.

\section{Forecast Assumptions and Comments}

The data reported are based on solid waste forecasts in all cases except 3 generators: Portsmouth, Pearl Harbor, and Puget Sound Naval Shipyards. For these generators, the Site Treatment Plans (STPs) are the basis for the data reported.

Note that for some of the generators other than the 3 noted above, the forecast waste levels are somewhat larger than waste levels set in their STPs. In each of these cases, the sites are currently negotiating with their respective states for an increase in the STP to meet the forecast level. 
For 3 generators, Hanford is not the first choice for solid waste management: Ames, Princeton, and the University of Utah.

The minimum and maximum ranges for this waste are $78 \%$ and $139 \%$ of the baseline. These ranges are based on uncertainty of project schedules, uncertainty with waste characterization and volumes, and minimization and consolidation techniques.

\section{Other Forecast Data}

\section{- Low Level Waste}

- A total of $46,500 \mathrm{~m}^{3}$ of LLW is expected the Offsite program.

- This forecast shows a $73 \%$ decrease from the FY96 forecast of $170,830 \mathrm{~m}^{3}$, primarily due to some sites no longer forecasting waste volumes for Hanford.

- The various generators will be sending seemingly every kind of container there is for LLW; yet, the three most common types should be Small boxes, Extra Large boxes, and then 208 liter drums.

- Physical LLW forms are for the most part debris $(91 \%)$. Soil and soil/gravel is the other waste form of considerable volume at $5 \%$. Inorganic solids, organic solids, lab packs and shielding represent the other $4 \%$.

\section{- Hazardous Waste}

- No hazardous waste is expected from the Offsite program for management by the CWC.

\section{GENERATORS:}

Ames Laboratory-Ames, Iowa - Argonne National Laboratory-East - Bates Accelerator-Massachusetts · Battelle Columbus Laboratories - Bettis Atomic Power-Laboratory - Bettis Atomic Power-Shipyards - Brookhaven National Laboratory - Fermi National Accelerator Laboratory · General Atomics - Knolls Atomic Power-Laboratory - Knolls Atomic Power-Shipyards - Lawrence Berkeley Laboratory - Paducah Energy Systems - Pearl Harbor Naval Shipyards . Portsmouth Energy Systems - Portsmouth Naval Shipyards - Princeton Plasma Physies Laboratory - Puget Sound Naval Shipyards - Rockwell-Canoga Park - Rocky Flats - Stanford Linear Accelerator Center - University of California-Davis University of Utah

\section{PROGRAMS}

Analytical Services · EM-40 - Facility Transitions - Landlord - Liquid Effluent - NP · Offsite · PNNL · RCRA - Solid Waste $\cdot$ SNF . TWRS

\begin{tabular}{|c|c|}
\hline $\begin{array}{c}\text { CHARACTERISTICS: } \\
\text { CH_LLMW } \cdot \text { RH_LLMW } \cdot \text { CH_TRU(M) } \cdot R H_{-} \text {TRU(M) } \cdot \\
\text { GTC III } \cdot \text { LLW } \cdot \text { HAZ }\end{array}$ & 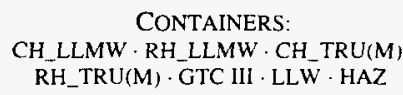 \\
\hline
\end{tabular}

\section{WASTE CLASSES:}

CH_LLMW $\cdot$ RH_LLMW $\cdot$ CH_TRU(M) $\cdot$ RH_TRU(M) - GTC III - LLW $\cdot$ HAZ

Home - Contents - Web Site Map - Glossary · Help · Reports · Data Requests · Feedback Form

NOTICE: This page is provided subject to our disclaimer. Contact: Oscar Valero at (509) 373-4752.

HNF-EP-0918 rev. 1 Approved for public release; distribution is unlimited. 
THE 


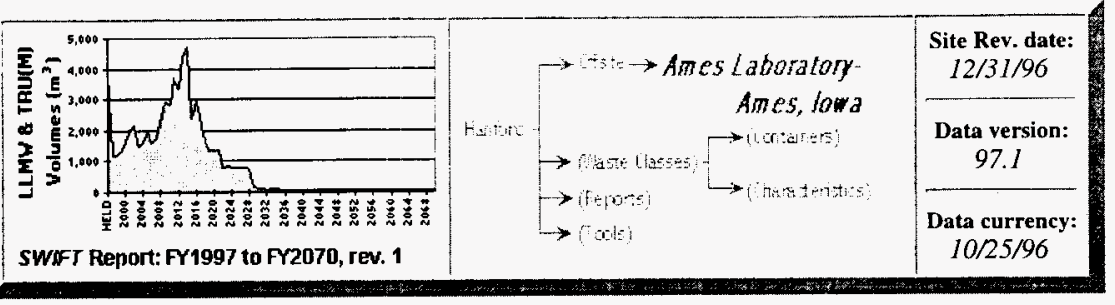

\section{Offsite - Ames Laboratory - Ames, Iowa}

\section{Contents}

» Highlights

»Annual Volumes

»Comparison to Previous Baseline(s)

» Background
》 Forecast Assumptions and Comments

» Other Ames Laboratory Forecast Data

»Detailed Forecast Data

\section{Highlights}

- The forecast life cycle for the Ames Laboratory generator ends in 2070.

- The life cycle total of TRU(M) waste for this generator is less than $1 \mathrm{~m}^{3}$.

- Only CH_TRU(M) waste is included in this forecast of solid waste to be shipped to Hanford.

- This generator expects to use Other drums as their sole TRU(M) waste container.

- The physical waste forms are heterogeneous debris and aqueous lab pack which split the volume $50 / 50$.

- TRU(M) waste hazardous constituents are $100 \%$ metals without mercury.

\section{Waste Class Distribution}

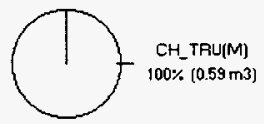

Total $=0.59 \mathrm{~ms}$ 
Physical Waste Form Distribution

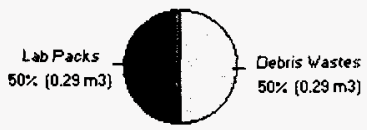

Total $=0.59 \mathrm{~m} 3$
Hazardous Constituent Distribution

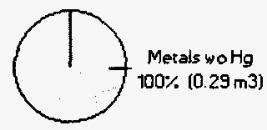

Total $=0.29 \mathrm{m3}$

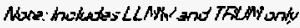

\section{Container Distribution}

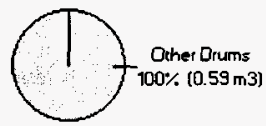

Total $=0.59 \mathrm{~m} 3$

Sum of totals may not add due to rounding: numbers over $10 \mathrm{~m}^{3}$ are rounded to the nearest $10 \mathrm{~m}^{3}$, numbers less than $10 \mathrm{~m}^{3}$ are rounded to integers, non-zero numbers less than 1 are rounded to 1 .

\section{Annual Volumes}

\section{Annual Baseline Volumes}

The graph shows LLMW and TRU(M) annual forecast volumes; note that the forecast in this case ends in 2064; LLW is forecast until 2070.

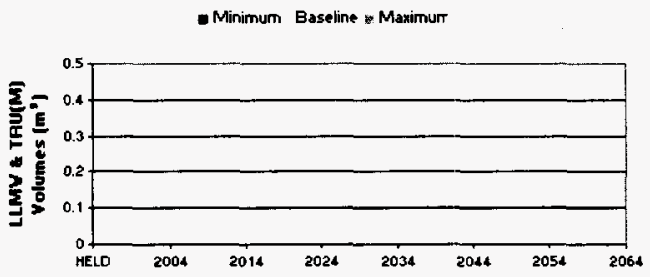

Annual Baseline by Waste Class 


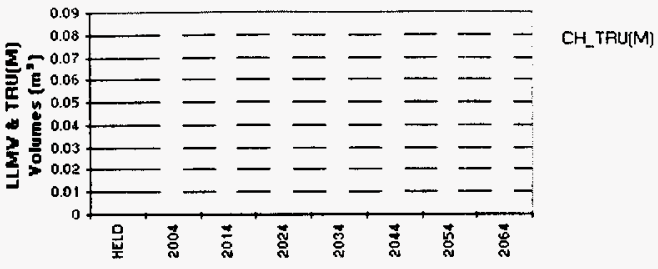

\section{Comparison to Previous Baseline(s)}

The FY97 forecast is consistent with the FY96 forecast of $<1 \mathrm{~m}^{3}$.

\section{Comparison to Previous Baseline(s) by Waste Class}

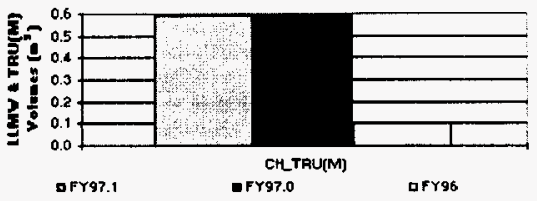

\begin{tabular}{|c|c|c|c|}
\hline $\begin{array}{l}\text { Ames Laboratory Comparison: } \\
\text { Vaste Class }\end{array}$ & $\begin{array}{c}\text { FY97.1 } \\
\text { Forecast } \\
\left(\mathrm{m}^{3}\right)\end{array}$ & $\begin{array}{l}\text { FY97.0 } \\
\text { Forecast } \\
\text { (m') }\end{array}$ & $\begin{array}{c}\text { FY9s } \\
\text { Forecast } \\
\text { (m') }\end{array}$ \\
\hline $\mathrm{CH}$ TRU(M) & 0.59 & 0.59 & 0 \\
\hline solvard & 258 & 25 & $\theta$ \\
\hline LLW & 130 & 130 & 110 \\
\hline Toxal & 100 & 100 & 110 \\
\hline
\end{tabular}

Sum of totals may not add due to rounding: numbers over $10 \mathrm{~m}^{3}$ are rounded to the nearest $10 \mathrm{~m}^{3}$, numbers less than $10 \mathrm{~m}^{3}$ are rounded to integers, non-zero numbers less than 1 are rounded to 1 .

\section{Background}

The primary mission of Ames Laboratory is to conduct basic and intermediate range applied research in physical, mathematical, and engineering sciences that underlie energy technologies and other areas of national importance. Ames Laboratory is involved in materials preparation and processing, chemical sciences and materials reliability to solve complex materials problems in energy production and utilization.

\section{Forecast Assumptions and Comments}

The minimum and maximum range for this waste volume is $1 \%$ and $100 \%$ of the baseline.

This forecast assumes that the Alpha Operations Facility will be funded and the planned transuranic work will proceed. Another assumption is that the facility renovation will continue, which is the main source for the LLW.

\section{Other Forecast Data}




\section{- Low Level Waste}

- $130 \mathrm{~m}^{3}$ of LLW is expected from Ames Laboratory.

- This forecast shows a $9 \%$ increase over the FY96 forecast of $110 \mathrm{~m}^{3}$, primarily due to the facility renovation.

- $64 \%$ of the LLW volume will be in 208 liter drums, while Small boxes and Medium boxes will each contain $18 \%$ of the volume.

- LLW physical forms are $10 \%$ (by volume) inorganic particulates and $90 \%$ debris.

\section{- Hazardous Waste}

- No hazardous waste is expected from Ames Laboratory for management by the CWC.

\begin{tabular}{|c|c|}
\hline \multicolumn{2}{|c|}{ 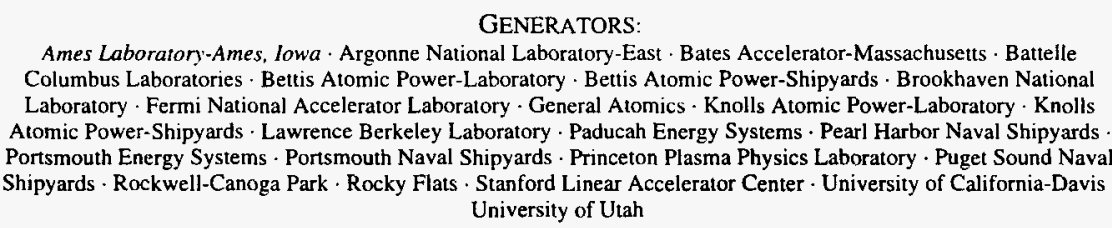 } \\
\hline \multicolumn{2}{|c|}{$\begin{array}{l}\text { PROGRAMS: } \\
\text { Analytical Services } \cdot \text { EM-40 } \cdot \text { Facility Transitions } \cdot \text { Landlord } \cdot \text { Liquid Effluent } \cdot \text { NP } \cdot \text { Offsite } \cdot \text { PNNL } \cdot \text { RCRA } \cdot \text { Solid } \\
\text { Waste } \cdot \text { SNF } \cdot \text { TWRS }\end{array}$} \\
\hline $\begin{array}{l}\text { CHARACTERISTICS: } \\
\text { CH_LLMW } \cdot \text { RH_LLMW } \cdot \text { CH_TRU(M) } \cdot \text { RH_TRU(M) } \\
\text { GTC III } \cdot \text { LLW } \cdot \text { HAZ }\end{array}$ & $\begin{array}{l}\text { CONTAINERS: } \\
\text { CH_LLMW } \cdot \text { RH_LLMW } \cdot \text { CH_TRU(M) } \\
\text { RH_TRU(M) } \cdot \text { GTC III } \cdot \text { LLW } \cdot \text { HAZ }\end{array}$ \\
\hline \multicolumn{2}{|c|}{$\begin{array}{l}\text { WASTE CLASSES: } \\
\text { CH_LLMW } \cdot \text { RH_LLMW } \cdot \text { CH_TRU(M) } \cdot \text { RH_TRU(M) GTC III } \cdot \text { LLW } \cdot \text { HAZ }\end{array}$} \\
\hline
\end{tabular}

NOTICE: This page is provided subject to our disclaimer. Contact: Oscar Valero at (509) 373-4752.

HNF-EP-0918 rev. 1 Approved for public release; distribution is unlimited. 


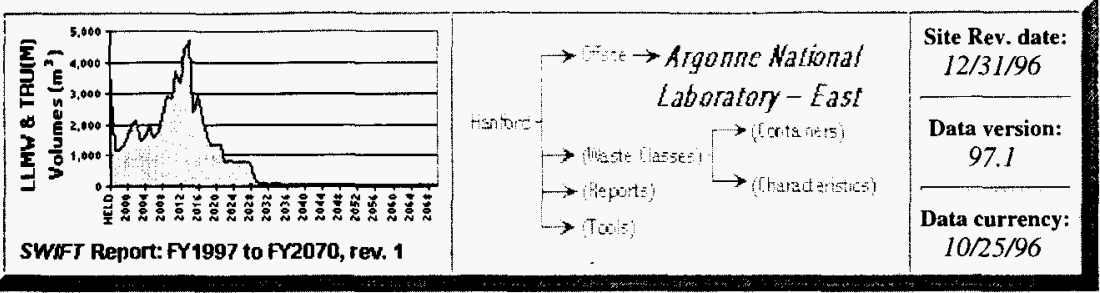

\section{Offsite - Argonne National Laboratory - East}

\section{Contents}

» Highlights

»Annual Volumes

»Comparison to Previous Baseline(s)

"Background
》 Forecast Assumptions and Comments

»Other Argonne National Laboratory - East Forecast Data

» Detailed Forecast Data

\section{Highlights}

- The forecast life cycle for the Argonne National Laboratory-East generator ends in 2070.

- Only LLW is included in this forecast of solid waste to be shipped to Hanford.

\section{Annual Volumes}

\section{Annual Baseline Volumes}

No LLMW or TRU(M) waste is expected from this generator.

\section{Annual Baseline by Waste Class}

Not applicable.

\section{Comparison to Previous Baseline(s)}

This generator did not forecast any LLMW or TRU(M) for FY97 because the waste will be treated onsite and sent elsewhere for disposal; including the $200 \mathrm{~m}^{3}$ of $\mathrm{CH}_{-}$TRU(M) waste previously forecast in FY96.

\section{Comparison to Previous Baseline(s) by Waste Class}




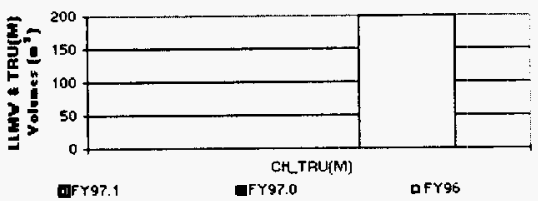

\begin{tabular}{|c|c|c|c|}
\hline $\begin{array}{l}\text { Argonne National Laboratory-East Comparison: } \\
\text { Yaste Class }\end{array}$ & $\begin{array}{c}\text { FY97.1 } \\
\text { Forecast } \\
\text { (m') }\end{array}$ & $\begin{array}{c}\text { FY97.0 } \\
\text { Forecast } \\
\left(\mathbf{m}^{3}\right)\end{array}$ & $\begin{array}{l}\text { FY96 } \\
\text { Forecast } \\
\text { (m') }\end{array}$ \\
\hline CH_TRU(M) & 0 & 0 & 200 \\
\hline subroes' & $\theta$ & $a$ & 209 \\
\hline LLW & 20,040 & 20,040 & 20,430 \\
\hline Tared & $2009 \theta$ & $2009 \theta$ & $20 \times 20$ \\
\hline
\end{tabular}

Sum of totals may not add due to rounding: numbers over $10 \mathrm{~m}^{3}$ are rounded to the nearest $10 \mathrm{~m}^{3}$, numbers less than $10 \mathrm{~m}^{3}$ are rounded to integers, non-zero numbers less than I are rounded to $I$.

\section{Background}

The current mission of Argonne National Laboratory-East is to conduct research.

\section{Forecast Assumptions and Comments}

This forecast assumes that D\&D projects and Remediation Cleanup Projects will receive funding, and that projects will be completed as scheduled. Additionally, general laboratory waste streams will remain unchanged, and that the wastes will be shipped as planned.

\section{Other Forecast Data}

\section{- Low Level Waste}

- A total of $20,040 \mathrm{~m}^{3}$ of LLW is expected from Argonne National Laboratory-East.

- This forecast shows a $2 \%$ decrease from the FY96 forecast of $20,430 \mathrm{~m}^{3}$.

- $21 \%$ of this waste is to be contained in 208 liter drums; the rest will be in Small Boxes.

- Debris accounts for $87 \%$ of the LLW physical waste forms. Soil and soil/gravel represents $9 \%$ of the waste form, and inorganic and organic solids are each $2 \%$.

\section{- Hazardous Waste}

o No hazardous waste is expected from Argonne National Laboratory-East for management by the CWC. 


\section{GENERATORS:}

Ames Laboratory-Ames, Iowa - Argonne National Laboratory-East - Bates Accelerator-Massachusetts - Battelle Columbus Laboratories - Bettis Atomic Power-Laboratory - Bettis Atomic Power-Shipyards - Brookhaven National Laboratory - Fermi National Accelerator Laboratory - General Atomics · Knolls Atomic Power-Laboratory · Knolls Atomic Power-Shipyards - Lawrence Berkeley Laboratory · Paducah Energy Systems · Pearl Harbor Naval Shipyards · Portsmouth Energy Systems · Portsmouth Naval Shipyards - Princeton Plasma Physics Laboratory - Puget Sound Naval Shipyards - Rockwell-Canoga Park - Rocky Flats - Stanford Linear Accelerator Center - University of California-Davis

University of Utah

PROGRAMS:

Analytical Services · EM-40 - Facility Transitions - Landlord - Liquid Effluent · NP · Offsite · PNNL · RCRA · Solid Waste - SNF - TWRS

\begin{tabular}{|c|c|}
\hline $\begin{array}{c}\text { CHARACTERISTICS: } \\
\text { CH_LLMW } \cdot \text { RH_LLMW } \cdot \text { CH_TRU(M) } \cdot \text { RH_TRU(M) } \\
\text { GTC III } \cdot \text { LLW } \cdot \text { HAZ }\end{array}$ & $\begin{array}{c}\text { CONTAINERS: } \\
\text { CH_LLMW } \cdot \text { RH_LLMW } \cdot \text { CH_TRU(M) } \\
\text { RH_TRU(M) } \cdot \text { GTC III } \cdot \text { LLW } \cdot \text { HAZ }\end{array}$ \\
\hline \multicolumn{2}{|c|}{ WASTE CLASSES: } \\
\hline
\end{tabular}

NOTICE: This page is provided subject to our disclaimer. Contact: Oscar Valero at (509) 373-4752.

HNF-EP-0918 rev. 1 Approved for public release; distribution is unlimited. 


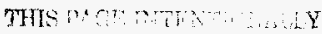
li... Sifing 

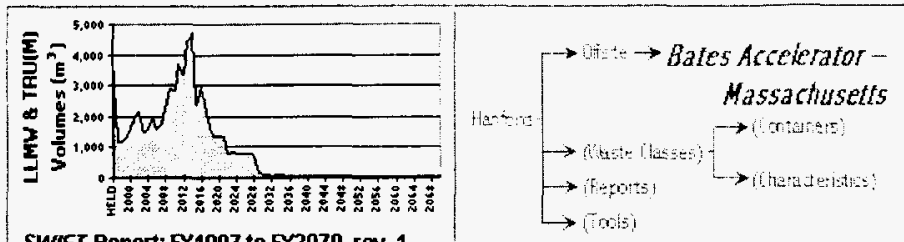

Site Rev. date:

$12 / 31 / 96$

Data version:

97.1

Data currency: 10/25/96

\section{Offsite - Bates Accelerator - Massachusetts}

\section{Contents}

» Highlights

» Annual Volumes

》Comparison to Previous Baseline(s)

» Background
》Forecast Assumptions and Comments

»Other Bates Accelerator Forecast Data

»Detailed Forecast Data

\section{Highlights}

- The forecast life cycle for the Bates Accelerator generator ends in 2030.

- No LLMW or TRU(M) waste is expected from Bates Accelerator.

- Only LLW is included in this forecast of solid waste to be shipped to Hanford.

\section{Annual Volumes}

\section{Annual Baseline Volumes}

No LLMW or TRU(M) waste is expected from this generator.

Annual Baseline by Waste Class

Not applicable.

\section{Comparison to Previous Baseline(s)}

Bates Accelerator forcasted no LLMW or TRU(M) waste in FY96 or FY97.

\section{Comparison to Previous Baseline(s) by Waste Class}

\begin{tabular}{|c|c|c|c|}
\hline $\begin{array}{l}\text { Bates Accelerator-Massachusetts Comparison: } \\
\text { Vaste Class }\end{array}$ & $\begin{array}{l}\text { FY97.1 } \\
\text { Forecast } \\
\text { (m²) }\end{array}$ & $\begin{array}{c}\text { FY97.0 } \\
\text { Forecast } \\
{\left[\mathrm{m}^{2}\right]}\end{array}$ & $\begin{array}{c}\text { FY96 } \\
\text { Forecast } \\
\left(\mathbf{m}^{2}\right)\end{array}$ \\
\hline LLW & 40 & 40 & 480 \\
\hline Fores & 10 & 10 & soce \\
\hline
\end{tabular}


Sum of totals may not add due to rounding: numbers over $10 \mathrm{~m}^{3}$ are rounded to the nearest $10 \mathrm{~m}^{3}$, numbers less than $10 \mathrm{~m}^{3}$ are rounded to integers, non-zero numbers less than 1 are rounded to 1.

\section{Background}

Bates Linear Accelerator is a medium energy electron facility with principal focus on electron scattering. This forecast is based on waste generated from existing operation. The generated waste will be limited to LLW and consist of resin used in the cooling water purification system.

\section{Forecast Assumptions and Comments}

This forecast assumes that all waste will be generated from existing operations.

\section{Other Forecast Data}

\section{- Low Level Waste}

- $40 \mathrm{~m}^{3}$ of LLW is expected from Bates Accelerator.

- This LLW forecast shows a $92 \%$ decrease from the FY 96 forecast of $480 \mathrm{~m}^{3}$, due primarily to the implementation of a waste reduction plan.

- 208 liter drums are projected to be the only container for this waste.

- $100 \%$ of the LLW has the physical form of organic particulates.

\section{- Hazardous Waste}

- No hazardous waste is expected from Bates Accelerator for management by the CWC. 


\section{GENERATORS:}

Ames Laboratory-Ames, Iowa - Argonne National Laboratory-East - Bates Accelerator-Massachusetts - Battelle Columbus Laboratories - Bettis Atomic Power-Laboratory - Bettis Atomic Power-Shipyards - Brookhaven National Laboratory - Fermi National Accelerator Laboratory - General Atomics - Knolls Atomic Power-Laboratory · Knolls Atomic Power-Shipyards - Lawrence Berkeley Laboratory - Paducah Energy Systems - Pearl Harbor Naval Shipyards . Portsmouth Energy Systems - Portsmouth Naval Shipyards - Princeton Plasma Physics Laboratory - Puget Sound Naval Shipyards - Rockwell-Canoga Park - Rocky Flats - Stanford Linear Accelerator Center - University of California-Davis

University of Utah

\section{PROGRAMS:}

Analytical Services · EM-40 - Facility Transitions - Landlord · Liquid Effluent $\cdot$ NP · Offsite $\cdot$ PNNL $\cdot$ RCRA $\cdot$ Solid Waste $\cdot$ SNF . TWRS

\begin{tabular}{|c|c|}
\hline $\begin{array}{l}\text { CHARACTERISTICS: } \\
\text { CH_LLMW } \cdot \text { RH_LLMW } \cdot \text { CH_TRU(M) } \cdot \text { RH_TRU(M) } \\
\text { GTC III } \cdot \text { LLW } \cdot \text { HAZ }\end{array}$ & $\begin{array}{l}\text { CONTAINERS: } \\
\text { CH_LLMW } \cdot \text { RH_LLMW } \cdot \text { CH_TRU(M) } \\
\text { RH_TRU(M) } \cdot \text { GTC III } \cdot \text { LLW } \cdot \text { HAZ }\end{array}$ \\
\hline \multicolumn{2}{|c|}{$\begin{array}{c}\text { WASTE CLASSES: } \\
\text { CH_LLMW } \cdot \text { RH_LLMW } \cdot \text { CH_TRU(M) } \cdot \text { RH_TRU(M) } \cdot \text { GTC III } \cdot \text { LLW } \cdot \text { HAZ }\end{array}$} \\
\hline
\end{tabular}

NOTICE: This page is provided subject to our disclaimer. Contact: Oscar Valero at (509) 373-4752.

HNF-EP-0918 rev. 1 Approved for public release; distribution is unlimited. 
THIS ME $12 . .6$ 


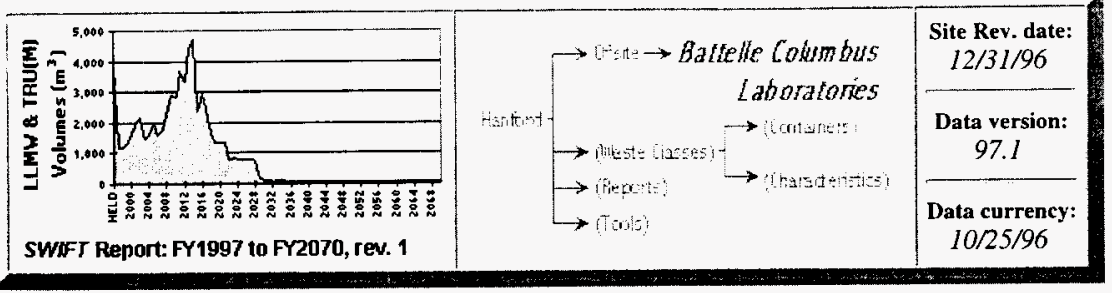

\section{Offsite - Battelle Columbus Laboratories}

\section{Contents}

» Highlights

" Annual Volumes

» Comparison to Previous Baseline(s)

» Background
》 Forecast Assumptions and Comments

» Other Battelle Columbus Laboratories Forecast

Data

» Detailed Forecast Data

\section{Highlights}

- The forecast life cycle for the Battelle Columbus Laboratory generator ends in 2003.

- The total LLMW forecast is $8 \mathrm{~m}^{3}$, or $4 \%$ of the total offsite waste volume.

- This forecast amount shows a $91 \%$ decrease from the FY96 forecast of $90 \mathrm{~m}^{3}$, primarily because the majority of the waste $\left(80 \mathrm{~m}^{3}\right.$ of RH_TRU(M) waste) is not allowed in Washington State and thus will be shipped elsewhere.

- This forecast also shows a $2 \mathrm{~m}^{3}$ increase from the FY97.0 volume due to the availability of better estimates.

- Only CH_LLMW is included in this forecast of solid waste to be shipped to Hanford.

- $100 \%$ of the CH_LLMW will be in 208 liter drums.

- $100 \%$ of this $\mathrm{CH}$ _LLMW has the physical waste form of inorganic solids.

- CH_LLMW hazardous constituents are $100 \%$ metals with mercury. 


\section{Waste Class Distribution}

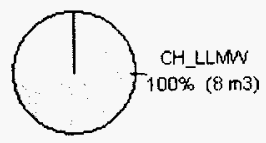

Total $=8 \mathrm{m3}$

\section{Physical Waste Form Distribution Hazardous Constituent Distribution}
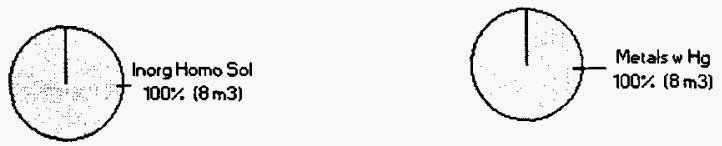

Total $=8 \mathrm{~m} 3$

Total $=8 \mathrm{~m} 3$

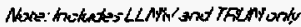

\section{Container Distribution}

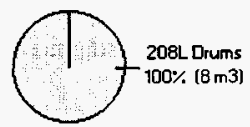

Total $=8 \mathbf{m} 3$

Sum of totals may not add due to rounding: numbers over $10 \mathrm{~m}^{3}$ are rounded to the nearest $10 \mathrm{~m}^{3}$, numbers less than $10 \mathrm{~m}^{3}$ are rounded to integers, non-zero numbers less than $I$ are rounded to $I$.

\section{Annual Volumes}

\section{Annual Baseline Volumes}

The graph shows LLMW annual forecast volumes; note that the forecast in this case ends in 2001; LLW is forecast until 2003.

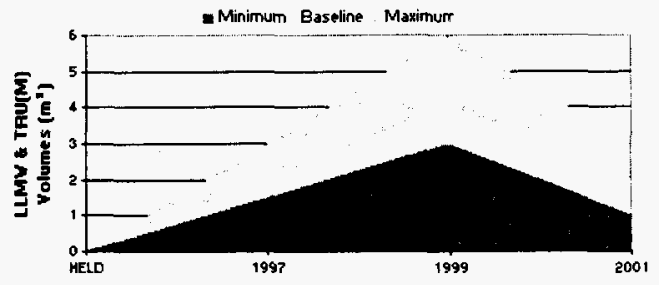


Annual Baseline by Waste Class

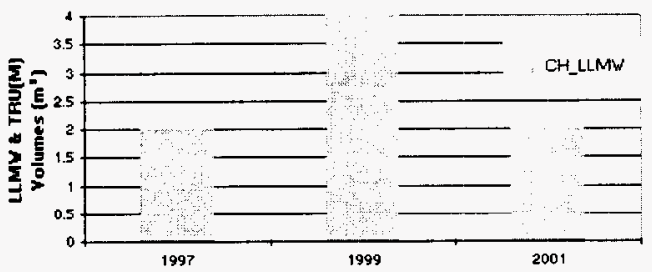

\section{Comparison to Previous Baseline(s)}

The FY97.1 forecast of $8 \mathrm{~m}^{3}$ shows a $91 \%$ decrease from the FY96 forecast of $90 \mathrm{~m}^{3}$. The main reason for this decrease is because the majority of the waste $\left(80 \mathrm{~m}^{3}\right.$ of $\mathrm{RH}_{-}$TRU(M) waste) is not allowed in Washington State and thus will be shipped elsewhere.

The 1996 physical waste form forecast showed $60 \%$ of the volume to be debris and shielding, which is a change from the current excpectation of only inorganic solids.

The 1996 hazardous constituents forecast showed $38 \%$ of the volume to be metals without mercury, $8 \%$ to be organic, and $54 \%$ to be other constituents, while the current forecast expects only metals with mercury.

\section{Comparison to Previous Baseline(s) by Waste Class}

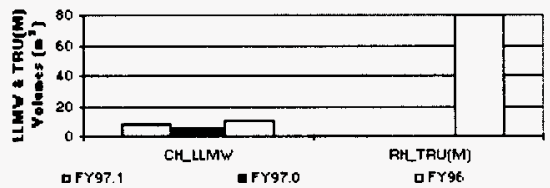

\begin{tabular}{|c|c|c|c|}
\hline $\begin{array}{l}\text { Battelle Columbus Laboratories Comparison: } \\
\text { Yaste Class }\end{array}$ & $\begin{array}{l}\text { FY97.1 } \\
\text { Forecast } \\
\text { (m) }\end{array}$ & $\begin{array}{l}\text { FYs7.0 } \\
\text { Forecast } \\
\text { (m') }\end{array}$ & $\begin{array}{l}\text { FY96 } \\
\text { Forecast } \\
\text { (m') }\end{array}$ \\
\hline CH LLMW & 8 & 6 & 10 \\
\hline RH TRU(M) & 0 & 0 & 80 \\
\hline spurorat & 8 & 6 & 9 \\
\hline$L L W$ & 1,030 & 1.030 & 1,270 \\
\hline Ford & 1.010 & 1.040 & 1.560 \\
\hline
\end{tabular}

Sum of totals may not add due to rounding: numbers over $10 \mathrm{~m}^{3}$ are rounded to the nearest $10 \mathrm{~m}^{3}$, numbers less than $10 \mathrm{~m}^{3}$ are rounded to integers, non-zero numbers less than $I$ are rounded to 1.

\section{Background}

The current mission of Battelle Columbus Laboratory is to decontaminate and decommission facilities that were used to perform DOE and commercial nuclear research to be returned to 
Battelle for use without radiological restrictions. The LLMW is a result the removal of radioactive drain lines.

\section{Forecast Assumptions and Comments}

The minimum and maximum percentages are $67 \%$ and $150 \%$ of the baseline volume. These percentages are based upon fluctuations in D\&D schedules which cause fluctuations in the beginning and end of year shipping schedules.

The main assumption for this forecast is that Battelle will receive DOE funding to decontaminate and decommission the former nuclear sciences area at the West Jefferson, Ohio site to completion.

\section{Other Forecast Data}

- Low Level Waste

- A total of $1,030 \mathrm{~m}^{3}$ of LLW is expected from Battelle Columbus Laboratories

- This forecast shows a $19 \%$ decrease from the FY96 forecast of $1,270 \mathrm{~m}^{3}$.

o The only containers for the LLW volume are MB-IV boxes.

- The physical LLW form forecast is $100 \%$ contaminated metal debris.

\section{- Hazardous Waste}

- No hazardous waste is expected from Battelle Columbus Laboratories for management by the CWC.

\section{GENERATORS:}

Ames Laboratory-Ames, Iowa - Argonne National Laboratory-East - Bates Accelerator-Massachusetts - Battelle Columbus Laboratories . Bettis Atomic Power-Laboratory · Bettis Atomic Power-Shipyards · Brookhaven National Laboratory - Fermi National Accelerator Laboratory - General Atomics - Knolls Atomic Power-Laboratory · Knolls Atomic Power-Shipyards - Lawrence Berkeley Laboratory - Paducah Energy Systems - Pearl Harbor Naval Shipyards Portsmouth Energy Systems · Portsmouth Naval Shipyards · Princeton Plasma Physics Laboratory · Puget Sound Naval

Shipyards - Rockwell-Canoga Park - Rocky Flats - Stanford Linear Accelerator Center - University of California-Davis · University of Utah

\section{PROGRAMS:}

Analytical Services - EM-40 - Facility Transitions - Landlord - Liquid Effluent - NP · Offsite · PNNL · RCRA - Solid Waste $\cdot$ SNF . TWRS

\begin{tabular}{|c|c|}
\hline 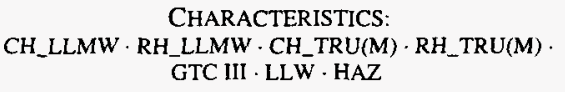 & $\begin{array}{c}\text { CONTAINERS: } \\
\text { CH_LLMW } \cdot \text { RH_LLMW } \cdot \text { CH_TRU(M) } \\
\text { RH_TRU(M) } \cdot \text { GTC III } \cdot \text { LLW } \cdot \text { HAZ }\end{array}$ \\
\hline \multicolumn{2}{|c|}{$\begin{array}{l}\text { WASTE CLASSES: } \\
\end{array}$} \\
\hline
\end{tabular}


NOTICE: This page is provided subject to our disclaimer. Contact: Oscar Valero at (509) 373-4752. HNF-EP-0918 rev. 1 Approved for public release; distribution is unlimited. 
THE ha' bith 


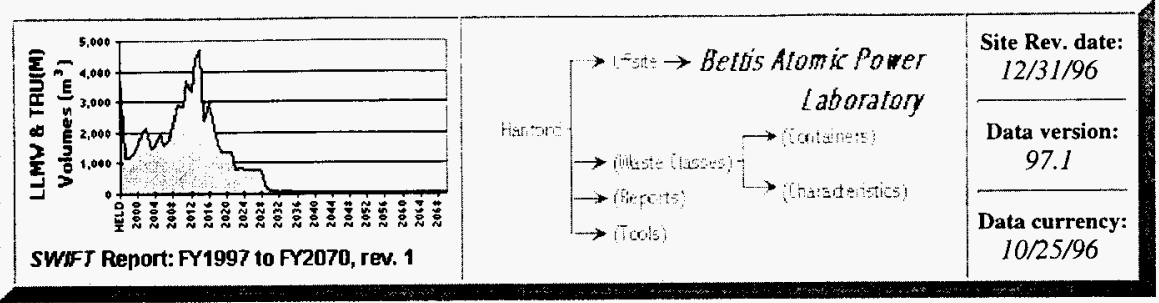

\section{Offsite - Bettis Atomic Power Laboratory}

\section{Contents}

» Highlights

" Annual Volumes

»Comparison to Previous Baseline(s)

» Background
» Forecast Assumptions and Comments

»Other Bettis Atomic Power Laboratory Forecast Data

»Detailed Forecast Data

\section{Highlights}

- The forecast life cycle for the Bettis Atomic Power Laboratory generator ends in 2009.

- Only LLW is included in this forecast of solid waste to be shipped to Hanford.

\section{Annual Volumes}

\section{Annual Baseline Volumes}

No LLMW or TRU(M) waste is expected from this generator.

\section{Annual Baseline by Waste Class}

Not applicable.

\section{Comparison to Previous Baseline(s)}

Similar to FY96, this generator did not forecast any LLMW or TRU(M) waste for FY97.

Comparison to Previous Baseline(s) by Waste Class

\begin{tabular}{|c|c|c|c|}
\hline $\begin{array}{l}\text { Bettis Atomic Pover-Laboratory Comparison: } \\
\text { Yaste Class }\end{array}$ & $\begin{array}{c}\text { FY97.1 } \\
\text { Forecast } \\
\left(\mathbf{m}^{*}\right)\end{array}$ & $\begin{array}{c}\text { Fr97.0 } \\
\text { Forecast } \\
{\left[\mathrm{m}^{2}\right)}\end{array}$ & $\begin{array}{l}\text { FY96 } \\
\text { Forecast } \\
\text { (m') }\end{array}$ \\
\hline LLW & 210 & 210 & \\
\hline Tard & 210 & 210 & 7 \\
\hline
\end{tabular}


Sum of totals may not add due to rounding: numbers over $10 \mathrm{~m}^{3}$ are rounded to the nearest $10 \mathrm{~m}^{3}$, numbers less than $10 \mathrm{~m}^{3}$ are rounded to integers, non-zero numbers less than $I$ are rounded 101 .

\section{Background}

The current mission of Bettis Atomic Power Laboratory is to conduct research, as well as decontamination and decommission.

\section{Forecast Assumptions and Comments}

This forecast assumes that removal of the L-Building inactive fuel processing equipment is expected to be completed by 2009 . Forecast of the research and development work is projected to the same year.

\section{Other Forecast Data}

\section{- Low Level Waste}

o A total of $210 \mathrm{~m}^{3}$ of LLW is expected from Bettis Atomic Power Laboratory.

- This forecast shows a more than 200 -fold $(21,000 \%)$ increase over the FY96 forecast of less than $1 \mathrm{~m}^{3}$, due primarily to increased D\&D activities.

$\circ 98 \%$ of this LLW will be shipped in MB-IV boxes, and the other $2 \%$ will be in 208 liter drums.

- Besides $2 \%$ of the volume having the form of organic solids, all of the waste is debris by physical form.

\section{- Hazardous Waste}

- No hazardous waste is expected from Bettis Atomic Power Laboratory for management by the CWC. 


\section{GENERATORS:}

Ames Laboratory-Ames, lowa - Argonne National Laboratory-East - Bates Accelerator-Massachusetts - Battelle Columbus Laboratories - Bettis Atomic Power-Laboratory - Bettis Atomic Power-Shipyards - Brookhaven National Laboratory - Fermi National Accelerator Laboratory - General Atomics - Knolls Atomic Power-Laboratory - Knolls Atomic Power-Shipyards - Lawrence Berkeley Laboratory - Paducah Energy Systems - Pearl Harbor Naval Shipyards · Portsmouth Energy Systems - Portsmouth Naval Shipyards - Princeton Plasma Physics Laboratory - Puget Sound Naval Shipyards - Rockwell-Canoga Park - Rocky Flats - Stanford Linear Accelerator Center - University of California-Davis .

University of Utah

\section{PROGRAMS:}

Analytical Services · EM-40 · Facility Transitions - Landlord · Liquid Effluent · NP · Offsite · PNNL · RCRA - Solid Waste - SNF - TWRS

\begin{tabular}{|c|c|}
\hline $\begin{array}{c}\text { CHARACTERISTICS: } \\
\text { CH_LLMW } \cdot \text { RH_LLMW } \cdot \text { CH_TRU(M) } \cdot \text { RH_TRU(M) } \\
\text { GTC III } \cdot \text { LLW } \cdot \text { HAZ }\end{array}$ & $\begin{array}{c}\text { CONTAINERS: } \\
\text { CH_LLMW } \cdot \text { RH_LLMW } \cdot \text { CH_TRU(M) } \\
\text { RH_TRU(M) } \cdot \text { GTC III } \cdot \text { LLW } \cdot \text { HAZ }\end{array}$ \\
\hline \multicolumn{2}{|c|}{$\begin{array}{l}\text { WASTE CLASSES: } \\
\text { CH_LLMW } \cdot \text { RH_LLMW } \cdot \text { CH_TRU(M) } \cdot \text { RH_TRU(M) } \cdot \text { GTC III } \cdot \text { LLW } \cdot \text { HAZ }\end{array}$} \\
\hline
\end{tabular}

NOTICE: This page is provided subject to our disclaimer. Contact: Oscar Valero at (509) 373-4752.

HNF-EP-0918 rev. 1 Approved for public release; distribution is unlimited. 


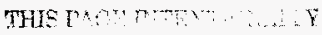

1... 


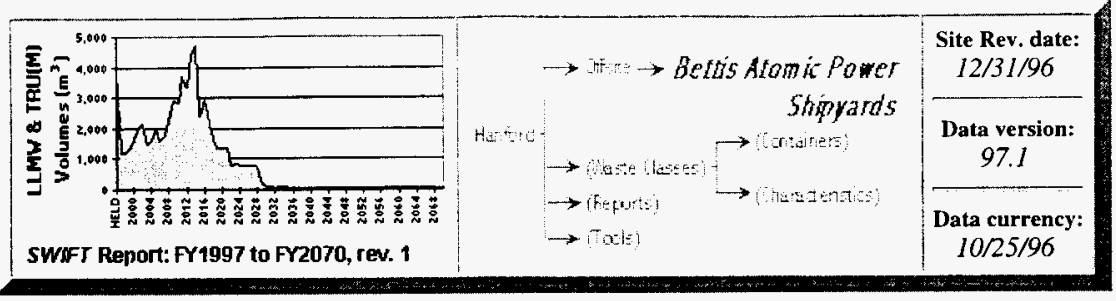

\section{Offsite - Bettis Atomic Power - Shipyards}

\section{Contents}

» Highlights

» Annual Volumes

"Comparison to Previous Baseline(s)

"Background
» Forecast Assumptions and Comments

" Other Bettis Atomic Power - Shipyards Forecast Data

" Detailed Forecast Data

\section{Highlights}

- The forecast life cycle for the Bettis Atomic Power-Shipyards generator ends in 2012.

- Only LLW is included in this forecast of solid waste to be shipped to Hanford.

\section{Annual Volumes}

\section{Annual Baseline Volumes}

No LLMW or TRU(M) waste is expected from this generator.

\section{Annual Baseline by Waste Class}

Not applicable.

\section{Comparison to Previous Baseline(s)}

Similar to FY96, this generator did not forecast any LLMW or TRU(M) waste for FY97.

\section{Comparison to Previous Baseline(s) by Waste Class}

\begin{tabular}{|l|r|r|r|}
\hline $\begin{array}{l}\text { Bettis Atomic Pover-Shipgards Comparison: } \\
\text { Vaste Cless }\end{array}$ & $\begin{array}{c}\text { FY97.1 } \\
\text { Foreeast } \\
\left(\mathrm{m}^{2}\right)\end{array}$ & $\begin{array}{c}\text { FY97.0 } \\
\text { Forecast } \\
\left(\mathrm{m}^{2}\right)\end{array}$ & $\begin{array}{c}\text { FY96 } \\
\text { Forecast } \\
\left(\mathrm{m}^{2}\right)\end{array}$ \\
\hline $\mathrm{LW} W$ & 50 & 50 & 40 \\
\hline
\end{tabular}


than $10 \mathrm{~m}^{3}$ are rounded to integers, non-zero numbers less than $/$ are rounded to $I$.

\section{Background}

The current mission of Bettis Atomic Power-Shipyards is submarine and surface ship reactor defueling operations.

\section{Forecast Assumptions and Comments}

The main assumption for this forecast is that the reactor components are removed during refueling.

\section{Other Forecast Data}

\section{Low Level Waste}

- A total of $50 \mathrm{~m}^{3}$ of LLW is expected from Bettis Atomic Power-Shipyards.

- This forecast shows a $25 \%$ increase over the FY96 forecast of $40 \mathrm{~m}^{3}$.

- $98 \%$ of the LLW is essentially split between Large (50\%) and Medium (48\%), boxes. The last $2 \%$ is contained in Small boxes.

- Contaminated metal debris is the physical waste form for $100 \%$ of the waste.

\section{- Hazardous Waste}

- No hazardous waste is expected from Bettis Atomic Power - Shipyards for management by the CWC.

\section{GENERATORS:}

Ames Laboratory-Ames, Iowa - Argonne National Laboratory-East - Bates Accelerator-Massachusetts - Battelle Columbus Laboratories - Bettis Atomic Power-Laboratory - Bettis Atomic Power-Shipyards - Brookhaven National

Laboratory · Fermi National Accelerator Laboratory - General Atomics · Knolls Atomic Power-Laboratory · Knolls Atomic Power-Shipyards - Lawrence Berkeley Laboratory - Paducah Energy Systerns · Pearl Harbor Naval Shipyards · Portsmouth Energy Systems - Portsmouth Naval Shipyards - Princeton Plasma Physics Laboratory - Puget Sound Naval Shipyards - Rockwell-Canoga Park - Rocky Flats · Stanford Linear Accelerator Center - University of California-Davis ·

University of Utah

\section{PROGRAMS}

Analytical Services - EM-40 - Facility Transitions · Landlord - Liquid Effluent - NP · Offsite · PNNL · RCRA · Solid Waste - SNF - TWRS

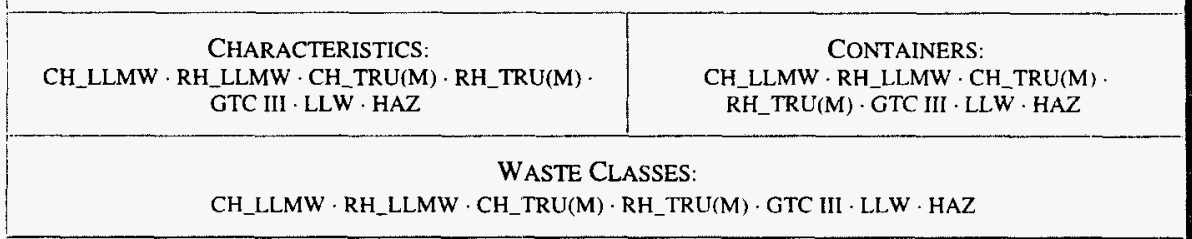

Home - Contents · Web Site Map - Glossary · Help · Reports · Data Requests · Feedback Form 
NOTICE: This page is provided subject to our disclaimer. Contact: Oscar Valero at (509) 373-4752.

HNF-EP-0918 rev. 1 Approved for public release; distribution is unlimited. 
THY 


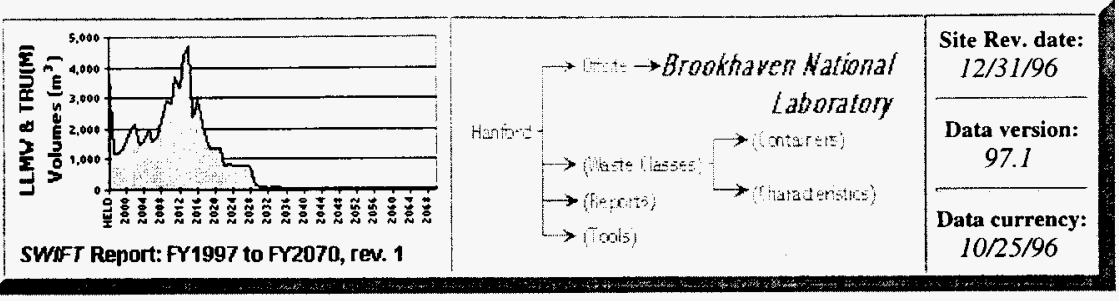

\section{Offsite - Brookhaven National Laboratory}

\section{Contents}

» Highlights

» Annual Volumes

»Comparison to Previous Baseline(s)

" Background
》Forecast Assumptions and Comments

»Other Brookhaven National Laboratory Forecast Data

» Detailed Forecast Data

\section{Highlights}

- The forecast life cycle for the Brookhaven National Laboratory generator ends in 2016.

- Only LLW is included in this forecast of solid waste to be shipped to Hanford.

\section{Annual Volumes}

\section{Annual Baseline Volumes}

No LLMW or TRU(M) waste is expected from this generator.

\section{Annual Baseline by Waste Class}

Not applicable.

\section{Comparison to Previous Baseline(s)}

As in FY96, no LLMW and TRU(M) waste is forecast from this generator.

\section{Comparison to Previous Baseline(s) by Waste Class}

\begin{tabular}{|c|c|c|c|}
\hline $\begin{array}{l}\text { Brookhaven National Laboratory Comparison: } \\
\text { Yaste Class }\end{array}$ & $\begin{array}{c}\text { FY\$7.1 } \\
\text { Forecast } \\
\left(\mathrm{m}^{3}\right)\end{array}$ & $\begin{array}{c}\text { Frs7.0 } \\
\text { Forecast } \\
\left(\mathrm{m}^{2}\right)\end{array}$ & $\begin{array}{l}\text { FY96 } \\
\text { Forecast } \\
\text { (m') }\end{array}$ \\
\hline LWW & 3.090 & 3,090 & 74,890 \\
\hline Tapd & $x \cos \theta$ & $x, 000$ & 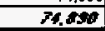 \\
\hline
\end{tabular}


than $10 \mathrm{~m}^{3}$ are rounded to integers, non-zero numbers less than 1 are rounded to $I$.

\section{Background}

The current mission of Brookhaven National Laboratory is to conceive, design, construct, and operate research facilities for fundamental scientific studies and to carry out both basic and applied research in the physical, biomedical, and environmental sciences. LLW are generated from the construction, operation, and dismantling of these facilities.

\section{Forecast Assumptions and Comments}

The main assumption for this forecast is that current funding projections remain and Brookhaven continues to operate under its current mission. Should additional funding be available, additional waste may be shipped to Hanford.

\section{Other Forecast Data}

\section{- Low Level Waste}

- A total of $3,090 \mathrm{~m}^{3}$ of LLW is expected from Brookhaven National Laboratory.

- This forecast shows a $96 \%$ decrease from the FY96 forecast of $74,890 \mathrm{~m}^{3}$, because less waste is expected to be shipped offsite for disposal due to decreases in funding.

- Four container types are forecast: MB-IV boxes ( $50 \%$ by volume), Medium boxes (42\%), Small boxes $(4 \%)$, and Other drums $(4 \%)$.

- $100 \%$ of the LLW has the physical form of debris: activated metal, contaminated metal, plastic/rubber, and heterogeneous.

\section{- Hazardous Waste}

- No hazardous waste is expected from Brookhaven National Laboratory for management by the CWC. 


\section{GENERATORS:}

Ames Laboratory-Ames, Iowa - Argonne National Laboratory-East - Bates Accelerator-Massachusetts - Battelle Columbus Laboratories - Bettis Atomic Power-Laboratory - Bettis Atomic Power-Shipyards - Brookhaven National Laboratory - Fermi National Accelerator Laboratory - General Atomics - Knolls Atomic Power-Laboratory · Knolls Atomic Power-Shipyards - Lawrence Berkeley Laboratory - Paducah Energy Systems - Pearl Harbor Naval Shipyards Portsmouth Energy Systems - Portsmouth Naval Shipyards - Princeton Plasma Physics Laboratory · Puget Sound Naval Shipyards - Rockwell-Canoga Park - Rocky Flats - Stanford Linear Accelerator Center - University of California-Davis .

University of Utah

\section{PROGRAMS:}

Analytical Services · EM-40 · Facility Transitions $\cdot$ Landlord $\cdot$ Liquid Effluent $\cdot$ NP $\cdot$ Offsite $\cdot$ PNNL $\cdot$ RCRA $\cdot$ Solid Waste - SNF - TWRS

\begin{tabular}{|c|c|}
\hline $\begin{array}{c}\text { CHARACTERISTICS: } \\
\text { CH_LLMW } \cdot \text { RH_LLMW } \cdot \text { CH_TRU(M) }) \text { RH_TRU(M) } \\
\text { GTC III } \cdot \text { LLW } \cdot \text { HAZ }\end{array}$ & $\begin{array}{c}\text { CONTAINERS: } \\
\text { CH_LLMW } \cdot \text { RH_LLMW } \cdot \text { CH_TRU(M) } \\
\text { RH_TRU(M) } \cdot \text { GTC III } \cdot \text { LLW } \cdot \text { HAZ }\end{array}$ \\
\hline CH_LLMW $\cdot$ RH_LLMW $\cdot$ CH_TRU(M) $\cdot$ RH_TRU(M) $\cdot$ GTC III $\cdot$ LLW $\cdot$ HAZ \\
\hline Wome $\cdot$ Contents $\cdot$ Web Site Map $\cdot$ Glossary $\cdot$ Help $\cdot$ Reports $\cdot$ Data Requests $\cdot$ Feedback Form
\end{tabular}

NOTICE: This page is provided subject to our disclaimer. Contact: Oscar Valero at (509) 373-4752.

HNF-EP-0918 rev. 1 Approved for public release; distribution is unlimited. 
The : 


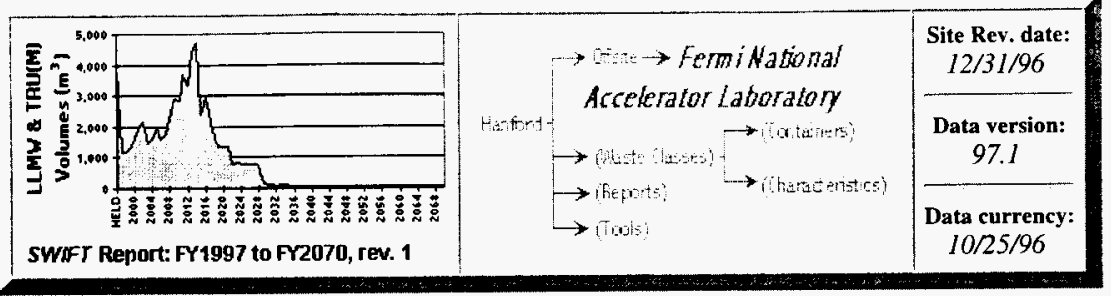

\section{Offsite - Fermi National Accelerator Laboratory}

\section{Contents}

》 Highlights

» Annual Volumes

»Comparison to Previous

Baseline(s)

» Background
" Forecast Assumptions and Comments

" Other Fermi National Accelerator Laboratory Forecast Data

»Detailed Forecast Data

\section{Highlights}

- The forecast life cycle for the Fermi National Accelerator Laboratory generator ends in 2027.

- No LLMW and TRU(M) waste is forecast from this generator.

- Only LLW is included in this forecast of solid waste to be shipped to Hanford.

\section{Annual Volumes}

\section{Annual Baseline Volumes}

No LLMW or TRU(M) waste is expected from this generator.

\section{Annual Baseline by Waste Class}

Not applicable.

\section{Comparison to Previous Baseline(s)}

As in FY96, no LLMW or TRU(M) waste is forecast by the Fermi National Accelerator Laboratory.

Comparison to Previous Baseline(s) by Waste Class 


\begin{tabular}{|c|c|c|c|}
\hline $\begin{array}{l}\text { Comparison: } \\
\text { Yaste Cless }\end{array}$ & $\begin{array}{c}\text { Fr97.1 } \\
\text { Forecast } \\
\text { (ms) }\end{array}$ & $\begin{array}{c}\text { FY97.0 } \\
\text { Forecast } \\
\left(\mathrm{m}^{2}\right)\end{array}$ & $\begin{array}{c}\text { FY96 } \\
\text { Forecast } \\
\text { (m') }\end{array}$ \\
\hline$L L W$ & 1,520 & 1,520 & 3.350 \\
\hline 7oral & 1,520 & 1,520 & 3.750 \\
\hline
\end{tabular}

Sum of totals may not add due to rounding: numbers over $10 \mathrm{~m}^{3}$ are rounded to the nearest $10 \mathrm{~m}^{3}$, numbers less than $10 \mathrm{~m}^{3}$ are rounded to integers, non-zero numbers less than 1 are rounded to 1 .

\section{Background}

The mission of Fermi National Accelerator Laboratory is to provide resources to conduct basic research in high-energy physics and related disciplines. The Fermi lab facility consists of a series of proton accelerators which became operational in 1972, producing higher energy protons than any other accelerator in the world. Beam losses from normal operations of the accelerators activate accelerator components and equipment. These components and equipment become waste when they fail and are removed or are no longer needed. Small volumes of protective clothing are generated by technicians working on contaminated equipment or in contamination areas.

\section{Forecast Assumptions and Comments}

The assumptions for this forecast are that radioactive waste will continue to be generated in approximately the same volumes as previous years and that nothing unforeseen will happen to increase the volumes. It is also assumed that the DOE will provide the necessary funds to ship the waste as it is generated.

\section{Other Forecast Data}

\section{- Low Level Waste}

- A total of $1,520 \mathrm{~m}^{3}$ of LLW is expected from the Fermi National Accelerator Laboratory.

- This forecast shows a 55\% decrease from the FY96 forecast of $3,350 \mathrm{~m}^{3}$, because the life cycle has been reduced from 2070 in FY96 to 2027 for FY97.

- 77\% of this volume will be contained in Small boxes, and the rest will use 208 liter drums.

- Physical waste forms include inorganic solids $(4 \%)$, soil/gravel $(3 \%)$, organic solids ( $1 \%)$, and debris $(92 \%)$ - of which activated metals compose $76 \%$.

\section{- Hazardous Waste}

- No hazardous waste is expected from Fermi for management by the CWC. 


\section{GENERATORS:}

Ames Laboratory-Ames, Iowa - Argonne National Laboratory-East - Bates Accelerator-Massachusetts · Battelle Columbus Laboratories - Bettis Atomic Power-Laboratory - Bettis Atomic Power-Shipyards · Brookhaven National Laboratory - Fermi National Accelerator Laboratory - General Atomics - Knolls Atomic Power-Laboratory · Knolls Atomic Power-Shipyards - Lawrence Berkeley Laboratory - Paducah Energy Systems - Pearl Harbor Naval Shipyards . Portsmouth Energy Systems · Portsmouth Naval Shipyards · Princeton Plasma Physics Laboratory · Puget Sound Naval Shipyards - Rockwell-Canoga Park - Rocky Flats · Stanford Linear Accelerator Center - University of California-Davis .

University of Utah

\section{PROGRAMS:}

Analytical Services · EM-40 - Facility Transitions - Landlord - Liquid Effluent - NP · Offsite · PNNL - RCRA - Solid Waste - SNF . TWRS

CHARACTERISTICS:
CH_LLMW $\cdot$ RH_LLMW $\cdot$ CH_TRU(M) $\cdot$ RH_TRU(M)
GTC III $\cdot$ LLW $\cdot$ HAZ

WASTE CLASSES:

CH_LLMW $\cdot$ RH_LLMW $\cdot$ CH_TRU(M) $\cdot$ RH_TRU(M) $\cdot$ GTC III $\cdot$ LLW $\cdot$ HAZ
CONTAINERS:

CH_LLMW $\cdot$ RH_LLMW $\cdot$ CH_TRU(M) . RH_TRU(M) $\cdot$ GTC III $\cdot$ LLW $\cdot$ HAZ

Home · Contents · Web Site Map · Glossary · Help · Reports · Data Requests · Feedback Form

NOTICE: This page is provided subject to our disclaimer. Contact: Oscar Valero at (509) 373-4752.

HNF-EP-0918 rev. I Approved for public release; distribution is unlimited. 
$9730: \ldots \cdots \cdots$ 


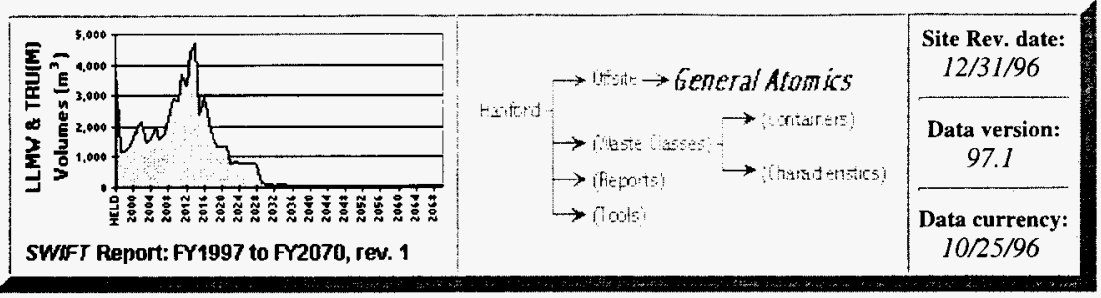

\section{Offsite - General Atomics}

\section{Contents}

» Highlights

"Annual Volumes

»Comparison to Previous Baseline(s)

$\gg$ Background
》 Forecast Assumptions and Comments

»Other General Atomics Forecast Data

"Detailed Forecast Data

\section{Highlights}

- The forecast life cycle for the General Atomics generator ends in 1999.

- A total of $7 \mathrm{~m}^{3}$ of LLMW is forecast from this generator for $3 \%$ of the Offsite total.

- This forecast shows a $133 \%$ increase over the FY96 forecast of $3 \mathrm{~m}^{3}$, due to the availability of more definitive information and that General Atomics is under contract with DOE to complete the Hot Cell D\&D project in FY2000.

- Only CH_LLMW is included in this forecast of solid waste to be shipped to Hanford.

- This waste is projected to be contained in 208 liter drums only.

- Physical LLMW forms are debris (71\%) and lab packs (29\%).

- LLMW hazardous constituents are expected to be metals without mercury ( $63 \%$ by volume), organic (22\%), corrosive (12\%), and PCBs (4\%). 


\section{Waste Class Distribution}

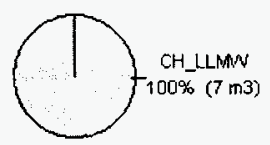

Total $=7 \mathrm{~m}^{3}$

\section{Physical Waste Form Distribution}

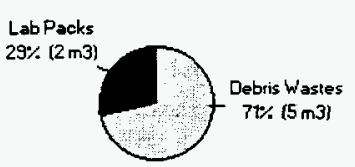

Total $=7 \mathrm{~m} 3$

\section{Hazardous Constituent Distribution}

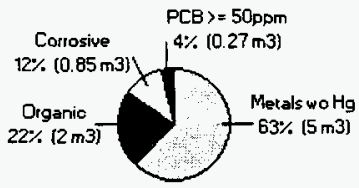

Total $=7 \mathrm{m3}$

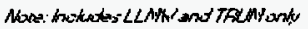

\section{Container Distribution}

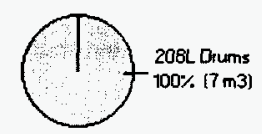

Total $=7 \mathrm{m3}$

Sum of totals may not add due to rounding: numbers over $10 \mathrm{~m}^{3}$ are rounded to the nearest $10 \mathrm{~m}^{3}$, numbers less than $10 \mathrm{~m}^{3}$ are rounded to integers, non-zero numbers less than 1 are rounded to 1 .

\section{Annual Volumes}

\section{Annual Baseline Volumes}




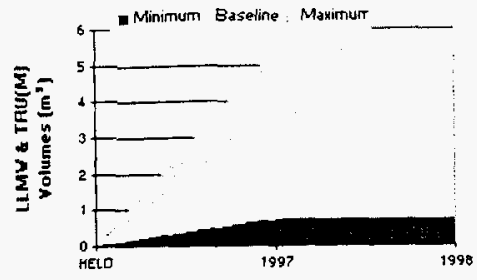

\section{Annual Baseline by Waste Class}

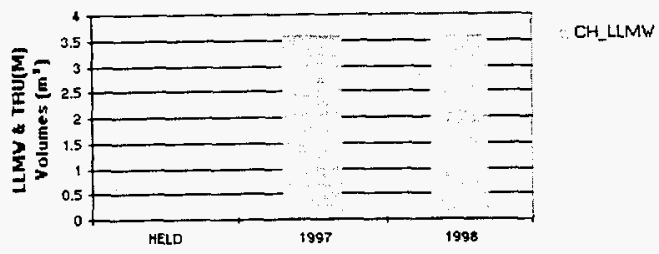

\section{Comparison to Previous Baseline(s)}

The FY97 forecast of $7 \mathrm{~m}^{3}$ of LLMW and TRU(M) waste shows a $133 \%$ increase over the FY96 forecast of $3 \mathrm{~m}^{3}$. This increase is due to the availability of more definitive information this year for forecast preparation. Additionally, General Atomics is under contract with DOE to complete the Hot Cell D\&D project in FY2000, which requires that the last waste shipment is to be made in 1999.

This year, the soil/gravel physical waste form is not expected. In 1996, that portion composed $30 \%$ of the volume.

While the 1997 hazardous constituents forecast shows metals without mercury, organic, corrosive, and PCBs, the 1996 forecast only expected metals without mercury constituents.

\section{Comparison to Previous Baseline(s) by Waste Class}

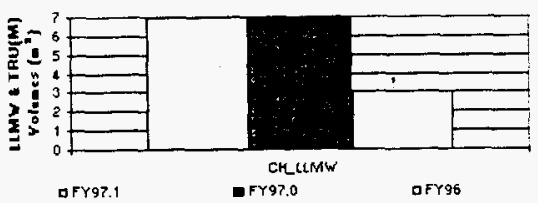




\begin{tabular}{|c|c|c|c|}
\hline $\begin{array}{l}\text { Gemeral Atomics Comparison: } \\
\text { Yaste Class }\end{array}$ & $\begin{array}{l}\text { FY97.I } \\
\text { Forecast } \\
\left(\mathrm{m}^{3}\right)\end{array}$ & $\begin{array}{l}\text { FYS7.0 } \\
\text { Forecast } \\
\left(\mathrm{m}^{3}\right)\end{array}$ & $\begin{array}{l}\text { FY96 } \\
\text { Forecast } \\
\text { [m] }\end{array}$ \\
\hline EH LLMW' & 7 & 7 & 3 \\
\hline suspory & 7 & 7 & 3 \\
\hline LLW & 660 & 660 & 850 \\
\hline Tord & 670 & 670 & 150 \\
\hline
\end{tabular}

Sum of totals may not add due to rounding: numbers over $10 \mathrm{~m}^{3}$ are rounded to the nearest $10 \mathrm{~m}^{3}$, numbers less than $10 \mathrm{~m}^{3}$ are rounded to integers, non-zero numbers less than 1 are rounded to 1 .

\section{Background}

The mission of General Atomics is to decontaminate and decommission the Hot Cell. The objective is to remove all radiologic and other contamination prior to the release of the site to unrestricted use.

\section{Forecast Assumptions and Comments}

The assumptions for this forecast are continued DOE funding consistent with project completion in FY2000, and the waste definitions will not change from those defined in the Hot Cell Decommissioning Plan.

The minimum and maximum ranges for this waste are $20 \%$ and $150 \%$.

\section{Other Forecast Data}

\section{- Low Level Waste}

- A total of $660 \mathrm{~m}^{3}$ of LLW is expected from General Atomics.

- This forecast shows a $22 \%$ decrease from the FY96 forecast of $850 \mathrm{~m}^{3}$, because of availability of more definitive information.

- $94 \%$ of the LLW will be shipped in Small Boxes, while $6 \%$ of the volume will be MB-IV boxes and Other drums.

- $100 \%$ of the LLW has the physical form of debris.

\section{- Hazardous Waste}

- No hazardous waste is expected from General Atomics for management by the CWC. 


\section{GENERATORS:}

Ames Laboratory-Ames, Iowa - Argonne National Laboratory-East - Bates Accelerator-Massachusetts - Battelle Columbus Laboratories · Bettis Atomic Power-Laboratory - Bettis Atomic Power-Shipyards - Brookhaven National Laboratory · Fermi National Accelerator Laboratory · General Atomics · Knolls Atomic Power-Laboratory - Knolls Atomic Power-Shipyards - Lawrence Berkeley Laboratory - Paducah Energy Systems . Pearl Harbor Naval Shipyards · Portsmouth Energy Systems · Portsmouth Naval Shipyards · Princeton Plasma Physics Laboratory - Puget Sound Naval Shipyards - Rockwell-Canoga Park - Rocky Flats - Stanford Linear Accelerator Center · University of California-Davis - University of Utah

\section{PROGRAMS:}

Analytical Services - EM-40 - Facitity Transitions - Landlord - Liquid Effluent · NP · Offsite - PNNL - RCRA · Solid Waste $\cdot$ SNF $\cdot$ TWRS

\begin{tabular}{|c|c|}
\hline $\begin{array}{c}\text { CHARACTERISTICS: } \\
\text { CH_LLMW } \cdot \text { RH_LLMW } \cdot \text { CH_TRU(M) } \cdot \text { RH_TRU(M) } \\
\text { GTC III } \cdot \text { LLW } \cdot \text { HAZ }\end{array}$ & $\begin{array}{c}\text { CONTAINERS: } \\
\text { CH_LLMW } \cdot \text { RH_LLMW } \cdot \text { CH_TRU(M) }^{\prime} \cdot \\
\text { RH_TRU(M) } \cdot \text { GTC III } \cdot \text { LLW } \cdot \text { HAZ }\end{array}$ \\
\hline \multicolumn{2}{|c|}{$\begin{array}{c}\text { WASTE CLASSES: } \\
\text { CH LLMW } \cdot \text { RH LLMW } \cdot \text { CH TRU(M) } \cdot \text { RH TRU(M) } \cdot \text { GTC III } \cdot \text { LLW } \cdot \text { HAZ }\end{array}$} \\
\hline
\end{tabular}

NOTICE: This page is provided subject to our disclaimer. Contact: Oscar Valero at (509) 373-4752.

HNF-EP-0918 rev. 1 Approved for public release; distribution is unlimited. 


$\therefore \quad \cdots+$ H.




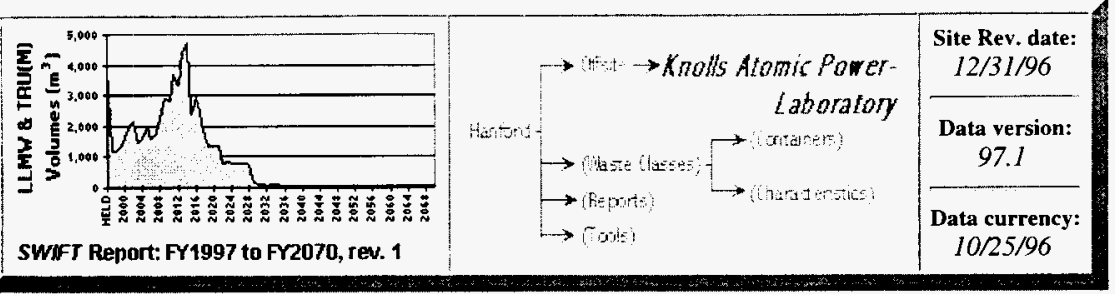

\section{Offsite - Knolls Atomic Power Laboratory}

\section{Contents}

» Highlights

» Annual Volumes

» Comparison to Previous Baseline(s)

» Background
» Forecast Assumptions and Comments

» Other Knolls Atomic Power Laboratory Forecast Data

» Detailed Forecast Data

\section{Highlights}

- The forecast life cycle for the Knolls Atomic Power Laboratory generator ends in 2001.

- A total of $20 \mathrm{~m}^{3}$ of LLMW is forecast from this generator for $10 \%$ of the Offsite total.

- This forecast shows a $100 \%$ increase over the FY96 forecast of $10 \mathrm{~m}^{3}$, due to improvements in forecasting accuracy.

- $\mathrm{CH}_{-}$LLMW is the primary waste class generated, representing $75 \%$ of the total waste volume.

- Waste is to be contained in 208 liter drums ( $70 \%$ by volume), Small boxes ( $25 \%$ ), and Other drums $(5 \%)$.

- LLMW physical forms will be $44 \%$ (by volume) special waste, $34 \%$ debris, $16 \%$ inorganic solids, and $6 \%$ lab packs.

- LLMW hazardous constituents are expected to be metals without mercury ( $60 \%$ by volume), metals with mercury (30\%), and several other hazardous constituents (10\%). 


\section{Waste Class Distribution}

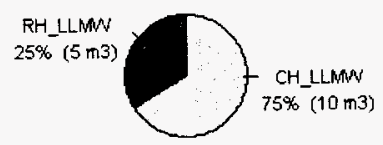

Total $=\mathbf{2 0} \mathbf{m} 3$

Physical Waste Form Distribution

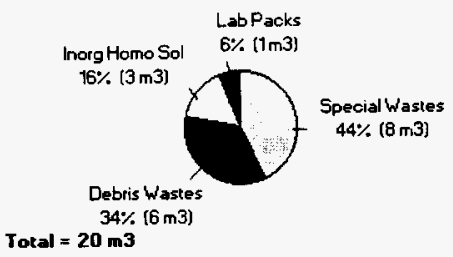

Hazardous Constituent Distribution

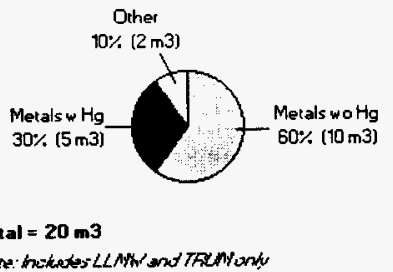

\section{Container Distribution}

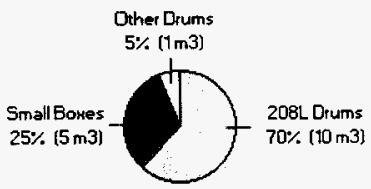

Total $=20 \mathrm{m3}$

Sum of totals may not add due to rounding: numbers over $10 \mathrm{~m}^{3}$ are rounded to the nearest $10 \mathrm{~m}^{3}$, numbers less than $10 \mathrm{~m}^{3}$ are rounded to integers, non-zero numbers less than $I$ are rounded to 1.

\section{Annual Volumes}

\section{Annual Baseline Volumes}




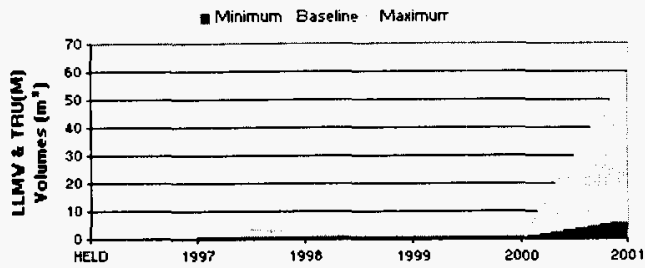

\section{Annual Baseline by Waste Class}

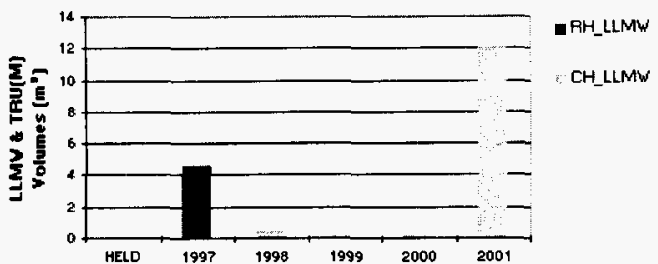

\section{Comparison to Previous Baseline(s)}

The FY97 forecast of $20 \mathrm{~m}^{3}$ of LLMW waste shows a $100 \%$ increase over the FY96 forecast of $10 \mathrm{~m}^{3}$. This increase is due to improvements in forecasting accuracy as a result of past experience regarding the generation of these wastes.

\section{Comparison to Previous Baseline(s) by Waste Class}

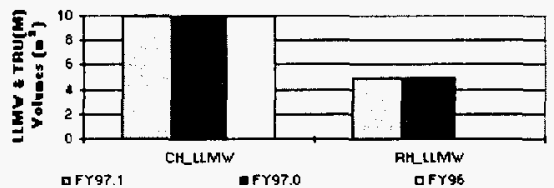

\begin{tabular}{|c|c|c|c|}
\hline $\begin{array}{l}\text { Knolls Atomic Pover-Labolatory Comparison: } \\
\text { Vaste Class }\end{array}$ & $\begin{array}{l}\text { FYg7.1 } \\
\text { Forecast } \\
\text { [m'] }\end{array}$ & $\begin{array}{l}\text { FY97.0 } \\
\text { Forecast } \\
\text { [m'] }\end{array}$ & $\begin{array}{c}\text { FYgis } \\
\text { Forecast } \\
\text { [m² }\end{array}$ \\
\hline CH LLMW & 10 & 10 & 10 \\
\hline RH LLMW & 5 & 5 & 0 \\
\hline Srabropy & 20 & 20 & se \\
\hline Tord & 20 & 28 & ta \\
\hline
\end{tabular}

Sum of totals may not add due to rounding: numbers over $10 \mathrm{~m}^{3}$ are rounded to the nearest $10 \mathrm{~m}^{3}$, numbers less than $10 \mathrm{~m}^{3}$ are rounded to integers, non-zero numbers less than 1 are rounded to 1 .

\section{Background}

Knolls Atomic Power Laboratory is engaged in research and development for the design and 
operation of naval nuclear propulsion plants. The facility includes machine shops, waste handling facilities, a boiler house, and chemistry, physics, and metallurgy laboratories. The activities related to development of naval propulsion systems generates various forms of wastes.

\section{Forecast Assumptions and Comments}

The minimum and maximum percentages are $39 \%$ and $395 \%$ of the baseline volume. This large fluctuation indicates that the shipped volumes may tend to be higher than the baseline forecast. These percentages reflect uncertainty in waste generation rates, possible use of commercial facilities, and uncertain future shipment rates.

\section{Other Forecast Data}

- Low Level Waste

- No low level waste is expected from Knolls Atomic Power Laboratory for management by the CWC.

\section{- Hazardous Waste}

- No hazardous waste is expected from Knolls Atomic Power Laboratory for management by the CWC.

\section{GENERATORS:}

Ames Laboratory-Ames, Iowa - Argonne National Laboratory-East - Bates Accelerator-Massachusetts · Battelle Columbus Laboratories - Bettis Atomic Power-Laboratory - Bettis Atomic Power-Shipyards - Brookhaven National Laboratory - Fermi National Accelerator Laboratory · General Atomics - Knolls Atomic Power-Laboraton' Knolls Atomic Power-Shipyards · Lawrence Berkeley Laboratory · Paducah Energy Systems · Pearl Harbor Naval Shipyards · Portsmouth Energy Systems · Portsmouth Naval Shipyards - Princeton Plasma Physics Laboratory · Puget Sound Naval Shipyards - Rockwell-Canoga Park - Rocky Flats - Stanford Linear Accelerator Center - Unjversity of California-Davis . University of Utah

\section{PROGRAMS:}

Analytica\} Services · EM-40 · Facility Transitions - Landlord · Liquid Effluent $\cdot$ NP · Offsite $\cdot$ PNNL $\cdot$ RCRA $\cdot$ Solid Waste $\cdot$ SNF . TWRS

\begin{tabular}{|c|c|}
\hline $\begin{array}{l}\text { CHARACTERISTICS: } \\
\text { CH_LLMW } \cdot \text { RH_LLMW } \cdot \text { CH_TRU(M) } \cdot \text { RH_TRU(M) } \\
\text { GTC III } \cdot \text { LLW } \cdot \text { HAZ }\end{array}$ & $\begin{array}{l}\text { CONTAINERS: } \\
\text { CH_LLMW } \cdot \text { RH_LLMW } \cdot \text { CH_TRU(M) } \\
\text { RH_TRU(M) } \cdot \text { GTC III } \cdot \text { LLW } \cdot \text { HAZ }\end{array}$ \\
\hline \multicolumn{2}{|c|}{ WASTE CLASSES: } \\
\hline
\end{tabular}

NOTICE: This page is provided subject to our disclaimer. Contact: Oscar Valero at (509) 373-4752.

HNF-EP-0918 rev, 1 Approved for public release; distribution is unlimited. 


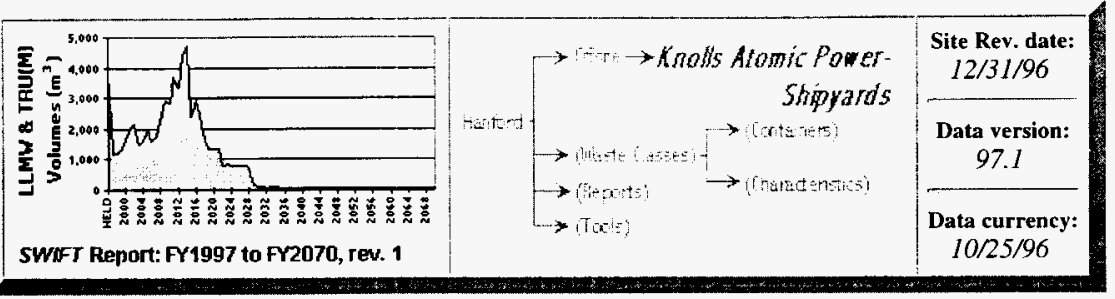

\section{Offsite - Knolls Atomic Power - Shipyards}

\section{Contents}

» Highlights

» Annual Volumes

» Comparison to Previous

Baseline(s)

» Background

\section{Highlights}

- The forecast life cycle for the Knolls Atomic Power Shipyards generator ends in 2004.

- No LLMW or TRU(M) waste is expected from Knolls Atomic Power Shipyards.

- Only LLW is included in this forecast of solid waste to be shipped to Hanford.

\section{Annual Volumes}

\section{Annual Baseline Volumes}

No LLMW or TRU(M) waste is expected from this generator.

\section{Annual Baseline by Waste Class}

Not applicable.

\section{Comparison to Previous Baseline(s)}

As in FY96, there is no LLMW or TRU(M) waste forecast in FY97 or FY97.1.

\section{Comparison to Previous Baseline(s) by Waste Class}




\begin{tabular}{|c|c|c|c|}
\hline $\begin{array}{l}\text { Knolls Atomic Pover-Shipgards Comparison: } \\
\text { Vaste Class }\end{array}$ & $\begin{array}{l}\text { FY97.1 } \\
\text { Forecast } \\
\text { (m') }\end{array}$ & $\begin{array}{c}\text { FY97.0 } \\
\text { Forecast } \\
\text { (m') }\end{array}$ & $\begin{array}{l}\text { FY96 } \\
\text { Forecast } \\
\text { (m') }\end{array}$ \\
\hline LLW & 320 & 320 & 240 \\
\hline Taral & 520 & 200 & 210 \\
\hline
\end{tabular}

Sum of totals may not add due to rounding: numbers over $10 \mathrm{~m}^{3}$ are rounded to the nearest $10 \mathrm{~m}^{3}$, numbers less than $10 \mathrm{~m}^{3}$ are rounded to integers, non-zero numbers less than 1 are rounded to 1.

\section{Background}

Knolls Atomic Power Shipyards is engaged in defueling and deactivation operations of nuclear vessels.

\section{Forecast Assumptions and Comments}

The forecast assumes that the reactor components are removed during defueling and deactivation operations.

\section{Other Forecast Data}

\section{- Low Level Waste}

- A total of $320 \mathrm{~m}^{3}$ of LLW is expected from Knolls Atomic Power-Shipyard.

- This forecast shows a $33 \%$ increase over the FY96 forecast of $240 \mathrm{~m}^{3}$, due to inclusion of some additional waste generating components into the forecast.

- Extra-Large boxes will hold $47 \%$ of this waste, and Large and Medium boxes will split the remaining volume by $27 \%$ and $26 \%$, respectively.

- $100 \%$ of the physical LLW form is equally split between activated and contaminated metal debris.

\section{- Hazardous Waste}

o No hazardous waste is expected from Knolls Atomic Power-Shipyard for management by the CWC. 


\section{GENERATORS:}

Ames Laboratory-Ames, Iowa - Argonne National Laboratory-East - Bates Accelerator-Massachusetts - Battelle Columbus Laboratories - Bettis Atomic Power-Laboratory · Bettis Atomic Power-Shipyards - Brookhaven National

Laboratory - Fermi National Accelerator Laboratory - General Atomics - Knolls Atomic Power-Laboratory - Knolls Atomic Power-Shipyards - Lawrence Berkeley Labosatory - Paducah Energy Systems - Pearl Harbor Naval Shipyards . Portsmouth Energy Systems · Portsmouth Naval Shipyards · Princeton Plasma Physics Laboratory · Puget Sound Naval Shipyards - Rockwell-Canoga Park - Rocky Flats - Stanford Linear Accelerator Center - University of California-Davis . University of Utah

PROGRAMS:

Analytical Services · EM-40 · Facility Transitions · Landlord - Liquid Effluent - NP · Offsite $\cdot$ PNNL $\cdot$ RCRA $\cdot$ Solid Waste - SNF - TWRS

\begin{tabular}{|c|c|}
\hline $\begin{array}{l}\text { CHARACTERISTICS: } \\
\text { CH_LLMW } \cdot \text { RH_LLMW } \cdot \text { CH_TRU(M) } \cdot \text { RH_TRU(M) } \\
\text { GTC III } \cdot \text { LLW } \cdot \text { HAZ }\end{array}$ & $\begin{array}{c}\text { CONTAINERS: } \\
\text { CH_LLMW } \cdot \text { RH_LLMW } \cdot \text { CH_TRU(M) } \\
\text { RH_TRU(M) } \cdot \text { GTC III } \cdot \text { LLW } \cdot \text { HAZ }\end{array}$ \\
\hline $\begin{array}{l}\text { WASTE C } \\
\text { CH_LLMW } \cdot \mathrm{RH}_{-} \text {LLMW } \cdot \mathrm{CH}_{-} \text {TRU(M) }\end{array}$ & $\mathrm{U}(\mathbf{M}) \cdot \mathrm{GTC}$ III $\cdot \mathbf{L L W} \cdot \mathrm{HAZ}$ \\
\hline
\end{tabular}

NOTICE: This page is provided subject to our disclaimer. Contact: Oscar Valero at (509) 373-4752.

HNF-EP-0918 rev. 1 Approved for public release; distribution is unlimited. 


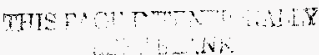

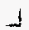




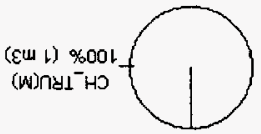

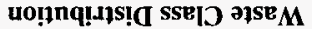

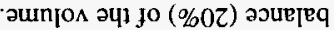

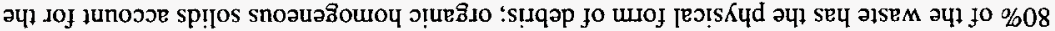

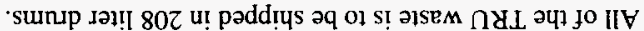

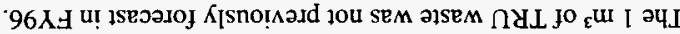

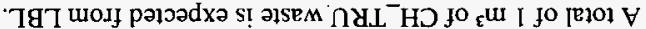

'000Z u! poloadxa Ќ

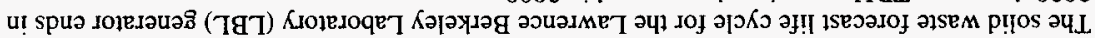

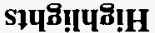

$$
\text { punolôxวeg * }
$$

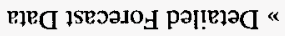

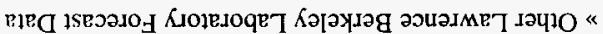

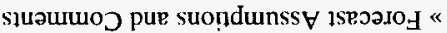

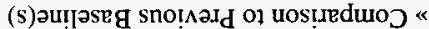
Sounjo $\Lambda$ jenuUV *

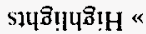

sұuวฺนо

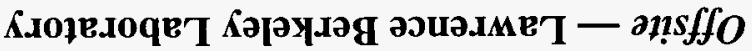

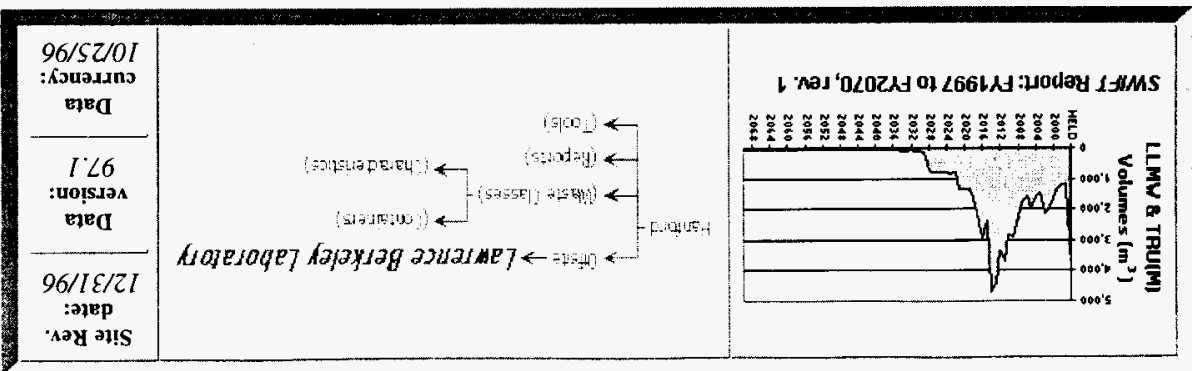




\section{Physical Waste Form Distribution}

Dighome Sol

$20 \%[0.2 \mathrm{~m} 3]$

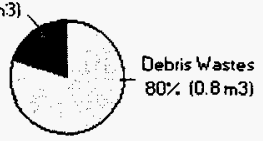

Total $=1 \mathrm{~m} 3$

\section{Container Distribution}

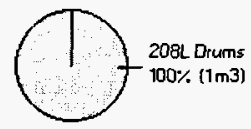

Total = $1 \mathrm{~m} 3$

Sum of totals may not add due to rounding: numbers over $10 \mathrm{~m}^{3}$ are rounded to the nearest $10 \mathrm{~m}^{3}$, numbers less than $10 \mathrm{~m}^{3}$ are rounded to integers, non-zero numbers less than 1 are rounded to 1.

\section{Annual Volumes}

\section{Annual Baseline Volumes}

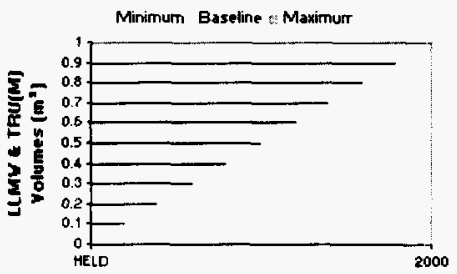

\section{Annual Baseline by Waste Class}




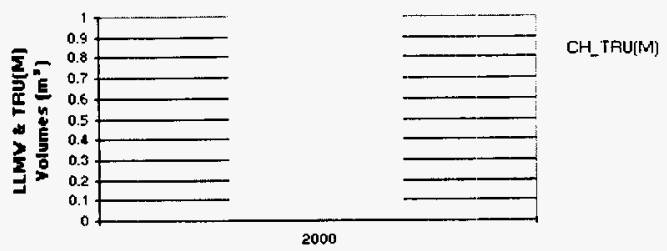

\section{Comparison to Previous Baseline(s)}

In comparing the LLW for LBL, the FY97 forecast of $11,520 \mathrm{~m}^{3}$ shows a $6 \%$ increase over the FY96 forecast of $10,870 \mathrm{~m}^{3}$. This increase is because this year LBL used a four-year average to derive the generation rate of $15 \mathrm{~m}^{3}$ per year. Last year's average of $14 \mathrm{~m}^{3}$ was based on a three-year average. The difference is well within tolerable error margins.

\section{Comparison to Previous Baseline(s) by Waste Class}

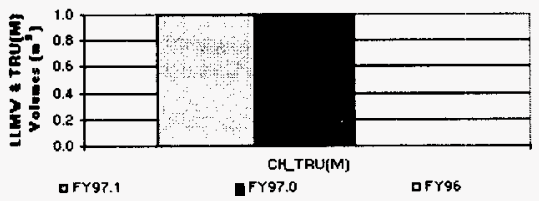

\begin{tabular}{|c|c|c|c|}
\hline $\begin{array}{l}\text { Lawrence Berkeley Laboratory Comparison: } \\
\text { Yaste Class }\end{array}$ & $\begin{array}{l}\text { FY97.1 } \\
\text { Forecast } \\
\left(\mathrm{m}^{5}\right)\end{array}$ & $\begin{array}{c}\text { FY97.0 } \\
\text { Forecast } \\
\left(\mathrm{m}^{\prime}\right)\end{array}$ & $\begin{array}{l}\text { FY96 } \\
\text { Forecast } \\
\text { (m") }\end{array}$ \\
\hline $\mathrm{CH}$ TRU(M) & 1 & 1 & 0 \\
\hline supropt & 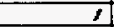 & $i$ & $\theta$ \\
\hline$L L W$ & 11,520 & 11,520 & 10.870 \\
\hline Tory & $11.5 n$ & 11.530 & raste \\
\hline
\end{tabular}

Sum of totals may not add due to rounding: numbers over $10 \mathrm{~m}^{3}$ are rounded to the nearest $10 \mathrm{~m}^{3}$, numbers less than $10 \mathrm{~m}^{3}$ are rounded to integers, non-zero numbers less than 1 are rounded to 1.

\section{Background}

LBL is a multi-purpose science research laboratory with emphasis on energy sciences, general sciences, life sciences, nuclear sciences, environmental sciences, earth sciences, material sciences, and computer sciences. During the research processes, certain types of low level radioactive waste are generated.

\section{Forecast Assumptions and Comments}

No variance in volume was forecast (minimum and maximum ranges are both $100 \%$ ).

\section{Other Forecast Data}




\section{- Low Level Waste}

- A total of $11,520 \mathrm{~m}^{3}$ of LLW is expected from LBL.

- This forecast shows a $6 \%$ increase over the FY96 forecast of $10,870 \mathrm{~m}^{3}$, due a slightly different forecasting method.

$093 \%$ of the LLW will arrive in Extra-Large boxes; the remaining 7\% will be shipped in 208 liter drums and $\mathrm{MB}-\mathrm{V}$ boxes.

- LLW forms are nearly all $(98 \%)$ debris $-86 \%$ of which is inorganic nonmetal debris. Lab packs essentially represent the other $2 \%$, with trace amounts of inorganic solids and soil/gravel.

\section{- Hazardous Waste}

- No hazardous waste is expected from LBL for management by the CWC.

\section{GENERATORS:}

Ames Laboratory-Ames, Iowa - Argonne National Laboratory-East - Bates Accelerator-Massachusetts - Battelle Columbus Laboratories - Bettis Atomic Power-Laboratory - Bettis Atomic Power-Shipyards - Brookhaven National Laboratory - Fermi National Accelerator Laboratory · General Atomics - Knolls Atomic Power-Laboratory · Knolls Atomic Power-Shipyards · Lawrence Berkeley Laboratory - Paducah Energy Systems · Pearl Harbor Naval Shipyards · Portsmouth Energy Systems · Portsmouth Naval Shipyards - Princeton Plasma Physics Laboratory - Puget Sound Naval Shipyards - Rockwell-Canoga Park - Rocky Flats - Stanford Linear Accelerator Center - University of California-Davis · University of Utah

\section{PROGRAMS:}

Analytical Services · EM-40 - Facility Transitions - Landlord - Liquid Effluent - NP · Offsite · PNNL · RCRA - Solid Waste $\cdot$ SNF $\cdot$ TWRS

\begin{tabular}{|c|c|}
\hline $\begin{array}{c}\text { CHARACTERISTICS: } \\
\text { CH_LLMW } \cdot \text { RH_LLMW } \cdot \text { CH_TRU(M) } \cdot \text { RH_TRU(M) } \\
\text { GTC III } \cdot \text { LLW } \cdot \text { HAZ }\end{array}$ & $\begin{array}{c}\text { CONTAINERS: } \\
\text { CH_LLMW } \cdot \text { RH_LLMW } \cdot \text { CH_TRU(M) } \\
\text { RH_TRU(M) } \cdot \text { GTC III } \cdot \text { LLW } \cdot \text { HAZ }\end{array}$ \\
\hline CH_LLMW $\cdot$ RH_LLMW $\cdot$ CH_TRU(M) $\cdot$ RH_TRU(M) $\cdot$ GTC III $\cdot$ LLW $\cdot$ HAZ \\
\hline Home $\cdot$ Contents $\cdot$ Web Site Map $\cdot$ Glostary $\cdot$ Help $\cdot$ Reports $\cdot$ Data Requests $\cdot$ Feedback Form
\end{tabular}

NOTICE: This page is provided subject to our disclaimer. Contact: Oscar Valero at (509) 373-4752. HNF-EP-0918 rev. 1 Approved for public release; distribution is unlimited. 


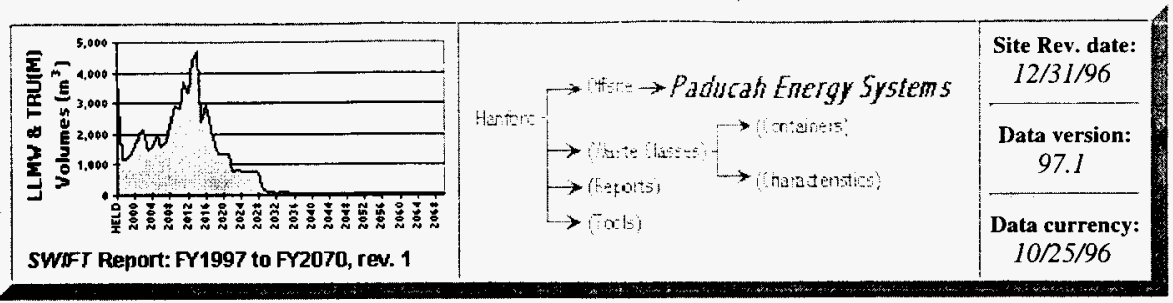

\section{Offsite — Paducah Energy Systems}

\section{Contents}

" Highlights

" Annual Volumes

» Comparison to Previous Baseline(s)

"Background
》 Forecast Assumptions and Comments

»Other Paducah Energy Systems Forecast Data

»Detailed Forecast Data

\section{Highlights}

- The solid waste forecast life cycle for the Paducah Energy Systems generator ends in 1998.

- $20 \mathrm{~m}^{3}$ of LLMW of waste is expected from Paducah Energy Systems.

- All of this volume will be contained in 322 liter drums.

- $100 \%$ of the LLMW has the physical form of contaminated metal debris.

- The LLMW hazardous constituents are $100 \%$ metals without mercury.

\section{Waste Class Distribution}

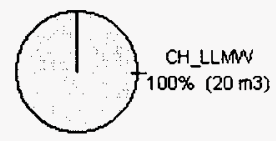

Total $=20 \mathrm{m3}$ 
Physical Waste Form Distribution

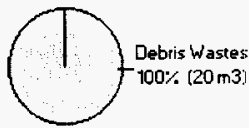

Total $=\mathbf{2 0} \mathrm{m3}$

\section{Hazardous Constituent Distribution}

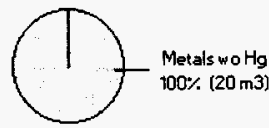

Total $=20 \mathrm{~m} 3$

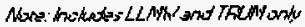

\section{Container Distribution}

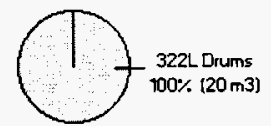

Toral $=\mathbf{2 0} \mathrm{m} 3$

Sum of totals may not add due to rounding; numbers over $10 \mathrm{~m}^{3}$ are rounded to the nearest $10 \mathrm{~m}^{3}$, numbers less than $10 \mathrm{~m}^{3}$ are rounded to integers, non-zero numbers less than 1 are rounded to 1 .

\section{Annual Volumes}

\section{Annual Baseline Volumes}

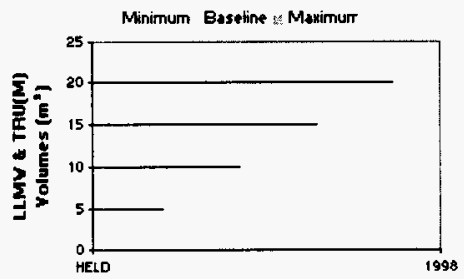

\section{Annual Baseline by Waste Class}




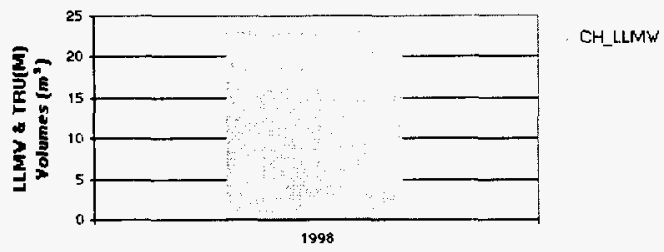

\section{Comparison to Previous Baseline(s)}

This forecast is a $20 \mathrm{~m}^{3}$ increase from the FY97.0 and FY96 versions due to the inclusion of the contaminated ash receivers to the 97.1 volumes.

\section{Comparison to Previous Baseline(s) by Waste Class}

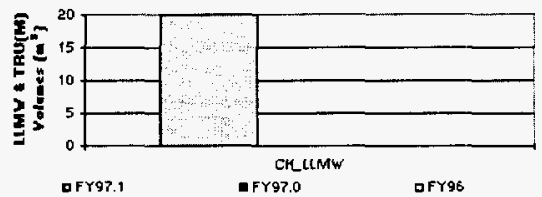

\begin{tabular}{|c|c|c|c|}
\hline $\begin{array}{l}\text { Paducah Energs Systems Comparison: } \\
\text { Yaste Class }\end{array}$ & $\begin{array}{c}\text { FY97.1 } \\
\text { Forecast } \\
\left(\mathrm{m}^{3}\right)\end{array}$ & $\begin{array}{c}\text { FY97.0 } \\
\text { Forecist } \\
\left(\mathrm{m}^{3}\right)\end{array}$ & $\begin{array}{c}\text { FY96 } \\
\text { Forecast } \\
\text { (mi) }\end{array}$ \\
\hline CHLLMW & 20 & 0 & 0 \\
\hline Seprored & 20 & $\Delta$ & $\theta$ \\
\hline LLW & 70 & 70 & 710 \\
\hline Toral & $s \theta$ & 70 & 710 \\
\hline
\end{tabular}

Sum of totals may not add due to rounding: numbers over $10 \mathrm{~m}^{3}$ are rounded to the nearest $10 \mathrm{~m}^{3}$, numbers less than $10 \mathrm{~m}^{3}$ are rounded to integers, non-zero numbers less than $/$ are rounded to $I$.

\section{Background}

Paducah Energy Systems is engaged in storage, treatment, and disposal of waste streams generated from Environmental Management and Enrichment Facilities projects at the Paducah Gaseous Diffusion Plant. In meeting the mission, LLW is generated continuously, in the form of ash and uranium precipitate. The LLMW is contaminated ash receivers constructed of carbon steel.

\section{Forecast Assumptions and Comments}

The LLMW minimum and maximum was not provided and is assumed to be $100 \%$.

\section{Other Forecast Data}

\section{- Low Level Waste}


- A total of $70 \mathrm{~m}^{3}$ of LLW is expected from Paducah Energy Systems.

- This LLW forecast shows a $90 \%$ decrease from the FY96 forecast of $710 \mathrm{~m}^{3}$, due primarily to the level of funding and the availability of other treatment and disposal options.

- 208 liter drums are expected to be used for $75 \%$ of the LLW, and MB-IV boxes will contain $25 \%$.

- $100 \%$ of the LLW has the physical form of organic particulates.

\section{- Hazardous Waste}

o No hazardous waste is expected from Paducah Energy Systems for management by the CWC.

\section{GENERATORS:}

Ames Laboratory-Ames, Iowa - Argonne National Laboratory-East - Bates Accelerator-Massachusetts - Battelle Columbus Laboratories - Bettis Atomic Power-Laboratory - Bettis Atomic Power-Shipyards - Brookhaven National Laboratory - Fermi National Accelerator Laboratory - General Atomics - Knolls Atomic Power-Laboratory - Knolls Atomic Power-Shipyards - Lawrence Berkeley Labotatory - Paducah Energy Systems - Pearl Harbor Naval Shipyards . Portsmouth Energy Systems - Portsmouth Naval Shipyards - Princeton Plasma Physics Laboratory - Puget Sound Naval Shipyards - Rockwell-Canoga Park - Rocky Flats - Stanford Linear Accelerator Center - University of California-Davis University of Utah

\section{PROGRAMS:}

Analytical Services · EM-40 - Facility Transitions · Landlord · Liquid Effluent · NP · Offsite $\cdot$ PNNL $\cdot$ RCRA $\cdot$ Solid Waste - SNF . TWRS

\begin{tabular}{|c|c|}
\hline $\begin{array}{c}\text { CHARACTERISTICS: } \\
\text { CH_LLMW } \cdot \text { RH_LLMW } \cdot \text { CH_TRU(M) } \cdot \text { RH_TRU(M) } \cdot \\
\text { GTC III } \cdot \text { LLW } \cdot \text { HAZ }\end{array}$ & $\begin{array}{c}\text { CONTAINERS: } \\
\text { CH_LLMW } \cdot \text { RH_LLMW } \cdot \text { CH_TRU(M) } \\
\text { RH_TRU(M) } \cdot \text { GTC III } \cdot \text { LLW } \cdot \text { HAZ }\end{array}$ \\
\hline \multicolumn{2}{|c|}{ WASTE CLASSES: } \\
\hline
\end{tabular}

NOTICE: This page is provided subject to our disclaimer. Contact: Oscar Valero at (509) 373-4752. HNF-EP-0918 rev. 1 Approved for public release; distribution is unlimited. 


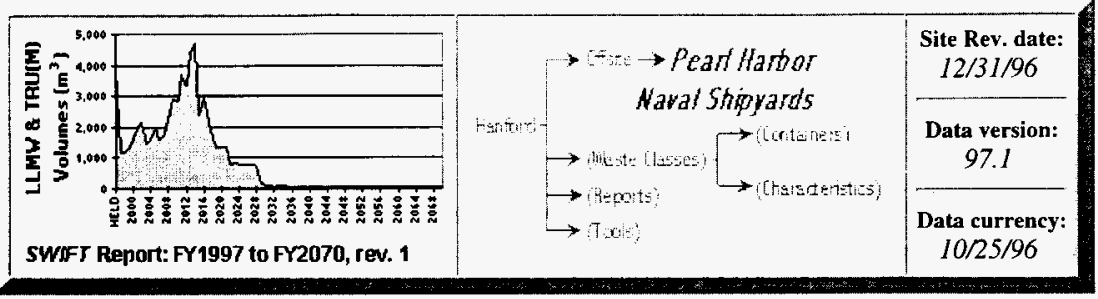

\section{Offsite - Pearl Harbor Naval Shipyards}

\section{Contents}

" Highlights

"Annual Volumes

»Comparison to Previous Baseline(s)

» Background
" Forecast Assumptions and Comments

»Other Pearl Harbor Naval Shipyards Forecast Data

»Detailed Forecast Data

\section{Highlights}

- The solid waste forecast life cycle for the Pearl Harbor generator starts in 2000 and ends in 2001.

- A total of $5 \mathrm{~m}^{3}$ of LLMW is expected from the Pearl Harbor Naval Shipyards.

- Only CH_LLMW is included in this forecast of solid waste to be shipped to Hanford.

- 208 liter drums will contain $100 \%$ of the LLMW.

- Two main physical waste forms are forecast: debris at $44 \%$ of the volume and organic solids at $41 \%$. Inorganic solids represent $10 \%$ of the waste and special waste represent $5 \%$.

- The LLMW hazardous constituents are $100 \%$ metals without mercury.

\section{Waste Class Distribution}

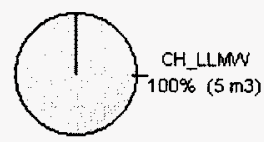

Total $=5 \mathrm{~ms}$ 
Physical Waste Form Distribution

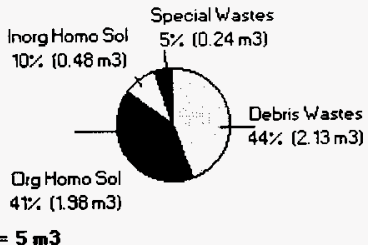

\section{Hazardous Constituent Distribution}

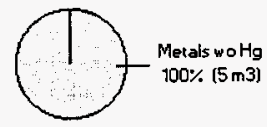

Total $=5 \mathrm{m3}$

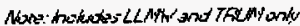

\section{Container Distribution}

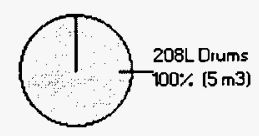

Total $=\mathbf{5} \mathbf{m 3}$

Sum of totals may not add due to rounding: numbers over $10 \mathrm{~m}^{3}$ are rounded to the nearest $10 \mathrm{~m}^{3}$, numbers less than $10 \mathrm{~m}^{3}$ are rounded to integers, non-zero numbers less than I are rounded to $I$.

\section{Annual Volumes}

\section{Annual Baseline Volumes}

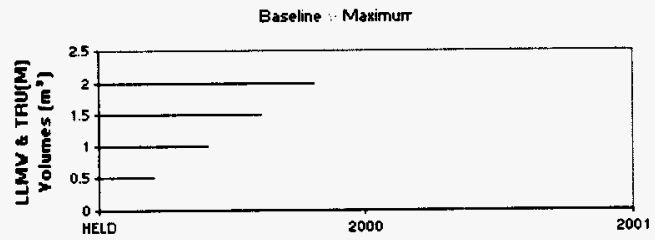

Annual Baseline by Waste Class 


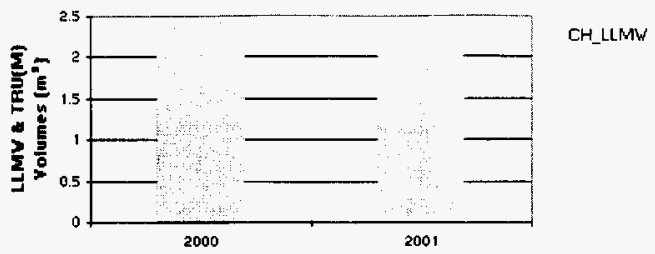

\section{Comparison to Previous Baseline(s)}

This forecast is similar to the FY96 forecast.

\section{Comparison to Previous Baseline(s) by Waste Class}

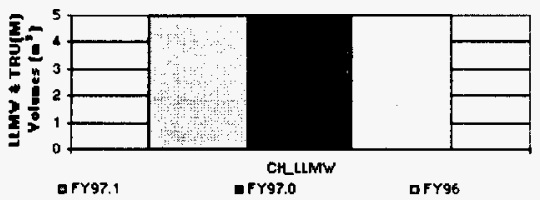

\begin{tabular}{|c|c|c|c|}
\hline $\begin{array}{l}\text { Pearl Harbor Naval Shipyards Comparison: } \\
\text { Yaste Class }\end{array}$ & $\begin{array}{c}\text { FY97.1 } \\
\text { Forecast } \\
\left(m^{3}\right)\end{array}$ & $\begin{array}{c}\text { FY97.0 } \\
\text { Forecast } \\
\text { (m²) }\end{array}$ & $\begin{array}{l}\text { FY96 } \\
\text { Forecast } \\
\text { (m') }\end{array}$ \\
\hline $\mathrm{CH}$ LLMW & 5 & 5 & 5 \\
\hline Subrares & 5 & 5 & 5 \\
\hline rotal & 5 & 5 & 5 \\
\hline
\end{tabular}

Sum of totals may not add due to rounding: numbers over $10 \mathrm{~m}^{3}$ are rounded to the nearest $10 \mathrm{~m}^{3}$, numbers less than $10 \mathrm{~m}^{3}$ are rounded to integers, non-zero numbers less than 1 are rounded to 1.

\section{Background}

Pearl Harbor Naval Shipyards is a U.S. Department of Navy facility that repairs, overhauls, and maintains Navy ships, including nuclear-powered ships.

\section{Forecast Assumptions and Comments}

The minimum and maximum percentages are assumed to be $100 \%$ of the baseline volume, since ranges were not provided.

This forecast is based on the Site Treatment Plan.

\section{Other Forecast Data}

- Low Level Waste

- As in FY96, no low level waste is expected from Pearl Harbor Naval Shipyards for 
management by the CWC.

\section{- Hazardous Waste}

o No hazardous waste is expected from Pearl Harbor Naval Shipyards for management by the CWC.

\section{GENERATORS:}

Ames Laboratory-Ames, lowa - Argonne National Laboratory-East - Bates Accelerator-Massachusetts · Battelle Columbus Laboratories - Bettis Atomic Power-Laboratory - Bettis Atomic Power-Shipyards - Brookhaven National Laboratory - Fermi National Accelerator Laboratory - General Atomics - Knolls Atomic Power-Laboratory - Knolls Atomic Power-Shipyards - Lawrence Berkeley Laboratory - Paducah Energy Systems - Pearl Harbor Naval Shipyards . Portsmouth Energy Systems · Portsmouth Naval Shipyards - Princeton Plasma Physics Laboratory · Puget Sound Naval Shipyards - Rockwell-Canoga Park - Rocky Flats - Stanford Linear Accelerator Center - University of California-Davis University of Utah

\section{PROGRAMS:}

Analytical Services · EM-40 · Facility Transitions - Landlord · Liquid Effluent · NP · Offsite · PNNL · RCRA · Solid Waste $\cdot$ SNF $\cdot$ TWRS

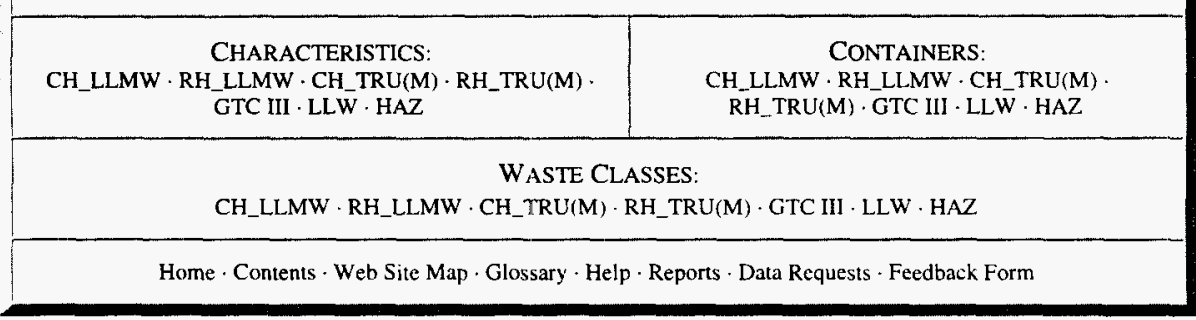

NOTICE: This page is provided subject to our disclaimer. Contact: Oscar Valero at (509) 373-4752

HNF.EP-0918 rev. 1 Approved for public release; distribution is unlimited. 


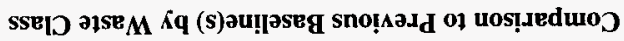

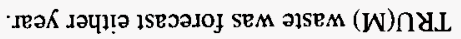

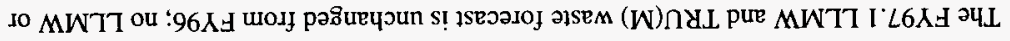

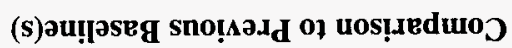

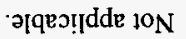

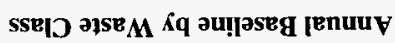

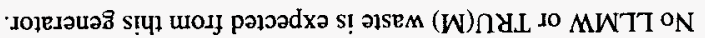

saunjo $\Lambda$ ou!jaseg jenuuv

saunjo $\Lambda$ jenuuv

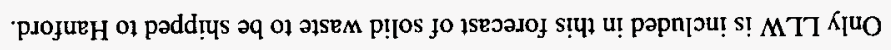

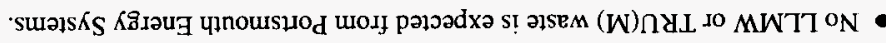

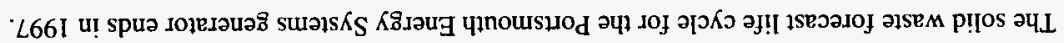

ราบชิ!โบี!!H

puno.8ิxpeg «

हाएव iseวajo

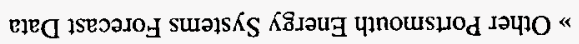
siuəuruo pur suoṇdunss $\forall$ ISeวə10

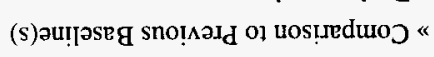
səun $0 \Lambda$ [enurV « ร1บชิ!กบฮิ!H «

słuวาน0อ

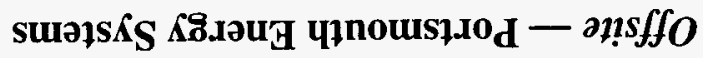

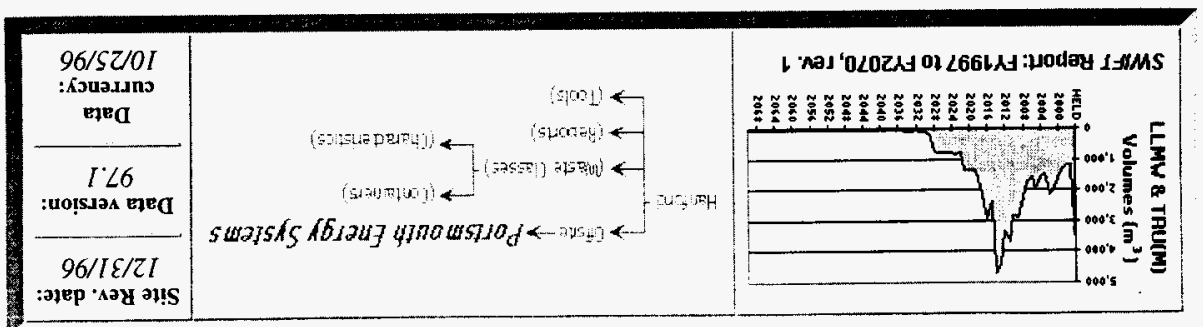




\begin{tabular}{|c|c|c|c|}
\hline $\begin{array}{l}\text { Portsmouth Energy Systems Comparis on: } \\
\text { Vaste Class }\end{array}$ & $\begin{array}{l}\text { FY97.1 } \\
\text { Forecast } \\
\text { (m') }\end{array}$ & $\begin{array}{l}\text { FY97_o } \\
\text { Forecast } \\
\text { (m') }\end{array}$ & $\begin{array}{l}\text { FY96 } \\
\text { Forecast } \\
\text { [mi] }\end{array}$ \\
\hline LLW & 310 & 310 & 34.810 \\
\hline Told & $5 / \theta$ & 210 & 34.810 \\
\hline
\end{tabular}

Sum of totals may not add due to rounding: numbers over $10 \mathrm{~m}^{3}$ are rounded to the nearest $10 \mathrm{~m}^{3}$, numbers less than $10 \mathrm{~m}^{3}$ are rounded to integers, non-zero numbers less than I are rounded to 1.

\section{Background}

The mission of Waste Management Division (WMD) at Lockheed Martin Energy Systems Portsmouth Site is to manage the Environmental Management and Enrichment Facilities treatment, storage, and disposal (TSD) of all wastes.

\section{Forecast Assumptions and Comments}

The LLW minimum and maximum percentages are $10 \%$ and $100 \%$ of the baseline volume. These percentages are based on known waste stream volume. Only the amount shipped in FY97 is variable, as some or all of that waste stream may be shipped to CWC in FY96.

The assumptions used for this forecast are based on information provided by the Portsmouth Waste Treatment \& Disposal Department, based on current waste stream characterization and future treatment and disposal planning.

\section{Other Forecast Data}

- Low Level Waste

- A total of $310 \mathrm{~m}^{3}$ LLW is expected from Portsmouth Energy Systems.

- This LLW forecast shows a $99 \%$ decrease from the FY96 forecast of $34,810 \mathrm{~m}^{3}$, because 7 out of 8 waste streams are no longer expected to be shipped to $\mathrm{CWC}$.

- FY97.0 volumes were changed from Category I to Category III for FY97.1

- This waste will be shipped in Other drums ( $74 \%$ by volume), MB-IV boxes (19\%), and Medium boxes (7\%).

- $100 \%$ of the LLW has the physical form of inorganic absorbed liquid/sludge.

\section{- Hazardous Waste}

- No hazardous waste is expected from Portsmouth Energy Systems for management by the CWC. 


\section{GENERATORS:}

Ames Laboratory-Ames, lowa - Argonne Nationai Laboratory-East · Bates Accelerator-Massachusetts - Battelle Columbus Laboratories - Bettis Atomic Power-Laboratory - Bettis Atomic Power-Shipyards - Brookhaven National Laboratory · Fermi National Accelerator Laboratory · General Atomics · Knolls Atomic Power-Laboratory - Knolls Atomic Power-Shipyards - Lawrence Berkeley Laboratory · Paducah Energy Systems - Pearl Harbor Naval Shipyards . Portsmouth Energy Systems · Portsmouth Naval Shipyards · Princeton Plasma Physics Laboratory · Puget Sound Naval Shipyards - Rockwell-Canoga Park - Rocky Flats - Stanford Linear Accelerator Center - University of California-Davis . University of Utah

PROGRAMS:

Analytical Services · EM-40 - Facility Transitions · Landlord · Liquid Effluent · NP · Offsite · PNNL · RCRA · Solid Waste $\cdot$ SNF $\cdot$ TWRS

CHARACTERISTICS:

CH_LLMW $\cdot$ RH_LLMW $\cdot$ CH_TRU(M) $\cdot$ RH_TRU(M) GTC III $\cdot$ LLW $\cdot$ HAZ

\section{CONTAINERS:}

CH_LLMW $\cdot$ RH_LLMW $\cdot \mathrm{CH}_{\mathbf{W}}$ TRU(M) . RH_TRU(M) $\cdot$ GTC III $\cdot$ LLW $\cdot$ HAZ

\section{Waste Classes:}

CH LLMW $\cdot$ RH_LLMW $\cdot$ CH_TRU(M) $\cdot$ RH_TRU(M) GTC III $\cdot$ LLW $\cdot$ HAZ

Home · Contents · Web Site Map · Glossary · Help · Reports - Data Requests · Feedback Form

NOTICE: This page is provided subject to our disclaimer. Contact: Oscar Valero at (509) 373-4752.

HNF-EP-0918 rev. 1 Approved for public release; distribution is unlimited. 
THL $\because \cdots$ i... 


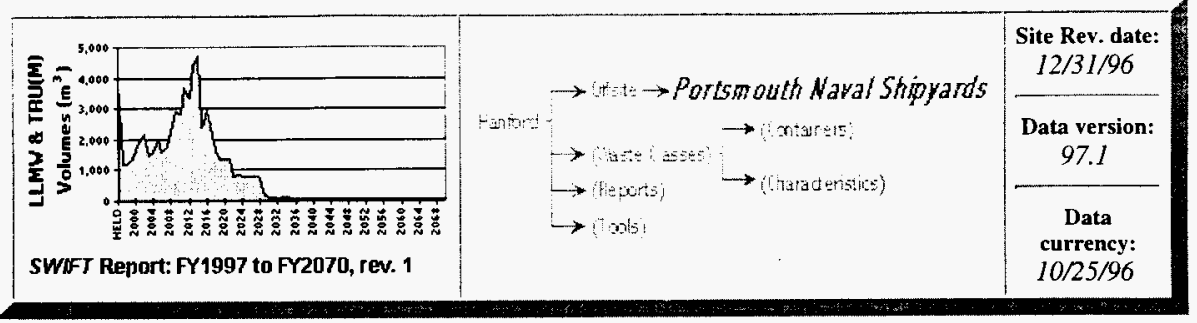

\section{Offsite - Portsmouth Naval Shipyards}

\section{Contents}

» Highlights

» Annual Volumes

»Comparison to Previous Baseline(s)

»Background
" Forecast Assumptions and Comments

»Other Portsmouth Naval Shipyards Forecast Data

»Detailed Forecast Data

\section{Highlights}

- The solid waste forecast life cycle for the Portsmouth Naval Shipyards generator ends in 2001.

- A total of $1 \mathrm{~m}^{3}$ of LLMW is expected from Portsmouth Naval Shipyards.

- Only CH_LLMW is included in this forecast of solid waste to be shipped to Hanford.

- The 208 liter drum is the one container type projected to be used.

- The physical forms of the LLMW are equal volumes of inorganic and organic solids (16\% each), and $68 \%$ debris.

- The LLMW hazardous constituents are $100 \%$ metals without mercury.

\section{Waste Class Distribution}

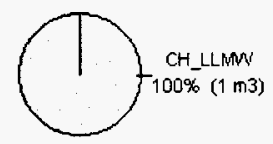

Total $=1 \mathrm{m3}$ 
Physical Waste Form Distribution

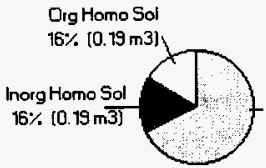

Total $=1 \mathrm{~m} 3$

Debris Wastes

\section{Hazardous Constituent Distribution}

$68 \%(0.82 \mathrm{~m} 3)$

\section{Total $=1 \mathrm{~m} 3$}

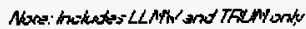

\section{Container Distribution}

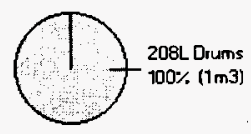

Total $=1 \mathrm{m3}$

Sum of totals may not add due to rounding: numbers over $10 \mathrm{~m}^{3}$ are rounded to the nearest $10 \mathrm{~m}^{3}$, numbers less than $10 \mathrm{~m}^{3}$ are rounded to integers, non-zero numbers less than 1 are rounded to 1 .

\section{Annual Volumes}

\section{Annual Baseline Volumes}

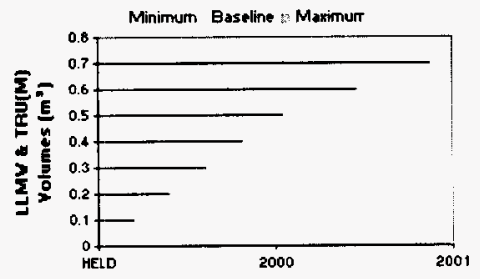

Annual Baseline by Waste Class 


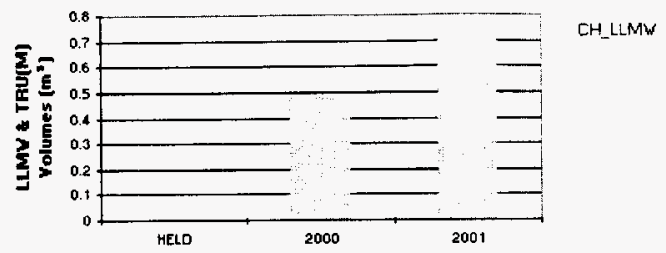

\section{Comparison to Previous Baseline(s)}

Forecast volumes are similar to those of the FY96 forecast.

The current hazardous constituent forecast of $100 \%$ metals without mercury is different from the 1996 forecast. For $1996,45 \%$ of the volume was expected to be metals without mercury, $2 \%$ was organic and corrosive, and $53 \%$ was other constituents.

\section{Comparison to Previous Baseline(s) by Waste Class}

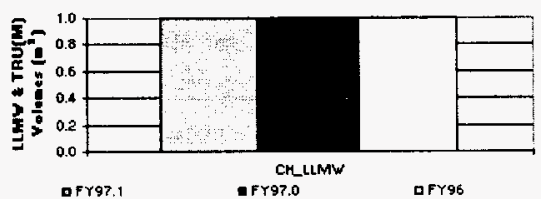

\begin{tabular}{|c|c|c|c|}
\hline $\begin{array}{l}\text { Portsmouth Naval Shipgards Comparison: } \\
\text { Yaste Class }\end{array}$ & $\begin{array}{l}\text { Frg7_1 } \\
\text { Forecast } \\
\text { (m') }\end{array}$ & $\begin{array}{l}\text { FY97.0 } \\
\text { Forecast } \\
\text { (min) }\end{array}$ & $\begin{array}{l}\text { FYs6 } \\
\text { Forecast } \\
\text { [m'] }\end{array}$ \\
\hline $\mathrm{CH} L L M W$ & 1 & 1 & 1 \\
\hline suprory & I & 1 & 1 \\
\hline Tover & 1 & I & $f$ \\
\hline
\end{tabular}

Sum of totals may not add due to rounding: numbers over $10 \mathrm{~m}^{3}$ are rounded to the nearest $10 \mathrm{~m}^{3}$, numbers less than $10 \mathrm{~m}^{3}$ are rounded to integers, non-zero numbers less than 1 are rounded to 1.

\section{Background}

Portsmouth Naval Shipyards is located on Seavey Island in the Piscataqua River, south of Kittery, Maine. The shipyard is a U.S. Navy facility that repairs, overhauls, and maintains Navy ships, including nuclear-powered ships.

\section{Forecast Assumptions and Comments}

The minimum and maximum percentages were not collected from Portsmouth Naval Shipyards, since the data are based on the Site Treatment Plan which does not collect ranges; therefore, $100 \%$ was assumed for the minimum and maximum.

\section{Other Forecast Data}




\section{- Low Level Waste}

- No low level waste is expected from Portsmouth Naval Shipyards for management by the CWC.

\section{- Hazardous Waste}

- No hazardous waste is expected from Portsmouth Naval Shipyards for management by the CWC.

\section{GENERATORS:}

Ames Laboratory-Ames, Iowa - Argonne National Laboratory-East - Bates Accelerator-Massachusetts · Battelle Columbus Laboratories - Bettis Atomic Power-Laboratory - Bettis Atomic Power-Shipyards - Brookhaven National

Laboratory - Fermi National Accelerator Laboratory - General Atomics - Knolls Atomic Power-Laboratory - Knolls Atomic Power-Shipyards - Lawrence Berkeley Laboratory - Paducah Energy Systems - Pearl Harbor Naval Shipyards . Portsmouth Energy Systems · Portsmouth Naval Shipyards - Princeton Plasma Physics Laboratory · Puget Sound Naval Shipyards · Rockwell-Canoga Park · Rocky Flats - Stanford Linear Accelerator Center - University of California-Davis University of Utah

PROGRAMS:

Analytical Services · EM-40 - Facility Transitions - Landlord - Liquid Effluent · NP · Offsite - PNNL · RCRA - Solid Waste $\cdot$ SNF $\cdot$ TWRS

\begin{tabular}{|c|c|}
\hline $\begin{array}{l}\text { CHARACTERISTICS: } \\
\text { CH_LLMW } \cdot \text { RH_LLMW } \cdot \text { CH_TRU(M) } \cdot \text { RH_TRU(M) } \cdot \\
\text { GTC III } \cdot \text { LLW } \cdot \text { HAZ }\end{array}$ & $\begin{array}{l}\text { CONTAINERS: } \\
\text { CH_LLMW } \cdot \text { RH_LLMW } \cdot \text { CH_TRU(M) } \\
\text { RH_TRU(M) } \cdot \text { GTC III } \cdot \text { LLW } \cdot \text { HAZ }\end{array}$ \\
\hline \multicolumn{2}{|c|}{$\begin{array}{l}\text { WASTE CLASSES: } \\
\text { CH_LLMW } \cdot \text { RH_LLMW } \cdot \text { CH_TRU(M) } \cdot \text { RH_TRU(M) } \cdot \text { GTC III } \cdot \text { LLW } \cdot \text { HAZ }\end{array}$} \\
\hline
\end{tabular}

NOTICE: This page is provided subject to our disclaimer. Contact: Oscar Valero at (509) 373-4752. HNF-EP-0918 rev. 1 Approved for public release; distribution is unlimited. 
cu $09=|\mathbf{p p o}|$

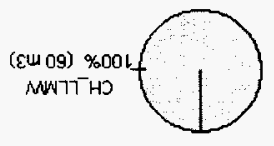

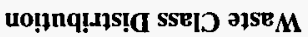

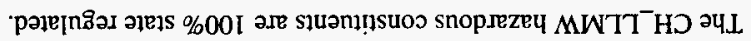

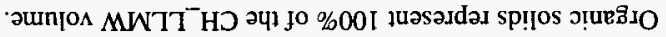

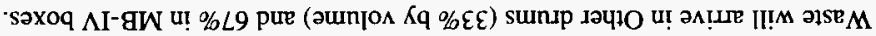

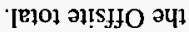

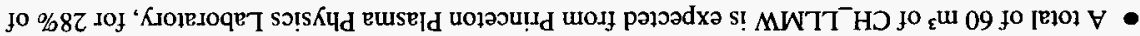
`ৃOZ

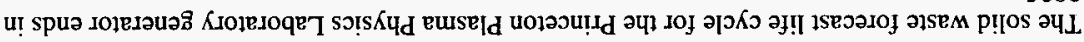

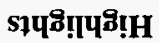

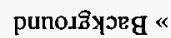

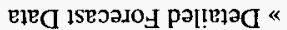
हाeव зseวa.roH

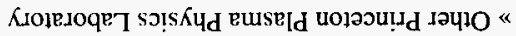

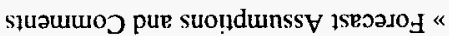

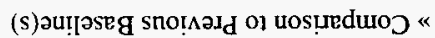
Səun[o $\Lambda$ Ienuu รมบธิเโบสิ!ก «

sาuวนนо

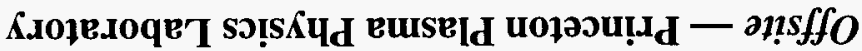

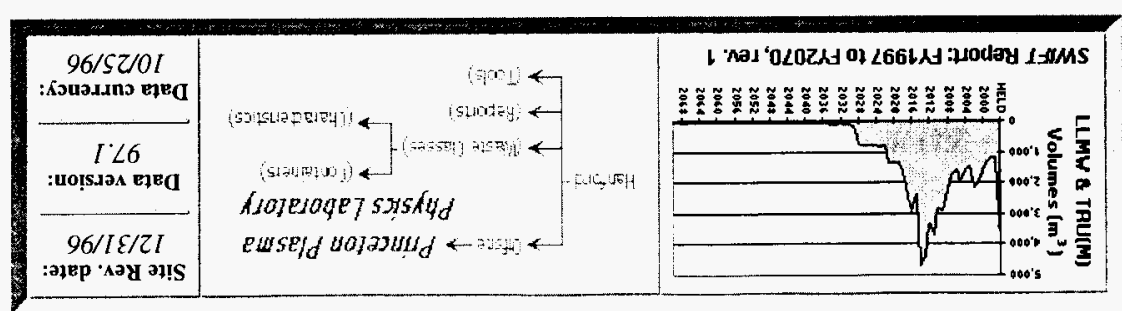


Physical Waste Form Distribution

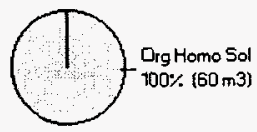

Total $=60 \mathrm{m3}$

\section{Hazardous Constituent Distribution}

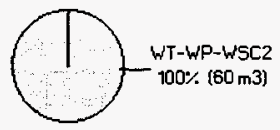

Total $=60 \mathrm{m3}$

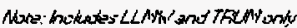

\section{Container Distribution}

Orhet Drums $33 \%(20 \mathrm{~m} 3)$

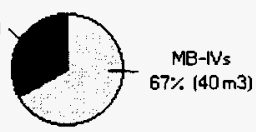

Total $=60 \mathrm{m3}$

Sum of totals may not add due to rounding: numbers over $10 \mathrm{~m}^{3}$ are rounded to the nearest $10 \mathrm{~m}^{3}$, numbers less than $10 \mathrm{~m}^{3}$ are rounded to integers, non-zero numbers less than I are rounded to I.

\section{Annual Volumes}

\section{Annual Baseline Volumes}

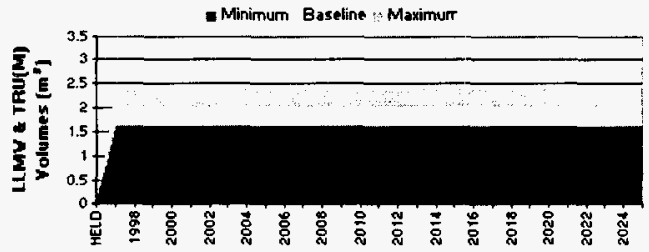

Annual Baseline by Waste Class 


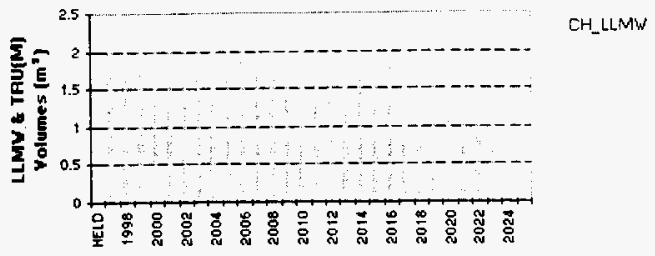

\section{Comparison to Previous Baseline(s)}

This is an increase, since no LLMW or TRU(M) waste was forecast by the Princeton Plasma Physics Laboratory in FY96.

\section{Comparison to Previous Baseline(s) by Waste Class}

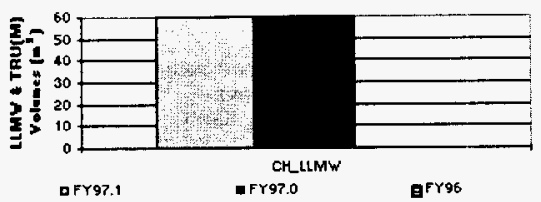

\begin{tabular}{|c|c|c|c|}
\hline $\begin{array}{l}\text { Prineeton Plasma Physies Lab Comparison: } \\
\text { Yaste Class }\end{array}$ & $\begin{array}{c}\text { FY97.1 } \\
\text { Forecast } \\
{\left[m^{*}\right]}\end{array}$ & $\begin{array}{c}\text { FY97_0 } \\
\text { Forecist } \\
\text { (m') }\end{array}$ & $\begin{array}{l}\text { FY96 } \\
\text { Forecsst } \\
\left(m^{2}\right)\end{array}$ \\
\hline $\mathrm{CH}$ LLMW & 60 & 60 & 0 \\
\hline Subrored & $\sigma$ & $s$ & $\theta$ \\
\hline LLW & 4,030 & 4,030 & 18,000 \\
\hline Tores & 1,000 & 8.000 & $\operatorname{sen}$ \\
\hline
\end{tabular}

Sum of totals may not add due to rounding: numbers over $10 \mathrm{~m}^{3}$ are rounded to the nearest $10 \mathrm{~m}^{3}$, numbers less than $10 \mathrm{~m}^{3}$ are rounded to integers, non-zero numbers less than $I$ are rounded to $I$.

\section{Background}

The Princeton Plasma Physics Laboratory is an Energy Research project dedicated to providing data to support the use of Magnetically Confined Fusion as an environmentally attractive energy alternative. In the course of this research, atoms of hydrogen are fused to form helium. As a result of this reaction, radioactive by-products are produced and must be disposed of in an approved manner.

\section{Forecast Assumptions and Comments}

The minimum and maximum percentages are $80 \%$ and $120 \%$ of the baseline volume. These percentages are based on the most recent Energy Research funding schedule for magnetic confinement fusion research.

\section{Other Forecast Data}




\section{Low Level Waste}

- A total of $4,030 \mathrm{~m}^{3}$ of $\mathrm{LLW}$ is expected for Princeton Plasma Physics Laboratory.

- This LLW forecast shows a $78 \%$ decrease from the FY 96 forecast of $18,000 \mathrm{~m}^{3}$, primarily because the life cycle has decreased from 2070 to 2025 , and the CWC is not the first option for Princeton Plasma Physics Laboratory to ship the waste.

- $55 \%$ of the LLW will be sent in MB-IV boxes, $40 \%$ will be in 208 liter drums, and Other drums will contain the remaining $5 \%$.

- LLW physical forms are nearly all (98\%) debris - of which plastic/rubber is $66 \%$ of the volume. The other $2 \%$ is composed of organic solids.

\section{- Hazardous Waste}

- No hazardous waste is expected from the Princeton Plasma Physics Laboratory for management by the CWC.

\section{GENERATORS:}

Amc - Laboratory-Ames, Iowa - Argonne National Laboratory-East · Bates Accelerator-Massachusetts · Battelle Columbus Laboratories - Bettis Atomic Power-Laboratory - Bettis Atomic Power-Shipyards - Brookhaven National

Laboratory - Fermi National Accelerator Laboratory - General Atomics - Knolls Atomic Power-Laboratory - Knolls Atomic Power-Shipyards - Lawrence Berkeley Laboratory · Paducah Energy Systems - Pearl Harbor Naval Shipyards · Portsmouth Energy Systems - Portsmouth Naval Shipyards - Princeton Plasma Physics Laboratory - Puget Sound Naval Shipy irds - Rockwell-Canoga Park - Rocky Flats - Stanford Linear Accelerator Center - University of California-Davis . University of Utah

\section{PROGRAMS:}

Analytical Services - EM-40 - Facility Transitions - Landlord - Liquid Effluent - NP · Offsite - PNNL - RCRA - Solid Waste $\cdot$ SNF. TWRS

\begin{tabular}{|c|c|}
\hline $\begin{array}{l}\text { CHARACTERISTICS: } \\
\text { CH_LLMW } \cdot \text { RH_LLMW } \cdot \text { CH_TRU(M) } \cdot \text { RH_TRU(M) } \\
\text { GTC III } \cdot \text { LLW } \cdot \text { HAZ }\end{array}$ & $\begin{array}{c}\text { CONTAINERS: } \\
\text { CH_LLMW } \cdot \text { RH_LLMW } \cdot \text { CH_TRU(M) } \\
\text { RH_TRU(M) } \cdot \text { GTC III } \cdot \text { LLW } \cdot \text { HAZ }\end{array}$ \\
\hline $\begin{array}{r}\text { WASTE C } \\
\text { CH_LLMW } \cdot \text { RH_LLMW } \cdot \text { CH_TRU(M) }\end{array}$ & $\mathrm{U}(\mathrm{M}) \cdot \mathrm{GTC}$ III $\cdot$ LLW $\cdot$ HAZ \\
\hline
\end{tabular}

NOTICE: This page is provided subject to our disclaimer. Contact: Oscar Valero at (509) 373-4752. HNF-EP-0918 rev. 1 Approved for public release; distribution is unlimited. 


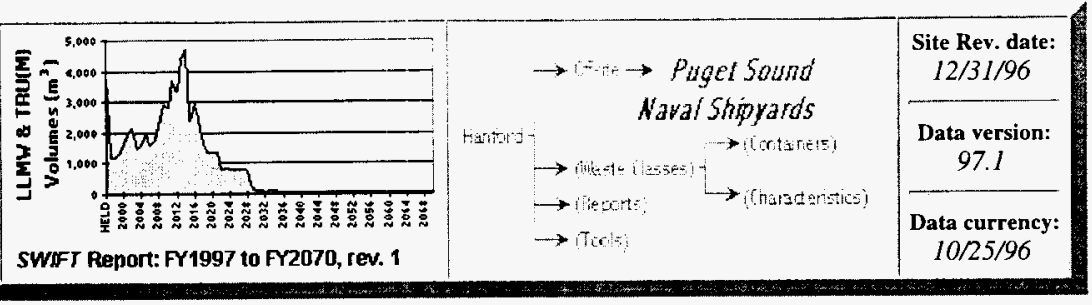

\section{Offsite - Puget Sound Naval Shipyards}

\section{Contents}

»Highlights

"Annual Volumes

»Comparison to Previous Baseline(s)

» Background
» Forecast Assumptions and Comments

» Other Puget Sound Naval Shipyards Forecast Data

" Detailed Forecast Data

\section{Highlights}

- The solid waste forecast life cycle for the Puget Sound Naval Shipyards generator ends in 2001.

- A total of $30 \mathrm{~m}^{3}$ of LLMW is expected from Puget Sound Naval Shipyards, for $14 \%$ of the Offsite total.

- Only CH_LLMW is included in this forecast of solid waste to be shipped to Hanford.

- This generator projects all of the waste to be sent in 208 liter containers.

- CH_LLWM physical forms vary from $80 \%$ of the waste as debris to $3 \%$ as lab packs. Special waste is expected to be $7 \%$ of the volume, and $10 \%$ should be inorganic solids.

- CH_LLMW hazardous constituents are $100 \%$ metals without mercury.

\section{Waste Class Distribution}

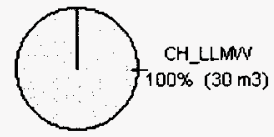

Total $=\mathbf{3 0} \mathbf{m} 3$ 
Physical Waste Form Distribution

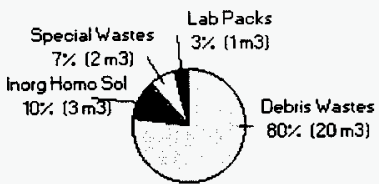

Total $=\mathbf{3 0} \mathrm{m} 3$

\section{Hazardous Constituent Distribution}

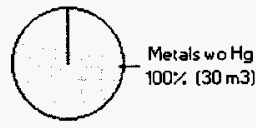

Total $=\mathbf{3 0} \mathrm{m} 3$

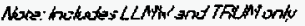

\section{Container Distribution}

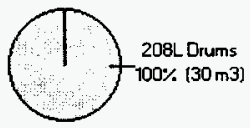

Total $=\mathbf{3 0} \mathrm{m} \mathbf{3}$

Sum of totals may not add due to rounding: numbers over $10 \mathrm{~m}^{3}$ are rounded to the nearest $10 \mathrm{~m}^{3}$, numbers less than $10 \mathrm{~m}^{3}$ are rounded to integers, non-zero numbers less than $I$ are rounded to $I$.

\section{Annual Volumes}

\section{Annual Baseline Volumes}

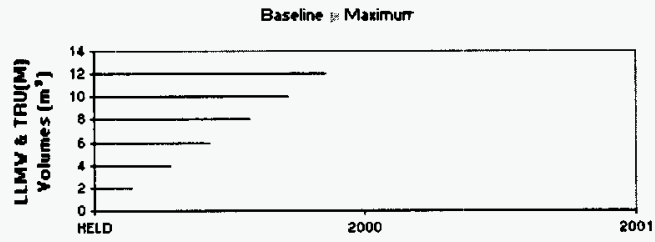

\section{Annual Baseline by Waste Class}




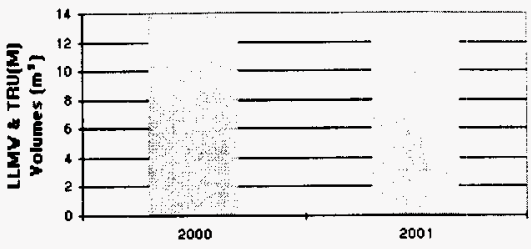

CH_LLMW

\section{Comparison to Previous Baseline(s)}

This forecast is similar to the FY96 forecast.

\section{Comparison to Previous Baseline(s) by Waste Class}

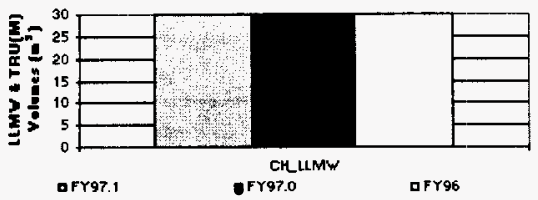

\begin{tabular}{|c|c|c|c|}
\hline $\begin{array}{l}\text { Puget Sound Naual Shipgards Comparison: } \\
\text { Yaste Class }\end{array}$ & $\begin{array}{c}\text { FY97.1 } \\
\text { Forecast } \\
{\left[\mathrm{m}^{*}\right]}\end{array}$ & $\begin{array}{l}\text { FY97.0 } \\
\text { Forecast } \\
\left(\mathrm{m}^{*}\right)\end{array}$ & $\begin{array}{c}\text { FY96 } \\
\text { Forecast } \\
\left(\mathrm{m}^{3}\right)\end{array}$ \\
\hline CH LLMW & 30 & 30 & 30 \\
\hline suporef & $m$ & $n$ & $n$ \\
\hline Tord & 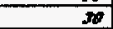 & 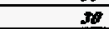 & $\pi$ \\
\hline
\end{tabular}

Sum of totals may not add due to rounding: numbers over $10 \mathrm{~m}^{3}$ are rounded to the nearest $10 \mathrm{~m}^{3}$, numbers less than $10 \mathrm{~m}^{3}$ are rounded to integers, non-zero numbers less than 1 are rounded to 1.

\section{Background}

Puget Sound Naval Shipyards is located on the west side of Sinclair Inlet on Puget Sound, south of Bremerton, Washington. The shipyard is a US Navy facility that repairs, overhauls, and maintains Navy ships, including nuclear-powered ships.

\section{Forecast Assumptions and Comments}

The minimum and maximum percentages were not collected from Puget Sound Naval Shipyards, since the data are based on the Site Treatment Plan, which does not collect ranges; therefore, $100 \%$ was assumed for the minimum and maximum.

\section{Other Forecast Data}

- Low Level Waste

- No low level waste is expected from Puget Sound Naval Shipyards for management by the 


\section{CWC.}

\section{- Hazardous Waste}

- No hazardous waste is expected from Puget Sound Naval Shipyards for management by the CWC.

\section{GENERATORS:}

Ames Laboratory-Ames, Iowa - Argonne National Laboratory-East - Bates Accelerator-Massachusetts - Battelle Columbus Laboratories - Bettis Atomic Power-Laboratory · Bettis Atomic Power-Shipyards - Brookhaven National Laboratory · Fermi National Accelerator Laboratory · General Atomics · Knolls Atomic Power-Laboratory - Knolls Atomic Power-Shipyards - Lawrence Berkeley Laboratory · Paducah Energy Systems - Pearl Harbor Naval Shipyards · Portsmouth Energy Systems - Portsmouth Naval Shipyards - Princeton Plasma Physics Laboratory · Puget Sound Naval Shipyards · Rockwell-Canoga Park - Rocky Flats - Stanford Linear Accelerator Center - University of California-Davis · University of Utah

\section{PROGRAMS:}

Analytical Services - EM-40 - Facility Transitions - Landlord - Liquid Effluent - NP · Offsite · PNNL - RCRA - Solid Waste SNF. TWRS

\begin{tabular}{|c|c|}
\hline $\begin{array}{c}\text { CHARACTERISTICS: } \\
\text { CH_LLMW } \cdot \text { RH_LLMW } \cdot \text { CH_TRU(M) } \cdot \text { RH_TRU(M) } \\
\text { GTC III } \cdot \text { LLW } \cdot \text { HAZ }\end{array}$ & $\begin{array}{c}\text { CONTAINERS: } \\
\text { CH_LLMW } \cdot \text { RH_LLMW } \cdot \text { CH_TRU(M) } \\
\text { RH_TRU(M) } \cdot \text { GTC III } \cdot \text { LLW } \cdot \text { HAZ }\end{array}$ \\
\hline CH_LLMW $\cdot$ RH_LLMW $\cdot$ CH_TRU(M) $\cdot$ RH_TRU(M) $\cdot$ GTC III $\cdot$ LLW $\cdot$ HAZ \\
\hline Home $\cdot$ Contents $\cdot$ Web Site Map $\cdot$ Glossary $\cdot$ Help $\cdot$ Reports $\cdot$ Data Requests $\cdot$ Feedback Form
\end{tabular}

NOTICE: This page is provided subject to our disclaimer. Contact: Oscar Valero at (509) 373-4752.

HNF-EP-0918 rev. 1 Approved for public release; distribution is unlimited. 


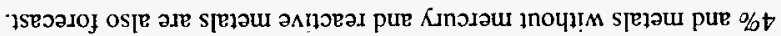

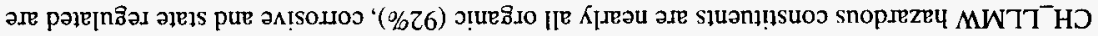

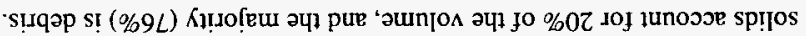

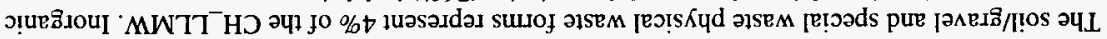

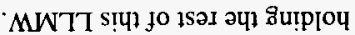

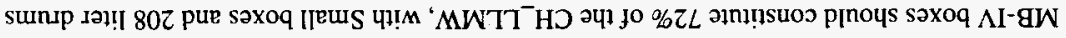

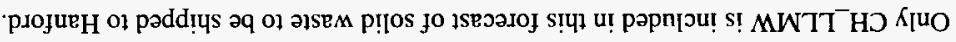
'عU 0 Jo 1SEวajof 96X

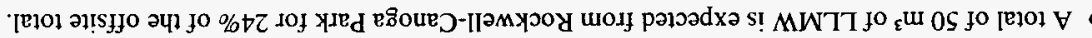

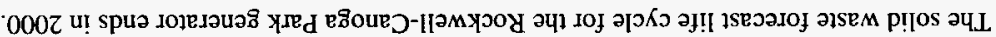

งาบชี!|บรี!ก

puno.sิyวeg *

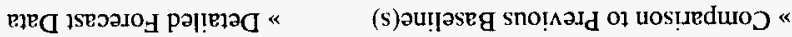

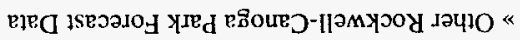
səumpo $\Lambda$ [enuu $\forall$ * słuaumo pue suondumss 1 1seวaso รมบฮิ!กบรึ! $\mathrm{H}$ *

Squąuo

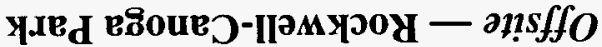

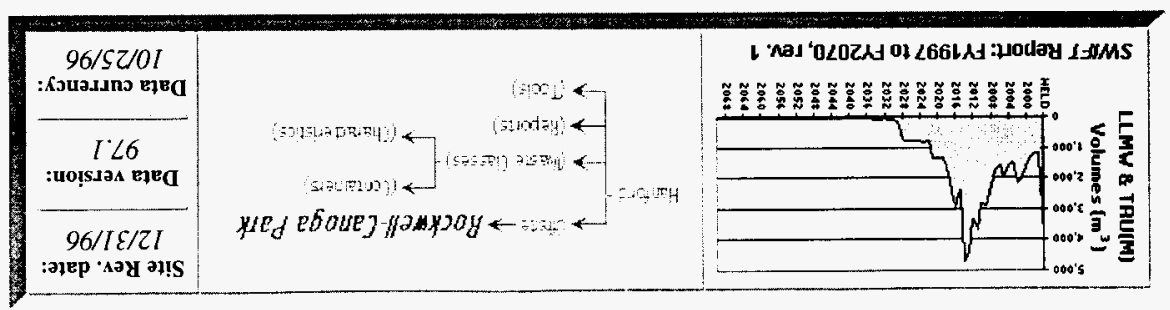




\section{Waste Class Distribution}

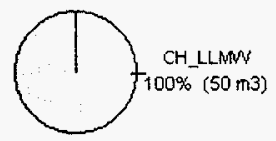

Total $=50 \mathrm{m3}$

\section{Physical Waste Form Distribution Hazardous Constituent Distribution}
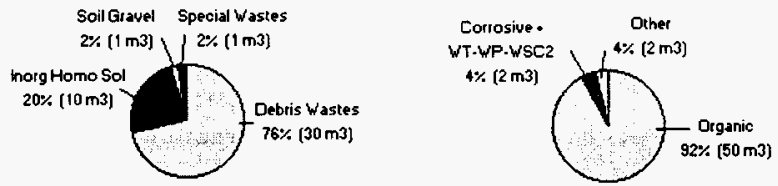

Total $=50 \mathrm{~m} 3$

Total $=50 \mathrm{m3}$

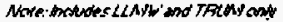

\section{Container Distribution}

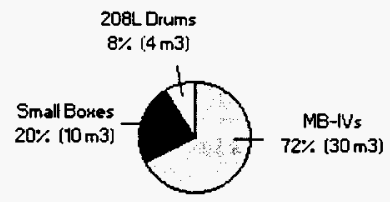

Total $=\mathbf{5 0 ~} \mathrm{m} \mathbf{3}$

Sum of totals may not add due to rounding: numbers over $10 \mathrm{~m}^{3}$ are rounded to the nearest $10 \mathrm{~m}^{3}$, numbers less than $10 \mathrm{~m}^{3}$ are rounded to integers, non-zero numbers less than 1 are rounded to 1 .

\section{Annual Volumes}

\section{Annual Baseline Volumes}




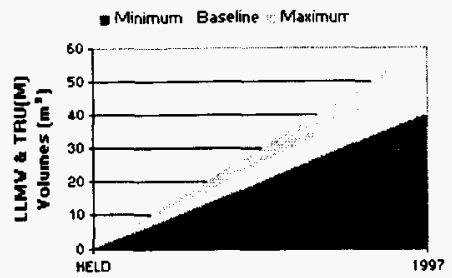

\section{Annual Baseline by Waste Class}

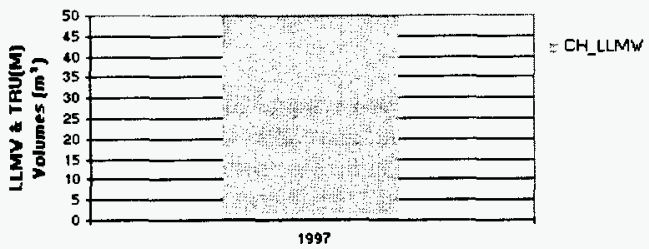

\section{Comparison to Previous Baseline(s)}

The FY97 forecast of $50 \mathrm{~m}^{3} \mathrm{LLMW}$ is an increase over the FY96 forecast of $0 \mathrm{~m}^{3} \mathrm{LLMW}$ and

TRU(M) waste. This increase of expected waste is due to the potential of a Site Treatment Plan being negotiated with Rockwell that allows shipment to Hanford.

\section{Comparison to Previous Baseline(s) by Waste Class}

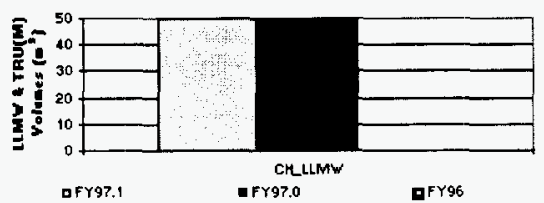

\begin{tabular}{|c|c|c|c|}
\hline $\begin{array}{l}\text { Rockwell-Canoga Park Comparison: } \\
\text { Yaste Class }\end{array}$ & $\begin{array}{l}\text { FY97.1 } \\
\text { Forecast } \\
\left(m^{2}\right)\end{array}$ & $\begin{array}{l}\text { FY97.0 } \\
\text { Forecast } \\
\text { (mil) }\end{array}$ & $\begin{array}{l}\text { FY96 } \\
\text { Forecast } \\
\text { (min) }\end{array}$ \\
\hline $\mathrm{CH}$ LLMW & 50 & 50 & 0 \\
\hline Subrord & $5 \theta$ & 50 & $\theta$ \\
\hline$L L W$ & 1,150 & 1,150 & 930 \\
\hline Tord & 1.200 & 1.200 & $\sin$ \\
\hline
\end{tabular}

Sum of totals may not add due to rounding: numbers over $10 \mathrm{~m}^{3}$ are rounded to the nearest $10 \mathrm{~m}^{3}$, numbers less than $10 \mathrm{~m}^{3}$ are rounded to integers, non-zero numbers less than $I$ are rounded to 1 .

\section{Background}

The mission of Rockwell-Canoga Park is the decontamination and decommissioning of old 
nuclear laboratories. LLW from Rockwell is mostly associated with these activities.

\section{Forecast Assumptions and Comments}

The minimum and maximum percentages are $80 \%$ and $120 \%$ of the baseline volume. These percentages account for uncertainty in the waste generation.

Forecast assumption is based on planned activities for D\&D operations that are within the budget and schedule in place at this time, and approval of a Site Treatment Plan for shipment to Hanford.

\section{Other Forecast Data}

\section{- Low Level Waste}

o A total of $1,150 \mathrm{~m}^{3}$ of $\mathrm{LLW}$ is expected from Rockwell-Canoga Park.

- This forecast shows a $24 \%$ increase over the FY96 forecast of $930 \mathrm{~m}^{3}$.

- More than two-thirds of the LLW will be contained in Small boxes, while MB-IV and Large boxes will hold $21 \%$ and $11 \%$, respectively.

- All of the LLW has the physical form of debris, except for $1 \%$ of shielding.

\section{- Hazardous Waste}

- No hazardous waste is expected from Rockwell-Canoga Park for management by the CWC.

\section{GENERATORS:}

Ames Laboratory-Ames, Iowa - Argonne National Laboratory-East - Bates Accelerator-Massachusetts - Battelle Columbus Laboratories - Bettis Atomic Power-Laboratory - Bettis Atomic Power-Shipyards - Brookhaven National

Laboratory - Fermi National Accelerator Laboratory - General Atomics · Knolls Atomic Power-Laboratory - Knolls Atomic Power-Shipyards - Lawrence Berkeley Laboratory - Paducah Energy Systems - Pearl Harbor Naval Shipyards · Portsmouth Energy Systems · Portsmouth Naval Shipyards - Princeton Plasma Physics Laboratory · Puget Sound Naval Shipyards - Rockwell-Canogo Park - Rocky Flats - Stanford Linear Accelerator Center - University of California-Davis .

University of Utah

PROGRAMS:

Analytical Services - EM-40 · Facility Transitions · Landlord · Liquid Effluent - NP · Offsite · PNNL · RCRA - Solid Waste - SNF - TWRS

\begin{tabular}{|c|c|}
\hline $\begin{array}{l}\text { CHARACTERISTICS: } \\
\text { CH_LLMW } \cdot \text { RH_LLMW } \cdot \text { CH_TRU(M) } \cdot \text { RH_TRU(M) } \\
\text { GTC III } \cdot \text { LLW } \cdot \text { HAZ }\end{array}$ & $\begin{array}{c}\text { CONTAINERS: } \\
\mathrm{CH}_{\text {_LLMW }} \cdot \mathrm{RH} \text { RLLMW } \cdot \text { CH_TRU(M) } \\
\text { RH_TRU(M) } \cdot \text { GTC III } \cdot \text { LLW } \cdot \text { HAZ }\end{array}$ \\
\hline \multicolumn{2}{|c|}{$\begin{array}{l}\text { WASTE CLASSES: } \\
\text { CH_LLMW } \cdot \text { RH_LLMW } \cdot \text { CH_TRU(M) } \cdot \text { RH_TRU(M) } \cdot \text { GTC III } \cdot \text { LLW } \cdot \text { HAZ }\end{array}$} \\
\hline
\end{tabular}

NOTICE: This page is provided subject to our disclaimer. Contact: Oscar Valero at (509) 373-4752. HNF-EP-0918 rev. 1 Approved for public release; distribution is unlimited. 

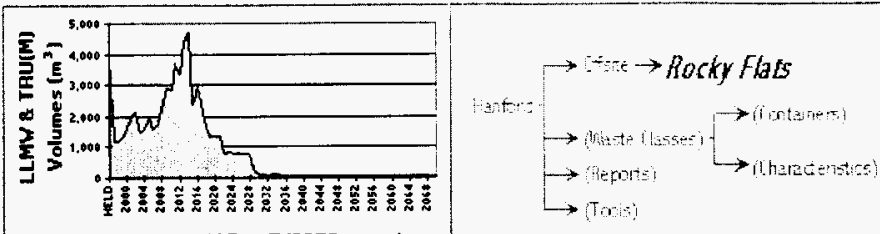

Site Rev. date:

$12 / 31 / 96$

Data version:

97.1

Data currency:

SWIFT Report: FY1997 to FY2070, rev. 1

$10 / 25 / 96$

\section{Offsite - Rocky Flats}

\section{Contents}

" Highlights

"Annual Volumes

»Comparison to Previous Baseline(s)

"Background
" Forecast Assumptions and Comments

" Other Rocky Flats Forecast Data

"Detailed Forecast Data

\section{Highlights}

- The solid waste forecast life cycle for Rocky Flats generator ends in 2000.

- No LLMW or TRU(M) waste is expected from Rocky Flats.

- Only LLW is included in this forecast of solid waste to be shipped to Hanford.

\section{Annual Volumes}

\section{Annual Baseline Volumes}

No LLMW or TRU(M) waste is expected from this generator.

\section{Annual Baseline by Waste Class}

Not applicable.

\section{Comparison to Previous Baseline(s)}

Similar to FY96, this generator did not forecast any LLMW or TRU(M) waste for FY97.

\section{Comparison to Previous Baseline(s) by Waste Class}

\begin{tabular}{|c|c|c|c|}
\hline $\begin{array}{l}\text { Roekg Flats Comparison: } \\
\text { Vaste Class }\end{array}$ & $\begin{array}{l}\text { FY9T.1 } \\
\text { Forecast } \\
\left(\mathrm{m}^{3}\right)\end{array}$ & $\begin{array}{c}\text { FY97.0 } \\
\text { Forecast } \\
{\left[\mathrm{m}^{3}\right]}\end{array}$ & $\begin{array}{l}\text { FY96 } \\
\text { Forecast } \\
{\left[\mathrm{m}^{2}\right]}\end{array}$ \\
\hline$L L W$ & 180 & 180 & 220 \\
\hline rores & $\operatorname{mos}$ & tose & 220 \\
\hline
\end{tabular}


Sum of totals may not add due to rounding: numbers over $10 \mathrm{~m}^{3}$ are rounded to the nearest $10 \mathrm{~m}^{3}$, numbers less than $10 \mathrm{~m}^{3}$ are rounded to integers, non-zero numbers less than $f$ are rounded to $I$.

\section{Background}

The mission of Rocky Flats is to manage waste and materials, clean up and convert the Rocky Flats Environmental Technology Site to beneficial use in a manner that is safe, environmentally and socially responsible, physically secure, and cost effective.

\section{Forecast Assumptions and Comments}

The LLW minimum and maximum percentages are $100 \%$ and $200 \%$ of the baseline volume. Maximum waste \% is based upon Rocky Flats obtaining additional approvals from DOE and Hanford for waste disposal at Hanford.

Forecast is based on the assumption that DOE and Hanford will continue their approval of shipping LLW from Rocky Flats to CWC.

\section{Other Forecast Data}

\section{- Low Level Waste}

- A total of $180 \mathrm{~m}^{3}$ of LLW is expected from Rocky Flats.

- This forecast shows a $20 \%$ decrease from the FY96 forecast of $220 \mathrm{~m}^{3}$.

- All of the LLW will utilize 208 liter drums for shipment.

- $100 \%$ of the LLW is debris.

\section{- Hazardous Waste}

- No hazardous waste is expected from Rocky Flats for management by the CWC. 


\section{GENERATORS:}

Ames Laboratory-Ames, Iowa - Argonne National Laboratory-East - Bates Accelerator-Massachusetts - Battelle Columbus Laboratories · Bettis Atomic Power-Laboratory - Bettis Atomic Power-Shipyards - Brookhaven National Laboratory - Fermi National Accelerator Laboratory . General Atomics - Knolls Atomic Power-Laboratory - Knolls Atomic Power-Shipyards - Lawrence Berkeley Laboratory · Paducah Energy Systems · Pearl Harbor Naval Shipyards . Portsmouth Energy Systems - Portsmouth Naval Shipyards - Princeton Plasma Physics Laboratory · Puget Sound Naval Shipyards - Rockwell-Canoga Park - Rocky Flats - Stanford Linear Accelerator Center - University of California-Davis .

University of Utah

\section{PROGRAMS:}

Analytical Services - EM-40 - Facility Transitions - Landlord - Liquid Effluent - NP · Offsite · PNNL · RCRA - Solid Waste - SNF . TWRS

\begin{tabular}{|c|c|}
\hline $\begin{array}{l}\text { CHARACTERISTICS: } \\
\text { CH_LLMW } \cdot \text { RH_LLMW } \cdot \text { CH_TRU(M) } \cdot \text { RH_TRU(M) } \\
\text { GTC III } \cdot \text { LLW } \cdot \text { HAZ }\end{array}$ & $\begin{array}{c}\text { CONTAINERS: } \\
\text { CH_LLMW } \cdot \text { RH_LLMW } \cdot \text { CH_TRU(M) } \\
\text { RH_TRU(M) } \cdot \text { GTC III } \cdot \text { LLW } \cdot \text { HAZ }\end{array}$ \\
\hline \multicolumn{2}{|c|}{ WASTE CLASSES: } \\
\hline
\end{tabular}

NOTICE: This page is provided subject to our disclaimer. Contact: Oscar Valero at (509) 373-4752. HNF-EP-0918 rev. 1 Approved for public release; distribution is unlimited. 
THIS CA:

L. …........ 


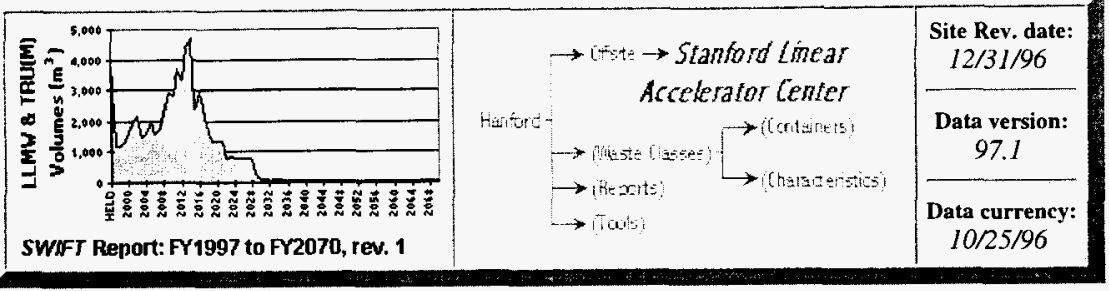

\section{Offsite - Stanford Linear Accelerator Center}

\section{Contents}

» Highlights

" Annual Volumes

» Comparison to Previous Baseline(s)

$\gg$ Background
» Forecast Assumptions and Comments

» Other Stanford Linear Accelerator Center Forecast Data

»Detailed Forecast Data

\section{Highlights}

- The solid waste forecast life cycle for the Stanford Linear Accelerator Center (Stanford) generator ends in 2070.

- No LLMW and TRU(M) waste is expected from Stanford.

- Only LLW is included in this forecast of solid waste to be shipped to Hanford.

\section{Annual Volumes}

\section{Annual Baseline Volumes}

No LLMW or TRU(M) waste is expected from this generator.

Annual Baseline by Waste Class

Not applicable.

\section{Comparison to Previous Baseline(s)}

As in FY96, this generator did not forecast any LLMW or TRU(M) waste for FY97 or for FY97.1.

\section{Comparison to Previous Baseline(s) by Waste Class}




\begin{tabular}{|c|c|c|c|}
\hline $\begin{array}{l}\text { Stanford Linear Accelerator Center Comparison: } \\
\text { Vaste Class }\end{array}$ & $\begin{array}{c}\text { Fr97.1 } \\
\text { Forecast } \\
{\left[\mathrm{m}^{3}\right]}\end{array}$ & $\begin{array}{c}\text { FY97.0 } \\
\text { Forecast } \\
\left(\mathrm{m}^{2}\right)\end{array}$ & $\begin{array}{c}\text { FY96 } \\
\text { Forecast } \\
\text { (m') }\end{array}$ \\
\hline LLW & 1,170 & 1.170 & 1,750 \\
\hline Tordy & 1.170 & 8.170 & $8,75 \theta$ \\
\hline
\end{tabular}

Sum of totals may not add due to rounding: numbers over $10 \mathrm{~m}^{3}$ are rounded to the nearest $10 \mathrm{~m}^{3}$, numbers less than $10 \mathrm{~m}^{3}$ are rounded to integers, non-zero numbers less than 1 are rounded to $l$.

\section{Background}

The Stanford Linear Accelerator Center (SLAC) is a National Laboratory involved in high energy particle physics. SLAC research facilities study the effects of electron-positron collisions to better understand the nature of the atomic nucleus and the relationship of subatomic particles. LLW is generated during normal operation of the accelerator, in which some electrons may strike beam line components. When electrons strike the pipe and components, radioactive nuclei can be produced in the material. Some of the pipe and components will be discarded as LLW. This waste is produced on an irregular basis due to the nature of operations, and as such the production of LLW is not a planned activity.

\section{Forecast Assumptions and Comments}

The LLW minimum and maximum percentages are $50 \%$ and $150 \%$ of the baseline volume. These percentages are based on process knowledge, and the amount of waste that is being received per documented records.

The forecast estimates are based on the following assumptions:

- No major modifications in the facility.

- The large activated shielding blocks may be declared waste.

- No closure of the facility.

\section{Other Forecast Data}

\section{- Low Level Waste}

- A total of $1,170 \mathrm{~m}^{3}$ is expected from the Stanford Linear Accelerator Center.

o This forecast shows a $33 \%$ decrease from the FY96 forecast of $1,750 \mathrm{~m}^{3}$.

o The MB-V box is forecast to hold all of this LLW.

- LLW physical forms are forecast to be concrete shielding (16\% by volume) and debris (84\%).

\section{- Hazardous Waste}

- No hazardous waste is expected from Stanford for management by the CWC. 


\section{GENERATORS:}

Ames Laboratory-Ames, Iowa - Argonne National Laboratory-East - Bates Accelerator-Massachusetts - Battelle Columbus Laboratories - Bettis Atomic Power-Laboratory - Bettis Atomic Power-Shipyards - Brookhaven National Laboratory · Fermi National Accelerator Laboratory · General Atomics · Knolls Atomic Power-Laboratory · Knolls Atomic Power-Shipyards - Lawrence Berkeley Laboratory - Paducah Energy Systems - Pearl Harbor Naval Shipyards . Portsmouth Energy Systems - Portsmouth Naval Shipyards · Princeton Plasma Physics Laboratory · Puget Sound Naval Shipyards - Rockwell-Canoga Park - Rocky Flats - Stanford Linear Accelerator Center - University of California-Davis University of Utah

\section{PROGRAMS:}

Analytical Services · EM-40 · Facility Transitions $\cdot$ Landlord $\cdot$ Liquid Effluent $\cdot$ NP $\cdot$ Offsite $\cdot$ PNNL $\cdot$ RCRA $\cdot$ Solid Waste - SNF - TWRS

\begin{tabular}{|c|c|}
\hline $\begin{array}{c}\text { CHARACTERISTICS: } \\
\text { CH_LLMW } \cdot \text { RH_LLMW } \cdot \text { CH_TRU(M) } / \text { RH_TRU(M) } \\
\text { GTC III } \cdot \text { LLW } \cdot \text { HAZ }\end{array}$ & $\begin{array}{c}\text { CONTAINERS: } \\
\text { CH_LLMW } \cdot \text { RH_LLMW } \cdot \text { CH_TRU(M) } \cdot \\
\text { RH_TRU(M) } \cdot \text { GTC III } \cdot \text { LLW } \cdot \text { HAZ }\end{array}$ \\
\hline CH_LLMW $\cdot$ RH_LLMW $\cdot$ CH_TRU(M) $\cdot$ RH_TRU(M) $\cdot$ GTC III $\cdot$ LLW $\cdot$ HAZ \\
\hline Wome $\cdot$ Contents $\cdot$ Web Site Map $\cdot$ Glossary $\cdot$ Help $\cdot$ Reports $\cdot$ Data Requests $\cdot$ Feedback Form
\end{tabular}

NOTICE: This page is provided subject to our disclaimer. Contact: Oscar Valero at (509) 373-4752.

HNF-EP-0918 rev. 1 Approved for public release; distribution is unlimited. 
7H1 $\cdots, \ldots$

i.s. 


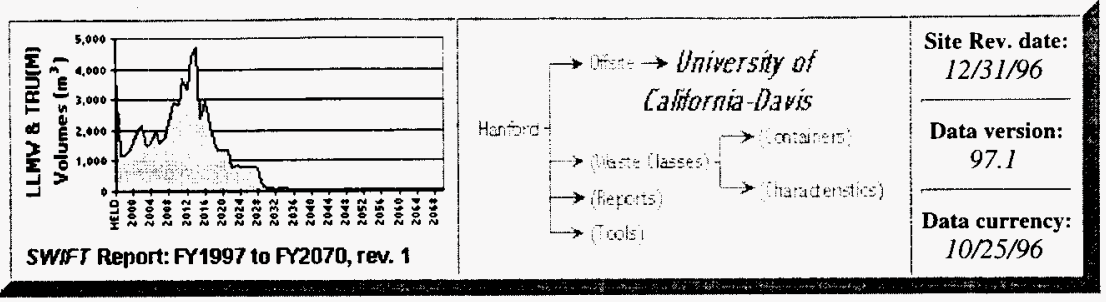

\section{Offsite - University of California-Davis}

\section{Contents}

» Highlights

»Annual Volumes

»Comparison to Previous Baseline(s)

"Background
» Forecast Assumptions and Comments

» Other University of California-Davis Forecast Data

»Detailed Forecast Data

\section{Highlights}

- The solid waste forecast life cycle for the University of California - Davis generator ends in 2003.

- No LLMW and TRU(M) waste is forecast from this generator.

- Only LLW is included in this forecast of solid waste to be shipped to Hanford.

\section{Annual Volumes}

\section{Annual Baseline Volumes}

No LLMW or TRU(M) waste is expected from this generator.

\section{Annual Baseline by Waste Class}

Not applicable.

\section{Comparison to Previous Baseline(s)}

As in FY96, this generator did not forecast any LLMW or TRU(M) waste for FY97 or for 97.1.

Comparison to Previous Baseline(s) by Waste Class 


\begin{tabular}{|c|c|c|c|}
\hline $\begin{array}{l}\text { Universitg of California-Davis Comparison: } \\
\text { Vaste Class }\end{array}$ & $\begin{array}{c}\text { FY97.1 } \\
\text { Forecast } \\
\left(\mathrm{m}^{3}\right)\end{array}$ & $\begin{array}{c}\text { FY97.0 } \\
\text { Forecast } \\
\text { (m") }\end{array}$ & $\begin{array}{l}\text { FY96 } \\
\text { Forecast } \\
\text { (m') }\end{array}$ \\
\hline LLW & 980 & 980 & 1,870 \\
\hline Tolar & sine & $s+9$ & 1.57 \\
\hline
\end{tabular}

Sum of totals may not add due to rounding: numbers over $10 \mathrm{~m}^{3}$ are rounded to the nearest $10 \mathrm{~m}^{3}$, numbers less than $10 \mathrm{~m}^{3}$ are rounded to integers, non-zero numbers less than 1 are rounded to 1.

\section{Background}

The current mission of University of California, Davis, generator is to remediate the site and turn it back over to the landlord by 2003 . LLW is a result of the remediation, and decontamination and decommissioning activities.

\section{Forecast Assumptions and Comments}

The assumption for this forecast is that DOE will maintain the level of funding indicated in the FYP ADSs for the site.

\section{Other Forecast Data}

- Low Level Waste

- A total of $980 \mathrm{~m}^{3}$ of LLW is expected from the University of California at Davis.

- This forecast shows a $48 \%$ decrease from the FY96 forecast of $1,870 \mathrm{~m}^{3}$, due mainly to more current information.

- $99 \%$ of this volume is to be contained in MB-IV boxes. 208 liter drums will contain the other $1 \%$.

- Most of the waste has the physical form of debris $(62 \%)$. Some of the volume is expected to be soil and soil/gravel (37\%), and organic solids are also forecast $(1 \%)$.

\section{- Hazardous Waste}

- No hazardous waste is expected from University of California-Davis for management by the CWC. 


\section{GENERATORS:}

Ames Laboratory-Ames, Iowa - Argonne National Laboratory-East - Bates Accelerator-Massachusetts - Battelle Columbus Laboratories - Bettis Atomic Power-Laboratory - Bettis Atomic Power-Shipyards - Brookhaven National Laboratory · Fermi National Accelerator Laboratory · General Atomics - Knolls Atomic Power-Laboratory - Knolls Atomic Power-Shipyards - Lawrence Berkeley Laboratory - Paducah Energy Systems - Pearl Harbor Naval Shipyards . Portsmouth Energy Systems - Portsmouth Naval Shipyards - Princeton Plasma Physics Laboratory - Puget Sound Naval Shipyards - Rockwell-Canoga Park - Rocky Flats - Stanford Lincar Accelerator Center - University of California-Davis . University of Utah

\section{PROGRAMS:}

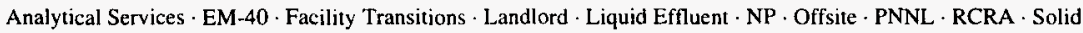
Waste $\cdot$ SNF - TWRS

\begin{tabular}{|c|c|}
\hline $\begin{array}{c}\text { CHARACTERISTICS: } \\
\text { CH_LLMW } \cdot \text { RH_LLMW } \cdot \text { CH_TRU(M) } \cdot \text { RH_TRU(M) }\end{array}$ & $\begin{array}{c}\text { CONTAINERS: } \\
\text { GTC III } \cdot \text { LLW } \cdot \text { HAZ }\end{array}$ \\
$\begin{array}{c}\text { CH_LLMW } \cdot \text { RH_LLMW } \cdot \text { CH_TRU(M) } \\
\text { RH_TRU(M) } \cdot \text { GTC III } \cdot \text { LLW } \cdot \text { HAZ }\end{array}$ \\
CH_LLMW $\cdot$ RH_LLMW $\cdot$ CH_TRU(M) $\cdot$ RH_TRU(M) $\cdot$ GTC III $\cdot$ LLW $\cdot$ HAZ
\end{tabular}

NOTICE: This page is provided subject to our disclaimer. Contact: Oscar Valero at (509) 373-4752.

HNF-EP-0918 rev. 1 Approved for public release; distribution is unlimited. 
THIS $1,+\cdots, y$

$-1$ 
cשU $L=$ IBpoI

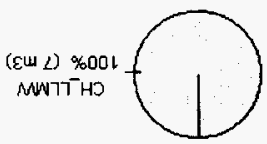

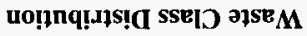

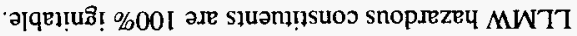

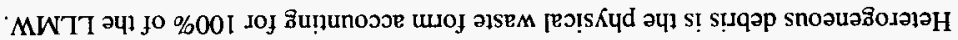

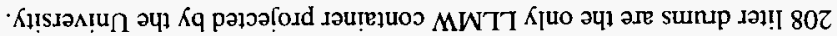

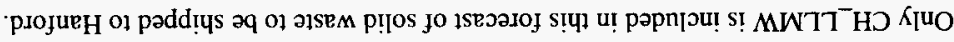

чче]ก jo K!!

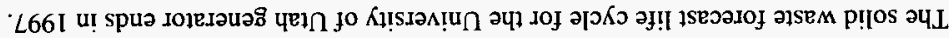

ง148ิ!|บช์!H

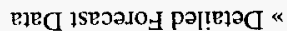

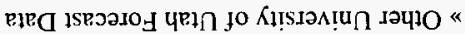

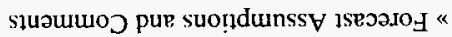
puno.ริyวeg *

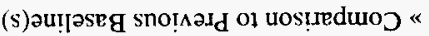 soun $0 \wedge$ jenuu $\forall$ * งาบชีเ!บฮิ!H «

sาuวนบ0ว

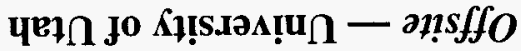

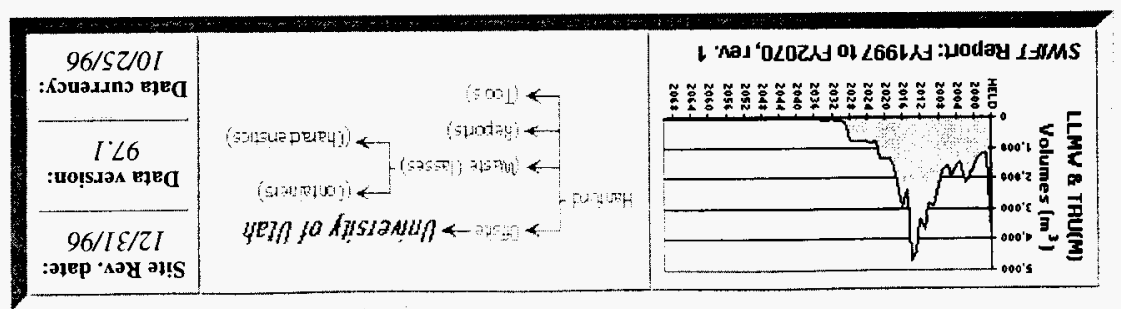


Physical Waste Form Distribution Hazardous Constituent Distribution
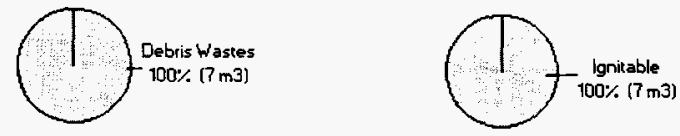

Total $=7 \mathbf{m 3}$

Total $=7 \mathrm{m3}$

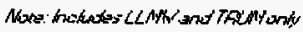

\section{Container Distribution}

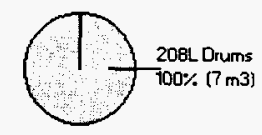

Total $=7 \mathrm{~m} 3$

Sum of totals may not add due to rounding: numbers over $10 \mathrm{~m}^{3}$ are rounded to the nearest $10 \mathrm{~m}^{3}$, numbers less than $10 \mathrm{~m}^{3}$ are rounded to integers, non-zero numbers less than 1 are rounded to $l$.

\section{Annual Volumes}

\section{Annual Baseline Volumes}

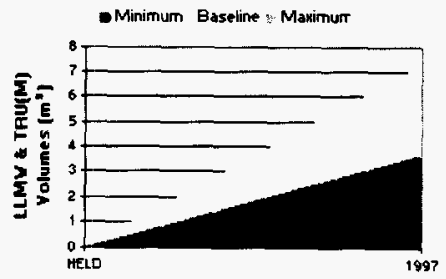

Annual Baseline by Waste Class 


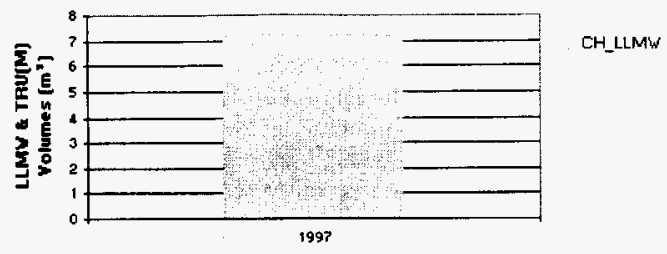

\section{Comparison to Previous Baseline(s)}

The entire amount of $7 \mathrm{~m}^{3}$ of LLMW is an increase over the FY96 forecast of $0 \mathrm{~m}^{3}$, primarily because analytical samples are being designated as waste.

\section{Comparison to Previous Baseline(s) by Waste Class}

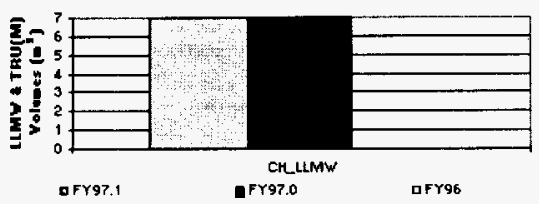

\begin{tabular}{|c|c|c|c|}
\hline $\begin{array}{l}\text { University of Utah Comparison: } \\
\text { Yaste Class }\end{array}$ & $\begin{array}{c}\text { FY97.1 } \\
\text { Forecast } \\
{\left[\mathrm{m}^{2}\right)}\end{array}$ & $\begin{array}{c}\text { FY97.0 } \\
\text { Forecast } \\
{\left[\mathrm{m}^{2}\right]}\end{array}$ & $\begin{array}{l}\text { FY96 } \\
\text { Forecast } \\
\text { (m) }\end{array}$ \\
\hline CHLLMW & 7 & 7 & 0 \\
\hline Sowpored & 7 & 5 & $\theta$ \\
\hline LLW & 7 & 7 & 20 \\
\hline rapey & 18 & 10 & 28 \\
\hline
\end{tabular}

Sum of totals may not add due to rounding: numbers over $10 \mathrm{~m}^{3}$ are rounded to the nearest $10 \mathrm{~m}^{3}$, numbers less than $10 \mathrm{~m}^{3}$ are rounded to integers, non-zero numbers less than $I$ are rounded to $I$.

\section{Background}

The University of Utah is involved in the disposal of laboratory wastes and biological samples from the Beagle study.

\section{Forecast Assumptions and Comments}

The minimum and maximum percentages are $50 \%$ and $100 \%$ of the baseline volume. The minimum percentage is based on the non-radioactive wastes being sent for incineration.

The forecast is based on the assumption that all animal samples will be designated as waste by the DOE.

\section{Other Forecast Data}


- A total of $7 \mathrm{~m}^{3}$ of LLW is expected from the University of Utah.

- This forecast shows a $65 \%$ decrease from the FY96 forecast of $20 \mathrm{~m}^{3}$, because some waste has been recharacterized as LLMW, and because CWC is not the first option for waste disposal.

- 208 liter drums are also the only container expected for LLW shipments.

- Heterogeneous debris is the physical waste form which accounts for $100 \%$ of the LLW.

\section{- Hazardous Waste}

- No hazardous waste is expected from University of Utah for management by the CWC.

\begin{tabular}{|c|c|}
\hline \multicolumn{2}{|c|}{ 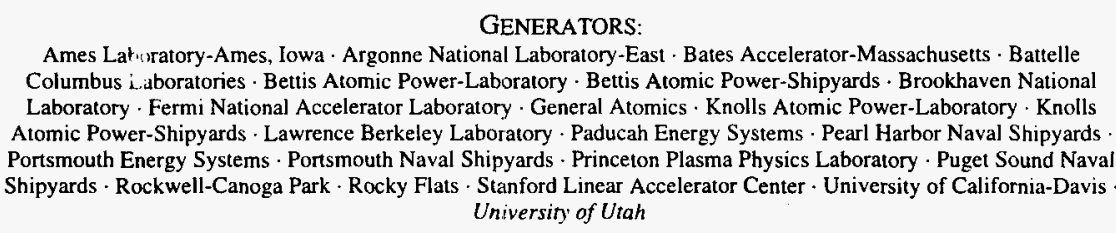 } \\
\hline \multicolumn{2}{|c|}{$\begin{array}{c}\text { PROGRAMS: } \\
\text { Analytical Services } \cdot \text { EM-40 } \cdot \text { Facility Transitions } \cdot \text { Landlord } \cdot \text { Liquid Effluent } \cdot \text { NP } \cdot \text { Offsite } \cdot \text { PNNL } \cdot \text { RCRA } \cdot \text { Solid } \\
\text { Waste } \cdot \text { SNF } \cdot \text { TWRS }\end{array}$} \\
\hline $\begin{array}{l}\text { CHARACTERISTICS: } \\
\text { CH_LLMW } \cdot \text { RH_LLMW } \cdot \text { CH_TRU(M) } \cdot \text { RH_TRU(M) } \\
\text { GTC III } \cdot \text { LLW } \cdot \text { HAZ }\end{array}$ & $\begin{array}{l}\text { CONTAINERS: } \\
\text { CH_LLMW } \cdot \text { RH_LLMW } \cdot \text { CH_TRU(M) } \\
\text { RH_TRU(M) } \cdot \text { GTC III } \cdot \text { LLW } \cdot \text { HAZ }\end{array}$ \\
\hline \multicolumn{2}{|c|}{$\begin{array}{l}\text { WASTE CLASSES: } \\
\text { CH_LLMW } \cdot \mathrm{RH}_{-} L L M W \cdot \mathrm{CH}_{-} \text {TRU(M) } \cdot \mathrm{RH}_{-} \text {TRU(M) } \cdot \text { GTC III } \cdot \text { LLW } \cdot \text { HAZ }\end{array}$} \\
\hline
\end{tabular}

NOTICE: This page is provided subject to our disclaimer. Contact: Oscar Valero at (509) 373-4752. HNF-EP-0918 rev. 1 Approved for public release; distribution is unlimited. 


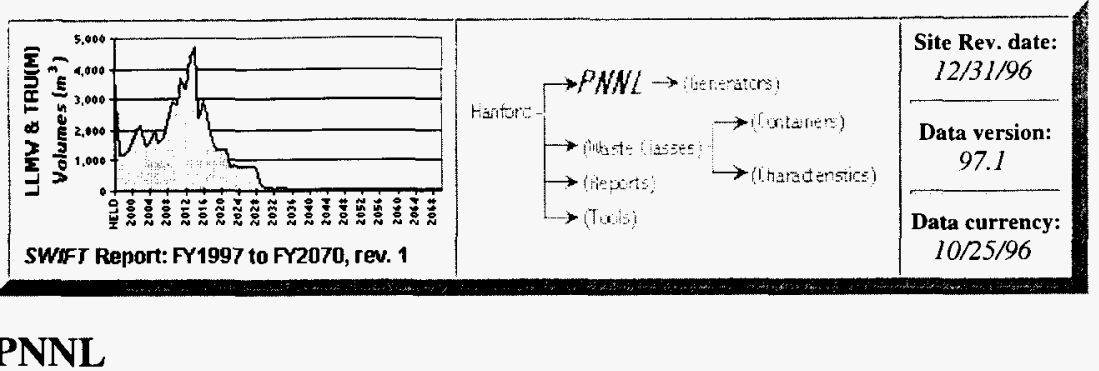

\section{Contents}

"Highlights

" Annual Waste Class Volumes

"Summary Table

»Comparison to Previous Baseline(s)
\Background

" Forecast Assumptions and Comments

»Other PNNL Forecast Data

\section{Highlights}

- The forecast life cycle for the PNNL Program Area ends in 2010.

- The life cycle total of LLMW and TRU(M) waste for PNNL is $900 \mathrm{~m}^{3}$, or $1 \%$ of the Hanford total.

- This forecast shows a $76 \%$ decrease from the FY96 forecast of $3,740 \mathrm{~m}^{3}$, due to a reduction in the forecast PNNL life cycle (from 2070 to 2010) as well as updated planning assumptions.

- This forecast shows a $70 \mathrm{~m}^{3}$ decrease from FY97.0 since the 324 and 327 Buildings have been transferred to Facility Transitions.

- CH_LLMW is the primary waste class generated, representing $54 \%\left(490 \mathrm{~m}^{3}\right)$ of the waste volume.

- 208 liter drums compose $67 \%$ of the LLMW and TRU(M) waste volume, SWBs are used for $20 \%$, and $13 \%$ is in MB-IV boxes.

- Many physical waste forms are expected from PNNL. Most of the volume should be debris (56\%), lab packs (20\%), and shielding (13\%). Smaller volumes represent special waste (4\%), organic solids (4\%), and inorganic solids (3\%).

- The LLMW and TRUM waste hazardous constituents are very diverse. Mixed corrosive, metals without mercury, state regulated constituents are the most common at $24 \%$ of the volume. Organic constituents account for $18 \%$ of the volume, metals without mercury are $13 \%$, mixed metals without mercury, organic, state regulated is $11 \%$. Various other hazardous constituents compose the remaining $34 \%$. 


\section{Waste Class Distribution}

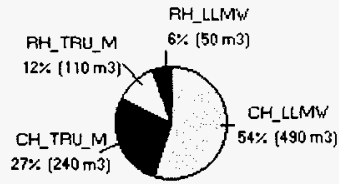

Total $=900 \mathrm{~m} 3$

Physical Waste Form Distribution

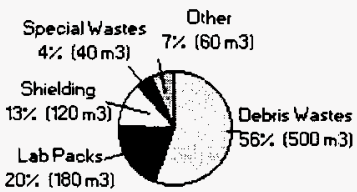

Total $=900 \mathrm{m3}$

\section{Generator Distribution}

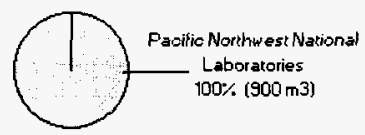

Total $=\mathbf{9 0 0} \mathrm{m3}$

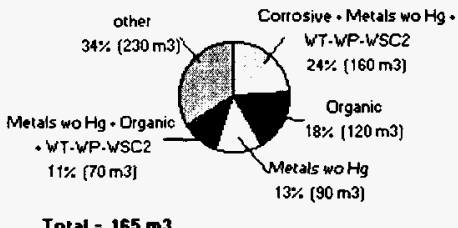

Total $=165 \mathrm{m3}$

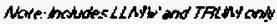

\section{Container Distribution}

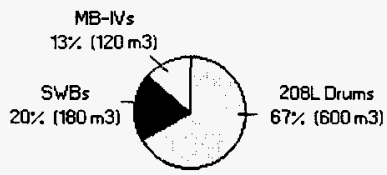

Total $=900 \mathrm{m3}$

Sum of totals may not add due to rounding: numbers over $10 \mathrm{~m}^{\mathrm{s}}$ are rounded to the nearest $10 \mathrm{~m}^{3}$, numbers less than $10 \mathrm{~m}^{3}$ are rounded to integers, non-zero numbers less than 1 are rounded to $\mathrm{J}$.

\section{Annual Waste Class Volumes}

PNNL will generate waste at a constant rate throughout the remainder of the life cycle.

\section{Annual Baseline Volumes}




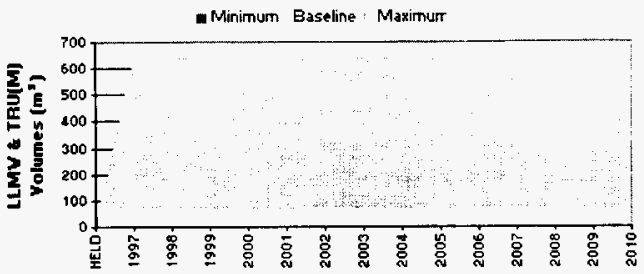

\section{Annual Baseline by Waste Class}

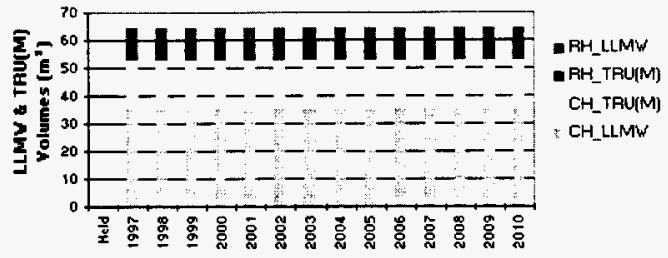

\section{Summary Table (Volumes in $\mathrm{m}^{3}$ )}

\begin{tabular}{|c|c|c|c|c|c|c|}
\hline $\begin{array}{l}\text { Pacific Northerest National Laboratories Summary: } \\
\text { Generator }\end{array}$ & CH LLMV & RH LLMY & CH TRU(M) & RH TRUPU] & Subtotal & PCT \\
\hline Pacific Northwest National Laboratories & 490 & 50 & 240 & 110 & 900 & $100 \%$ \\
\hline Tord & 158 & 58 & 219 & 110 & $\sin$ & $100 \%$ \\
\hline PCT & $54 \%$ & $6 \%$ & $27 \%$ & $12 \%$ & $99 \%$ & \\
\hline
\end{tabular}

Sum of totals may not add due to rounding: numbers over $10 \mathrm{~m}^{3}$ are rounded to the nearest $10 \mathrm{~m}^{3}$, numbers less than $10 \mathrm{~m}^{3}$ are rounded to integers, non-zero numbers less than $I$ are rounded to $I$.

\section{Comparison to Previous Baseline(s)}

The FY97.1 forecast shows a significant decrease from the FY96 forecast of $3,740 \mathrm{~m}^{3}$. One key reason for this reduction is the change in life cycle from 2070 to 2010 . This change in life cycle is a result of the following new assumptions: 1) the 300 Area will be closed down by 2010, and 2) PNNL will be sending any subsequent radioactive solid waste to a disposal site other than Hanford.

In addition to overall reductions in waste estimates, LLMW greater-than-category III shows a significant reduction from $530 \mathrm{~m}^{3}$ to $0 \mathrm{~m}^{3}$. This reduction arises because PNNL only included that waste or potential waste for which a disposal pathway exists.

\section{Comparison to Previous Baseline(s) by Waste Class}




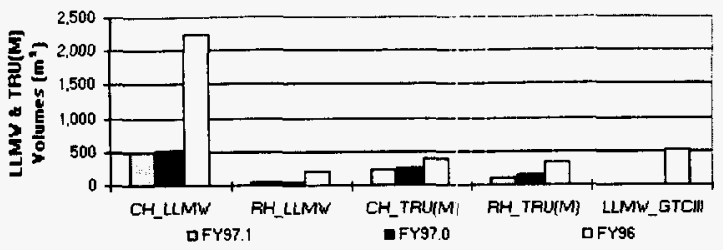

\begin{tabular}{|c|c|c|c|}
\hline $\begin{array}{l}\text { PNNL Comparison: } \\
\text { Waste Cless }\end{array}$ & $\begin{array}{c}\text { FY97.1 } \\
\text { Forecast } \\
\left(\mathrm{m}^{3}\right)\end{array}$ & $\begin{array}{c}\text { FY97.0 } \\
\text { Forecast } \\
\text { (m) }\end{array}$ & $\begin{array}{c}\text { FY96 } \\
\text { Forecast } \\
\text { (m) }\end{array}$ \\
\hline $\mathrm{CH}$ LLMMN & 490 & 510 & 2,250 \\
\hline RH LLMN & 50 & 50 & 220 \\
\hline $\mathrm{CH}, \mathrm{TRU}(\mathrm{M})$ & 240 & 250 & 390 \\
\hline RH_TRU(M) & 110 & 150 & 350 \\
\hline LLMN GTCIII & 임 & 0 & 530 \\
\hline Subtotesf & 900 & 970 & 3,740 \\
\hline LLW & 7,880 & 8,780 & 53,280 \\
\hline LLW GTCIII & 0 & 0 & 350 \\
\hline Total & 8780 & 3.750 & 57,370 \\
\hline
\end{tabular}

Sum of totals may not add due to rounding: numbers over $10 \mathrm{~m}^{3}$ are rounded to the nearest $10 \mathrm{~m}^{3}$, numbers less than $10 \mathrm{~m}^{3}$ are rounded to integers, non-zero numbers less than 1 are rounded to 1.

\section{Background}

PNNL is a national research laboratory that conducts research for DOE, other government agencies, and private industry to solve problems of national importance. Solid waste is generated on an ongoing basis during research and decontamination activities. Operational and clean-out waste generated prior to transitioning facilities from PNNL are included.

\section{Forecast Assumptions and Comments}

The 324 and 327 facilities were transferred from PNNL to the M\&I contractor on 11/1/96; these facilities are no longer included as separate generators in this forecast but are included in the Facility Transitions program.

The minimum and maximum ranges for this waste are $1 \%$ and $1,000 \%$ respectively, and are based on the variability in Research and Development projects.

\section{Other Forecast Data}

\section{- Low Level Waste}

- A total of $7,880 \mathrm{~m}^{3}$ of LLW is expected from PNNL.

- This forecast shows an $85 \%$ decrease from the FY96 forecast of $53,630 \mathrm{~m}^{3}$, again due to a reduction in life cycle as well as changes in planning assumptions. There is also a $900 \mathrm{~m}^{3}$ decrease from the FY97.0 volume of 8,780 due to the transition of 324 and 327 to Facility Transitions.

- LLW containers include MB-IV boxes (61\%), MB-V boxes (18\%), 208 liter drums (15\%), and 322 liter drums $(6 \%)$. 
- Physical LLW forms are $100 \%$ debris (heterogeneous debris totals $89 \%$ of the forecast).

- Hazardous Waste

- No hazardous waste is expected from PNNL for management by the CWC.

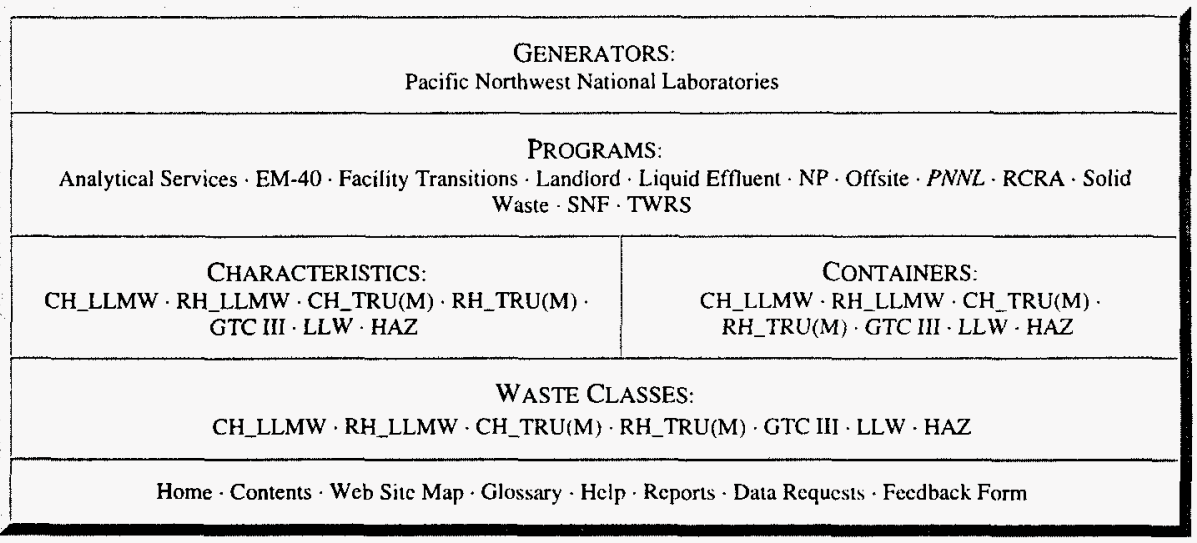

NOTICE: This page is provided subject to our disclaimer. Contact: Oscar Valero at (509) 373-4752. HNF-EP-0918 rev. 1 Approved for public release; distribution is unlimited. 


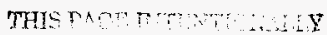
l.... s.ivis. 


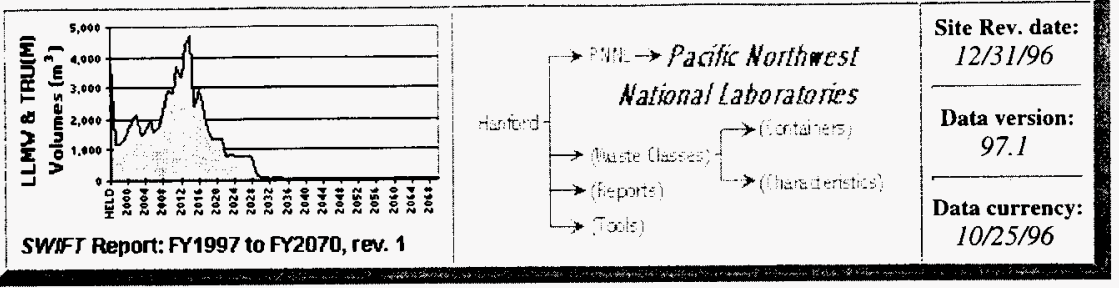

\section{$P N N L$ - Pacific Northwest National Laboratories}

Because Pacific Northwest National Laboratories is the only generator within the PNNL program that will ship waste to the CWC, waste information for this generator is identical to that found on the program page.

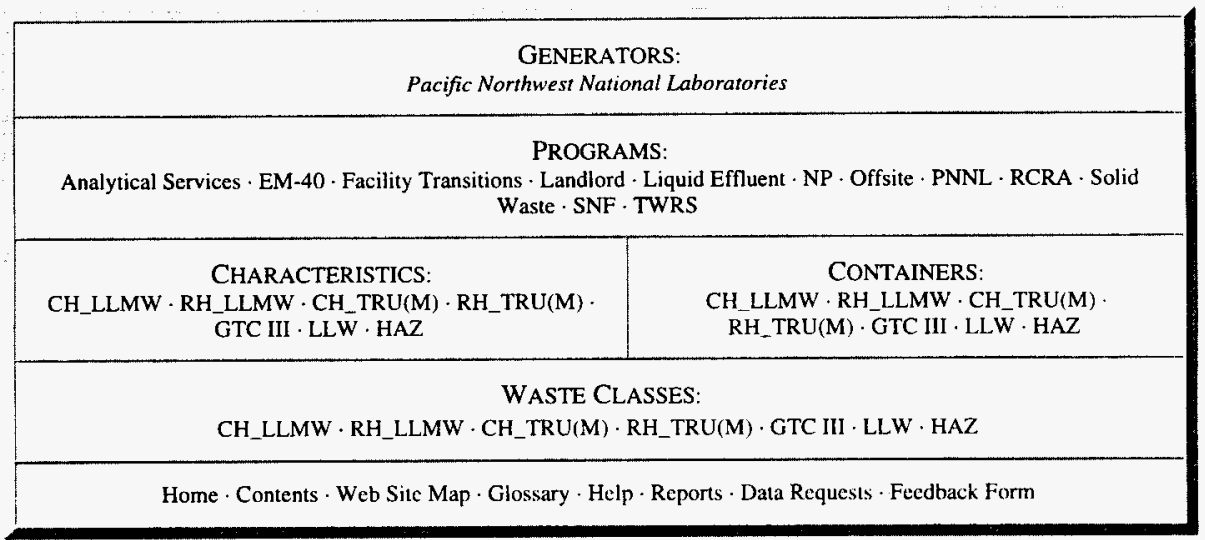

NOTICE: This page is provided subject to our disclaimer. Contact: Oscar Valero at (509) 373-4752.

HNF-EP-0918 rev. 1 Approved for public release; distribution is unlimited. 
THIS PAR "?

h. . ....... 


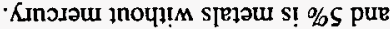

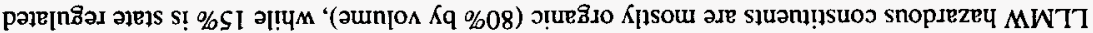

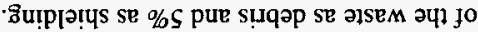

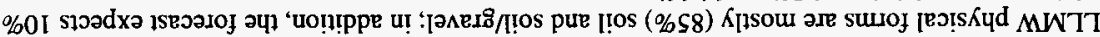

$\cdot(\%$ (I) sunup Iə!!̣

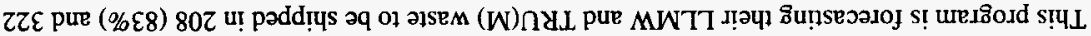

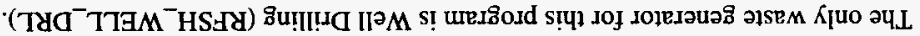

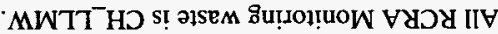

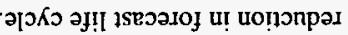

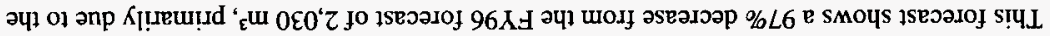
әч] jo \%[> 10 "

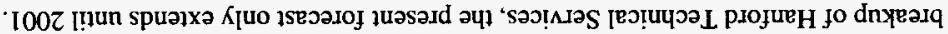

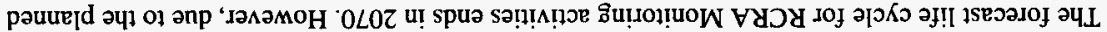

ราบชึ!บธึ!ก

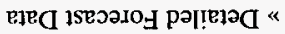

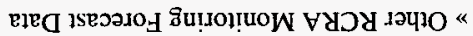

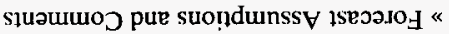
punoנ8̊xəeg * (s)əuṭəseg snoțəدd of uostreduo «

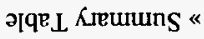
soun[o $\Lambda$ sselD əุse $M$ fenuu งฺบริ!!บธิ!H «

รquวนบ0ว

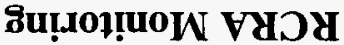

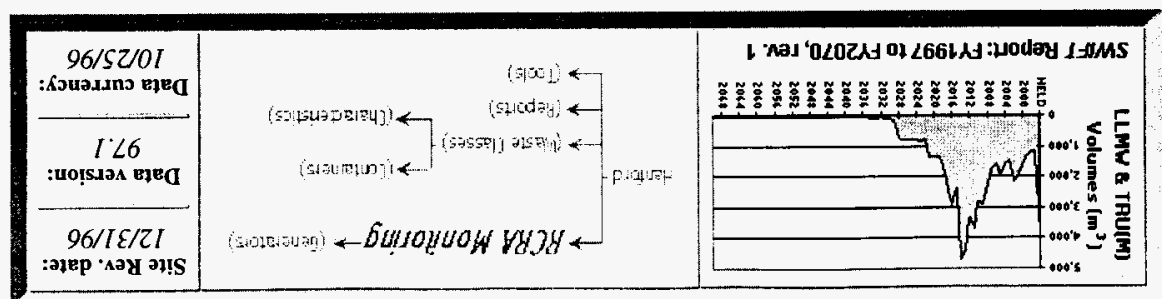


Waste Class Distribution

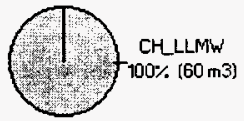

Total $=60 \mathrm{m3}$

Physical Waste Form Distribution

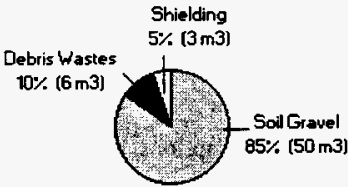

Total $=60 \mathrm{~m} 3$
Generator Distribution

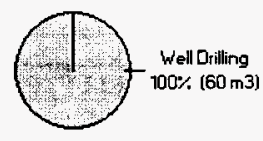

Total $=60 \mathrm{m3}$

\section{Hazardous Constituent Distribution}

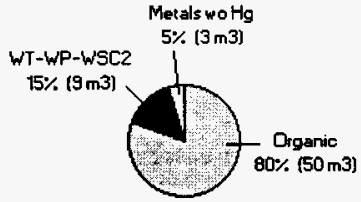

Total $=60 \mathrm{m3}$

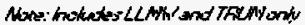

\section{Container Distribution}

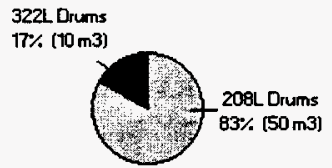

Total $=60 \mathrm{m3}$

Sum of totals may not add due to rounding: numbers over $10 \mathrm{~m}^{3}$ are rounded to the nearest $10 \mathrm{~m}^{3}$, numbers less than $10 \mathrm{~m}^{3}$ are rounded to integers, non-zero numbers less than $I$ are rounded to 1 .

\section{Annual Waste Class Volumes}

RCRA Monitoring waste will be generated on a steady basis from 1997 to 2001 , as a result of yearly well drilling operations. Waste generated for this activity after 2001 will be the responsibility of a new (currently unidentified) generator.

Annual Baseline Volumes 


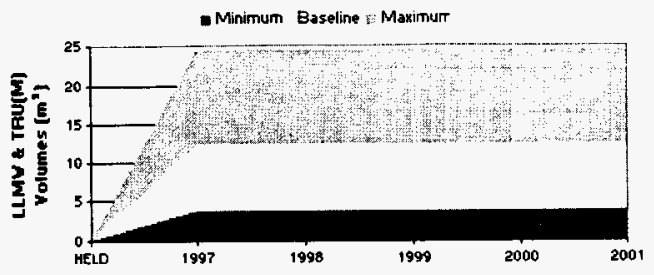

\section{Annual Baseline by Waste Class}

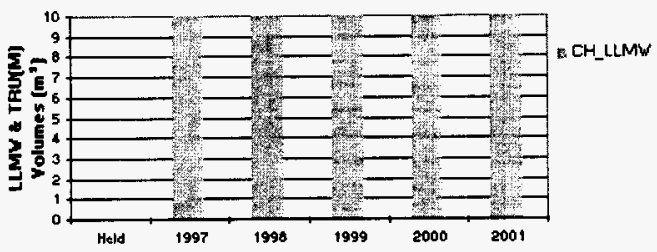

\section{Summary Table (Volumes in $\mathbf{m}^{3}$ )}

\begin{tabular}{|c|c|c|c|}
\hline $\begin{array}{l}\text { RCRA Summars: } \\
\text { Generator }\end{array}$ & CH LLMY & surpore & PCT \\
\hline Well Drilling & 60 & 60 & $100 \%$ \\
\hline Total & 60 & 60 & $\cos :$ \\
\hline PCT & $100 \%$ & thess & \\
\hline
\end{tabular}

Sum of totals may not add due to rounding: numbers over $10 \mathrm{~m}^{3}$ are rounded to the nearest $10 \mathrm{~m}^{3}$, numbers less than $10 \mathrm{~m}^{3}$ are rounded to integers, non-zero numbers less than $l$ are rounded to 1.

\section{Comparison to Previous Baseline(s)}

The FY97.1 waste forecast for RCRA Monitoring of $60 \mathrm{~m}^{3}$ shows a $97 \%$ decrease from the FY96 forecast of $2,030 \mathrm{~m}^{3}$. This program has limited the life cycle to 5 years due to uncertain programmatic responsibility as a result of the PHMC transition.

An additional reason for the reduction in forecast is that the generator this year has forecast a reduction in well drilling work scope (only 1 well is currently planned to be drilled per year while last year's forecast included estimates based on drilling 5 wells per year).

The 1996 hazardous constituents forecast showed that most of the LLMW was state regulated $(89 \%)$ and that organics represented $7 \%$. The current forecast expects organic constituents to be the majority $(80 \%)$ and state regulated to be second. Also, last year's forecast had relatively less metals without mercury, but had corrosives forecast, which are not expected for 1997.

\section{Comparison to Previous Baseline(s) by Waste Class}




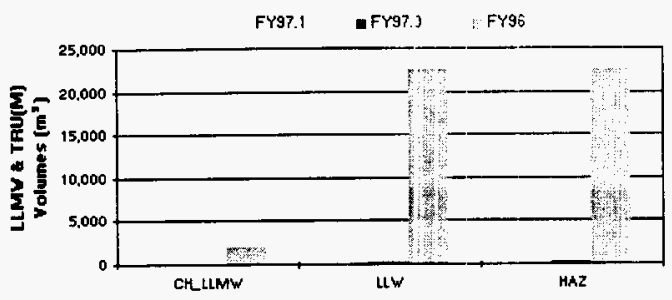

\begin{tabular}{|c|c|c|c|}
\hline $\begin{array}{l}\text { RCRA Monitoring Comparison: } \\
\text { Waste Class }\end{array}$ & $\begin{array}{c}\text { FY97.1 } \\
\text { Forecast } \\
\left(\mathrm{m}^{3}\right)\end{array}$ & $\begin{array}{l}\text { FY97.9 } \\
\text { Forecast } \\
\text { (m) }\end{array}$ & $\begin{array}{l}\text { FY96 } \\
\text { Forecast } \\
\text { (m) }\end{array}$ \\
\hline $\mathrm{CH}$ LLMN & 60 & 60 & 2,030 \\
\hline Subtotal & 60 & 60 & 2,030 \\
\hline LLW & 130 & 130 & 22,500 \\
\hline HAZ & 150 & 150 & 22,500 \\
\hline Total & 330 & 330 & 47,020 \\
\hline
\end{tabular}

Sum of totals may not add due to rounding: numbers over $10 \mathrm{~m}^{3}$ are rounded to the nearest $10 \mathrm{~m}^{3}$, numbers less than $10 \mathrm{~m}^{3}$ are rounded to integers, non-zero numbers less than $I$ are rounded to 1.

\section{Background}

The mission of RCRA Monitoring Well Drilling is to monitor groundwater for potential contamination and to ensure that radioactive and hazardous materials are not leaving the site. There is only one generator within the RCRA Monitoring program: Well Drilling (RFSH_WELL_DRL).

Waste generating activities include well installation, well remediation, well decommissioning, well maintenance, and some sampling and analysis work. Other than the non-regulated waste category and hazardous waste, Well Drilling operations generate drilling spills that are radioactive or mixed in nature, debris generated during facility renovation, and some laboratory wastes. These wastes may contain any of the radioactive and/or hazardous contaminants found on and under the Hanford site, however generation of TRU(M) waste is unlikely since RCRA monitoring wells are not expected to be located in highly contaminated areas.

\section{Forecast Assumptions and Comments}

The main assumption of the forecast on 6/96 was that Hanford Technical Services would be broken up and distributed to various contractors prior to the PHMC transition.

Estimates are based on past experiences and represent the confidence levels inherent in estimating uncertain quantities.

The minimum and maximum range for this waste is $30 \%$ and $200 \%$ of the baseline.

\section{Other Forecast Data}




\section{Low Level Waste}

- A total of $130 \mathrm{~m}^{3}$ of LLW is expected from RCRA Monitoring until 2001.

- This forecast shows a $99 \%$ decrease from the FY96 forecast of $22,500 \mathrm{~m}^{3}$, primarily due to the reduction in forecast lifecycle.

- All RCRA Monitoring LLW is contact-handled.

- $76 \%$ of the LLW will be shipped in 208 liter drums. MB-V boxes will be used for $16 \%$, and 322 liter drums will be used for $8 \%$.

- LLW forms are mostly (77\%) soil and soil/gravel while the rest is debris (23\%).

- Hazardous Waste

- A total of $150 \mathrm{~m}^{3}$ of hazardous waste is expected from RCRA Monitoring until 2001 for management by the CWC.

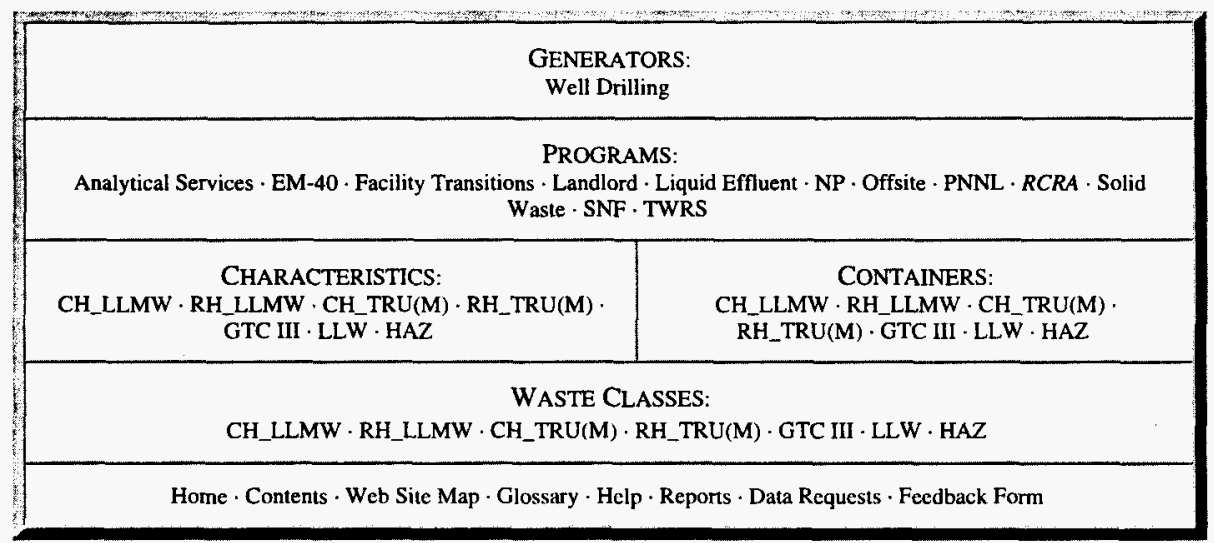

NOTICE: This page is provided subject to our disclaimer. Contact: Oscar Valero at (509) 373-4752.

HNF-EP-0918 rev. 1 Approved for public release; distribution is unlimited. 


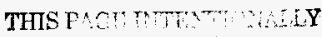

lie: blidve 


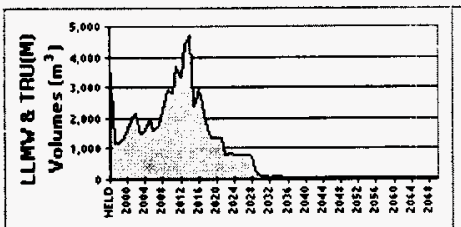

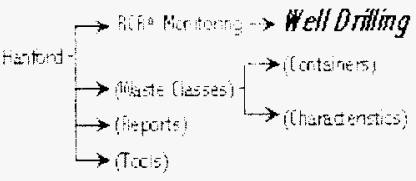

Site Rev. date: $12 / 31 / 96$

Data version: 97.1

Data currency: SWFI Report: FY1997 to FY2070, rev. 1 $10 / 25 / 96$

\section{RCRA Monitoring - Well Drilling}

Because Well Drilling is the only generator within the RCRA Monitoring program that will ship waste to the CWC, waste information for this generator is identical to that found on the program page.

\begin{tabular}{|c|c|}
\hline \multicolumn{2}{|c|}{$\begin{array}{l}\text { GENERATORS: } \\
\text { Well Drilling }\end{array}$} \\
\hline \multicolumn{2}{|c|}{$\begin{array}{l}\text { PROGRAMS: } \\
\text { Analytical Services } \cdot \text { EM-40 } \cdot \text { Facility Transitions } \cdot \text { Landlord } \cdot \text { Liquid Effluent } \cdot \text { NP } \cdot \text { Offsite } \cdot \text { PNNL } \cdot \text { RCRA } \cdot \text { Solid } \\
\text { Waste } \cdot \text { SNF } \cdot \text { TWRS }\end{array}$} \\
\hline $\begin{array}{l}\text { CHARACTERISTICS: } \\
\text { CH_LLMW } \cdot \text { RH_LLMW } \cdot \text { CH_TRU(M) } \cdot \text { RH_TRU(M) } \\
\text { GTC III } \cdot \text { LLLW } \cdot \text { HAZ }\end{array}$ & $\begin{array}{l}\text { CONTAINERS: } \\
\text { CH_LLMW } \cdot \text { RH_LLMW } \cdot \text { CH_TRU(M) } \\
\text { RH_TRU(M) } \cdot \text { GTC III } \cdot \text { LLW } \cdot \text { HAZ }\end{array}$ \\
\hline \multicolumn{2}{|c|}{$\begin{array}{l}\text { WASTE CLASSES: } \\
\text { CH_LLMW } \cdot \text { RH_LLMW } \cdot \text { CH_TRU(M) }_{-} \cdot \text { RH_TRU(M) }_{-} \cdot \mathrm{GTC} \text { III } \cdot \text { LLW } \cdot \text { HAZ }\end{array}$} \\
\hline
\end{tabular}

NOTICE: This page is provided subject to our disclaimer. Contact: Oscar Valero at (509) 373-4752.

HNF-EP-0918 rev. 1 Approved for public release; distribution is unlimited. 
THE PACR T THY

Li. W ive 


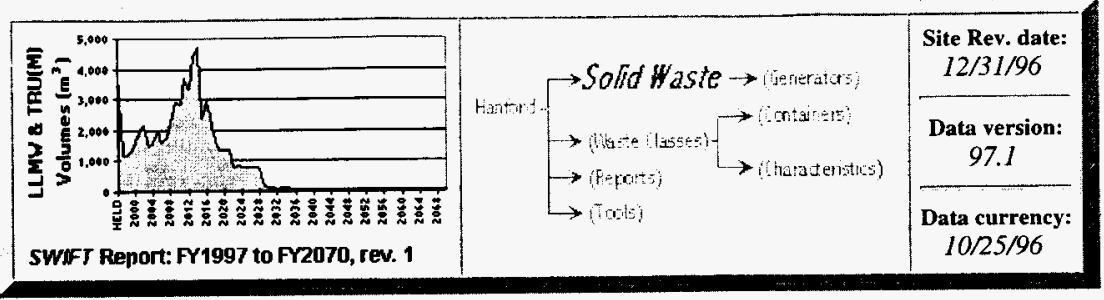

\section{Solid Waste}

\section{Contents}

" Highlights

"Annual Waste Class Volumes

»Summary Table

»Comparison to Previous Baseline(s)
" Background

» Forecast Assumptions and Comments

»Other Solid Waste Forecast Data

\section{Highlights}

- The forecast life cycle for Solid Waste ends in 2070.

- The life cycle generation total of LLMW and TRU(M) waste for Solid Waste is $400 \mathrm{~m}^{3}$, or $1 \%$ of the Hanford total.

- This forecast shows a $4 \%$ decrease from the FY96 forecast of $420 \mathrm{~m}^{3}$.

- CH_LLMW is the primary waste class generated, representing $78 \%\left(310 \mathrm{~m}^{3}\right)$ of the Solid Waste volume.

- T Plant is the major source of waste, generating $74 \%\left(300 \mathrm{~m}^{3}\right)$ of the waste volume.

- $52 \%$ of the LLMW and TRU(M) waste will be shipped in Medium boxes, with $48 \%$ in 208 liter drums.

- Physical waste forms are forecast to be mainly debris ( $85 \%$ of the volume). Inorganic solids account for $8 \%$, and shielding accounts for $5 \%$. The remaining $2 \%$ is composed of lab pack, soil/gravel, special waste, and organic solids.

- LLMW and TRU(M) waste hazardous constituents are $50 \%$ (by volume) organic, $18 \%$ metals with mercury, $13 \%$ state regulated, and $10 \%$ metals without mercury. Corrosive constituents represent $5 \%$ of the waste, while ignitable and reactive metals each represent $2 \%$. 


\section{Waste Class Distribution}

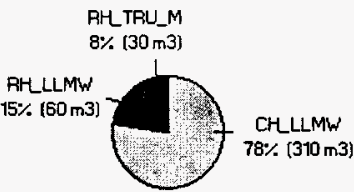

Totel $=400 \mathrm{m3}$

Physical Waste Form Distribution

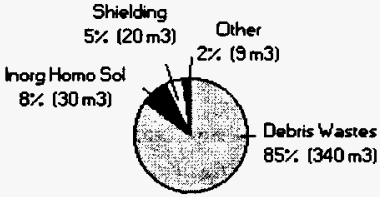

Total $=400 \mathrm{m3}$

\section{Generator Distribution}

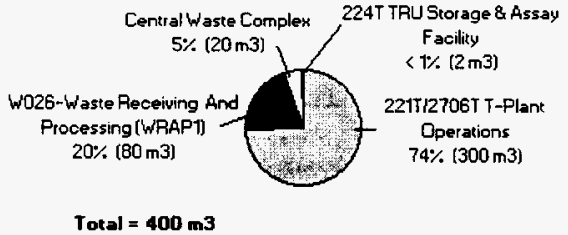

Hazardous Constituent Distribution

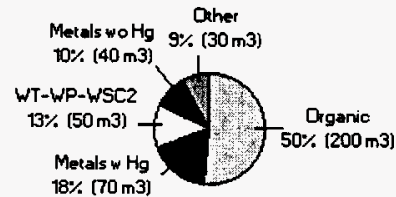

Total $=400 \mathrm{~m} 3$

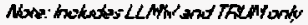

\section{Container Distribution}

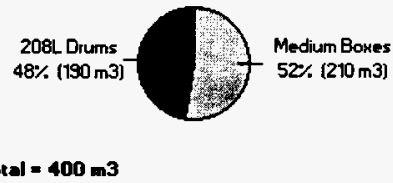

Sum of totals may not add due to rounding: numbers over $10 \mathrm{~m}^{3}$ are rounded to the nearest $10 \mathrm{~m}^{3}$, numbers less than $10 \mathrm{~m}^{3}$ are rounded to integers, non-zero numbers less than $I$ are rounded to 1 .

\section{Annual Waste Class Volumes}

Solid Waste will be generating waste from 1997 to the end of life cycle in 2070 . An initial peak of waste (about $25 \mathrm{~m}^{3}$ per year) will be generated from 1997 to 2000 , during T Plant canyon clean-up and upgrades. From 2001 to 2027, the major source of the waste will be ongoing activities at T Plant (about $7 \mathrm{~m}^{3}$ per year). As of 2028 , waste generation will drop to around $1 \mathrm{~m}^{3}$ per year, arising from general waste management activities.

\section{Annual Baseline Volumes}




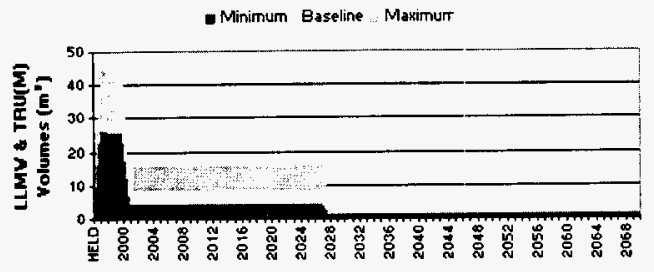

\section{Annual Baseline by Waste Class}

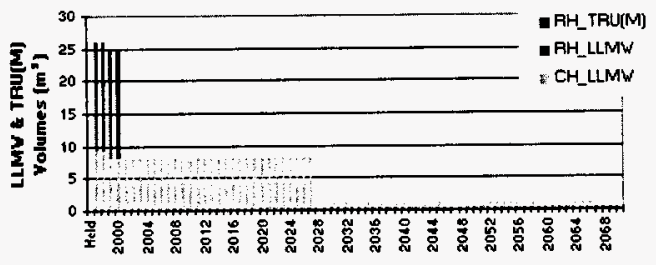

\section{Summary Table (Volumes in $\mathbf{m}^{3}$ )}

\begin{tabular}{|c|c|c|c|c|c|}
\hline $\begin{array}{l}\text { Solid Yaste Summary: } \\
\text { Generator }\end{array}$ & CH_LLMY & RH_LLMY & RH_TRU[M] & Subtotal & PCT \\
\hline 221 T2706T T-Plant Operations & 220 & 60 & 30 & 300 & $74 \%$ \\
\hline M026-Yvaste Receiving And Processing (MRAP1) & 80 & 0 & of & 80 & $20 \%$ \\
\hline Central Waste Compiex & 20 & 0 & 0 & 20 & $5 \%$ \\
\hline 224T TRU Storage \& Assay Facilty & 2 & 0 & 0 & 2 & $<1 \%$ \\
\hline Totols & 310 & 60 & 30 & 400 & $100 \%$ \\
\hline PCT & $77 \%$ & $15 \%$ & $8 \%$ & $100 \%$ & \\
\hline
\end{tabular}

Sum of totals may not add due to rounding: numbers over $10 \mathrm{~m}^{3}$ are rounded to the nearest $10 \mathrm{~m}^{3}$, numbers less than $10 \mathrm{~m}^{3}$ are rounded to integers, non-zero numbers less than 1 are rounded 101 .

\section{Comparison to Previous Baseline(s)}

The FY97.1 forecast for Solid Waste of $400 \mathrm{~m}^{3}$ shows a $4 \%$ decrease from the FY96 forecast of $420 \mathrm{~m}^{3}$. While this overall volume change is relatively insignificant, there have been several changes to the mix of waste being generated. In particular, one major change to the baseline results from the fact that HEPA filters previously classified by the Low Level Burial Grounds as LLMW have been reclassified as LLW. In addition, 2 new generators have been added: the CWC and WRAP1. They will generate about $100 \mathrm{~m}^{3}$ of waste over their life cycle.

\section{Comparison to Previous Baseline(s) by Waste Class}




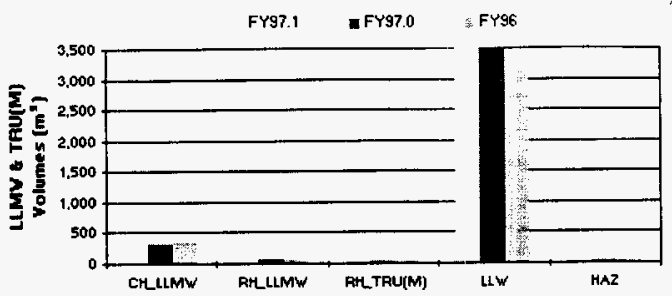

\section{Summary Table (Volumes in $\mathbf{m}^{3}$ )}

\begin{tabular}{|c|c|c|c|}
\hline $\begin{array}{l}\text { Solid Waste Comparison: } \\
\text { Waste Class }\end{array}$ & $\begin{array}{l}\text { FYg7.1 } \\
\text { Forecast } \\
\text { (m) }\end{array}$ & $\begin{array}{c}\text { FYgr.d } \\
\text { Forecest } \\
\left(\mathrm{m}^{2}\right)\end{array}$ & $\begin{array}{c}\text { Frg6 } \\
\text { Forecest } \\
\left(\mathrm{m}^{2}\right)\end{array}$ \\
\hline $\mathrm{CH}$ LLMN & 310 & 310 & 320 \\
\hline RH_LMMN & 60 & 60 & 70 \\
\hline RH_TRU(M) & 30 & 30 & 30 \\
\hline Subtotaf & 400 & 400 & 420 \\
\hline LLW & 3.500 & 3,500 & 3,090 \\
\hline HAZ & 30 & 30 & 40 \\
\hline Totel & 3930 & 3,930 & 3560 \\
\hline
\end{tabular}

Sum of totals may not add due to rounding: numbers over $10 \mathrm{~m}^{3}$ are rounded to the nearest $10 \mathrm{~m}^{3}$, numbers less than $10 \mathrm{~m}^{3}$ are rounded to integers, non-zero numbers less than $I$ are rounded to $I$.

\section{Background}

Solid Waste's mission is to receive, store, treat, decontaminate, and dispose of solid radioactive and nonradioactive hazardous waste in a safe, cost-effective and environmentally compliant manner. Secondary solid waste will be generated to achieve this mission.

The Solid Waste program has 4 LLMW and TRU(M) waste generators within its program: T Plant, the TRU Storage and Assay Facility (TRUSAF), Waste Receiving and Processing (WRAP1), and the Central Waste Complex (CWC). Additional waste volumes are expected from future treatment facilities; however, forecasts for these facilities are not available.

\section{Forecast Assumptions and Comments}

The minimum range reported for the Solid Waste program is $69 \%$ of baseline, and the maximum is $169 \%$ of baseline. The wide range in minimum to maximum volumes is primarily due to uncertainty in T Plant operations.

Solid Waste generators assume that operations in future years will be similar to the present. Furthermore, it is assumed that routine generation will not vary significantly over the period.

\section{Other Forecast Data}

\section{- Low Level Waste}

- A total of $3,500 \mathrm{~m}^{3}$ of LLW is expected from Solid Waste. 
- This forecast shows a $13 \%$ increase from the FY 96 forecast of $3,090 \mathrm{~m}^{3}$, primarily due to an increase in the $\mathrm{T}$ Plant estimate.

- MB-V boxes are expected to contain most LLW (82\%), followed by 322 liter drums (13\%) and 208 liter drums.

- Physical forms for LLW vary from $3 \%$ organic solids to $88 \%$ debris. Inorganic solids and soil/gravel are also forecast - in similar amounts ( $5 \%$ and $4 \%$ respectively).

\section{- Hazardous Waste}

- A total of $30 \mathrm{~m}^{3}$ of hazardous waste was reported by Solid Waste for management at the CWC.

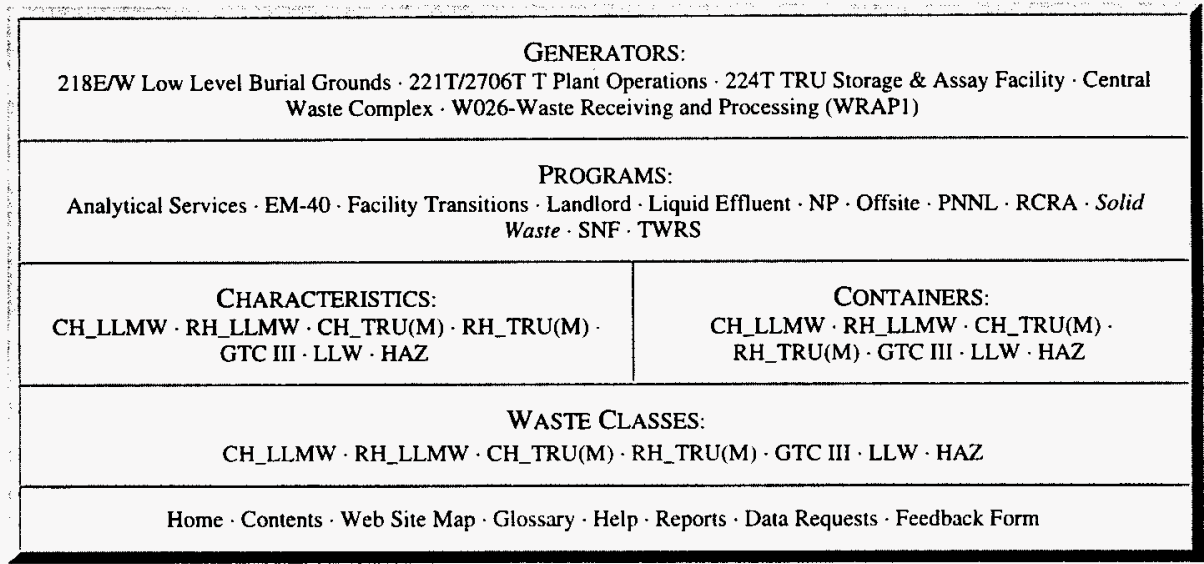

NOTICE: This page is provided subject to our disclaimer. Contact: Oscar Valero at (509) 373-4752.

HNF-EP-0918 rev. 1 Approved for public release; distribution is unlimited. 


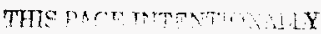
1.1. . anivis 


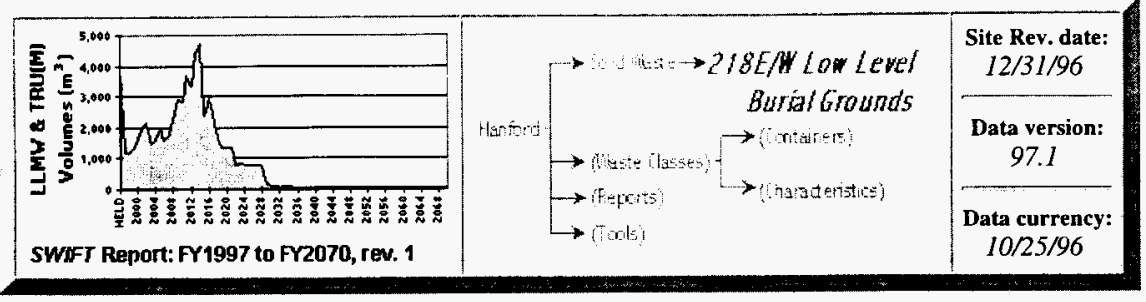

\section{Solid Waste - 218E/W Low Level Burial Grounds}

\section{Contents}

" Highlights

»Comparison to Previous Baseline(s)

" Background
》 Forecast Assumptions and Comments

»Other 218E/W Low Level Burial Grounds Forecast Data

»Detailed Forecast Data

\section{Highlights}

- The Low Level Burial Grounds (LLBG) estimate that no LLMW or TRU(M) waste will be generated during its life cycle.

- LLW is the only waste class generated.

- The LLBG forecast life cycle ends in 2070.

\section{Annual Volumes}

\section{Annual Baseline Volumes}

No LLMW or TRU(M) waste is expected from this generator.

\section{Annual Baseline by Waste Class}

Not applicable.

\section{Comparison to Previous Baseline(s)}

The LLBG waste forecast has decreased significantly from the $80 \mathrm{~m}^{3}$ of LLMW forecast in FY96. This decrease is a result of the fact that previous forecasts included CH_LLMW from HEPA filter changeout. HEPA filters are no longer considered mixed waste due to changes in WAC-173-303.

\section{Comparison to Previous Baseline(s) by Waste Class}




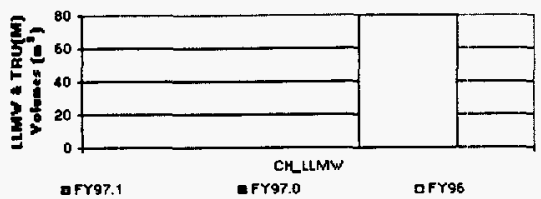

\begin{tabular}{|c|c|c|c|}
\hline $\begin{array}{l}\text { 218ErY Lou Level Burial Grounds Comparison: } \\
\text { Vaste Class }\end{array}$ & $\begin{array}{c}\text { FY97.1 } \\
\text { Forecast } \\
{\left[\mathbf{m}^{2}\right]}\end{array}$ & $\begin{array}{l}\text { FY97.0 } \\
\text { Forecast } \\
\text { (m'] }\end{array}$ & $\begin{array}{l}\text { FYss } \\
\text { Foreast } \\
\left(m^{2}\right)\end{array}$ \\
\hline $\mathrm{CH}$ LLMW & 0 & 0 & 80 \\
\hline soperat & 0 & 2 & $\theta$ \\
\hline LLW & 40 & 40 & 460 \\
\hline Totol & 10 & 4A & 59 \\
\hline
\end{tabular}

Sum of totals may not add due to rounding: numbers over $10 \mathrm{~m}^{3}$ are rounded to the nearest $10 \mathrm{~m}^{3}$, numbers less than $10 \mathrm{~m}^{3}$ are rounded to integers, non-zero numbers less than $I$ are rounded to $I$.

\section{Background}

The Low-Level Burial Grounds (RFSH_LLBG) forecasts only operational waste that results from disposing of LLW received by the CWC by burying the waste in trenches. Disposal of LLMW and TRU waste has occurred in the past; future disposal of mixed waste is planned in lined trenches.

\section{Forecast Assumptions and Comments}

It is assumed that LLBG operations in future years will be similar to current operations.

The planned TRU-retrieval project (W-113) may generate waste; it has not been forecasted.

The minimum waste range is $0 \%$ of the baseline, indicating the possibility that no waste will be generated. The maximum range of $100 \%$ is based on engineering judgment.

\section{Other Forecast Data}

\section{- Iow Level Waste}

- A total of $40 \mathrm{~m}^{3}$ of LLW is expected from the LLBG.

- This forecast shows a $91 \%$ decrease from the FY96 forecast of $460 \mathrm{~m}^{3}$; revised estimates are based on operating experience.

- All of the LLW is to be contained in 208 liter drums.

- Physical LLW forms from the LLBG split the volume equally between soil/gravel and plastic/rubber debris.

\section{- Hazardous Waste}

- No hazardous waste is expected from LLBG for management by the CWC. 


\section{GENER:ATORS:}

218EN Low Level Burial Grounds · 221 T/2706T T Plant Operations · 224T TRU Storage \& Assay Facility · Central Waste Complex - W026-Waste Receiving and Processing (WRAP1)

\section{PROGRAMS:}

Analytical Services - EM-40 - Facility Transitions - Landlord · Liquid Effluent · NP · Offsite · PNNL · RCRA · Solid Waste $\cdot$ SNF $\cdot$ TWRS

\begin{tabular}{|c|c|}
\hline $\begin{array}{c}\text { CHARACTERISTICS: } \\
\text { CH_LLMW } \cdot \text { RH_LLMW } \cdot \text { CH_TRU(M) } \cdot R H \_T R U(M) \\
\text { GTC III } \cdot \text { LLW } \cdot \text { HAZ }\end{array}$ & $\begin{array}{c}\text { CONTAINERS: } \\
\text { CH_LLMW } \cdot \text { RH_LLMW } \cdot \text { CH_TRU(M) } \\
\text { RH_TRU }(M) \cdot \text { GTC III } \cdot \text { LLW } \cdot \text { HAZ }\end{array}$ \\
\hline \multicolumn{2}{|c|}{$\begin{array}{l}\text { WASTE CLASSES: } \\
\text { CH_LLMW } \cdot \text { RH_LLMW } \cdot \mathrm{CH}_{-} \text {TRU(M) } \cdot \mathrm{RH}_{-} \text {TRU(M) } \cdot \mathrm{GTC} \text { III } \cdot \mathrm{LLW} \cdot \mathrm{HAZ}\end{array}$} \\
\hline
\end{tabular}

NOTICE: This page is provided subject to our disclaimer. Contact: Oscar Valero at (509) 373-4752. HNF-EP-0918 rev. 1 Approved for public release; distribution is unlimited. 


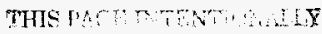

Lis iscive 


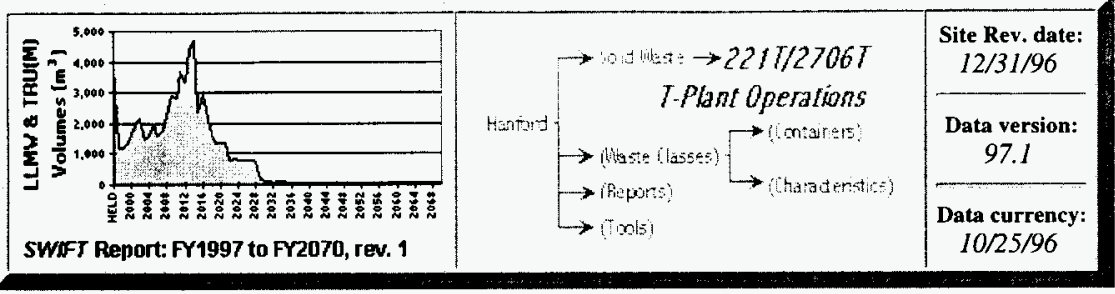

\section{Solid Waste - 221T/2706T T Plant Operations}

\section{Contents}

» Highlights

» Annual Volumes

»Comparison to Previous Baseline(s)

» Background
» Forecast Assumptions and Comments

" Other 221T/2706T T Plant Operations Forecast Data

»Detailed Forecast Data

\section{Highlights}

- T Plant contributes $300 \mathrm{~m}^{3}(75 \%)$ of the Solid Waste program's solid waste forecast.

- $\mathrm{CH} \_$LLMW is the primary waste class generated, representing $70 \%$ of the waste $\left(220 \mathrm{~m}^{3}\right)$.

- T Plant's forecast life cycle ends in 2027.

- LLMW and TRU(M) waste will be sent using Medium boxes for $70 \%$ of the volume, and 208 liter drums for $30 \%$ of the waste.

- Physical waste forms will mostly be debris, accounting for $80 \%$ of the volume. Inorganic solids and shielding account for $10 \%$ and $7 \%$, respectively. The last $3 \%$ of the waste is composed of lab packs, organic solids, soil/gravel, and special waste.

- LLMW and TRU(M) waste hazardous constituents are organic ( $55 \%$ by volume), metals with mercury (23\%), and metals without mercury (13\%). Corrosive constituents account for $3 \%$ of the waste, ignitable and reactive metals each represent $2 \%$, and $2 \%$ is state regulated. 


\section{Waste Class Distribution}

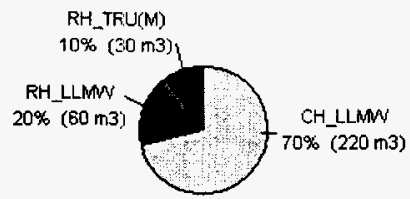

Total $=300 \mathrm{m3}$

\section{Physical Waste Form Distribution}

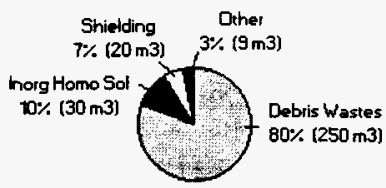

Total $=300 \mathrm{m3}$

\section{Hazardous Constituent Distribution}

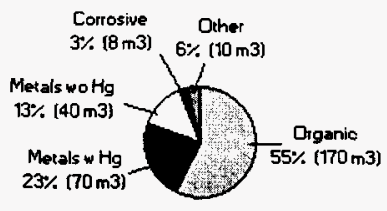

Totel $=300 \mathrm{~m} 3$

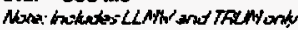

\section{Container Distribution}

208L Drums $30 \%$ (90 m3)

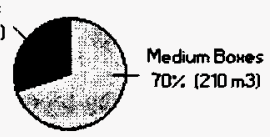

Total $=300 \mathrm{~m} 3$

Sum of totals may not add due to rounding: numbers over $10 \mathrm{~m}^{3}$ are rounded to the nearest $10 \mathrm{~m}^{3}$, numbers less than $10 \mathrm{~m}^{3}$ are rounded to integers, non-zero numbers less than I are rounded to 1.

\section{Annual Volumes}

\section{Annual Baseline Volumes}




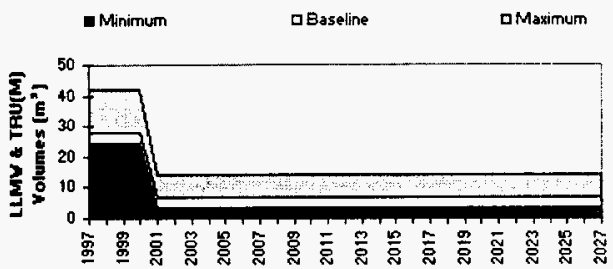

\section{Annual Baseline by Waste Class}

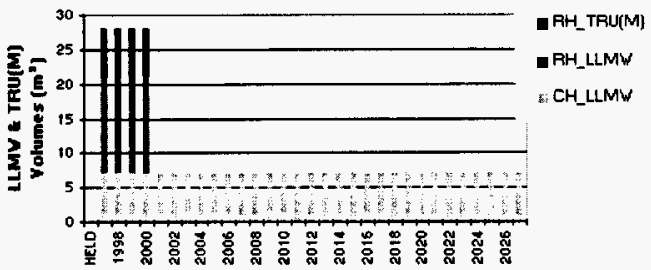

\section{Comparison to Previous Baseline(s)}

The T Plant waste forecast has decreased only marginally from the $310 \mathrm{~m}^{3}$ forecast in FY96 and is based on new estimates of waste generation.

\section{Comparison to Previous Baseline(s) by Waste Class}

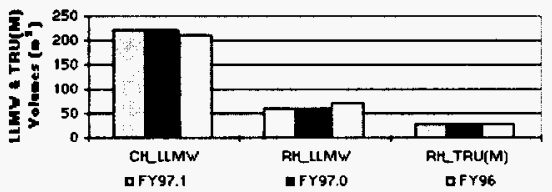

\begin{tabular}{|c|c|c|c|}
\hline $\begin{array}{l}221 T 12706 T \text { I Plant Dperations Comparison: } \\
\text { Yaste Class }\end{array}$ & $\begin{array}{l}\text { Frs7.1 } \\
\text { Forecast } \\
\left(\mathrm{m}^{2}\right)\end{array}$ & $\begin{array}{l}\text { Frs7.0 } \\
\text { Forecast } \\
\text { (m") }\end{array}$ & $\begin{array}{l}\text { FY9s } \\
\text { Forecast } \\
\left(\mathrm{m}^{\mathrm{n}}\right)\end{array}$ \\
\hline CH LLMW & 220 & 220 & 210 \\
\hline RH LLMW & 60 & 60 & 70 \\
\hline RH TRU(M) & 30 & 30 & 30 \\
\hline subrory & 30 & 200 & $3 / 0$ \\
\hline LLW & 3,070 & 3,070 & 2,620 \\
\hline $\mathrm{HAZ}$ & 30 & 30 & 40 \\
\hline Topd & $3 \operatorname{sep}$ & $x+96$ & 2.79 \\
\hline
\end{tabular}

Sum of totals may not add due to rounding: numbers over $10 \mathrm{~m}^{3}$ are rounded to the nearest $10 \mathrm{~m}^{3}$, numbers less than $10 \mathrm{~m}^{3}$ are rounded to integers, non-zero numbers less than 1 are rounded to 1 .

\section{Background}


T Plant (RFSH_T_PLANT) is a canyon building used to decontaminate equipment and sort and package waste from other onsite facilities. The T Plant forecast includes both operational and transitional wastes. Operational activities include maintenance, decontamination, and routine clean-up. The transitional waste includes T Plant canyon clean-up and upgrades and will occur from 1997 to 2000 . After canyon clean-up, it is not expected that significant waste generation would be required to decommission $T$ Plant. The average waste generation rate of the period should account for Terminal Cleanout and Stabilization waste and D\&D waste.

Wastes will be in various forms, including waste produced during decontamination activities, equipment and material that has been in RCA's, and other waste from routine maintenance.

\section{Forecast Assumptions and Comments}

Assumptions going into the forecast include:

1. Only waste actually generated at T Plant is included. Other waste brought there for repackaging or decontamination is included in the originating facilities' forecast.

2. Some RH_LLW and RH_LLMW may be generated during T Plant canyon clean up.

3. Some RH_TRUM may be generated during canyon clean up. This waste will be removed under Project W-259 during 1997 - 2000.

4. Physical waste distributions are estimates based on best available knowledge.

5. Waste will be segregated as much as practicable, although segregation may not be possible in all cases.

6. Radiation types are estimated based on the T Plant Waste Characterization Plan. It is assumed the radioactive contamination will be evenly distributed throughout the waste.

7. Routine generation-based on routine maintenance, decontamination, and clean-up-will not vary significantly over the period.

8. LLW volumes will be reduced through the use of a compactor.

The TPA Milestone M-32 Dangerous Waste Tank Upgrades is on schedule and is accounted for in the forecast. The upgrades will be completed under Project W-259 and is scheduled for completion in 1999.

1e minimum and maximum ranges of $64 \%$ and $181 \%$ are based on general historical knowledge of $\mathrm{T}$ Plant operating practices.

\section{Other Forecast Data}

\section{- Low Level Waste}

- A total of $3,070 \mathrm{~m}^{3}$ of LLW is expected from T Plant.

o This forecast shows a $17 \%$ increase from the FY96 forecast of $2,620 \mathrm{~m}^{3}$, primarily due to revised estimates of waste from clean-up and decontamination.

- MB-V boxes will be used for $95 \%$ of the LLW, while 208 liter drums will contain the last $5 \%$.

o Physical forms for the LLW will be largely $(87 \%)$ debris. Three other forms are forecast: inorganic solids $(6 \%)$, soil/gravel $(4 \%)$, and organic solid $(3 \%)$.

\section{- Hazardous Waste}

- A total of $30 \mathrm{~m}^{3}$ of hazardous waste was reported by T Plant for management at the CWC. 


\begin{tabular}{|c|c|c|c|c|} 
GENERATORS: \\
$218 \mathrm{E} / \mathrm{W}$ Low Level Burial Grounds $\cdot 22 / T / 2706 T$ T Plant Operations $\cdot 224 T$ TRU Storage \& Assay Facility $\cdot$ Central \\
Waste Complex $\cdot$ W026-Waste Receiving and Processing (WRAP1)
\end{tabular}

NOTICE: This page is provided subject to our disclaimer. Contact: Oscar Valero at (509) 373-4752.

HNF-EP-0918 rev. 1 Approved for public release; distribution is unlimited. 
THL: $\therefore \quad \therefore$. त ins. 


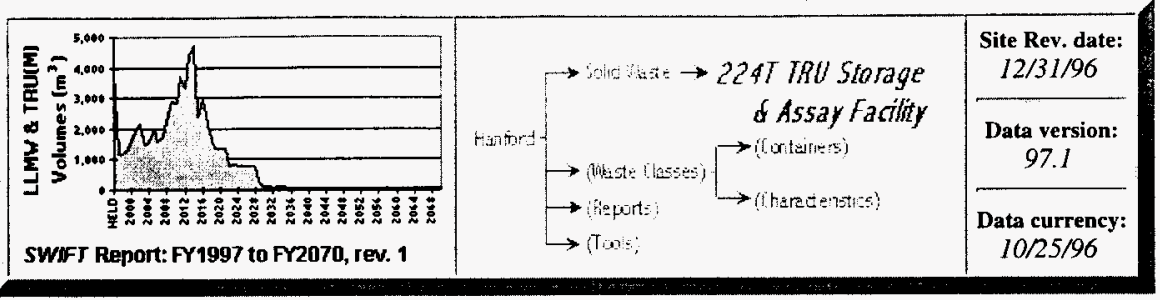

\section{Solid Waste - 224T TRU Storage \& Assay Facility}

\section{Contents}

» Highlights

" Annual Volumes

»Comparison to Previous Baseline(s)

»Background
》Forecast Assumptions and Comments

» Other 224T TRU Storage \& Assay Facility Forecast Data

»Detailed Forecast Data

\section{Highlights}

- The TRU Storage and Assay Facility (TRUSAF) contributes $2 \mathrm{~m}^{3}(<1 \%)$ of the Solid Waste program's solid waste forecast.

- $\mathrm{CH} \_$LLMW is the only waste class generated, representing $100 \%$ of the waste $\left(2 \mathrm{~m}^{3}\right)$.

- TRUSAF's forecast life cycle ends in 1998.

- The only container to be used for this waste is the 208 liter drum.

- $100 \%$ of the LLMW will have the physical form of debris.

- State regulated hazardous constituents represent $100 \%$ of the LLMW.

\section{Waste Class Distribution}

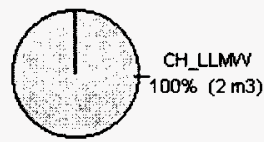

Total $=2 \mathrm{m3}^{3}$ 
Physical Waste Form Distribution

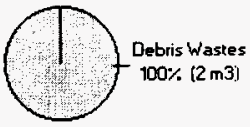

Total $=2 \mathrm{~ms}$

\section{Hazardous Constituent Distribution}

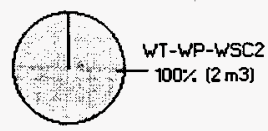

Total $=2 \mathrm{m3}$

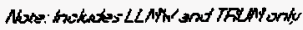

\section{Container Distribution}

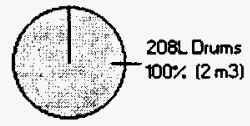

Totel $=2 \mathrm{m3}$

Sum of totals may not add due to rounding: numbers over $10 \mathrm{~m}^{3}$ are rounded to the nearest $10 \mathrm{~m}^{3}$, numbers less than $10 \mathrm{~m}^{3}$ are rounded to integers, non-zero numbers less than 1 are rounded to 1 .

\section{Annual Volumes}

\section{Annual Baseline Volumes}

QBaseline

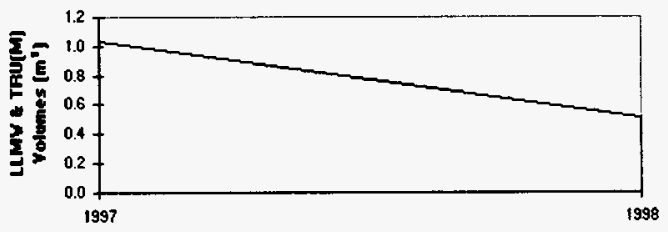

Annual Baseline by Waste Class 


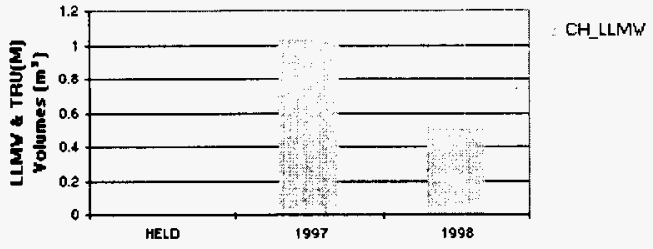

\section{Comparison to Previous Baseline(s)}

The TRUSAF waste forecast has decreased $93 \%$ from the $30 \mathrm{~m}^{3}$ forecast in FY96. This decrease is based on more recent estimates which include waste minimization activities.

\section{Comparison to Previous Baseline(s) by Waste Class}

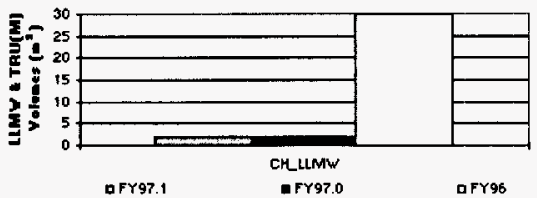

\begin{tabular}{|c|c|c|c|}
\hline $\begin{array}{l}224 T \text { TRU Storage \& Assag Facility Comparison: } \\
\text { Vaste Class }\end{array}$ & $\begin{array}{c}\text { FY97.1 } \\
\text { Foreosst } \\
\text { (m') }\end{array}$ & $\begin{array}{c}\text { FY97.0 } \\
\text { Forecast } \\
\text { (m) }\end{array}$ & $\begin{array}{l}\text { FY96 } \\
\text { Forecast } \\
\text { (m') }\end{array}$ \\
\hline $\mathrm{CH}$ LLMW & 2 & 2 & 30 \\
\hline subrory & 2 & 2 & $m$ \\
\hline$\angle L W$ & 2 & 2 & 10 \\
\hline Fary & 2 & 2 & 10 \\
\hline
\end{tabular}

Sum of totals may not add due to rounding: numbers over $10 \mathrm{~m}^{3}$ are rounded to the nearest $10 \mathrm{~m}^{3}$, numbers less than $10 \mathrm{~m}^{3}$ are rounded to integers, non-zero numbers less than $/$ are rounded to I.

\section{Background}

The current mission of TRUSAF is storage of TRU waste prior to repackaging and / or WIPP certification. An additional mission is the use of RTR for verification of LLW, LLMW, and TRU waste.

\section{Forecast Assumptions and Comments}

It is assumed that TRUSAF transition will remove waste from TRUSAF to CWC in FY1997. It is also assumed that a cell entry will be required in preparation for transition.

Transition to decommissioning and decontamination will occur soon thereafter. Waste generated from actual D\&D of the facility has not been forecasted.

The minimum waste range is $0 \%$ of the baseline, indicating the possibility that no waste will be generated. The maximum range of $100 \%$ is based on engineering judgement. 


\section{Other Forecast Data}

\section{- Low Level Waste}

- A total of $2 \mathrm{~m}^{3}$ of LLW is expected from TRUSAF.

- This forecast shows an $80 \%$ decrease from the FY 96 forecast of $10 \mathrm{~m}^{3}$, primarily due to waste minimization activities.

- LLW is to be contained only in the 208 liter drum.

- $100 \%$ of the LLW will have the physical form of debris.

\section{- Hazardous Waste}

o No hazardous waste was reported by TRUSAF for management by the CWC.

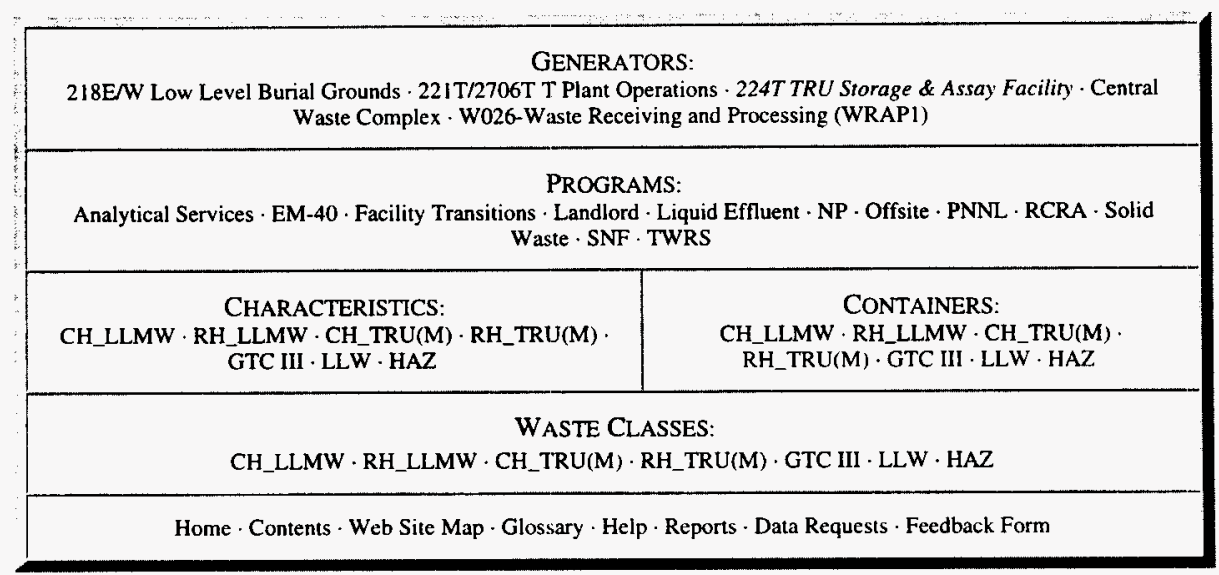

NOTICE: This page is provided subject to our disclaimer. Contact: Oscar Valero at (509) 373-4752.

HNF-EP-0918 rev. 1 Approved for public release; distribution is unlimited. 


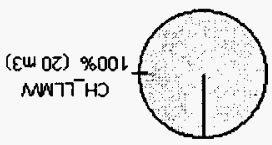

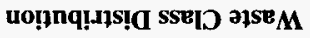

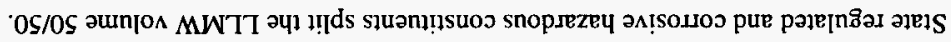

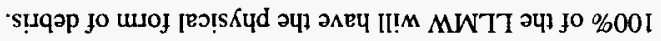

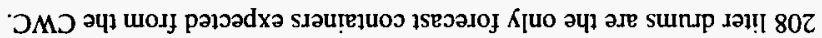

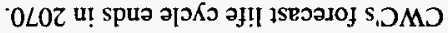

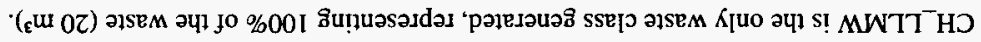

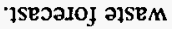

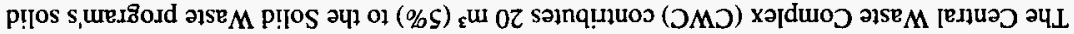

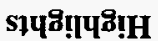

punosoิxวeg «

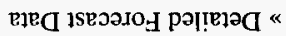

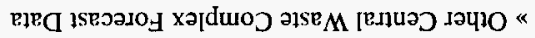

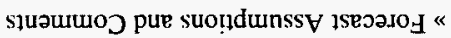

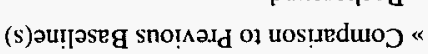

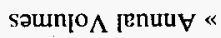

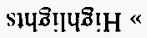

squวนบ0ว

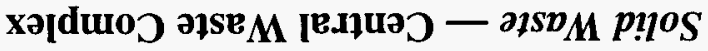

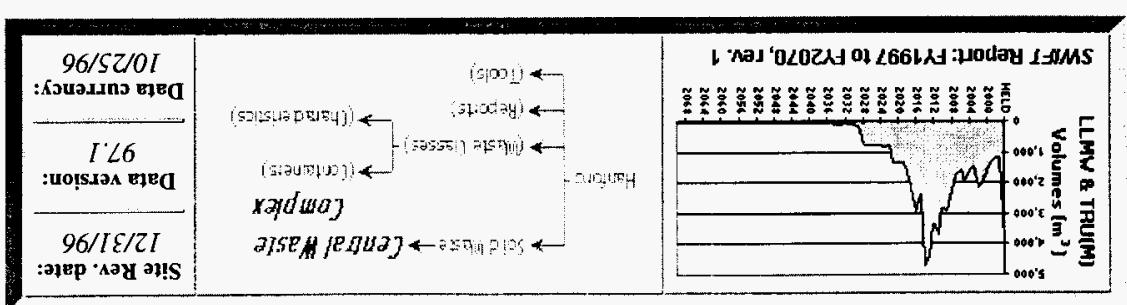


Physical Waste Form Distribution

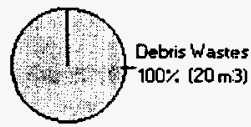

Total $=\mathbf{2 0} \mathbf{m 3}$

\section{Hazardous Constituent Distribution}

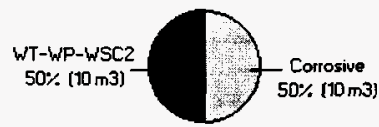

Total $=20 \mathrm{~m} 3$

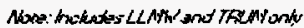

\section{Container Distribution}

Total $=20 \mathrm{~m} 3$

Sum of totals may not add due to rounding: numbers over $10 \mathrm{~m}^{3}$ are rounded to the nearest $10 \mathrm{~m}^{3}$, numbers less than $10 \mathrm{~m}^{3}$ are rounded to integers, non-zero numbers less than I are rounded to 1.

\section{Annual Volumes}

\section{Annual Baseline Volumes}

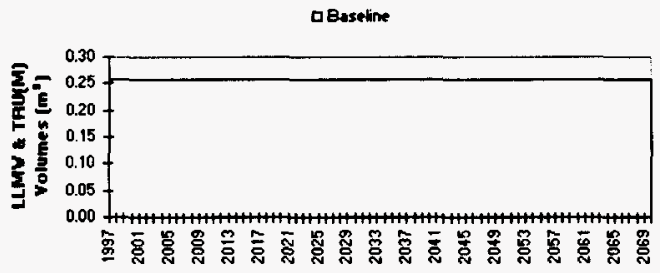

\section{Annual Baseline by Waste Class}




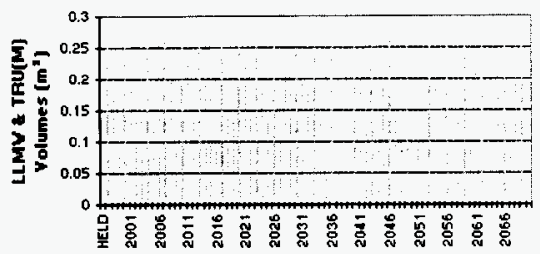

\section{Comparison to Previous Baseline(s)}

This is a new forecast, no waste has previously been forecast for CWC.

\section{Comparison to Previous Baseline(s) by Waste Class}

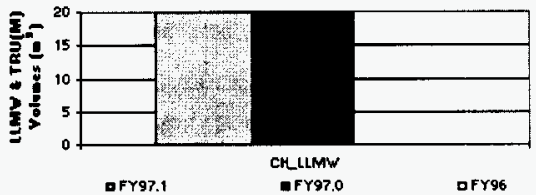

\begin{tabular}{|c|c|c|c|}
\hline $\begin{array}{l}\text { Central Yaste Complea Comparison: } \\
\text { Yaste Class }\end{array}$ & $\begin{array}{c}\text { FY97.1 } \\
\text { Forecast } \\
\text { (m') }\end{array}$ & $\begin{array}{l}\text { FY97.0 } \\
\text { Forecast } \\
\left(\mathrm{m}^{3}\right)\end{array}$ & $\begin{array}{c}\text { FY96 } \\
\text { Forecast } \\
\text { (m') }\end{array}$ \\
\hline CH LLMW & 20 & 20 & 0 \\
\hline suplayed & 20 & $\boldsymbol{A P}$ & $\theta$ \\
\hline Tovel & 20 & 20 & $a$ \\
\hline
\end{tabular}

Sum of totals may not add due to rounding: numbers over $10 \mathrm{~m}^{3}$ are rounded to the nearest $10 \mathrm{~m}^{3}$, numbers less than $10 \mathrm{~m}^{3}$ are rounded to integers, non-zero numbers less than 1 are rounded to 1.

\section{Background}

CWC's mission is the storage of mixed waste for eventual treatment and disposal. Waste may be generated from spill response or operational activities which require the use of PPE.

\section{Forecast Assumptions and Comments}

CWC operations in future years will be similar to current operations.

Although some Class III and TRU wastes are stored in CWC, it is expected that any waste that is generated will be Class I.

The minimum waste range is $0 \%$ of the baseline, indicating the possibility that no waste will be generated. The maximum range of $100 \%$ indicates that the forecast volume is at the maximum potential level.

\section{Other Forecast Data}




\section{- Low Level Waste}

- No low level waste was reported by CWC for management by the CWC.

- No comparison with FY96 data is possible, since this generator was previously combined with other generators.

- Hazardous Waste

- No hazardous waste was reported by CWC for management by the CWC.

\begin{tabular}{|c|c|}
\hline \multicolumn{2}{|c|}{$\begin{array}{l}\text { GENERATORS: } \\
\text { 218E/W Low Level Burial Grounds } \cdot 221 \text { T/2706T T Plant Operations } \cdot 224 T \text { TRU Storage \& Assay Facility } \cdot \text { Central } \\
\text { Waste Complex } \cdot \text { W026-Waste Receiving and Processing (WRAP1) }\end{array}$} \\
\hline \multicolumn{2}{|c|}{$\begin{array}{l}\text { PROGRAMS: } \\
\text { Analytical Services } \cdot \text { EM-40 } \text { Facility Transitions } \cdot \text { Landlord } \cdot \text { Liquid Effluent } \cdot \text { NP } \cdot \text { Offsite } \cdot \text { PNNL } \cdot \text { RCRA } \cdot \text { Solid } \\
\text { Waste } \cdot \text { SNF } \cdot \text { TWRS }\end{array}$} \\
\hline $\begin{array}{l}\text { CHARACTERISTICS: } \\
\text { CH_LLMW } \cdot \text { RH_LLMW } \cdot \text { CH_TRU(M) } \cdot \text { RH_TRU(M) } \\
\text { GTC III } \cdot \text { LLW } \cdot \text { HAZ }\end{array}$ & $\begin{array}{l}\text { CONTAINERS: } \\
\text { CH_LLMW } \cdot \text { RH_LLMW } \cdot \text { CH_TRU(M) } \\
\text { RH_TRU(M) } \cdot \text { GTC III } \cdot \text { LLW } \cdot \text { HAZ }\end{array}$ \\
\hline Home - Contents - Web Site Map - Glossary - & rts - Data Requests - Feedback Form \\
\hline
\end{tabular}

NOTICE: This page is provided subject to our disclaimer. Contact: Oscar Valero at (509) 373-4752.

HNF-EP-0918 rev. 1 Approved for public release; distribution is unlimited. 


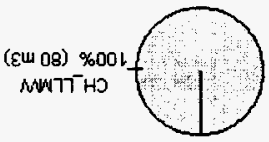

uog̣nq!.11s!a sselo apse $M$

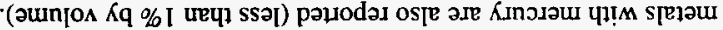

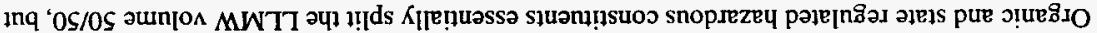

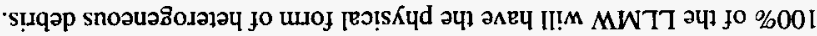

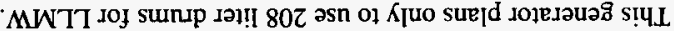

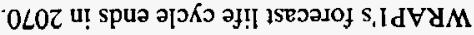

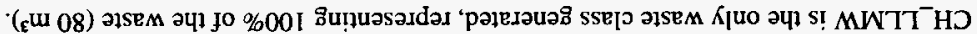

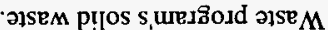

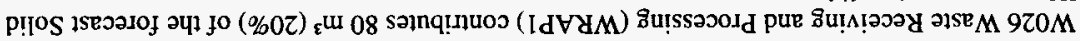

puno.18×peg *

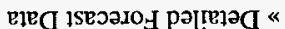

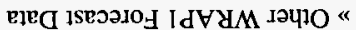

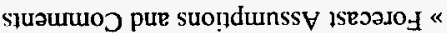

(s)วutjaseg snotsaId ol uos!reduro) « Saunjo $\Lambda$ [enuu *

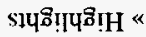

sұบวนบо

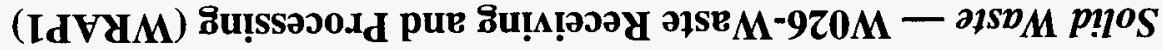

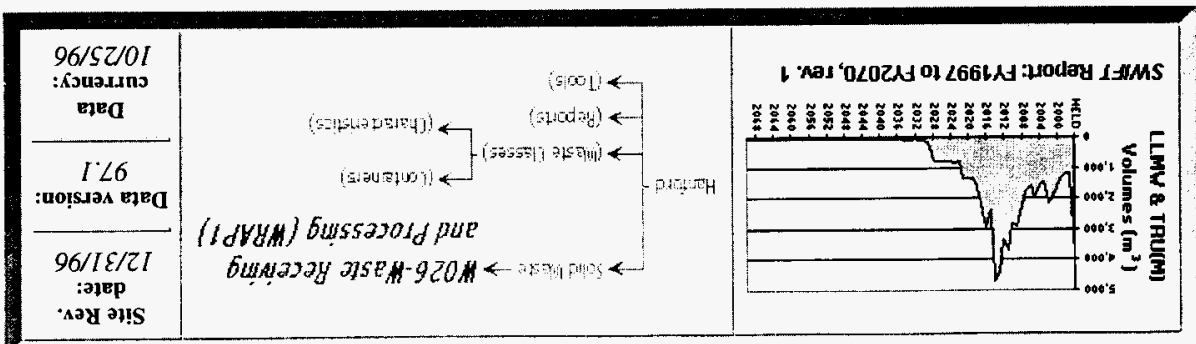


Physical Waste Form Distribution

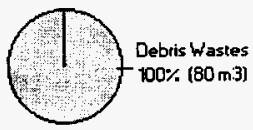

Toral $=80 \mathrm{~m} 3$

\section{Hazardous Constituent Distribution}

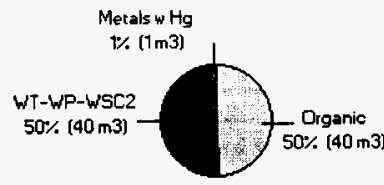

Total $=80 \mathrm{~m} 3$

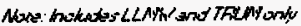

\section{Container Distribution}

Total $=80 \mathrm{m3}$

Sum of totals may not add due to rounding: numbers over $10 \mathrm{~m}^{3}$ are rounded to the nearest $10 \mathrm{~m}^{3}$, numbers less than $10 \mathrm{~m}^{\mathrm{s}}$ are rounded to integers, non-zero numbers less than 1 are rounded to 1.

\section{Annual Volumes}

\section{Annual Baseline Volumes}

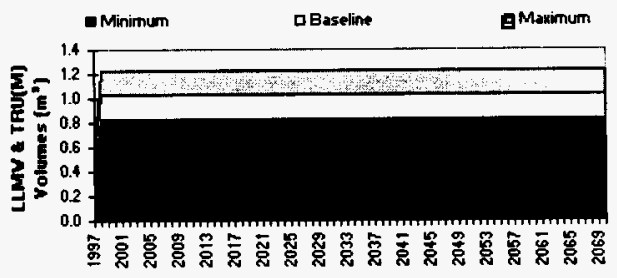

\section{Annual Baseline by Waste Class}




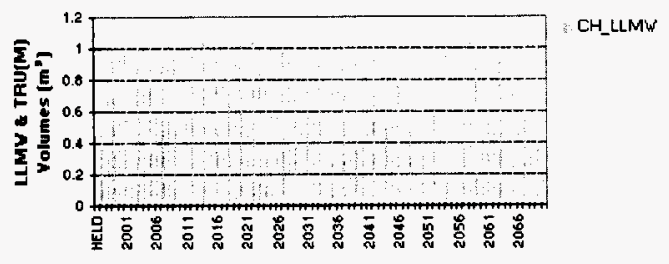

\section{Comparison to Previous Baseline(s)}

This is a new forecast; no waste has previously been forecast for WRAPI.

\section{Comparison to Previous Baseline(s) by Waste Class}

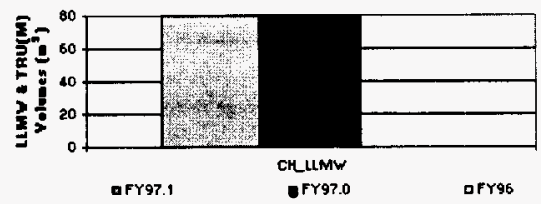

\begin{tabular}{|c|c|c|c|}
\hline $\begin{array}{l}\text { Y026-Vaste Receiving and Processing (YRAP I) Comparison: } \\
\text { Yaste Class }\end{array}$ & $\begin{array}{c}\text { FY97.1 } \\
\text { Forecast } \\
\left(m^{\prime}\right)\end{array}$ & $\begin{array}{c}\text { FY97.0 } \\
\text { Forecast } \\
{\left[m^{2}\right]}\end{array}$ & $\begin{array}{c}\text { FY9B } \\
\text { Forecast } \\
\text { (m') }\end{array}$ \\
\hline $\mathrm{CH} L L M W$ & 80 & 80 & 0 \\
\hline swopord & $\infty$ & $\infty$ & $\theta$ \\
\hline LLW & 390 & 390 & 0 \\
\hline 7ord & 178 & 478 & $\theta$ \\
\hline
\end{tabular}

Sum of totals may not add due to rounding: numbers over $10 \mathrm{~m}^{3}$ are rounded to the nearest $10 \mathrm{~m}^{3}$, numbers less than $10 \mathrm{~m}^{3}$ are rounded to integers, non-zero numbers less than 1 are rounded to 1.

\section{Background}

WRAP1 will process $\mathrm{CH}$ _LLMW, $\mathrm{CH}$ _TRU(M) waste, and $\mathrm{CH}$ _LLW for verification and repackaging to meet disposal requirements.

\section{Forecast Assumptions and Comments}

The waste which is processed through WRAP1 is already included in the forecast of the originating generators. The waste that is part of this WRAP1 forecast is limited to secondary waste generated as part of the facility operations.

The majority of the waste generated by WRAPl consists of PPE used during repackaging.

Although WRAP1 will process Class III and TRU wastes, it is expected that any waste generated will be Class I. 
Minimum and maximum ranges for the waste are $80 \%$ and $120 \%$ respectively, and are based on engineering judgment of the variabilities of the process.

\section{Other Forecast Data}

- Low Level Waste

- A total of $390 \mathrm{~m}^{3}$ of LLW is expected from WRAPl.

- No comparison with FY96 data is possible, since this generator was previously combined with other generators.

- All of the LLW is to come in 322 liter drums.

- $100 \%$ of the LLW will have the physical form of heterogeneous debris.

\section{- Hazardous Waste}

- No hazardous waste was reported by WRAP1 for management by the CWC.

\begin{tabular}{|c|c|}
\hline \multicolumn{2}{|c|}{$\begin{array}{l}\text { GENERATORS: } \\
\text { 218E/W Low Level Burial Grounds } \cdot 221 \mathrm{~T} / 2706 \mathrm{~T} \text { T Plant Operations } \cdot 224 \mathrm{~T} \text { TRU Storage \& Assay Facility } \cdot \text { Central } \\
\text { Waste Complex } \cdot \text { W026-Waste Receiving and Processing }(\text { WRAPI) }\end{array}$} \\
\hline \multicolumn{2}{|c|}{$\begin{array}{l}\text { PROGRAMS: } \\
\text { Analytical Services } \cdot \text { EM-40 } \cdot \text { Facility Transitions } \cdot \text { Landlord } \cdot \text { Liquid Effluent } \cdot \text { NP } \cdot \text { Offsite } \cdot \text { PNNL } \cdot \text { RCRA } \cdot \text { Solid } \\
\text { Waste } \cdot \text { SNF } \cdot \text { TWRS }\end{array}$} \\
\hline $\begin{array}{l}\text { CHARACTERISTICS: } \\
\text { CH_LLMW } \cdot \text { RH_LLMW }- \text { CH_TRU(M) } \cdot \text { RH_TRU(M) } \\
\text { GTC III } \cdot \text { LLWW } \cdot \text { HAZ }\end{array}$ & $\begin{array}{l}\text { CONTAINERS: } \\
\text { CH_LLMW } \cdot \text { RH_LLMW } \cdot \text { CH_TRU(M) } \\
\text { RH_TRU }(M) \cdot \text { GTC III } \cdot \text { LLW } \cdot \text { HAZ }\end{array}$ \\
\hline Home - Contents - Web Site Map - Glossary - H & rts - Data Requests - Feedback Form \\
\hline
\end{tabular}

NOTICE: This page is provided subject to our disclaimer. Contact: Oscar Valero at (509) 373-4752.

HNF-EP-0918 rev. 1 Approved for public release; distribution is unlimited. 
Kinarau y

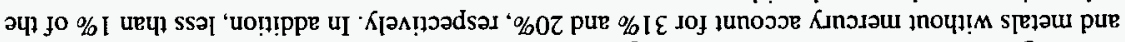

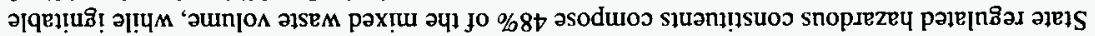

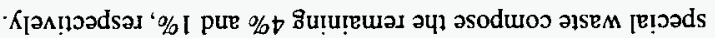

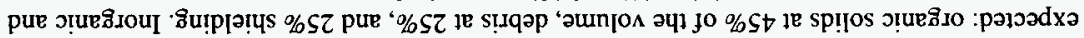

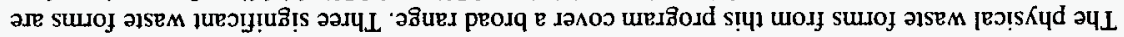

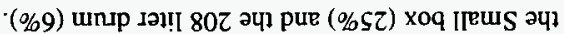

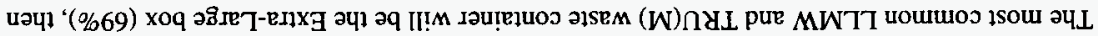

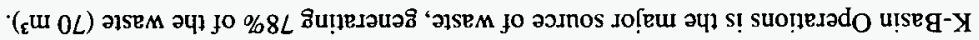

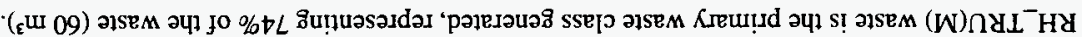
MTT

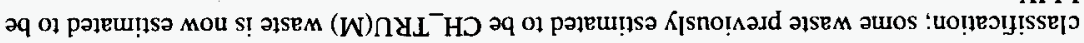

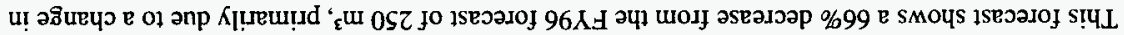

[r]O1 pjojureH

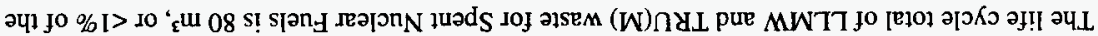

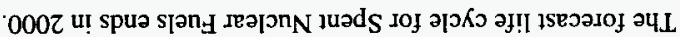

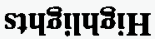

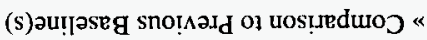

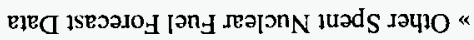

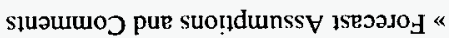
punod8ิxyeg * วqе $\perp$ Kreununs «

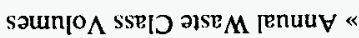
ราบชี!กบธิ!H «

sาบวาบоอ

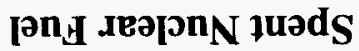

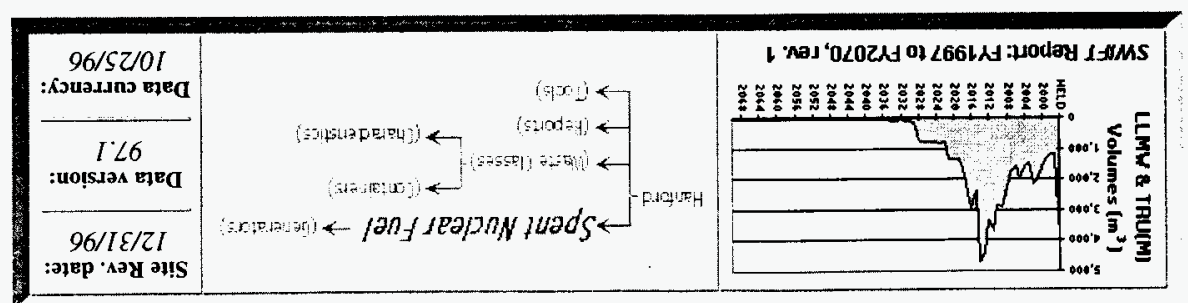


Waste Class Distribution

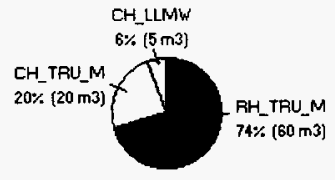

Total = $00 \mathrm{~ms}$

Physical Waste Form Distribution

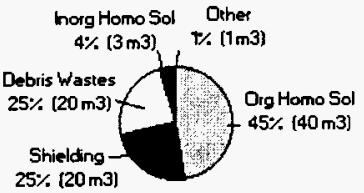

Total $=80 \mathrm{~m} 3$

\section{Generator Distribution}

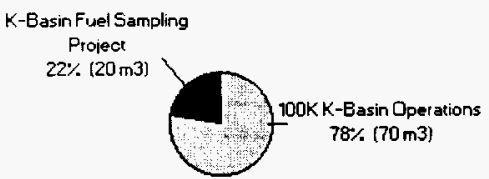

Total $=80 \mathrm{~m} 3$

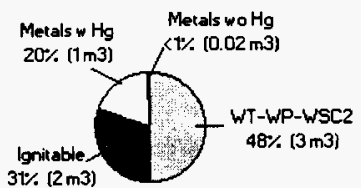

Total $=5 \mathrm{~m} 3$

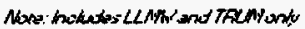

\section{Container Distribution}

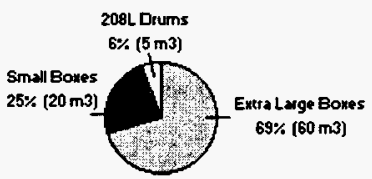

Total $=00 \mathrm{~m}$

Sum of totals may not add due to rounding: numbers over $10 \mathrm{~m}^{3}$ are rounded to the nearest $10 \mathrm{~m}^{3}$, numbers less than $10 \mathrm{~m}^{3}$ are rounded to integers, non-zero numbers less than $I$ are rounded to $I$.

\section{Annual Waste Class Volumes}

Spent Nuclear Fuel waste will be generated from 1997 to the end of life cycle in 2000 . The major amount of waste will occur in 1998, corresponding to the shipment of ion exchange columns classified as RH_TRU waste.

\section{Annual Baseline Volumes}




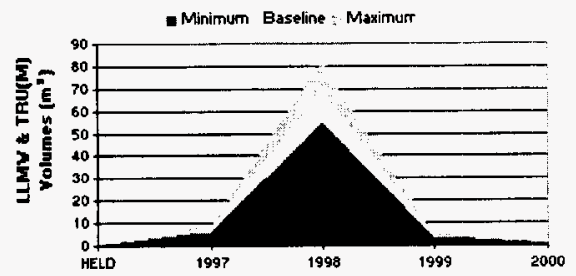

Annual Baseline by Waste Class

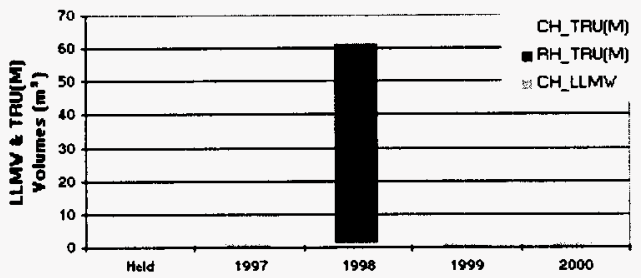

\section{Summary Table (Volumes in $\mathbf{m}^{3}$ )}

\begin{tabular}{|c|c|c|c|c|c|}
\hline $\begin{array}{l}\text { Spent Muclear Fuel Summary: } \\
\text { Generator }\end{array}$ & CH_LLMY & CH_TRU[M] & RH_TRU(M) & Subtota: & PCT \\
\hline 100k K-Basin Operations & 5 & 0 & 60 & 70 & $78 \%$ \\
\hline K-Basin Fuel Sampling Project & 0 & 20 & 0 & 20 & $22 \%$ \\
\hline Totals & $\mathbf{5}$ & 20 & 60 & 80 & $100 \%$ \\
\hline $\mathrm{PCT}$ & $6 \%$ & $25 \%$ & $69 \%$ & $100 \%$ & \\
\hline
\end{tabular}

Sum of totals may not add due to rounding: numbers over $10 \mathrm{~m}^{3}$ are rounded to the nearest $10 \mathrm{~m}^{3}$, numbers less than $10 \mathrm{~m}^{3}$ are rounded to integers, non-zero numbers less than $I$ are rounded to $I$.

\section{Comparison to Previous Baseline(s)}

The FY97.1 waste forecast shows a $66 \%$ decrease from the FY96 forecast of $250 \mathrm{~m}^{3}$. The primary reason for this decrease is a change in classification in which some waste previously estimated to be $\mathrm{CH}_{-}$TRU is now estimated to be LLW.

Other changes in the forecast from FY96 include the following: 1) this program's life cycle has been changed from 2001 to $2000 ; 2$ ) waste estimated as HELD waste last year has been determined to be equipment; 3) RH_TRU(M) waste will be managed in FY97 rather than in FY98.

One scenario considered for K-Basin sludge in FY96 was the option to grout the waste for shipment to the CWC, which would have resulted in much larger amounts of waste generation. This scenario is no longer considered viable as of the FY97 forecast. 
The 1996 hazardous constituents forecast reported organic (3\% by volume) and corrosive (9\%) constituents while the 1997 data expects ignitable and metals with mercury. State regulated and metals without mercury constituents are common to both forecasts, but state regulated currently contributes to a larger percent of the whole.

\section{Comparison to Previous Baseline(s) by Waste Class}

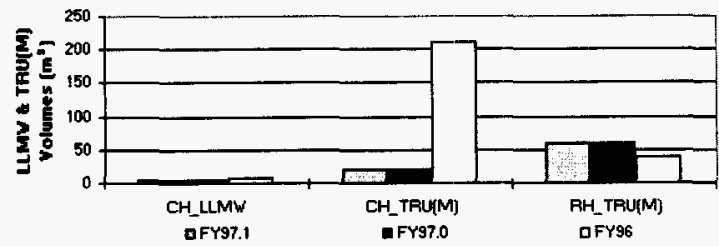

\begin{tabular}{|c|c|c|c|}
\hline $\begin{array}{l}\text { Spent Muclear Fuel Comparison: } \\
\text { Waste Class }\end{array}$ & $\begin{array}{l}\text { Frg7.1 } \\
\text { Forecast } \\
\text { (m) }\end{array}$ & $\begin{array}{l}\text { FY97.0 } \\
\text { Forecast } \\
\left(\mathrm{m}^{3}\right)\end{array}$ & $\begin{array}{l}\text { FY96 } \\
\text { Forecast } \\
\text { (m) }\end{array}$ \\
\hline $\mathrm{CH}$ LLMN & 5 & 5 & 7 \\
\hline CH TRUYM & 20 & 20 & 210 \\
\hline RH_TRU(M) & 60 & 60 & 40 \\
\hline Sustotel & 80 & 80 & 250 \\
\hline LLW & 1.990 & 1,990 & 1.520 \\
\hline $\mathrm{HAZ}$ & 0 & D & 10 \\
\hline Total & 2,070 & 2,070 & 1,790 \\
\hline
\end{tabular}

Sum of totals may not add due to rounding: numbers over $10 \mathrm{~m}^{3}$ are rounded to the nearest $10 \mathrm{~m}^{3}$, numbers less than $10 \mathrm{~m}^{3}$ are rounded to integers, non-zero numbers less than $I$ are rounded to $I$.

\section{Background}

Spent Nuclear Fuel's mission is to provide safe storage of spent nuclear fuel (SNF); remedy unsafe conditions; design, construct, operate, and maintain interim storage facilities until final disposition of SNF is determined; and stage the SNF for final disposition once further direction is received. The current program mission, as defined in the Multi-Year Program Plan, addresses the SNF stored at the K-Basin only.

There are 2 generators included in the Spent Nuclear Fuel program (both within the K-Basin area): K-Basin Operations (DESH_K_OPER) and K-Basin Fuel Sampling Project (DESH_K_PROJ). Currently, the K-Basin provides wet storage for spent fuel. Solid waste will be generated during the disposition of the spent fuel at K-Basin. Waste generating activities include: maintenance and preparation of the K-Basins for storage and removal of all spent nuclear fuel, debris, and sludge; constructing, as necessary, new systems and facilities to condition and store the fuel; relocating the fuel to interim storage; and accepting spent nuclear fuel from other Hanford locations. Main categories of waste include housekeeping refuse and other debris; debris, piping, scrap metal from basin clean-up; spent ion exchange columns and water filters used to maintain water quality inside the basins.

\section{Forecast Assumptions and Comments}

In preparation of this forecast, known waste was addressed, and estimates were calculated 
according to waste shipped so far this year and/or expected waste streams.

The K-Basins major milestone: "Remove all Fuel and Sludge from both K-East and K-West Basins in an Encapsulated Form." (M-34-00-T08) is not reflected in this forecast, given the uncertainty in the basin clean-out.

The minimum and maximum range for this waste is $80 \%$ and $120 \%$ of the baseline.

\section{Other Forecast Data}

\section{- Low Level Waste}

- A total of $1,990 \mathrm{~m}^{3}$ of LLW is expected from Spent Nuclear Fuel until 2000.

- This forecast shows a $31 \%$ increase from the FY96 forecast of $1,520 \mathrm{~m}^{3}$, primarily due to a reclassification of certain waste streams as LLW rather than TRU waste.

- All Spent Nuclear Fuel LLW is CH_LLW.

- Medium boxes will be used for $36 \%$ of the LLW, while MB-V boxes and 322 liter drums will be used for $28 \%$ and $24 \%$ respectively, and MB-IV boxes will hold $12 \%$.

- The physical form of the LLW is composed by $68 \%$ debris, $31 \%$ concrete shielding, and $1 \%$ organic particulates.

\section{- Hazardous Waste}

- No hazardous waste was reported by Spent Nuclear Fuel for management at the CWC.

\begin{tabular}{|c|c|}
\hline \multicolumn{2}{|c|}{$\begin{array}{l}\text { GENERATORS: } \\
\text { I00K K-Basin Operations - K-Basin Fuel Sampling Project }\end{array}$} \\
\hline \multicolumn{2}{|c|}{$\begin{array}{l}\text { PROGRAMS: } \\
\text { Analytical Services } \cdot \text { EM-40 } \cdot \text { Facility Transitions } \cdot \text { Landlord } \cdot \text { Liquid Effluent } \cdot \text { NP } \cdot \text { Offsite } \cdot \text { PNNL } \cdot \text { RCRA } \cdot \text { Solid } \\
\text { Waste } \cdot \text { SNF } \cdot \text { TWRS }\end{array}$} \\
\hline $\begin{array}{l}\text { CHARACTERISTICS: } \\
\text { CH_LLMW } \cdot \text { RH_LLMW } \cdot \text { CH_TRU(M) } \cdot \text { RH_TRU(M) } \\
\text { GTC III } \cdot \text { LLW } \cdot \text { HAZ }\end{array}$ & $\begin{array}{l}\text { CONTAINERS: } \\
\text { CH_LLMW } \cdot \text { RH_LLMW } \cdot \text { CH_TRU(M) } \\
\text { RH_TRU(M) } \cdot \text { GTC III } \cdot \text { LLW } \cdot \text { HAZ }\end{array}$ \\
\hline \multicolumn{2}{|c|}{$\begin{array}{c}\text { WASTE CLASSES: } \\
\text { CH_LLMW } \cdot \text { RH_LLMW } \cdot \text { CH_TRU(M) } \cdot \text { RH_TRU(M) } \cdot \text { GTC III } \cdot \text { LLW } \cdot \text { HAZ }\end{array}$} \\
\hline
\end{tabular}

NOTICE: This page is provided subject to our disclaimer. Contact: Oscar Valero at (509) 373-4752.

HNF-EP-0918 rev. 1 Approved for public release; distribution is unlimited. 
THIS PACE TTENTHNLLY

lit. a divis 


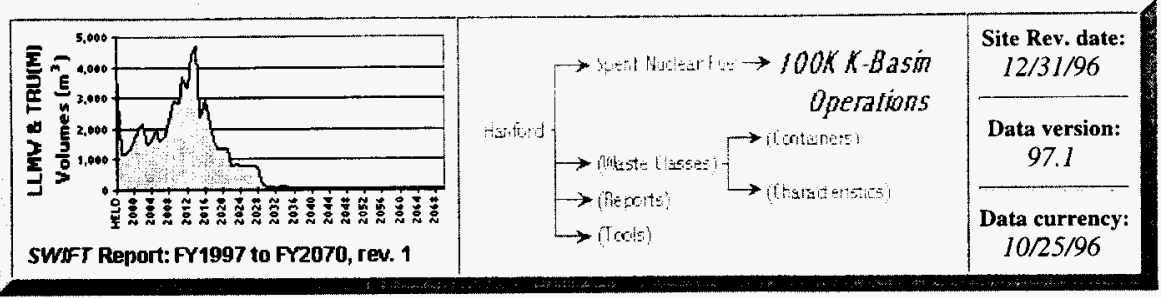

\section{Spent Nuclear Fuel - 100K K-Basin Operations}

\section{Contents}

" Highlights

»Annual Volumes

" Comparison to Previous Baseline(s)

" Background
» Forecast Assumptions and Comments

"Other 100K K-Basin Operations Forecast Data

»Detailed Forecast Data

\section{Highlights}

- K-Basin Operations contributes $70 \mathrm{~m}^{3}(78 \%)$ of the Spent Nuclear Fuels solid waste forecast.

- The K-Basin Operations waste is composed primarily of RH_TRU waste (93\% or $60 \mathrm{~m}^{3}$ ).

- K-Basin Operations forecast life cycle ends in 2000.

- Extra-Large boxes are expected to contain nearly all (93\%) of this waste, and 208 liter drums will cover the remaining $7 \%$.

- The physical waste forms are varied: $51 \%$ of the volume is organic solids, $29 \%$ is concrete shielding, $14 \%$ is debris, $5 \%$ is inorganic solids, and special waste accounts for $1 \%$.

- State regulated hazardous constituents (WT-WP-WSC2) comprise 50\% of the LLMW volume, while ignitable and metals without mercury account for $30 \%$ and $20 \%$, respectively. In addition, less than $1 \%$ of the volume is reported as metals with mercury. 


\section{Waste Class Distribution}

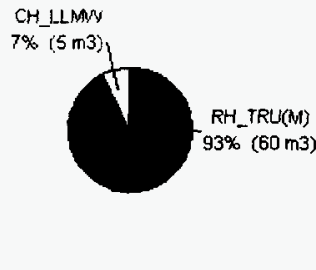

\section{Physical Waste Form Distribution Hazardous Constituent Distribution}
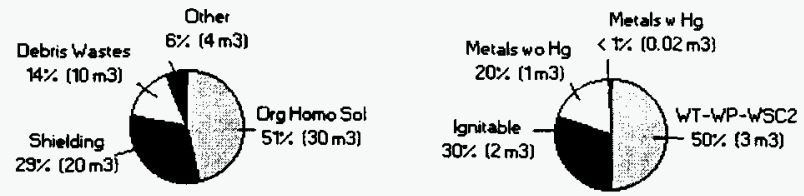

Toral $=70 \mathrm{m3}$

\section{Totel $=5 \mathrm{~m}^{3}$}

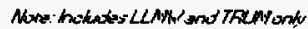

\section{Container Distribution}

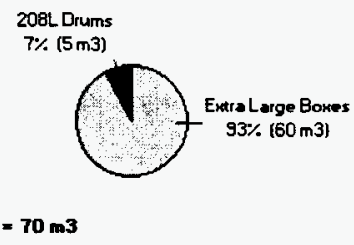

Sum of totals may not add due to rounding: numbers over $10 \mathrm{~m}^{3}$ are rounded to the nearest $10 \mathrm{~m}^{3}$, numbers less than $10 \mathrm{~m}^{3}$ are rounded to integers, non-zero numbers less than 1 are rounded 101 .

\section{Annual Volumes}

\section{Annual Baseline Volumes}




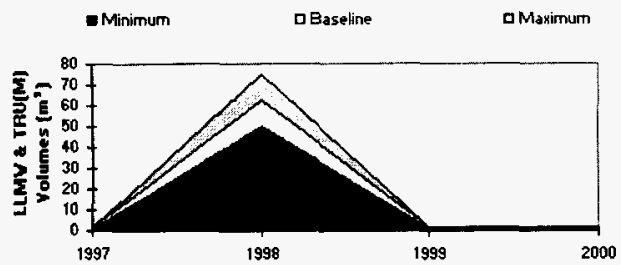

\section{Annual Baseline by Waste Class}

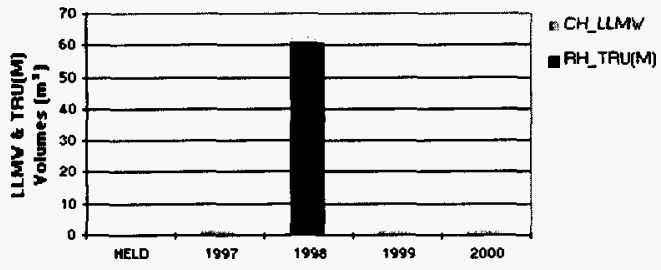

\section{Comparison to Previous Baseline(s)}

The K-Basin Operations waste forecast has decreased significantly from the $250 \mathrm{~m}^{3}$ forecast in FY96. This decrease is a result of the fact that a significant amount of waste was determined to be LLW and to be the responsibility of the K-Basin Fuel Sampling Project.

The 1996 hazardous constituents forecast reported organic ( $3 \%$ by volume) and corrosive (9\%) constituents while the 1997 data expects ignitable and metals with mercury. State regulated and metals without mercury constituents are common to both forecasts, but state regulated currently contributes to a larger percent of the whole.

\section{Comparison to Previous Baseline(s) by Waste Class}

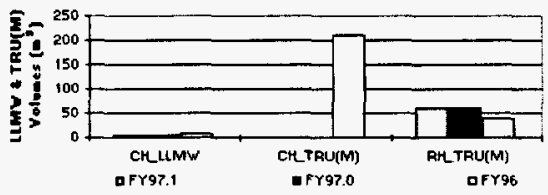




\begin{tabular}{|c|c|c|c|}
\hline $\begin{array}{l}\text { 100K K-Basin Operations Comparison: } \\
\text { Vaste Class }\end{array}$ & $\begin{array}{c}\text { Fr97.1 } \\
\text { Forecast } \\
{\left[\mathrm{m}^{2}\right]}\end{array}$ & $\begin{array}{c}\text { FY97.0 } \\
\text { Forecast } \\
\left(\mathrm{m}^{2}\right)\end{array}$ & $\begin{array}{l}\text { FY96 } \\
\text { Forecast } \\
\text { [m'] }\end{array}$ \\
\hline $\mathrm{CH}$ LLMW & 5 & 5 & 7 \\
\hline CH_TRU(M) & 0 & - & 210 \\
\hline RH TRU(M) & 60 & 60 & 40 \\
\hline Suprory & 79 & 70 & 250 \\
\hline LIW & 960 & 960 & 1.210 \\
\hline HAZ & 0 & 0 & 10 \\
\hline Tords & 8,20 & 1,220 & 1.470 \\
\hline
\end{tabular}

Sum of totals may not add due to rounding: numbers over $10 \mathrm{~m}^{3}$ are rounded to the nearest $10 \mathrm{~m}^{3}$, numbers less than $10 \mathrm{~m}^{3}$ are rounded to integers, non-zero numbers less than 1 are rounded to 1 .

\section{Background}

$\mathrm{K}$-Basin Operations is responsible for maintenance and preparation of the K-Basins for storage and removal of all spent nuclear fuel, debris, and sludge; constructing, as necessary, new systems and facilities to condition and store the fuel; relocating the fuel to interim storage; and accepting spent nuclear fuel from other Hanford locations.

\section{Forecast Assumptions and Comments}

In preparation of this forecast, known waste was addressed, and estimates were calculated according to waste shipped so far this year. Upcoming revisions to plant configuration were also considered and forecast, including expected waste generation due to routine maintenance and housekeeping.

The K-Basin major milestone: "Remove all Fuel and Sludge from both K-East and K-West Basins in an Encapsulated Form." (M-34-00-T08) is not reflected in this forecast, given the uncertainty in the basin clean-out.

The K-Basin Operations baseline waste estimate may vary from $80 \%$ to $120 \%$. The minimum value is based on the uncertainty of actual volume to be generated by basin clean-out and the long-term status of the facility after the stored fuel has either been contained or removed. The maximum value is based in the short term on not knowing the precise amount of waste to be generated by basin clean-out and pilot project. Long term expectations are that, regardless of chosen interim fuel storage method, waste generation in general should not exceed predicted amounts.

\section{Other Forecast Data}

\section{- Low Level Waste}

- A total of $960 \mathrm{~m}^{3}$ of LLW is expected from K-Basin Operations.

- This represents a $21 \%$ decrease from the FY96 estimate of $1,210 \mathrm{~m}^{3}$ due to reassignment of some LLW to the K-Basin Fuel Sampling Project.

- LLW will be shipped in MB-V boxes (51\%) and 322 liter drums (49\%).

- $100 \%$ of the LLW has the physical form of debris.

\section{- Hazardous Waste}


- No hazardous waste is expected from K-Basin Operations for management by the CWC.

GENERATORS:

I0OK K-Basin Operations · K-Basin Fuel Sampling Project

PROGRAMS:

Analytical Services · EM-40 - Facility Transitions - Landlord · Liquid Effluent - NP · Offsite - PNNL · RCRA · Solid Waste $\cdot$ SNF $\cdot$ TWRS

CHARACTERISTICS:

CH_LLMW $\cdot$ RH_LLMW $\cdot$ CH_TRU(M) $\cdot$ RH_TRU(M) .

GTC III $\cdot$ LLW $\cdot$ HAZ

CONTAINERS:

CH_LLMW $\cdot$ RH_LLMW $\cdot$ CH_TRU(M) . RH_TRU(M) $\cdot$ GTC III $\cdot$ LLW $\cdot$ HAZ

\section{WASTE Classes:}

CH_LLMW $\cdot$ RH_LLMW $\cdot$ CH_TRU(M) $\cdot$ RH_TRU(M) $\cdot$ GTC III $\cdot$ LLW $\cdot$ HAZ

Home - Contents - Web Site Map - Glossary · Help - Reports - Data Requests - Feedback Form

NOTICE: This page is provided subject to our disclaimer. Contact: Oscar Valero at (509) $373-4752$.

HNF-EP-0918 rev. 1 Approved for public release; distribution is unlimited. 


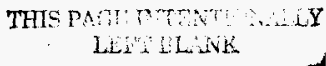


cu: $0 z=18701$

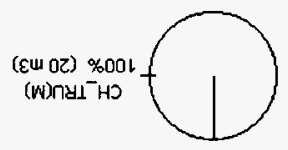

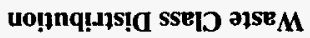

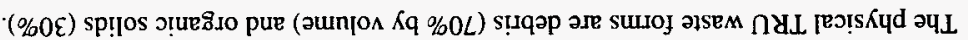

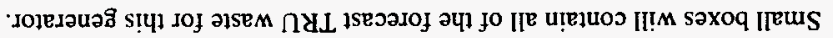

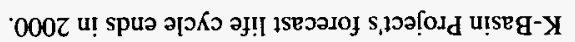

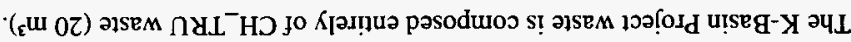

'15EJวJoI

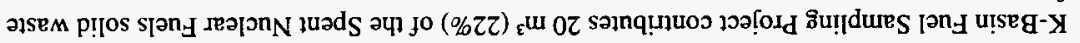

\section{งาบริ!โบชับ}

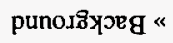

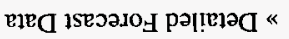

ęed

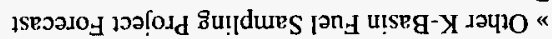

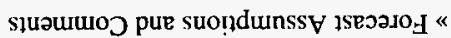

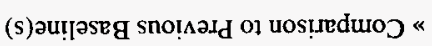
Saunjo $\Lambda$ jenưV « งเบรี!โบชิเก *

sұบวนแ0อ

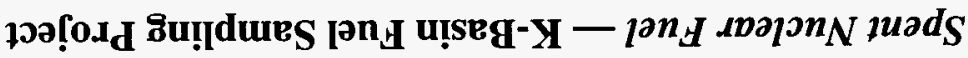

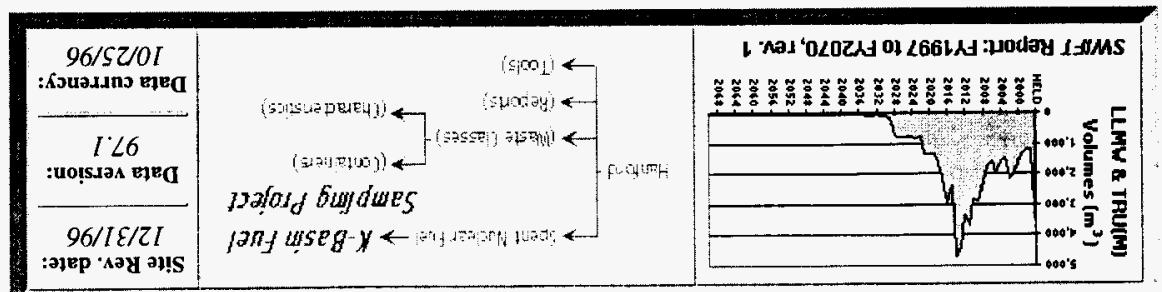


Physical Waste Form Distribution

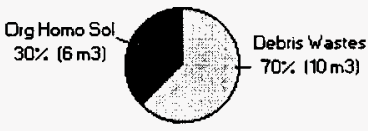

Iotal $=20 \mathrm{m3}$

\section{Hazardous Constituent Distribution}

NOHCs

are forecast

for this

Waste

Generator)

\section{Container Distribution}

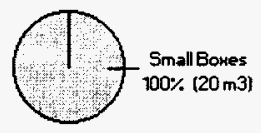

Total $=20 \mathrm{~m} 3$

Sum of totals may not add due to rounding: numbers over $10 \mathrm{~m}^{3}$ are rounded to the nearest $10 \mathrm{~m}^{3}$, numbers less than $10 \mathrm{~m}^{3}$ are rounded to integers, non-zero numbers less than 1 are rounded to 1 .

\section{Annual Volumes}

\section{Annual Baseline Volumes}

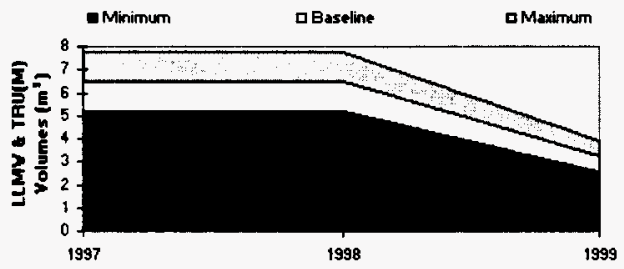

Annual Baseline by Waste Class 


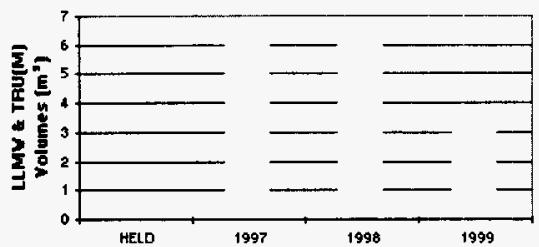

CH_TRU(M)

\section{Comparison to Previous Baseline(s)}

The K-Basin Project waste forecast has increased significantly from the $0.3 \mathrm{~m}^{3}$ forecast in FY96. This is a result of accounting for CH_TRU spent cartridge filters used to maintain basin water quality.

\section{Comparison to Previous Baseline(s) by Waste Class}

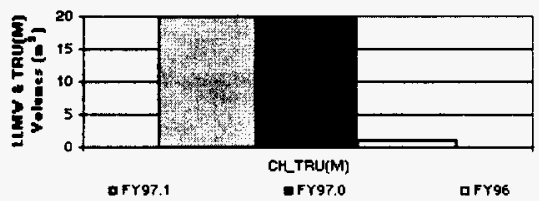

\begin{tabular}{|c|c|c|c|}
\hline $\begin{array}{l}\text { K-Basin Fuel Sampling Project Comparison: } \\
\text { Vaste Class }\end{array}$ & $\begin{array}{c}\text { FY97.1 } \\
\text { Forecast } \\
\left(\mathrm{m}^{2}\right)\end{array}$ & $\begin{array}{c}\text { FY97.0 } \\
\text { Foreease } \\
\text { (min) }\end{array}$ & $\begin{array}{c}\text { FY96 } \\
\text { Forecast } \\
\text { (min) }\end{array}$ \\
\hline CH_TAU(M) & 20 & 20 & \\
\hline selorel & 28 & 20 & 1 \\
\hline LLW & 1,030 & 1,030 & 310 \\
\hline 70 ed & 1.05\% & 1.000 & 210 \\
\hline
\end{tabular}

Sum of totals may not add due to rounding: numbers over $10 \mathrm{~m}^{3}$ are rounded to the nearest $10 \mathrm{~m}^{3}$, numbers less than $10 \mathrm{~m}^{3}$ are rounded to integers, non-zero numbers less than 1 are rounded to 1.

\section{Background}

$\mathrm{K}$-Basin Project is responsible for maintenance and preparation of the $\mathrm{K}$-Basin for storage and removal of all spent nuclear fuel, debris, and sludge; constructing, as necessary, new systems and facilities to condition and store the fuel; relocating the fuel to interim storage; and accepting spent nuclear fuel from other Hanford locations.

\section{Forecast Assumptions and Comments}

In preparation of this forecast, known waste was addressed, and estimates were calculated according to Projects and expected waste streams.

The K-Basin major milestone: "Remove all Fuel and Sludge from both K-East and K-West Basins in an Encapsulated Form." (M-34-00-T08) is not reflected in this forecast, given the 
uncertainty in the basin clean-out.

The K-Basin Project baseline waste estimate may vary from $80 \%$ to $120 \%$. The minimum value is based on the uncertainty of actual volume to be generated by basin clean-out and the long-term status of the facility after the stored fuel has either been contained or removed. The maximum value is based in the short term on not knowing the precise amount of waste to be generated by basin clean-out and pilot project. Long term expectations are that, regardless of chosen interim fuel storage method, waste generation in general should not exceed predicted amounts.

\section{Other Forecast Data}

\section{- Low Level Waste}

- A total of $1,030 \mathrm{~m}^{3}$ of $\mathrm{LLW}$ is expected from K-Basin Project.

- This represents an increase of $232 \%$ from the FY96 estimate of $310 \mathrm{~m}^{3}$ due to addition of spent ion exchange modules to the forecast, as well as the reassignment of some LLW from K-Basin Operations.

- Medium boxes will contain $70 \%$ of the LLW, $24 \%$ will come in MB-IV boxes, and MB-V boxes will hold the remaining $6 \%$.

- The major LLW physical form is concrete shielding at $60 \%$ of the volume, debris at $38 \%$, and $2 \%$ organic particulates.

\section{- Hazardous Waste}

o No hazardous waste is expected from K-Basin Project for management by the CWC.

\begin{tabular}{|c|c|}
\hline \multicolumn{2}{|c|}{$\begin{array}{l}\text { GENERATORS: } \\
\text { 100K K-Basin Operations } \cdot \text { K-Basin Fuel Sampling Project }\end{array}$} \\
\hline \multicolumn{2}{|c|}{$\begin{array}{c}\text { PROGRAMS: } \\
\text { Analytical Services } \cdot \text { EM-40 - Facility Transitions } \cdot \text { Landlord } \cdot \text { Liquid Effluent } \cdot \text { NP } \cdot \text { Offsite } \cdot \text { PNNL } \cdot \text { RCRA } \cdot \text { Solid } \\
\text { Waste } \cdot \text { SNF } \cdot \text { TWRS }\end{array}$} \\
\hline $\begin{array}{l}\text { CHARACTERISTICS: } \\
\text { CH_LLMW } \cdot \text { RH_LLMW } \cdot \text { CH_TRU(M) } \cdot \text { RH_TRU(M) } \\
\text { GTC III } \cdot \text { LLW } \cdot \text { HAZ }\end{array}$ & $\begin{array}{l}\text { CONTAINERS: } \\
\text { CH_LLMW } \cdot \text { RH_LLMW } \cdot \text { CH_TRU(M) } \\
\text { RH_TRU(M) } \cdot \text { GTC III } \cdot \text { LLW } \cdot \text { HAZ }\end{array}$ \\
\hline \multicolumn{2}{|c|}{$\begin{array}{l}\text { WASTE CLASSES: } \\
\text { CH_LLMW } \cdot \text { RH_LLMW } \cdot \text { CH_TRU(M) } \cdot \text { RH_TRU(M) } \cdot \text { GTC III } \cdot \text { LLW } \cdot \text { HAZ }\end{array}$} \\
\hline
\end{tabular}

NOTICE: This page is provided subject to our disclaimer. Contact: Oscar Valero at (509) 373-4752.

HNF-EP-0918 rev. 1 Approved for public release; distribution is unlimited. 


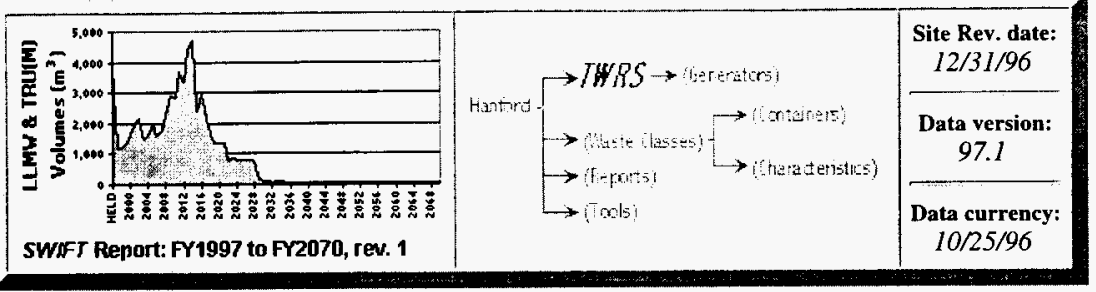

\section{Tank Waste Remediation System (TWRS)}

\section{Contents}

" Highlights

» Annual Waste Class Volumes

» Summary Table

»Comparison to Previous Baseline(s)
» Background

» Forecast Assumptions and Comments

» Other TWRS Forecast Data

\section{Highlights}

- The forecast life cycle for TWRS ends in 2032, although most activities will be completed by 2028 .

- The life cycle total of LLMW and TRU(M) waste for TWRS is $50,120 \mathrm{~m}^{3}$, or $74 \%$ of the Hanford total.

- This forecast shows a $22 \%$ decrease from the FY96 forecast of $64,170 \mathrm{~m}^{3}$ due to revised programmatic assumptions that reduced the volume of long length equipment being retrieved.

- RH_LLMW is the primary waste class generated, representing $58 \%\left(29,040 \mathrm{~m}^{3}\right)$ of the TWRS waste volume.

- SST Long Length Equipment is the major source of waste, generating $47 \%\left(23,500 \mathrm{~m}^{3}\right)$ of the waste volume.

- The TWRS program uses more container types than any other program. LECs are expected to contain a little more than half of the LLMW and TRU(M) waste volume. 208 liter drums is the other substantial container, responsible for $30 \%$ of the volume.

- The physical waste forms forecast are almost entirely debris, corresponding to $94 \%$ of the volume. Shielding is the only other significant form, equal to $4 \%$. The remaining $2 \%$ of the waste is expected to be soil/gravel (1\%), organic solids, special waste, and inorganic solids.

- Essentially all of the LLMW and TRU(M) waste hazardous constituents are state regulated (73\% by volume) and organic ( $25 \%$ ). The remaining $2 \%$ is composed of other miscellaneous hazardous constituents. 


\section{Waste Class Distribution}

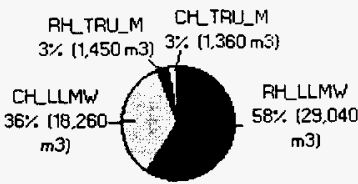

Total $=50,120 \mathrm{m3}$
Generator Distribution

DST Retrieval Systems Other

$8 \%[4,010 \mathrm{~m} 3) \quad 12 \%(5,830 \mathrm{~m} 3]$

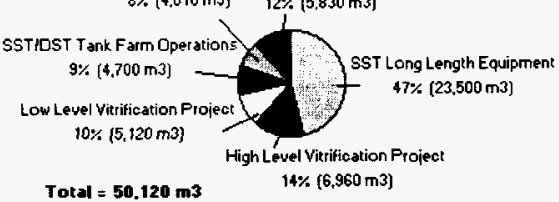

Physical Waste Form Distribution Hazardous Constituent Distribution

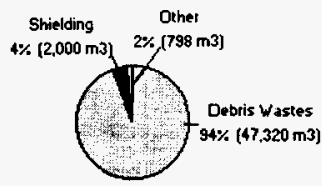

Total $=50.120 \mathrm{~m}^{3}$

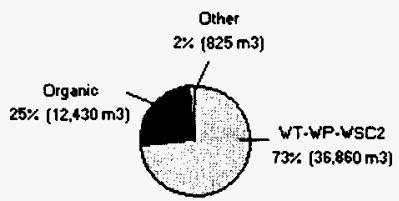

Total $=50.120 \mathrm{~m} 3$

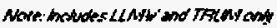

\section{Container Distribution}

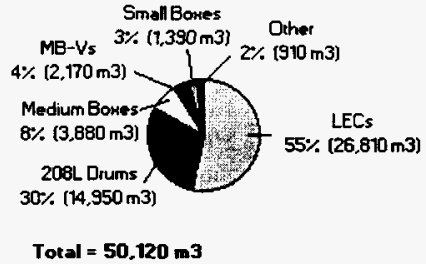

Sum of totals may not add due to rounding: numbers over $10 \mathrm{~m}^{3}$ are rounded to the nearest $10 \mathrm{~m}^{3}$. numbers less than $10 \mathrm{~m}^{3}$ are rounded to integers, non-zero numbers less than 1 are rounded to 1 .

\section{Annual Waste Class Volumes}

TWRS will be generating waste from 1997 to the end of life cycle in 2032. Major waste generation will occur during the period 2001 to 2021 with a peak of about $4,307 \mathrm{~m}^{3}$ in 2014 . The main activity during this period is the retrieval of the high level waste from the tanks (including removal of the long-length contaminated equipment). Other important sources of waste include the High Level and Low Level Vitrification Projects, which will generate waste during the general time period from 2011 to 2028 .

\section{Annual Baseline Volumes}




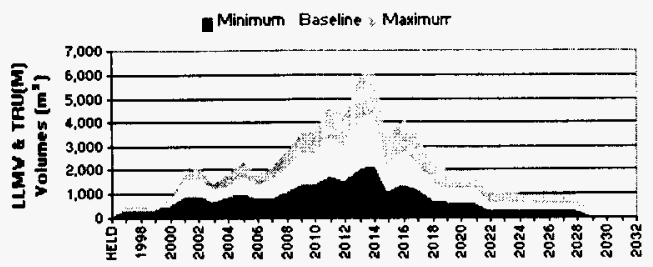

\section{Annual Baseline by Waste Class}

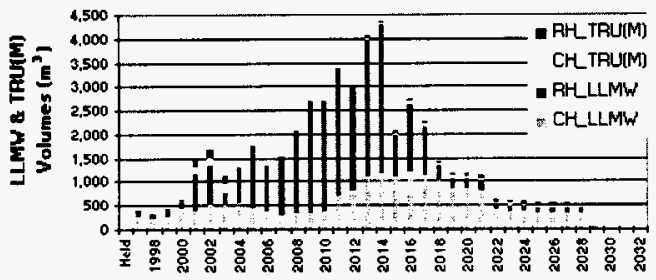

\section{Summary Table (Volumes in $\mathbf{m}^{3}$ )}

\begin{tabular}{|c|c|c|c|c|c|c|}
\hline $\begin{array}{l}\text { TYRS Surmmary: } \\
\text { Generator }\end{array}$ & CH_LLMY & AH_LLMY & CH_TRLYM] & RH_TRU(M) & Subtotal & PCT \\
\hline SST Long Length Equipment & 0 & 22,520 & 490 & 490 & 23,500 & $47 \%$ \\
\hline High Level Vitrification Project & 5,220 & 0 & 870 & 870 & 6,960 & $14 \%$ \\
\hline Low Level Vitrification Project & 5,120 & 0 & 0 & 0 & 5,120 & $10 \%$ \\
\hline SSTIOST Tank Farm Operations & 3,760 & $\$ 40$ & 0 & 0 & 4.700 & $9 \%$ \\
\hline DST Retrieval Systems (10 tenks) & 870 & 3050 & 0 & 90 & 4.010 & $8 \%$ \\
\hline W343 DST Retrieval (17 Tanks) & 1,480 & 1,760 & 0 & 0 & 3,240 & $6 \%$ \\
\hline SST Retrieval (149 tanks) & 890 & 390 & a & 0 & 1,280 & $3 \%$ \\
\hline Tenk Ferm Restor ation & 880 & 380 & 0 & 0 & 1260 & $3 \%$ \\
\hline Tank Farm Ventilation Upgrade & 40 & 0 & 0 & 0 & 40 & $0 \%$ \\
\hline Cross-Site Transfer System & 5 & 0 & 0 & 0 & 5 & $0 \%$ \\
\hline Totals & $+8,260$ & 29,040 & 1,360 & $t, 450$ & 50,120 & $100 \%$ \\
\hline PCT & $36 \%$ & $58 \%$ & $3 \%$ & $3 \%$ & $100 \%$ & \\
\hline
\end{tabular}

Sum of totals may not add due to rounding: numbers over $10 \mathrm{~m}^{3}$ are rounded to the nearest $10 \mathrm{~m}^{3}$, numbers less than $10 \mathrm{~m}^{3}$ are rounded to integers, non-zero numbers less than I are rounded to $I$.

\section{Comparison to Previous Baseline(s)}

The FY97.1 waste forecast for TWRS of $50,120 \mathrm{~m}^{3}$ shows a $22 \%$ decrease from the FY96 forecast of $64,170 \mathrm{~m}^{3}$.

This change primarily stems from new estimates by the SST Long-Length Equipment generator of the amount of existing equipment and the amount of equipment used for retrieval. In particular, as previously documented in Hanford's Remote-Handled Transuranic and Transuranic Mixed Waste Volume Assessment, PNNL-11206 (1996), there has been a revision 
to the programmatic baseline for the disposition of the long-length equipment. The new programmatic baseline assumes that only long-length equipment retrieved prior to 2003 will be managed by the Waste Management Project prior to disposal at the WIPP; the remaining long-length equipment will be disposed on site in a similar manner as the underground tanks. Decontamination is expected to occur so that most of the equipment is not considered transuranic waste.

It should be noted that the decrease in SST Long-Length Equipment waste volume estimates is somewhat balanced by increases in other waste generators' estimates. Major sources of waste estimate increases include W343 DST Retrieval, DST 101AZ Retrieval, and the Low Level Vitrification Project, all of which are based on new operational baselines.

An additional key change in the FY97.1 forecast is the significant decrease from the FY96 forecast in the level of RH_TRU(M) waste generated (from $12,490 \mathrm{~m}^{3}$ to $1,450 \mathrm{~m}^{3}$ ). This decrease is again largely due to the change in baseline for SST Long-Length Equipment, but also arises from decreases in RH_TRU estimates by W343 DST Retrieval and the High Level Vitrification Project.

Another change in the forecast is that there is no longer any waste forecast as greater-than-category III waste.

The 1997 hazardous constituents forecast shows state regulated constituents accounting for most of the waste, and organics representing the rest. Last year's forecast showed organic constituents as accounting for almost all of the volume, and state regulated composing the next largest portion. Also, the current forecast does not include corrosive constituents as did the previous.

\section{Comparison to Previous Baseline(s) by Waste Class}

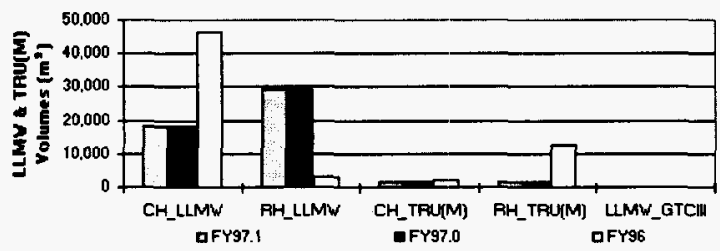

\begin{tabular}{|c|c|c|c|}
\hline $\begin{array}{l}\text { TwRS Comparison: } \\
\text { Waste Class }\end{array}$ & $\begin{array}{c}\text { FY97.1 } \\
\text { Forecast } \\
\text { (m) }\end{array}$ & $\begin{array}{c}\text { FYaz.8 } \\
\text { Forecast } \\
\left(\mathrm{m}^{3}\right)\end{array}$ & $\begin{array}{c}\text { Fy96 } \\
\text { Forecast } \\
\text { (m) }\end{array}$ \\
\hline CH LLMM & 18.260 & 18.260 & 46,310 \\
\hline RH LLMN & 29,040 & 29,040 & 3,080 \\
\hline $\mathrm{CH}$ JRU $(M)$ & 1,360 & 1,360 & 2,180 \\
\hline RH TRU(M) & 1,450 & 1,450 & 12,490 \\
\hline LLMNV GTCII & 0 & D & 110 \\
\hline Subetel & $50,+20$ & 50,520 & 64170 \\
\hline LLW & 63,600 & 63,600 & 59,110 \\
\hline HAI & 2,360 & 2,380 & 790 \\
\hline Totel & 116,100 & 116,100 & 124070 \\
\hline
\end{tabular}


than $10 \mathrm{~m}^{3}$ are rounded to integers, non-zero numbers less than I are rounded to 1.

\section{Background as of $9 / 96$}

The TWRS program mission is to store, treat, and immobilize highly radioactive Hanford waste in an environmentally sound, safe, and cost-effective manner. Tank waste includes current tank waste, future tank waste, and the $\mathrm{Cs} / \mathrm{Sr}$ capsules currently stored at the Waste Encapsulation and Storage Facility (WESF) (Valero, et al., 1995).

Completion of this mission will be performed by the maintenance and integration (M\&I) contractor and a private contractor, currently not determined. Privatization will be performed in two phases. The scope in Phase 1 includes privatization of pretreatment, low-level waste immobilization, and an optional high-level waste immobilization to the extent that proof of concept is established. Phase 2 will include privatization of tank waste retrieval, interim storage of wastes, pretreatment, LLW/HLW immobilization, disposition of $\mathrm{Cs} / \mathrm{Sr}$ capsules, and interim storage of immobilized wastes. Decontaminating and decommissioning equipment and treatment facilities is also the responsibility of the private contractor. All secondary waste disposition is the responsibility of M\&I contractor; however, the secondary waste generated during D\&D has not been estimated.

The TWRS program has four primary activities identified in the Tank Waste Remediation System Baseline System Description (1995) that could generate solid waste: managing tank waste, retrieving tank waste, processing tank waste, and disposing of secondary generated waste. The tasks included under each of these primary activities are listed below. Each of these primary activities is expected to generate solid waste that could potentially be managed at the CWC.

\section{Manage Tank Waste:}

This activity includes tank farm operations and upgrades, waste tank safety and characterization, waste transfer, and waste concentration. This activity will be performed by the M\&I contractor. All potential solid waste that could be generated from this activity has been forecast.

\section{Retrieve Tank Waste:}

This activity will hydraulically retrieve waste from the single-shell tanks and double-shell tanks. The retrieval method for the miscellaneous underground storage tanks will be determined by the private contractor. This activity will be performed by the M\&I contractor during the proof-of concept phase (Phase 1) and the private contractor during Phase 2 . The solid waste generated during this activity includes primarily the long-length contaminated equipment (LLE). The volume of LLE shipped to the CWC is dependent on the retrieval technology and may vary once the final technologies are selected.

\section{Process Waste:}

This activity includes preparing the $\mathrm{Cs} / \mathrm{Sr}$ capsules for disposal, tank waste pretreatment, LLW immobilization, HLW immobilization, and storage of in-process waste. The private contractor is responsible for designing the pretreatment and immobilization technologies. Solid waste resulting from operations and interim storage has been adequately forecast; however, the 
volumes may fluctuate once the final technology has been determined. Potential solid waste generated during the disposition of the $\mathrm{Cs} / \mathrm{Sr}$ capsules has not been forecast.

\section{Dispose of Waste:}

The main tasks associated with this primary activity are interim storage of solidified high level waste, disposal of immobilized LLW, and closure of the MUSTs. The M\&I contractor is responsible for completing these tasks. Large volumes of solid waste are not expected from these activities; therefore, forecasts have not been provided.

\section{Forecast Assumptions and Comments}

As mentioned previously, there has been a revision to the programmatic baseline for the disposition of the long-length equipment. The new programmatic baseline assumes that only long-length equipment retrieved prior to 2003 will be managed by the Waste Management Program prior to disposal at the WIPP; the remaining long-length equipment will be disposed on site in a similar manner as the underground tanks. Decontamination is expected to occur so that most of the equipment is not considered transuranic waste.

The minimum range reported for the TWRS program is $54 \%$ of baseline, and the maximum is $145 \%$ of baseline. This range is based largely on uncertainties in estimates provided by SST Long-Length Equipment, High Level Vitrification Project (HLVP), and Low Level Vitrification Project (LLVP).

\section{Other Forecast Data}

\section{- Low Level Waste}

o A total of $63,600 \mathrm{~m}^{3}$ of LLW is expected from TWRS.

- This forecast shows an $8 \%$ increase from the FY96 forecast of $59,110 \mathrm{~m}^{3}$, with various generators showing decreases and others showing increases, based on new baselines.

- $93 \%$ of the LLW is to be contained by MB-V boxes. Other drums and boxes contain the remaining $7 \%$.

- Essentially $100 \%$ of the LLW has the physical form of debris; however, organic and inorganic forms are reported, but in negligible volumes.

\section{- Hazardous Waste}

- A total of $2,380 \mathrm{~m}^{3}$ of hazardous waste was reported by TWRS for management by the CWC. 


\section{GENERATORS:}

Cross-Site Transfer System - DST Retrieval Systems - High Level Vitrification Project - Low Level Vitrification Project SST Long Length Equipment - SST Retrieval - SST/DST Tank Farm Operations - Tank Farm Restoration - Tank Farm Ventilation Upgrade · W343 DST Retrieval

\section{PROGRAMS:}

Analytical Services · EM-40 · Facility Transitions · Landlord · Liquid Effluent · NP · Offsite · PNNL · RCRA · Solid Waste $\cdot$ SNF $\cdot$ TWRS

\begin{tabular}{|c|c|}
\hline $\begin{array}{c}\text { CHARACTERISTICS: } \\
\text { CH_LLMW } \cdot \text { RH_LLMW } \cdot \text { CH_TRU(M) } \cdot \text { RH_TRU(M) }) \\
\text { GTC III } \cdot \text { LLW } \cdot \text { HAZ }\end{array}$ & $\begin{array}{c}\text { CONTAINERS: } \\
\text { CH_LLMW } \cdot \text { RH_LLMW } \cdot \text { CH_TRU(M) } \\
\text { RH_TRU(M) } \cdot \text { GTC III } \cdot \text { LLW } \cdot \text { HAZ }\end{array}$ \\
\hline CH_LLMW $\cdot$ RH_LLMW $\cdot$ CH_TRU(M) $\cdot$ RH_TRU(M) $\cdot$ GTC III $\cdot$ LLW $\cdot$ HAZ \\
\hline Home $\cdot$ Contents $\cdot$ Web Site Map $\cdot$ Glossary $\cdot$ Help $\cdot$ Reports $\cdot$ Data Requests $\cdot$ Feedback Form
\end{tabular}

NOTICE: This page is provided subject to our disclaimer. Contact: Oscar Valero at (509) 373-4752.

HNF-EP-0918 rev, 1 Approved for public release; distribution is unlimited. 


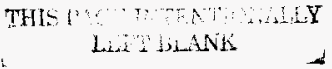



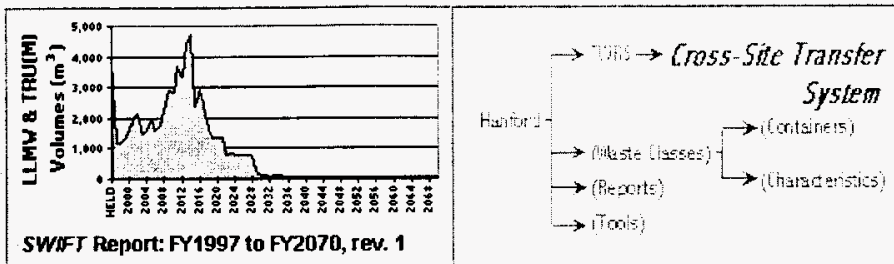

Site Rev. date:

$12 / 31 / 96$

Data version:

97.1

Data currency: $10 / 25 / 96$

\section{TWRS - Cross-Site Transfer System}

\section{Contents}

» Highlights

» Annual Volumes

»Comparison to Previous Baseline(s)

» Background
》 Forecast Assumptions and Comments

» Other Cross-Site Transfer System Forecast Data

"Detailed Forecast Data

\section{Highlights}

- Cross Site Transfer System (W-058) (NHC_TWP_W058) contributes $5 \mathrm{~m}^{3}(<1 \%)$ of the TWRS program's solid waste forecast.

- The W-058 forecast life cycle extends only through 1997.

- $\mathrm{CH} \_$LLMW is the only waste class generated, representing $100 \%$ of the waste $\left(5 \mathrm{~m}^{3}\right)$.

- The 208 liter drum container will hold $100 \%$ of the LLMW.

- $100 \%$ of the LLMW has the physical form of soil and soil/gravel.

- Mixed organic and PCB hazardous constituents represent $100 \%$ of the LLMW.

\section{Waste Class Distribution}

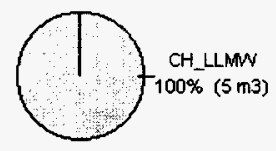

Total $=5 \mathrm{m3}$ 
Physical Waste Form Distribution

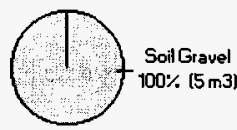

Total $=5 \mathbf{m} \mathbf{3}$

\section{Hazardous Constituent Distribution}

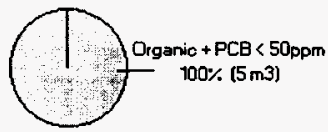

Total $=5 \mathbf{m 3}$

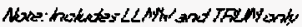

\section{Container Distribution}

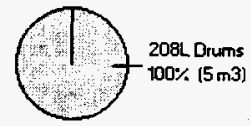

Total $=5 \mathrm{~m} 3$

Sum of totals may not add due to rounding: numbers over $10 \mathrm{~m}^{\mathrm{s}}$ are rounded to the nearest $10 \mathrm{~m}^{3}$, numbers less than $10 \mathrm{~m}^{3}$ are rounded to integers, non-zero numbers less than $I$ are rounded to $I$.

\section{Annual Volumes}

\section{Annual Baseline Volumes}

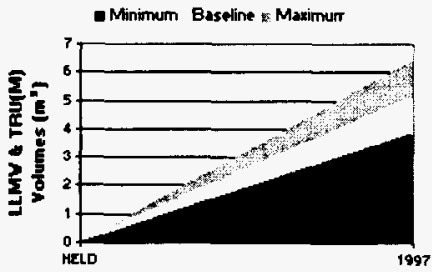

Annual Baseline by Waste Class 


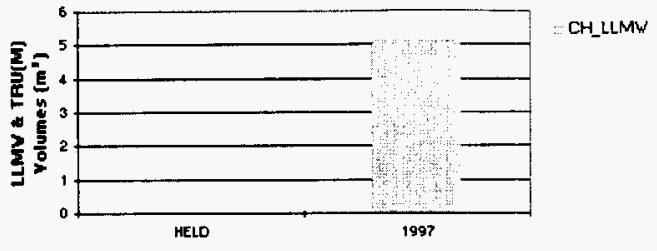

\section{Comparison to Previous Baseline(s)}

The W-058 FY97.1 waste forecast is essentially the same as the FY96 forecast of $7 \mathrm{~m}^{3}$, with the slight reduction based on favorable experiences in excavating within the SY tank farm. Additionally, it has been determined that the waste is LLMW rather than TRU(M) waste as previously forecasted.

\section{Comparison to Previous Baseline(s) by Waste Class}

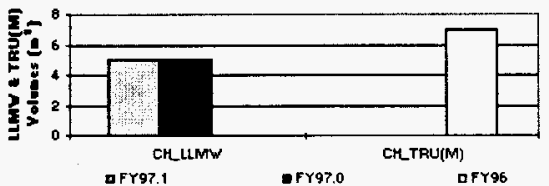

\begin{tabular}{|c|c|c|c|}
\hline $\begin{array}{l}\text { Cross-Site Transfer System Comparison: } \\
\text { Waste Class }\end{array}$ & $\begin{array}{c}\text { Frg7.1 } \\
\text { Forecast } \\
{\left[\mathbf{m}^{2}\right]}\end{array}$ & $\begin{array}{c}\text { FY97.0 } \\
\text { Forecsst } \\
\text { [m'] }\end{array}$ & $\begin{array}{l}\text { FY96 } \\
\text { Forecast } \\
\text { (m') }\end{array}$ \\
\hline $\mathrm{CH} U \mathrm{MW}$ & 5 & 5 & 0 \\
\hline CH TRU(M) & 0 & 0 & 7 \\
\hline Srobrorer & 5 & 5 & 7 \\
\hline$\underline{L W}$ & 0 & 0 & 120 \\
\hline Tores & 5 & 5 & $1 x$ \\
\hline
\end{tabular}

Sum of totals may not add due to rounding: numbers over $10 \mathrm{~m}^{3}$ are rounded to the nearest $10 \mathrm{~m}^{3}$, numbers less than $10 \mathrm{~m}^{3}$ are rounded to integers, non-zero numbers less than $I$ are rounded to $I$.

\section{Background}

The mission of the W-058 project is the construction of a replacement cross-site transfer system. Waste results from excavation of soil within contaminated areas, including the SY tank farm and the 244A lift station. Generated waste consists of LLMW in the form of soil and gravel.

\section{Forecast Assumptions and Comments}

Volumes were originally estimated during conceptual design of the project. They have been revised as a result of pre-construction surveys and actual construction experience to date.

Waste will be packaged in its "as-found" state. 
Minimum and maximum ranges for the waste are $75 \%$ and $125 \%$ respectively, and are based on engineering judgment and the current status of excavation activities.

\section{Other Forecast Data}

- Low Level Waste

- No low level waste is expected from W-058 for management by the CWC; which reflects a $100 \%$ decrease from the FY 96 Forecast of $120 \mathrm{~m}^{3}$.

\section{- Hazardous Waste}

- No hazardous waste is expected from W-058 for management by the CWC.

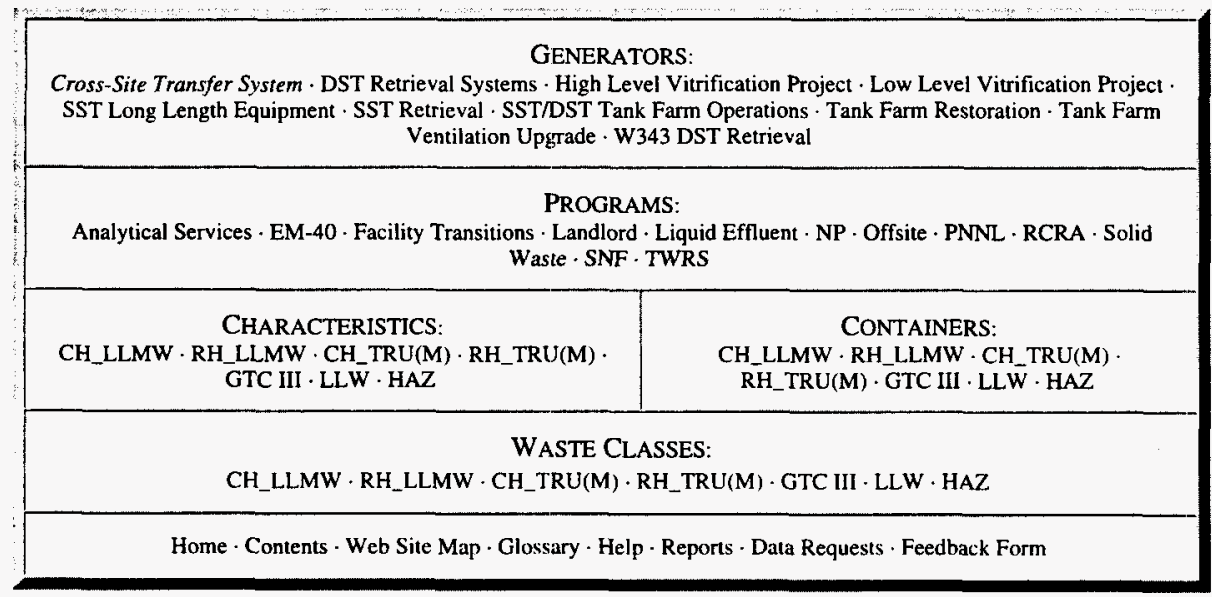

NOTICE: This page is provided subject to our disclaimer. Contact: Oscar Valero at (509) 373-4752.

HNF-EP-0918 rev. 1 Approved for public release; distribution is unlimited. 
\%0 [ st Kinosau ]noyı!m

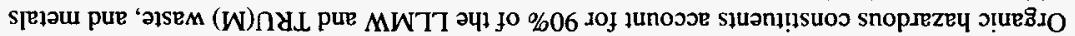

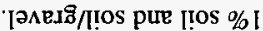

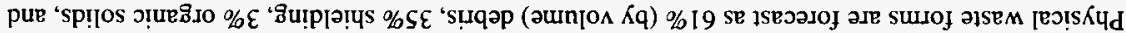

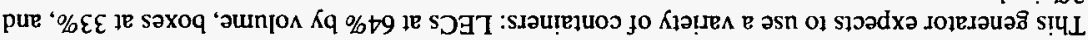

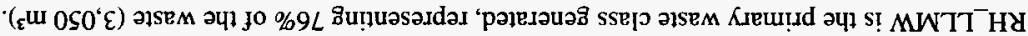

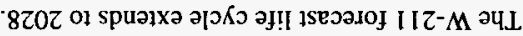

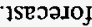

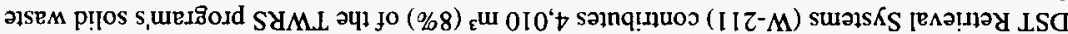

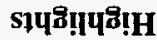

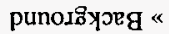

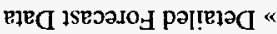

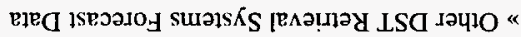

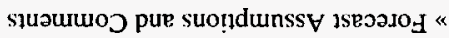

\section{$\bullet$}




\section{Waste Class Distribution}

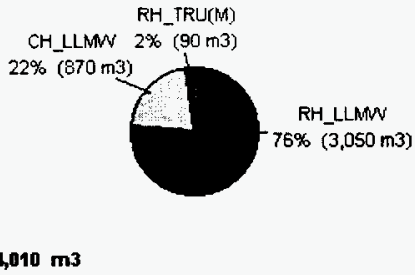

Physical Waste Form Distribution

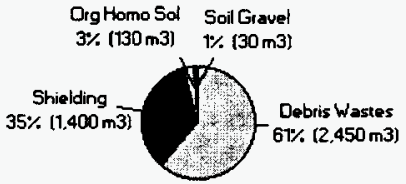

Totel = 4,010 $\mathrm{m}^{3}$
Hazardous Constituent Distribution

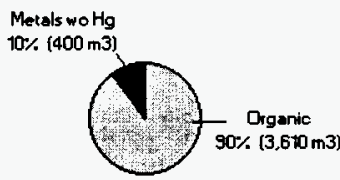

Total $=4.010 \mathrm{m3}$

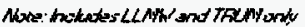

\section{Container Distribution}

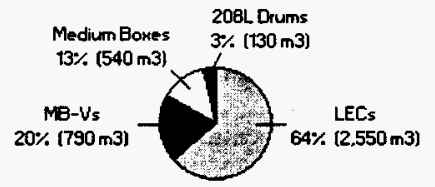

Tokal $=4,010 \mathrm{~m} 3$

Sum of totals may not add due to rounding: numbers over $10 \mathrm{~m}^{3}$ are rounded to the nearest $10 \mathrm{~m}^{3}$, numbers less than $10 \mathrm{~m}^{3}$ are rounded to integers, non-zero numbers less than 1 are rounded to $l$.

\section{Annual Volumes}

\section{Annual Baseline Volumes}




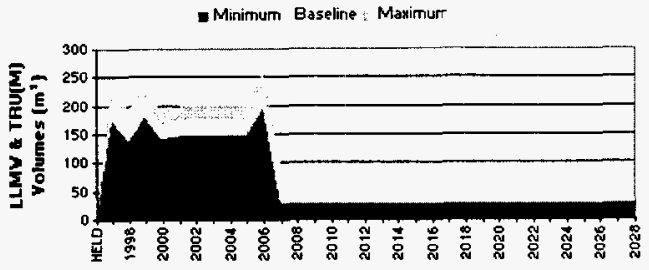

\section{Annual Baseline by Waste Class}

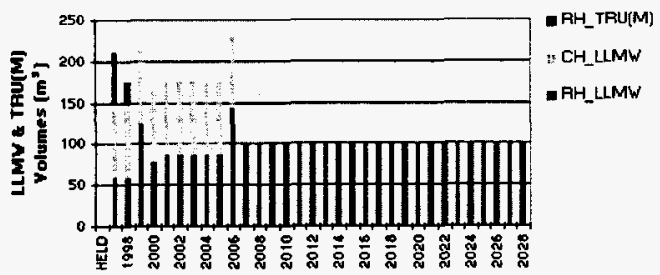

\section{Comparison to Previous Baseline(s)}

The FY97.1 forecast for W-211 is significantly greater than the FY96 estimate of $260 \mathrm{~m}^{3}$. This increase is due to the fact that the FY97.1 forecast is based on current project information and a completed Title I report. For example, the schedule has been compressed so that all ten W-211 tanks are complete by 2008 instead of 2010. Also, tanks 102-SY and 105-AW replaced 106-AN and 101-AP in the project scope. The anticipated waste volume generated during construction is better defined.

\section{Comparison to Previous Baseline(s) by Waste Class}

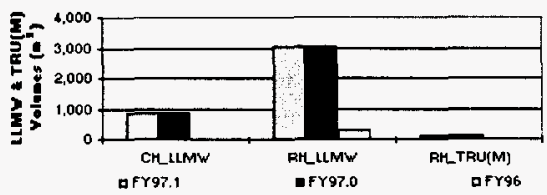

\begin{tabular}{|c|c|c|c|}
\hline $\begin{array}{l}\text { DST Retrieval Systems [10 tanks] Comparison: } \\
\text { Vaste Class }\end{array}$ & $\begin{array}{l}\text { FY97.t } \\
\text { Forecast } \\
\text { (m") }\end{array}$ & $\begin{array}{c}\text { FY97.B } \\
\text { Forecast } \\
\text { (mi) }\end{array}$ & $\begin{array}{c}\text { Frs6 } \\
\text { Forecast } \\
(\mathbf{m} 3)\end{array}$ \\
\hline $\mathrm{CH} L \mathrm{LMW}$ & 870 & 870 & 0 \\
\hline RH LLMW & 3,050 & 3.050 & 260 \\
\hline RH TRU(M) & 90 & 90 & 0 \\
\hline Subrord & 4010 & 1010 & 200 \\
\hline LWW & 0 & 0 & 1.980 \\
\hline Tord & $601 \theta$ & 1.010 & 2,210 \\
\hline
\end{tabular}

Sum of totals may not add due to rounding: numbers over $10 \mathrm{~m}^{3}$ are rounded to the nearest $10 \mathrm{~m}^{3}$, numbers less 
than $10 \mathrm{~m}^{3}$ are rounded to integers, non-zero numbers less than I are rounded to I.

\section{Background}

The W-211 mission is to retrieve DST waste for processing, management of existing storage capacity, and continued safe storage. Waste classes result from construction activities in existing tank farms and from replacement of items during the operating life cycle.

CH_LLMW will be generated from excavation and demolition of non in-tank equipment/structures and from work in such areas as pits. RH_LLMW will result from removing components that have been exposed to tank waste. $\mathrm{RH}$ _TRU waste will result from removing components from high TRU tanks $102-\mathrm{SY}$ and 105-AW.

\section{Forecast Assumptions and Comments}

Solid waste generated during the facility life cycle (only for project related upgrades) has been included in the FY97.1 forecast.

Ten DST retrieval systems will be installed and operated from 1998 through 2009. Most removed in-tank components are assumed to be LLW based on decontamination by a high pressure spray wash system during removal. All waste is assumed to be mixed.

There are no assumptions in the W-211 forecast related to commercial disposal of solid radioactive mixed waste.

Average annual minimum and maximum ranges for the waste are $55 \%$ and $107 \%$ respectively. In early years, the minimum/maximum values are based on uncertainties in the assumed waste generation volumes. In the outyears, they are based on uncertainties about pump replacement durations.

\section{Other Forecast Data}

- Low Level Waste

- No LLW is expected from W-211 for management by the CWC.

- This forecast shows a $100 \%$ decrease from the FY96 forecast of $1,980 \mathrm{~m}^{3}$, due to a new baseline.

\section{- Hazardous Waste}

- No hazardous waste is expected from W-211 for management by the CWC. 


\section{GENERATORS:}

Cross-Site Transfer System - DST Retrieval Systems - High Level Vitrification Project - Low Level Vitrification Project . SST Long Length Equipment · SST Retrieval · SST/DST Tank Farm Operations · Tank Farm Restoration · Tank Farm Ventilation Upgrade · W343 DST Retrieva!

\section{PROGRAMS:}

Analytical Services · EM-40 - Facility Transitions - Landlord · Liquid Effluent - NP · Offsite · PNNL · RCRA · Solid Waste $\cdot$ SNF $\cdot$ TWRS

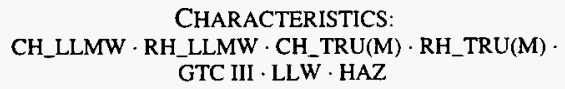

CHARACTERISTICS:

CH_LLMW $\cdot$ RH_LLMW $\cdot$ CH_TRU(M) $\cdot$ RH_TRU(M) . GTC III $\cdot$ LLW $\cdot$ HAZ

\section{CONTAINERS:}

CH_LLMW $\cdot$ RH_LLMW $\cdot$ CH_TRU(M) $_{-}$

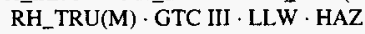

\section{WASTE Classes:}

CH_LLMW $\cdot$ RH_LLMW $\cdot$ CH_TRU(M) $\cdot$ RH_TRU(M) $\cdot$ GTC III $\cdot$ LLW $\cdot$ HAZ

Home · Contents · Web Site Map · Glossary $\cdot$ Help $\cdot$ Reports $\cdot$ Data Requests $\cdot$ Feedback Form

NOTICE: This page is provided subject to our disclaimer. Contact: Oscar Valero at (509) 373-4752.

HNF-EP-0918 rev. 1 Approved for public release; distribution is unlimited. 


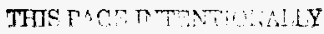
LEO ULLNK 


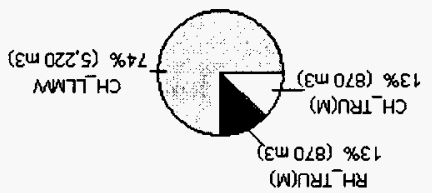

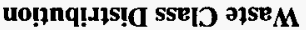

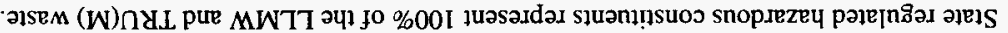

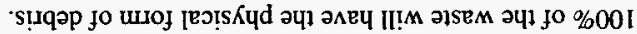

(\%E I) sgMS pure

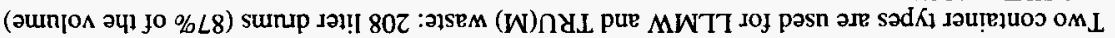

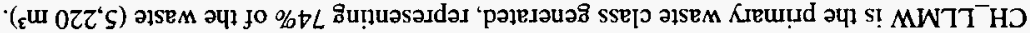

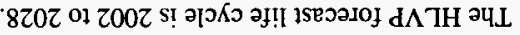

JSEכajoJ כisem p!jOS

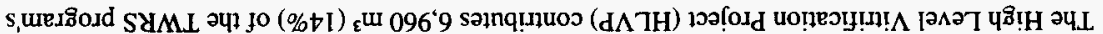

รานถ์เโบชึ!ก

punolôx

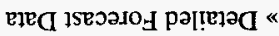

हIEव

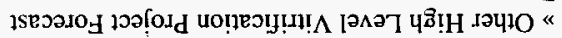
sluəuسo pue suo!̣dunss $\forall$ 1seวajo

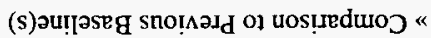
soun งมบชิ!โบชิเก «

รานวนบัว

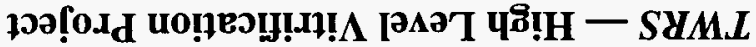

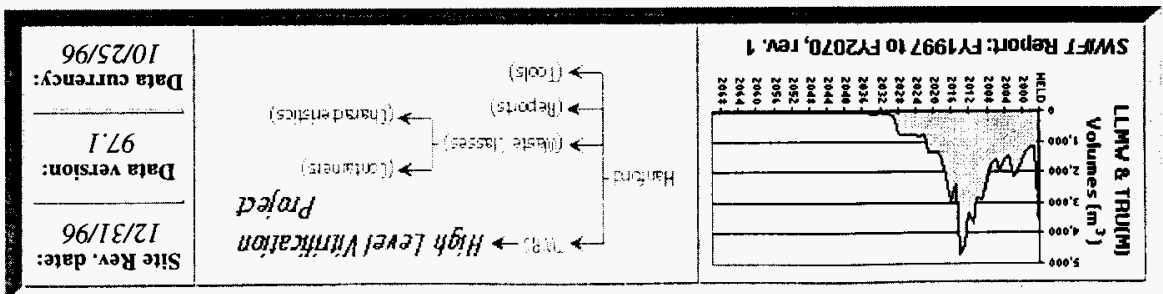


Physical Waste Form Distribution

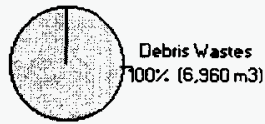

Total $=6,960 \mathrm{m3}$

\section{Hazardous Constituent Distribution}

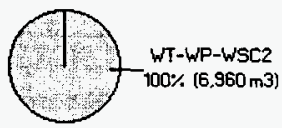

Total $=6,960 \mathrm{m3}$

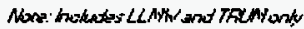

\section{Container Distribution}

SWBS $13 \%\{870 \mathrm{~m} 3\}$

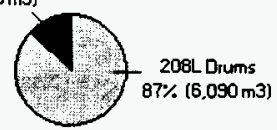

Total $=6,960 \mathrm{~m} 3$

Sum of totals may not add due to rounding: numbers over $10 \mathrm{~m}^{3}$ are rounded to the nearest $10 \mathrm{~m}^{3}$, numbers less than $10 \mathrm{~m}^{3}$ are rounded to integers, non-zero numbers less than $I$ are rounded to $I$.

\section{Annual Volumes}

\section{Annual Baseline Volumes}

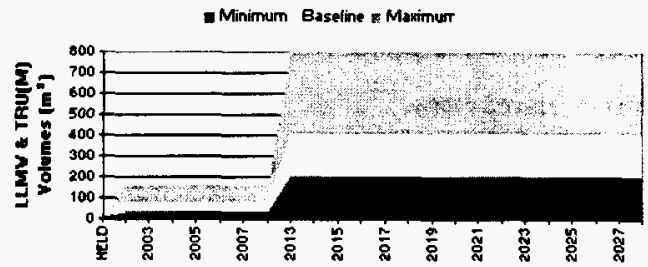

Annual Baseline by Waste Class 


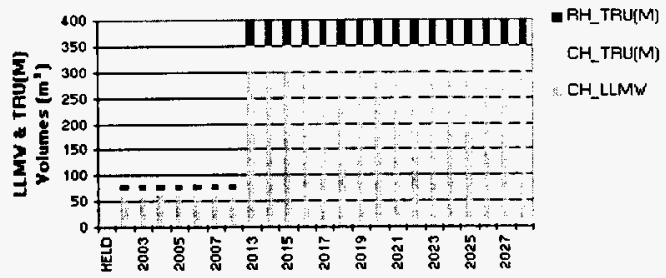

\section{Comparison to Previous Baseline(s)}

The overall FY97.1 forecast is $41 \%$ greater than the FY96 forecast of $4,920 \mathrm{~m}^{3}$. This change is due to the fact that current estimates are based on the new baseline of privatization that uses PUREX as a model for waste generation.

In addition, this year's forecast includes estimates that were previously reported by the TWRS Pretreatment Facility (WHC_PRETRT_TW). This year, pretreatment estimates are no longer being reported separately, but instead have been folded into the HLVP and LLVP forecasts.

Both CH_TRU and RH_TRU waste estimates have decreased from the FY96 forecast. This is based on an examination of historical waste data for PUREX, which indicated that high-TRU waste feeds did not lead to high-TRU waste.

Physical waste forms forecast last year included 40 cubic meters of inorganic solids and 200 cubic meters of lead shielding. Only debris has been forecast for 1997.

The 1996 forecast expected several hazardous constituents, unlike the current forecast. Metals without mercury, organic, corrosive, and ignitable constituents were all reported along with state regulated, the only constituent reported this year.

\section{Comparison to Previous Baseline(s) by Waste Class}

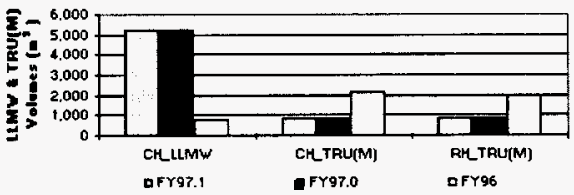

\begin{tabular}{|c|c|c|c|}
\hline $\begin{array}{l}\text { High Level Vitrification Project Comparison: } \\
\text { Yaste Class }\end{array}$ & $\begin{array}{c}\text { FY97.1 } \\
\text { Forecast } \\
\left(\mathbf{m}^{*}\right)\end{array}$ & $\begin{array}{c}\text { Frs7.0 } \\
\text { Forecast } \\
\left(\mathrm{m}^{3}\right)\end{array}$ & $\begin{array}{l}\text { Frs6 } \\
\text { Forecast } \\
\left(m^{3}\right) \\
\end{array}$ \\
\hline $\mathrm{CH} L \mathrm{LMW}$ & 5,220 & 5,220 & 800 \\
\hline $\mathrm{CH}$ TRU(M) & 870 & 870 & 2,170 \\
\hline $\mathrm{RH}$ TRU(M) & 870 & 870 & 1,960 \\
\hline suerorer & ssti & asto & $1 . \operatorname{sen}$ \\
\hline LLW & 20.880 & 20,880 & 25,650 \\
\hline HAZ & 870 & 870 & 90 \\
\hline ropar & 2678 & $207 / 6$ & nefore \\
\hline
\end{tabular}

Sum of torals may not add due to rounding: numbers over $10 \mathrm{~m}^{3}$ are rounded to the nearest $10 \mathrm{~m}^{3}$, numbers less 
than $10 \mathrm{~m}^{3}$ are rounded to integers, non-zero numbers less than 1 are rounded to $I$.

\section{Background}

HLVP is a planned treatment/ processing facility for high activity tank waste, and waste volumes associated with the HLVP are based on preconceptual design criteria and best engineering judgment. Secondary waste will be generated from activities such as spill clean-up and decontamination, general maintenance and housekeeping, and laboratory activities. The waste will generally consist of contaminated failed equipment (not including melters), metals, paper, plastic, rubber, and other miscellaneous debris. The interim storage of in-process waste is also included for this waste generator.

\section{Forecast Assumptions and Comments}

Current estimates are based on the new baseline of privatization which consists of two phases. The first phase is a demonstration (2002-2008) and the second phase is full scale (2013-2028). The waste volume during the demonstration is one fifth of the volume generated during the full scale operation. The full scale operation is expected to generate about the same amount of waste annually as the PUREX plant generated annually during the $1980 \mathrm{~s}$. The schedule for activities is based on the TWRS Disposal Program OWVP for March 1,1996, updated May $14,1996$.

Again, it is assumed that high-TRU waste feeds will not lead to high-TRU waste, as was the experience at PUREX.

The current forecast does not include terminal clean-out and D\&D of this facility.

Minimum and maximum ranges for the waste are $50 \%$ and $200 \%$ respectively, and are primarily due to the uncertainty of dealing with preliminary facility and processing concepts.

\section{Other Forecast Data}

\section{- Low Level Waste}

- A total of $20,880 \mathrm{~m}^{3}$ of LLW is expected from HLVP.

- This forecast shows a $19 \%$ decrease from the FY96 forecast of $25,650 \mathrm{~m}^{3}$, primarily due to the new baseline.

- The LLW will be shipped in MB-V boxes.

- $100 \%$ of the LLW will have the physical form of debris.

\section{- Hazardous Waste}

- A total of $870 \mathrm{~m}^{3}$ of hazardous waste was reported by HLVP for management by the CWC. 


\section{GENERATORS:}

Cross-Site Transfer System - DST Retrieval Systems · High Level Vitrification Project - Low Level Vitrification Project SST Long Length Equipment - SST Retrieval - SST/DST Tank Farm Operations - Tank Farm Restoration - Tank Farm Ventilation Upgrade $\cdot$ W343 DST Retrieval

\section{PROGRAMS:}

Analytical Services - EM-40 - Facility Transitions · Landlord - Liquid Effluent · NP · Offsite · PNNL - RCRA · Solid Waste $\cdot$ SNF - TWRS

\begin{tabular}{|c|c|}
\hline $\begin{array}{c}\text { CHARACTERISTICS: } \\
\text { CH_LLMW } \cdot \text { RH_LLMW } \cdot \text { CH_TRU(M) }) \text { RH_TRU(M) } \\
\text { GTC III } \cdot \text { LLW } \cdot \text { HAZ }\end{array}$ & $\begin{array}{c}\text { CONTAINERS: } \\
\text { CH_LLMW } \cdot \text { RH_LLMW } \cdot \text { CH_TRU(M) } \\
\text { RH_TRU(M) } \cdot \text { GTC III } \cdot \text { LLW } \cdot \text { HAZ }\end{array}$ \\
\hline CH_LLMW $\cdot$ RH_LLMW $\cdot$ CH_TRU(M) $\cdot$ RH_TRU(M) $\cdot$ GTC III $\cdot$ LLW $\cdot$ HAZ \\
\hline Home $\cdot$ Contents $\cdot$ Web Site Map $\cdot$ Glossary $\cdot$ Help $\cdot$ Reports $\cdot$ Data Requests $\cdot$ Feedback Form \\
\hline
\end{tabular}

NOTICE: This page is provided subject to our disclaimer. Contact: Oscar Valero at (509) 373-4752.

HNF-EP-0918 rev. 1 Approved for public release; distribution is unlimited. 


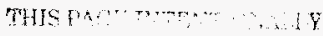

L... . . in 


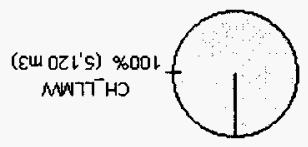

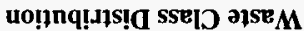

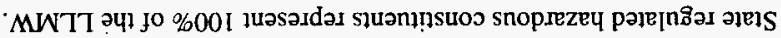

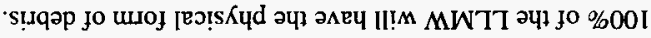

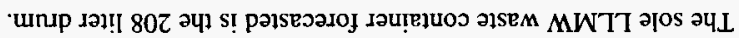

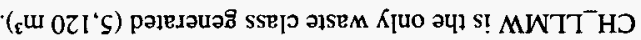

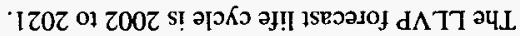

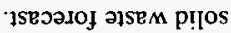

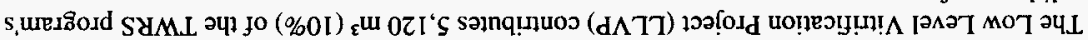

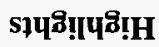

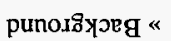

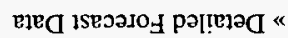
घied 18Eวajo

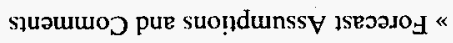

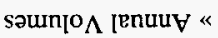

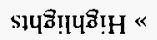

ราuวาน0ว

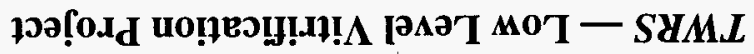

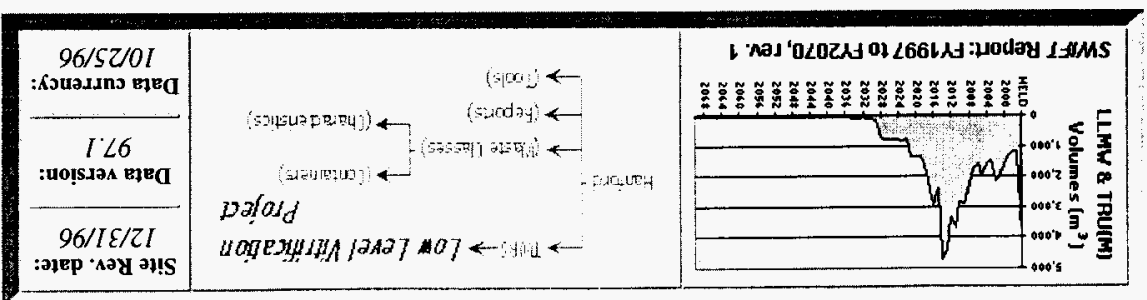


Physical Waste Form Iistribution

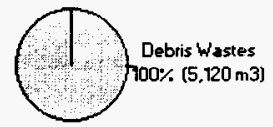

Total $=5.120 \mathrm{~m} 3$

\section{Hazardous Constituent Distribution}

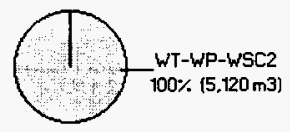

Total $=\mathbf{5 . 1 2 0 ~} \mathrm{m3}$

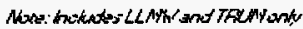

\section{Container Distribution}

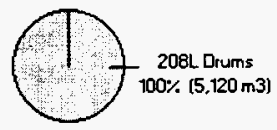

Total $=5,120 \mathrm{~m} 3$

Sum of totals may not add due to rounding: numbers over $10 \mathrm{~m}^{3}$ are rounded to the nearest $10 \mathrm{~m}^{3}$, numbers less than $10 \mathrm{~m}^{3}$ are rounded to integers, non-zero numbers less than $I$ are rounded to 1.

\section{Annual Volumes}

\section{Annual Baseline Volumes}

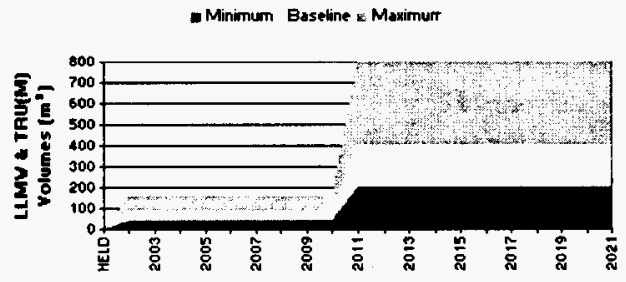

Annual Baseline by Waste Class 


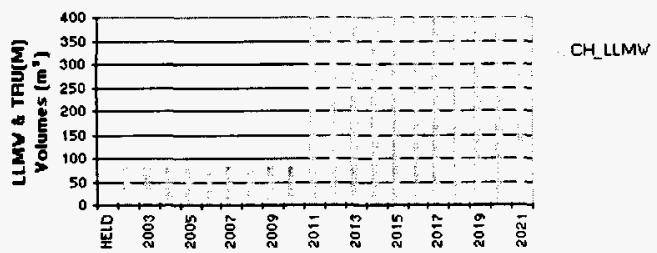

\section{Comparison to Previous Baseline(s)}

The overall FY97.1 forecast is significantly greater than the FY96 forecast of $60 \mathrm{~m}^{3}$. This change is due to the fact that current estimates are based on the new baseline of privatization that uses PUREX as a model for waste generation.

In addition, this year's forecast includes estimates that were previously reported by the TWRS Pretreatment Facility (WHC_PRETRT_TW). This year, pretreatment estimates are no longer being reported separately, but instead have been folded into the HLVP and LLVP forecasts.

Unlike the 1996 forecast, the current forecast expects only one kind of hazardous constituent: state regulated. Last year, organic, state regulated, metals without mercury, corrosive, and other constituents were all reported in similar volumes.

\section{Comparison to Previous Baseline(s) by Waste Class}

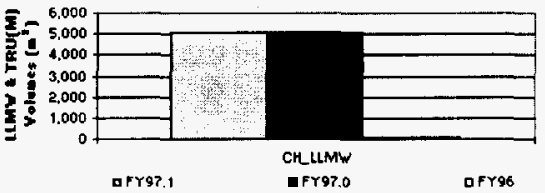

\begin{tabular}{|c|c|c|c|}
\hline $\begin{array}{l}\text { Lou Level Vitrification Project Comparison: } \\
\text { Yaste Class }\end{array}$ & $\begin{array}{l}\text { FY97.1 } \\
\text { Forecast } \\
\left(m^{2}\right)\end{array}$ & $\begin{array}{l}\text { FY97.0 } \\
\text { Forecast } \\
\text { [my] }\end{array}$ & $\begin{array}{l}\text { FY96 } \\
\text { Forecast } \\
\text { (ms) }\end{array}$ \\
\hline CH_LLMW' & 5.120 & 5.120 & 60 \\
\hline sobromed & 5.128 & $5 / 20$ & 60 \\
\hline LLW & 34.560 & 34,560 & 13,250 \\
\hline HAZ & 1,280 & 1.280 & 80 \\
\hline Torel & $1 a \sin$ & 12560 & 13.350 \\
\hline
\end{tabular}

Sum of totals may not add due to rounding: numbers over $10 \mathrm{~m}^{3}$ are rounded to the nearest $10 \mathrm{~m}^{3}$, numbers less than $10 \mathrm{~m}^{3}$ are rounded to integers, non-zero numbers less than 1 are rounded to 1 .

\section{Background}

LLVP is a planned treatment/ processing facility for low activity tank waste, and waste volumes associated with the LLVP are based on preconceptual design criteria and best engineering judgment. It should be noted that the LLVP is planned to be significantly larger than the HLVP. 
Secondary waste will be generated from activities such as spill clean-up and decontamination, general maintenance and housekeeping, and laboratory activities. The waste will generally consist of contaminated failed equipment (not including melters), metals, paper, plastic, rubber, and other miscellaneous debris. The interim storage of in-process waste is also included for this waste generator.

\section{Forecast Assumptions and Comments}

Current estimates are based on the new baseline of privatization which consists of two phases. The first phase is a demonstration (2002-2011) and the second phase is full scale (2011-2021). The waste volume during the demonstration is one fifth of the volume generated during the full scale operation. The full scale operation is expected to generate about $2 x$ the amount of waste annually as the PUREX plant generated annually during the 1980 s. The schedule for activities is based on the TWRS Disposal Program OWVP for March 1,1996, updated May $14,1996$.

The current forecast does not include terminal clean-out and D\&D of this facility.

Minimum and maximum ranges for the waste are $50 \%$ and $200 \%$ respectively, and are primarily due to the uncertainty of dealing with preliminary facility and processing concepts.

\section{Other Forecast Data}

- Low Level Waste

- A total of $34,560 \mathrm{~m}^{3}$ of LLW is expected from LLVP.

- This forecast shows a $161 \%$ increase from the FY96 forecast of $13,250 \mathrm{~m}^{3}$, due to the new baseline.

- MB-V boxes will be used for $100 \%$ of the volume.

- $100 \%$ of the LLW will have the physical form of debris.

\section{- Hazardous Waste}

- A total of $1,280 \mathrm{~m}^{3}$ of hazardous waste was reported by LLVP for management by the CWC 


\section{GENERATORS:}

Cross-Site Transfer System · DST Retrieval Systems - High Level Vitrification Project - Low Level Vitrification Project SST Long Length Equipment - SST Retrieval - SST/DST Tank Farm Operations - Tank Farm Restoration - Tank Farm Ventilation Upgrade · W343 DST Retrieval

PROGRAMS:

Analytical Services · EM-40 · Facility Transitions - Landiord - Liquid Effluent - NP · Offsite · PNNL - RCRA · Solid Waste $\cdot$ SNF . TWRS

\begin{tabular}{|c|c|}
\hline $\begin{array}{c}\text { CHARACTERISTICS: } \\
\text { CH_LLMW } \cdot \text { RH_LLMW } \cdot \text { CH_TRU(M) } \cdot \text { RH_TRU(M) } \\
\text { GTC III } \cdot \text { LLW } \cdot \text { HAZ }\end{array}$ & $\begin{array}{c}\text { CONTAINERS: } \\
\text { CH_LLMW } \cdot \text { RH_LLMW } \cdot \text { CH_TRU(M) } \\
\text { RH_TRU(M) } \cdot \text { GTC III } \cdot \text { LLW } \cdot \text { HAZ }\end{array}$ \\
\hline \multicolumn{2}{|c|}{$\begin{array}{l}\text { WASTE CLASSES: } \\
\text { CH_LLMW } \cdot \text { RH_LLMW } \cdot \mathrm{CH}_{-} \text {TRU(M) } \cdot \mathrm{RH}_{-} \text {TRU(M) } \cdot \text { GTC III } \cdot \text { LLW } \cdot \text { HAZ }\end{array}$} \\
\hline
\end{tabular}

NOTICE: This page is provided subject to our disclaimer. Contact: Oscar Valero at (509) 373-4752.

HNF-EP-0918 rev. I Approved for public release; distribution is unlimited. 


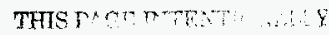

his bith. 


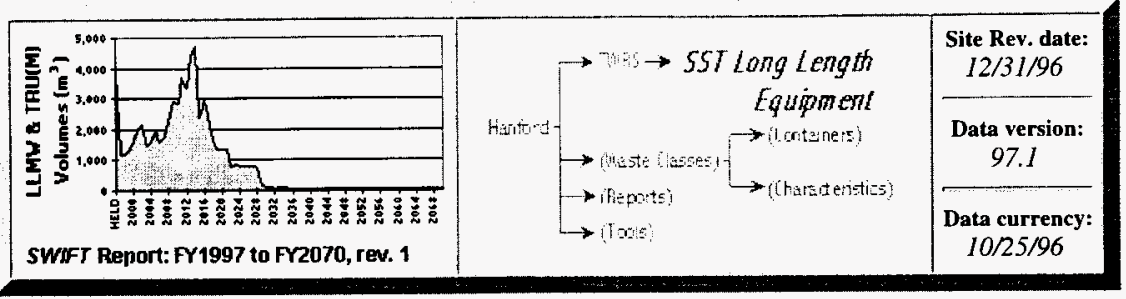

\section{TWRS — SST Long Length Equipment}

\section{Contents}

" Highlights

"Annual Volumes

»Comparison to Previous Baseline(s)

» Background
" Forecast Assumptions and Comments

» Other SST Long Length Equipment Forecast Data

»Detailed Forecast Data

\section{Highlights}

- The SST Long Length Equipment generator (SST_LLE) contributes $23,500 \mathrm{~m}^{3}$ (47\%) of the TWRS program's solid waste forecast.

- The SST_LLE forecast life cycle is 2001 to 2017.

- RH_LLMW is the primary waste class generated, representing $96 \%$ of the waste $\left(22,520 \mathrm{~m}^{3}\right)$.

- The only container to be used is the LEC.

- $100 \%$ of the waste will have the physical form of debris.

- State regulated hazardous constituents represent $100 \%$ of the LLMW and TRU(M) waste.

\section{Waste Class Distribution}

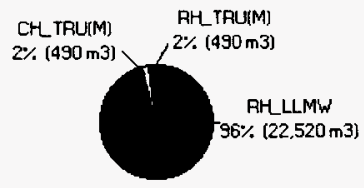

Total $=23,500 \mathrm{m3}$ 
Physical Waste Form Distribution

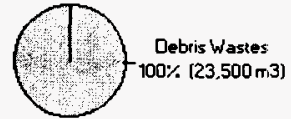

Total $=23,500 \mathrm{~m} 3$

\section{Hazardous Constituent Distribution}

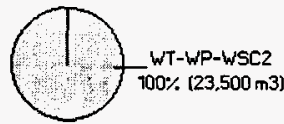

Total $=23.500 \mathrm{~m} 3$

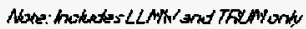

\section{Container Distribution}

Sum of totals may not add due to rounding: numbers over $10 \mathrm{~m}^{3}$ are rounded to the nearest $10 \mathrm{~m}^{3}$, numbers less than $10 \mathrm{~m}^{3}$ are rounded to integers, non-zero numbers less than 1 are rounded to 1 .

\section{Annual Volumes}

\section{Annual Baseline Volumes}

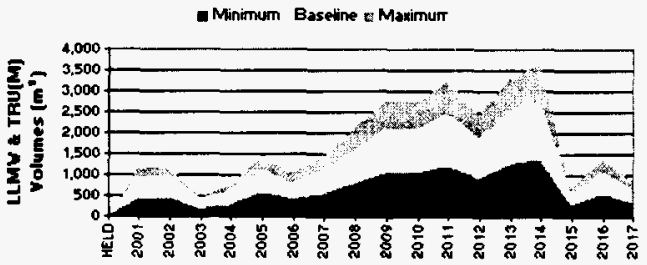

Annual Baseline by Waste Class 


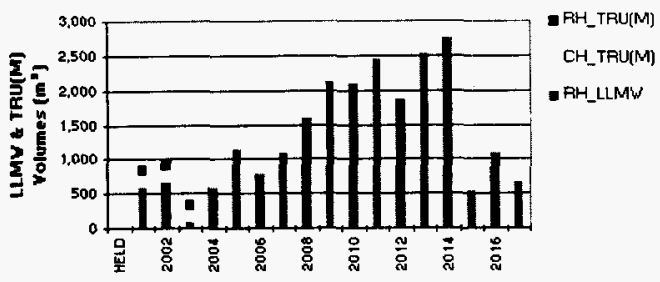

\section{Comparison to Previous Baseline(s)}

The overall FY97.1 forecast is significantly (46\%) less than the FY96 forecast of $43,260 \mathrm{~m}^{3}$. This change is due to a new estimate of the amount of existing equipment and the amount of equipment used for retrieval. In addition, an agreement was reached with DOE for the eventual disposal of the long-length equipment (see Assumptions below).

RH_TRU waste estimates have decreased significantly from the FY96 forecast, based on a new analysis of the amount of waste which will be TRU.

The 1996 hazardous constituents forecast showed only organic and metals without mercury constituents, while this year only state regulated waste is forecast.

\section{Comparison to Previous Baseline(s) by Waste Class}

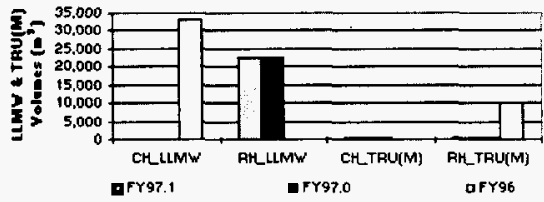

\begin{tabular}{|c|c|c|c|}
\hline $\begin{array}{l}\text { 5ST Long Length Equipment Comparison: } \\
\text { Yaste Class }\end{array}$ & $\begin{array}{l}\text { FY97.1 } \\
\text { Forecsst } \\
\text { (m") }\end{array}$ & $\begin{array}{l}\text { FY97.0 } \\
\text { Forecast } \\
\text { (m) }\end{array}$ & $\begin{array}{l}\text { FY96 } \\
\text { Forecast } \\
\text { (m') }\end{array}$ \\
\hline CH LLMW & 0 & 0 & 32,980 \\
\hline RH_LLMW & 22520 & 22520 & 0 \\
\hline $\mathrm{CH}$ TRU(M) & 490 & 490 & 0 \\
\hline RH_TRU[M] & 490 & 490 & 10.280 \\
\hline sworored & $2 \pi \mathrm{sen}$ & 2250 & 12,260 \\
\hline Tard & $2 x 500$ & $2 \pi 50$ & 12260 \\
\hline
\end{tabular}

Sum of totals may not add due to rounding: numbers over $10 \mathrm{~m}^{3}$ are rounded to the nearest $10 \mathrm{~m}^{3}$, numbers less than $10 \mathrm{~m}^{3}$ are rounded to integers, non-zero numbers less than I are rounded to 1.

\section{Background}

The single-shell tanks contain radioactive waste generated by Hanford operations starting in 1944. This waste will be retrieved for disposal from 2004 through 2018 . Retrieval will require some (but not all) long-length equipment to be removed from the tanks. The equipment used for retrieval will also be long-length equipment, and some will require disposal. 
The long-length equipment in the tanks is greater than 12 feet in length, with some pieces in excess of 60 feet. Because of the unusual configuration of these wastes, special storage and handling requirements will be necessary for any long-length equipment that is removed. In addition to the equipment currently in the tanks, estimates have been included for pumps and other miscellaneous equipment that will be used for retrieval of tank waste. The retrieval pumps and equipment are also expected to be sent to the CWC for processing and will have many of the same storage and handling requirements as the equipment currently in the tanks.

\section{Forecast Assumptions and Comments}

As previously documented in Hanford's Remote-Handled Transuranic and Transuranic Mixed Waste Volume Assessment, PNNL-1 1206 (1996), there has been a revision to the programmatic baseline for the disposition of the long-length equipment. The new programmatic baseline assumes that only long-length equipment retrieved prior to 2003 will be managed by the Waste Management project prior to disposal at the WIPP; the remaining long-length equipment will be disposed on site in a similar manner as the underground tanks. Decontamination is expected to occur so that most of the equipment is not considered transuranic waste.

Other forecast assumptions include:

1. The forecast is based on the worst case removal of equipment from the SST. The removal of existing equipment occurs about three years before retrieval is scheduled to begin based on the latest retrieval sequence.

2. Retrieval is expected to use an average of two pumps and two sluicers per tank. One half of this equipment is included in the forecast. Disposal of this equipment occurs during the retrieval years. The other equipment is disposed in the same manner as the tanks and is not included in the forecast.

Finally, it should be noted that the LLMW that is generated during long-length equipment retrieval could also possibly be handled in a manner similar to that of the long-length equipment - that is, by being disposed of within the tanks. If this scenario were adopted, it would result in significant reductions in the current estimates for LLMW. However, TWRS is not yet able to include such an assumption in the forecast, given the lack of information and experience with the process.

Average annual minimum and maximum ranges for the waste are $49 \%$ and $132 \%$ respectively, and are primarily due to the uncertainty of dealing with preliminary facility and processing concepts.

\section{Other Forecast Data}

\section{- Low Level Waste}

- No LLW is expected from SST_LLE for management by the CWC.

\section{- Hazardous Waste}

- No hazardous waste is expected from SST_LLE for management by the CWC. 


\begin{tabular}{|c|c|}
\hline \multicolumn{2}{|c|}{$\begin{array}{l}\text { GENERATORS: } \\
\text { Cross-Site Transfer System - DST Retrieval Systems · High Level Vitrification Project - Low Level Vitrification Project } \\
\text { SST Long Length Equipment - SST Retrieval - SST/DST Tank Farm Operations · Tank Farm Restoration · Tank Farm } \\
\text { Ventilation Upgrade - W343 DST Retrieval }\end{array}$} \\
\hline $\begin{array}{r}\text { PROGF } \\
\text { Analytical Services } \cdot \text { EM-40 } \cdot \text { Facility Transitions } \cdot \text { Landlo } \\
\text { Waste } \cdot \text { SN }\end{array}$ & Effluent $\cdot$ NP $\cdot$ Offsite $\cdot$ PNNL $\cdot$ RCRA $\cdot$ Solid \\
\hline $\begin{array}{l}\text { CHARACTERISTICS: } \\
\text { CH_LLMW } \cdot \text { RH_LLMW } \cdot \text { CH_TRU(M) } \cdot \text { RH_TRU(M) } \\
\text { GTC III } \cdot \text { LLW } \cdot \text { HAZ }\end{array}$ & $\begin{array}{l}\text { CONTAINERS: } \\
\mathrm{CH}_{\text {_LLMW }} \cdot \mathrm{RH} \text { _LLMW } \cdot \text { CH_TRU(M) } \\
\text { RH_TRU(M) } \cdot \text { GTC III } \cdot \text { LLW } \cdot \text { HAZ }\end{array}$ \\
\hline \multicolumn{2}{|c|}{$\begin{array}{l}\text { WASTE CLASSES: } \\
\mathrm{CH} \_L L M W \cdot R H \_L L M W \cdot C H \_T R U(M) \cdot R H \_T R U(M) \cdot G T C \text { III } \cdot \text { LLW } \cdot \text { HAZ }\end{array}$} \\
\hline
\end{tabular}

NOTICE: This page is provided subject to our disclaimer. Contact: Oscar Valero at (509) 373-4752.

HNF-EP-0918 rev. 1 Approved for public release; distribution is unlimited. 


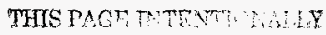

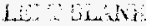




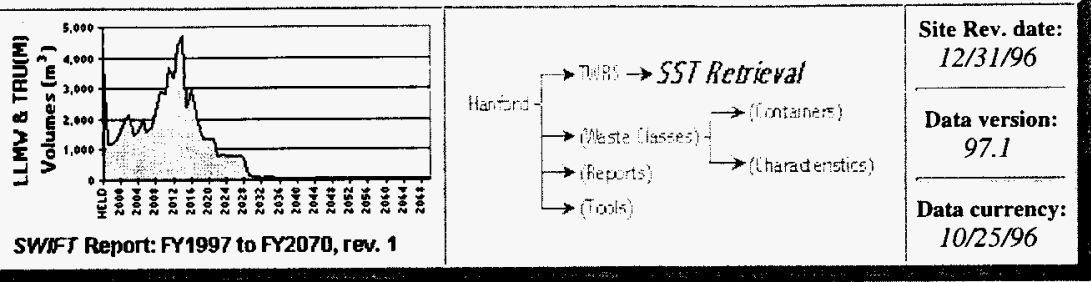

\section{TWRS - SST Retrieval (149 tanks)}

\section{Contents}

» Highlights

»Annual Volumes

»Comparison to Previous Baseline(s)

» Background
» Forecast Assumptions and Comments

» Other SST Retrieval Forecast Data

»Detailed Forecast Data

\section{Highlights}

- The SST Retrieval generator contributes $1,280 \mathrm{~m}^{3}(3 \%)$ of the TWRS program's solid waste forecast.

- The SST Retrieval forecast life cycle is 2004 to 2017.

- $\mathrm{CH} \_$LLMW is the primary waste class generated, representing $70 \%$ of the waste $\left(890 \mathrm{~m}^{3}\right)$.

- All of this volume will be in 208 liter drums.

- $100 \%$ of the LLMW will have the physical form of debris.

- State regulated hazardous constituents represent $100 \%$ of the LLMW.

\section{Waste Class Distribution}

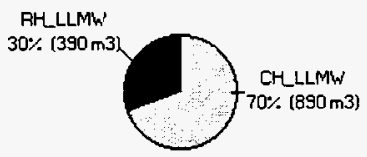

Total $=1,280 \mathrm{m3}$ 
Physical Waste Form Distribution

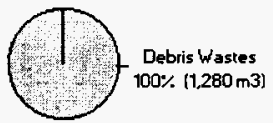

Totel $=1,28 B \mathrm{m3}$

\section{Hazardous Constituent Distribution}

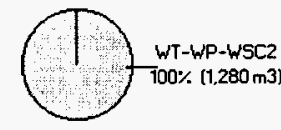

Total $=1,280 \mathrm{m3}$

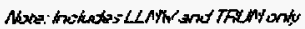

\section{Container Distribution}

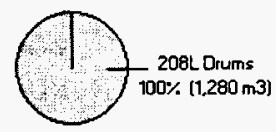

Total $=1,260 \mathrm{m3}$

Sum of totals may not add due to rounding: numbers over $10 \mathrm{~m}^{3}$ are rounded to the nearest $10 \mathrm{~m}^{3}$, numbers less than $10 \mathrm{~m}^{3}$ are rounded to integers, non-zero numbers less than $I$ are rounded to $I$.

\section{Annual Volumes}

\section{Annual Baseline Volumes}

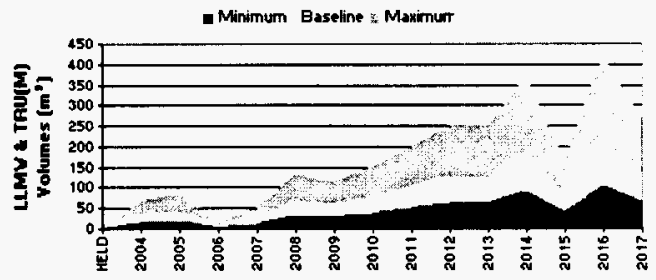

\section{Annual Baseline by Waste Class}




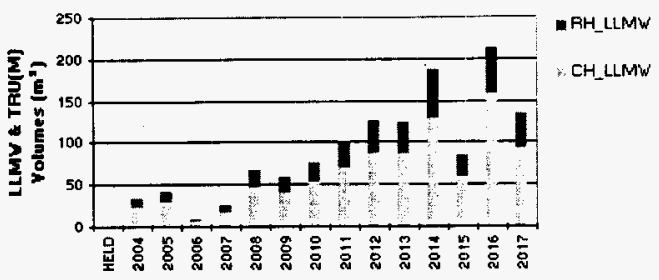

\section{Comparison to Previous Baseline(s)}

The overall FY97.1 forecast is essentially the same as the FY96 forecast of $1,250 \mathrm{~m}^{3}$.

Different from the current physical form forecast of $100 \%$ debris, the 1996 forecast expected 80 cubic meters of soil and soil/gravel.

The 1996 hazardous constituents forecast showed only organic and metals without mercury constituents, while this year only state regulated waste is forecast.

\section{Comparison to Previous Baseline(s) by Waste Class}

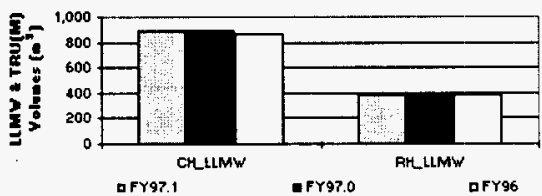

(in descending order by waste class)

\begin{tabular}{|c|c|c|c|}
\hline $\begin{array}{l}\text { SST Retrieval (149 tanks) Compasison: } \\
\text { Yasle Class }\end{array}$ & $\begin{array}{c}\text { FY97.1 } \\
\text { Forecast } \\
\left(\mathrm{m}^{3}\right)\end{array}$ & $\begin{array}{c}\text { Frg7.0 } \\
\text { Forecast } \\
\left(m^{3}\right)\end{array}$ & $\begin{array}{c}\text { FYgs } \\
\text { Forecast } \\
\left(m^{*}\right)\end{array}$ \\
\hline CH LLMW & 890 & 890 & 860 \\
\hline RH LLMW & 390 & 390 & 390 \\
\hline suporef & f,20\% & 1.200 & 1,259 \\
\hline LLW & 600 & 600 & 600 \\
\hline Tord & tones & thase & 1,050 \\
\hline
\end{tabular}

Sum of totals may not add due to rounding: numbers over $10 \mathrm{~m}^{3}$ are rounded to the nearest $10 \mathrm{~m}^{3}$, numbers less than $10 \mathrm{~m}^{3}$ are rounded to integers, non-zero numbers less than $I$ are rounded to 1.

\section{Background}

The single-shell tanks contain radioactive waste generated by Hanford operations starting in 1944. This generator will retrieve the waste for processing and disposal.

\section{Forecast Assumptions and Comments}

Waste is proportioned to each year based on the number of tanks being retrieved. 
Minimum and maximum ranges for the waste are $50 \%$ and $200 \%$ respectively, primarily due to the uncertainty of dealing with preliminary facility and processing concepts.

\section{Other Forecast Data}

- Low Level Waste

- Similar to the FY96 forecast, a total of $600 \mathrm{~m}^{3}$ of LLW is expected from SST Retrieval.

- This waste will be shipped in 208 liter drums only.

- $100 \%$ of the LLW will have the physical form of debris.

\section{- Hazardous Waste}

o No hazardous waste is expected from SST Retrieval for management by the CWC.

\section{GENERATORS:}

Cross-Site Transfer System - DST Retrieval Systems - High Level Vitrification Project - Low Level Vitrification Project -

SST Long Length Equipment - SST Retrieval - SST/DST Tank Farm Operations - Tank Farm Restoration - Tank Farm Ventilation Upgrade · W343 DST Retrieval

PROGRAMS:

Analytical Services · EM-40 - Facility Transitions - Landlord - Liquid Effluent - NP · Offsite - PNNL - RCRA · Solid Waste $\cdot$ SNF $\cdot$ TWRS

\begin{tabular}{|c|c|c|}
$\begin{array}{c}\text { CHARACTERISTICS: } \\
\text { CH_LLMW } \cdot \text { RH_LLMW } \cdot \text { CH_TRU(M) } \cdot \text { RH_TRU(M) } \\
\text { GTC III } \cdot \text { LLW } \cdot \text { HAZ }\end{array}$ & $\begin{array}{c}\text { CONTAINERS: } \\
\text { CH_LLMW } \cdot \text { RH_LLMW } \cdot \text { CH_TRU(M) } \\
\text { RH_TRU(M) } \cdot \text { GTC III } \cdot \text { LLW } \cdot \text { HAZ }\end{array}$ \\
\hline CH_LLMW $\cdot$ RH_LLMW $\cdot$ CH_TRU(M) $\cdot$ RH_TRU(M) $\cdot$ GTC III $\cdot$ LLW $\cdot$ HAZ \\
WASTE CLASSES:
\end{tabular}

NOTICE: This page is provided subject to our disclaimer. Contact: Oscar Valero at (509) 373-4752.

HNF-EP-0918 rev. 1 Approved for public release; distribution is unlimited. 
วเป็ชึ.10

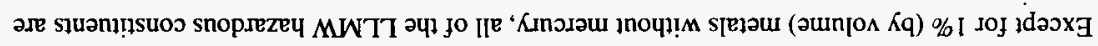

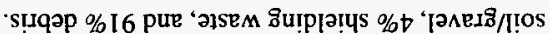

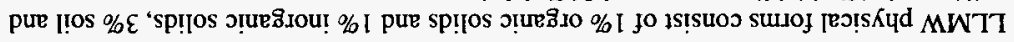

sunup มวฺ!!

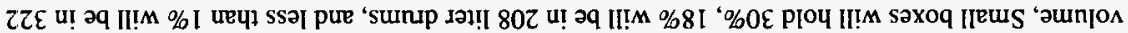

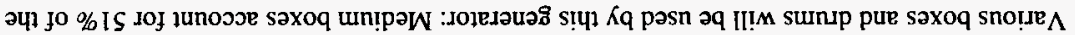

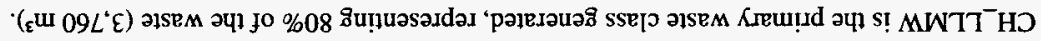

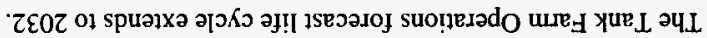

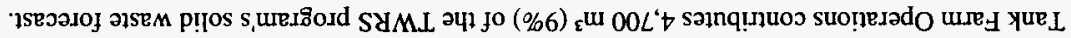

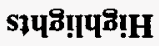

puno.8ิxyeg «

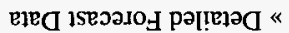

eled

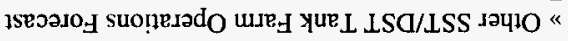
słuəuruo pue suoṇdunss? 158วa.0

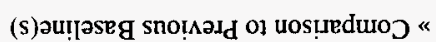
Saunjo $\Lambda$ [enuuV «

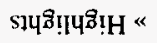

ราบวนบัว

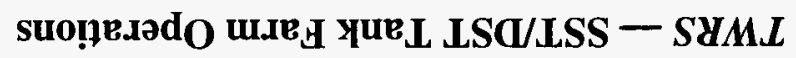

\begin{tabular}{|c|c|c|c|}
\hline 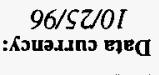 & $\begin{array}{c}(a 01) \\
(G+a)+\end{array}$ & & 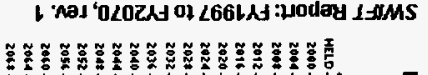 \\
\hline $\begin{array}{c}I \angle 6 \\
\text { :uo!sJas med }\end{array}$ & & & \\
\hline 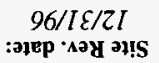 & WE & & .000's \\
\hline
\end{tabular}




\section{Waste C.lass Distribution}

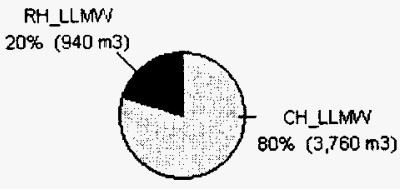

Total $=4,700 \mathrm{~m}^{3}$

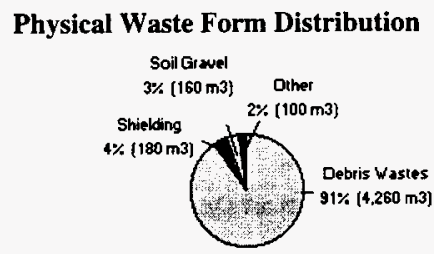

Total $=4.700 \mathrm{~m} 3$
Hazardous Constituent Distribution

Metals wo Hg
$1 \%(50 \mathrm{~m} 3)$

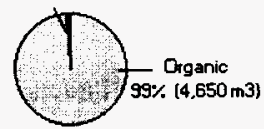

Total $=4.700 \mathrm{~m} 3$

Nare: hokates LLAW'and TFentonk

\section{Container Distribution}

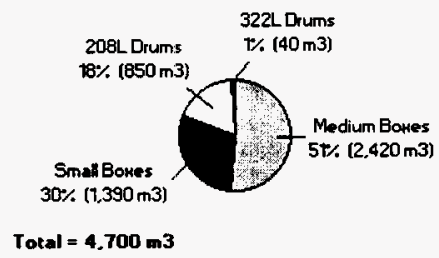

Sum of totals may not add due to rounding: numbers over $10 \mathrm{~m}^{\mathrm{s}}$ are rounded to the nearest $10 \mathrm{~m}^{3}$, numbers less than $10 \mathrm{~m}^{3}$ are rounded to integers, non-zero numbers less than 1 are rounded to 1.

\section{Annual Volumes}

\section{Annual Baseline Volumes}




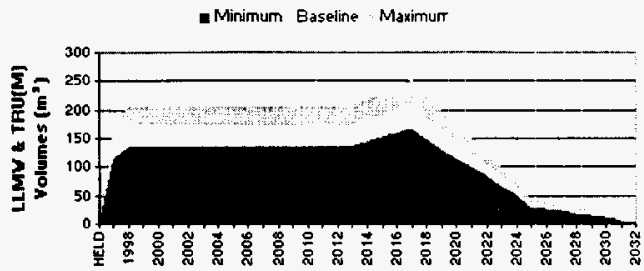

Annual Baseline by Waste Class

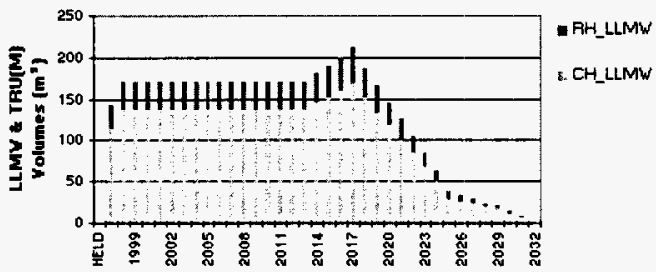

\section{Comparison to Previous Baseline(s)}

The overall FY97.1 forecast shows a decrease from the FY96 forecast of $8,520 \mathrm{~m}^{3}$. Estimates in all waste classes have been reduced based on this past year's actual shipped quantities.

\section{Comparison to Previous Baseline(s) by Waste Class}

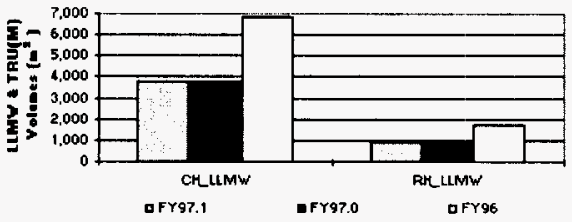

\begin{tabular}{|c|c|c|c|}
\hline $\begin{array}{l}\text { SSTrOST Tank Farm Dperations Comparison: } \\
\text { Yaste Class }\end{array}$ & $\begin{array}{l}\text { Fr97.1 } \\
\text { Forecast } \\
\text { (mn') }\end{array}$ & $\begin{array}{l}\text { FY97.0 } \\
\text { Foreeast } \\
\text { [n'] }\end{array}$ & $\begin{array}{l}\text { Frs6 } \\
\text { Forecast } \\
\text { (m) }\end{array}$ \\
\hline CH_LLMW & 3,760 & 3,760 & 6,830 \\
\hline RH_LLMW & 940 & 940 & 1.690 \\
\hline Sowpory & 1,70 & 1.700 & 2528 \\
\hline LLW & 7,490 & 7,490 & 9.640 \\
\hline HAZ & 230 & 230 & 590 \\
\hline Tory & 12,120 & 12,120 & ARTSO \\
\hline
\end{tabular}

Sum of totals may not add due to rounding: numbers over $10 \mathrm{~m}^{3}$ are rounded to the nearest $10 \mathrm{~m}^{3}$, numbers less than $10 \mathrm{~m}^{3}$ are rounded to integers, non-zero numbers less than $I$ are rounded to $I$.

\section{Background}


Tank Farm Operations' mission is to manage the tank farm waste and facilities in a safe, compliant, and cost-effective manner. The waste generated from this project includes day-to-day operational and maintenance waste from the $200 \mathrm{E}$ and $200 \mathrm{~W}$ tank farm facilities and old tank farm excess equipment.

\section{Forecast Assumptionș and Comments}

The forecast is based on the actual quantity shipped between March 1995 and May 1996 and the expected increases or decreases in shipping quantities in the future.

Secondary solid waste generated during closure of the tanks is not included in this forecast.

Minimum and maximum ranges for the waste are $80 \%$ and $120 \%$ respectively, and are based on the work in Tank Farms increasing or decreasing unexpectedly.

\section{Other Forecast Data}

\section{- Low Level Waste}

- A total of $7,490 \mathrm{~m}^{3}$ of LLW is expected from Tank Farm Operations.

- This forecast shows a $22 \%$ decrease from the FY96 forecast of $9,640 \mathrm{~m}^{3}$, primarily due to a revision of forecast estimates based on FY96 actual shipping rates.

- LLW is to be contained in various boxes and drums. MB-V boxes will contain just more than half of the volume. The second most common container category is Other drums at $18 \%$.

- The LLW physical forms are entirely debris. Organic and inorganic solids are expected, but they contribute less than one percent.

\section{- Hazardous Waste}

o A total of $230 \mathrm{~m}^{3}$ of hazardous waste was reported by Tank Farms Operations for management by the CWC. 


\section{GENERATORS:}

Cross-Site Transfer System - DST Retrieval Systems - High Level Vitrification Project - Low Level Vitrification Project • SST Long Length Equipment - SST Retrieval - SST/LST Tank Farm Operations · Tank Farm Restoration - Tank Farm Ventilation Upgrade · W343 DST Retrieval

\section{PROGRAMS:}

Analytical Services - EM-40 - Facility Transitions - Landlord - Liquid Effluent - NP · Offsite - PNNL - RCRA - Solid Waste $\cdot$ SNF . TWRS

\begin{tabular}{|c|} 
CHARACTERISTICS: \\
CH_LLMW $\cdot$ RH_LLMW $\cdot$ CH_TRU(M) $\cdot$ RH_TRU(M) \\
GTC III $\cdot$ LLW $\cdot$ HAZ
\end{tabular}

\section{WASTE CLASSES:}

CH_LLMW $\cdot$ RH_LLMW $\cdot$ CH_TRU(M) $\cdot$ RH_TRU(M) $\cdot$ GTC III $\cdot$ LLW $\cdot$ HAZ

NOTICE: This page is provided subject to our disclaimer. Contact: Oscar Valero at (509) 373-4752.

HNF-EP-0918 rev. 1 Approved for public release; distribution is unlimited. 


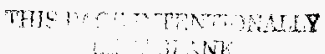
Inisk 


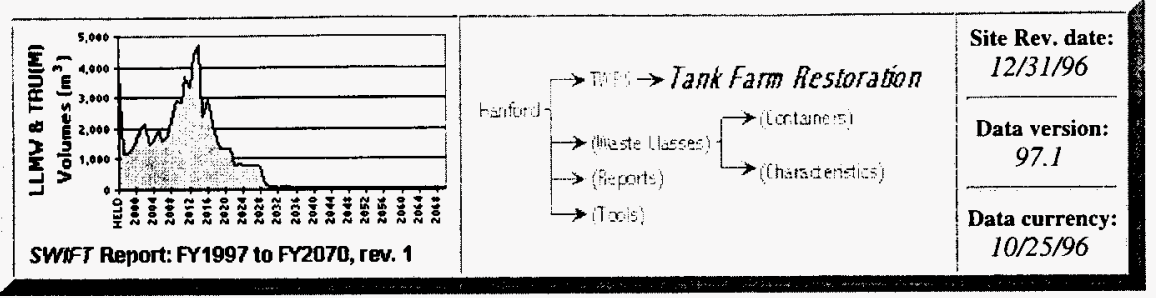

\section{TWRS - Tank Farm Restoration (W-314)}

\section{Contents}

» Highlights

"Annual Volumes

» Comparison to Previous Baseline(s)

» Background
"Forecast Assumptions and Comments

" Other Tank Farm Restoration (W-314) Forecast Data

» Detailed Forecast Data

\section{Highlights}

- Tank Farm Restoration (W-314) contributes $1,260 \mathrm{~m}^{3}(3 \%)$ of the TWRS program's solid waste forecast.

- The W-314 forecast life cycle is 1999 to 2005.

- CH_LLMW is the primary waste class generated, representing $70 \%$ of the waste $\left(880 \mathrm{~m}^{3}\right)$.

- 208 liter drums are the sole forecast containers for LLMW waste.

- LLMW is expected in two physical forms: debris ( $79 \%$ by volume) and soil and soil/gravel (21\%).

- Except for $1 \%$ (by volume) metals without mercury, all of the LLMW hazardous constituents are organic.

\section{Waste Class Distribution}

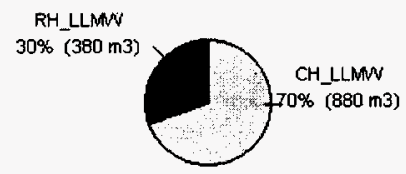

Total $=1,260 \mathrm{m3}$ 
Physical Waste Form Distribution

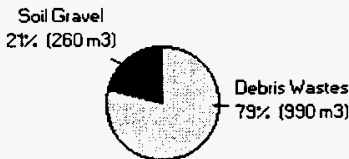

Total $=1,260 \mathrm{~m} 3$

\section{Hazardous Constituent Distribution}

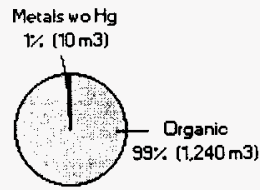

Total $=1,260 \mathrm{m3}$

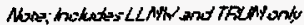

\section{Container Distribution}

Sum of totals may not add due to rounding: numbers over $10 \mathrm{~m}^{3}$ are rounded to the nearest $10 \mathrm{~m}^{3}$, numbers less than $10 \mathrm{~m}^{3}$ are rounded to integers, non-zero numbers less than I are rounded to 1.

\section{Annual Volumes}

\section{Annual Baseline Volumes}

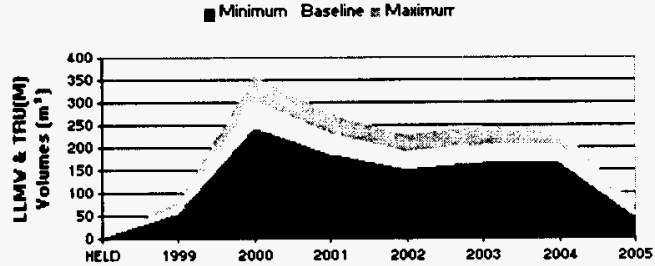

Annual Baseline by Waste Class 


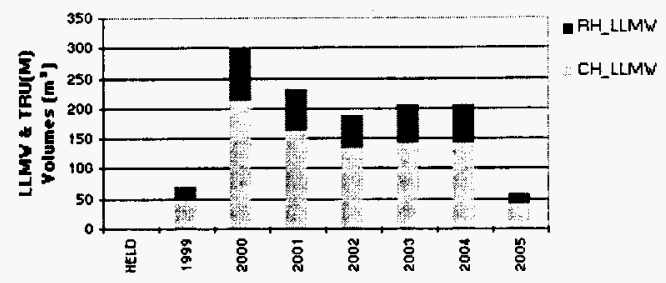

\section{Comparison to Previous Baseline(s)}

The FY97.1 forecast is significantly $(71 \%)$ less than the FY96 forecast of $4,490 \mathrm{~m}^{3}$. This decrease is due to the fact that previous estimates were "best guesses" only, while the current forecast is based on a completed conceptual design for the project. This new estimate has a much higher level of confidence.

The physical LLMW forms forecast last year showed that soil/gravel was to contribute $71 \%$ of the waste; thus, the major physical form has switched for 1997 from soil/gravel to debris.

The 1996 hazardous constituents forecast reported $52 \%$ of the volume as state regulated waste, with organic and metals without mercury each at $24 \%$. For 1997 , only metals without mercury $(1 \%)$ and organic constituents are expected $(99 \%)$.

\section{Comparison to Previous Baseline(s) by Waste Class}

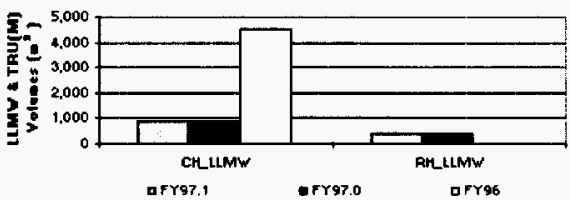

\begin{tabular}{|c|c|c|c|}
\hline $\begin{array}{l}\text { Tank Farm Restoration Comparison: } \\
\text { Vaste Class }\end{array}$ & $\begin{array}{c}\text { Frst.1 } \\
\text { Forecast } \\
{\left[\mathrm{m}^{3}\right)}\end{array}$ & $\begin{array}{c}\text { FY97.0 } \\
\text { Forecast } \\
\text { (m) }\end{array}$ & $\begin{array}{l}\text { FYss } \\
\text { Forecast } \\
\text { (m'] }\end{array}$ \\
\hline CH_LLMW & 880 & 880 & 4.490 \\
\hline $\mathrm{RH} L L M W$ & 380 & 380 & 0 \\
\hline Sroperal & 0,200 & 1,200 & 1.100 \\
\hline$L L W$ & 60 & 60 & 0 \\
\hline Tored & 0.220 & 1.20 & 1.199 \\
\hline
\end{tabular}

Sum of totals may not add due to rounding: numbers over $10 \mathrm{~m}^{3}$ are rounded to the nearest $10 \mathrm{~m}^{3}$, numbers less than $10 \mathrm{~m}^{3}$ are rounded to integers, non-zero numbers less than $I$ are rounded to 1 .

\section{Background}

Project W-314, "Tank Farm Restoration," is a planned FY96 new start major system acquisition project that will upgrade instrumentation, ventilation, waste transfer, and electrical systems associated with the existing Hanford tank farm activities. Waste generated by this project will typically be contaminated soil, debris from construction activities, and removal of 
outdated or unused tank farm equipment.

\section{Forecast Assumptions and Comments}

1. Waste generation volumes are based on the approved Conceptual Design Report (CDR), WHC-SD-W314-CDR-001, Rev.0. Breakdown of these waste volumes by fiscal year was approximated based on the summary level conceptual project schedule contained in the CDR.

2. Contaminated soils requiring disposal are assumed to be classified as LLMW. Assume $70 \%$ contact handled and $30 \%$ remote handled.

3. Contaminated equipment, tools, construction materials, and debris are assumed to be $\mathrm{LLW} ; 100 \%$ as contact handled.

4. Tank farm equipment removed and disposed of by the project that may have come into contact with tank waste through operation (e.g., instrument trees, pipe jumpers, cover blocks, ventilation trains, etc.) are assumed to be classified as LLMW.

Minimum and maximum ranges for the waste are $80 \%$ and $120 \%$ respectively, and result from uncertainties associated with actual waste volumes produced during a given fiscal year.

\section{Other Forecast Data}

\section{- Low Level Waste}

- A total of $60 \mathrm{~m}^{3}$ of LLW is expected from W-314.

- This forecast shows an increase from the FY96 forecast of $0 \mathrm{~m}^{3}$.

- MB-V boxes will hold $100 \%$ of this LLW.

- $100 \%$ of the physical LLW form will be debris.

\section{- Hazardous Waste}

- No hazardous waste is expected from W-314 for management by the CWC.

\section{GENERATORS:}

Cross-Site Transfer System - DST Retrieval Systems - High Level Vitrification Project - Low Level Vitrification Project . SST Long Length Equipment - SST Retrieval · SST/DST Tank Farm Operations · Tank Farm Restoration · Tank Farm Ventilation Upgrade - W343 DST Retrieval

\section{PROGRAMS:}

Analytical Services - EM-40 - Facility Transitions - Landlord - Liquid Effluent - NP - Offsite - PNNL - RCRA - Solid Waste - SNF - TWRS

CHARACTERISTICS:
CH_LLMW $\cdot$ RH_LLMW $\cdot$ CH_TRU(M) $\cdot$ RH_TRU(M)
GTC III $\cdot$ LLW $\cdot$ HAZ

WASTE CLASSES:
CONTAINERS:

CH_LLMW $\cdot$ RH_LLMW $\cdot$ CH_TRU(M) . RH_TRU(M) $\cdot$ GTC III $\cdot$ LLW $\cdot$ HAZ

Home - Contents - Web Site Map · Glossary · Help - Reports - Data Requests · Feedback Form 
NOTICE: This page is provided subject to our disclaimer. Contact: Oscar Valero at (509) 373-4752.

HNF-EP-0918 rev. 1 Approved for public release; distribution is unlimited. 


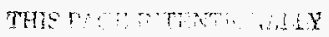

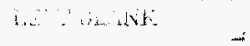




\begin{tabular}{|c|c|c|}
\hline$\Sigma_{-1,000}^{5,000}$ & $\rightarrow$ Nif $\rightarrow$ Tank Fam Ventalion & $\begin{array}{c}\text { Site Rev, date: } \\
12 / 31 / 96\end{array}$ \\
\hline$\sqrt{1000}$ & 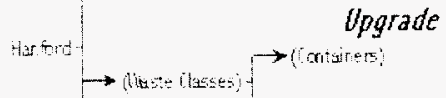 & $\begin{array}{c}\text { Data version: } \\
97.1\end{array}$ \\
\hline $\begin{array}{l}\text { SWET Report: FY1997 to FY2070, rev. } 1 \\
\text { SW }\end{array}$ & 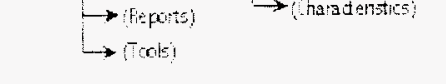 & $\begin{array}{l}\text { Data currency: } \\
10 / 25 / 96\end{array}$ \\
\hline
\end{tabular}

\section{TWRS - Tank Farm Ventilation Upgrade}

\section{Contents}

》 Highlights

»Annual Volumes

" Comparison to Previous Baseline(s)

» Background
》 Forecast Assumptions and Comments

» Other Tank Farm Ventilation Upgrade Forecast Data

»Detailed Forecast Data

\section{Highlights}

- Tank Farm Ventilation Upgrade (W-030) contributes $40 \mathrm{~m}^{3}(<1 \%)$ of the TWRS program's solid waste forecast.

- The W-030 forecast life cycle extends to 1997.

- CH_LLMW is the only waste class generated, representing $100 \%$ of the waste $\left(40 \mathrm{~m}^{3}\right)$.

- $95 \%$ of this waste will be contained in MB-V boxes, and $5 \%$ will be in 208 liter drums.

- The LLMW physical forms are varied: $3 \%$ is soil and soil/gravel, $20 \%$ is special waste, $25 \%$ is organic solids, and $52 \%$ is debris.

- LLMW hazardous constituents are to be metals without mercury ( $38 \%$ by volume), reactive metals $(36 \%)$, and organic $(26 \%)$.

\section{Waste Class Distribution}

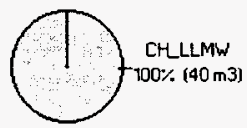

Total $=40 \mathrm{m3}$ 
Physical Waste Form Distribution

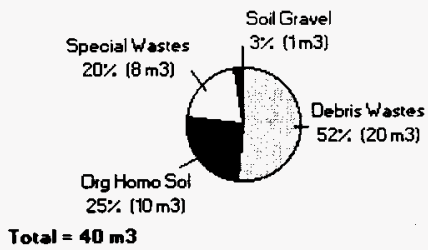

\section{Hazardous Constituent Distribution}

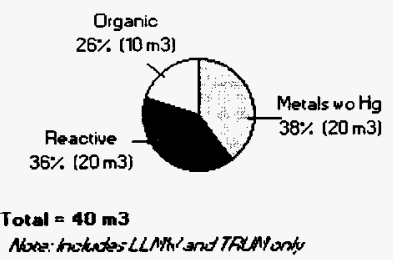

\section{Container Distribution}

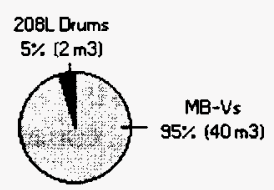

Total $=40 \mathrm{m3}$

Sum of totals may not add due to rounding: numbers over $10 \mathrm{~m}^{3}$ are rounded to the nearest $10 \mathrm{~m}^{3}$, numbers less than $10 \mathrm{~m}^{3}$ are rounded to integers, non-zero numbers less than 1 are rounded $t o l$.

\section{Annual Volumes}

\section{Annual Baseline Volumes}

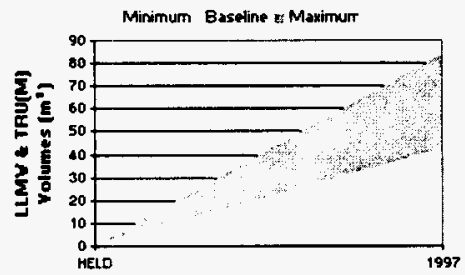

\section{Annual Baseline by Waste Class}




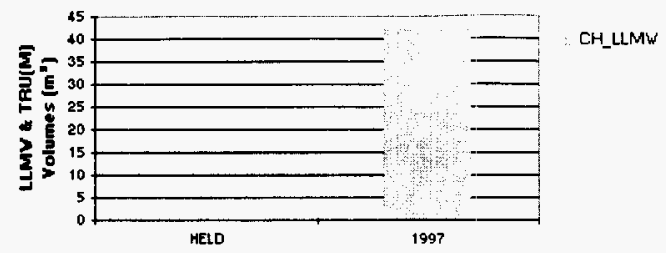

\section{Comparison to Previous Baseline(s)}

The FY97.1 forecast shows an increase from the FY96 forecast of $0 \mathrm{~m}^{3}$. This is due to the fact that waste that was classified as LLW last year has been reclassified as LLMW.

\section{Comparison to Previous Baseline(s) by Waste Class}

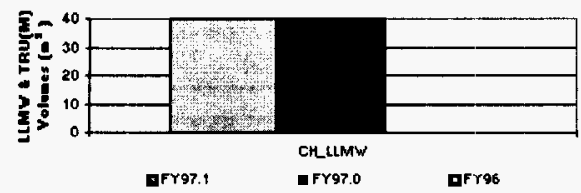

\begin{tabular}{|c|c|c|c|}
\hline $\begin{array}{l}\text { Tank Farm Ventilation Upgrade Comparison: } \\
\text { Yaste Class }\end{array}$ & $\begin{array}{c}\text { FY97.1 } \\
\text { Forecast } \\
{\left[\mathrm{m}^{2}\right)}\end{array}$ & $\begin{array}{c}\text { FY97.0 } \\
\text { Forecast } \\
\text { (m") }\end{array}$ & $\begin{array}{l}\text { FY96 } \\
\text { Forecast } \\
{\left[m^{2}\right]}\end{array}$ \\
\hline CH LLMW & 40 & 40 & 0 \\
\hline smepored & 98 & $\theta$ & 8 \\
\hline LLW & 0 & 0 & 30 \\
\hline Topd & 98 & 10 & $s o$ \\
\hline
\end{tabular}

Sum of totals may not add due to rounding: numbers over $10 \mathrm{~m}^{3}$ are rounded to the nearest $10 \mathrm{~m}^{3}$, numbers less than $10 \mathrm{~m}^{3}$ are rounded to integers, non-zero numbers less than $I$ are rounded to $I$.

\section{Background}

W-030 will provide a new ventilation and cooling system to the AY/AZ Tank Farms.

\section{Forecast Assumptions and Comments}

The AY/AZ ventilation system will be replaced in FY97.

Process flow diagrams were used for waste classes and concentration, based on 1992 information from sample data and known transfers.

Minimum and maximum ranges for the waste are $100 \%$ and $200 \%$ respectively. The minimum estimate is based on the final estimate form definitive design; the maximum is based on considering unknown factors during construction (e.g., route of links).

\section{Other Forecast Data}


- Low Level Waste

- No LLW is expected from W-030.

- This forecast shows a $100 \%$ decrease from the FY96 forecast of $30 \mathrm{~m}^{3}$, primarily due to the reclassification of previously forcasted LLW to LLMW.

- Hazardous Waste

o No hazardous waste is expected from W-030 for management by the CWC.

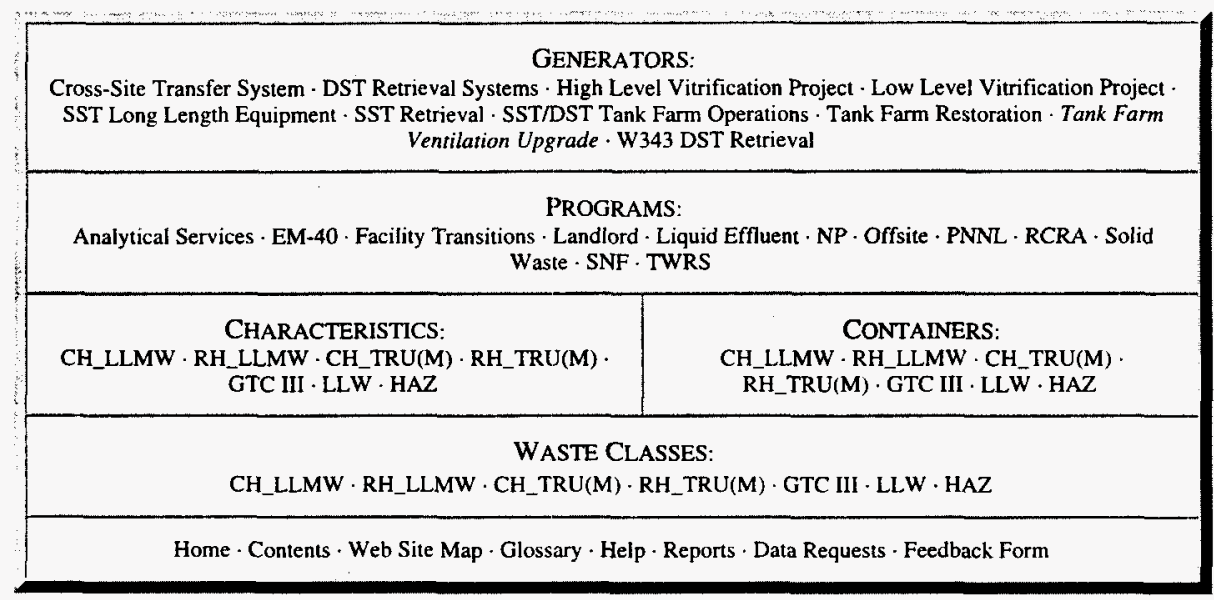

NOTICE: This page is provided subject to our disclaimer. Contact: Oscar Valero at (509) 373-4752.

HNF-EP-0918 rev. I Approved for public release; distribution is unlimited. 


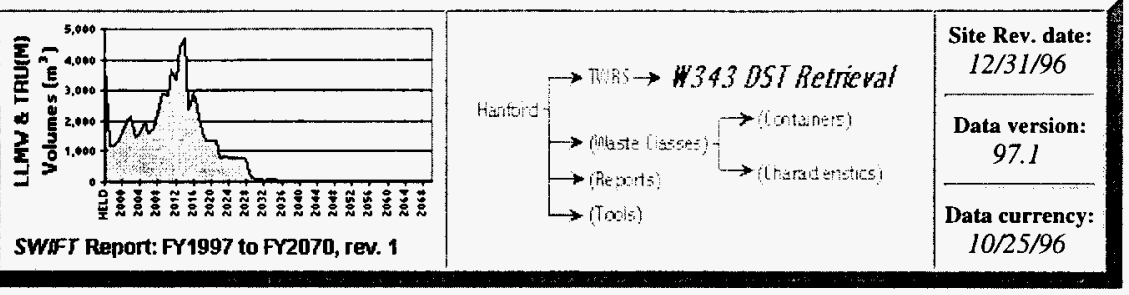

\section{TWRS - W-343 DST Retrieval (17 tanks)}

\section{Contents}

》 Highlights

» Annual Volumes

" Comparison to Previous Baseline(s)

» Background
" Forecast Assumptions and Comments

"Other W-343 DST Retrieval Forecast Data

»Detailed Forecast Data

\section{Highlights}

- W-343 DST Retrieval Systems (W-343) contributes $3,240 \mathrm{~m}^{3}(6 \%)$ of the TWRS program's solid waste forecast.

- The W-343 forecast life cycle is 2009 to 2021 .

- CH_LLMW and RH_LLMW are the only waste classes generated, representing about equal portions of the waste $\left(1,480\right.$ and $1,760 \mathrm{~m}^{3}$ respectively).

- This generator reports four different container types: MB-V boxes at $42 \%$ by volume, Medium boxes at $28 \%$, LECs at $23 \%$, and 208 liter drums at $7 \%$.

- Physical LLMW forms are forecast as $84 \%$ (by volume) debris, $13 \%$ shielding, $2 \%$ soil and soil/gravel, and $1 \%$ organic solids.

- LLMW hazardous constituents are $10 \%$ (by volume) metals without mercury and $90 \%$ organic. 


\section{Waste Class Distribution}

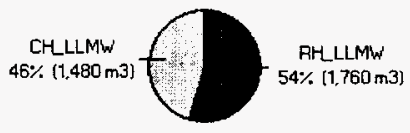

Total $=\mathbf{3 , 2 4 0} \mathrm{m3}$

Physical Waste Form Distribution

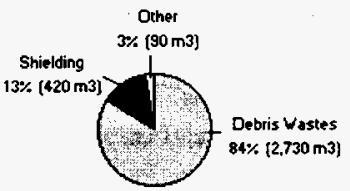

\section{Hazardous Constituent Distribution}

Metals wo Hg
$10 \%(320 \mathrm{~m} 3)$

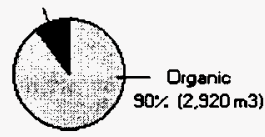

Total $=3,240 \mathrm{m3}$

Toral $=3,240 \mathrm{~m} 3$

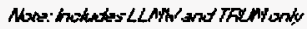

\section{Container Distribution}

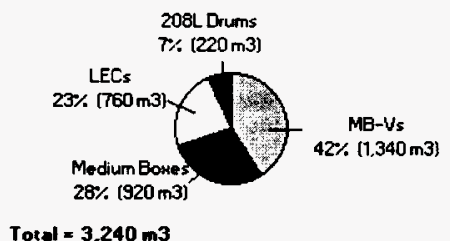

Sum of totals may not add due to rounding: numbers over $10 \mathrm{~m}^{3}$ are rounded to the nearest $10 \mathrm{~m}^{3}$, numbers less than $10 \mathrm{~m}^{3}$ are rounded to integers, non-zero numbers less than 1 are rounded to 1 .

\section{Annual Volumes}

\section{Annual Baseline Volumes}




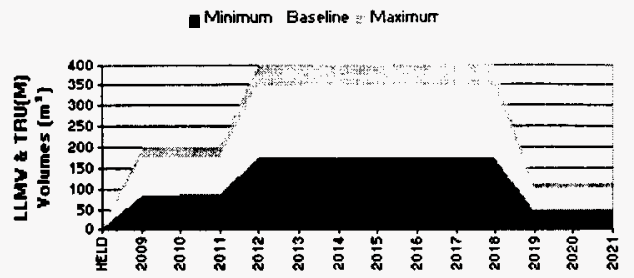

\section{Annual Baseline by Waste Class}

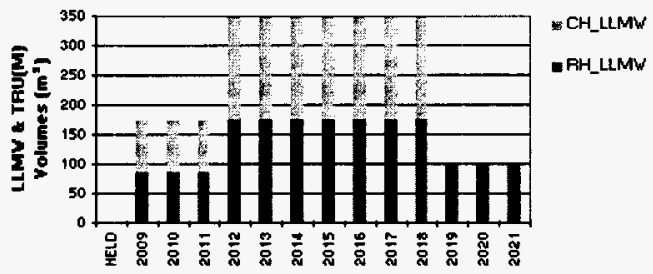

\section{Comparison to Previous Baseline(s)}

The FY97.1 forecast for W-343 is significantly (220\%) greater than the FY96 forecast of $1,010 \mathrm{~m}^{3}$. Increases have occurred for both $\mathrm{CH} \_$LLMW and RH_LLMW and are a result of the fact that anticipated solid waste volumes generated during construction are better defined by the experience of Project W-151 for tank AZ-101. Also, solid waste generated by equipment replacements during the operating life cycle is now included.

An additional change is that the FY97.1 forecast does not include an estimate for RH_TRU waste. This is because the equipment removed from TRU tanks is now assumed to be decontaminated to non-TRU with the planning baseline of assuming a Decontamination facility available after 2003.

The FY97.1 forecast also does not include an estimate for greater-than-category III waste, again due to revised baseline estimates.

Finally, the 1996 hazardous constituents forecast showed $100 \%$ of the volume as organic constituents, while the current data includes metals without mercury as well.

\section{Comparison to Previous Baseline(s) by Waste Class}

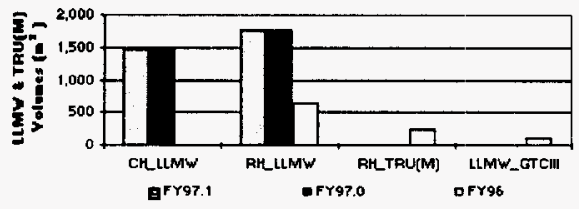




\begin{tabular}{|c|c|c|c|}
\hline $\begin{array}{l}\text { Y-343 DST Retrieval [ } 17 \text { Tanks] Comparison: } \\
\text { Yaste Class }\end{array}$ & $\begin{array}{c}\text { FY97.1 } \\
\text { Forecast } \\
\left(\mathrm{m}^{3}\right)\end{array}$ & $\begin{array}{c}\text { FY97.0 } \\
\text { Foreeast } \\
\left(\mathbf{m}^{3}\right)\end{array}$ & $\begin{array}{l}\text { FY96 } \\
\text { Forecast } \\
\text { (m') }\end{array}$ \\
\hline CH_LLMW & 1,480 & 1.480 & 0 \\
\hline RHLLLMW & 1,760 & 1,760 & 640 \\
\hline RH TRU(M) & 0 & 0 & 250 \\
\hline LLMW GTCIII & 0 & 0 & 110 \\
\hline strores & 2210 & 220 & S.010 \\
\hline LWW & 0 & 0 & 670 \\
\hline Tory & 2240 & 2210 & t,ses \\
\hline
\end{tabular}

Sum of totals may not add due to rounding: numbers over $10 \mathrm{~m}^{3}$ are rounded to the nearest $10 \mathrm{~m}^{3}$, numbers less than $10 \mathrm{~m}^{3}$ are rounded to integers, non-zero numbers less than $I$ are rounded to $I$.

\section{Background}

The W-343 mission is to retrieve waste in 17 DSTs for processing and management of existing storage capacity. Waste classes result from construction activities involved when installing mixer pumps and transfer piping and replacing existing transfer pumps and mixer pumps during the operating life cycle.

CH_LLMW will be generated from excavation and demolition of non in-tank equipment/structures and from work in such areas as pits. RH_LLMW will result from removing components that have been exposed to tank waste.

\section{Forecast Assumptions and Comments}

The current baseline is assumed to be valid through 2028 in order to provide an estimate, even though Retrieval Operations is scheduled to be privatized in 2011 . There is a high probability that the baseline for a number of DSTs receiving mixer pumps will decrease, but the amount of waste generated per tank is well based on the experience of project W-151 for installation of mixer pumps in AZ-101. The estimate is considered conservative since the waste forecast is for the maximum number of tanks receiving mixer pumps.

The equipment removed from TRU tanks is assumed to be decontaminated to non-TRU with the planning baseline of assuming a Decontamination facility available after 2003 . It should be noted, however, that it will be challenging to reach the non-TRU status for this waste.

It is assumed that tank closure activities will start in 2022 for the first DST. Closure of the remaining tanks will commence after final retrieval and processing of the waste and be completed in 2034.

Average annual minimum and maximum ranges for the waste are $50 \%$ and $115 \%$ respectively. Minimum waste percentages are based on the uncertainty in the number of mixer pumps required and the useful life of mixer pumps and transfer pumps. The maximum waste percentages assumes all DSTs will have 2 mixer pumps and one transfer pump installed and accounts for the uncertainty in the waste generation volumes based on AZ-101 experiences. The number of mixer pumps required is considered conservative.

\section{Other Forecast Data}


- Low Level Waste

- No LLW is expected from W-343 for management by the CWC.

- This forecast shows a significant decrease from the FY96 forecast of $670 \mathrm{~m}^{3}$, primarily due to better estimates of waste generation.

\section{- Hazardous Waste}

- No hazardous waste is expected from W-343 for management by the CWC.

\begin{tabular}{|c|}
\hline $\begin{array}{c}\text { GENERATORS: } \\
\text { Cross-Site Transfer System - DST Retrieval Systems - High Level Vitrification Project } \text { - Low Level Vitrification Project } \\
\text { SST Long Length Equipment · SST Retrieval - SST/DST Tank Farm Operations - Tank Farm Restoration - Tank Farm } \\
\text { Ventilation Upgrade - W-343 DST Retrieval }\end{array}$ \\
\hline $\begin{array}{l}\text { PROGRAMS: } \\
\begin{array}{c}\text { Analytical Services } \cdot \text { EM-40 } \cdot \text { Facility Transitions } \cdot \text { Landlord } \cdot \text { Liquid Effluent } \cdot \text { NP } \cdot \text { Offsite } \cdot \text { PNNL } \cdot \text { RCRA } \cdot \text { Solid } \\
\text { Waste } \cdot \text { SNF } \cdot \text { TWRS }\end{array}\end{array}$ \\
\hline $\begin{array}{c}\text { CHARACTERISTICS: } \\
\text { CH_LLMW } \cdot \text { RH_LLMW } \cdot \text { CH_TRU(M) } \cdot \text { RH_TRU(M) } \\
\text { GTC III } \cdot \text { LLW } \cdot \text { HAZ }\end{array}$ \\
\hline $\begin{array}{c}\text { WASTE CLASSES: } \\
\text { CH_LLMW } \cdot \text { RH_LLMW } \cdot \text { CH_TRU(M) } \cdot \text { RH_TRU(M) } \cdot \text { GTC III } \cdot \text { LLW } \cdot \text { HAZ }\end{array}$ \\
\hline Home $\cdot$ Contents $\cdot$ Web Site Map $\cdot$ Glossary $\cdot$ Help $\cdot$ Reports $\cdot$ Data Requests $\cdot$ Feedback Form \\
\hline
\end{tabular}

NOTICE: This page is provided subject to our disclaimer. Contact: Oscar Valero at (509) 373-4752.

HNF-EP-0918 rev. 1 Approved for public release; distribution is unlimited. 
THTS PA TH 


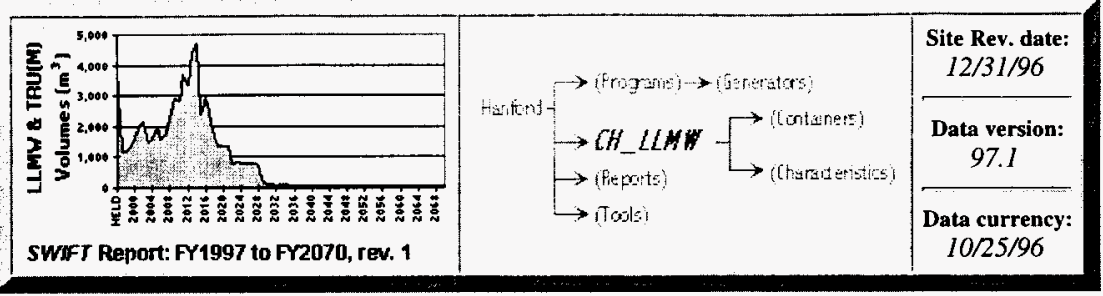

\section{FY97 Forecast of CH_LLMW}

\section{Contents}
» Highlights
» Comparison to Previous Baseline(s)
» Annual Volumes
»CH_LLMW Definitions
»Summary Table

\section{Highlights}

- A total of $30,440 \mathrm{~m}^{3}$ of contact-handled LLMW is forecast for shipment to Hanford Waste Management (WM) by onsite and offsite generators.

- This forecast shows a $58 \%$ reduction from the FY96 forecast of $73,040 \mathrm{~m}^{3}$, due mainly to forecast reductions from TWRS and Facility Transitions programs. It also is a $30 \mathrm{~m}^{3}$ increase from FY97.0 primarily due to an increase by Paducah Energy Systems and slight modifications to Battelle Columbus Laboratory and 327 Building.

- TWRS program is the main source of contact-handled LLMW, accounting for $60 \%$, or $18,260 \mathrm{~m}^{3}$ of the total waste volume.

- The annual baseline, minimum, and maximum graph shows the majority of waste volume is expected from 1997 to 2029, reflecting the activities of the TWRS program.

- Of the $30,440 \mathrm{~m}^{3}$ of CH_LLMW, $69 \%$ will be shipped in 208-liter drums, $13 \%$ in Large boxes, $11 \%$ in Medium boxes, and $6 \%$ in other containers.

- $86 \%$ of the waste will be debris, $7 \%$ inorganic solids, $3 \%$ organic solids, and $4 \%$ other physical waste forms.

- The hazardous constituent volume of CH_LLMW will consist of state regulated waste (37\%); organic (24\%), metals without mercury and organic (13\%); metals without mercury, organic, and state regulated $(11 \%)$; and various combinations of these hazardous constituents $(14 \%)$. 


\section{Program Distribution}

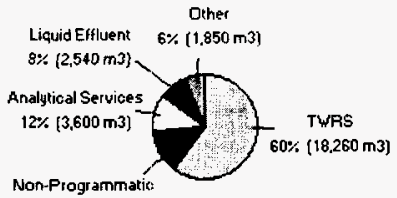

$14 \%[4,190 \mathrm{~m} 3]$

Total $=30.440 \mathrm{~ms}$

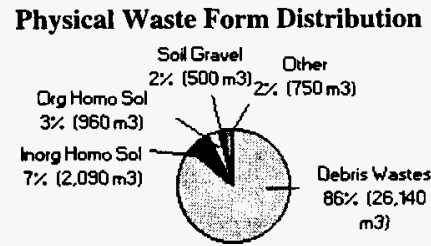

Total $=30,440 \mathrm{m3}$

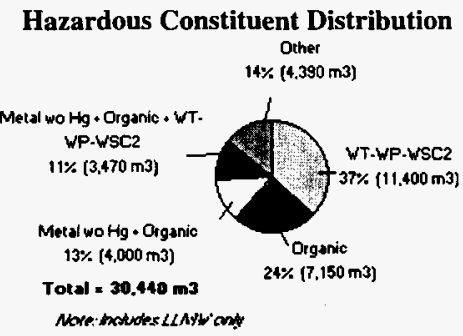

Container Distribution

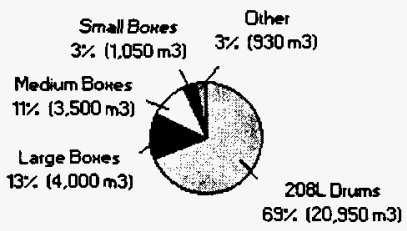

Total $=30,440 \mathrm{m3}$

Sum of totals may not add due to rounding: numbers over $10 \mathrm{~m}^{3}$ are rounded to the nearest $10 \mathrm{~m}^{3}$, numbers less than $10 \mathrm{~m}^{3}$ are rounded to integers, non-zero numbers less than 1 are rounded to 1 .

\section{Annual CH_LLMW Volumes}

\section{CH_LLMW Annual Baseline Volumes}




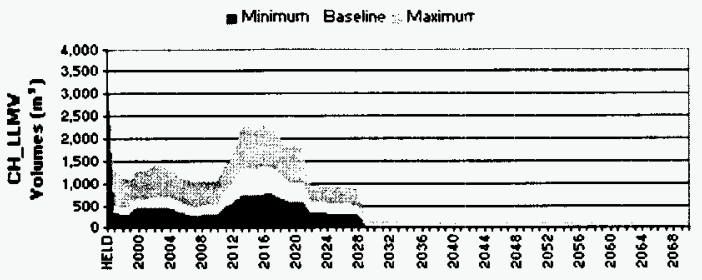

\section{Summary Table (volumes in $\mathbf{m}^{3}$ )}

Forecast by Programmatic Area (in descending order by program and generator volume)

\begin{tabular}{|c|c|c|}
\hline $\begin{array}{l}\text { CH-LLMV Forecast: } \\
\text { Program }\end{array}$ & $\begin{array}{c}\text { Frs7.1 } \\
\text { Foreosst } \\
\text { (m') }\end{array}$ & $\begin{array}{l}x \text { of } \\
\text { Total }\end{array}$ \\
\hline TWRS & 18,260 & $60 \%$ \\
\hline Non-Plogrammatic & 4.190 & $14 \%$ \\
\hline Analytical Services & 3,600 & $12 \%$ \\
\hline Liguid Effiluent & 2540 & $8 \%$ \\
\hline Facility Transitions & 770 & $3 \%$ \\
\hline PNNL & 490 & 20 \\
\hline Solid Waste & 310 & $1 \%$ \\
\hline Offsite & 200 & $1 \%$ \\
\hline RCRA Monitoring & 60 & $<1 \%$ \\
\hline EM-40 & 10 & $<1 \%$ \\
\hline Spent Nuclear Fuel & 5 & $<1 \%$ \\
\hline Tory & 52,40 & serex \\
\hline
\end{tabular}

Sum of totals may not add due to rounding: numbers over $10 \mathrm{~m}^{3}$ are rounded to the nearest $10 \mathrm{~m}^{3}$, numbers less than $10 \mathrm{~m}^{3}$ are rounded to integers, non-zero numbers less than 1 are rounded to 1 .

\section{Comparison to Previous Baseline(s)}

The FY97 forecast of $30,410 \mathrm{~m}^{3}$ of contact-handled LLMW shows a $58 \%$ decrease from the FY96 forecast of $73,040 \mathrm{~m}^{3}$. This decrease reflects the forecast reductions primarily from TWRS, Facility Transitions, Liquid Effluent, and RCRA programs. The FY97.1 increase is due to an increase in CH_LLMW from Paducah Energy Systems. The apparent increase in Facility Transitions volume is the reassignment of 324 and 327 Buildings from PNNL to Facility Transitions.

\section{Comparison to Previous Baseline(s) by Program Area}

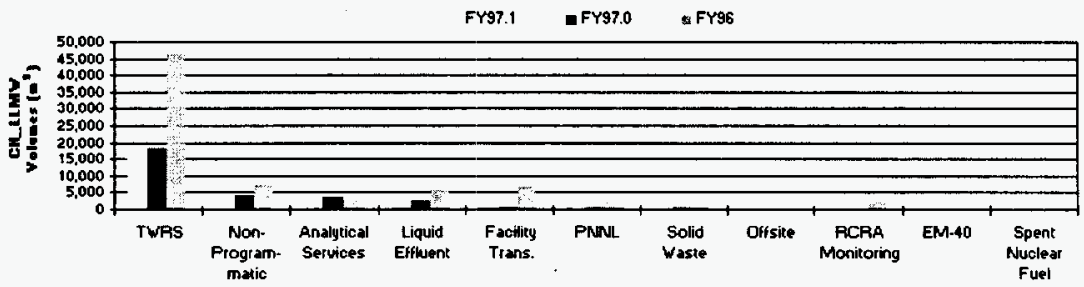




\begin{tabular}{|c|c|c|c|}
\hline $\begin{array}{l}\text { CH-LLMY Compatison: } \\
\text { Program }\end{array}$ & $\begin{array}{c}\text { FY91.1 } \\
\text { Forecast } \\
{\left[\mathrm{m}^{\prime} \mathrm{I}\right.}\end{array}$ & $\begin{array}{c}\text { FY97.0 } \\
\text { Forecast } \\
\text { (m") }\end{array}$ & $\begin{array}{c}\text { FY96 } \\
\text { Forecast } \\
\text { (min) }\end{array}$ \\
\hline TYRS & 1...119,260 & 18,260 & 46.310 \\
\hline High Lesel Yitrification Proiect. & 5,220 & 5,220 & 800 \\
\hline Low Level Virtification Project & 5,120 & 5,120 & 60 \\
\hline SSTRDST Tank Farm Qperations. & 3.760 & 3.760 & 6.830 \\
\hline W3430STRetrieval[1] Tonks] & 1480 & 1480 & ..... \\
\hline SST Retrieval (149 tonks) & 890 & 890 & 860 \\
\hline Tank Farm Restoration ........... & 880 & 880 & $\$ 490$ \\
\hline osT Retuipua Systems (10 tanks). & 870 & 870 & 0 \\
\hline Tank $F$ arm Yentilation Upgrade & 40 & 40 & 0 \\
\hline Cross-Site Transter System... & 5 & 5 & $\ldots 0$ \\
\hline SST Long Length Eguipment & 0 & 0 & 32980 \\
\hline SST Tank 106-C Sluicing & 0 & of & 270 \\
\hline ... Tank WastePretreatment. & 0 & .... & 30 \\
\hline Won-Programpatic & A.190 & 4.190 & 7.270 \\
\hline Stored Equipment & 4,000 & 4.000 & 7.080 \\
\hline PFP Non-Transition & ....80 & 80 & .180 \\
\hline 300 Ares F ucltips Non Trensition. & 60 & 60 & 60 \\
\hline PUREX Non-Transition & 40 & 40 & 40 \\
\hline REOTOXNon-T!ansition?. & 2 & ...? & ..? \\
\hline UPlant Non-Transition. & $\ldots . . .3$ & .............. & (n.......3 \\
\hline Anahtical Services & 3,600 & 3.600 & 2,370 \\
\hline ...225 Andlytical Laboratory & 3.570 & .3570 & 2.290 \\
\hline 6256 Waste Sumpling \& Chusucterization Facility & 30 & 30 & 80 \\
\hline Liquid Ef flatent & 2,540 & 2,540 & $\mathbf{5}, \mathbf{6 2 0}$ \\
\hline Co18H-200Ares Effhuent Treatment Fucility & 2,540 & -2.540 & 5620 \\
\hline Fooilies Transitions & 770 & 770 & 6710 \\
\hline 2345z Plutonium Finishing Plant & 710 & 7iö & 3.280 \\
\hline Waste EncapsulutiontStorage Facility &. .30 &. .30 &.. .9 \\
\hline 324 Building & 20 & 20 & 0 \\
\hline 202 A Puex Operations & 10 & 10 & 20 \\
\hline .32? Building............. & .4 & . & $\ldots$ \\
\hline 225B BPlant & |a & 2 & 3,360 \\
\hline 309 PATR Vault Waste [lon Exchinge Mod] & i) & i & 0 \\
\hline .335 Sodium Test Facility ....................... & 11 &. & 0 \\
\hline FFTF Transition Project. & 1 & 1 & 20 \\
\hline 303K Fuels Fabrication & o & 0 & 20 \\
\hline PNAl & 490 & 490 & 2250 \\
\hline Pacific Northwess National Laboratories. & . & 490 & 2250 \\
\hline Solid Vaste & 3ii & 310 & 320 \\
\hline ..221T!2706T T Plant Qperations & .220 & .220 & 210 \\
\hline Wo26-Wuste Receiving ond Processing (WRAPII & 80 & 80 & \\
\hline Central waste Complen & 20 & 20 & 0 \\
\hline 224T TRU Skorege \& Assay Facility. & 2 & $\ldots$ & 30 \\
\hline $218 E$ w Low Level BurialGround & ..... & 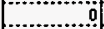 & .80 \\
\hline Difsite & 200 & irö & 60 \\
\hline Princeton Plasma Physites Lab. & 60 & 60 & $\ldots$ \\
\hline Aockwelt-Conoga Pank & 50 & 50 & 0 \\
\hline Puget Sound Nawal Shipyards & 30 & 30 & 0 \\
\hline Puducah Energy Systems..... & 20 & 0 & $\therefore$ \\
\hline Knolls Atomic Power Laboratory & 10 & 10 & 10 \\
\hline Battelle Columbus Laboratories & 8 & 6 & 10 \\
\hline General Alomics ............... & $?$ & .? & \\
\hline Universtity of Utah. & ? & 3 & - \\
\hline Peal Hasbor Naval Shipyatds & 5 & 5 & \\
\hline Pontsmouth Nayal Shipyards & .1 & ..? & \\
\hline Puget Sound Noyal Shipyads & $\cdots$ & 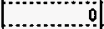 & 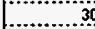 \\
\hline PCAA Monitoring & so & 60 & 2.030 \\
\hline .....e!!Drilling............ & 60 & 60 & 2.030 \\
\hline EMP40 & to & 10 & 100 \\
\hline Surplus $F$ acilities & 10 & 10 & 100 \\
\hline Spent Nucleat Fue!.... & 5 & 5 & $\ldots 7$ \\
\hline $100 \mathrm{~K} \mathrm{~K}-\mathrm{B}$ asin Operations & 5 & 5 & \\
\hline Tares & $\pi 440$ & $n a+r$ & 72000 \\
\hline
\end{tabular}

Sum of totals may not add due to rounding: numbers over $10 \mathrm{~m}^{3}$ are rounded to the nearest $10 \mathrm{~m}^{3}$, numbers less than $10 \mathrm{~m}^{3}$ are rounded to integers, non-zero numbers less than $I$ are rounded to $I$. 
The reasons for the volume changes are explained in each of the program and waste generator pages.

\section{Definitions}

Contact-handled LLMW has a dose rate equal to or less than $200 \mathrm{mrem} / \mathrm{h}$ and contains radioactivity not classified as spent nuclear fuel or transuranic waste (concentrations of transuranic radionuclides less than or equal to $100 \mathrm{nCi} / \mathrm{g}$ of the waste matrix.) The waste is also defined as dangerous (hazardous) waste in the Washington Administrative Code (WAC) 173-303.

\begin{tabular}{|c|c|}
\hline \multicolumn{2}{|c|}{$\begin{array}{l}\text { WASTE CLASSES: } \\
C H \_L M W \cdot \text { RH_LLMW } \cdot \text { CH_TRU(M) } \cdot \text { RH_TRU(M) } \cdot \text { GTC III } \cdot \text { LLW } \cdot \text { HAZ }\end{array}$} \\
\hline $\begin{array}{c}\text { CHARACTERISTICS: } \\
\text { CH_LLMW } \cdot \text { RH_LLMW } \cdot \text { CH_TRU(M) } \cdot \text { RH_TRU(M) } \cdot \\
\text { GTC III } \cdot \text { LLW } \cdot \text { HAZ }\end{array}$ & $\begin{array}{c}\text { CONTAINERS: } \\
\text { CH_LLMW } \cdot \text { RH_LLMW } \cdot \text { CH_TRU(M) } \\
\text { RH_TRU(M) } \cdot \text { GTC III } \cdot \text { LLW } \cdot \text { HAZ }\end{array}$ \\
\hline \multicolumn{2}{|c|}{$\begin{array}{c}\text { PROGRAMS: } \\
\text { Analytical Services } \cdot \text { EM-40 } \cdot \text { Facility Transitions } \cdot \text { Landlord } \cdot \text { Liquid Effluent } \cdot \text { NP } \cdot \text { Offsite } \cdot \text { PNNL } \cdot \text { RCRA } \cdot \text { Solid } \\
\text { Waste } \cdot \text { SNF } \cdot \text { TWRS }\end{array}$} \\
\hline
\end{tabular}

NOTICE: This page is provided subject to our disclaimer. Contact: Oscar Valero at (509) 373-4752.

HNF-EP-0918 rev. 1 Approved for public release; distribution is unlimited. 


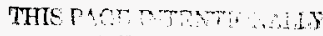

1..... 3inines 


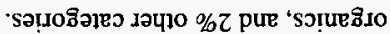

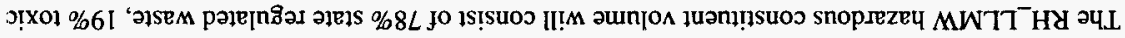

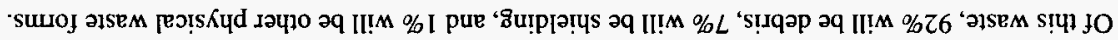
ureıึo.d

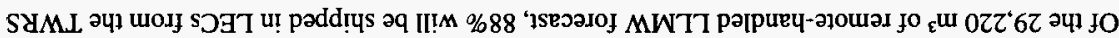

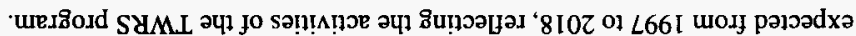

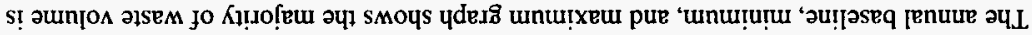

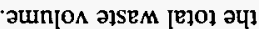

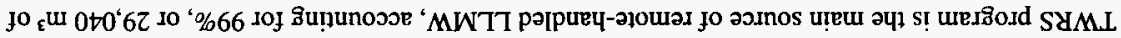

'SYML WOH әSEวगU!

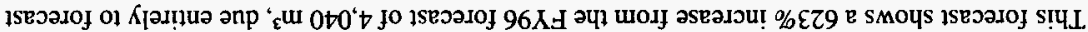

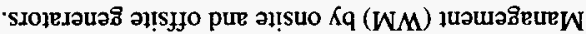

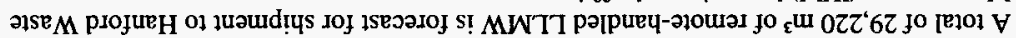

\section{รุบธี!กบชิ!ก}

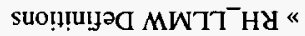

(s)วu!̣วseg sno!̣ әqq $L$ Kreuruns « Səun[o $\Lambda$ [enuu $\forall$ 《

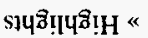

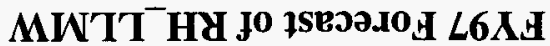

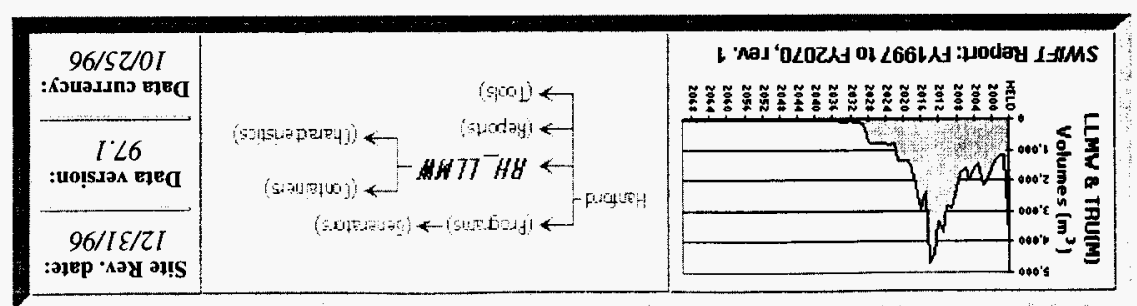




\section{Program Distribution}

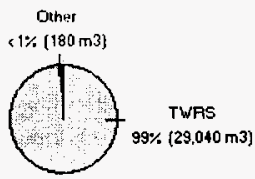

Total $=29.220 \mathrm{m3}$

Physical Waste Form Distribution

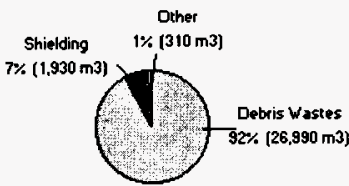

Total $=29,220 \mathrm{~m}^{3}$
Hazardous Constituent Distribution

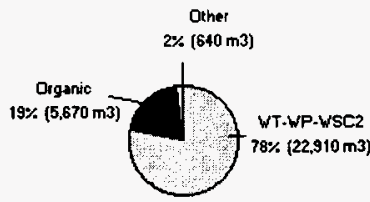

Total $=29,220 \mathrm{m3}$

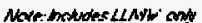

\section{Container Distribution}

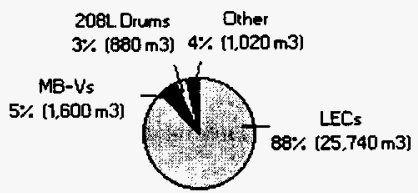

Total $=29,220 \mathrm{m3}$

Sum of totals may not add due to rounding: numbers over $10 \mathrm{~m}^{3}$ are rounded to the nearest $10 \mathrm{~m}^{3}$, numbers less than $10 \mathrm{~m}^{3}$ are rounded to integers, non-zero numbers less than I are rounded to 1.

\section{Annual RH_LLMW Volumes}

\section{RH_LLMW Annual Baseline Volumes}




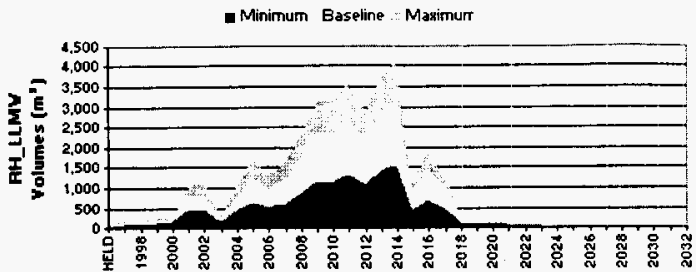

\section{Summary Table (Volumes in $\mathbf{m}^{3}$ )}

Forecast by Programmatic Area (in descending order by program and generator volume)

\begin{tabular}{|c|c|c|}
\hline $\begin{array}{l}\text { AH-LLMY Forecast: } \\
\text { Program }\end{array}$ & $\begin{array}{l}\text { FY97.1 } \\
\text { Forecast } \\
\text { (m') }\end{array}$ & $\begin{array}{l}x a x \\
\text { rated }\end{array}$ \\
\hline TWRS & 29,040 & 898 \\
\hline Facility Transitions & 70 & $<1 \%$ \\
\hline Solid Waske & 60 & $<1 \%$ \\
\hline PNNL & 50 & $\leqslant 1 \%$ \\
\hline Offsite & 5 & $<1 \%$ \\
\hline Torel & 20.220 & fover \\
\hline
\end{tabular}

Sum of totals may not add due to rounding: numbers over $10 \mathrm{~m}^{3}$ are rounded to the nearest $10 \mathrm{~m}^{3}$, numbers less than $10 \mathrm{~m}^{3}$ are rounded to integers, non-zero numbers less than $/$ are rounded to 1 .

\section{Comparison to Previous Baseline(s)}

The FY97 forecast of $29,220 \mathrm{~m}^{3}$ of remote-handled LLMW shows a 7-fold increase from the FY96 forecast of $4,040 \mathrm{~m}^{3}$. This increase is due almost entirely from the SST Long Length Equipment generator within the TWRS program; based on new programmatic definitions, SST Long Length Equipment expects more RH_LLMW and less CH_LLMW than in the FY96 forecast.

\section{Comparison to Previous Baseline(s) by Program Area}

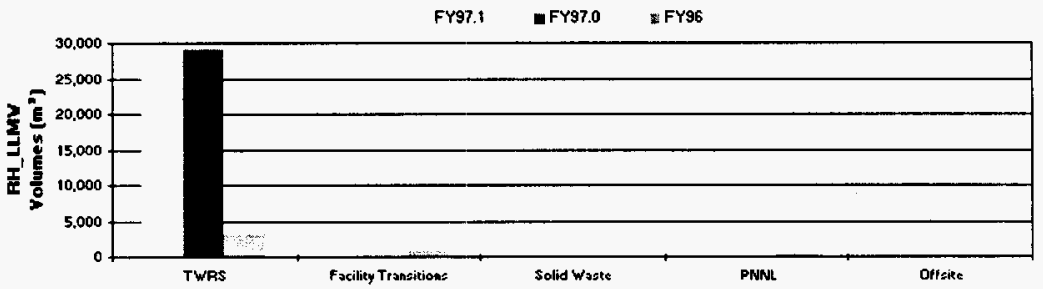




\begin{tabular}{|c|c|c|c|}
\hline $\begin{array}{l}\text { RH-LLMV Comparison: } \\
\text { Program }\end{array}$ & $\begin{array}{c}\text { Fytio.1 } \\
\text { Forecast } \\
\text { fm }^{*} \text { l }\end{array}$ & $\begin{array}{c}\text { FY97.0 } \\
\text { Forecast } \\
\left.\text { (m) }^{2}\right)\end{array}$ & $\begin{array}{c}\text { FY96 } \\
\text { Forecast } \\
\left.\mathrm{cm}^{\prime}\right)\end{array}$ \\
\hline TYRS $\ldots \ldots \ldots \ldots \ldots \ldots$ & 243.040 & 29,040 & 3,080 \\
\hline SSTLOngLength Equipment & 22520 & 22,520 & 연 \\
\hline DST Retrieval Systems (10 tanks) & 3.050 & 3.050 & 260 \\
\hline W3430ST Retrieval [17 Tanks) & 1,760 & 1,760 & 640 \\
\hline SSTIDST T ank Farm Qperations. & 940 & 940 & 1,690 \\
\hline SST Retuieud 149 tanks) & 390 & 390 & 390 \\
\hline Tank Farm Piestoration & $380]$ & 380 & 0 \\
\hline DST 101:AZ Ratrieual [ ! tank] & 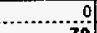 & $\ldots 0$ & 110 \\
\hline Freflites Transitions........... & 70 & 70 & 660 \\
\hline 303 K Fueis F abrication Transition & 70 & 70 & 660 \\
\hline 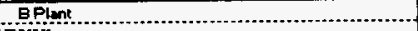 & 0 & . & 660 \\
\hline PNMLL & 50 & 50 & 220 \\
\hline Pacific Norknwest National Laboratories & 50 & 50 & 220 \\
\hline Solid Yasle & 60 & 60 & 70 \\
\hline 221T12706T T Plant Qpetations. & 60 & 60 & 70 \\
\hline Qffsite & 5 & 5 & 0 \\
\hline Knolis Atomic Power-Laboratory & 5 & 5 & D \\
\hline Tory & $2 \times 22 d$ & 21220 & t. 410 \\
\hline
\end{tabular}

Sum of totals may not add due to rounding: numbers over $10 \mathrm{~m}^{3}$ are rounded to the nearest $10 \mathrm{~m}^{3}$, numbers less than $10 \mathrm{~m}^{3}$ are rounded to integers, non-zero numbers less than 1 are rounded to 1.

\section{Definitions}

Remote-handled LLMW has a dose rate greater than $200 \mathrm{mrem} / \mathrm{h}$ and contains radioactivity not classified as spent nuclear fuel or transuranic waste (concentrations of transuranic radionuclides less than or equal to $100 \mathrm{nCi} / \mathrm{g}$ of the waste matrix.) The waste is also defined as dangerous (hazardous) waste in the Washington Administrative Code (WAC) 173-303.

\begin{tabular}{|c|c|}
\hline \multicolumn{2}{|c|}{$\begin{array}{l}\text { WASTE CLASSES: } \\
\text { CH_LLMW } \cdot R H \_L L M W \cdot \text { CH_TRU(M) } \cdot \text { RH_TRU(M) } \cdot \text { GTC III } \cdot \text { LLW } \cdot \text { HAZ }\end{array}$} \\
\hline $\begin{array}{l}\text { CHARACTERISTICS: } \\
\text { CH_LLMW } \cdot \text { RH_LLMW } \cdot \text { CH_TRU(M) } \cdot \text { RH_TRU(M) } \\
\text { GTC III } \cdot \text { LLWW } \cdot \text { HAZ }\end{array}$ & $\begin{array}{l}\text { CONTAINERS: } \\
\text { CH_LLMW } \cdot \text { RH_LLMW } \cdot \text { CH_TRU(M) } \\
\text { RH_TRU(M) } \cdot \text { GTC III } \cdot \text { LLW } \cdot \text { HAZ }\end{array}$ \\
\hline \multicolumn{2}{|c|}{$\begin{array}{c}\text { PROGRAMS: } \\
\text { Analytical Services } \cdot \text { EM-40 } \cdot \text { Facility Transitions } \cdot \text { Landlord } \cdot \text { Liquid Effluent } \cdot \text { NP } \cdot \text { Offsite } \cdot \text { PNNL } \cdot \text { RCRA } \cdot \text { Solid } \\
\text { Waste } \cdot \text { SNF } \cdot \text { TWRS }\end{array}$} \\
\hline
\end{tabular}

NOTICE: This page is provided subject to our disclaimer. Contact: Oscar Valero at (509) 373-4752. HNF-EP-0918 rev. 1 Approved for public release; distribution is unlimited. 


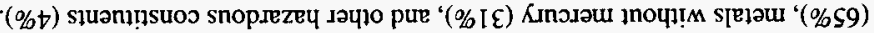

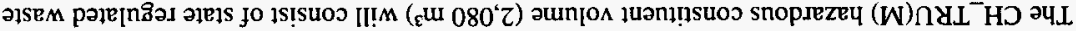

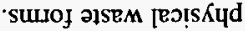

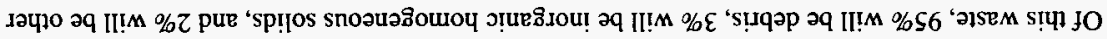

'Sว月T U! \%8 pue 'sgMS U! \% I I

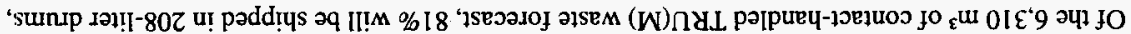

-suresoిosd

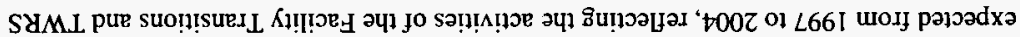

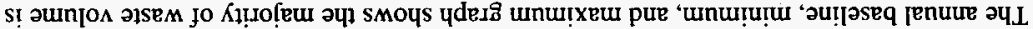

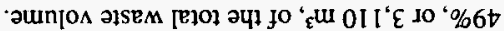

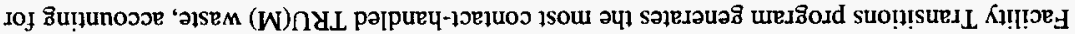

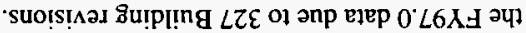

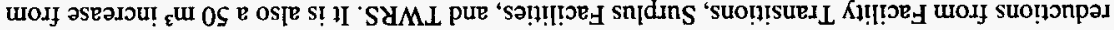

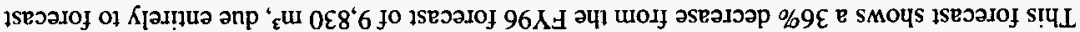

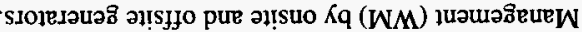

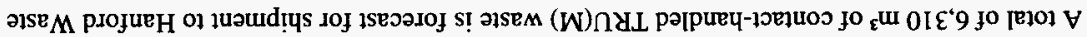

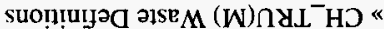

(s)วu!
วqqL Kreuruns " sounjo $\Lambda$ [enuü * ราบฮิ!!บชิ!H «

squวนน0

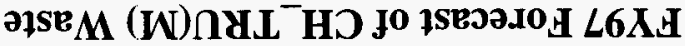

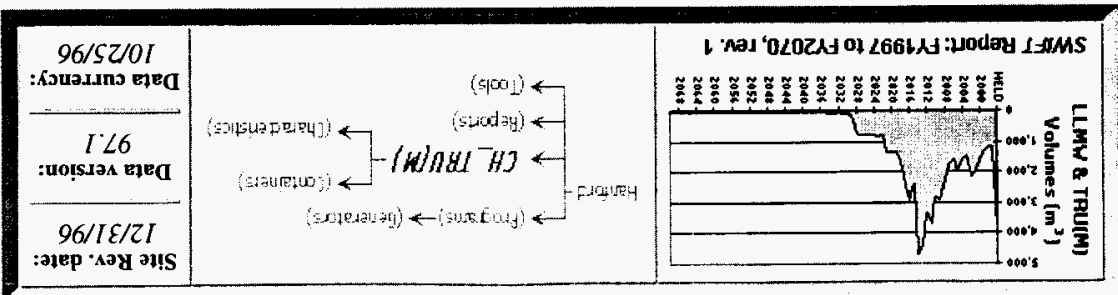




\section{Program Distribution}

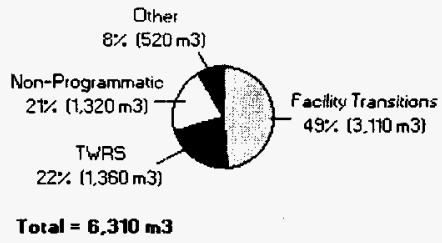

Physical Waste Form Distribution

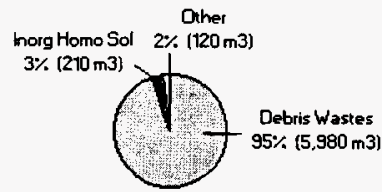

Hazardous Constituent Distribution

Reactive - Metals wo Hg * Organic $3 \%[60 \mathrm{~m} 3]$

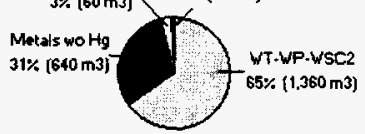

Total $=6.370 \mathrm{~m} 3$

Total $=2.080 \mathrm{m3}$

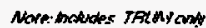

\section{Container Distribution}

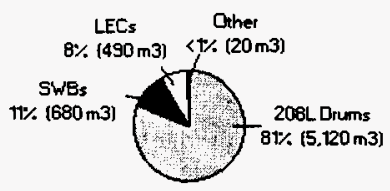

Total $=6.310 \mathrm{m3}$

Sum of totals may not add due to rounding: numbers over $10 \mathrm{~m}^{3}$ are rounded to the nearest $10 \mathrm{~m}^{3}$, numbers less than $10 \mathrm{~m}^{3}$ are rounded to integers, non-zero numbers less than I are rounded to 1.

\section{Annual Volumes}

\section{CH_TRU(M) Waste Annual Baseline Volumes}




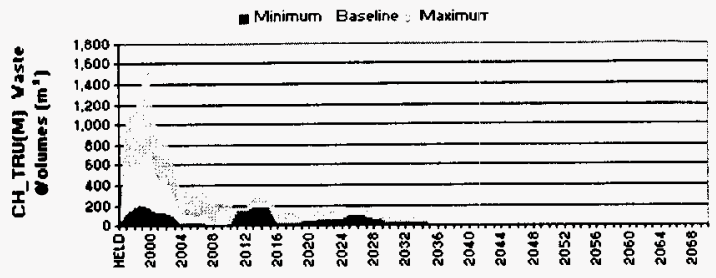

\section{Summary Table (Volumes in $\left.\mathbf{m}^{3}\right)$}

Forecast by Programmatic Area (in descending order by program and generator volume)

\begin{tabular}{|c|c|c|}
\hline $\begin{array}{l}\text { CH-TRU(M) Yaste Forecast: } \\
\text { Program }\end{array}$ & $\begin{array}{c}\text { FY97.1 } \\
\text { Forecast } \\
\left(\mathrm{m}^{\mathrm{g}}\right)\end{array}$ & $\begin{array}{l}x \text { of } \\
\text { Toral } \\
\end{array}$ \\
\hline Fucility Transitions & 3,110 & $49 \%$ \\
\hline TWRS & 1,360 & $22 \%$ \\
\hline Non-Programmatic & 1,320 & $21 \%$ \\
\hline PNNL & $\begin{array}{r}240 \\
-\end{array}$ & $+\%$ \\
\hline EM-40 & 230 & 4 \\
\hline Andytical Services & 20 & 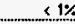 \\
\hline Spent Nuele ar Fuel & 20 & $1 \%$ \\
\hline Offsite & 2 & 11 \\
\hline Tores & a.5/e & todex \\
\hline
\end{tabular}

Sum of totals may not add due to rounding: numbers over $10 \mathrm{~m}^{3}$ are rounded to the nearest $10 \mathrm{~m}^{3}$, numbers less than $10 \mathrm{~m}^{3}$ are rounded to integers, non-zero numbers less than $I$ are rounded to $I$.

\section{Comparison to Previous Baseline(s)}

The FY97.1 forecast of $6,310 \mathrm{~m}^{3}$ of contact-handled TRU(M) waste shows a $36 \%$ decrease from the FY96 forecast of $9,830 \mathrm{~m}^{3}$. This decrease is due to decreases from the Plutonium Finishing Plant (Facility Transitions), Surplus Facilities (Environmental Restoration), and High Level Vitrification Project (TWRS).

The FY97.1 data also shows a $50 \mathrm{~m}^{3}$ increase from 97.0 due to 327 Building revisions.

\section{Comparison to Previous Baseline(s) by Program}

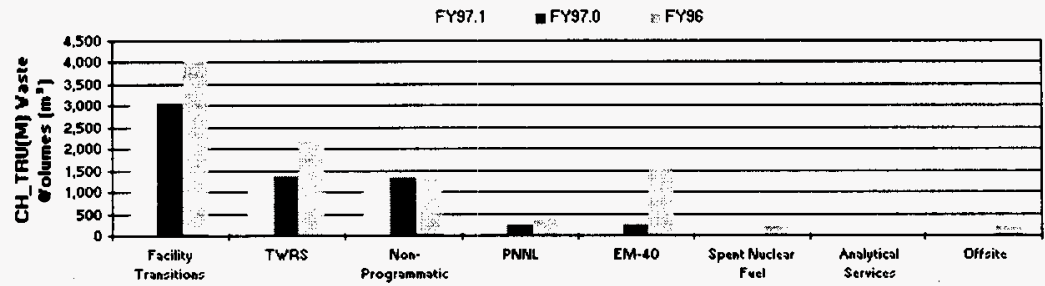




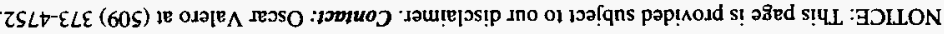

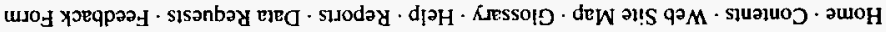

SYML + INS · JISEM

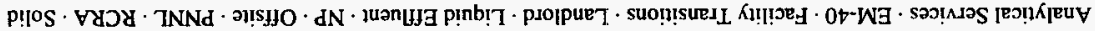
:SWFYOOYd

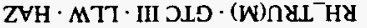

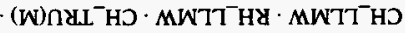
:SUבNIVINOJ
ZVH $\cdot M T 7 \cdot I I I$ OLS

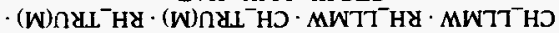
:SDILSIYGLOVZVD

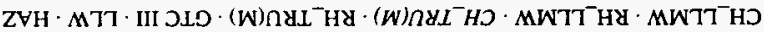 :S马SSVTD $\exists I S \forall M$}

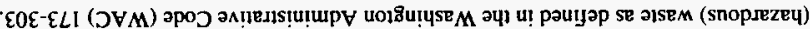

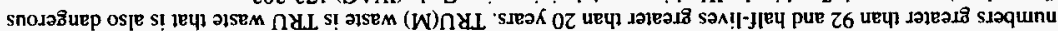

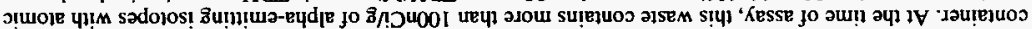

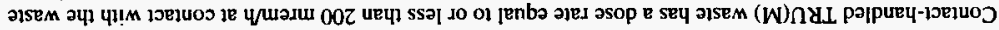

suo!!uyวa

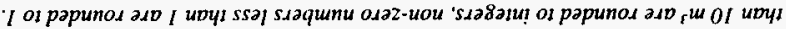
ssal sגaqunu ;

\begin{tabular}{|c|c|c|c|}
\hline ares & 2079 & $215 y$ & exol \\
\hline 002 & 0 & 0 & 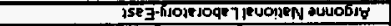 \\
\hline 0 & 12 & 12 & 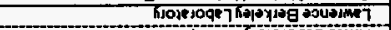 \\
\hline 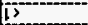 & 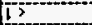 & is & 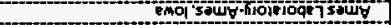 \\
\hline 002 & $z$ & 2 & 3isido \\
\hline 012 & 0 & a & 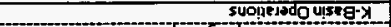 \\
\hline - & Q2 & 02 & 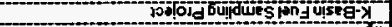 \\
\hline 012 & 02 & $0 z$ & jonjirejonn joos \\
\hline $0 z$ & Qz & $0 z$ & 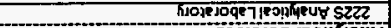 \\
\hline $\overrightarrow{02}$ & 02 & az & sopinas jeopifous \\
\hline 025 & $0 \varepsilon$ & $\underline{0 \varepsilon 2}$ & sompiory snjoing \\
\hline Q29! & OEZ & Dez & of \\
\hline 068 & $0+2$ & $0+2$ & 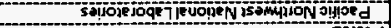 \\
\hline 068 & otz & $0+2$ & רNd \\
\hline Ql & 인. & 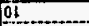 & nop!sueJ1-40N furidn \\
\hline $\bar{\alpha}$ & $0 \varepsilon$ & $\underline{\varepsilon}$ & uon!suei-uôn irodans an!s \\
\hline ôt & ot & $\mathrm{OH}$ & Uộtsuei I-von jueld \\
\hline 09 & 09 & 9 & Uolj!sut 1 -UOM dst \\
\hline ags & 09 & 9 & Uom!sut 1 -UON juelde \\
\hline $\bar{a}$ & 02 & 02 & Uolyiste i- \\
\hline oll! & 011 & 011 & Uot]!sue 1 -uON X \\
\hline ồ & oitz & ais & 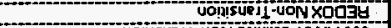 \\
\hline$\overline{O E L}$ & $\overline{0} \mathrm{~L}$ & $\bar{a} \hat{\varepsilon} L$ & 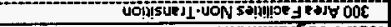 \\
\hline $02 E^{\prime}$ & $028^{\circ} !$ & DZE'I & 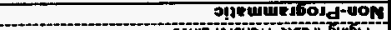 \\
\hline 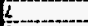 & 0 & (1)- & 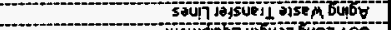 \\
\hline 0 & $06+$ & (16t) & 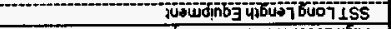 \\
\hline $0 \leq 12$ & $0<8$ & 1 & 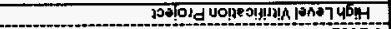 \\
\hline 0812 & $08 \varepsilon^{2}$ & ogeri & SUAI \\
\hline 4 & 0 & (i) & IIJ \\
\hline 01. & $\underline{0}$ & II & suolje Jado (8Z0Z) waind \\
\hline 0 & II & 1 & lpow s6uryjx \\
\hline 0 & 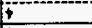 & to & boupling $-2 x$ \\
\hline 0 & $z$ & 69 & 6U!Pा!ng $\angle 2 \mathrm{E}$ \\
\hline $06 \varepsilon^{2}$ & $0 \mathrm{go}$ & $\cos 0$ & 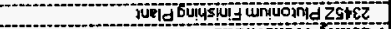 \\
\hline 000 & $090 \varepsilon$ & 0 & suomisueit bupes \\
\hline $\begin{array}{c}1.9 \\
1=30104 \\
96 \alpha 1\end{array}$ & $\begin{array}{c}\text { Tad } \\
\text { sesosed } \\
026 \lambda 4\end{array}$ & $\begin{array}{c}{[.01} \\
0 \leq 0010] \\
1-26 \alpha\end{array}$ & 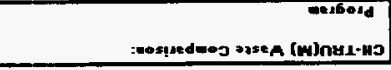 \\
\hline
\end{tabular}


HNF-EP-0918 rev. 1 Approved for public release; distribution is unlimited. 
THIS PACETMTNNT ...LY

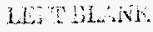




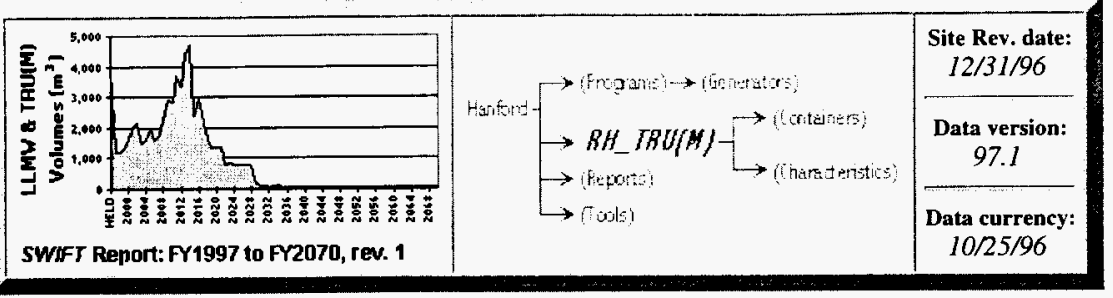

\section{FY97 Forecast of RH_TRU(M) Waste}

\section{Contents}
» Highlights
»Comparison to Previous Baseline(s)
» Annual Volumes
» RH_TRU(M) Waste Definitions
» Summary Table

\section{Highlights}

- A total of 1,670 $\mathrm{m}^{3}$ of remote-handled TRU(M) waste is forecast for shipment to Hanford Waste Management (WM) by onsite and offsite generators.

- This forecast shows a $87 \%$ decrease from the FY96 forecast of $13,350 \mathrm{~m}^{3}$, due almost entirely to forecast reductions from TWRS and a $30 \mathrm{~m}^{3}$ decrease from the FY97.0 forecast of 1,700 due to 327 Building revisions.

- TWRS program generates the most remote-handled TRU(M) waste, accounting for $87 \%$, or 1,450 $\mathrm{m}^{3}$ of the total waste volume.

- The annual baseline, minimum, and maximum graph shows that waste generation is fragmented through the years, with the peaks corresponding to increases in volumes from TWRS.

- Of the $1,670 \mathrm{~m}^{3}$ of remote-handled TRU(M) waste forecast, $56 \%$ will be shipped in $\mathrm{SWBs}, 35 \%$ in LECs, $5 \%$ in 208 -liter drums, and $4 \%$ in extra large boxes.

- Of this waste, $89 \%$ will be debris, $6 \%$ will be shielding, and $5 \%$ will be other physical waste forms.

- The RH_TRU(M) hazardous constituent waste volume $\left(1,550 \mathrm{~m}^{3}\right)$ will consist of Washington State regulated waste $(88 \%)$, toxic organics $(7 \%)$, and other hazardous constituents $(5 \%)$. 


\section{Program Distribution}

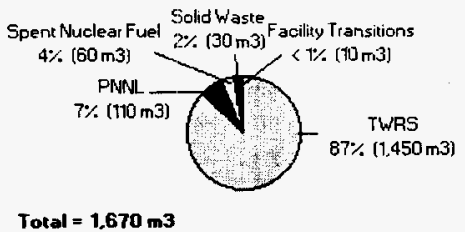

\section{Physical Waste Form Distribution}

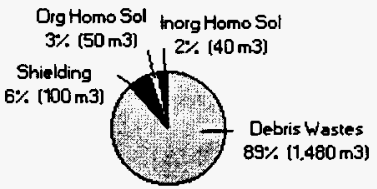

Total $=1.670 \mathrm{m3}$

\section{Hazardous Constituent Distribution}

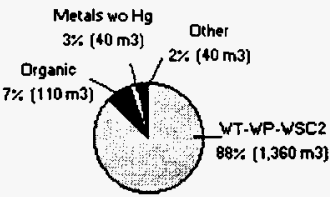

Total $=1,550 \mathrm{m3}$

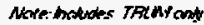

\section{Container Distribution}

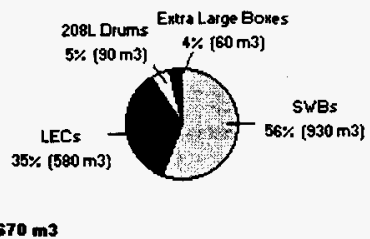

Sum of rotals may not add due so rounding: numbers over $10 \mathrm{~m}^{3}$ are rounded to the nearest $10 \mathrm{~m}^{3}$, numbers less than $10 \mathrm{~m}^{3}$ are rounded to integers, non-zero numbers less than $I$ are rounded to 1 .

\section{Annual Volumes}

\section{RH_TRU(M) Waste Annual Baseline Volumes}




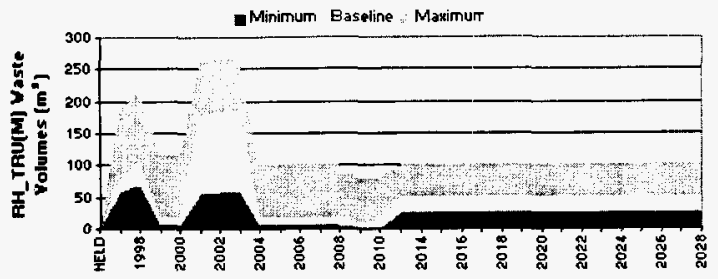

Summary Table (Volumes in $\mathbf{m}^{3}$ )

Forecast by Programmatic Area (in descending order by program and generator volume)

\begin{tabular}{|c|c|c|}
\hline $\begin{array}{l}\text { PIH-TRU(M) Yaste Forecast: } \\
\text { Program }\end{array}$ & $\begin{array}{c}\text { FY97.1 } \\
\text { Folecast } \\
\text { (m') }\end{array}$ & $\begin{array}{l}x \text { of } \\
\text { Total }\end{array}$ \\
\hline TWRS & 1450 & $87 \%$ \\
\hline PNN & 110 & 78 \\
\hline Spent Nuclear Fuel & 60 & $4 \%$ \\
\hline Solid Waste & 30 & $2 \%$ \\
\hline Focility Transitions & 10 & $1 \%$ \\
\hline Taty & $1.6 \pi$ & fotar \\
\hline
\end{tabular}

Sum of totals may not add due to rounding: numbers over $10 \mathrm{~m}^{3}$ are rounded to the nearest $10 \mathrm{~m}^{3}$, numbers less than $10 \mathrm{~m}^{3}$ are rounded to integers, non-zero numbers less than I are rounded to 1 .

\section{Comparison to Previous Baseline(s)}

The FY97.1 forecast of $1,670 \mathrm{~m}^{3}$ of remote-handled TRU(M) waste shows a $87 \%$ decrease from the FY 96 forecast of $13,350 \mathrm{~m}^{3}$. This decrease is due almost entirely to decreases in the TWRS program - the SST Long Length Equipment generator alone decreased the forecast from $10,280 \mathrm{~m}^{3}$ in FY96 to $490 \mathrm{~m}^{3}$ in FY97, while the High Level Vitrification Project dropped from $1,960 \mathrm{~m}^{3}$ to $870 \mathrm{~m}^{3}$.

The FY97.1 forecast is also $30 \mathrm{~m}^{3}$ less than 97.0 due to revisions in the 327 Building.

\section{Comparison to Previous Baseline(s) by Program}

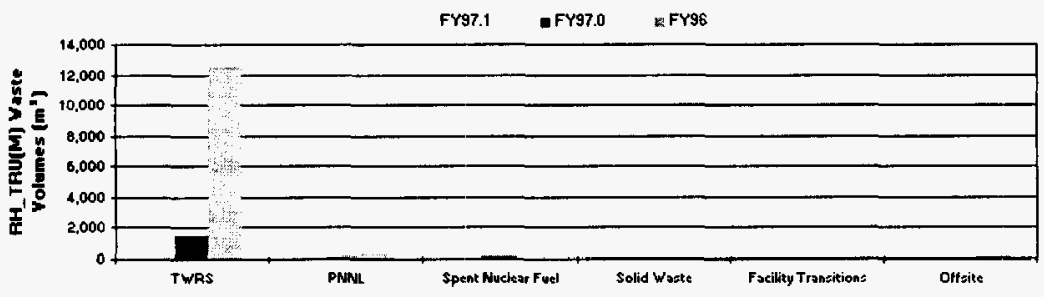




\begin{tabular}{|c|c|c|c|}
\hline $\begin{array}{l}\text { RH-TRU(M) Vaste Comparison: } \\
\text { Program }\end{array}$ & $\begin{array}{c}\text { FY97.1 } \\
\text { Forecast } \\
\left(\mathrm{m}^{3}\right)\end{array}$ & $\begin{array}{c}\text { FY97. } \\
\text { Forecast } \\
\text { fm"1 }\end{array}$ & $\begin{array}{c}\text { FYgt: } \\
\text { Foreciast } \\
\mathrm{m}^{3} \mathbf{m}\end{array}$ \\
\hline TYAS $\ldots \ldots \ldots \ldots \ldots$ & 1.450 & 1.450 & 12,490 \\
\hline High Level Vitrification Project. & 870 & 870 & 1960 \\
\hline SST Long Length Equipment & 490 & 490 & 10280 \\
\hline DST Retrieval Systems (10 tanks). & 90 & 90 & $\ldots 0$ \\
\hline W343 DST Retrieyal 11? tanksl. & 0 & 0 & 250 \\
\hline PWNL & 110 & 150 & 350 \\
\hline Pacific Northwest National Labor atories. & 110 & 110 & 350 \\
\hline 327 Building & 0 & 30 & . \\
\hline 324 Building & 0 & 10 & 0 \\
\hline Spent Nuclear Fuel & 60 & 60 & 40. \\
\hline 100k K-Basin QpeIatjons & 60 & 60 & 40 \\
\hline Solid Vaste & 30 & 30 & 30 \\
\hline 221T12706T I Plan! Qperations & 30 & 30 & 39 \\
\hline Fopilite Transitions & 100 & o. & 0 \\
\hline 324 Building & $\$ 0$ & 0 & . \\
\hline ENA-40 $\ldots \ldots \ldots \ldots \ldots$ & . & D. & 360 \\
\hline Surplus Facilities. & 0 & & 360 \\
\hline Offsite & - & i) & 80 \\
\hline Battelle Columbus Laboratories & 0 & 0 & 80 \\
\hline torat & 4.57 & t.7m & 12,359 \\
\hline
\end{tabular}

Sum of totals may not add due to rounding: numbers over $10 \mathrm{~m}^{3}$ are rounded to the nearest $10 \mathrm{~m}^{3}$, numbers less than $10 \mathrm{~m}^{3}$ are rounded to integers, non-zero numbers less than 1 are rounded to 1.

In addition, the FY97.1 volume is $30 \mathrm{~m}^{3}$ due to 327 Building revisions.

\section{Definitions}

Remote-handled TRU(M) waste has a dose rate greater than $200 \mathrm{mrem} / \mathrm{h}$ at contact with the waste container. At the time of assay, this waste contains more than $100 \mathrm{nCi} / \mathrm{g}$ of alpha-emitting isotopes with atomic numbers greater than 92 half-lives greater than 20 years. TRU(M) waste is TRU waste that is also dangerous (hazardous) waste as defined in the Washington Administrative Code (WAC) 173-303.

\section{WASTE Classes:}

CH_LLMW $\cdot$ RH_LLMW $\cdot$ CH_TRU(M) $\cdot R H \_T R U(M) \cdot G T C$ III $\cdot$ LLW $\cdot$ HAZ

\begin{tabular}{|c|c|}
\hline $\begin{array}{c}\text { CHARACTERISTICS: } \\
\text { CH_LLMW } \cdot \text { RH_LLMW } \cdot \text { CH_TRU(M) }\end{array}$ & CONTAINERS: \\
GTCIII $\cdot$ LLW $\cdot$ HAZ & $\begin{array}{c}\text { CH_LLMW } \cdot \text { RH_LLMW } \cdot \text { CH_TRU(M) } \\
\text { RH_TRU(M) } \cdot \text { GTC III } \cdot \text { LLW } \cdot \text { HAZ }\end{array}$ \\
\hline
\end{tabular}

PROGRAMS:

Analytical Services - EM-40 - Facility Transitions - Landlord - Liquid Effluent - NP - Offsite - PNNL - RCRA - Solid Waste $\cdot$ SNF $\cdot$ TWRS

Home - Contents - Web Sitc Map - Glossary - Help · Reports - Data Requests - Feedback Form

NOTICE: This page is provided subject to our disclaimer. Contact: Oscar Valero at (509) 373-4752.

HNF-EP-0918 rev. 1 Approved for public release; distribution is unlimited. 


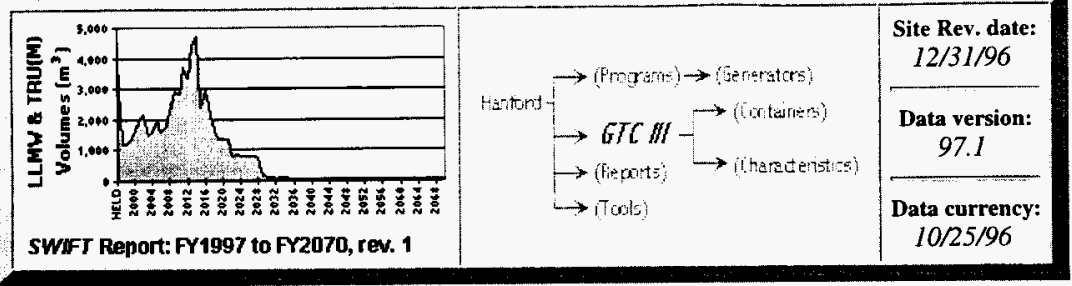

\section{FY97 Forecast of GTC III}

\section{Contents}

» Highlights

"Summary Table
» Comparison to Previous Baseline(s)

» GTC III Definitions

\section{Highlights}

- No LLW or LLMW greater-than-class III (GTCIII) is forecast for shipment to the Hanford SW Project by onsite and offsite generators.

- This forecast shows a significant reduction from the FY96 forecast of $990 \mathrm{~m}^{3}\left(640 \mathrm{~m}^{3}\right.$ of LLMW_GTCIII and $350 \mathrm{~m}^{3}$ of LLW_GTCIII).

\section{Summary Table (Volumes in $\mathrm{m}^{3}$ )}

[Not applicable]

\section{Comparison to Previous Baseline(s)}

The FY97 forecast of no GTCIII waste shows a significant reduction from the FY96 forecast of $990 \mathrm{~m}^{3}$. This reduction arises because the 2 generators that reported GTCIII waste last year - DST Retrieval and PNNL - have both changed their planning assumptions for the current year's forecast. DST Retrieval is using a new baseline for waste forecasts based on the experience of Project W-151. PNNL has determined that they would include in their forecast only waste for which a disposal pathway exists. As a result, no GTCIII waste has been forecast for that program. No GTC III was reported for FY97.1.

\begin{tabular}{|c|c|c|c|}
\hline $\begin{array}{l}\text { GTCIII Vaste Comparison: } \\
\text { Program }\end{array}$ & $\begin{array}{c}\text { FY97.1 } \\
\text { Forecast } \\
\text { (m') }\end{array}$ & $\begin{array}{c}\text { FY97.0 } \\
\text { Forecast } \\
\text { (m') }\end{array}$ & $\begin{array}{c}\text { FY96 } \\
\text { Forecast } \\
\text { (m'l }\end{array}$ \\
\hline PUNL & 0 & 0 & 890 \\
\hline Pacific Northwest National Laborarories & 0 & 0 & 880 \\
\hline TVRS & o & - & 110 \\
\hline W-343 DST Retrieval (17 tanks) & 0 & 0 & 110 \\
\hline Tord & $\theta$ & $\theta$ & $\infty$ \\
\hline
\end{tabular}

Sum of totals may not add due to rounding: numbers over $10 \mathrm{~m}^{3}$ are rounded to the nearest $10 \mathrm{~m}^{3}$, numbers less than $10 \mathrm{~m}^{3}$ are rounded to integers, non-zero numbers less than 1 are rounded to 1 . 


\section{Definitions}

LLW greater-than-class III meets the definition for LLW and is determined to be GTCIII when the sum of the fractions of the radionuclides' Class III concentration limits are greater than one, as defined in the Hanford Site Solid Waste Acceptance Criteria, WHC-EP-0063 Rev. 4, November 1993.

LLMW greater-than-class III has radiation Jevels as defined for LLW greater-than-class-III, and is also defined as dangerous (hazardous) waste in WAC 173-303.

\begin{tabular}{|c|c|}
\hline \multicolumn{2}{|c|}{$\begin{array}{c}\text { WASTE CLASSES: } \\
\text { CH_LLMW } \cdot \text { RH_LLMW } \cdot \text { CH_TRU(M) } \cdot \text { RH_TRU(M) } \cdot G T C ~ I I \cdot \cdot \mathrm{LLW} \cdot \mathrm{HAZ}\end{array}$} \\
\hline $\begin{array}{l}\text { CHARACTERISTTCS: } \\
\text { CH_LLMW } \cdot \text { RH_LLMW } \cdot \text { CH_TRU(M) } \cdot \text { RH_TRU(M) } \\
\text { GTC III } \cdot \text { LLW } \cdot \text { HAZ }\end{array}$ & $\begin{array}{l}\text { CONTAINERS: } \\
\text { CH_LLMW } \cdot \text { RH_LLMW } \cdot \text { CH_TRU(M) } \\
\text { RH_TRU(M) } \cdot \text { GTC III } \cdot \text { LLW } \cdot \text { HAZ }\end{array}$ \\
\hline \multicolumn{2}{|c|}{$\begin{array}{l}\text { PROGRAMS: } \\
\text { Analytical Services } \cdot \text { EM-40 } \cdot \text { Facility Transitions } \cdot \text { Landlord } \cdot \text { Liquid Effluent } \cdot \text { NP } \cdot \text { Offsite } \cdot \text { PNNL } \cdot \text { RCRA } \cdot \text { Solid } \\
\text { Waste } \cdot \text { SNF } \cdot \text { TWRS }\end{array}$} \\
\hline
\end{tabular}

NOTICE: This page is provided subject to our disclaimer. Contact: Oscar Valero at (509) 373-4752.

HNF-EP-0918 rev. 1 Approved for public release; distribution is unlimited. 


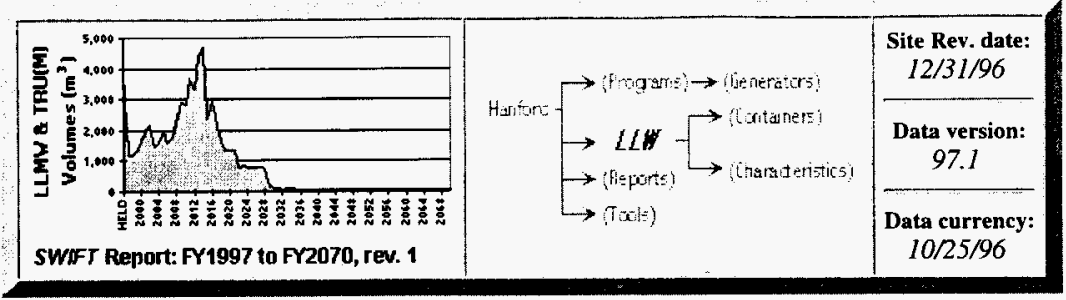

\section{FY97 Forecast of LLW}

\section{Contents}

» Highlights

» Annual Volumes

»Summary Table
»Comparison to Previous Baseline(s)

»LLW Definitions

\section{Highlights}

- A total of $152,540 \mathrm{~m}^{3}$ of LLW is forecast for shipment to Hanford Waste Management (WM) by onsite and offsite generators.

- This forecast shows a $57 \%$ reduction from the FY96 forecast of $353,160 \mathrm{~m}^{3}$, reflecting large waste volume reductions from Offsite, PNNL, and RCRA programs.

- CH_LLW is the main waste class, representing $94 \%$, or $144,010 \mathrm{~m}^{3}$ of the total LLW volume.

- TWRS program is the main source of LLW, accounting for $42 \%$, or $63,600 \mathrm{~m}^{3}$ of the total waste volume.

- The annual baseline, minimum, and maximum graph shows that most of the LLW volume is expected to be generated between 1997 and 2029, reflecting the scheduled activities of TWRS and Analytical Services program.

- Of the $152,540 \mathrm{~m}^{3} \mathrm{LLW}$ forecast, $52 \%$ will be shipped in MB-Vs, $12 \%$ in small boxes, $12 \%$ in 208 -liter drums, $8 \%$ in MB-IVs, and $16 \%$ in other containers.

- Of this waste, $92 \%$ will be debris, $4 \%$ will be inorganic homogenous solids, $3 \%$ will be soil and gravel, and $1 \%$ will be other physical waste forms. 


\section{Program Distribution}

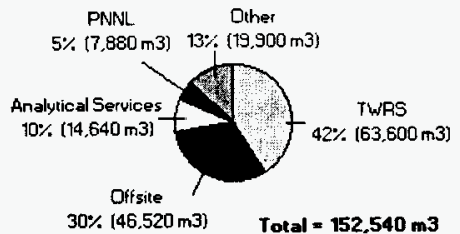

\section{Physical Waste Form Distribution}

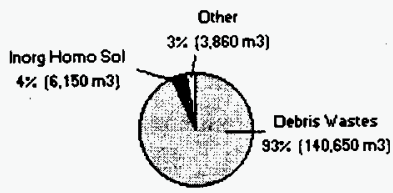

Total $=152,540 \mathrm{~ms}^{3}$

\section{Container Distribution}

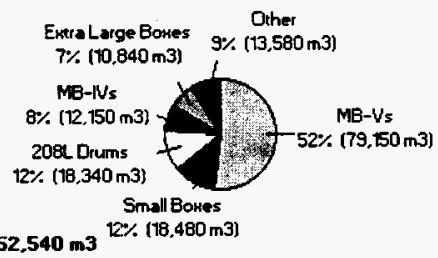

Sum of totals may not add due to rounding: numbers over $10 \mathrm{~m}^{3}$ are rounded to the nearest $10 \mathrm{~m}^{3}$, numbers less than $10 \mathrm{~m}^{3}$ are rounded to integers, non-zero numbers less than 1 are rounded to 1 .

\section{Annual LLW Volumes}

\section{LLW Annual Baseline Volumes}

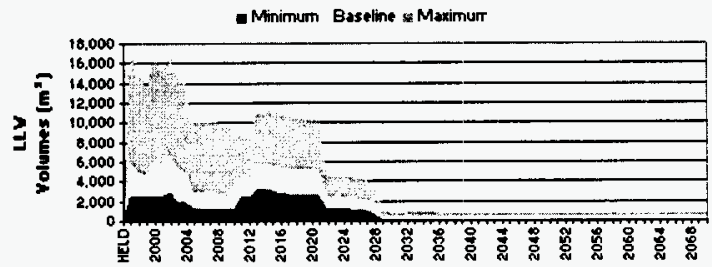




\section{Summary Table (Volumes in $\mathbf{m}^{3}$ )}

Forecast by Programmatic Area (in descending order by program and generator volume)

\begin{tabular}{|c|c|c|}
\hline $\begin{array}{l}\text { LUV Foreoast: } \\
\text { Program }\end{array}$ & $\begin{array}{c}\text { FY97.1 } \\
\text { Forecast } \\
\text { (m'] }\end{array}$ & $\begin{array}{l}x \text { of } \\
\text { Total }\end{array}$ \\
\hline TWRS & 63,600 & $42 \%$ \\
\hline Offsile & 46,520 & $30 \%$ \\
\hline Analutical Services & 14,640 & $10 \%$ \\
\hline PNNL & 7.880 & $5 \%$ \\
\hline Facility Transitions & 6470 & $4 \%$ \\
\hline Liquid EFsluent & 5.490 & $4 \%$ \\
\hline Solid W/aste & 3500 & $2 \%$ \\
\hline Non-Plogrammatic & 2,330 & $2 \%$ \\
\hline Spent Nuclear Fuel & 1,990 & $1 \%$ \\
\hline RCRA Monitoring & 130 & $<1 \%$ \\
\hline Tord & 152.510 & rotes \\
\hline
\end{tabular}

Sum of totals may not add due to raunding: numbers over $10 \mathrm{~m}^{3}$ are rounded to the nearest $10 \mathrm{~m}^{3}$, numbers less than $10 \mathrm{~m}^{3}$ are rounded to integers, non-zero numbers less than 1 are rounded to 1.

\section{Comparison to Previous Baseline(s)}

As in previous forecasts, all of the major program areas are expected to generate LLW. Although the volumes of LLW are considerably greater than the LLMW and TRU(M) waste volumes, they do not represent as great a concern because the vast majority of this waste can be sent directly to disposal. Therefore, it is unlikely that the LLW volumes presented will have a significant impact on the solid waste system.

The FY97.1 forecast of $152,540 \mathrm{~m}^{3}$ of LLW waste shows a $57 \%$ decrease from the FY96 forecast of $353,510 \mathrm{~m}^{3}$. This decrease reflects the significant waste volume reductions from Offsite, PNNL, and RCRA programs. The LLW volume reductions from these 3 programs account for almost the entire reduction of LLW volume for Hanford.

In the case of Offsite program, the LLW reductions are due to the fact that a number of sites no longer intend to send waste to the CWC for storage and disposal. For PNNL and RCRA generators, the waste volume reductions are due to reduced life cycles and changes in planning assumptions.

The FY97.1 Volume changes result from minor offsite and Facility Transitions changes. PNNL's reduced volumes are due to the transfer of 324 and 327 Buildings to the Facility Transitions Program. The amount of waste volume reduction and reasons for the decrease are further explained in each of the program and waste generator pages.

\section{Comparison to Previous Baseline(s) by Program}




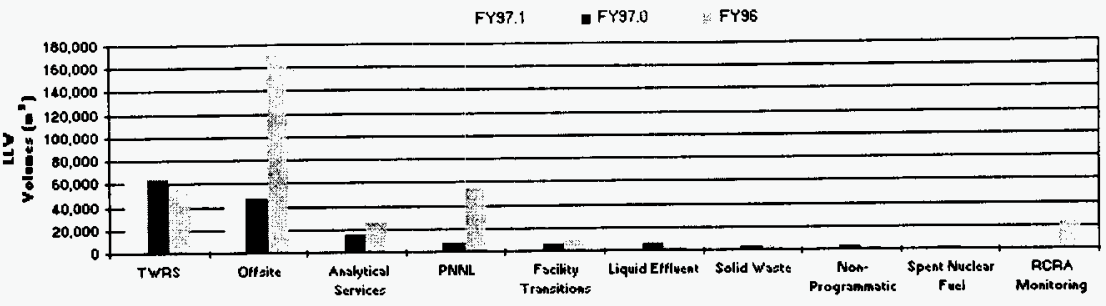

\begin{tabular}{|c|c|c|c|}
\hline $\begin{array}{l}\text { LLY Comparison: } \\
\text { Progtan }\end{array}$ & $\begin{array}{c}\text { FYa7.1 } \\
\text { Forecast } \\
{\left[\mathrm{m}^{3}\right]}\end{array}$ & $\begin{array}{c}\text { FY97.0 } \\
\text { Forecast } \\
\text { (m') }\end{array}$ & $\begin{array}{c}\text { FY96 } \\
\text { Forecast } \\
\text { (mi) }\end{array}$ \\
\hline TYRS $\ldots . .$. & 63.600 & 63,600 & 58.110 \\
\hline Low Leyel Vitrification Proiect & 34.550 & 34560 & 13,250 \\
\hline Hilgh Level Vitrifiestion Proiest & 20,880 & 20,880 & 25,650 \\
\hline SST!DST T ank Farm Opetations & 7.490 & .7490 & 9,640 \\
\hline SSTRetrieval(149(4nks) & 600 & 600 & 600 \\
\hline Innk Farm Restoration & 60 & so & 0 \\
\hline DST RetrieyslSystens (10.tenks). & 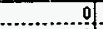 & . & 1980 \\
\hline W430STRetrieyal (1? Tanks) & 0 & 0 & 670 \\
\hline Cross-She Tiznsfer System & 苛 & o) & 120 \\
\hline Tank F arm Yentilation Upgrade.... & . & 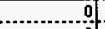 & 30 \\
\hline Tonk Waste Pretresement Focility. & 0 & 0. & 7,000 \\
\hline SST Tenk 106-C sluioing & of & o] & 170 \\
\hline DST 101:AZRetrieyt... & ........... & of & $\ldots . . . .4$ \\
\hline 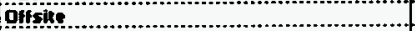 & 46,520 & 46.500 & 170,830 \\
\hline Algonne National Liboratory East & 20,040 & 20,040 & 20,420 \\
\hline Lawreque Berkelen Leboratory & 11.520 & 11.520 & 10,870 \\
\hline Princeton Plasma Physics Lab. & +030 & 4040 & 78,000 \\
\hline Brookhaven National L boratory & 3,090 & $3,090^{\circ}$ & 74,890 \\
\hline Fermi Nationg Acoelerato: Leporatory. & 1.520 & 1,520 & 3,350 \\
\hline Syonford Line Accelerator Centet..... & 1170 & 1.170 & 1750 \\
\hline Rockwell-Canogapark & t.150 & 1,150 & 930 \\
\hline Battede Coturntus Laboratories. & 1,030 & 1.030 & 1,270 \\
\hline Universiky of Chatoinia - Qayis & 980 & 990 & 1870 \\
\hline General Alornics & 660 & 660 & 850 \\
\hline Knolls Alomic Power:Shipyards. & 320 & 320 & 240 \\
\hline Portsmouth Energy Systems..... & 310 & 310 & 34810 \\
\hline Bettis Alomic Pomer-Laboratory & 210 & 210 & \\
\hline Rocky Flats & 180 & 180 & 220 \\
\hline Ames Laboratory-Ames lowa. & 130. & .1200 & .110 \\
\hline Paducah Enorgu Sustems & 70 & 701 & \\
\hline
\end{tabular}




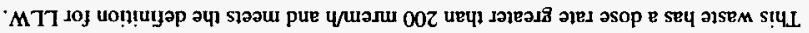

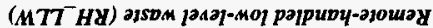

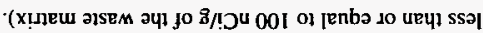

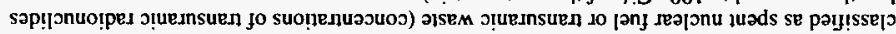

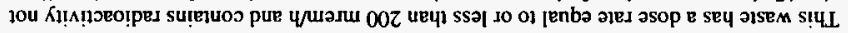

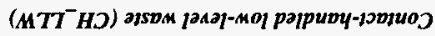

suọ̣!̣ฏəa

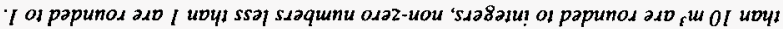

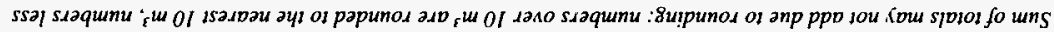

\begin{tabular}{|c|c|c|c|}
\hline dof $x$ & $20 x^{2} 3 y$ & 001237 & ProI \\
\hline $0\lfloor\leq \ldots . . . .$. & 0 & $0 \ldots \ldots$ & son!lat y sn|duns \\
\hline oili & 0 & ö. & ofivi \\
\hline $00 \bar{s}^{\prime} z z^{-}$ & óci & ö́ci & Buning \\
\hline $009^{\prime} z z$ & $0 \varepsilon !$ & $0 \varepsilon !$ & 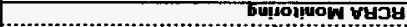 \\
\hline 0 & $\dddot{0096}$ & 096 & suouge \\
\hline 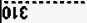 & 1 & $0800^{\circ}$ & 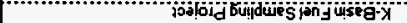 \\
\hline 0Zs' & 006 & $0 \sec ^{\circ} 1$ & pong stoponn judeds \\
\hline $0 \varepsilon$ & ö & os & 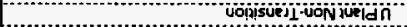 \\
\hline $0 \mathrm{~g}$ & $\ddot{\alpha} \vec{g}$ & $\ddot{0} \ddot{g}$ & 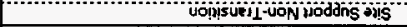 \\
\hline $0 L$ & 02 & $O L$ & 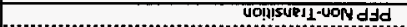 \\
\hline 08 & 08 & 08 & uópisueitivonjued \\
\hline 06 & 06 & $106^{\circ}$ & 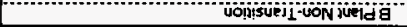 \\
\hline 001 & $00 !$ & $00 t$ & 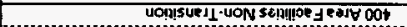 \\
\hline bii & öii & $0<i$ & 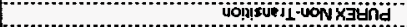 \\
\hline $00 \tilde{\varepsilon}$ & $00 \bar{\varepsilon}$ & 000 & 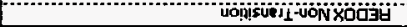 \\
\hline $02+1$ & ozt'i & $02+1$ & 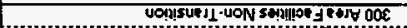 \\
\hline očz & ocez & $\operatorname{acc} 2$ & 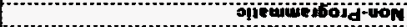 \\
\hline $0 i$ & 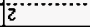 & $i$ & 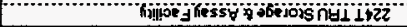 \\
\hline $09+$ & at & $0+$. & 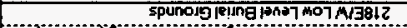 \\
\hline 0 & ose & $06 \hat{\varepsilon}$ & 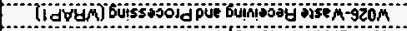 \\
\hline 029 & $0<0^{\prime}$ & 020 & 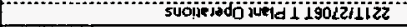 \\
\hline $060 \varepsilon$ & Dog'E & $\overline{00 g} \varepsilon$ & MSEA PHOS \\
\hline $0 z i^{\cdots}$ & 0 & 0 & 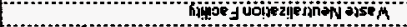 \\
\hline $0^{\circ}$ & 08 & 08 & 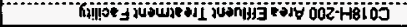 \\
\hline $09 \varepsilon^{\prime}$ & otrs & $01+9$ & 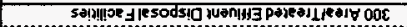 \\
\hline 080. & $06 \%$ & osts & jugnija pinbij \\
\hline $0^{6}$ & $i$ & ina... & 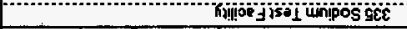 \\
\hline 0 & 02 & $0 L$ & 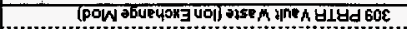 \\
\hline 0 & 0 & 08 & 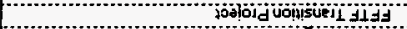 \\
\hline 6 & öiz & $0 \ddot{z z}$ & 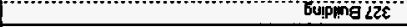 \\
\hline 0 & 0,2 & $0 \angle 2$ & vued $89 \mathrm{gzz}$ \\
\hline 060 & ös & $06 \bar{c}$ & süopicisado xän d vicoz \\
\hline $0 \mathrm{q} 2$ & ösiz & 000 & 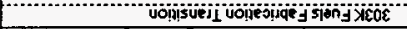 \\
\hline 0 & 096 & $09 t$ & (2) \\
\hline 0 & 069 & 069 & vuippiä ize \\
\hline 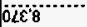 & 0886 & 088 & 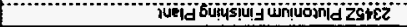 \\
\hline 00976 & OzE's & $0<+9$ & suopusued hnoes \\
\hline $0 \ddot{z} z \bar{s}$ & 088 & 088 & 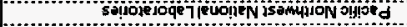 \\
\hline $08 z \varepsilon$ & $088^{2} L$ & $008 i$ & inirid \\
\hline OG! & 09 & 09 & 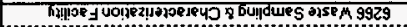 \\
\hline ogs $9 \mathrm{z}$ & $069+1$ & $069 i$ & 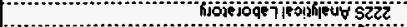 \\
\hline oicisiz & $0+9^{\circ}+i$ & otgiti & 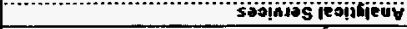 \\
\hline 02 & 2 & 2 & 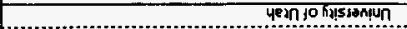 \\
\hline 084 & öt & 0 & 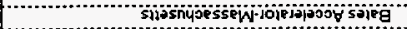 \\
\hline ât. & $\ddot{\partial g}$ & og & spierdins amod oivojy sinag \\
\hline
\end{tabular}




\section{WASTE Classes:}

CH_LLMW $\cdot$ RH_LLMW $\cdot$ CH_TRU(M) $\cdot$ RH_TRU(M) $\cdot$ GTC III $\cdot L L W \cdot H A Z$

\section{CHARACTERISTICS:}

CH_LLMW $\cdot$ RH_LLMW $\cdot$ CH_TRU(M) $\cdot$ RH_TRU(M) . GTC III $\cdot$ LLW $\cdot$ HAZ

\section{CONTAINERS:}

CH_LLMW $\cdot$ RH_LLMW $\cdot$ CH_TRU(M) . RH_TRU(M) $\cdot$ GTC III $\cdot$ LLW $\cdot$ HAZ

\section{P'ROGRAMS:}

Analytical Services - EM-40 - Facility Transitions · Landlord - Liquid Effluent - NP · Offsíte - PNNL - RCRA · Solid Waste $\cdot$ SNF $\cdot$ TWRS

Home - Contents - Web Site Map · Glossary · Help · Reports · Data Requests · Feedback Form

NOTICE: This page is provided subject to our disclaimer. Contact: Oscar Valero at (509) 373 4752.

HNF-EP-0918 rev. 1 Approved for public release; distribution is unlimited. 


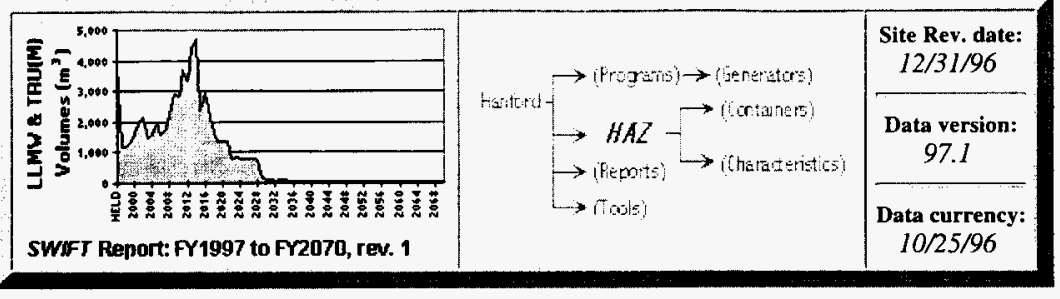

\section{Hazardous Waste (HAZ)}

\section{Contents}

» Highlights $\quad$ Summary Table

\section{Highlights}

- A total of $2,770 \mathrm{~m}^{3}$ of hazardous waste has been forecast for management by CWC; other Hanford-generated hazardous waste will be shipped offsite for disposition.

- Hazardous waste is waste defined under the Washington Administrative Code 173-303.

- Of the $2,770 \mathrm{~m}^{3}$ of hazardous waste that has been forecast for management by CWC, $96 \%\left(2660 \mathrm{~m}^{3}\right)$ will be shipped in 208-liter drums. The remaining $4 \%$ will be shipped in 114-liter drums, 322-liter drums, other drums, medium boxes, and small boxes.

\section{Summary Table (Volumes in $\mathbf{m}^{3}$ )}

Forecast by Programmatic Area (in descending order by program and generator volume)

\begin{tabular}{|c|c|c|}
\hline $\begin{array}{l}\text { Hazardous Vaste Forecost: } \\
\text { Program }\end{array}$ & $\begin{array}{l}\text { FY97.1 } \\
\text { Forecast } \\
\text { (m) }\end{array}$ & $\begin{array}{l}x \text { of } \\
\text { Total }\end{array}$ \\
\hline TWRS & 2,380 & $86 \%$ \\
\hline RCRA Monitoring & 150 & $5 \%$ \\
\hline Analutical Services & 120 & $4 \%$ \\
\hline Liquid EFfluent & 80 & $3 \%$ \\
\hline Solid W/aste & 30 & $1 \%$ \\
\hline Facility Transitions & 10 & $<1 \%$ \\
\hline Tord & 2.770 & soles \\
\hline
\end{tabular}

Sum of totals may not add due to rounding: numbers over $10 \mathrm{~m}^{3}$ are rounded to the nearest $10 \mathrm{~m}^{3}$, numbers less than $10 \mathrm{~m}^{3}$ are rounded to integers, non-zero numbers less than 1 are rounded to $l$. 


\section{WASTE CLASSES:}

CH_LLMW $\cdot$ RH_LLMW $\cdot$ CH_TRU(M) $\cdot$ RH_TRU(M) $\cdot$ GTC III $\cdot$ LLW $\cdot$ HAZ

CHARACTERISTICS:

CH_LLMW $\cdot$ RH_LLMW $\cdot$ CH_TRU(M) $\cdot$ RH_TRU(M) . GTC III $\cdot$ LLW $\cdot$ HAZ

\section{CONTAINERS:}

CH_LLMW $\cdot$ RH_LLMW . CH_TRU(M) . RH_TRU(M) $\cdot$ GTC III $\cdot$ LLW $\cdot$ HAZ

\section{PROGRAMS:}

Analytical Services - EM-40 - Facility Transitions - Landlord - Liquid Effluent - NP - Offsite - PNNL - RCRA - Solid Waste $\cdot$ SNF $\cdot$ TWRS

Home · Contents · Web Site Map · Glossary · Help · Reports - Data Requests · Feedback Form

NOTICE: This page is provided subject to cur disclaimer. Contact: Oscar Valero at (509) 373-4752.

HNF-EP-0918 rev. 1 Approved for public release; distribution is unlimited. 


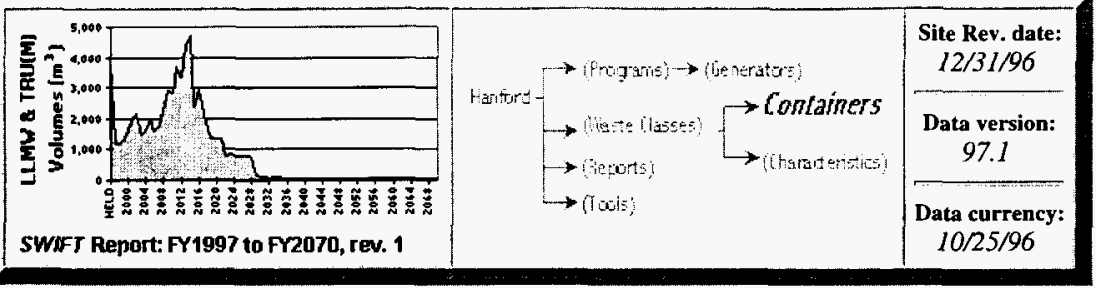

\section{Container Summary}

\section{Contents}
》 Links to Specific Waste Class Container Data
"Summary Tables
" Highlights
»Comparison to Previous Baseline(s)
»Annual Container Volumes
»Container Definitions

\section{Links to Specific Waste Class Container Data}

\begin{tabular}{|l|l|l|}
\hline CH_LLMW Containers & CH_TRU(M) Waste Containers & LLW Containers \\
\hline RH_LLMW Containers & RH_TRU(M) Waste Containers & HAZ Waste Containers \\
\hline
\end{tabular}

\section{Highlights}

- A total of $67,630 \mathrm{~m}^{3}$ of LLMW and TRU(M) waste is forecast for shipment to the Hanford Waste Management Project by onsite and offsite generators. Of this waste, most will be shipped in 208-liter boxes $(40 \%)$ and LECs $(40 \%)$.

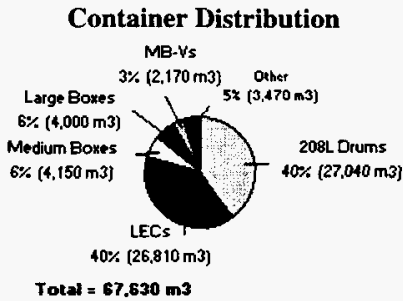

Sum of totals may not add due to rounding: numbers over $10 \mathrm{~m}^{3}$ are rounded to the nearest $10 \mathrm{~m}^{3}$, numbers less than $10 \mathrm{~m}^{3}$ are rounded to integers, non-zero numbers less than 1 are rounded to 1 .

\section{Annual Container Volumes}

Life Cycle Volumes by Container 
The total baseline volume of waste is approximately $67,630 \mathrm{~m}^{3}$. The minimum expected volume is approximately $37,680 \mathrm{~m}^{3}$, and the maximum expected volume is $108,280 \mathrm{~m}^{3}$. The minimum, baseline, and maximum waste forecast volumes are distributed as follows:

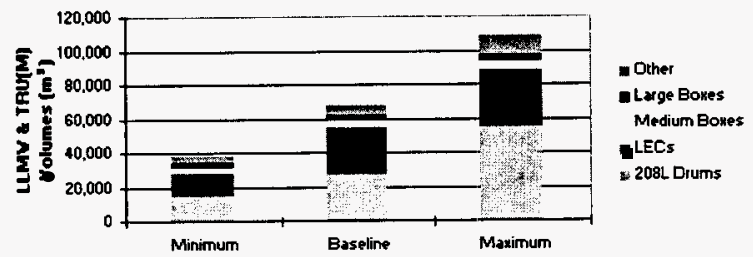

\section{Annual Baseline Volumes by Container}

The graph shows the LLMW and TRU(M) waste volume for 1997 through 2070. Waste generation will peak in 2013-2014, due primarily to retrieval of the long-length contaminated equipment (from the TWRS program), which will be shipped in LECs. Waste volume from 2038 through 2070 is virtually constant at about $50 \mathrm{~m}^{3}$. The only facility operating during this period will be the $222 \mathrm{~S}$ Analytical Laboratory which will be shipping its waste in 208-liter ( > $99 \%$ ) and other drums.

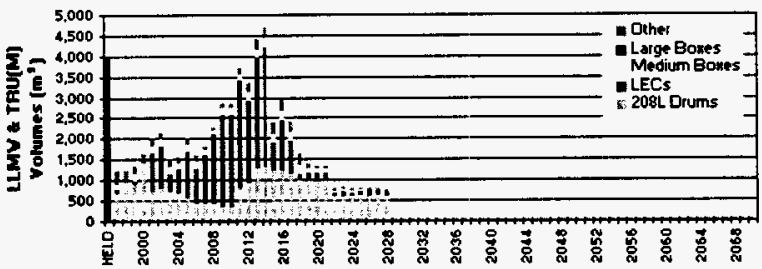

\section{Summary Tables (Volumes in $\mathbf{m}^{\mathbf{3}}$ )}

\section{Forecast by Container Type}

(in descending order by container volume) 


\begin{tabular}{|c|c|c|}
\hline Container & $\begin{array}{c}97.1 \text { Forecast } \\
\left(\mathrm{m}^{\prime}\right)\end{array}$ & $\begin{array}{l}X \text { of } \\
\text { Tatal }\end{array}$ \\
\hline 208L Drums & 27,040 & $40 x$ \\
\hline LECs & 26810 & $40 x$ \\
\hline Medium Boxes & 4,150 & $6 x$ \\
\hline Large Boxes & 4.000 & $6 x$ \\
\hline Me.vs & 2.170 & $3 x$ \\
\hline SWBS & 1,610 & $2 x$ \\
\hline Small Boxes & 1,440 & $2 x$ \\
\hline MB.lvs & 210 & $0 x$ \\
\hline 322 Lrums & 130 & $0 x$ \\
\hline Exua L arge Bokes & 60 & $0 x$ \\
\hline Othet Drums & 20 & $0 x$ \\
\hline 114L Drums & 1 & $0 x$ \\
\hline $\begin{array}{r}\text { Total } \\
\end{array}$ & 67,630 & $100 x$ \\
\hline
\end{tabular}

Sum of totals may not add due to rounding: numbers over $10 \mathrm{~m}^{3}$ are rounded to the nearest $10 \mathrm{~m}^{3}$, numbers less than $10 \mathrm{~m}^{3}$ are rounded to integers, non-zero numbers less than I are rounded to $I$.

\section{Life Cycle Baseline Volumes}

(in descending order by Program and Generator volume)

\begin{tabular}{|c|c|c|c|c|c|c|c|}
\hline $\begin{array}{l}\text { LLMY \& TRU(M) Waste Containers: } \\
\text { Progran }\end{array}$ & 208L & LEC & $\begin{array}{c}\text { Medium } \\
\text { Bo: }\end{array}$ & $\begin{array}{l}\text { Large } \\
\text { Bos }\end{array}$ & MBYY & Deher & Total \\
\hline TWRS & 14,950 & 26,810 & 3.880 & 0 & 2.170 & 2,300 & 50.120 \\
\hline Non-Programmatic & 1,350 & 0 & O & 7,000 & 0 & 1600 & 5,510 \\
\hline Faility Transikions & 3,480 & 0 & 50 & 年 & ô & 436 & 3,970 \\
\hline Bnalytical Services & 3,560 & 0 & 0 & $\overline{0}$ & 0 & 60 & 3.610 \\
\hline Liquid Ériluent & 2,540 & 0 & 0 & 0 & ô & o. & 2,540 \\
\hline PNNLL & 600 & 0 & 0 & 0 & 0 & 300 & 900 \\
\hline Solid Waste & 190 & 0 & 210 & 0 & 6 & 0 & 400 \\
\hline$E M-40$ & 240 & 0 & 0 & ô & (n) & ôf & 240 \\
\hline Offsite & 70 & 0 & 0 & 0 & 0 & 130 & 210 \\
\hline Spent Nuclear Fue & 5 & 0 & 0 & 0 & 0 & 80 & 80 \\
\hline RCRA Monikoting & 50 & 0 & 0 & 0 & 0 & 10 & 60 \\
\hline Tater & 27,9 & 25810 & 1,150 & 40 & 200 & 347 & 676 \\
\hline
\end{tabular}

Sum of totals may not add due to rounding: numbers over $10 \mathrm{~m}^{\mathrm{s}}$ are rounded to the nearest $10 \mathrm{~m}^{3}$, numbers less than $10 \mathrm{~m}^{3}$ are rounded to integers, non-zero numbers less than $I$ are rounded to $I$.

\section{Comparison to Previous Baseline(s)}

This year both 208 liter drums and LECs are the most used containers. Last year, 208 liter drums were second to the LECs. The change was caused by significant reductions in RH_TRU(M) and CH_LLMW wastes in LECs from the Single Shell Tank Long Length Equipment retrievals among the TWRS program. Also, Unknown boxes are not reported in this year's forecast. The two generators, Non-Programmatic Stored Equipment and PNNL, have redesignated their containers as Large and Small boxes, respectively. Lastly, SWBs are relatively less of the whole due mostly to TWRS HLVP reductions.

Of the total waste volume, these container types are not interspersed within each waste category; rather, a single waste category often represents the major use of a single container. For example, 69\% of CH_LLMW is forecast to be shipped in 208 liter drums. This amount also represents $78 \%$ of the total Hanford-wide use of 208 liter drums. LEC containers are $88 \%$ of the containers used for RH_LLMW and $96 \%$ of all the LECs coming to Hanford. The other striking example is that the volume in Large boxes is nearly all (99\%) CH_LLMW. 
The 1996 forecast showed the same occurrence but with different waste classes and containers. All of the Unknown boxes were CH_LLMW. All of the Small boxes were RH_LLMW. All of the Extra-Large boxes were RH_TRU(M), and all of the MB-V boxes

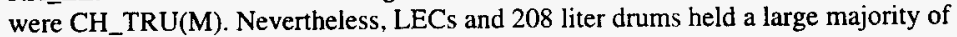
CH_LLMW, similar to this year's forecast.

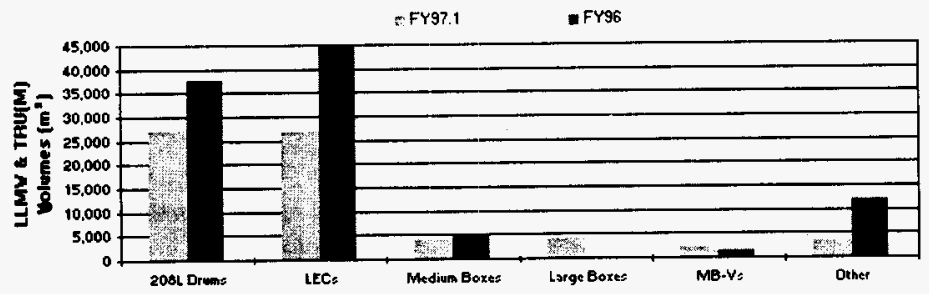

(in descending order by container volume)

\begin{tabular}{|c|c|c|}
\hline $\begin{array}{l}\text { LLMY \& TRutM) Yaste Comparison: } \\
\text { Containers }\end{array}$ & $\begin{array}{c}\text { FY } \$ 7.1 \\
\text { Forecas: }\left(\mathrm{m}^{2}\right)\end{array}$ & $\begin{array}{c}\text { Frse } \\
\text { Foreoast (ms) }\end{array}$ \\
\hline 208 Drums & 27.040 & 37.680 \\
\hline LECs & 26,810 & 4.630 \\
\hline Medium Bones & 4,150 & 5.010 \\
\hline Large Boxes & 4,000 & \\
\hline $\mathrm{MB} \mathrm{Ys}_{\mathrm{s}}$ & 2,170 & 1,610 \\
\hline SWEs & 1,610 & 2,530 \\
\hline Small Boyes & 1,440 & 1,710 \\
\hline MB-lYs & 210 & 50 \\
\hline 3221 Drums & 130 & 400 \\
\hline Extra Large Bones & 60 & 40 \\
\hline Qther Diums & 20 & 10 \\
\hline 114 L Drums & 1 & - \\
\hline Unknown Bo* & 0 & 7,230 \\
\hline Tard & $67.0 \times 8$ & 30 \\
\hline
\end{tabular}

Sum of totals may' not add due to rounding: numbers over $10 \mathrm{~m}^{3}$ are rounded to the nearest $10 \mathrm{~m}^{3}$, numbers less than $10 \mathrm{~m}^{3}$ are rounded to integers, non-zero numbers less than 1 are rounded to 1.

\section{Definitions}

For the 1997 forecast, 12 different container types have been reported for solid waste shipment to Waste Management during its life cycle. The following is a brief description of these containers:

114-liter drum: This is a small standard drum equivalent to 30 U.S. gallons.

208-liter drum: This is a standard-size drum equal to 55 U.S. gallons.

322-liter drum: Often used as an overpack for 208 liter drums, this is a large standard-size drum equivalent to 85 U.S. gallons.

Extra-large box: This shipping container is defined by an external volume greater than $28.3 \mathrm{~m}^{3}(1,000$ $\mathrm{ft}^{3}$ ). Boxes of this size are too big to be accepted at the STP treatment facility.

Large box: The size of this container is defined as greater than $16.3 \mathrm{~m}^{3}$ and less than $28.3 \mathrm{~m}^{3}$ in external volume $\left(576-1,000 \mathrm{ft}^{3}\right)$. This size is too large to be accepted at the STP facility.

Long-length equipment container (LEC): These containers vary in size, but are used only for 
equipment retrieved from the Hanford Tank. Farms. The waste in these containers will be almost all RH_LLMW.

MB-IV: This metal box measures $1.95 \mathrm{~m}$ long by $1.32 \mathrm{~m}$ wide by $1.11 \mathrm{~m}$ high.

MB-V: Made of either metal or plywood, this box measures $2.43 \mathrm{~m}$ long by $1.22 \mathrm{~m}$ wide by $1.33 \mathrm{~m}$ high.

Medium box: Any size in between an external volume of 3.6 and $16.3 \mathrm{~m}^{3}\left(128-576 \mathrm{ft}^{3}\right)$ classifies as a medium box. All Medium boxes can he handled by STP treatment facility.

Other drums: This category represents various container sizes used less often than the standard drums, such as 57-liter drums, 76-liter drums, or 416 -liter drums.

Small box: A small box has an external volume less than $3.6 \mathrm{~m}^{3}\left(128 \mathrm{ft}^{3}\right)$.

Standard waste box (SWB): This container is used only for TRU(M) waste and is constructed of carbon steel for the Waste Isolation Pilot Plant (WIPP).

\begin{tabular}{|c|c|}
\hline $\begin{array}{l}\text { CHARACTERISTICS: } \\
\text { CH_LLMW } \cdot \text { RH_LLMW } \cdot \text { CH_TRU(M) } \cdot \text { RH_TRU(M) } \\
\text { GTC III } \cdot \text { LLW } \cdot \text { HAZ }\end{array}$ & $\begin{array}{l}\text { CONTAINERS: } \\
\text { CH_LLMW } \cdot \text { RH_LLMW } \cdot \text { CH_TRU(M) } \\
\text { RH_TRU(M) } \cdot \text { GTC III } \cdot \text { LLW } \cdot \text { HAZ }\end{array}$ \\
\hline \multicolumn{2}{|c|}{$\begin{array}{c}\text { WASTE CLASSES: } \\
\text { CH_LLMW } \cdot \text { RH_LLMW } \cdot \text { CH_TRU(M) } \cdot \text { RH_TRU(M) } \cdot \text { GTC III } \cdot \text { LLW } \cdot \text { HAZ }\end{array}$} \\
\hline \multicolumn{2}{|c|}{$\begin{array}{l}\text { PROGRAMS: } \\
\text { Analytical Services } \cdot \text { EM-40 } \cdot \text { Facility Transitions } \cdot \text { Landlord } \cdot \text { Liquid Effluent } \cdot \text { NP } \cdot \text { Offsite } \cdot \text { PNNL } \cdot \text { RCRA } \cdot \text { Solid } \\
\text { Waste } \cdot \text { SNF } \cdot \text { TWRS }\end{array}$} \\
\hline
\end{tabular}

NOTICE: This page is provided subject to our disclaimer. Contact: Oscar Valero at (509) 373-4752. HNF-EP-0918 rev. 1 Approved for public release; distribution is unlimited. 
THIS Mand 


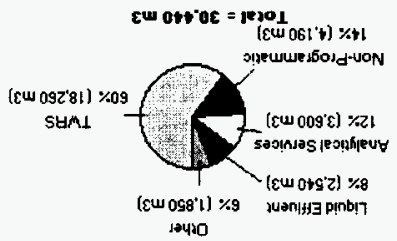

uo!̣nq!มฺ!

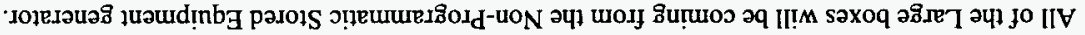

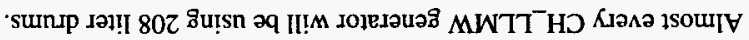

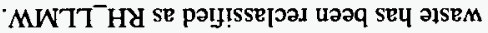

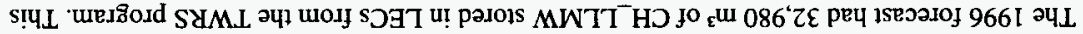

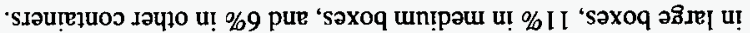

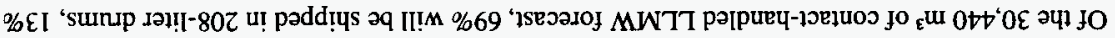

ร148ิ!|บฮి!ก

sगqqe L Kreuruns «

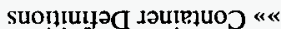

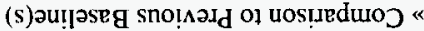

soun[O $\Lambda$ MWTT HD [enuUY «

ง]บสิโโบชิ!H *

sาuวาuo

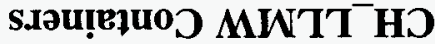

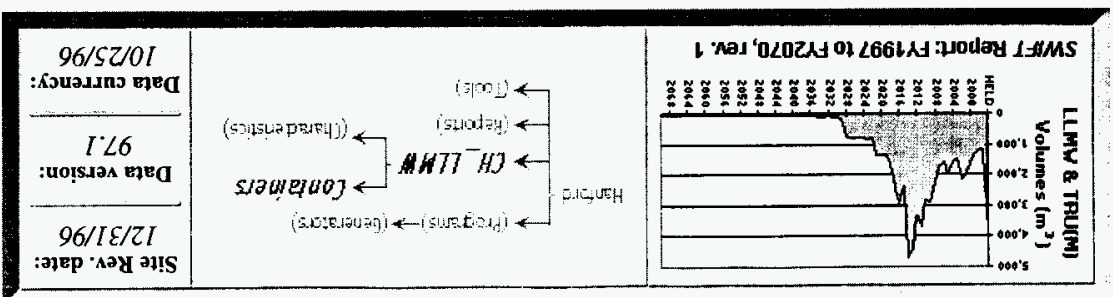



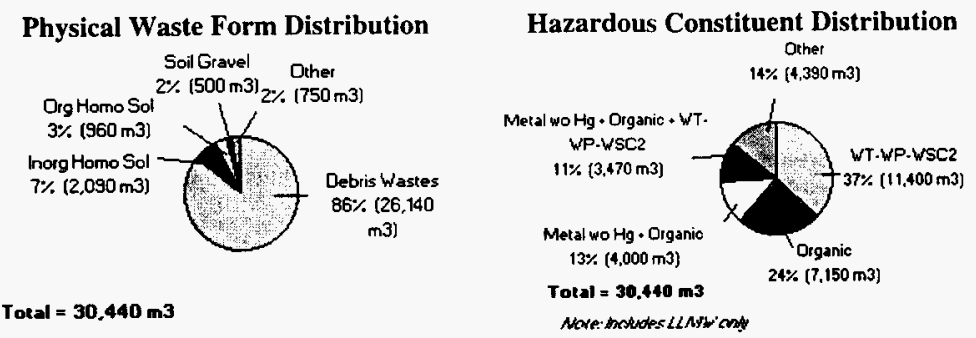

\section{Container Distribution}

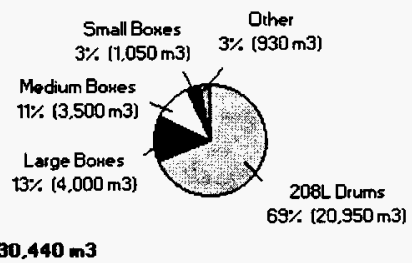

Sum of totals may not add due to rounding: numbers over $10 \mathrm{~m}^{3}$ are rounded to the nearest $10 \mathrm{~m}^{3}$, numbers less than $10 \mathrm{~m}^{3}$ are rounded to integers, non-zero numbers less than 1 are rounded 101 .

\section{Annual CH_LLMW Volumes}

\section{CH_LLMW Life Cycle Volumes by Container}

The total baseline volume of waste is approximately $30,440 \mathrm{~m}^{3}$. The minimum expected volume is approximately $19,180 \mathrm{~m}^{3}$, and the maximum expected volume is $53,080 \mathrm{~m}^{3}$. The minimum, baseline, and maximum waste forecast volumes are distributed as follows:

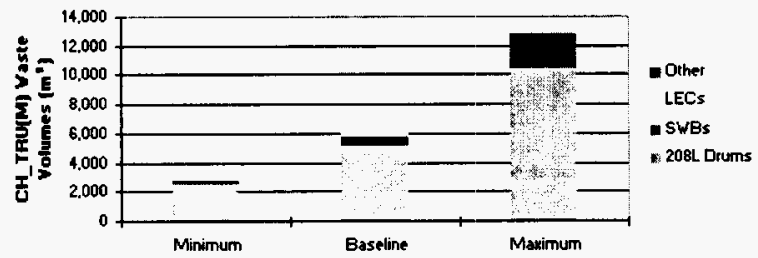

\section{CH_LLMW Annual Baseline Volumes by Container}

The graph shows the CH_LLMW volume for 1997 through 2070 . The $4,000 \mathrm{~m}^{3}$ of Held waste in large boxes is from the Stored Equipment waste generator. This waste currently exists but does not have a shipping schedule; thus, it is reported as Held waste. The remaining waste will 
be sent primarily in 208-liter drums and medium boxes. Waste generation will peak in 2014-2016, due primarily to waste associated with the retrieval of the long-length contaminated equipment. Waste volume from 2038 through 2070 is virtually constant at about $50 \mathrm{~m}^{3}$. The only facility operating during this period will be the $222 \mathrm{~S}$ Analytical Laboratory which will be shipping its waste in 208 -liter (>99\%) and other drums.

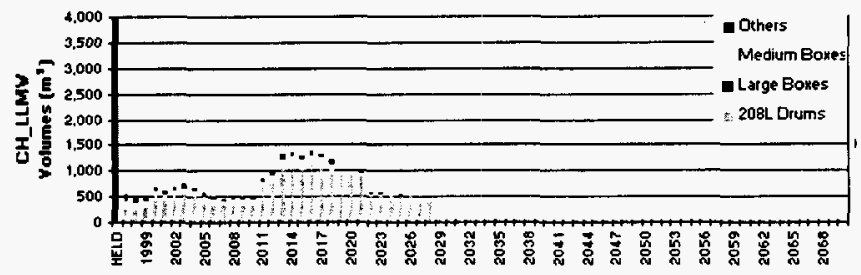

\section{Summary Tables (Volumes in $\mathbf{m}^{\mathbf{3}}$ )}

\section{Forecast by Container Type}

(in descending order by container volumes)

\begin{tabular}{|c|c|c|}
\hline $\begin{array}{l}\text { CH_LLMY Forooast: } \\
\text { Containers }\end{array}$ & $\begin{array}{l}37.1 \text { Foreesst } \\
\text { (m') }\end{array}$ & $\begin{array}{l}\text { tor } \\
\text { Tored }\end{array}$ \\
\hline $208 \mathrm{~L}$ Drums & 20,950 & sex \\
\hline Large Boyes & 4,000 & $r 2 x$ \\
\hline Medium Boxes & 3,500 & 112 \\
\hline Small Boyes & 1,050 & $x$ \\
\hline MB-Ys & 570 & $2 x$ \\
\hline MB.rvs & 210 & $\operatorname{ce}$ \\
\hline $322 L$ Diurns & 130 & $<18$ \\
\hline Other Drums & 20 & 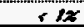 \\
\hline 114LDrums & 1 & 612 \\
\hline Torol & saled & 1000 \\
\hline
\end{tabular}

Sum of totals may not add due to rounding: numbers over $10 \mathrm{~m}^{3}$ are rounded to the nearest $10 \mathrm{~m}^{3}$, numbers less than $10 \mathrm{~m}^{3}$ are rounded to integers, non-zero numbers less than 1 are rounded to 1 .

\section{Life Cycle Baseline Volumes}

(in descending order by Program and Generator Volumes) 


\begin{tabular}{|c|c|c|c|c|c|c|c|}
\hline $\begin{array}{l}\text { CH_LLMV Containers: } \\
\text { Program }\end{array}$ & $\begin{array}{l}208 \mathrm{~L} \\
\text { Drum } \\
\end{array}$ & $\begin{array}{c}\text { Large } \\
\text { Bas }\end{array}$ & $\begin{array}{c}\begin{array}{c}\text { Medium } \\
\text { Box }\end{array} \\
\end{array}$ & $\begin{array}{c}\text { Small } \\
\text { Bos }\end{array}$ & MB-V & Dther & Total \\
\hline TYAS & 13,320 & o & 3,290 & 1.040 & 570 & 40 & 18.260 \\
\hline High Level Vitrific ation Project & 5,220 & 0 & 0 & 0 & 0 & 0 & 5,220 \\
\hline Low Level Yitrilication Project & 5,120 & 0 & - & of & 0 & 0 & 5,120 \\
\hline SSTROST T ank Falm Operations & 850 & of & 1,830 & 1040 & 0 & 40 & 3.760 \\
\hline W3430ST Retrieual (17 Tanks) & $2200^{\circ}$ & . & 920 & 임... & 340 & 0 & 1.480 \\
\hline SST Retrieual (1+9 tanks) & 890] & 0 & of & of & of & of & 890 \\
\hline Tank FarmRestolation & 881 & 0 & 0 & 0 & 0 & 0 & 880 \\
\hline OST Retrieval Systems (10 tanksl. & (130) & 0 & 540 & 0 & 200 & a & 870 \\
\hline Tank F arm Ventilation Upgrade & 3 & 0 & a. & of & 40 & 0 & 40 \\
\hline Cross-Site Itansfer System & 5 & -0 & 0 & of & a & 0 & 5 \\
\hline Non-Programmatic & 180 & 4.000 & of & o. & o & 10 & 4.190 \\
\hline Stored Equipment & - & 4,000 & 0 & o] & 0 & 0 & 4,000 \\
\hline PFP Non-Transition & 80 & 0 & 0 & 0 & a) & 0 & 80 \\
\hline 300 Area Facilities Non-Transition & 6io & 0 & 0 & 0 & of & 1 & 60 \\
\hline PUREX Non-Transition & $300^{\circ}$ & 0 & 0 & of & of & 10 & 50 \\
\hline UPlant Non-Transition & 2 & 0 & 0 & of & of & 1 & 3 \\
\hline REDOXNon-Transition & 1 & 0 & 0 & 0 & 0 & 1 & 2 \\
\hline Anahotical Services & 3.540 & 0 & 0 & a & - & 60 & 3.600 \\
\hline 2225 Amalytical Labotatory & 3,510 & 0 & 0 & of & of & 60 & 3,570 \\
\hline 6266 Vaste Sampling \& Characterization Facility & 30 & a & 0 & 0 & 0 & 0 & 30 \\
\hline Liguid Effluent & 2.540 & 0 & of & 0 & of & (0) & 2.540 \\
\hline C018H-200 Alea Effluent Trearment Facility & 2,540 & of & 0 & 0 & of & 0 & 2540 \\
\hline Facilite Transitions & 770 & 0 & e. & . & e) & 6 & 770 \\
\hline 23452 Plutonium Finishing Plant & 710 & - & 管 & a & 0 & of & 710 \\
\hline Woste Encapsulation'Storage Facility & 30 & 0 & 0 & 0 & 0 & 아. & 30 \\
\hline 324 Building & 20 & 0 & 0 & of & of & 0 & 20 \\
\hline 202A Purex Operations & -7 & 0 & 0 & 势 & of & 5 & 10 \\
\hline 327 Building & 4 & of & . & 0 & a & of & 4 \\
\hline 2258 B Plant & 2 & 0 & 0 & of & of & 0 & \\
\hline FFTF Transition Project & 1 & 0 & a) & 0 & of & 0. & \\
\hline 309PRTR Yaul Waste (lon Exchange Mod) & 1 & 0 & of & 요 & 0 & 0 & 1 \\
\hline 335 Sodium Test Facility & 0 & of & of & o) & . & 1 & \\
\hline PWNL & 370 & 0 & 0 & 0 & 0 & 120 & 490 \\
\hline Pacific Northwest National Laboratories & 370 & 요 & 0 & 0 & of & 120 & 490 \\
\hline Solid Yaste & 110 & of & 210 & of & of & 0 & 310 \\
\hline $221 T / 2706 \mathrm{~T}$ T Plant Operations & 10 & 0 & 210 & - & 0 & 管 & 220 \\
\hline W026-Waste Receiving and Processing (WRAP1) & 80 & . & 0 & 然 & 0 & 0 & 80 \\
\hline Central waste Complex & 30 & . & 0 & 然 & 0 & 0 . & 20 \\
\hline $224 T$ TRU Storage \& Assay Facility & 2 & of & 0 & 0 & 0 & 0 & 2 \\
\hline Offsite & 70 & . & e. & 10 & D. & 310 & 200 \\
\hline Princecon Plasma Physios Lab & 0 & of & of & of & 0 & 60 & 60 \\
\hline Rockwell-Canoga Park & 4 & of & 0 & 10 & 0 & 30 & 50 \\
\hline Puget Sound Naya! Shipyards & 30 & a & 아. & 0 & ㅇ. & 0 & 30 \\
\hline Paducan Energy Systems & 0 & 0 & 0 & 0 & 0 & 20 & 20 \\
\hline Knolls Atomic Power-Laboratoiy & -10 & 0 & of & of & 0 & 1 & 10 \\
\hline Batrelle Columbus Labolatories & 8 & 0 & of & of & of & 0 & 8 \\
\hline General Acomics & 7 & 0 & 0 & 0 & 0 & 0 & $?$ \\
\hline University of Utah & 7 & 0 & 0 & 0 & 0 & a) & 7 \\
\hline Pearl Harbor Nava! Shipyards & 5 & 0 & 0 & of & 0 & ? & 5 \\
\hline Poresmouth Naual Shipyards & 1 & 0 & of & 임 & 0 & 0 & 1 \\
\hline RCAA Monitoring & 50 & 贯 & a & o & - & 10 & 60 \\
\hline Well Drilling & 50 & of & 0 & 0 & 0 & 10 & 60 \\
\hline EM-40 & 10 & . & - & of & o] & o & 10 \\
\hline Surplus Facilities & 10 & 0 & 0 & 0 & 0 & 0. & 10 \\
\hline Seent Nuclear Fuel & 5 & 0 & of & of & 0 & 0 & 5 \\
\hline $100 \mathrm{~K}$ K-Basin Operations & 5 & 0 & 0 & 0 & 0 & 0 & 5 \\
\hline Total & 20.950 & 4.000 & 3.500 & 1.050 & 570 & 361 & 30.440 \\
\hline
\end{tabular}

Sum of totals may not add due to rounding: numbers over $10 \mathrm{~m}^{3}$ are rounded to the nearest $10 \mathrm{~m}^{3}$, numbers less than $10 \mathrm{~m}^{3}$ are rounded to integers, non-zero numbers less than $I$ are rounded to $I$.

\section{Comparison to Previous Baseline(s)}

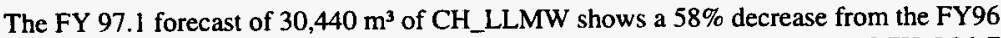
forecast of $73,040 \mathrm{~m}^{3}$. The reduction is due to the elimination of $32,980 \mathrm{~m}^{3}$ of CH_LLMW in 
LECs from the 1996 data. No CH_LLMW will be shipped in LECs since this waste has been reclassified as RH_LLMW. Other container categories have changed as well. First, the Unknown boxes from PNNL are reported to be Small boxes this year. Large boxes are a new CH_LLMW container, coming only from Non-Programmatic Stored Equipment. Also, the group entitled Other containers is reduced in volume due to the TWRS program. Both forecasts report similar volumes for 208 liter drums and Medium boxes.

\section{Comparison to Previous Baseline(s) by Container}

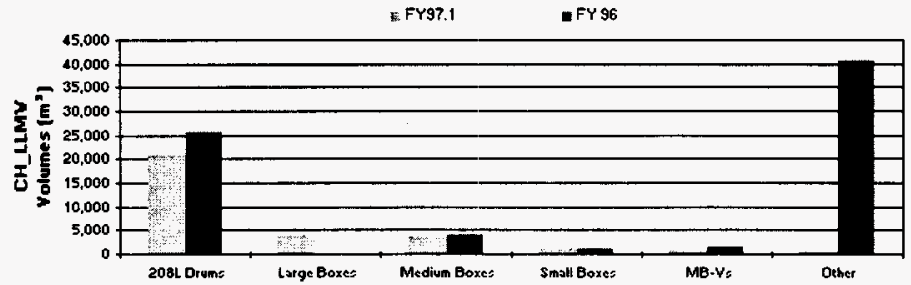

(in descending order by container volumes)

\begin{tabular}{|c|c|c|}
\hline $\begin{array}{l}\text { CH-LLMY Comparison: } \\
\text { Containers }\end{array}$ & $\begin{array}{c}\text { FY } 37.1 \\
\text { Foreeast }\left(\mathrm{m}^{\prime}\right)\end{array}$ & $\begin{array}{c}\text { FY96 } \\
\text { Forecast (m') }\end{array}$ \\
\hline 208L Drums & 20,950 & $\begin{array}{r}25,780 \\
\end{array}$ \\
\hline Large Bowes & 4,000 & 0 \\
\hline Medium Boxes & 3,500 & 3,880 \\
\hline Small Boxes & 1,050 & 1,120 \\
\hline MB-Ys & 570 & 1,610 \\
\hline MB-IVs & 210 & 50 \\
\hline 322L Drums & 130 & 400 \\
\hline Other Drums & 20 & 10 \\
\hline 114L Drums & 1 & 0 \\
\hline LECs & 0 & 32,980 \\
\hline Unknown Box & 0 & 7,230 \\
\hline Torel & $\operatorname{secte}$ & 72,010 \\
\hline
\end{tabular}

Sum of totals may not add due to rounding: numbers over $10 \mathrm{~m}^{3}$ are rounded to the nearest $10 \mathrm{~m}^{3}$, numbers less than $10 \mathrm{~m}^{3}$ are rounded to integers, non-zero numbers less than 1 are rounded to 1.

\begin{tabular}{|c|c|}
\hline $\begin{array}{l}\text { CHARACTERISTICS: } \\
\text { CH_LLMW } \cdot \text { RH_LLMW } \cdot \text { CH_TRU(M) } \cdot R \text { RH_TRU(M) }_{-} \cdot \\
\text { GTC III } \cdot \mathrm{LLW} \cdot \mathrm{HAZ}\end{array}$ & $\begin{array}{c}\text { CONTAINERS: } \\
\mathrm{CH}_{\text {_LLMW }} \cdot \mathrm{RH} \text { RLLMW } \cdot \mathrm{CH} \text { TRU(M) } \\
\mathrm{RH} \text { _TRU }(\mathrm{M}) \cdot \mathrm{GTC} \text { III } \cdot \mathrm{LLW} \cdot \mathrm{HAZ}\end{array}$ \\
\hline \multicolumn{2}{|c|}{$\begin{array}{c}\text { WASTE CLASSES: } \\
\text { CH_LLMW } \cdot \text { RH_LLMW } \cdot \text { CH_TRU(M) } \cdot \text { RH_TRU(M) } \cdot \text { GTC III } \cdot \text { LLW } \cdot \text { HAZ }\end{array}$} \\
\hline $\begin{array}{r}\text { PROGF } \\
\text { Analytical Services } \cdot \text { EM-40 } \cdot \text { Facility Transitions } \cdot \text { Landlo } \\
\text { Waste } \cdot \text { SN }\end{array}$ & Effluent $\cdot$ NP $\cdot$ Offsite $\cdot$ PNNL $\cdot$ RCRA $\cdot$ Solid \\
\hline
\end{tabular}


NOTICE: This page is provided subject to our disclaimer. Contact: Oscar Valero at (509) 373-4752.

HNF-EP-0918 rev. I Approved for public release; distribution is unlimited. 


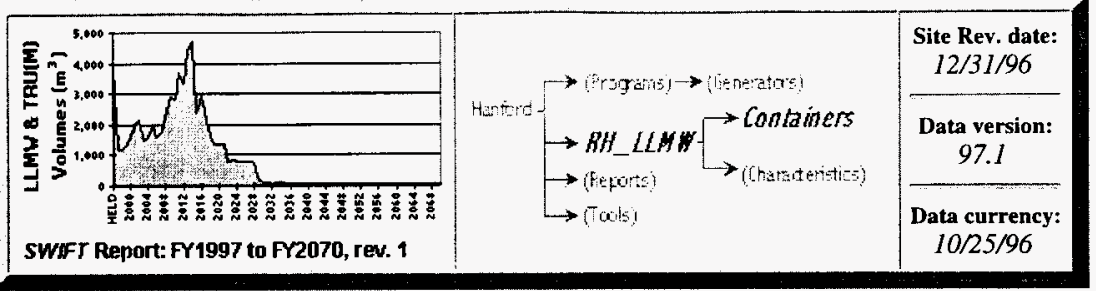

\section{RH_LLMW Containers}

\section{Contents}

» Highlights

》Annual RH_LLMW Volumes

» Summary Tables
»Comparison to Previous Baseline(s)

»» Container Definitions

\section{Highlights}

- Of the $29,220 \mathrm{~m}^{3}$ of remote-handled LLMW forecast, $88 \%$ will be in the form of LECs from the TWRS program, $5 \%$ of the waste will be stored in MB-Vs, and the remaining $7 \%$ will be shipped in other containers.

\section{Program Distribution}

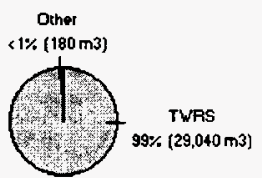

Total $=29,220 \mathrm{m3}$

\section{Physical Waste Form Distribution}

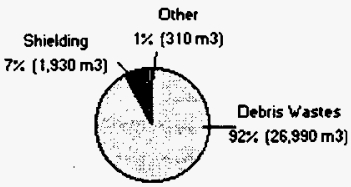

Tolal = 29,220 $\mathrm{m3}$

\section{Hazardous Constituent Distribution}

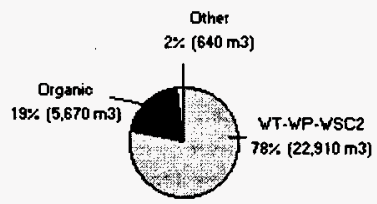

Total = 29,220 m3

Nowe:hotedes LLA' ant 


\section{Container Distribution}

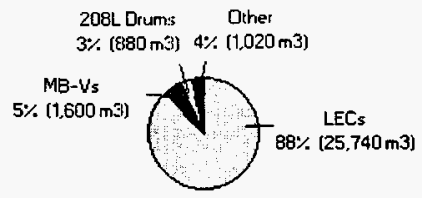

Total $=29.220 \mathrm{m3}$

Sum of totals may not add due to rounding: numbers over $10 \mathrm{~m}^{3}$ are rounded to the nearest $10 \mathrm{~m}^{3}$, numbers less than $10 \mathrm{~m}^{3}$ are rounded to integers, non-zero numbers less than 1 are rounded to 1.

\section{Annual RH_LLMW Volumes}

\section{RH_LLMW Life Cycle Volumes by Container}

The total baseline volume of waste is approximately $29,220 \mathrm{~m}^{3}$. The minimum expected volume is approximately $14,870 \mathrm{~m}^{3}$, and the maximum expected volume is $38,190 \mathrm{~m}^{3}$. The minimum, baseline, and maximum waste forecast volumes are distributed as follows:

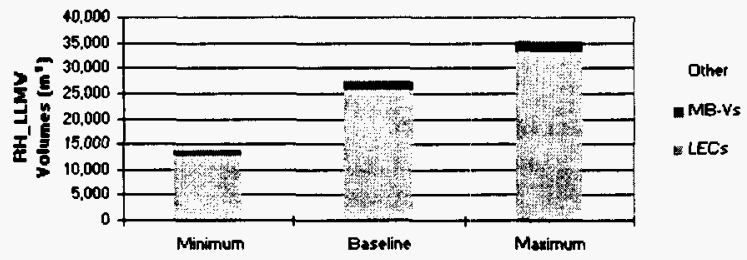

\section{RH_LLMW Annual Baseline Volumes by Container}

The graph shows the RH_LLMW volume for 1997 through 2032. The TWRS program accounts for more than 99\% of the RH_LLMW. Waste generation will peak in 2013-2014, due primarily to retrieval of the long-length contaminated equipment (from the TWRS program), which will be shipped in LECs.

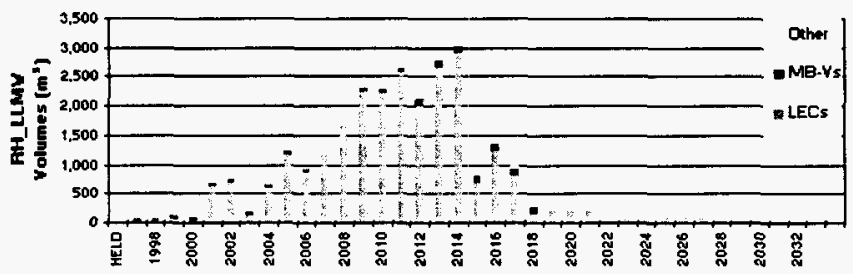




\section{Summary Tables (Volumes in $\mathbf{m}^{3}$ )}

\section{Forecast by Container Type}

(in descending order by container volumes)

\begin{tabular}{|c|c|c|}
\hline $\begin{array}{l}\text { PH_LLMY Foreeast: } \\
\text { Containers }\end{array}$ & $\begin{array}{l}97.1 \text { Forecast } \\
\left(\mathrm{m}^{3}\right)\end{array}$ & $\begin{array}{l}x \text { ar } \\
\text { roted }\end{array}$ \\
\hline LECs & 25,740 & $2 x$ \\
\hline$M B \cdot V_{5}$ & 1,600 & $5 z$ \\
\hline 208 Lrums & 880 & 25 \\
\hline Medium Boxes & 650 & $2 x$ \\
\hline Small Boxes & 370 & $1 x$ \\
\hline Tord & 2020 & $100 x$ \\
\hline
\end{tabular}

Sum of totals may not add due to rounding: numbers over $10 \mathrm{~m}^{3}$ are rounded to the nearest $10 \mathrm{~m}^{3}$, numbers less than $10 \mathrm{~m}^{3}$ are rounded to integers, non-zero numiers less than $/$ are rounded to $I$.

\section{Life Cycle Baseline Volumes}

(in descending order by Program and Generator Volumes)

\begin{tabular}{|c|c|c|c|c|c|c|}
\hline $\begin{array}{l}\text { RH_LLMH Containers: } \\
\text { Program }\end{array}$ & LEC & $\mathbf{M B - Y}$ & $\begin{array}{l}208 L \\
\text { Drum }\end{array}$ & $\begin{array}{c}\text { Medium } \\
\text { Bor }\end{array}$ & $\begin{array}{c}\text { Small } \\
\text { Box }\end{array}$ & Iotal \\
\hline TrkS & 25,746 & 1.600 & 770 & 58 & 350 & 29.040 \\
\hline SST LongLength Equipment & 22520 & 0 & 0 & 0 & 0 & 22,520 \\
\hline DST Retrieval Systems (io tanks) & 2.450 & 590 & 0 & 0 & 0 & 3.050 \\
\hline W3430ST Retrieval[ [17 Tanks] & 760 & 1,010 & 0 & 0 & 0 & 1,760 \\
\hline SSTIDST Tank Farm Operations & 0 & ont & 0̈ & 590 & 350 & 940 \\
\hline SST Retrieval ( 149 tanks) & 0 & of & 390 & 0 & 0 & $390^{\circ}$ \\
\hline Tank FarmRestoration & 0 & 0 & 380 & 0 & 0 & 380 \\
\hline Facilf Transikions & o & bo & 7 & 50 & 10 & 70 \\
\hline $303 \mathrm{~K}$ Fuels Fabrication Transition & "o & - & 7 & 50 & 10 & 70 \\
\hline Solid Wuste & 0 & $\mathbf{0}$ & 50 & B & $\mathbf{D}$ & 60 \\
\hline $221 T 2706$ T Plant Doerations & "0 & 药 & 50 & 6 & "o & 60 \\
\hline PNWL & 0 & 0 & 50 & 0 & i & 50 \\
\hline Pacfic Northwest National Laboratories & 0 & 0 & 50 & 0 & 0 & 50 \\
\hline Offsite & 6 & b & 0 & 0 & $\mathbf{5}$ & 5 \\
\hline Knolls Alomic Power-Laboratory & 0 & "0) & io & 0 & 5 & 5 \\
\hline Tot & 2570 & $\operatorname{sog}$ & $\sin$ & 20 & 370 & 23220 \\
\hline
\end{tabular}

Sum of totals may not add due to rounding: numbers over $10 \mathrm{~m}^{3}$ are rounded to the nearest $10 \mathrm{~m}^{3}$, numbers less than $10 \mathrm{~m}^{3}$ are rounded to integers, non-zero numbers less than $I$ are rounded to 1.

\section{Comparison to Previous Baseline(s)}

The usage of LECs has increased dramatically for RH_LLMW. Much of the CH_LLMW from the Single Shell Tank Long Length Equipment generator in the TWRS program has been redesignated as remote-handled this year. This item is the cause of the $623 \%$ increase in RH_LLMW volume over the 1996 level. The TWRS DST Retrieval and Retrieval System volume has increased, reporting MB-V boxes for 1997. Besides these, the containers used are the same but the volumes are generally smaller.

\section{Comparison to Previous Baseline(s) by Container}




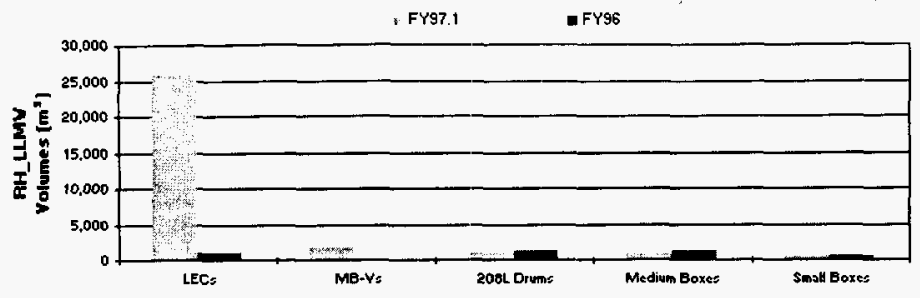

(in descending order by container volumes)

\begin{tabular}{|c|c|c|}
\hline $\begin{array}{l}\text { RH-LLAY Comparison: } \\
\text { Containers }\end{array}$ & $\begin{array}{c}\text { FY } 97.1 \\
\text { Forecast (m") }\end{array}$ & $\begin{array}{c}\text { Frst } \\
\text { Forecast }\left(\mathrm{m}^{2}\right)\end{array}$ \\
\hline LECs & 25,740 & 1,010 \\
\hline Misevs & 1.600 & 0 \\
\hline 208L Drums & 880 & 1,330 \\
\hline Medum Bones & 650 & 1.110 \\
\hline Small Bones & 370 & 590 \\
\hline Tord & $22+24$ & 1000 \\
\hline
\end{tabular}

Sum of totals may not add due to rounding: numbers over $10 \mathrm{~m}^{3}$ are rounded to the nearest $10 \mathrm{~m}^{3}$, numbers less than $10 \mathrm{~m}^{3}$ are rounded to integers, non-zero numbers less than $I$ are rounded to $I$.

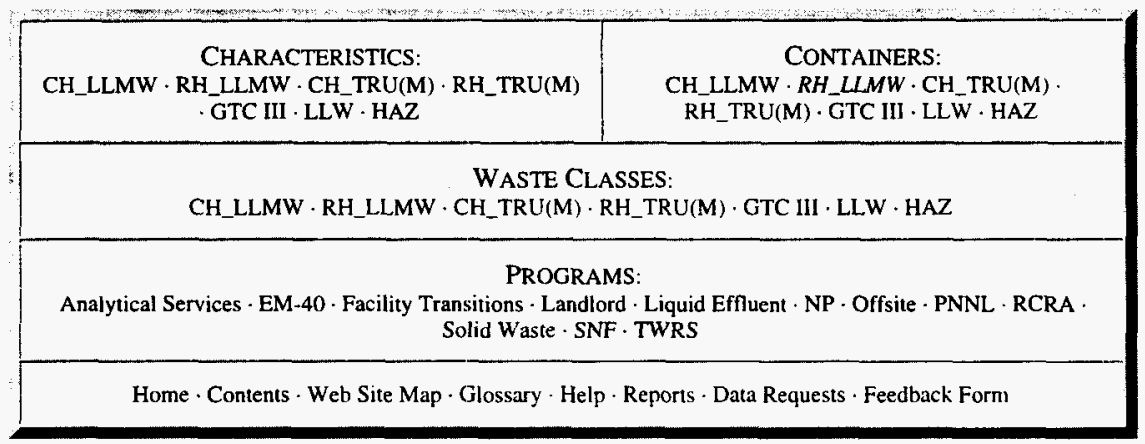

NOTICE: This page is provided subject to our disclaimer. Contact: Oscar Valero at (509) 373-4752.

HNF-EP-0918 rev. 1 Approved for public release; distribution is unlimited. 


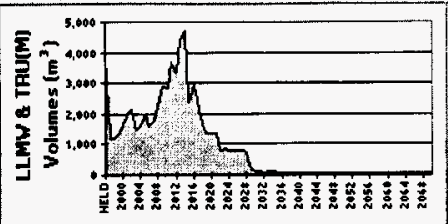

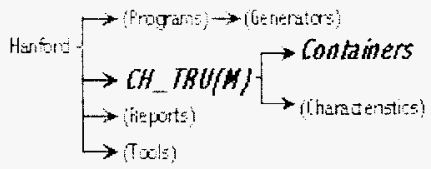

Site Rev. date:

12/31/96

Data version:

97.1

SWIFT Report: FY1997 to FY2070, rev. 1

\section{CH_TRU(M) Waste Containers}

\section{Contents}

» Highlights

» Annual CH_TRU(M) Waste Containers

"Summary Tables
»Comparison to Previous Baseline(s)

») Container Definitions

\section{Highlights}

- Of the $6,310 \mathrm{~m}^{3}$ of contact-handled TRU(M) forecast, $81 \%$ will be shipped in 208 -liter drums, $11 \%$ in SWBs, and $8 \%$ in LECs.

- Every waste generator except Spent Nuclear Fuel will use 208-liter drums for this waste category.

\section{Program Distribution}

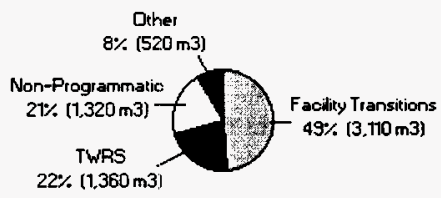

Total = 6,310 m3

\section{Physical Waste Form Distribution}

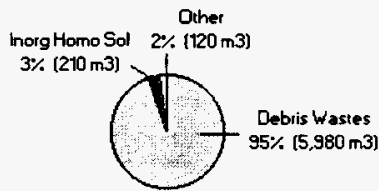

Total $=6,310 \mathrm{m3}$

\section{Hazardous Constituent Distribution}

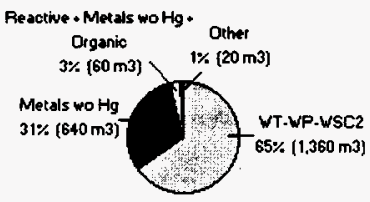

Total $=2,080 \mathrm{m3}$

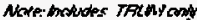




\section{Container Distribution}

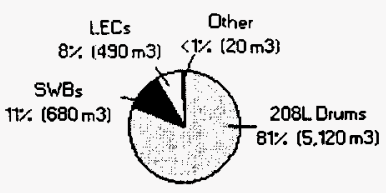

Total $=6,310 \mathrm{m3}$

Sum of totals may not add due to rounding: numbers over $10 \mathrm{~m}^{3}$ are rounded to the nearest $10 \mathrm{~m}^{3}$, numbers less than $10 \mathrm{~m}^{3}$ are rounded to integers, non-zero numbers less than 1 are rounded 101.

\section{Annual CH_TRU(M) Waste Containers}

\section{CH_TRU(M) Waste Life Cycle Volumes by Containers}

The total baseline volume of waste is approximately $6,310 \mathrm{~m}^{3}$. The minimum expected volume is approximately $2,900 \mathrm{~m}^{3}$, and the maximum expected volume is $13,290 \mathrm{~m}^{3}$. The minimum, baseline, and maximum waste forecast volumes are distributed as follows:

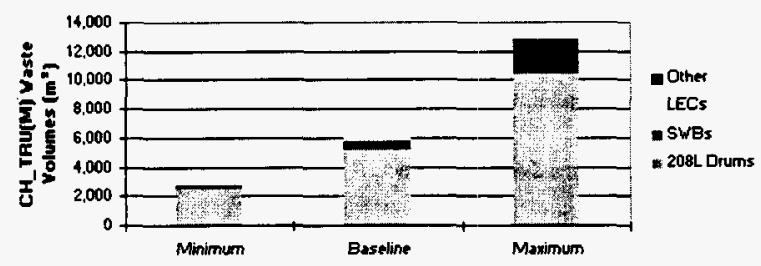

\section{CH_TRU(M) Waste Annual Baseline Volumes by Containers}

The graph shows the CH_TRU(M) waste volume for 1997 through 2070. Facility Transitions will ship waste in 208-liter drums and SWBs from 1997 through 2034. This accounts for $49 \%$ of the CH_TRU(M) waste. TWRS will ship waste in 208-liter boxes (2002 through 2028) and LECs (2001 through 2003). Waste from TWRS accounts for about $22 \%$ of the CH_TRU(M) waste. The Non-Programmatic (NP) program accounts for about $21 \%$ of the CH_TRU(M) waste. Waste from NP, in the form of 208-liter drums and SWBs, will be shipped from 2011 through 2035 . The remaining waste, about $8 \%$, mostly in 208-liter drums, will be shipped from Analytical Laboratories, EM-40, Offsite, Pacific Northwest National Laboratory, and the Spent Nuclear Fuel program. 

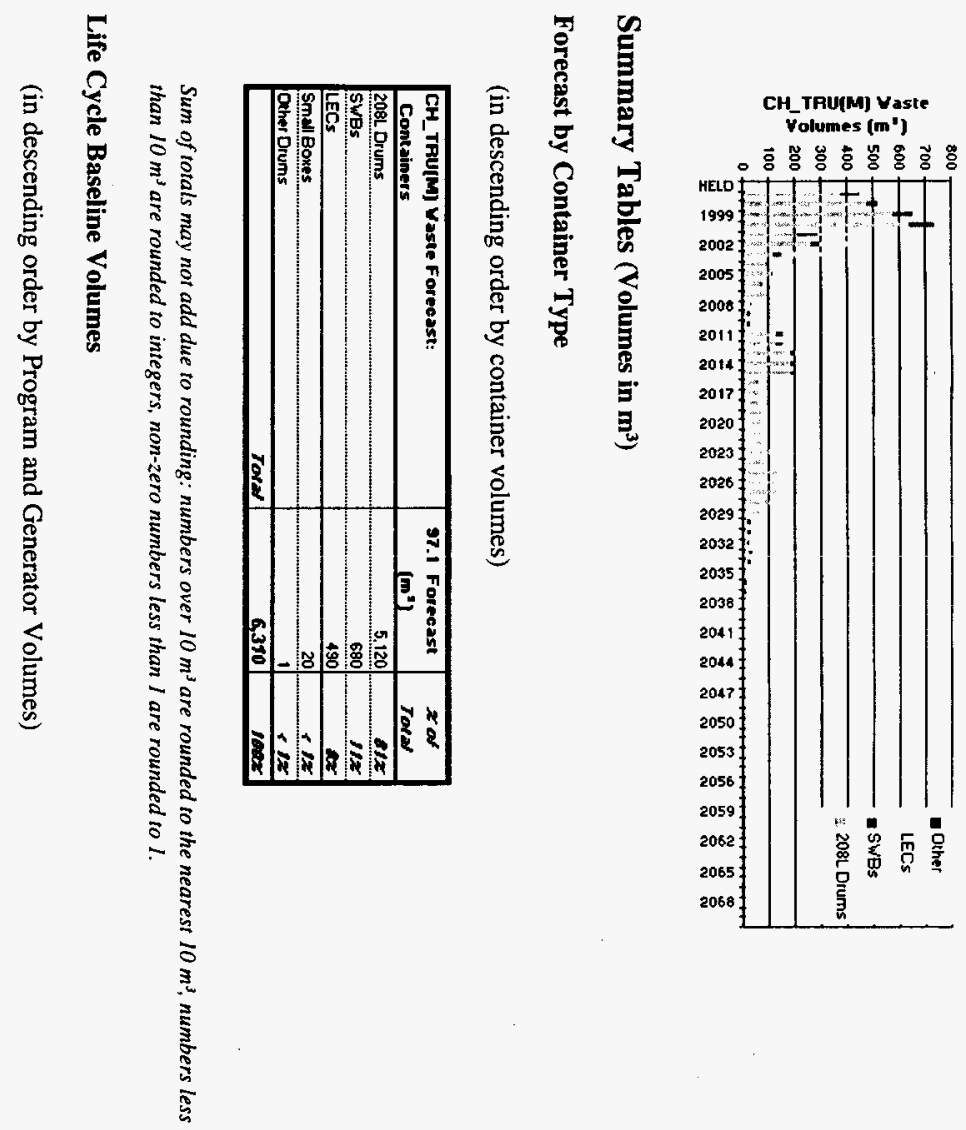


\begin{tabular}{|c|c|c|c|c|c|c|}
\hline $\begin{array}{l}\text { CH_TAU(M) Containers: } \\
\text { Program }\end{array}$ & $\begin{array}{l}\text { 2081. } \\
\text { Drum }\end{array}$ & SYE & LEC & $\begin{array}{c}\text { Small } \\
\text { Box }\end{array}$ & $\begin{array}{l}\text { Other } \\
\text { Drum }\end{array}$ & Toral \\
\hline Faciling Transitions & 2,700 & 420 & 0 & 0 & 0 & 3.110 \\
\hline 23452 Plutonium Finishing Plant & $2,6+0$ & 420 & 0 & 0 & o & 3,050 \\
\hline 327 Building & 60 & 0 & 0 & 0 & 0 & 60 \\
\hline 324 Builiding & 4 & 0 & o & of & 0 & \\
\hline 309 PRTR Vaut Waste (lon Exchange Mod) & & 0 & 0 & 0 & 0 & \\
\hline TVAS & 870 & 0 & 790 & of & 0 & 1,360 \\
\hline High Level Virrification Project & 870 & 0 & 0 & 0 & 0 & 870 \\
\hline SST Long Length Equipment & of & 0 & $490^{\circ}$ & of & 0 & 490 \\
\hline Non-Programmatic & 1,170 & 100 & 0 & 官 & 0 & 1.320 \\
\hline 300 Area Facilities Non-Transition & 1510 & 120 & 0 & 0 & 0 & 730 \\
\hline REDOX Non-Transition & 2100 & 0 & 0 & 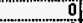 & 0 & 210 \\
\hline PUREXNOA-Transition & 100 & 0 & of & of & a & 110 \\
\hline 400 Area F acikties Non-Transition & 70 & 8 & 0 & 0 & 0 & 70 \\
\hline BPlank Non-Transition & $50 t$ & 7 & 0 & on & 0 & 60 \\
\hline PFP" Non-Transition & 50 & 9 & 0 & 0 & 0 & 50 \\
\hline TPlant Non-Transition & 40 & 0 & 0 & 0 & 0 & 40 \\
\hline Site Support Non-Transition & 30 & 6 & 0 & 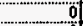 & 00 & 30 \\
\hline ÜPlane Nán-Transition & 9 & 2 & 0 & of & "ä] & 10 \\
\hline PNNL & 150 & 120 & 0 & D & (0) & 240 \\
\hline Pacific Northwest National Laboratories & 130 & 120 & 0 & 0 & 0 & 240 \\
\hline EM-40 & 230 & o & 0 & a & 0 & 230 \\
\hline Surplus Facilities & 230 & 0 & 0 & 0 & 0 & 230 \\
\hline Analitical Services & 20 & 0 & a & b. & fi & 20 \\
\hline 2225 Analyzical Labolatory & 20 & 0 & 0 & 0 & 0 & 20 \\
\hline Spent Nuclear Fuel & D & 0 & D & 20 & a & 20 \\
\hline K. Basin Fuel Sampling Proinct & 0 & 0 & 0 & 20 & 0 & 20 \\
\hline Ofifite & 1 & o & 0 & 0 & 1 & 2 \\
\hline Ames Laborstory-Ames, lowa & 0 & 0 & 0 & 0 & 1 & 1 \\
\hline Lowrence Berkeley Laboratony & & 0 & 0 & 0 & 0 & \\
\hline Toret & 5,120 & $\operatorname{sen}$ & $\infty$ & 2 & 7 & G.310 \\
\hline
\end{tabular}

Sum of totals may not add due to rounding: numbers over $10 \mathrm{~m}^{3}$ are rounded to the nearest $10 \mathrm{~m}^{3}$, numbers less than $10 \mathrm{~m}^{3}$ are rounded to integers, non-zero numbers less than I are rounded to 1.

\section{Comparison to Previous Baseline(s)}

The FY97.1 forecast of $6,310 \mathrm{~m}^{3}$ of CH_TRU(M) waste shows a $36 \%$ decrease from the FY96 forecast of $9,830 \mathrm{~m}^{3}$. For 1997 , the kinds of containers are different from the 1996 forecast data. Medium and MB-V boxes are no longer reported since their generators are not sending CH_TRU(M) waste this year, and as a new source in 1997, the TWRS SST LLE will send waste in LECs. Also, the Spent Nuclear Fuel K-Basin Sampling Project reported waste in 208 liter drums in 1996 but has currently changed to Small boxes. Lastly, this year's forecast includes SWBs from PNNL and an Other drum category from Ames Laboratory.

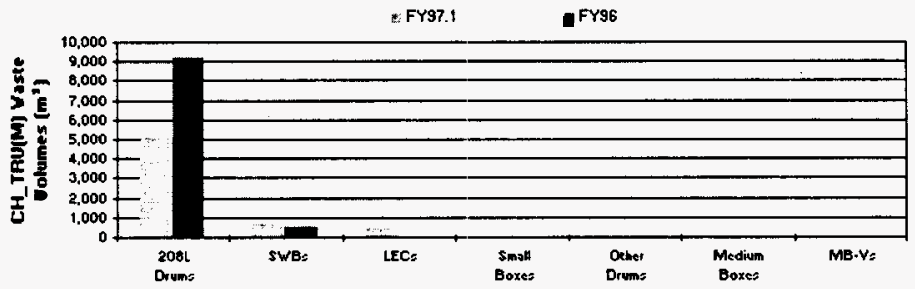

(in descending order by container volumes) 


\begin{tabular}{|c|c|c|}
\hline $\begin{array}{l}\text { CH-TRU[M] Vaste Comparison: } \\
\text { Containers }\end{array}$ & $\begin{array}{c}\text { FY } 97.1 \\
\text { Forecast }\left(\mathrm{m}^{3}\right)\end{array}$ & $\begin{array}{c}\text { FYgs } \\
\text { Forecast }\left(\mathrm{m}^{3}\right)\end{array}$ \\
\hline 208L Drums & 5,120 & 9,220 \\
\hline SWES & 680 & 570 \\
\hline LECS & 490 & 0 \\
\hline Small Boxes & 20 & 0 \\
\hline Other Drums & 1 & 0 \\
\hline Medium Bones & 0 & 30 \\
\hline MB.Vs & 0 & $\begin{array}{r}7 \\
\end{array}$ \\
\hline Toral & $65 / 0$ & $2 \cos$ \\
\hline
\end{tabular}

Sum of totals may not add due to rounding: numbers over $10 \mathrm{~m}^{3}$ are rounded to the nearest $10 \mathrm{~m}^{3}$, numbers less than $10 \mathrm{~m}^{3}$ are rounded to integers, non-zero numbers less than 1 are rounded to 1 .

\begin{tabular}{|c|c|}
\hline $\begin{array}{c}\text { CHARACTERISTICS: } \\
\text { CH_LLMW } \cdot \text { RH_LLMW } \cdot \text { CH_TRU(M) }) \cdot R H \_T R U(M) \\
\text { GTC III } \cdot \text { LLWW } \cdot \text { HAZ }\end{array}$ & $\begin{array}{c}\text { CONTAINERS: } \\
\text { CH_LLMW } \cdot \text { RH_LLMW } \cdot \text { CH_TRU(M) } \\
\text { RH_TRU(M) } \cdot \text { GTC III } \cdot \text { LLW } \cdot \text { HAZ }\end{array}$ \\
\hline \multicolumn{2}{|c|}{$\begin{array}{c}\text { WASTE CLASSES: } \\
\text { CH_LLMW } \cdot \text { RH_LLMW } \cdot \text { CH_TRU(M }) \cdot \text { RH_TRU(M) } \cdot \text { GTC III } \cdot \text { LLW } \cdot \text { HAZ }\end{array}$} \\
\hline $\begin{array}{r}\text { PROG } \\
\text { Analytical Services } \cdot \text { EM-40 } \cdot \text { Facility Transitions } \cdot \text { Landl } \\
\text { Waste } \cdot \text { SI }\end{array}$ & Effluent $\cdot$ NP $\cdot$ Offsite $\cdot$ PNNL $\cdot$ RCRA $\cdot$ Solid \\
\hline
\end{tabular}

NOTICE: This page is provided subject to our disclaimer. Contact: Oscar Valero at (509) 373-4752.

HNF-EP-0918 rev. 1 Approved for public release; distribution is unlimited. 


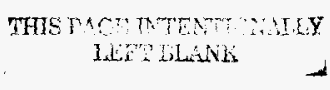




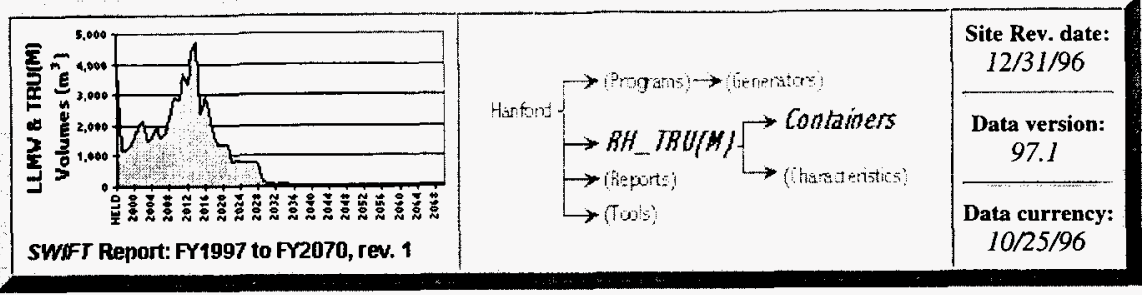

\section{RH_TRU(M) Waste Containers}

\section{Contents}

» Highlights

" Annual RH_TRU(M) Waste Containers

»Summary Tables
»Comparison to Previous Baseline(s)

") Container Definitions

\section{Highlights}

- Of the $1,670 \mathrm{~m}^{3}$ of remote-handled TRU(M) waste forecast, $56 \%$ will be shipped in SWBs, $35 \%$ in LECs, $5 \%$ in 208 -liter drums, and $4 \%$ in extra large boxes.

\section{Program Distribution}

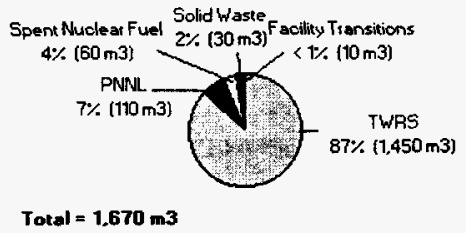

\section{Physical Waste Form Distribution}

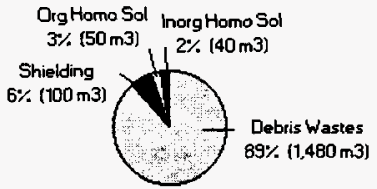

Total = $1,670 \mathrm{~m} 3$

\section{Hazardous Constituent Distribution}

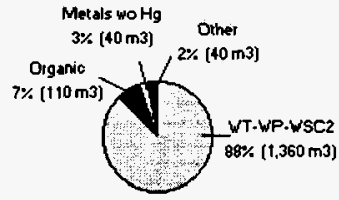

Total $=1,550 \mathrm{m3}$

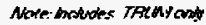




\section{Container Distribution}

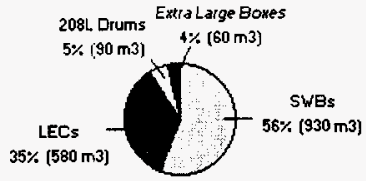

Total $=1,670 \mathrm{~m} 3$

Sum of totals may not add due to rounding: numbers over $10 \mathrm{~m}^{3}$ are rounded to the nearest $10 \mathrm{~m}^{3}$, numbers less than $10 \mathrm{~m}^{3}$ are rounded to integers, non-zero numbers less than $I$ are rounded to $I$.

\section{Annual RH_TRU(M) Waste Containers}

\section{RH_TRU(M) Waste Life Cycle Volumes by Container}

The total baseline volume of RH_TRU(M) waste is approximately $1,670 \mathrm{~m}^{3}$. The minimum expected volume is approximately $740 \mathrm{~m}^{3}$, and the maximum expected volume is $3,710 \mathrm{~m}^{3}$. The minimum, baseline, and maximum waste forecast volumes are distributed as follows:

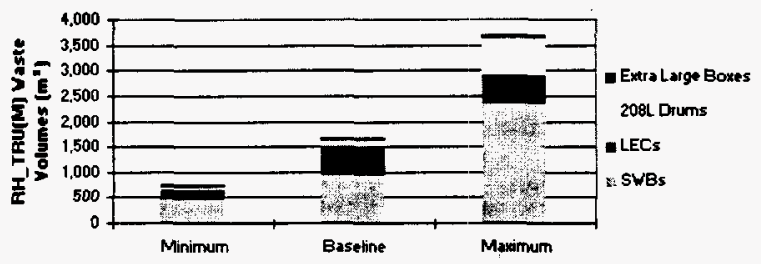

\section{RH_TRU(M) Waste Annual Baseline Volumes by Container}

The graph shows the RH_TRU(M) waste volume from 1997 through 2028 . LECs $\left(580 \mathrm{~m}^{3}\right)$ will be shipped from TWRS in the years 1997, 1998, and 2001 through 2003 . SWBs $\left(60 \mathrm{~m}^{3}\right)$ will be shipped by PNNL from 1997 through 2010 and by TWRS $\left(870 \mathrm{~m}^{3}\right)$ from 2002 through 2028. The remaining waste will be shipped in 208-liter drums from Pacific Northwest National Laboratory, Solid Waste, Facility Transitions, and TWRS, and in Extra Large boxes (in 1998) from the Spent Nuclear Fuel program.

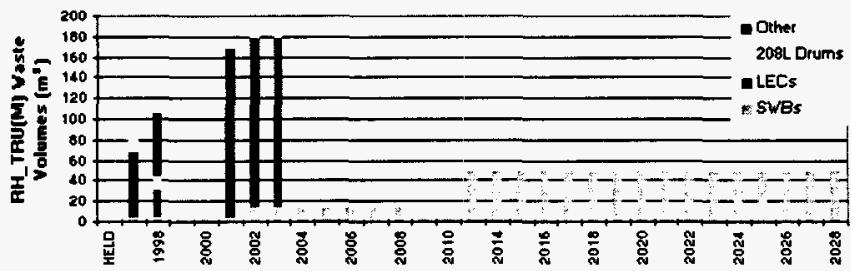




\section{Summary Tables (Volumes in $\mathbf{m}^{\mathbf{3}}$ )}

Forecast by Container Type (in descending order by container volumes)

\begin{tabular}{|c|c|c|}
\hline $\begin{array}{l}\text { CH_TRU(M) Yaste Forecast: } \\
\text { Containers }\end{array}$ & $\begin{array}{l}97.1 \text { Forecast } \\
\left(\mathrm{m}^{3}\right)\end{array}$ & $\begin{array}{l}\text { Zat } \\
\text { Tared }\end{array}$ \\
\hline SWBs & $\begin{array}{r}930 \\
\end{array}$ & $56 x$ \\
\hline LECs & 580 & 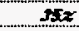 \\
\hline 208 L Drums & 90 & $5 x$ \\
\hline Extra Laige Boxes & 60 & $1 z$ \\
\hline Tory & 1.670 & $100 x$ \\
\hline
\end{tabular}

Sum of totals may not add due to rounding: numbers over $10 \mathrm{~m}^{3}$ are rounded to the nearest $10 \mathrm{~m}^{3}$, numbers less than $10 \mathrm{~m}^{3}$ are rounded to integers, non-zero numbers less than 1 are rounded to 1 .

Life Cycle Baseline Volumes (in descending order by container volumes)

\begin{tabular}{|c|c|c|c|c|c|}
\hline $\begin{array}{l}\text { RH_TRU(M) Containers: } \\
\text { Program }\end{array}$ & SYB & LEC & $\begin{array}{l}208 \mathrm{~L} \\
\text { Drum }\end{array}$ & $\begin{array}{l}\text { Entra } \\
\text { Large } \\
\text { Bon }\end{array}$ & Total \\
\hline TYAS & 870 & 580 & 0 & 0 & 1,450 \\
\hline High Level Vitrification Profect & 870 & 0 & 0 & 0 & 870 \\
\hline SSTL Long Length Equipment & 0 & 490 & 0 & 0 & 790 \\
\hline DST Rerrieval Systems (10 tanks) & 0 & 90 & 0 & 0 & 90 \\
\hline PNLL $\quad-\quad-1$ & 60 & 0 & 50 & 0 & 110 \\
\hline Pocific Northwest National Laboratories & 60 & 0 & 50 & 8 & 110 \\
\hline Spent Wuclear Foel & 0 & 0 & $\frac{5}{0}$ & 60 & 60 \\
\hline $100 \mathrm{~K}$ K-Basin Opertions & 0 & 0 & 0 & 60 & 60 \\
\hline Solid Yaste & 0 & 0 & 30 & o & 30 \\
\hline 221 TR27065 T Plant Operations & $-\frac{1}{0}$ & 0 & $\frac{50}{30}$ & ठै & 30 \\
\hline Facilit Tronsitions & \% & 0 & 10 & 0 & 10 \\
\hline 324 Building & & 0 & 10 & (ت) & 10 \\
\hline Fope: & $9 \infty$ & $\operatorname{sen}$ & $\infty$ & GP & 267 \\
\hline
\end{tabular}

Sum of totals may not add due to rounding: numbers over $10 \mathrm{~m}^{3}$ are rounded to the nearest $10 \mathrm{~m}^{3}$, numbers less than $10 \mathrm{~m}^{3}$ are rounded to integers, non-zero numbers less than 1 are rounded to 1 .

\section{Comparison to Previous Baseline(s)}

A large volume decrease has occurred because no LECs were forecast from TWRS Single Shell Tank Long Length Equipment containing RH_TRU(M) waste. Some container categories have changed. PNNL is using both SWBs and 208-liter drums. Also, the ER and Offsite generators are not projecting RH_TRU(M) wastes in 1997, which contributes to the general reduction in SWBs and 208 liter drums for this waste class.

Comparison to Previous Baseline(s) by Container (in descending order by container volumes)

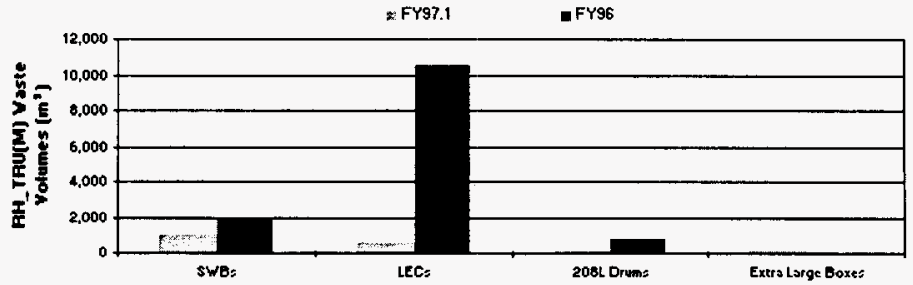




\begin{tabular}{|c|c|c|}
\hline $\begin{array}{l}\text { RH-TRU(M) Vaste Comparison: } \\
\text { Containers }\end{array}$ & $\begin{array}{c}\text { FY } 97.1 \\
\text { Fouecast (m') }\end{array}$ & $\begin{array}{c}\text { FY96 } \\
\text { Forecast [m²] }\end{array}$ \\
\hline SW'Bs & 930 & 1960 \\
\hline LECs & 580 & 10,530 \\
\hline $200 \mathrm{~L}$ Drums & 90 & 820 \\
\hline Entra Large Boxes & 60 & 40 \\
\hline Tord & 1.67 & $12 \times 50$ \\
\hline
\end{tabular}

Sum of totals may not add due to rounding: numbers over $10 \mathrm{~m}^{3}$ are rounded to the nearest $10 \mathrm{~m}^{3}$, numbers less than $10 \mathrm{~m}^{3}$ are rounded to integers, non-zero numbers less than $I$ are rounded to $I$.

\begin{tabular}{|c|c|}
\hline $\begin{array}{l}\text { CHARACTERISTICS: } \\
\text { CH_LLMW } \cdot \text { RH_LLMW } \cdot \text { CH_TRU(M) } \cdot \text { RH_TRU(M) } \\
\text { GTC III } \cdot \text { LLWW } \cdot \text { HAZ }\end{array}$ & $\begin{array}{l}\text { CONTAINERS: } \\
\text { CH_LLMW } \cdot \text { RH_LLMW } \cdot \text { CH_TRU(M) } \\
R H_{-} T R U(M) \cdot \text { GTC HI } \cdot \text { LLW } \cdot \text { HAZ }\end{array}$ \\
\hline \multicolumn{2}{|c|}{$\begin{array}{l}\text { WASTE CLASSES: } \\
\text { CH_LLMW } \cdot \text { RH_LLMW } \cdot \text { CH_TRU(M) } \cdot \text { RH_TRU(M) } \cdot \text { GTC III } \cdot \text { LLW } \cdot \text { HAZ }\end{array}$} \\
\hline \multicolumn{2}{|c|}{$\begin{array}{l}\text { PROGRAMS: } \\
\text { Analytical Services - EM-40 - Facility Transitions - Landlord } \cdot \text { Liquid Effluent } \cdot \text { NP } \cdot \text { Offsite } \cdot \text { PNNL } \cdot \text { RCRA } \cdot \text { Solid } \\
\text { Waste } \cdot \text { SNF } \cdot \text { TWRS }\end{array}$} \\
\hline
\end{tabular}

NOTICE: This page is provided subject to our disclaimer. Contact: Oscar Valero at (509) 373-4752.

HNF-EP-0918 rev, 1 Approved for public release; distribution is unlimited. 


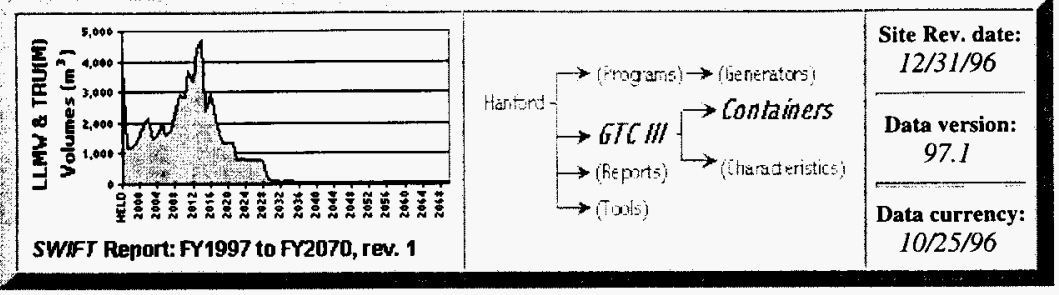

\section{GTC III Waste Containers}

\section{Contents}

» Highlights

»Summary Table
» Comparison to Previous Baseline(s)

») Container Definitions

\section{Highlights}

- No LLW or LLMW greater-than-class III (GTCIII) is forecast for shipment to the Hanford SW Project by onsite and offsite generators.

- This forecast shows a significant reduction from the FY96 forecast of $990 \mathrm{~m}^{3}\left(640 \mathrm{~m}^{3}\right.$ of LLMW_GTCIII and $350 \mathrm{~m}^{3}$ of LLW_GTCIII).

\section{Summary Table (Volumes in $\mathrm{m}^{3}$ )}

[Not applicable]

\section{Comparison to Previous Baseline(s)}

The FY97 forecast of no GTCIII waste shows a significant reduction from the FY96 forecast of $990 \mathrm{~m}^{3}$. This reduction arises because the 2 generators that reported GTCIII waste last year - DST Retrieval and PNNL - have both changed their planning assumptions for the current year's forecast. DST Retrieval is using a new baseline for waste forecasts based on the experience of Project W-151. PNNL has determined that they would include in their forecast only waste for which a disposal pathway exists. As a result, no GTCIII waste has been forecast for that program. No GTC III was reported for FY97.1.

\begin{tabular}{|l|r|r|}
\hline $\begin{array}{l}\text { GTCIII Comparison: } \\
\text { Containers }\end{array}$ & $\begin{array}{c}\text { FY 97.1 } \\
\text { Forecast }(\mathrm{m})\end{array}$ & $\begin{array}{c}\text { FY96 } \\
\text { Forecast }(\mathrm{m})\end{array}$ \\
\hline 208 L Drums & 0 & 880 \\
\hline LECs & 0 & 110 \\
\hline & 0 & 990 \\
\hline
\end{tabular}

Sum of totals may not add due to rounding: numbers over $10 \mathrm{~m}^{3}$ are rounded to the nearest $10 \mathrm{~m}^{3}$, numbers less than $10 \mathrm{~m}^{3}$ are rounded to integers, non-zero numbers less than $I$ are rounded to $I$. 


\begin{tabular}{|c|c|}
\hline $\begin{array}{l}\text { CHARACTERISTICS: } \\
\text { CH_LIMW } \cdot \text { RH_LLMW } \cdot \text { CH_TRU(M) } \cdot \text { RH_TRLY(M) } \\
\text { GTC III } \cdot \text { LLW } \cdot \text { HAZ }\end{array}$ & $\begin{array}{l}\text { CONTAINERS: } \\
\text { CH_LLMW } \cdot \text { RH_LLMW } \cdot \text { CH_TRU(M) } \\
\text { RH_TRU(M) } \cdot G T C I I \cdot \cdot \mathrm{LLW} \cdot \mathrm{HAZ}\end{array}$ \\
\hline \multicolumn{2}{|c|}{$\begin{array}{c}\text { WASTE CLASSES: } \\
\text { CH_LLMW } \cdot \text { RH_LLMW } \cdot \text { CH_TRU(M) } \cdot \text { RH_TRU(M) } \cdot \text { GTC III } \cdot \text { LLW } \cdot \text { HAZ }\end{array}$} \\
\hline \multicolumn{2}{|c|}{$\begin{array}{l}\text { PROGRAMS: } \\
\text { Analytical Services - EM-40 - Facility Transitions - Landlord - Liquid Effluent - NP - Offsite - PNNL - RCRA - Solid } \\
\text { Waste - SNF - TWRS }\end{array}$} \\
\hline
\end{tabular}

NOTICE: This page is provided subject to our disclaimer. Contact: Oscar Valero at (509) 373-4752. HNF-EP-0918 rev. 1 Approved for public release; distribution is unlimited. 


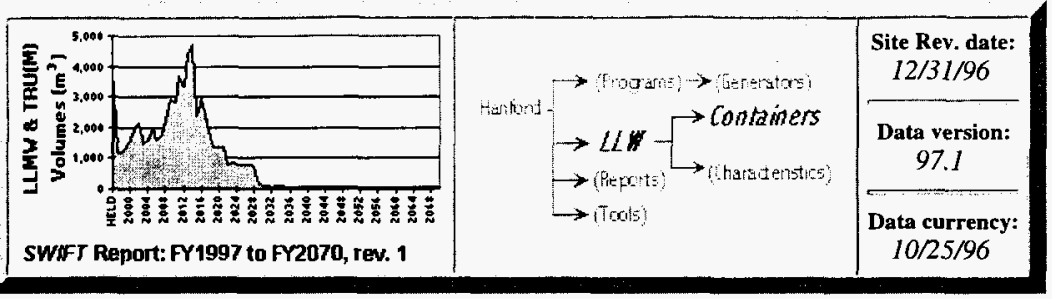

\section{LLW Containers}

\section{Contents}
" Highlights
„Comparison to Previous Baseline(s)
" Annual LLW Container Volumes »» Container Definitions
» Summary Tables

\section{Highlights}

- Of the $152,540 \mathrm{~m}^{3} \mathrm{LLW}$ forecast, $52 \%$ will be shipped in MB-Vs, $12 \%$ in small boxes, $12 \%$ in 208 -liter drums, $8 \%$ in MB-IVs, and $16 \%$ in other containers.

- The container distribution for the FY97.1 forecast is similar to the FY96 forecast.

- MB-V boxes will be sent from every program except Liquid Effluents.

- The Low Level Vitrification Project (LLVP) contributes $44 \%$ of the MB-V boxes forecast.

\section{Program Distribution}

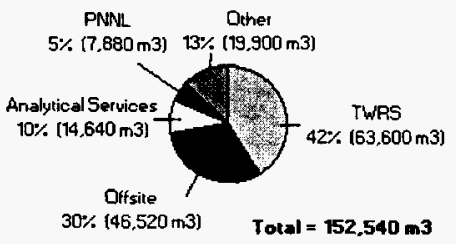




\section{Physical Waste Form Distribution}

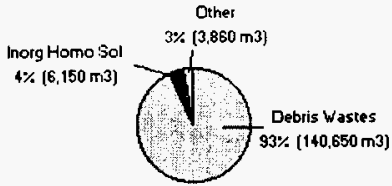

Total $=152.540 \mathrm{~m}^{3}$

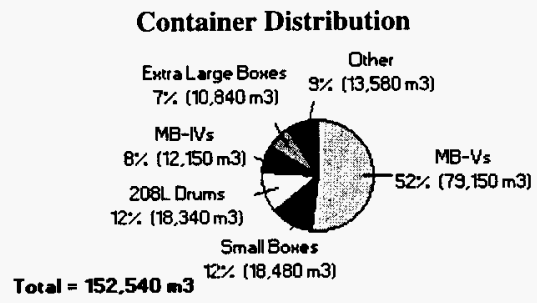

Sum of totals may not add due to rounding: numbers over $10 \mathrm{~m}^{3}$ are rounded to the nearest $10 \mathrm{~m}^{3}$, numbers less than $10 \mathrm{~m}^{3}$ are rounded to integers, non-zero numbers less than 1 are rounded $t o 1$.

\section{Annual LLW Container Volumes}

\section{LLW Life Cycle Volumes by Container}

The total baseline volume of waste is approximately $152,540 \mathrm{~m}^{3}$. The minimum expected volume is approximately $71,220 \mathrm{~m}^{3}$, and the maximum expected volume is $361,960 \mathrm{~m}^{3}$. The minimum, baseline, and maximum waste forecast volumes are distributed as follows:

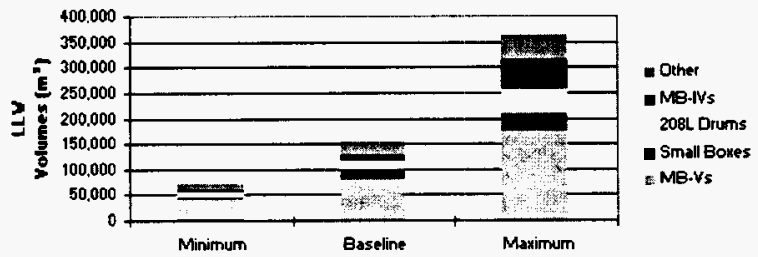

\section{LLW Annual Baseline Volumes by Container}

The graph shows the LLW volume for 1997 to 2070 . TWRS is the main source of LLW, accounting for about $42 \%$, or $63,600 \mathrm{~m}^{3}$, of the total LLW volume. 


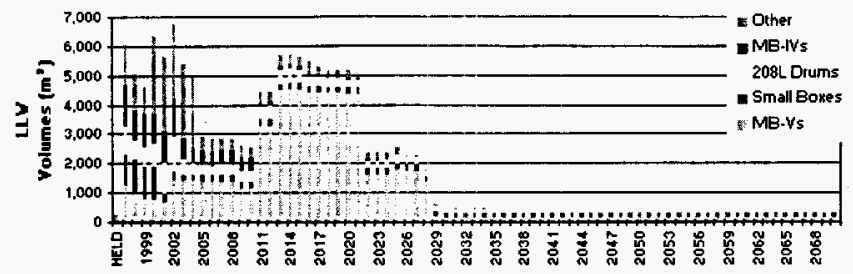

\section{Summary Tables (Volumes in $\mathbf{m}^{3}$ )}

\section{Forecast by Container Type}

(in descending order by container volumes)

\begin{tabular}{|c|c|c|}
\hline $\begin{array}{l}\text { LLV Foreeast: } \\
\text { Containers }\end{array}$ & $\begin{array}{l}97.1 \text { Forecest } \\
\left(m^{2}\right)\end{array}$ & $\begin{array}{l}x \text { ar } \\
\text { Tored }\end{array}$ \\
\hline$M B \cdot V_{s}$ & $\begin{array}{r}79,150 \\
\end{array}$ & $52 x$ \\
\hline Small Bokes & 18480 & $12 x$ \\
\hline 208L Drums & 18,340 & $12 x$ \\
\hline ME. IVs & 12,150 & 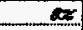 \\
\hline Extra Lyge Bones & 10.840 & $\pi$ \\
\hline Medium Bokes & 9,180 & $6 x$ \\
\hline Other Drums & 2.110 & ex \\
\hline 322L Drums & 2.040 & $1 x$ \\
\hline Large Boxes & 250 & ax \\
\hline rord & ISZ,50 & rever \\
\hline
\end{tabular}

Sum of totals may not add due to rounding: numbers over $10 \mathrm{~m}^{3}$ are rounded to the nearest $10 \mathrm{~m}^{3}$, numbers less than $10 \mathrm{~m}^{3}$ are rounded to integers, non-zero numbers less than $/$ are rounded to 1 .

\section{Life Cycle Baseline Volumes}

(in descending order by Program and Generator Volumes) 


\begin{tabular}{|c|c|c|c|c|c|c|c|}
\hline $\begin{array}{l}\text { LLV Containers: } \\
\text { Program }\end{array}$ & HB-Y & $\begin{array}{c}\text { Small } \\
\text { Bos }\end{array}$ & $\begin{array}{l}208 \mathrm{~L} \\
\text { Drum }\end{array}$ & MB-IY & $\begin{array}{c}\text { Eatra } \\
\text { Large } \\
\text { Bon }\end{array}$ & Other & Torer \\
\hline TVAS & 59,400 & $\begin{array}{r}0 \\
\end{array}$ & 1,500 & $\mathbf{0}$ & 6 & 2690 & $\operatorname{cxp}$ \\
\hline Low Level Yitrification Project & 34.560 & 0 & 0 & 0 & 0 & 0 & 3450 \\
\hline High Level Yirrification Project & 20,880 & 0 & 웅 & 0 & 0 & 0 & Mon \\
\hline SSTIDST Tank Farm Operations & 3,900 & 0 & 900 & ? & 照 & 2,690 & 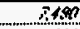 \\
\hline SST Retrieval (149 canks) & 0 & 0 & 600 & 0 & 0 & 0 & $M$ \\
\hline$T$ ank $F$ arm Restoration & 60 & o. & 0 & 0 & 0 & 0 & m \\
\hline Offsite & 1.320 & 18.480 & 7,940 & 5.730 & 10,920 & 2.230 & 1950 \\
\hline Argonne National Laboratort-East & 0 & 15,770 & 4.270 & 0 & 0 & - & nose \\
\hline Lawrence Berkeley Laboratory & 150 & 0 & 710 & o & 10,670 & o. & $t, .20$ \\
\hline Pringeton Plasma Physics Lab & 0 & ? & 2,230 & 1,620 & o & 180 & 190 \\
\hline Brookhaven National Labolatory & 0 & 130 & of & 1.550 & 0 & 1,410 & .2009 \\
\hline Fermi National Accoleratos Laboratoay & 0 & 1.160 & 360 & of & 0 & 0 & 1,50 \\
\hline Stanford Linear Accelerator Center & 1.170 & 0 & 0 & o & 0 & 0 & $1,1,0$ \\
\hline Rookwell-Canoga Park & o & 770 & 0 & 240 & 0 & 140 & 1100 \\
\hline Battelle Columbus Laboratories & 0 & of & 0 & 1,030 & 0 & 0 & 1,000 \\
\hline Univer sity of California-Davis & o & 0 & 10 & 970 & 0 & 0 & 20 \\
\hline Genetal Atomics & 0 & 620 & 0 & 40 & 0 & 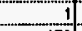 & sna \\
\hline Knolls Aromic Power-Shipyards & a & 0 & a. & 0 & 150 & 170 & $.2 n$ \\
\hline Poitsmouth Energy Systems & 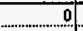 & of & of & 60 & 0 & 250 & $2 \%$ \\
\hline Bettis Asomic Power-Laboratory & 0 & of & 3 & 200 & of & 0 & $2+9$ \\
\hline Rocky Flats & 0 & 0 & 180 & 0 & of & 0 & $\sin$ \\
\hline Ames Laboratory-Ames, lowa & 0 & 20 & 80 & 0 & 0 & 20 & $\sin$ \\
\hline Puduch En rogy Systems & 0 & 0 & 50 & 20 & 0 & 0 & $7 ?$ \\
\hline Betis Alomic Power-Shipyards & 0. & 1 & 0 & 0 & 0 & 40 & 50 \\
\hline Eates Acceleratol-Mussachusetts & 2 & 0 & 40 & 0 & 0 & 0 & 19 \\
\hline University of Uxah & 0 & o & 7 & 0 & 0 & 0 & 5 \\
\hline Anclicicol Services & 11,050 & of & 3,500 & of & 0 & 80 & rese \\
\hline 222 S Andutical l aboratory . . & 11,060 & of & 3,440 & 0 & ? & 80 & 1450 \\
\hline 6266 Voste Sumpling \& Characterization Faclity & 0 & of & 60 & 0 & of & 0 & $m$ \\
\hline PNNL & 1,590 & 0 & 1,240 & 4,650 & - & 400 & 7.00 \\
\hline Preific Nothwest Mational Labolatories & 1.590 & 0 & 1240 & 4650 & 0 & 400 & Fin? \\
\hline Fapiling Iransitions & 1,260 & 0 & 2.850 & 1,520 & e & 840 & 697 \\
\hline 324 Building & 400 & 0 & 130 & 0 & 0 & 160 & $\Leftrightarrow$ \\
\hline 32 ? Building & 130 & 0 & 90 & 0 & 0 & 0 & $2 n$ \\
\hline 225B B Plant & 170 & 0 & 20 & 0 & 0 & 80 & 20 \\
\hline FFTF Transition Proiect & 20 & 0 & 30 & 0 & 0 & 30 & $m$ \\
\hline 303K Fuels Fabrication Transition & 0 & 0. & 30 & 0 & 요 & 370 & 19 \\
\hline 23452 Plutonium Finishing Plant & 40 & 0 & 2,320 & 1,520 & 0 & 0 & 2000 \\
\hline J09 PATR Yault Waste (lon Exehange Mod) & 0 & 0 & 50 & 0 & of & 11 & 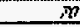 \\
\hline 2028 Purex Operations & 210 & 0 & 90 & 0 & 0 & 90 & sin \\
\hline 335 sodium Test Facility & 0 & 0 & 0 & 0 & 0 & 1 & 1 \\
\hline Waste Encapsulation'Storage Facility" & 280 & 0 & 80 & 0 & - & 100 & $\sin$ \\
\hline Liquid Effluent & 0 & a & 140 & g. & o. & 5.360 & 519 \\
\hline 300 ArealTreared Effluen Disposal F acilities & 0 & 0 & 50 & 0 & a & 5,360 & 5110 \\
\hline $\mathrm{CO} 1 \mathrm{BH}-200$ Area Effluent Treatment $\mathrm{Facility}$ & 0 & 0. & 80 & 贯 & 0 & of & $m$ \\
\hline Solid Yaste & 2,320 & 0 & 190 & o & 0 & 390 & $x+50$ \\
\hline 2211 12706T T Plant Operations & 2920 & 0 & 150 & 0 & 0 & 0 & 309 \\
\hline W026-W/aste Receiving and Processing [WRAP I] & 0 & - & 0 & a & 0 & 390 & $x 90$ \\
\hline $218 E$ W Low Level Butial Grounds & i & 0 & 40 & 0 & 0 & 0 & 10 \\
\hline $224 T$ TRU Storage \& Assay Facility & a & 0 & 2 & 0 & 0 & 0 & 2 \\
\hline Non-Progonmmatic & 1,050 & 0 & 880 & 6 & 20 & 370 & 2,350 \\
\hline 300 Area F acilities Non-Transition & 640 & $a$ & 620 & 6 & 8 & 156 & $1+20$ \\
\hline REDOXNon-Trensition & 160 & 0 & 70 & 0 & 0 & 70 & $m$ \\
\hline PUREXNOn-Transition & 90 & 0 & 40 & 0 & 0 & 40 & Non \\
\hline 400 Area Facilities Non-Transition & 20 & 0 & +0 & 0 & 0 & 40 & 190 \\
\hline BPlant Non-Transition & 20 & 0 & 10 & 0 & 9 & 50 & $m$ \\
\hline TPlant Non-Transition & 40 & 0 & 20 & 0 & 0 & 20 & An \\
\hline PFPNon-Transition & 30 & 0 & 40 & 1 & 0 & 0 & $\pi$ \\
\hline Site Supporn Non-Transition & 20 & 0 & 20 & 1 & 1 & if & 5 \\
\hline UPlant Non-Transition & 10 & o & 10 & 1 & 1 & 5 & $m$ \\
\hline Spent Nuclear Fuel & 550 & 0 & o & 250 & 0 & 1.190 & 450 \\
\hline K-Basin Fuel Sampling Project & 80 & 0 & of & 250 & 0 & 720 & $10 m$ \\
\hline $100 \mathrm{~K}$ K-Busin Operations & 490 & 0 & of & 0 & 0 & 470 & $\$$ \\
\hline RCPA Monitoring & 20 & 0 & 100 & e. & o & 10 & 19 \\
\hline WellDrilling & 20 & of & 100 & 0 & 0 & 10 & $1 M$ \\
\hline Tares & $\mathrm{sen} / \mathrm{se}$ & 12400 & 12,310 & 12,150 & 10010 & 1250 & 152510 \\
\hline
\end{tabular}


Sum of totals may not add due to rounding: numbers over $10 \mathrm{~m}^{3}$ are rounded to the nearest $10 \mathrm{~m}^{3}$. numbers less than $10 \mathrm{~m}^{3}$ are rounded to integers, non-zero numbers less than 1 are rounded to $I$.

\section{Comparison to Previous Baseline(s)}

The FY97.1 forecast of $152,540 \mathrm{~m}^{3}$ of LLW shows a $57 \%$ decrease from the FY96 forecast of $353,160 \mathrm{~m}^{3}$. This decrease reflects the significant waste volume reductions from Offsite, Pacific Northwest National Laboratory, and RCRA programs.

\section{Comparison to Previous Baseline(s) by Container}

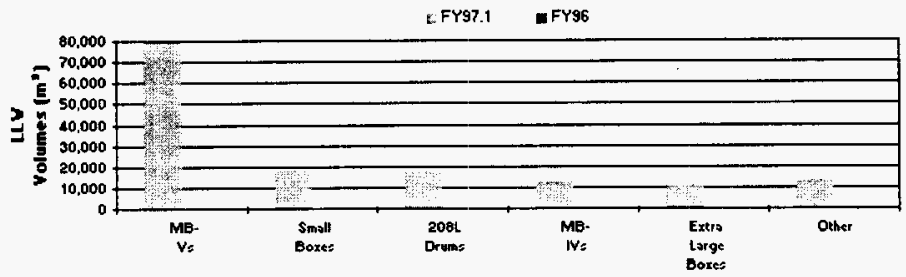

(in descending order by container volumes)

\begin{tabular}{|c|c|c|}
\hline $\begin{array}{l}\text { LLV Comparison: } \\
\text { Containess }\end{array}$ & $\begin{array}{c}\text { FY } 97.1 \\
\text { Forecast }\left[\mathrm{m}^{\prime \prime}\right]\end{array}$ & $\begin{array}{c}\text { FYs6 } \\
\text { Forecast }\left[\mathrm{m}^{n}\right]\end{array}$ \\
\hline MB.4s & 79,150 & 123.160 \\
\hline Sman Boxes & 18,480 & 23.700 \\
\hline 208L Drums & 18,340 & 63.160 \\
\hline MB-Ns & 12.150 & 55.460 \\
\hline Encra Large Bones & 10,640 & 20 \\
\hline Medium Boxes & 9,180 & $\$ 1,770$ \\
\hline Qther Drums & 2.110 & 5,870 \\
\hline 322 L Ditns & 2.040 & 4.240 \\
\hline Large Boxes & 250 & 22,570 \\
\hline Unknown Bon & 0 & 13.170 \\
\hline LECs & 0 & 110 \\
\hline SW/Bs & 0 & 40 \\
\hline 114 Drums & 0 & 20 \\
\hline Torel & 152,501 & s5x row \\
\hline
\end{tabular}

Sum of totals may not add due to rounding: numbers over $10 \mathrm{~m}^{3}$ are rounded to the nearest $10 \mathrm{~m}^{3}$, numbers less than $10 \mathrm{~m}^{3}$ are rounded to integers, non-zero numbers less than $I$ are rounded to $I$. 


\begin{tabular}{|c|c|}
\hline $\begin{array}{c}\text { CHARACTERISTICS: } \\
\text { CH_LLMW } \cdot \text { RH_LLMW } \cdot \text { CH_TRU(M) }) \cdot R_{-} H_{-} \text {TRU(M) } \cdot \\
\text { GTC III } \cdot \text { LLW } \cdot \text { HAZ }\end{array}$ & $\begin{array}{c}\text { CONTAINERS: } \\
\mathrm{CH}_{\text {_LLMW }} \cdot \mathrm{RH} \_L L M W \cdot \mathrm{CH}_{-} \text {TRU(M) } \\
\text { RH_TRU(M) } \cdot \text { GTC III } \cdot L L W \cdot \mathrm{HAZ}\end{array}$ \\
\hline \multicolumn{2}{|c|}{$\begin{array}{l}\text { WASTE CLASSES: } \\
\text { CH_LLMW } \cdot \text { RH_LLMW } \cdot \text { CH_TRU(M) } \cdot \text { RH_TRU(M) } \cdot \text { GTC III } \cdot \text { LLW } \cdot \text { HAZ }\end{array}$} \\
\hline $\begin{array}{r}\text { PROG } \\
\text { Analytical Services } \cdot \text { EM-40 } \cdot \text { Facility Transitions } \cdot \text { Land } \\
\text { Waste } \cdot S N\end{array}$ & Effluent $\cdot$ NP $\cdot$ Offsite $\cdot$ PNNL $\cdot$ RCRA $\cdot$ Solid \\
\hline
\end{tabular}

NOTICE: This page is provided subject to our disclaimer. Contact: Oscar Valero at (509) 373-4752. HNF-EP-0918 rev. 1 Approved for public release; distribution is unlimited. 


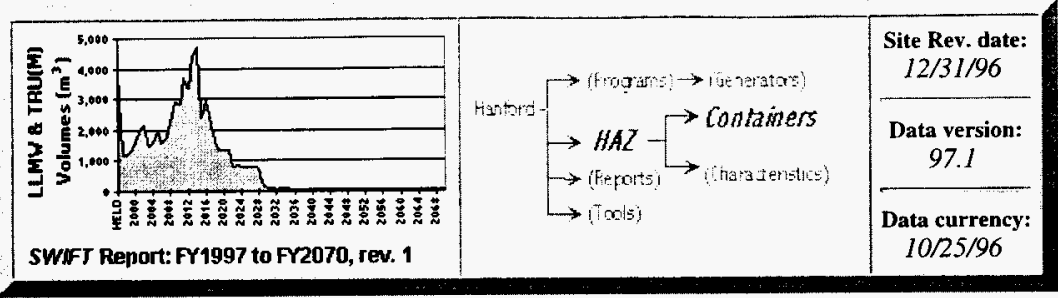

\section{Hazardous Waste (HAZ) Containers}

\section{Contents}

» Highlights

» Annual Hazardous Volumes

» Summary Tables
»Comparison to Previous Baseline(s)

»" Container Definitions

\section{Highlights}

- Of the $2,770 \mathrm{~m}^{3}$ of hazardous waste that has been forecast for management by CWC, $96 \%(2,660$ $\mathrm{m} 3$ ) will be shipped in 208 -liter drums. The remaining $4 \%$ will be shipped in 114-liter drums, 322-liter drums, other drums, medium boxes, and small boxes.

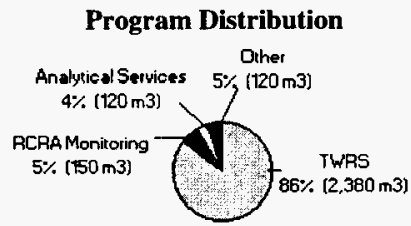

Total $=2,770 \mathrm{~m} 3$

\section{Physical Waste Form Distribution \\ Other $7 \%(200 \mathrm{~m} 3)$}

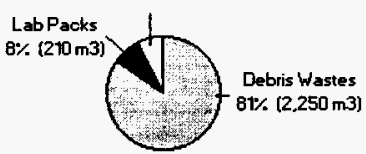

Total $=2,770 \mathrm{~m} 3$
Hazardous Constituent Distribution

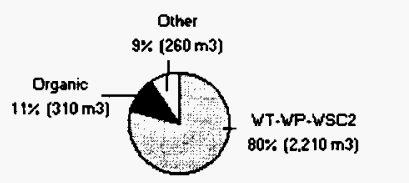

Total $=2,770 \mathrm{~mm}$ 


\section{Container Distribution}

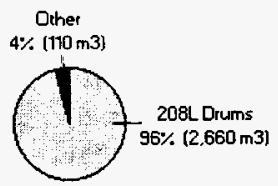

Total $=2,770 \mathrm{m3}$

Sum of totals may not add due to rounding: numbers over $10 \mathrm{~m}^{3}$ are rounded to the nearest $10 \mathrm{~m}^{3}$, numbers less than $10 \mathrm{~m}^{3}$ are rounded to integers, non-zero numbers less than 1 are rounded to $I$.

\section{Annual HAZ Waste Volumes}

\section{HAZ Waste Life Cycle Volumes by Container}

The total baseline volume of waste is approximately $2,770 \mathrm{~m}^{3}$. The minimum expected volume is approximately $1,430 \mathrm{~m}^{3}$, and the maximum expected volume is $5,300 \mathrm{~m}^{3}$. The minimum, baseline, and maximum waste forecast volumes are distributed as follows:

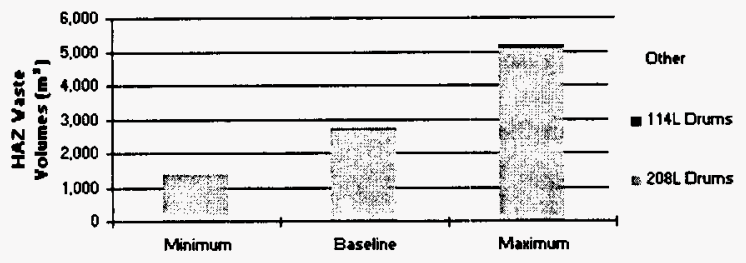

\section{HAZ Waste Annual Baseline Volumes by Container}

The graph shows the HAZ waste volume for 1997 through 2034 . About $86 \%$ of the waste is generated by TWRS, $5 \%$ by RCRA and $4 \%$ by Analytical Laboratories.

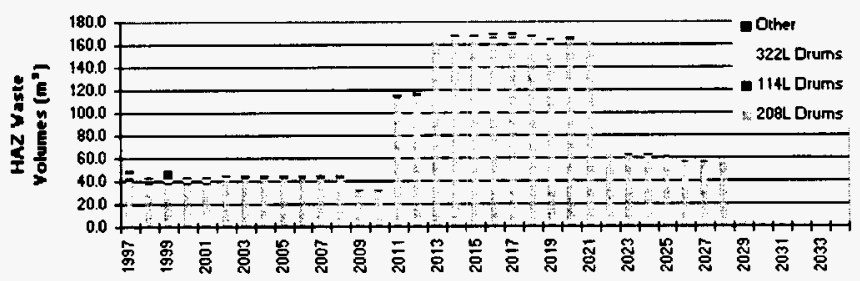

\section{Summary Tables (Volumes in $\mathbf{m}^{3}$ )}




\section{Forecast by Container Type}

(in descending order by container volumes)

\begin{tabular}{|c|c|c|}
\hline $\begin{array}{l}\text { HAZ Waste Forecast: } \\
\text { Containers }\end{array}$ & $\begin{array}{c}\text { FY97.1 } \\
\text { Forecast }\left(\mathrm{m}^{3}\right)\end{array}$ & Percent \\
\hline 208L Drums & 2,560 & $55 x$ \\
\hline 114 L Drums & 40 & $x$ \\
\hline 3222 Drums & 40 & $\pi$ \\
\hline Other Drums & 30 & $x$ \\
\hline Medium Bohes & 7 & $r \pi$ \\
\hline SmallBowes & 2 & $r x$ \\
\hline Total & 2.770 & Doox \\
\hline
\end{tabular}

Sum of totals may not add due to rounding: numbers over $10 \mathrm{~m}^{3}$ are rounded to the nearest $10 \mathrm{~m}^{3}$, numbers less than $10 \mathrm{~m}^{3}$ are rounded to integers, non-zero numbers less than 1 are rounded to 1 .

\section{Life Cycle Baseline Volumes}

(in descending order by Program and Generator Volumes)

\begin{tabular}{|c|c|c|c|c|c|c|c|}
\hline $\begin{array}{l}\text { HAZ Conteiners: } \\
\text { Program }\end{array}$ & $\begin{array}{c}2082 \\
\text { Drums }\end{array}$ & $\begin{array}{c}114 L \\
\text { Drums }\end{array}$ & $\begin{array}{c}3221 . \\
\text { Drums }\end{array}$ & $\begin{array}{l}\text { Dither } \\
\text { Drums }\end{array}$ & $\begin{array}{l}\text { Medium } \\
\text { Boses }\end{array}$ & $\begin{array}{l}\text { Small } \\
\text { Bores }\end{array}$ & Tord \\
\hline TYAS & 20 & 20 & 30 & 20 & $<1$ & $<1$ & $2,5: 5$ \\
\hline High Level Vitrification Project & 870 & 0 & 0 & 0 & 0 & 0 & $s p$ \\
\hline Low Level Vitrifiastion Projet & 1,280 & 0 & 0 & 0 & 0 & 0 & 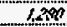 \\
\hline SSTIOST T ank Farm Operations & 160 & 20 & 30 & 20 & $\underline{0}$ & 0 & 329 \\
\hline RCPA Monitoring & 130 & 8 & 10 & 51 & $<$ & $<1$ & 10 \\
\hline Well Drilling & 130 & 8 & 10 & 0 & of & 0 & 19 \\
\hline Andytiel Serviees & 110 & $\leqslant 1$ & 61 & e & $<1$ & $<1$ & 20 \\
\hline 6266 Waste Sumpling \& Characterization F acility & 110 & 0 & 0 & 6 & 0 & 0 & 10 \\
\hline Liguid Enfluent & 80 & $<1$ & 1 & 1 & $<1$ & $\leq 1$ & 9 \\
\hline C018H-200 Area Effluent Treatment Focility & 80 & 0 & 0 & 0 & 0 & 0 & . \\
\hline Solid Yaste & 20 & 8 & $<1$ & $<1$ & $<1$ & $<1$ & $s$ \\
\hline $221 \mathrm{~T} 12706 \mathrm{~T}$ T Plant Opetations & 20 & 8 & 0 & 0 & 0 & 0 & $n$ \\
\hline Foeilin Trensitions & 4 & $<1$ & 21 & 11 & 7 & 2 & 18 \\
\hline 202A Purex Operations & 3 & $<1$ & 0 & 41 & of & $\leq 1$ & 4 \\
\hline 309 PRTR Youlr Woste (lon Exchange Mod) & $<1$ & 0 & 0 & 0 & of & 0 & if \\
\hline 335 Sodium Test Facility & 1 & 0 & 0 & 0 & 7 & 2 & 8 \\
\hline Tord & 2.000 & 10 & $\infty$ & $m$ & $\gamma$ & 2 & 2,779 \\
\hline
\end{tabular}

Sum of totals may not add due to rounding: numbers over $10 \mathrm{~m}^{3}$ are rounded to the nearest $10 \mathrm{~m}^{3}$, numbers less than $10 \mathrm{~m}^{3}$ are rounded to integers, non-zero numbers less than 1 are rounded to 1.

\section{Comparison to Previous Baseline(s)}

The FY97.1 forecast of $2,770 \mathrm{~m} 3$ of hazardous waste shows a $99.4 \%$ decrease from the FY96 forecast of $488,450 \mathrm{~m}^{3}$. The reason for the enormous change between the two forecasts is that the WM program is no longer the central collection point for hazardous waste generated on the Hanford Site. Many generators have elected to send their hazardous waste directly to other vendors for waste management. Only those generators who plan to have the WM program manage their waste are included in the FY 97 forecast.

\section{Comparison to Previous Baseline(s) by Container}




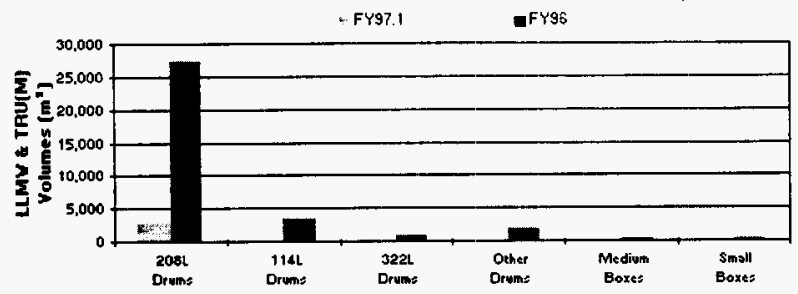

(in descending order by container volumes)

\begin{tabular}{|c|c|c|}
\hline $\begin{array}{l}\text { HAZ Waste Comparison: } \\
\text { Container }\end{array}$ & $\begin{array}{c}\text { FYg7.1 } \\
\text { Forecast } \\
\left(\mathbf{m}^{2}\right)\end{array}$ & $\begin{array}{c}\text { FY96 } \\
\text { Forecest } \\
\left(m^{3}\right)\end{array}$ \\
\hline $208 \mathrm{~L}$ Drums & 2660 & 27,320 \\
\hline 114 L Dums & 40 & 3450 \\
\hline $322 \mathrm{~L}$ Drums & 40 & 710 \\
\hline Other Drums & 30 & 1.876 \\
\hline Mediun Boxes & $?$ & 150 \\
\hline Small Boxes & 2 & 330 \\
\hline Total & 2770 & 33830 \\
\hline
\end{tabular}

Sum of totals may not add due to rounding: numbers over $10 \mathrm{~m}^{3}$ are rounded to the nearest $10 \mathrm{~m}^{3}$, numbers less than $10 \mathrm{~m}^{3}$ are rounded to integers, non-zero numbers less than $I$ are rounded to $I$.

\begin{tabular}{|c|c|}
\hline $\begin{array}{c}\text { CHARACTERISTICS: } \\
\text { CH_LLMW } \cdot \text { RH_LLMW } \cdot \text { CH_TRU(M) }_{\text {GTC III } \cdot \text { LLW }} \cdot \text { RH_TRU(M) } \\
\text { GHAZ }\end{array}$ & $\begin{array}{c}\text { CONTAINERS: } \\
\text { CH_LLMW } \cdot \text { RH_LLMW } \cdot \text { CH_TRU(M) } \\
\text { RH_TRU(M) } \cdot \text { GTC III } \cdot \text { LLW } \cdot H A Z\end{array}$ \\
\hline \multicolumn{2}{|c|}{$\begin{array}{l}\text { WASTE CLASSES: } \\
\text { CH_LLMW } \cdot \text { RH_LLMW } \cdot \text { CH_TRU(M) } \cdot \text { RH_TRU(M) } \cdot \text { GTC III } \cdot \text { LLW } \cdot \text { HAZ }\end{array}$} \\
\hline $\begin{array}{r}\text { PROG } \\
\text { Analytical Services } \cdot \text { EM-40 } \cdot \text { Facility Transitions } \cdot \text { Landlc } \\
\text { Waste } \cdot \text { SN }\end{array}$ & 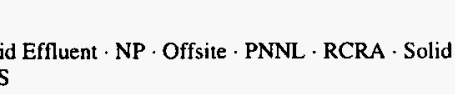 \\
\hline
\end{tabular}

NOTICE: This page is provided subject to our disclaimer. Contact: Oscar Valero at (509) 373-4752.

HNF-EP-0918 rev. 1 Approved for public release; distribution is unlimited. 

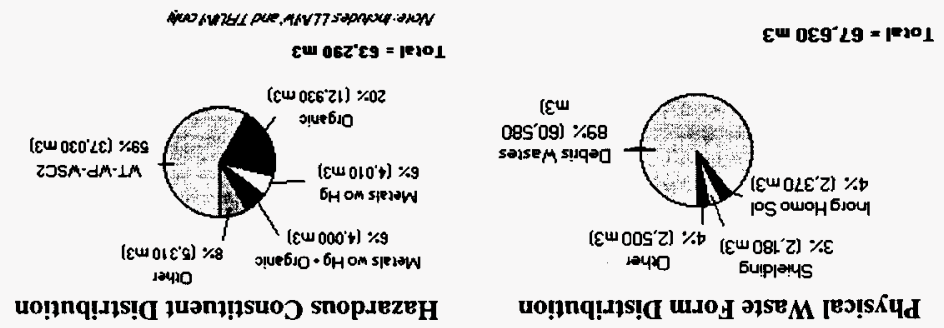

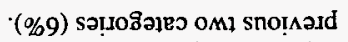

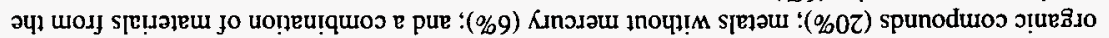

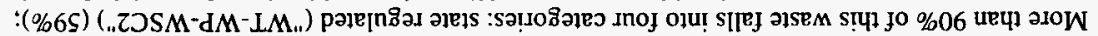

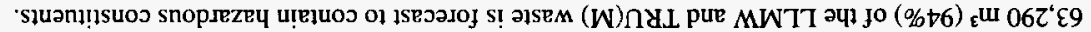

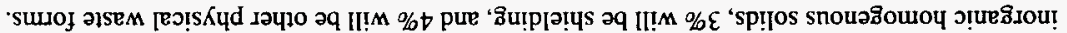

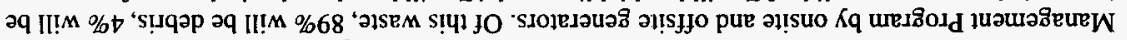
ә1se $M$ Plojue

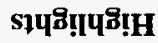

\begin{tabular}{|c|c|c|}
\hline 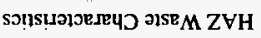 & 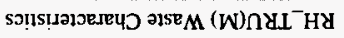 & 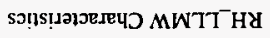 \\
\hline 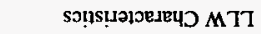 & 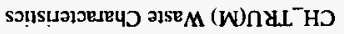 & 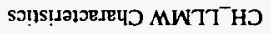 \\
\hline
\end{tabular}

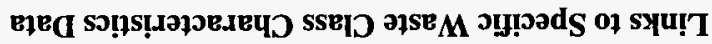

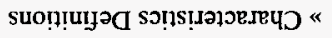

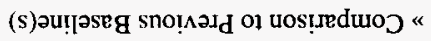

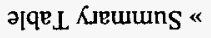

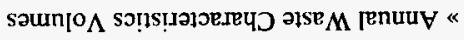

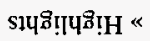

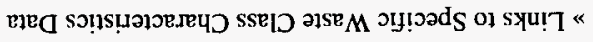

sұนวนบо

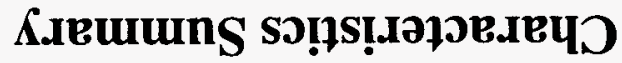

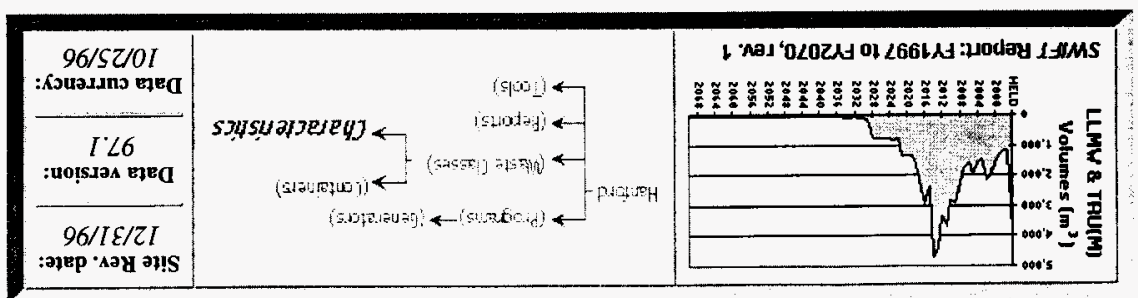


Sum of totals may not add due to rounding: numbers over $10 \mathrm{~m}^{3}$ are rounded to the nearest $10 \mathrm{~m}^{3}$, numbers less than $10 \mathrm{~m}^{3}$ are rounded to integers, non-zero numbers less than l are rounded to 1.

\section{Annual Waste Characteristics Volumes}

\section{Physical Waste Forms (PWFs)}

\section{LLMW \& TRU(M) Waste Life Cycle Volumes by Physical Waste Form}

The total baseline volume of waste is approximately $67,630 \mathrm{~m}^{3}$. The minimum expected volume is approximately $37,680 \mathrm{~m}^{3}$, and the maximum expected volume is $108,280 \mathrm{~m}^{3}$. The minimum, baseline, and maximum waste forecast volumes are distributed as follows:

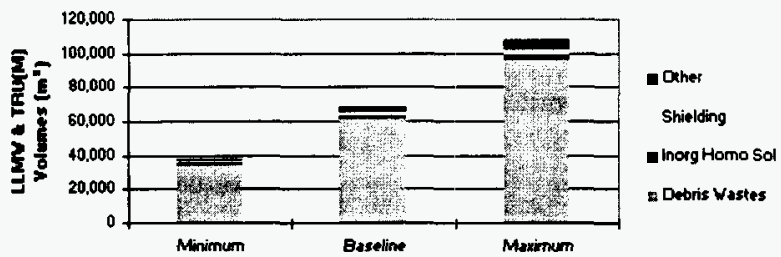

(In descending order, by Physical Waste Form)

\begin{tabular}{|c|c|c|c|}
\hline $\begin{array}{l}\text { LLMU \& TRU[M] Yaste Lile Cyele: } \\
\text { Pansical Yaste Form }\end{array}$ & Mrainen & Beseline & Merimem \\
\hline Dopis Wostes & 33,680 & 60,580 & 95,220 \\
\hline Inosg Homo Sol & 1,730 & 2,370 & 3,430 \\
\hline Shividing & 930 & 2,180 & 3,390 \\
\hline Other & 1,340 & 2,500 & 6.240 \\
\hline Tary & stere & OF,est & $10 x 20$ \\
\hline
\end{tabular}

Sum of rotals may not add due to rounding: numbers over $10 \mathrm{~m}^{3}$ are rounded to the nearest $10 \mathrm{~m}^{3}$, numbers less than $10 \mathrm{~m}^{3}$ are rounded to integers, non-zero numbers less than 1 are rounded to 1.

\section{LLMW \& TRU(M) Waste Annual Baseline Volumes by Physical Waste Form}

The graph shows the LLMW and TRU(M) waste volume for 1997 through 2070. Waste generation will peak in 2013-2014, due primarily to debris waste from retrieval of the long-length contaminated equipment (from the TWRS program). Waste volume from 2038 through 2070 is virtually constant at about $50 \mathrm{~m}^{3}$. The only facility operating during this period will be the $222 \mathrm{~S}$ Analytical Laboratory which will be shipping mostly debris waste (79\%).

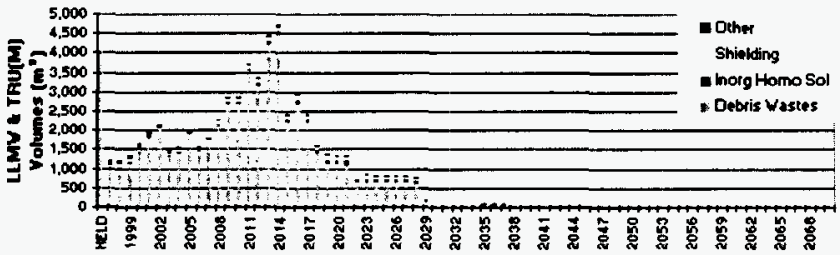




\section{Hazardous Constituents ( $\mathrm{HCs})$}

LLMW \& TRU(M) Waste Life-Cycle Volumes by Hazardous Constituent

The total baseline volume of waste is approximately $63,290 \mathrm{~m}^{3}$. The minimum expected volume is approximately $35,740 \mathrm{~m}^{3}$, and the maximum expected volume is $98,680 \mathrm{~m}^{3}$. The minimum, baseline, and maximum waste forecast volumes are distributed as follows:

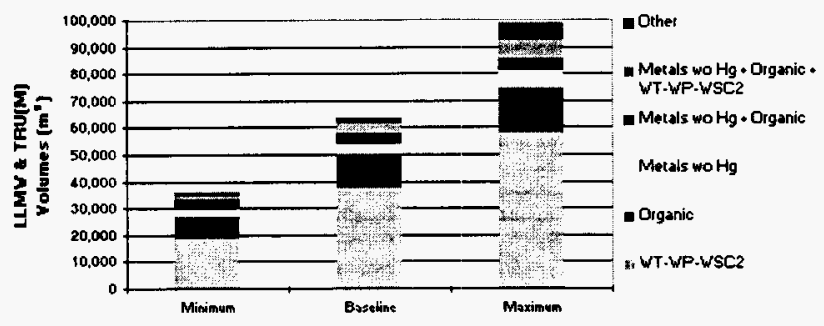

(In descending order, by Hazardous Constituent volume)

\begin{tabular}{|c|c|c|c|}
\hline $\begin{array}{l}\text { LLMW \& TRUS(M) Waste Life Cyele: } \\
\text { Hazardous Constituents }\end{array}$ & Minimum & Baseline & Maximum \\
\hline WI-WP-WSC2 & 18,380 & 37,030 & 57,940 \\
\hline Organic & 8,400 & 12,930 & 16.270 \\
\hline Metals wo Hg & 2,660 & 4,010 & 6.800 \\
\hline Metals wo Hg + Organic & 4,000 & 4,000 & 4,000 \\
\hline Metals wo Hg + Organic + WT-WP-WSC2 & 1.350 & 3490 & 7.140 \\
\hline Other & 950 & 1,830 & 6.520 \\
\hline Tord & sirece & $\cos 2 x$ & siger \\
\hline
\end{tabular}

Sum of totals may not add due to rounding: numbers over $10 \mathrm{~m}^{3}$ are rounded to the nearest $10 \mathrm{~m}^{3}$, numbers less than $10 \mathrm{~m}^{3}$ are rounded to integers, non-zero numbers less than $I$ are rounded to $I$.

\section{LLMW \& TRU(M) Waste Annual Baseline Volumes by Hazardous Constituent}

The graph shows the LLMW and TRU(M) hazardous constituent waste volume for 1997 through 2070. Waste generation will peak in 2013-2014, due primarily to Washington State regulated waste from retrieval of the long-length contaminated equipment (from the TWRS program). The waste volume from 2038 through 2070 is constant at about $45 \mathrm{~m}^{3}$. The only facility operating during this period will be the $222 \mathrm{~S}$ Analytical Laboratory which will be shipping mostly metals without mercury, toxic organic, state regulated waste $(93 \%)$.

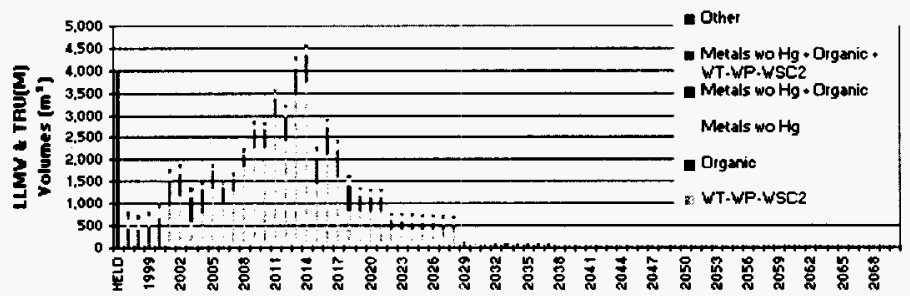




\section{Summary Tables (LLMW and TRU(M) waste volumes in $\mathbf{m}^{3}$ )}

Physical Waste Forms (PWFs)

LLMW \& TRU(M) Waste Baseline Forecast by Physical Waste Form

(In descending order, by Physical Waste Form volume)

\begin{tabular}{|c|c|c|}
\hline $\begin{array}{l}\text { LLMV \& TRU(M) Forecast: } \\
\text { Phnsical Vaste Form }\end{array}$ & $\begin{array}{c}\text { FY97.1 Forecast } \\
\left(\mathrm{m}^{2}\right)\end{array}$ & $x$ of Total \\
\hline Debris Wastes & 60.580 & $90 \%$ \\
\hline hoog Homo Sol & 2,370 & $4 \%$ \\
\hline Shielding & 2.180 & $3 \%$ \\
\hline Oig Homo Sol & 1,210 & $2 \%$ \\
\hline Soll Grouel & 580 & $1 \%$ \\
\hline Other & 710 & $1 \%$ \\
\hline Tord & ar,are & rear \\
\hline
\end{tabular}

Sum of totals may not add due to rounding: numbers over $10 \mathrm{~m}^{3}$ are rounded to the nearest $10 \mathrm{~m}^{3}$, numbers less than $10 \mathrm{~m}^{3}$ are rounded 10 integers, non-zero numbers less than $I$ are rounded $10 \mathrm{I}$.

\section{LLMW \& TRU(M) Waste Life Cycle Baseline Volumes by Physical Waste Form}

(In descending order, by Physical Waste Form volume)

\begin{tabular}{|c|c|c|c|c|c|c|c|}
\hline $\begin{array}{l}\text { LLsin \& TRU(M) } \\
\text { Physical waste Forma: } \\
\text { Prorrem }\end{array}$ & $\begin{array}{l}\text { Debris } \\
\text { Waztes }\end{array}$ & $\begin{array}{l}\text { hota } \\
\text { lomo } \\
\text { Sol }\end{array}$ & Shielding & $\begin{array}{l}\text { Oro } \\
\text { fomo } \\
\text { Sol }\end{array}$ & $\begin{array}{c}\text { Soll } \\
\text { Gravel }\end{array}$ & other & Totel \\
\hline IWRS & 47,320 & 50 & 2,000 & 220 & 520 & 8 & 50,120 \\
\hline Non-Programmatic & 5,390 & 1 & 0 & 2 & 1 & 120 & 5510 \\
\hline Facilty Transitions & 3,470 & 230 & 30 & 5 & 1. & 230 & 3970 \\
\hline Analytical Services & 2,870 & 0 & 0 & 710 & 0 & 30 & 3610 \\
\hline Licuid Effluent & 330 & 2,000 & 0 & 130 & 0 & 80 & 2540 \\
\hline PNNL & 500 & 30 & 120 & 30 & 0 & 220 & 900 \\
\hline Sold Waste & 340 & 30 & 20 & 1 & 3 & 5 & 400 \\
\hline EM-40 & 220 & 1 & 0 & 10 & 3 & 0 & 240 \\
\hline Offsite & 100 & 30 & 0 & 60 & 1 & 10 & 210 \\
\hline Spent Nucleor Fuel & 20 & 3 & 20 & 40 & 0 & 9 & 80 \\
\hline RCRA Monitoring & 6 & 0 & 3 & 0 & 50 & 0 & 60 \\
\hline Totel & 60,590 & 2,370 & 2,180 & 1,210 & 580 & 710 & 67,630 \\
\hline
\end{tabular}

Sum of totals may not add due to rounding: numbers over $10 \mathrm{~m}^{3}$ are rounded to the nearest $10 \mathrm{~m}^{3}$, numbers less than $10 \mathrm{~m}^{\mathrm{s}}$ are rounded to integers, non-zero numbers less than $/$ are rounded to 1 .

\section{Hazardous Constituents (HCs)}

\section{LLMW \& TRU(M) Waste Baseline Forecast by Hazardous Constituent}

(In descending order, by Hazardous Constituent volume)

\begin{tabular}{|c|c|c|}
\hline $\begin{array}{l}\text { LRMY E TRU(M) Yaste: } \\
\text { Hezardous Constituent }\end{array}$ & $\begin{array}{c}\text { FY97.1 } \\
\text { Forecast } \\
\text { (mi) }\end{array}$ & Percent \\
\hline WT-WP.WSC2 & 37,030 & $59 \%$ \\
\hline Organc & 12,930 & $20 \%$ \\
\hline Metals wo Hg & 4,010 & $6 \%$ \\
\hline Metal wo HG : Organic & 4000 & $6 \%$ \\
\hline Mery yo HG - Organic - G & 3,490 & $6 \%$ \\
\hline Other & 1.830 & $<1 \%$ \\
\hline roev & $6 \times 200$ & ther \\
\hline
\end{tabular}

Sum of totals may not add due to rounding: numbers over $10 \mathrm{~m}^{3}$ are rounded to the nearest $10 \mathrm{~m}^{3}$, numbers less 
than $10 \mathrm{~m}^{3}$ are rounded to integers, non-zero numbers less than I are rounded to $I$.

LLMW \& TRU(M) Waste Life Cycle Baseline Volumes by Hazardous Constituent

(In descending order, by Hazardous Constituent volume)

\begin{tabular}{|c|c|c|c|c|c|c|c|}
\hline $\begin{array}{l}\text { LMV \& TRU(M) Yaste } \\
\text { Hazardous Constituents: } \\
\text { Prominm. }\end{array}$ & $\begin{array}{l}\text { MT-MP. } \\
\text { YSC2 }\end{array}$ & Organic & $\begin{array}{l}\text { Metals } \\
\text { wo } \mathrm{Hg}\end{array}$ & $\begin{array}{l}\text { Metals } \\
\text { wo Hg* } \\
\text { Organie }\end{array}$ & $\begin{array}{c}\text { Metals wo Hg } \\
\text { - Drganic } \\
\text { YT-YP-YSC2 }\end{array}$ & Dther & Tord \\
\hline TWRS & 36,860 & $\begin{array}{r}12,430 \\
\end{array}$ & 800 & 0 & 0 & 0 & 58124 \\
\hline Non-Programmatic & 6 & $\begin{array}{r}1 \\
\end{array}$ & 200 & 4.000 & 60 & 100 & 437 \\
\hline Analytical Services & a. & of & 0 & 0 & 3,350 & 270 & 2610 \\
\hline Liquid Effluent & 의 & 0 & 1990 & 0 & 0 & 680 & 2580 \\
\hline Facility Transitions & 40 & 80 & 730 & $\underline{0}$ & 5 & 280 & 110 \\
\hline PNNL & 3 & 120 & 110 & 0 & 70 & 250 & 720 \\
\hline Solid Waste & 50 & 200 & 40 & ? & 0 & 260 & 19 \\
\hline Oifsite & 60 & 50 & 70 & 0 & 0 & 30 & 20 \\
\hline EM-40 & 0 & 1 & 140 & 0 & 0 & 7 & 110 \\
\hline FCAA Monitoring & 9 & 50 & 3 & $\underline{0}$ & 0 & 0 & $\theta$ \\
\hline Spent Nuclea Fuel & 3 & o & 1 & 0 & 0 & 3 & 5 \\
\hline Tory & $\operatorname{res}$ & 12,300 & 1010 & $\operatorname{sen}$ & $x+\infty$ & 1.500 & $6 \times 200$ \\
\hline
\end{tabular}

Sum of totals may not add due to rounding: numbers over $10 \mathrm{~m}^{3}$ are rounded to the nearest $10 \mathrm{~m}^{3}$, numbers less than $10 \mathrm{~m}^{3}$ are rounded to integers, non-zero numbers less than 1 are rounded to 1 .

\section{Comparison to Previous Baseline(s)}

This forecast of $67,630 \mathrm{~m}^{3}$ shows a $33 \%$ decrease from the FY96 forecast of $100,900 \mathrm{~m}^{3}$. The largest source of reduction arises from the TWRS program estimate, although almost all programs reported estimate reductions. The FY97.1 forecast $\left(67,630 \mathrm{~m}^{3}\right)$ is $0.13 \%$ higher than the FY97.0 forecast of $67,540 \mathrm{~m}^{3}$.

\section{LLMW \& TRU(M) Waste Comparison to Previous Baseline(s) by Physical Waste Form}

For the FY 97.1 forecast the volume percent of the three most significant physical waste forms are: debris waste $(89 \%)$, inorganic homogeneous solids $(4 \%)$ and shielding $(3 \%)$. For the FY96 forecast the percentages are: debris waste $(79 \%)$, inorganic homogeneous solids (7\%), and labpacks $(4 \%)$.

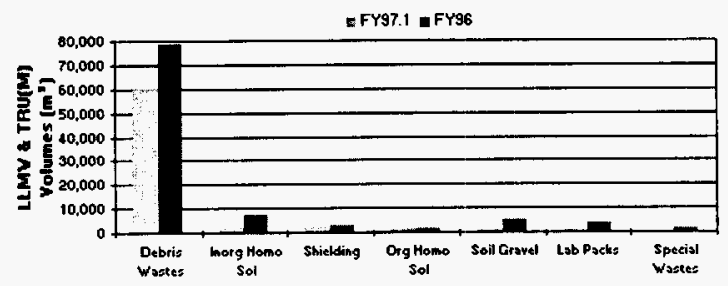

(in descending order by Physical Waste Form volume) 


\begin{tabular}{|c|c|c|}
\hline $\begin{array}{l}\text { LLMW a TRU(M) Vaste Comparison: } \\
\text { Physical Yaste Form }\end{array}$ & $\begin{array}{c}\text { FY97.1 Forecast } \\
\text { (m') }\end{array}$ & $\begin{array}{c}\text { FY96 Forecast } \\
\left(m^{2}\right)\end{array}$ \\
\hline Debris Wastes & 60.580 & $\ldots . \ldots 7870$ \\
\hline Inorg Homo Sol & 2370 & .3 .440 \\
\hline Shieiding & 2,180 & 2.790 \\
\hline Org Homp Sol. & 1,210 & 1,740 \\
\hline Sol Gravel. & 580 & 5.330 \\
\hline Lab Packs & 420 & 3,760 \\
\hline Special Wastes & 290 & 1,090 \\
\hline Tard & GT.6re & resser \\
\hline
\end{tabular}

Sum of totals may not add due to rounding: numbers over $10 \mathrm{~m}^{3}$ are rounded to the nearest $10 \mathrm{~m}^{3}$, numbers less than $10 \mathrm{~m}^{3}$ are rounded to integers, non-zero numbers less than 1 are rounded to $I$.

\section{LLMW \& TRU(M) Waste Comparison to Previous Baseline(s) by Hazardous Constituent}

For the FY 97.1 forecast the volume percent of the three most significant hazardous waste constituents are: Washington State regulated $(59 \%)$; toxic organics $(20 \%)$; and metals without mercury $(6 \%)$. For the FY96 forecast the percentages are: toxic organics $(69 \%)$; state regulated (9\%); corrosives $(9 \%)$; and metals without mercury $(8 \%)$.

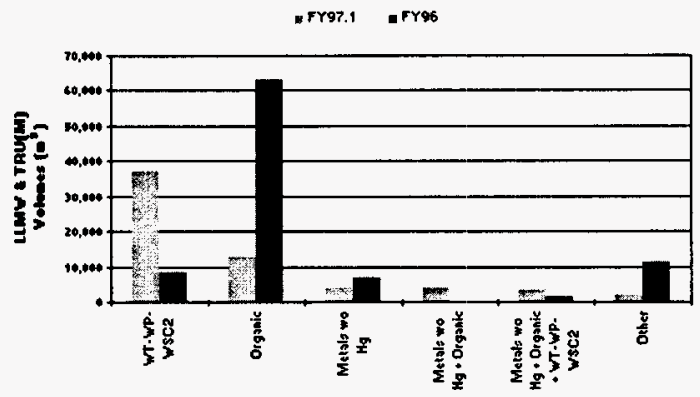

(in descending order by Hazardous Constituent volume)

\begin{tabular}{|c|c|c|}
\hline $\begin{array}{l}\text { LLWN \& Tau(W) Waste Comporison } \\
\text { Hazardous Constituent }\end{array}$ & $\begin{array}{c}\text { FYg7.1 Forecast } \\
\left(\mathrm{m}^{3}\right) \\
\end{array}$ & $\begin{array}{c}\text { FY9s Forecest } \\
\left(\mathrm{m}^{3}\right)\end{array}$ \\
\hline w1-np-nsc2 & 37,030 & 8,210 \\
\hline Orgenic & 12,930 & 63.020 \\
\hline Metals wo Hg & 4,010 & 7,090 \\
\hline Metals wo Hg + Organic & 4,000 & 0 \\
\hline Metals wo Hg + Organic + WT-WP-WSC? & 3,490 & 1,540 \\
\hline Other & 1,824 & 11,460 \\
\hline Total & 63200 & 91,320 \\
\hline
\end{tabular}

Sum of rotals may not add due to rounding: numbers over $10 \mathrm{~m}^{3}$ are rounded to the nearest $10 \mathrm{~m}^{3}$, numbers less than $10 \mathrm{~m}^{3}$ are rounded to integers, non-zero numbers less than $I$ are rounded to $I$.

\section{Definitions}

\section{Physical Waste Forms (PWFs)}


The primary physical waste forms of most waste volumes can be delineated in the following categories, based on the DOE Waste Treatability Group Guidance Document (DOE/LLW-217 Revision 0):

Debris Wastes: Wastes that meet the U.S. Environmental Protection Agency (EPA) criteria for "debris." Debris materials are divided into four groups as either metal (inorganic), inorganic non-metal, combustible (organic), or mixtures of materials (heterogeneous). If the waste is dominated by one type of material it should be classified as that material; otherwise it is classified as heterogeneous.

Inorganic Homogeneous Solids: Material that has an inorganic matrix or content, and does not meet the criteria for debris.

Organic Homogeneous Solids: Material that has an organic matrix or content (i.e., material that includes chemical compounds based on carbon, hydrogen, and oxygen), and does not meet the criteria for debris.

Labpacks: Various quantities of compatible waste within the same Department of Transportation hazard class, packaged in vessels such as cans or bottles.

Soils/Gravel: Soil or gravel contaminated with hazardous and/or radioactive materials.

Shielding: Three types of shielding include steel, lead, and concrete. It is assumed that, if shielding is required, then the shiclding material is handled as solid waste. A fourth type of shielding is also included: void space, which is space within a container that is not occupied by waste.

Special Wastes: waste containing one or more of the following: elemental mercury, elemental lead, beryllium waste, batteries, reactive metals, explosives/propellants, and aerosols/compressed gases.

\section{Hazardous Constituents (HCs)}

Hazardous constituents as defined by the Resource Conservation and Recovery Act (RCRA) are an important characteristic of the waste that will be generated. These hazardous constituents can be grouped into eight main categories that may be individual or mixed. Several hazardous constituents might be present in a particular waste form and require definition by waste volume percentages as mixed hazardous constituents (e.g., if a 208-liter drum contains both ignitables and corrosives, then the package is $100 \%$ ignitables and corrosives). The relevant hazardous constituent groups are:

Ignitables (RCRA code: D001): Waste that can cause a fire through friction, absorption of moisture, or spontaneous chemical action.

Corrosives (RCRA code: D002): Any liquid or solid that causes destruction of human skin tissue or that has a severe corrosion rate on steel.

Reactive Metals (RCRA code: D003): Typically sodium metal or alkali metal alloys but can also be particulate fines of aluminum, uranium, zirconium, or other pyrophoric materials, and may be mixed with stabilizing materials.

Metals Without Mercury (RCRA codes: D004-D011): Toxic metals that are not contaminated with mercury.

Metals With Mercury (RCRA codes: D009, P065, P092, and U151): Toxic metals that are specifically contaminated with mercury.

Toxic Organics (RCRA codes: D018-D043): Toxic organic compounds.

State Regulated (Washington State codes: WT, WP, WSC2): Waste that is defined as hazardous only under Washington State regulations.

PCBs: Polychlorinated biphenyl-contaminated materials (designated in 40 CFR 761 or WAC 173-303-071) where PCB concentration is further divided into two categories: less than 50 parts per million (ppm), and greater than or equal to $50 \mathrm{ppm}$. 


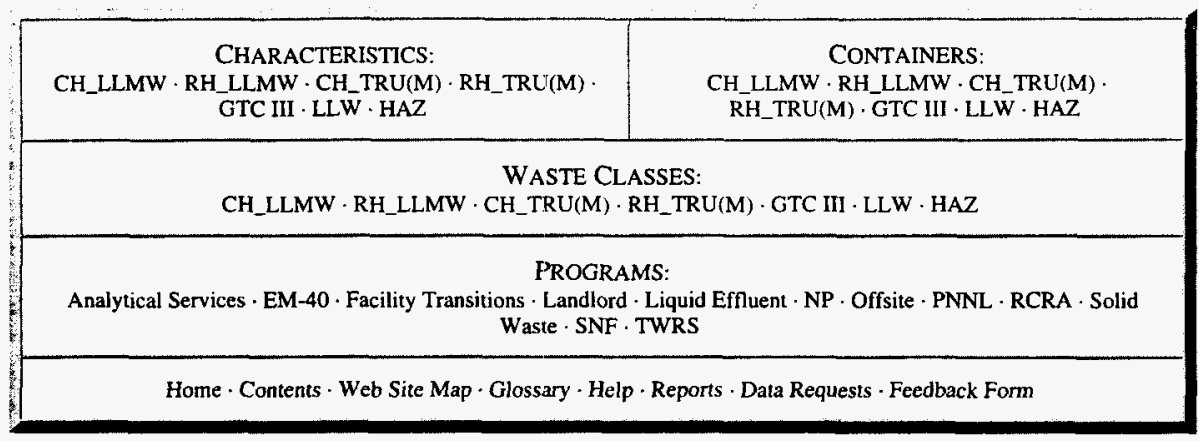

NOTICE: This page is provided subject to our disclaimer. Contact: Oscar Valero at (509) 373-4752.

HNF-EP-0918 rev. 1 Approved for public release; distribution is unlimited. 


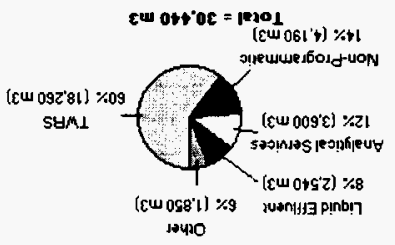

uọnq!ג19!a ue.180.dd

$\cdot(\%$ l $)$ słuən!̣ısuos snoprezey әsəul jo suoṇeutquoo

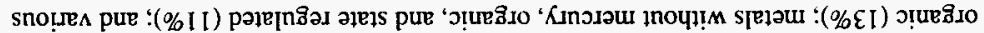

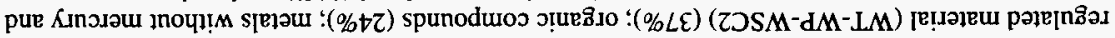

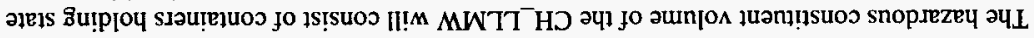

sunof

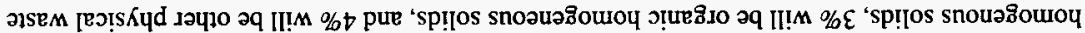

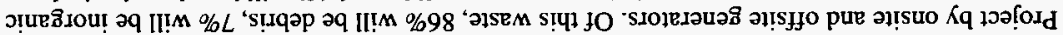

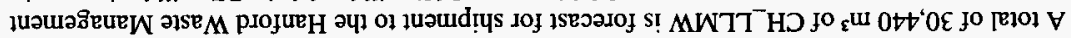

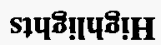

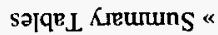

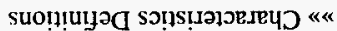

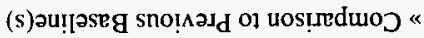

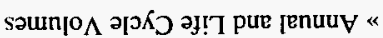

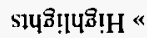

ราบวิน⿰冫

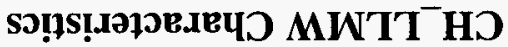

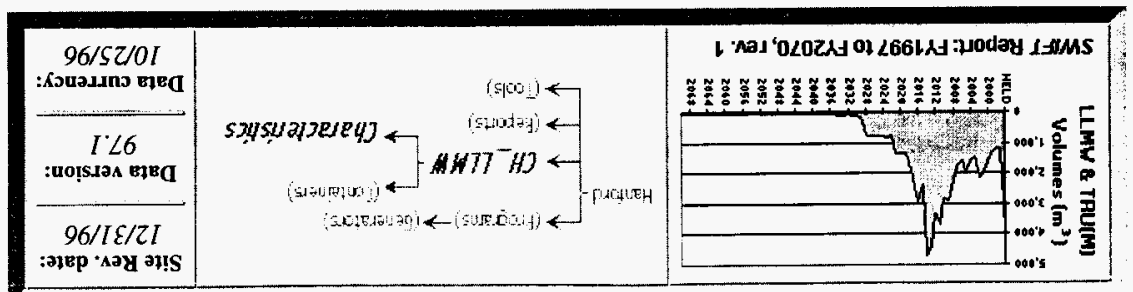




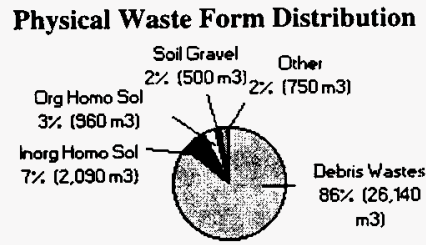

Total $=30,440 \mathrm{m3}$

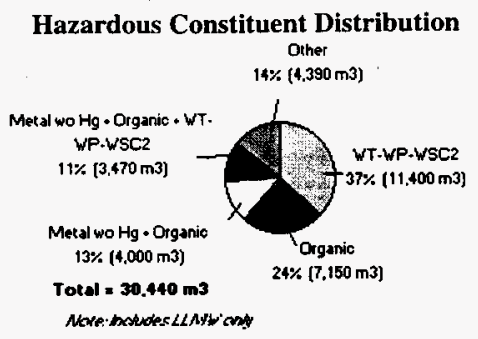

Container Distribution

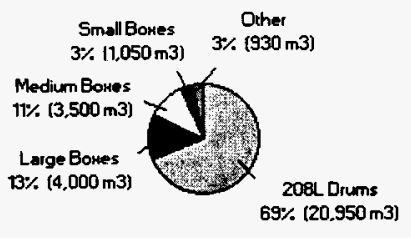

Toral $=30,440 \mathrm{~m} 3$

Sum of totals may not add due to rounding: numbers over $10 \mathrm{~m}^{3}$ are rounded to the nearest $10 \mathrm{~m}^{3}$, numbers less than $10 \mathrm{~m}^{3}$ are rounded to integers, non-zero numbers less than 1 are rounded to 1 .

\section{Annual Characteristics Volumes}

\section{Physical Waste Forms (PWFs)}

\section{CH_LLMW Life Cycle Volumes by Physical Waste Form}

The total baseline volume of waste is approximately $30,440 \mathrm{~m}^{3}$. The minimum expected volume is approximately $19,180 \mathrm{~m}^{3}$, and the maximum expected volume is $53,080 \mathrm{~m}^{3}$. The minimum, baseline, and maximum waste forecast volumes are distributed as follows:

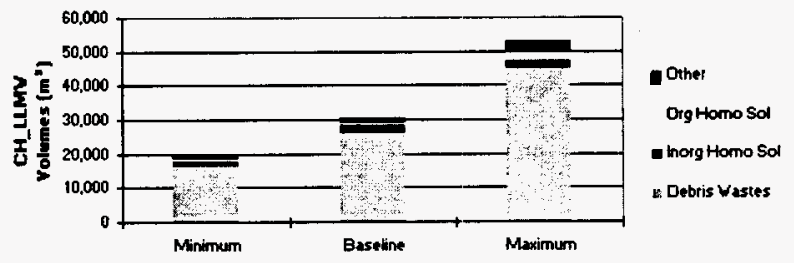

(In descending order, by Physical Waste Form volume) 


\begin{tabular}{|c|c|c|c|}
\hline $\begin{array}{l}\text { CH_LLMV Life Cycle: } \\
\text { Phosical Yaste Form }\end{array}$ & Minimum & Baseline & Maximum \\
\hline $\begin{array}{l}\text { Debris Wastes } \\
\text { Inorg Homo Sol } \\
\text { Org Homo Sol } \\
\text { Other }\end{array}$ & $\begin{array}{r}16,350 \\
1,650 \\
460 \\
720 \\
\end{array}$ & $\begin{array}{r}26,140 \\
2,090 \\
960 \\
1,240 \\
\end{array}$ & $\begin{array}{r}44,970 \\
2,470 \\
1,650 \\
3,990 \\
\end{array}$ \\
\hline Tordy & 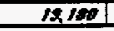 & $\pi x+16$ & $5 x, 000$ \\
\hline
\end{tabular}

Sum of totals may not add due to rounding: numbers over $10 \mathrm{~m}^{3}$ are rounded to the nearest $10 \mathrm{~m}^{3}$, numbers less than $10 \mathrm{~m}^{3}$ are rounded to integers, non-zero numbers less than 1 are rounded to 1.

CH_LLMW Annual Baseline Volumes by Physical Waste Form

The graph shows the CH_LLMW volume for 1997 through 2070 . The $4,000 \mathrm{~m}^{3}$ (100\% debris waste) of Held waste is from the Stored Equipment Waste Generator. This waste currently exists but does not have a shipping schedule; thus, it is reported as Held waste. Waste generation will peak in 2014-2016, due primarily to waste associated with the retrieval of the long-length contaminated equipment. Waste volume from 2038 through 2070 is virtually constant at about $50 \mathrm{~m}^{3}$. The only facility operating during this period will be the $222 \mathrm{~S}$ Analytical Laboratory, which will be shipping mostly debris waste.

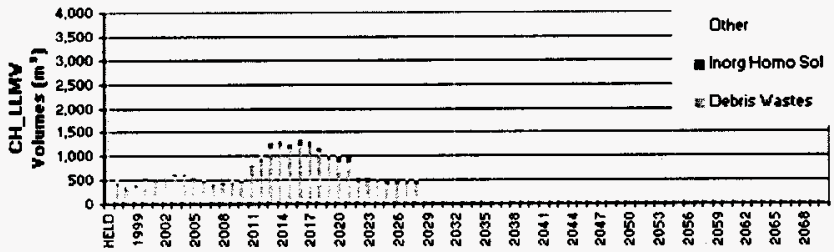

\section{Hazardous Constituents (HCs)}

\section{CH_LLMW Life-Cycle Volumes by Hazardous Constituent}

The total baseline volume of waste is approximately $30,440 \mathrm{~m}^{3}$. The minimum expected volume is approximately $19,180 \mathrm{~m}^{3}$, and the maximum expected volume is $53,080 \mathrm{~m}^{3}$. The minimum, baseline, and maximum waste forecast volumes are distributed as follows:

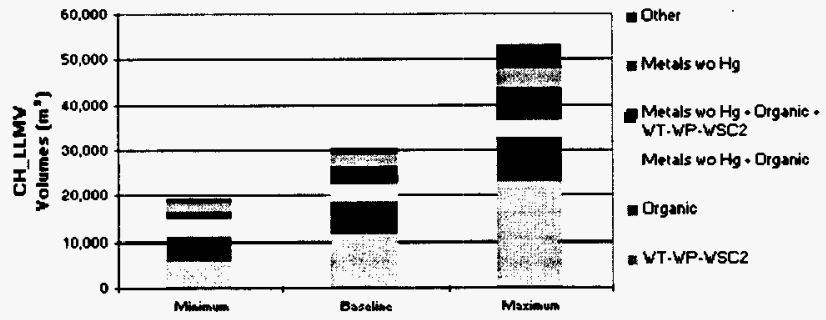

(In descending order, by Hazardous Constituent volume) 


\begin{tabular}{|c|c|c|c|}
\hline \multicolumn{4}{|l|}{ CH-LLMW Life Cycle: } \\
\hline Hazardous Constituents & Minimum & Baseline & Maximum \\
\hline WT-MP-MSC2 & 5.730 & 11.400 & 22,750 \\
\hline Orgenjc & 5,190 & 7,150 & 9750 \\
\hline Metals $\mathrm{wo} \mathrm{Ha}+$ Organic & 4,000 & 4,000 & 4,000 \\
\hline Metals wo Hg + Organic + WT-WyP-WSC2 & 1330 & 3470 & 7,100 \\
\hline Metals woHg & 1990 & 2730 & 4280 \\
\hline Other & 940 & 1.690 & 5,200 \\
\hline Toter & Asero & 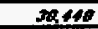 & $5 x \sin$ \\
\hline
\end{tabular}

Sum of totals may not add due to rounding: numbers over $10 \mathrm{~m}^{3}$ are rounded to the nearest $10 \mathrm{~m}^{3}$, numbers less than $10 \mathrm{~m}^{3}$ are rounded to integers, non-zero numbers less than $I$ are rounded to $I$.

\section{CH_LLMW Annual Baseline Volumes by Hazardous Constituent}

The graph shows the CH_LLMW hazardous constituent volume for 1997 through 2070 . The $4,000 \mathrm{~m}^{3}$ (100\% metals without mercury, organic) of Held waste is from the Stored Equipment Waste Generator. Waste generation will peak in 2013-2014, due primarily to Washington State regulated waste and toxic organic waste from retrieval of the long-length contaminated equipment (from the TWRS program). Waste volume from 2038 through 2070 is constant at about $45 \mathrm{~m}^{3}$. The only facility operating during this period will be the $222 \mathrm{~S}$ Analytical Laboratory.

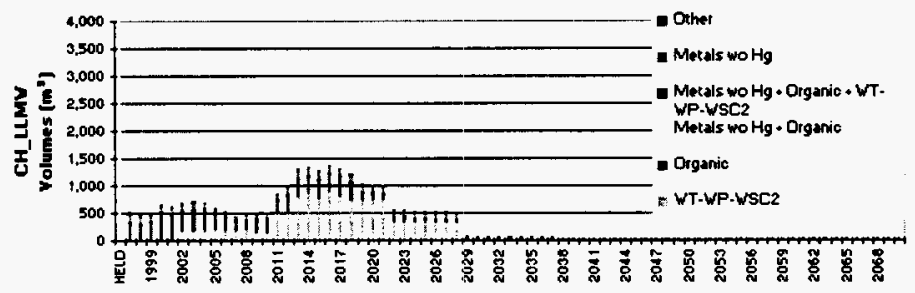

\section{Summary Tables (Volumes in $\mathbf{m}^{3}$ )}

Physical Waste Forms (PWFs)

CH_LLMW Forecast by Physical Waste Form

(In descending order, by Physical Waste Form volume)

\begin{tabular}{|c|c|c|}
\hline $\begin{array}{l}\text { CH_LLMY Forecast: } \\
\text { Physioal Vaste Form }\end{array}$ & $\begin{array}{c}\text { FY97.1 Folreast } \\
\left(m^{\prime}\right)\end{array}$ & $x$ of Tolal \\
\hline Debris Wastes & 26.140 & $86 \%$ \\
\hline Inorg Homo Sol & 2090 & $7 \%$ \\
\hline Org Homo Sol & 960 & $3 \%$ \\
\hline Soll Gravel & 500 & $2 \%$ \\
\hline LabPacks & 420 & $\%$ \\
\hline Special wastes & 200 & $1 \%$ \\
\hline Shielding & 50 & $<1 \%$ \\
\hline Tors & 3040 & rove \\
\hline
\end{tabular}

Sum of totals may not add due to rounding: numbers over $10 \mathrm{~m}^{3}$ are rounded to the nearest $10 \mathrm{~m}^{3}$, numbers less than $10 \mathrm{~m}^{3}$ are rounded to integers, non-zero numbers less than 1 are rounded $\mathrm{s} 1$. 
CH_LLMW Life-Cycle Baseline Volumes by Physical Waste Form ( $\mathbf{m}^{3}$ )

(In descending order, by Physical Waste Form volume)

\begin{tabular}{|c|c|c|c|c|c|c|c|}
\hline $\begin{array}{l}\text { CH_LLMW } \\
\text { Physical Waste Forms: } \\
\text { Program }\end{array}$ & $\begin{array}{l}\text { Debris } \\
\text { Wastes }\end{array}$ & $\begin{array}{l}\text { Inorg } \\
\text { Homo } \\
\text { Sol }\end{array}$ & $\begin{array}{c}\text { Org } \\
\text { Homo } \\
\text { Sol }\end{array}$ & $\begin{array}{c}\text { Soil } \\
\text { Gravel }\end{array}$ & $\begin{array}{c}\text { Lab } \\
\text { Packs } \\
\end{array}$ & Other & Toter \\
\hline MRS & 17,690 & 40 & 50 & 440 & 0 & 50 & $\$ 8,260$ \\
\hline Non-Programmatic & 4070 & 1 & 2 & 1 & 90 & 30 & 4790 \\
\hline Analytical Services & 2,850 & 0 & 710 & 0 & 30 & 0 & 3,600 \\
\hline Liguid Eftluent & 330 & 2,000 & 130 & D & 30 & 50 & 2540 \\
\hline Facilty Transitions & 510 & 20 & 5 & 1 & 80 & 150 & 770 \\
\hline PNNL & 270 & 0 & 0 & 0 & 180 & 40 & 490 \\
\hline Solid Waste & 300 & 1 & 1 & 1 & 1 & 10 & 310 \\
\hline Offsite & 100 & 30 & 60 & 1 & 3 & 6 & 200 \\
\hline RCRA Monitoring & 5 & 0 & 0 & 50 & 0 & 3 & 60 \\
\hline EM-40 & 6 & 1 & 1 & 3 & 요 & 마 & 10 \\
\hline Spent Nuclear Fuel & 2 & 3 & 1 & 0 & 0 & 1 & 5 \\
\hline Tota! & 26,140 & 2,090 & 960 & 500 & 420 & 330 & 30,440 \\
\hline
\end{tabular}

Sum of totals may not add due to rounding: numbers over $10 \mathrm{~m}^{3}$ are rounded to the nearest $10 \mathrm{~m}^{3}$, numbers less than $10 \mathrm{~m}^{3}$ are rounded to integers, non-zero numbers less than 1 are rounded to 1.

\section{Hazardous Constituents (HCs)}

\section{CH_LLMW Forecast by Hazardous Constituent Volumes ( $\mathbf{m}^{3}$ )}

(In descending order, by Hazardous Constituent volume)

\begin{tabular}{|c|c|c|}
\hline $\begin{array}{l}\text { CH_LLMV Forecast: } \\
\text { Hezerdous constiluent }\end{array}$ & $\begin{array}{c}\text { FY97.1 Forecast } \\
{\left[\mathrm{m}^{\prime \prime}\right)}\end{array}$ & Percent \\
\hline WT-WP-WSC2 & $\begin{array}{r}11,400 \\
-19 \\
-10\end{array}$ & $37 \%$ \\
\hline Organic & 7.150 & $24 \%$ \\
\hline Metal wo Hg - Organic & 4,000 & $13 \%$ \\
\hline Metal wo Hg - Organic + WT.WP-WSC2 & 3,470 & $11 \%$ \\
\hline Mecals woHg & 2730 & $9 \%$ \\
\hline Other & 1.690 & $6 \%$ \\
\hline Tares & $\mathrm{nese}$ & 1000 \\
\hline
\end{tabular}

Sum of totals may not add due to rounding: numbers over $10 \mathrm{~m}^{3}$ are rounded to the nearest $10 \mathrm{~m}^{3}$, numbers less than $10 \mathrm{~m}^{3}$ are rounded to integers, non-zero numbers less than 1 are rounded to $J$.

\section{CH_LLMW Life-Cycle Baseline Volumes by Hazardous Constituent Volumes (m³)}

(In descending order, by Hazardous Constituent volume)

\begin{tabular}{|c|c|c|c|c|c|c|c|}
\hline $\begin{array}{l}\text { CH_LLMY } \\
\text { Hazardous Constituents: } \\
\text { Program }\end{array}$ & $\begin{array}{c}\text { VT-YP- } \\
\text { YSC2 }\end{array}$ & Organic & $\begin{array}{c}\text { Metal wo Hg } \\
\text { - Organic }\end{array}$ & $\begin{array}{c}\text { Metal wo Hg } \\
\text { Organic * } \\
\text { YT-YP-YSC2 }\end{array}$ & $\begin{array}{c}\text { Metals } \\
\text { vo Hg }\end{array}$ & Other & Tores \\
\hline TWRS & 11230 & 6.710 & 0 & on & 300 & 30 & 1stese \\
\hline Non-P fogammatic & 6 & 1 & $+\quad+000$ & 60 & 30 & 100 & 110 \\
\hline Analytical Services & 0 & 0 & 0 & 3,330 & 0 & 270 & 200 \\
\hline Liquid Effluent & D & 0 & 0 & 0 & 1.900 & 630 & 2518 \\
\hline Facility Transitions & 40 & 80 & 0 & 5 & 360 & 290 & 70 \\
\hline PNAL & 0 & 110 & 0 & 70 & 40 & 260 & 10 \\
\hline Solid Wesce. & 50 & 150 & 0 & 0 & 20 & 90 & sro \\
\hline Offsite & 60 & 50 & 0 & a & 70 & 30 & 200 \\
\hline RCRAMonitoring & 9 & 50 & $\underline{0}$ & 0 & 3 & 0 & 9 \\
\hline EM-40 & 0 & 1 & 0 & 0 & 9 & 1 & 10 \\
\hline Spene Nuclear Fuel & 3 & 0 & 0 & 0 & 1 & 3 & 5 \\
\hline Tory & 11.000 & 7.150 & $4, \infty$ & $x+7$ & 2,790 & 1.60s & seese \\
\hline
\end{tabular}

Sum of torals may not add due to rounding: numbers over $10 \mathrm{~m}^{3}$ are rounded to the nearest $10 \mathrm{~m}^{3}$, numbers less than $10 \mathrm{~m}^{3}$ are rounded to integers, non-zero numbers less than I are rounded to 1. 


\section{Comparison to Previous Baseline(s)}

This forecast of $30,440 \mathrm{~m}^{3}$ shows a $58 \%$ decrease from the FY96 forecast of $73,040 \mathrm{~m}^{3}$. The largest source of reduction arises from the elimination of $32,980 \mathrm{~m}^{3}$ of CH_LLMW in LECs from the 1996 data. No CH_LLMW will be shipped in LECs since this waste has been reclassified as RH_LLMW. The FY 97.1 forecast $\left(30,440 \mathrm{~m}^{3}\right)$ is $0.13 \%$ higher than the FY97.0 forecast of $30,400 \mathrm{~m}^{3}$.

\section{CH_LLMW Comparison to Previous Baseline(s) by Physical Waste Form}

For the FY 97.1 forecast the volume percent of the three most significant physical waste forms are: debris waste $(86 \%)$, inorganic homogeneous solids (7\%) and organic homogeneous solids (3\%). For the FY96 forecast the percentages are: debris waste $(75 \%)$, inorganic homogeneous solids (9\%), and labpacks (5\%).

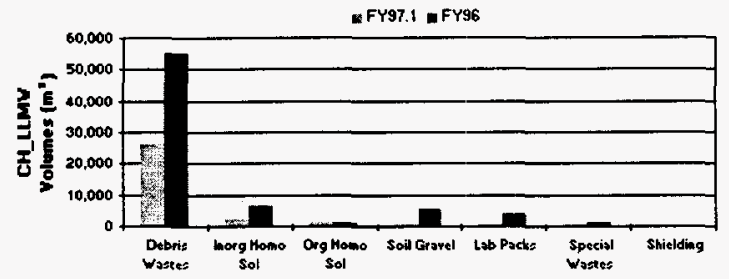

(In descending order, by Physical Waste Form volume)

\begin{tabular}{|c|c|c|}
\hline $\begin{array}{l}\text { CH_LLMV Comparison: } \\
\text { Physieal Vaste Form }\end{array}$ & $\begin{array}{c}\text { Fra7. I Forecast } \\
\left(\mathrm{m}^{3}\right)\end{array}$ & $\begin{array}{l}\text { FYSS Forecast } \\
\left(m^{2}\right)\end{array}$ \\
\hline Debris Wastes & 26,140 & 54,860 \\
\hline norg Homo Sol & 2090 & 6.670 \\
\hline Org Homo Sol & 960 & 1,350 \\
\hline Soil Graved & 500 & 5,290 \\
\hline LabPacks & 120 & 3,600 \\
\hline Special Wastes & 280 & 1,050 \\
\hline Shielding & 50 & 230 \\
\hline Tores & nete & racese \\
\hline
\end{tabular}

Sum of totals may not add due to rounding: numbers over $10 \mathrm{~m}^{3}$ are rounded to the nearest $10 \mathrm{~m}^{3}$, numbers less than $10 \mathrm{~m}^{3}$ are rounded to integers, non-zero numbers less than $/$ are rounded to $/$.

\section{CH_LLMW Comparison to Previous Baseline(s) by Hazardous Constituent}

For the FY 97.1 forecast the volume percent of the three most significant hazardous waste constituents are: Washington State regulated (37\%), toxic organics $(24 \%)$, and metals without mercury, toxic organics (13\%). For the FY96 forecast the percentages are: toxic organics $(68 \%)$, Washington State regulated waste $(10 \%)$, and metals without mercury $(7 \%)$. 


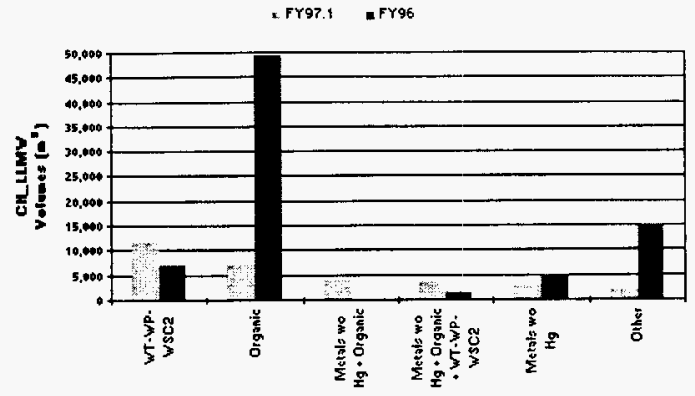

(In descending order, by Hazardous Constituent volume)

\begin{tabular}{|c|c|c|}
\hline $\begin{array}{l}\text { CH_LLMWW Comparison } \\
\text { Hazardous Constituent }\end{array}$ & $\begin{array}{c}\text { FY97.1 Forecest } \\
\left(\mathrm{m}^{3}\right)\end{array}$ & $\begin{array}{c}\text { FYg6 Forecast } \\
\left(\mathrm{m}^{3}\right)\end{array}$ \\
\hline WT-WP-WSC2 & 11.400 & 7,160 \\
\hline Organic & 7.150 & 49,400 \\
\hline Metals wo Hg + Organic & 4,000 & (na) \\
\hline Metels wo Hg + Organic + WT-WP-WSC2 & 3470 & 1.540 \\
\hline Metals wo Hig & 2,730 & 4900 \\
\hline Other & 1.664 & 14,930 \\
\hline Total & 30,440 & 73,040 \\
\hline
\end{tabular}

Sum of totals may not add due to rounding: numbers over $10 \mathrm{~m}^{3}$ are rounded to the nearest $10 \mathrm{~m}^{3}$, numbers less than $10 \mathrm{~m}^{3}$ are rounded to integers, non-zero numbers less than 1 are rounded to $I$.

\begin{tabular}{|c|c|}
\hline 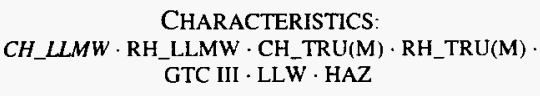 & $\begin{array}{l}\text { CONTAINERS: } \\
\text { CH_LLMW } \cdot \text { RH_LLMW } \cdot \text { CH_TRU(M) } \\
\text { RH_TRU(M) } \cdot \text { GTC III } \cdot \text { LLW } \cdot \text { HAZ }\end{array}$ \\
\hline \multicolumn{2}{|c|}{ 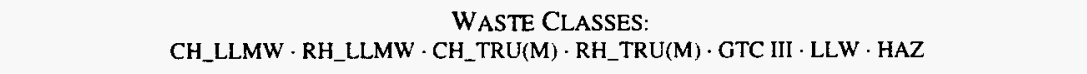 } \\
\hline $\begin{array}{r}\text { PROC } \\
\text { Analytical Services } \cdot \text { EM-40 - Facility Transitions } \cdot \text { Land! } \\
\text { Waste } \cdot \mathrm{SI}\end{array}$ & 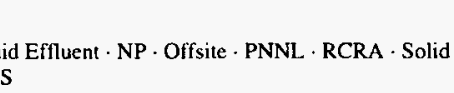 \\
\hline
\end{tabular}

NOTICE: This page is provided subject to our disclaimer. Contact: Oscar Valero at (509) 373-4752.

HNF-EP-0918 rev. I Approved for public release; distribution is unlimited. 
THIS TART MTWN WLY

Li........ 


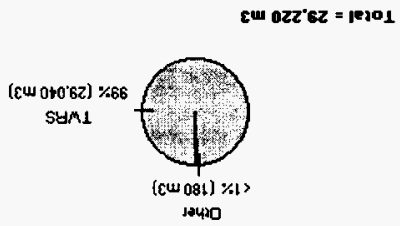

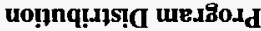

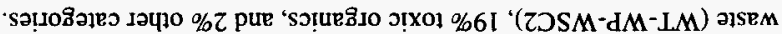

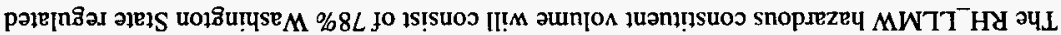

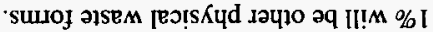

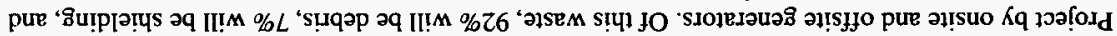

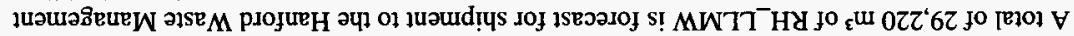

งาบริเบบริเก

sə|qе $L$ Kreurum

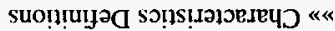

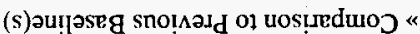

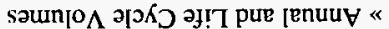

งเบำ!บำ!H «

Sุนวุบoว

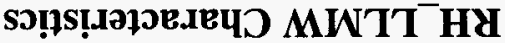

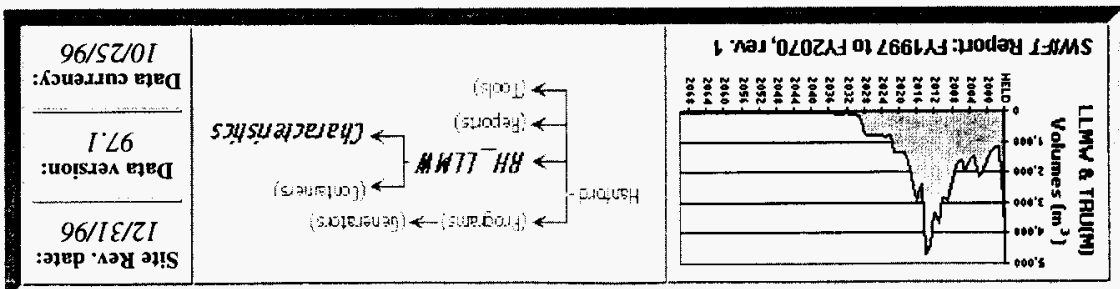




\section{Physical Waste Form Distribution}

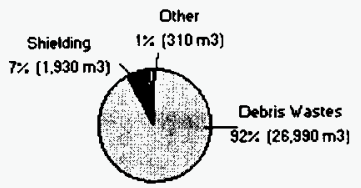

Total $=29.220 \mathrm{m3}$

\section{Hazardous Constituent Distribution}

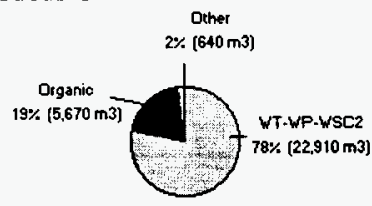

Total = $29.220 \mathrm{m3}$

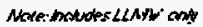

\section{Container Distribution}

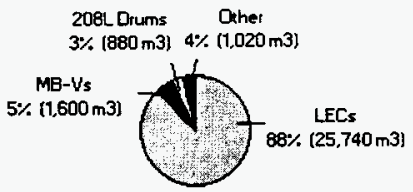

Total $=29,220 \mathrm{~m} 3$

Sum of totals may not add due to rounding: numbers over $10 \mathrm{~m}^{3}$ are rounded to the nearest $10 \mathrm{~m}^{3}$, numbers less than $10 \mathrm{~m}^{3}$ are rounded to integers, non-zero numbers less than 1 are rounded to 1 .

\section{Annual RH_LLMW Characteristics}

\section{Physical Waste Forms (PWFs)}

\section{RH_LLMW Life Cycle Volumes by Physical Waste Form}

The total baseline volume of waste is approximately $29,220 \mathrm{~m}^{3}$. The minimum expected volume is approximately $14,870 \mathrm{~m}^{3}$, and the maximum expected volume is $38,190 \mathrm{~m}^{3}$. The minimum, baseline, and maximum waste forecast volumes are distributed as follows:

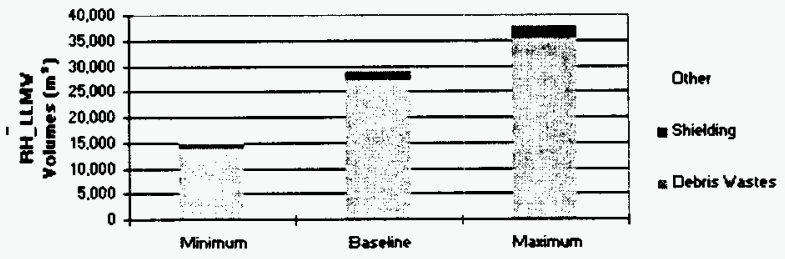

(in descending order by Physical Waste Form volumes) 


\begin{tabular}{|c|c|c|c|}
\hline $\begin{array}{l}\text { AH_LLMV Vaste Life Cgale: } \\
\text { Physical Vaste Form }\end{array}$ & Minimum & Buseline & Maximoum \\
\hline Debris Wostes & 13,890 & 26.990 & 35,320 \\
\hline Shielding & 820 & 1930 & 2,240 \\
\hline Other & 150 & 310 & 620 \\
\hline Tord & Pl.sp & $2 \times 220$ & $x / 20$ \\
\hline
\end{tabular}

Sum of totals may not add due to rounding: numbers over $10 \mathrm{~m}^{3}$ are rounded to the nearest $10 \mathrm{~m}^{3}$, numbers less than $10 \mathrm{~m}^{3}$ are rounded to integers, non-zero numbers less than 1 are rounded to $I$.

\section{RH_LLMW Annual Baseline Volumes by Physical Waste Form}

The graph shows the RH_LLMW volume for 1997 through 2032. The TWRS program accounts for more than $99 \%$ of the RH_LLMW. Waste generation will peak in 2013-2014, due primarily to retrieval of the long-length contaminated equipment, from the TWRS program.

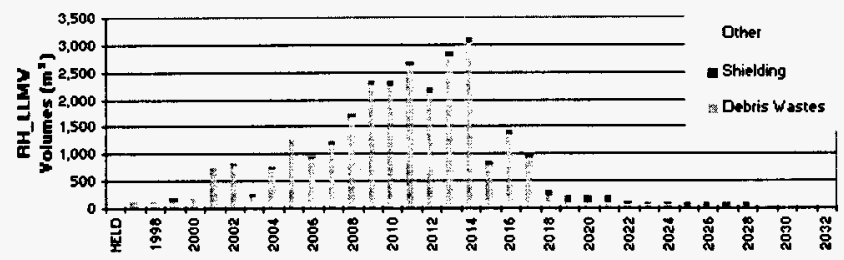

\section{Hazardous Constituents (HCs)}

\section{RH_LLMW Life-Cycle Volumes by Hazardous Constituent}

The total baseline volume of waste is approximately $29,220 \mathrm{~m}^{3}$. The minimum expected volume is approximately $14,870 \mathrm{~m}^{3}$, and the maximum expected volume is $38,190 \mathrm{~m}^{3}$. The minimum, baseline, and maximum waste forecast volumes are distributed as follows:

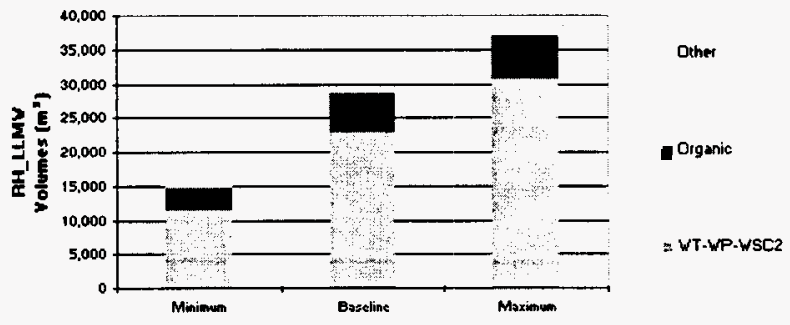

(in descending order by Hazardous Constituent volumes)

\begin{tabular}{|c|c|c|c|}
\hline $\begin{array}{l}\text { RH-LLMW Life Cycle: } \\
\text { Hazardous Conetituents }\end{array}$ & Minimum & Baseline & Maximum \\
\hline MI-WP-WSC2 & 11,460 & 22,910 & 30730 \\
\hline Organic & 3,140 & 5,670 & 6.290 \\
\hline Other & 270 & 640 & 1,170 \\
\hline & 11.sert & 22,220 & 3220 \\
\hline
\end{tabular}

Sum of tolals may not add due to rounding: numbers over $10 \mathrm{~m}^{3}$ are rounded to the nearest $10 \mathrm{~m}^{3}$, numbers less 
than $10 \mathrm{~m}^{3}$ are rounded to integers, non-zero numbers less than 1 are rounded to $\mathrm{l}$.

RH_LLMW Annual Baseline Volumes by Hazardous Constituent

The graph shows the RH_LLMW volume for 1997 through 2032. The TWRS program accounts for more than $99 \%$ of the RH_LLMW. Waste generation will peak in 2013-2014, due primarily to retrieval of the long-length contaminated equipment from the TWRS program.

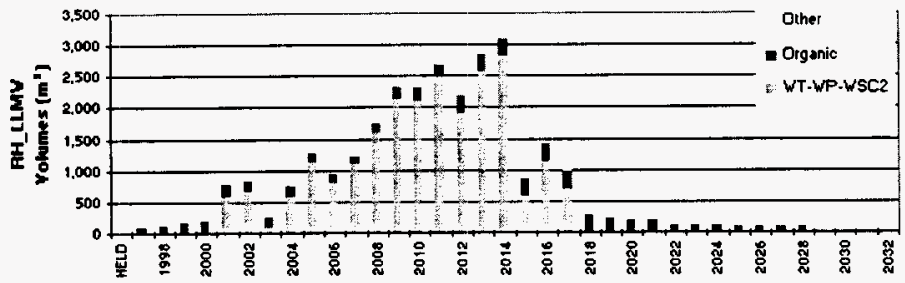

\section{Summary Tables (Volumes in $\mathbf{m}^{3}$ )}

\section{Physical Waste Forms (PWFs)}

\section{RH_LLMW Forecast by Physical Waste Form}

(in descending order by Physical Waste Form volumes)

\begin{tabular}{|c|c|c|}
\hline $\begin{array}{l}\text { RH_LLMY Forecast: } \\
\text { Phnsical Yeste Form }\end{array}$ & $\begin{array}{c}\text { FY97.1 Forecast } \\
\text { (m') }\end{array}$ & $x$ of Total \\
\hline Debris Wastes & 28,990 & $92 \%$ \\
\hline Shietding & 1.930 & $7 \%$ \\
\hline Org Homo Sol & 190 & $\%$ \\
\hline Soll Giavel & 80 & $<1 \%$ \\
\hline horg Homo Sol & 30 & $\leq 1 \%$ \\
\hline Special wastes & 6 & $<1 \%$ \\
\hline Lab Packs & 3 & $<1 \%$ \\
\hline Ford & 20220 & Nover \\
\hline
\end{tabular}

Sum of totals may not add due to rounding: numbers over $10 \mathrm{~m}^{3}$ are rounded to the nearest $10 \mathrm{~m}^{3}$, numbers less than $10 \mathrm{~m}^{3}$ are rounded to integers, non-zero numbers less than I are rounded to $I$.

RH_LLMW Life-Cycle Baseline Volumes by Physical Waste Form (m³)

(in descending order by Physical Waste Form volumes)

\begin{tabular}{|c|c|c|c|c|c|c|c|}
\hline $\begin{array}{l}\text { RH_LLMW } \\
\text { Phyraical Woete Forms: } \\
\text { Program }\end{array}$ & $\begin{array}{c}\text { Debris } \\
\text { Wastes }\end{array}$ & Shielding & $\begin{array}{c}\text { Oro } \\
\text { Homo } \\
\text { Sol }\end{array}$ & $\begin{array}{c}\text { Soll } \\
\text { Graval }\end{array}$ & $\begin{array}{l}\text { Inora } \\
\text { Homo } \\
\text { Sol }\end{array}$ & Other & Total \\
\hline TMRS & 26.870 & 1910 & 170 & 80 & 9 & 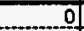 & 29,040 \\
\hline Focility Transitions & 70 & a & 0 & 0 & ] & - & 70 \\
\hline Solid Waste & 40 & 3 & 1 & 3 & 2 & 5 & 60 \\
\hline PNN & 0 & 20 & 20 & 요 & 20 & 요 & 50 \\
\hline Otfsite & 1 & 0 & 0 & 0 & 0 & 4. & 5 \\
\hline Total & 26,990 & 1,930 & 190 & 80 & 30 & 9 & 29,220 \\
\hline
\end{tabular}

Sum of totals may not add due to rounding: numbers over $10 \mathrm{~m}^{3}$ are rounded to the nearest $10 \mathrm{~m}^{3}$, numbers less than $10 \mathrm{~m}^{3}$ are rounded to integers, non-zero numbers less than $I$ are rounded to 1 . 
$(\%$ ) sp! $[\mathrm{os}$

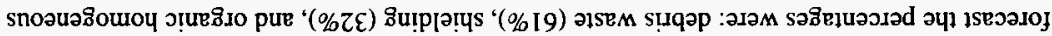

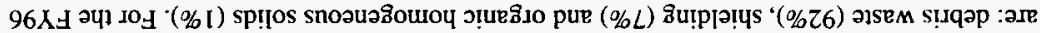

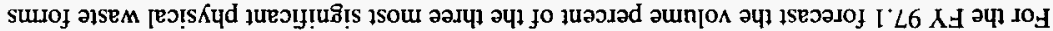

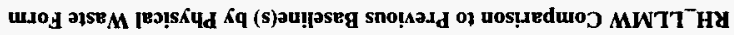

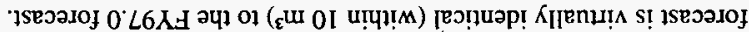

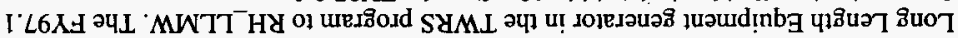

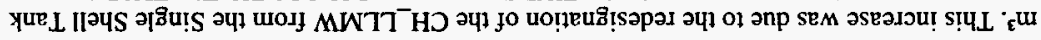

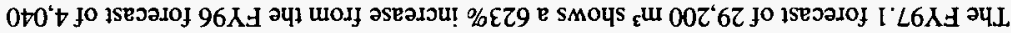

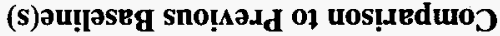

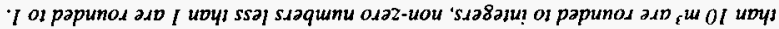

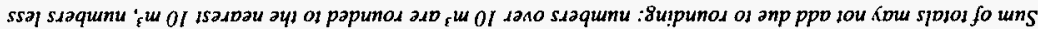

\begin{tabular}{|c|c|c|c|c|c|c|c|}
\hline $2 z z$ & 9 & $\tau$ & H & 10 & ars & AISZZ & AdOI \\
\hline f & I & 0 & 10 & $t$ & 0 & 0 & דistyo \\
\hline 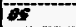 & 0 & 0 & $\overline{\alpha E}$ & $0 z$ & 0 & $\overline{0}$ & TNNA \\
\hline 25 & $\mathbf{s}$ & $\bar{c}$ & 10 & $0 t$ & $0+$ & 4 & PISEMPIIOS \\
\hline 21 & $\overline{0}$ & 0 & 0 & 102 & 0 & o & 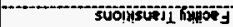 \\
\hline $6 \operatorname{sos}$ & to & $\overline{0}$ & 10 & 106t & $0+95$ & $6162 \overline{2}$ & sGMI \\
\hline AroI & 12480 & Dhisonog & 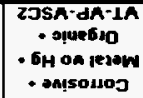 & DH on SpFidn & ग!णह 600 & $\begin{array}{c}205 n \\
-d A-1 A\end{array}$ & 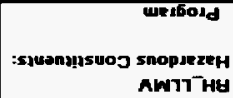 \\
\hline
\end{tabular}

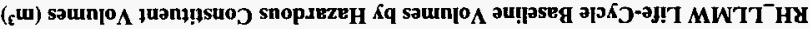

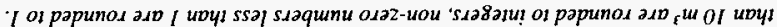

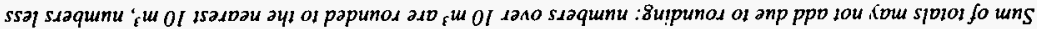

\begin{tabular}{|c|c|c|}
\hline $\operatorname{send}$ & $\arg$ & pedol \\
\hline \%1 & $0 t$ & 1940 \\
\hline$\pi z$ & 009 & DHOM SFEJWW \\
\hline$\% 61$ & $0 \angle 9 \mathrm{~S}$ & 901850 \\
\hline$\% 8 L$ & $016 \mathrm{Zz}$ & $20 S M \cdot d M-L A$ \\
\hline Fo. & 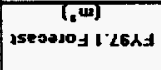 & 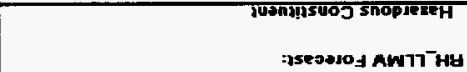 \\
\hline
\end{tabular}

(saunion „uanmisuoj snopıv2pH iq sapio \&utpua.ssap u!)

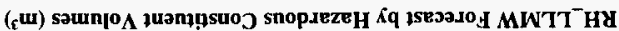




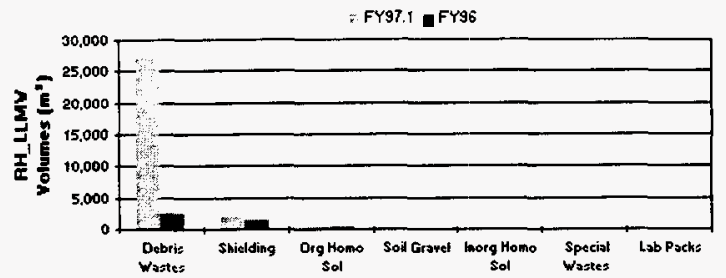

(in descending order by Physical Waste Form volumes)

\begin{tabular}{|c|c|c|}
\hline $\begin{array}{l}\text { AH_LLMV Comparison: } \\
\text { Physical Vaste Form }\end{array}$ & $\begin{array}{c}\text { FY } 97.1 \\
\text { Forecast }\left(\mathrm{m}^{2}\right)\end{array}$ & $\begin{array}{c}\text { FYss } \\
\text { Forecast }\left(m^{3}\right)\end{array}$ \\
\hline Debris Vastes & 26,990 & 2480 \\
\hline Shielding & 1,930 & 1.290 \\
\hline DrgHoma Sol & 190 & 140 \\
\hline Soil Gruval & 80 & 30 \\
\hline inorg Homo Sol & 30 & 90 \\
\hline Special Wustes & 6 & 2 \\
\hline LobPacks & 3 & 3 \\
\hline Torel & 21220 & $\operatorname{cose}$ \\
\hline
\end{tabular}

Sum of totals may not add due to rounding: numbers over $10 \mathrm{~m}^{3}$ are rounded to the nearest $10 \mathrm{~m}^{3}$, numbers less than $10 \mathrm{~m}^{3}$ are rounded to integers, non-zero numbers less than $I$ are rounded to $I$.

\section{RH_LLMW Comparison to Previous Baseline(s) by Hazardous Constituent}

For the FY 97.1 forecast the volume percent of the three most significant hazardous waste constituents are: Washington State regulated waste (78\%), toxic organics (19\%), and metals without mercury ( $2 \%)$. For the FY96 forecast the percentages were: toxic organics $(74 \%)$, Washington State regulated waste (12\%), and metals without mercury (10\%).

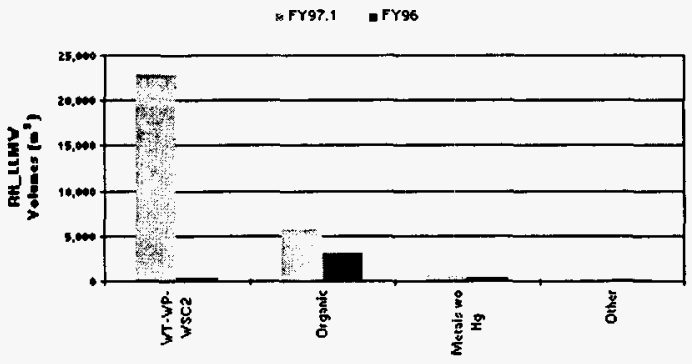

(in descending order by Hazardous Constituent volumes)

\begin{tabular}{|c|c|c|}
\hline $\begin{array}{l}\text { RH_LLM Comparison } \\
\text { Harardous Constituent }\end{array}$ & $\begin{array}{c}\text { FY97.1 } \\
\text { Forecast }\left(\mathrm{m}^{2}\right)\end{array}$ & $\begin{array}{c}\text { FYse Foreeast } \\
{\left[\mathrm{m}^{*}\right)}\end{array}$ \\
\hline WT-WP-WSC2 & 22,910 & 470 \\
\hline Organic & 5.670 & 2,990 \\
\hline Motals woHo & 600 & 410 \\
\hline Other & 40 & 170 \\
\hline Taty & 21220 & 1010 \\
\hline
\end{tabular}

Sum of totals may not add due to rounding: numbers over $10 \mathrm{~m}^{3}$ are rounded to the nearest $10 \mathrm{~m}^{3}$, numbers less than $10 \mathrm{~m}^{3}$ are rounded to integers, non-zero numbers less than 1 are rounded to $I$. 


\begin{tabular}{|c|c|}
\hline $\begin{array}{c}\text { CHARACTERISTICS: } \\
\text { CH_LLMW } \cdot R H \_L L M W \cdot \text { CH_TRU(M) } \cdot \text { RH_TRU(M) } \\
\text { GTC III } \cdot \text { LLW } \cdot \text { HAZ }\end{array}$ & $\begin{array}{c}\text { CONTAINERS: } \\
\text { CH_LLMW } \cdot \text { RH_LLMW } \cdot \text { CH_TRU(M) } \\
\text { RH_TRU(M) } \cdot \text { GTC III } \cdot \text { LLW } \cdot \text { HAZ }\end{array}$ \\
\hline \multicolumn{2}{|c|}{$\begin{array}{c}\text { WASTE CLASSES: } \\
\text { CH_LLMW } \cdot \text { RH_LLMW } \cdot \text { CH_TRU(M) } \cdot \text { RH_TRU(M) } \cdot \text { GTC III } \cdot \text { LLW } \cdot \text { HAZ }\end{array}$} \\
\hline $\begin{array}{r}\text { PROG } \\
\text { Analytical Services } \cdot \text { EM-40 } \text {. Facility Transitions } \cdot \text { Landl } \\
\text { Waste } \cdot \text { SN }\end{array}$ & id Effluent $\cdot$ NP $\cdot$ Offsite $\cdot$ PNNL $\cdot$ RCRA $\cdot$ Solid \\
\hline
\end{tabular}

NOTICE: This page is provided subject to our disclaimer. Contact: Oscar Valero at (509) 373-4752. HNF-EP-0918 rev. 1 Approved for public release; distribution is unlimited. 


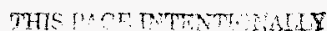
L.... Sinte 


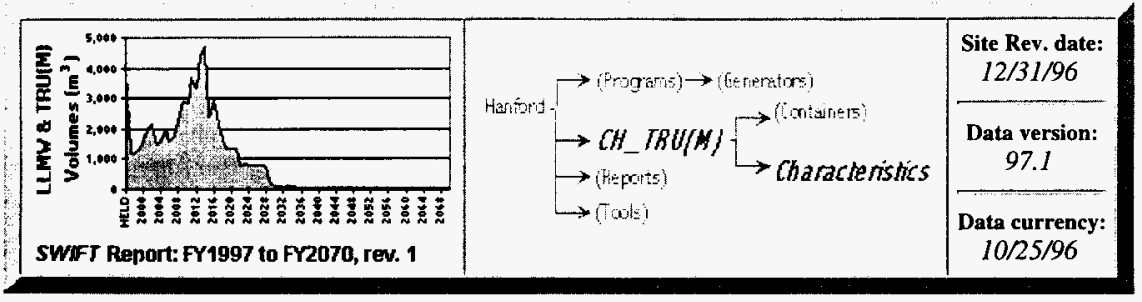

\section{CH_TRU(M) Waste Characteristics}

\section{Contents}

\author{
" Highlights \\ " Annual and Life Cycle Volumes \\ »Summary Tables
}

\begin{abstract}
»Comparison to Previous Baseline(s)
»» Characteristics Definitions
\end{abstract}

\section{Highlights}

- A total of $6,310 \mathrm{~m}^{3}$ of $\mathrm{CH}_{-}$TRU(M) waste is forecast for shipment to the Hanford Waste Management Project by onsite and offsite generators. Of this waste, $95 \%$ will be debris, $3 \%$ will be inorganic homogeneous solids, and $2 \%$ will be other physical waste forms.

- The CH_TRU(M) waste hazardous constituent volume $\left(2,080 \mathrm{~m}^{3}\right)$ will consist of Washington State regulated waste (WT-WP-WSC2) $(65 \%)$, metals without mercury (31\%), and other hazardous constituents (4\%).

\section{Program Distribution}

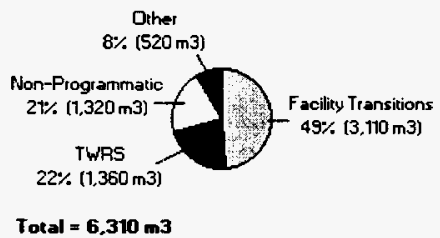


Physical Waste Form Distribution

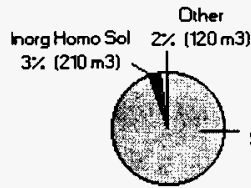

Debris Wastes

$95 \%(5,980 \mathrm{~m} 3)$

Total $=6.310 \mathrm{~m} 3$

\section{Hazardous Constituent Distribution}

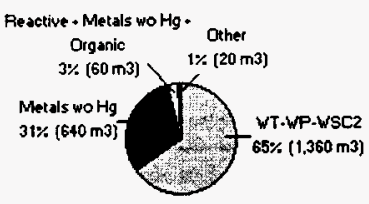

Tokal $=2,080 \mathrm{~m} 3$

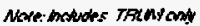

\section{Container Distribution}

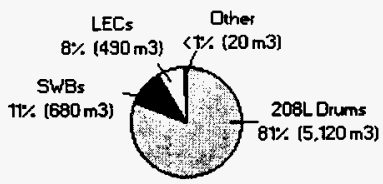

Total $=6,310 \mathrm{m3}$

Sum of totals may not add due to rounding: numbers over $10 \mathrm{~m}^{3}$ are rounded to the nearest $10 \mathrm{~m}^{3}$, numbers less than $10 \mathrm{~m}^{3}$ are rounded to integers, non-zero numbers less than 1 are rounded to 1.

\section{Annual CH_TRU(M) Waste Characteristics Volumes}

\section{Physical Waste Forms (PWFs)}

\section{CH_TRU(M) Waste Life Cycle Volumes by Physical Waste Form}

The total baseline volume of waste is approximately $6,310 \mathrm{~m}^{3}$. The minimum expected volume is approximately $2,900 \mathrm{~m}^{3}$, and the maximum expected volume is $13,290 \mathrm{~m}^{3}$. The minimum, baseline, and maximum waste forecast volumes are distributed as follows:

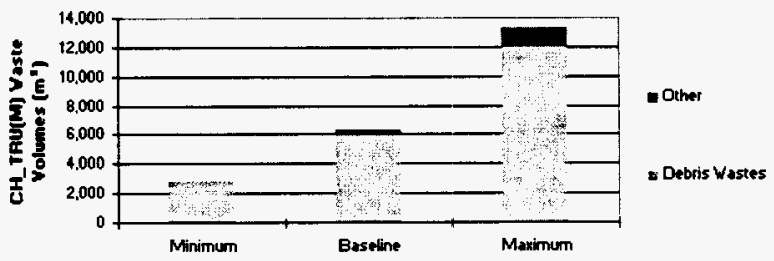

(In descending order, by Physical Waste Form volume) 


\begin{tabular}{|l|r|r|r|}
\hline $\begin{array}{l}\text { CH_TRu(M) Vaste Lile Cgcle: } \\
\text { Physieal Vaste Form }\end{array}$ & Minimum & Baseline & Maximum \\
\hline Debsis Wastes & 2,800 & 5,980 & 11,980 \\
\hline Othet & 90 & 320 & 1,310 \\
\hline
\end{tabular}

Sum of totals may not add due to rounding: numbers over $10 \mathrm{~m}^{3}$ are rounded to the nearest $10 \mathrm{~m}^{3}$, numbers less than $10 \mathrm{~m}^{3}$ are rounded to integers, non-zero numbers less than 1 are rounded to 1.

\section{CH_TRU(M) Waste Annual Baseline Volumes by Physical Waste Form}

The graph shows the $\mathrm{CH} \_$TRU(M) waste volume for 1997 through 2070. Facility Transitions will ship debris waste and inorganic homogenous solids, primarily, from 1997 through 2034. This accounts for $49 \%$ of the CH_TRU(M) waste. TWRS will ship debris waste from 2001 through 2028 , accounting for about $22 \%$ of the $\mathrm{CH}_{-}$TRU(M) waste. The Non-Programmatic (NP) program will ship debris waste from 2011 through 2037 , accounting for about $21 \%$ of the $\mathrm{CH}_{-}$TRU(M) waste. The remaining waste, about $8 \%$, will be shipped from Analytical Laboratories, EM-40, Offsite, Pacific Northwest National Laboratory, and the Spent Nuclear Fuel program.

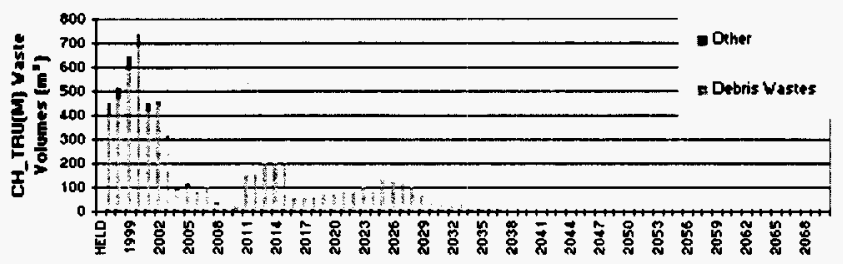

\section{Hazardous Constituents (HCs)}

\section{CH_TRU(M) Waste Life-Cycle Volumes by Hazardous Constituent}

The total baseline volume of waste is approximately $2,080 \mathrm{~m}^{3}$. The minimum expected volume is approximately $1,000 \mathrm{~m}^{3}$, and the maximum expected volume is $4,270 \mathrm{~m}^{3}$. The minimum, baseline, and maximum waste forecast volumes are distributed as follows:

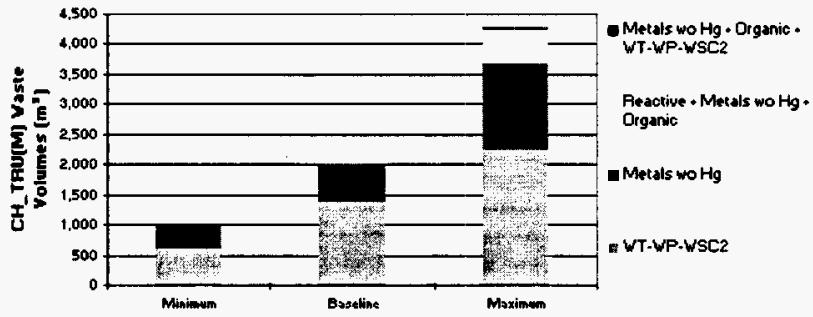

(In descending order, by Hazardous Constituent volume) 


\begin{tabular}{|c|c|c|c|}
\hline $\begin{array}{l}\text { CH-TRU(M) Waste Life Cycle: } \\
\text { Hazardous Constituents }\end{array}$ & Minimum & Baseline & Maximum \\
\hline WT-WP.WSC2 & 600 & 1360 & 2.230 \\
\hline Metys woHg & 380 & 640 & 1,440 \\
\hline Reactive - Metals wo Hg + Organic & -1 & 60 & 560 \\
\hline Metals wo Ho- Organic-WT-WP.WSC2 & 20 & 20 & 40 \\
\hline Tory & 1,00 & $2, \operatorname{an}$ & $1.2 \pi$ \\
\hline
\end{tabular}

Sum of totals may not add due to rounding: numbers over $10 \mathrm{~m}^{3}$ are rounded to the nearest $10 \mathrm{~m}^{3}$, numbers less than $10 \mathrm{~m}^{3}$ are rounded to integers, non-zero numbers less than 1 are rounded to $I$.

\section{CH_TRU(M) Waste Annual Baseline Volumes by Hazardous Constituent}

The graph shows the CH_TRUM waste hazardous constituent volume for 1997 through 2070. TWRS, shipping $100 \%$ debris waste from 2001 to 2028 , accounts for $66 \%$ of this volume. Transition projects, shipping metals without mercury (>99\%) from 1997 to 2005, accounts for $15 \%$. EM-40, Non-programmatic, and Offsite, all shipping $100 \%$ metals without mercury, contribute $15 \%$. The remaining $4 \%$ is contributed by Pacific Northwest National Laboratory and Analytical laboratories.

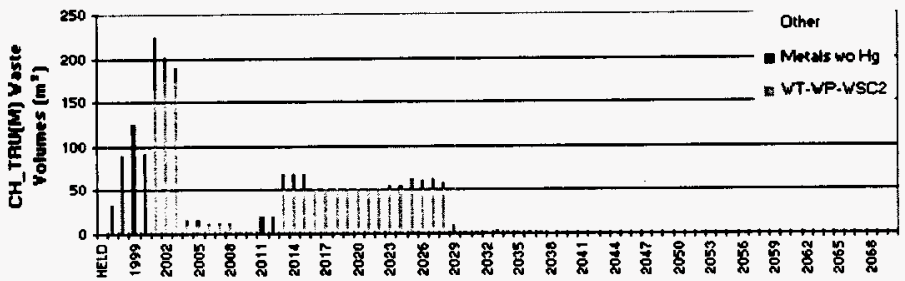

\section{Summary Tables (Volumes in $\mathbf{m}^{3}$ )}

\section{Physical Waste Forms (PWFs)}

\section{CH_TRU(M) Waste Forecast by Physical Waste Form}

(in descending order by Physical Waste Form volumes)

\begin{tabular}{|c|c|c|}
\hline $\begin{array}{l}\text { CH_TAU(M) Yaste Foreoust: } \\
\text { Phosical Yaste Form }\end{array}$ & $\begin{array}{c}\text { FYs7.1 Forecast } \\
\text { (m') }\end{array}$ & Percent \\
\hline Debris W/astes & 5,980 & $95 \%$ \\
\hline Inorg Homo sol & 210 & $3 \%$ \\
\hline Shielding & 90 & $1 \%$ \\
\hline Org Homo Sol & 20 & 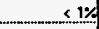 \\
\hline Special Wastes & 5 & $\leqslant 1 \%$ \\
\hline Lab Packs & 1 & $<1 \%$ \\
\hline Tory & $a s / 0$ & $100 x$ \\
\hline
\end{tabular}

Sum of totals may not add due to rounding: numbers over $10 \mathrm{~m}^{3}$ are rounded to the nearest $10 \mathrm{~m}^{3}$, numbers less than $10 \mathrm{~m}^{3}$ are rounded to integers, non-zero numbers less than 1 are rounded to 1 .

CH_TRU(M) Waste Life-Cycle Baseline Volumes by Physical Waste Form ( $\mathbf{m}^{3}$ )

(in descending order by Physical Waste Form volumes) 


\begin{tabular}{|c|c|c|c|c|c|c|c|}
\hline $\begin{array}{l}\text { CH_TRU(M) Waste } \\
\text { Phyrsical Waste Forms: } \\
\text { Program }\end{array}$ & $\begin{array}{c}\text { Debris } \\
\text { Wastes }\end{array}$ & $\begin{array}{l}\text { Inorg } \\
\text { Homo } \\
\text { Sol }\end{array}$ & Shielding & $\begin{array}{c}\text { Org } \\
\text { Homo } \\
\text { Sol }\end{array}$ & $\begin{array}{r}\text { Special } \\
\text { Wastes } \\
\end{array}$ & $\begin{array}{c}\text { Lab } \\
\text { Packs } \\
\end{array}$ & Total \\
\hline Facility Transitions. & 2,870 & 210 & 30 & 0 & o & 0 & 3,150 \\
\hline TMRS & 1,360 & 0 & a & 0 & $\underline{0}$ & - & +360 \\
\hline Non-Programmatic & 1,320 & 0 & 0 & 0 & 0 & ㅇ. & $\mathbf{1 , 3 2 0}$ \\
\hline PNML & 180 & 0 & 60 & - & 5 & 0 & 240 \\
\hline EM-40 & 220 & 0 & 0 & 10 & 0 & 0 & 230 \\
\hline Analytical Services & 20 & 0 & of & 0 & 0 & 0 & 20 \\
\hline Spent Nuclear Fuel & 10 & $\underline{a}$ & 0 & 6 & 0 & 0 & 20 \\
\hline Offsite & 1 & 0 & 0 & 1 & 0 & $<1$ & 2 \\
\hline Totes & 5980 & 210 & 90 & 20 & 5 & $<1$ & 6350 \\
\hline
\end{tabular}

Sum of totals may not add due to rounding: numbers over $10 \mathrm{~m}^{3}$ are rounded to the nearest $10 \mathrm{~m}^{3}$, numbers less than $10 \mathrm{~m}^{3}$ are rounded to integers, non-zero numbers less than $l$ are rounded to 1.

\section{Hazardous Constituents (HCs)}

CH_TRU(M) Waste Forecast by Hazardous Constituent Volumes ( $\left.\mathbf{m}^{3}\right)$

(in descending order by Hazardous Constituent volumes)

\begin{tabular}{|c|c|c|}
\hline $\begin{array}{l}\text { CH_TRU[M] Vaste Forecast: } \\
\text { Hezordous Constituent }\end{array}$ & $\begin{array}{c}\text { FY97. } 1 \text { Forecast } \\
\left(\mathrm{m}^{\prime \prime}\right)\end{array}$ & Percent \\
\hline WT-WP-WSC2 & 1,360 & $66 \%$ \\
\hline Motals wo $\mathrm{Hg}$ & 640 & $31 \%$ \\
\hline Pesctive - Metals wo Hg - Organic & 60 & $3 \%$ \\
\hline Metal vo HG - Organic -WT-WP.WSC2 & 20 & $1 \%$ \\
\hline Corrosive & 4 & $<1 \%$ \\
\hline Torot & 2.00 & reer \\
\hline
\end{tabular}

Sum of totals may not add due to rounding: numbers over $10 \mathrm{~m}^{3}$ are rounded to the nearest $10 \mathrm{~m}^{3}$, numbers less than $10 \mathrm{~m}^{3}$ are rounded to integers, non-zero numbers less than 1 are rounded to 1.

\section{CH_TRU(M) Waste Life-Cycle Baseline Volumes by Haxardous Constituent Volumes ( $\mathrm{m}^{3}$ )}

(in descending order by Hazardous Constituent volumes)

\begin{tabular}{|c|c|c|c|c|c|c|}
\hline $\begin{array}{l}\text { CH_TRU(M) } \\
\text { Hazardous Constituents: } \\
\text { Program }\end{array}$ & $\begin{array}{l}\text { VT-VP. } \\
\text { YSC2 }\end{array}$ & $\begin{array}{l}\text { Metals } \\
\text { ro Hg }\end{array}$ & $\begin{array}{l}\text { Resctive: } \\
\text { Metal wo } \mathrm{Hg} \\
\text { Ouganic }\end{array}$ & $\begin{array}{l}\text { Metwl wo Hy - } \\
\text { Drganie. } \\
\text { YT-YP-VSC2 }\end{array}$ & Corrosive & Tord \\
\hline TWRS & 1,360 & 0 & 0 & 0 & 0 & 1.20 \\
\hline Faoiticy Transikions & 0 & 310 & 0 & 0 & 0 & $\pi / 0$ \\
\hline Non-Programmatic & of & 170 & of & 0 & 0 & 170 \\
\hline EM-40 & 0 & 130 & 0 & 0 & 0 & 1,50 \\
\hline PNNI & 0 & 20 & 60 & 0 & 4 & 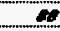 \\
\hline Analgtical Services & 0 & 0 & 0 & 20 & 요 & 20 \\
\hline Offsite & of & 1 & 0 & 0 & of & $t$ \\
\hline Total & 1,360 & 610 & 60 & 20 & 4 & 2,000 \\
\hline
\end{tabular}

Sum of totals may not add due to rounding: numbers over $10 \mathrm{~m}^{3}$ are rounded to the nearest $10 \mathrm{~m}^{3}$, numbers less than $10 \mathrm{~m}^{3}$ are rounded to integers, non-zero numbers less than 1 are rounded to $l$.

\section{Comparison to Previous Baseline(s)}

The FY97.1 forecast of $6,310 \mathrm{~m}^{3}$ of $\mathrm{CH}$ _TRU(M) waste shows a $36 \%$ decrease from the FY96 forecast of $9,830 \mathrm{~m}^{3}$ due entirely to forecast reductions from Facility Transitions, Surplus Facilities, and TWRS. The FY97.1 forecast shows a 1\% increase over the FY 97.0 forecast of $6,250 \mathrm{~m}^{3}$. 
CH_TRU(M) Waste Comparison to Previous Baseline(s) by Physical Waste Form

The FY97.1 forecast shows $95 \%$ debris waste and 3\% inorganic homogeneous solids as contrasted with the FY96 forecast of $92 \%$ debris waste and $2 \%$ inorganic homogeneous solids.

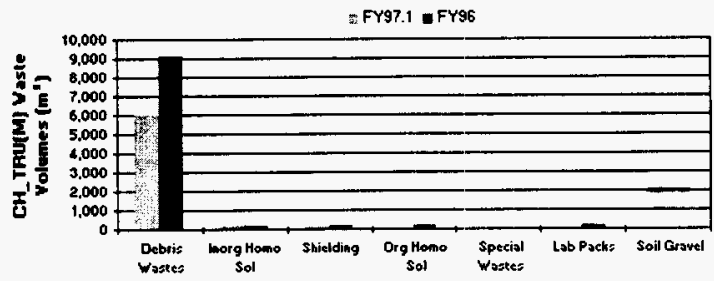

(in descending order by Physical Waste Form volumes)

\begin{tabular}{|c|c|c|}
\hline $\begin{array}{l}\text { CH_TRU(M) Waste Comparison: } \\
\text { Phygical Waste Form }\end{array}$ & $\begin{array}{c}\text { FY } 97.1 \\
\text { Fourease (m') }\end{array}$ & $\begin{array}{c}\text { FYss } \\
\text { Forecast }\left(m^{\prime \prime}\right)\end{array}$ \\
\hline Depris Wuskes. & 5,980 & 9.070 \\
\hline horgtomo Sol & 210 & 200 \\
\hline Shivelding & 90 & 200 \\
\hline Oig Homo Sol & 20 & 160 \\
\hline Speoial Wastes & 5 & 40 \\
\hline Lab Packs & 1 & 160 \\
\hline Soil Grovel & 0 & 7 \\
\hline Tord & 6,350 & 9830 \\
\hline
\end{tabular}

Sum of totals may not add due to rounding: numbers over $10 \mathrm{~m}^{3}$ are rounded to the nearest $10 \mathrm{~m}^{3}$, numbers less than $10 \mathrm{~m}^{3}$ are rounded to integers, non-zero numbers less than 1 are rounded to 1.

\section{CH_TRU(M) Waste Comparison to Previous Baseline(s) by Hazardous Constituent}

The FY 97.1 forecast of $2,080 \mathrm{~m}^{3}$ of $\mathrm{CH}_{\text {_TRUM }}$ waste shows a $13 \%$ increase from the FY96 forecast of $1,840 \mathrm{~m}^{3}$. This change is due to increases in forecast volumes from EM-40, PNNL, and TWRS. These increases more than offset the decrease in volume forecast by Facility Transitions. The FY 97.1 forecast of hazardous constituents shows $66 \%$ Washington State regulated waste, $31 \%$ metals without mercury, and $4 \%$ other hazardous constituents. The FY96 forecast is significantly different: $44 \%$ metals without mercury, $22 \%$ Washington State regulated waste, $13 \%$ ignitables, $6 \%$ corrosives and $15 \%$ other hazardous constituents.

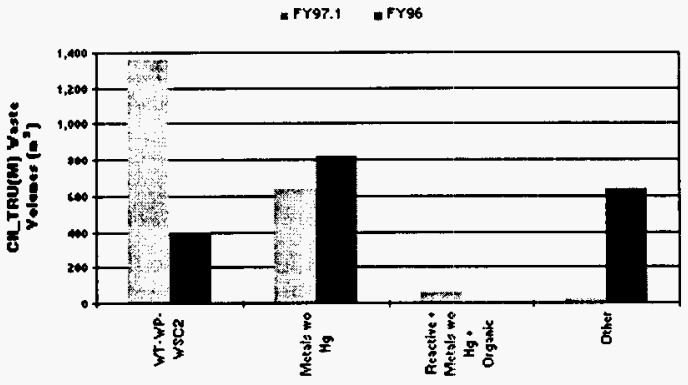


(in descending order by Hazardous Constituent volumes)

\begin{tabular}{|c|c|c|}
\hline $\begin{array}{l}\text { CH_TFU(M) Vaste Comparison } \\
\text { Hazatdous Constituent }\end{array}$ & $\begin{array}{c}\text { FY97.1 } \\
\text { Forecast (m') }\end{array}$ & $\begin{array}{c}\text { FY96 } \\
\text { Forecast (m:) }\end{array}$ \\
\hline WT-WP-WSC2 & 1,360 & 400 \\
\hline Metals wo $\mathrm{Hg}$ & 640 & 820 \\
\hline Retcrive - Metals wo Hg. Organie & 60 & \\
\hline Other & 20 & 640 \\
\hline Tard & 2,000 & 0,010 \\
\hline
\end{tabular}

Sum of totals may not add due to rounding: numbers over $10 \mathrm{~m}^{3}$ are rounded to the nearest $10 \mathrm{~m}^{3}$, numbers less than $10 \mathrm{~m}^{3}$ are rounded to integers, non-zero numbers less than 1 are rounded $t o l$.

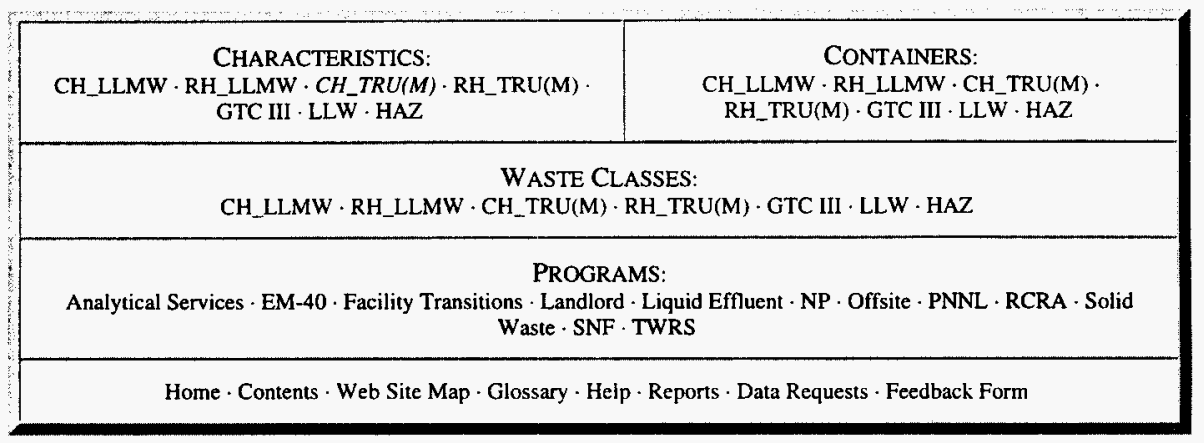

NOTICE: This page is provided subject to our disclaimer. Contact: Oscar Valero at (509) 373-4752.

HNF-EP-0918 rev. 1 Approved for public release; distribution is unlimited. 


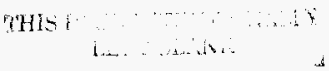




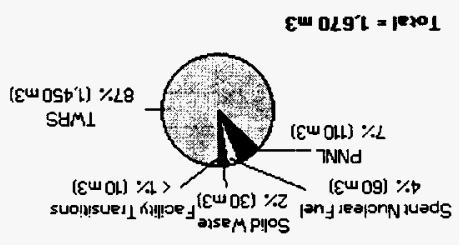

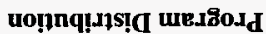

$\cdot(\%)$

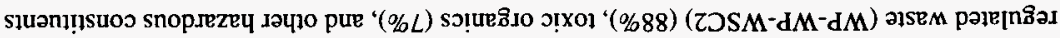
әle1S uoloి

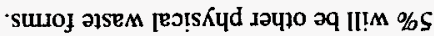

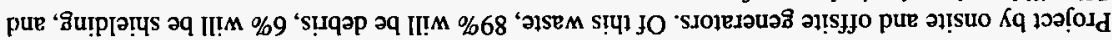

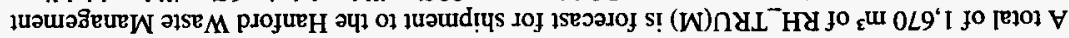

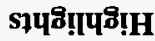

SəqR $\mathbf{L}$ Kreurums «

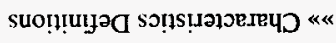

(s)əu!̣əoseg sno!n

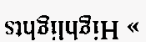

sұนวนแ0อ

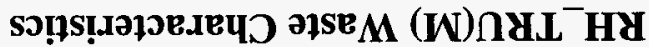

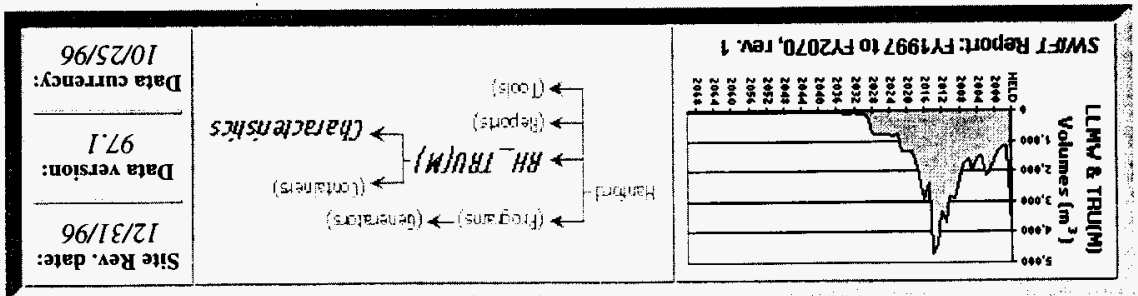


Physical Waste Form Distribution

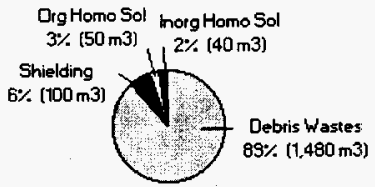

Total $=1,670 \mathrm{~m} 3$

\section{Hazardous Constituent Distribution}

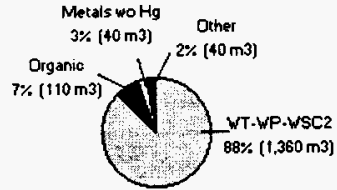

Total $=1.550 \mathrm{~m}^{3}$

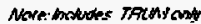

\section{Container Distribution}

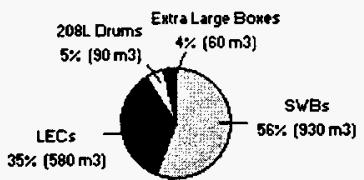

Total $=1,570 \mathrm{~ms}$

Sum of totals may not add due to rounding: numbers over $10 \mathrm{~m}^{3}$ are rounded to the nearest $10 \mathrm{~m}^{3}$, numbers less than $10 \mathrm{~m}^{3}$ are rounded to integers, non-zero numbers less than $I$ are rounded to 1 .

\section{Annual RH_TRU(M) Waste Characteristics}

Physical Waste Forms (PWFs)

\section{RH_TRU(M) Waste Life Cycle Volumes by Physical Waste Form}

The total baseline volume of waste is approximately $1,670 \mathrm{~m}^{3}$. The minimum expected volume is approximately $740 \mathrm{~m}^{3}$, and the maximum expected volume is $3,710 \mathrm{~m}^{3}$. The minimum, baseline, and maximum waste forecast volumes are distributed as follows:

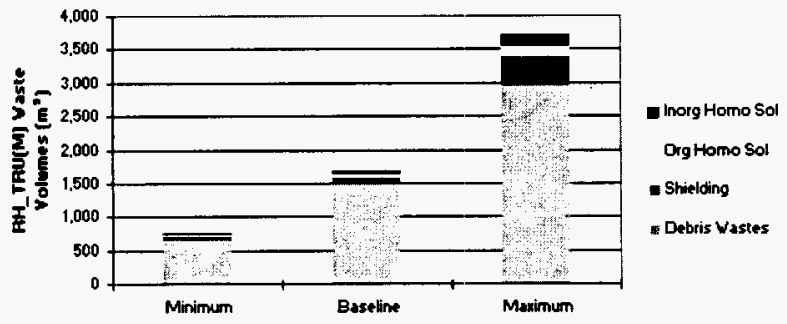

(In descending order, by Physical Waste Form volume) 


\begin{tabular}{|c|c|c|c|}
\hline $\begin{array}{l}\text { RH_TRU(M) Yaste Life Cycle: } \\
\text { Phnsical Vaste Form }\end{array}$ & Mînimum & Baseline & Maximum \\
\hline Debris Wastes & $\ldots .630$ & 1,480 & 2.350 \\
\hline Shielding & 50 & 100 & 430 \\
\hline Oig Homo Sol & 30 & 50 & 150 \\
\hline Inorg Homo Sol & 30 & 40 & 180 \\
\hline Tord & 700 & 1,670 & 3710 \\
\hline
\end{tabular}

Sum of totals may not add due to rounding: numbers over $10 \mathrm{~m}^{3}$ are rounded to the nearest $10 \mathrm{~m}^{3}$, numbers less than $10 \mathrm{~m}^{3}$ are rounded to integers, non-zero numbers less than $l$ are rounded to 1.

RH_TRU(M) Waste Annual Baseline Volumes by Hazardous Constituent

The graph shows the RH_TRU(M) volume from 1997 through 2028 . TWRS accounts for $87 \%$ of this waste, and $96 \%$ of the TWRS waste is debris waste. The second largest contributor (from 1997 through 2010) is Pacific Northwest National Laboratory, which accounts for 7\% of the waste, mostly in the form of debris waste $(50 \%)$ and shielding $(31 \%)$. The remaining contributors (1997 - 2001) are SNF, Solid Waste, and Facilities Transitions.

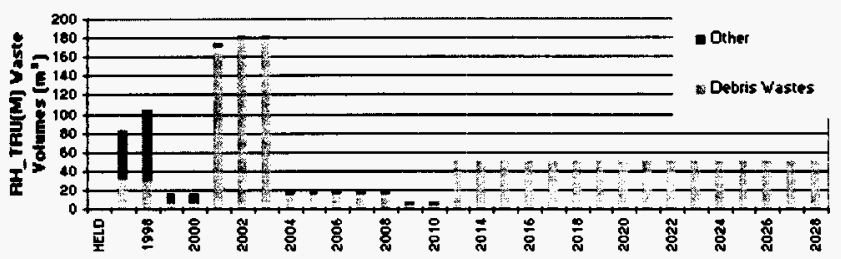

\section{Hazardous Constituents (HCs)}

\section{RH_TRU(M) Waste Life-Cycle Volumes by Hazardous Constituent}

The total baseline volume of waste is approximately $1,550 \mathrm{~m}^{3}$. The minimum expected volume is approximately $690 \mathrm{~m}^{3}$, and the maximum expected volume is $3,100 \mathrm{~m}^{3}$. The minimum, baseline, and maximum waste forecast volumes are distributed as follows:

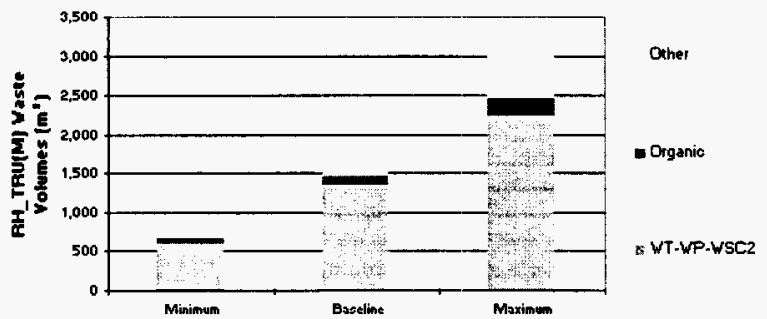

(In descending order, by Physical Waste Form volume) 


\begin{tabular}{|c|c|c|c|}
\hline $\begin{array}{l}\text { RH-TRU(M) Waste Life Oycle: } \\
\text { Hazardous Constituems }\end{array}$ & Minimum & Baseline & Maximum \\
\hline WT-WP-WSC2 & 600 & 1,360 & $\begin{array}{r}2230 \\
2.20\end{array}$ \\
\hline Organic & 70 & 110 & 230 \\
\hline Other & 20 & 80 & 630 \\
\hline Total & 700 & 1,550 & 3700 \\
\hline
\end{tabular}

Sum of totals may not add due to rounding: numbers over $10 \mathrm{~m}^{3}$ are rounded to the nearest $10 \mathrm{~m}^{3}$, numbers less than $10 \mathrm{~m}^{3}$ are rounded to integers, non-zero numbers less than 1 are rounded to 1 .

\section{RH_TRU(M) Waste Annual Baseline Volumes by Hazardous Constituent}

The graph shows the RH_TRUM hazardous constituent volume from 1997 through 2028. TWRS accounts for $94 \%$ of this volume, nearly all in the form of Washington State regulated waste. The second most significant contributor $(4 \%)$ is Pacific Northwest National Laboratory (1997 - 2010) whose waste consists primarily of mixed corrosive, metals without mercury, toxic organics, state regulated (52\%), and metals without mercury (23\%). The remaining contributors (1997 - 2001) are Solid Waste and Facility Transitions.

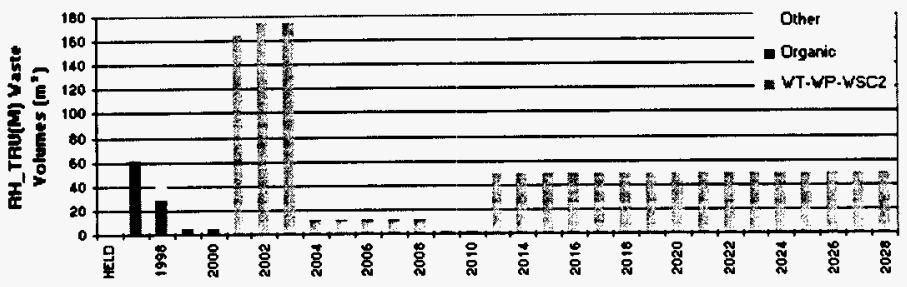

\section{Summary Tables (Volumes in $\mathbf{m}^{3}$ )}

\section{Physical Waste Forms (PWFs)}

\section{RH_TRU(M) Waste Forecast by Physical Waste Form}

(in descending order by Physical Waste Form volumes)

\begin{tabular}{|c|c|c|}
\hline $\begin{array}{l}\text { PH_TRU(M) Forecast: } \\
\text { Phrsical Yasle Form }\end{array}$ & $\begin{array}{c}\text { FYs?.1 Foreest } \\
{\left[m^{2}\right]}\end{array}$ & $x$ of Total \\
\hline Depris Vastes & $\begin{array}{r}1,480 \\
\end{array}$ & $89 \%$ \\
\hline Shietding & 100 & $6 \%$ \\
\hline Org Homo Sol & 50 & $3 \%$ \\
\hline norg Homo Sol & 40 & $2 \%$ \\
\hline Tare & s,core & senes \\
\hline
\end{tabular}

Sum of totals may not add due to rounding: numbers over $10 \mathrm{~m}^{3}$ are rounded to the nearest $10 \mathrm{~m}^{3}$, numbers less than $10 \mathrm{~m}^{3}$ are rounded to integers, non-zero numbers less than 1 are rounded to $I$.

RH_TRU(M) Waste Life-Cycle Baseline Volumes by Physical Waste Form (m ${ }^{3}$ )

(in descending order by Physical Waste Form volumes) 


\begin{tabular}{|c|c|c|c|c|c|}
\hline $\begin{array}{l}\text { RH_TRU(M) Waste } \\
\text { Physical Waste Forms: } \\
\text { Program }\end{array}$ & $\begin{array}{l}\text { Debris } \\
\text { Wostes }\end{array}$ & Shielding & $\begin{array}{l}\text { Org } \\
\text { Horno } \\
\text { Sol } \\
\end{array}$ & $\begin{array}{l}\text { Inorg } \\
\text { Homo } \\
\text { Sol }\end{array}$ & Total \\
\hline TNRS & 1400 & 50 & 5 & 0 & 1,450 \\
\hline PNNL & 60 & 40 & 10 & 10 & 110 \\
\hline Spent Nuclear Fuel & 10 & 20 & 30 & 0 & 60 \\
\hline Solid Waste & 0 & 1 & 0 & 30 & 30 \\
\hline Facility Transitions & 10 & 0 & 0 & 2 & 10 \\
\hline Total & 5,460 & 100 & 50 & 40 & 1,670 \\
\hline
\end{tabular}

Sum of totals may not add due to rounding: numbers over $10 \mathrm{~m}^{3}$ are rounded to the nearest $10 \mathrm{~m}^{3}$, numbers less than $10 \mathrm{~m}^{3}$ are rounded to integers, non-zero numbers less than $/$ are rounded to 1.

\section{Hazardous Constituents (HCs)}

RH_TRU(M) Waste Forecast by Hazardous Constituent Volumes ( $\left.\mathbf{m}^{3}\right)$

(in descending order by Hazardous Constituent volumes)

\begin{tabular}{|c|c|c|}
\hline $\begin{array}{l}\text { RH_TRU[M] Vaste Forecast: } \\
\text { Hazardous Constituent }\end{array}$ & $\begin{array}{c}\text { Fra7.1 Forecast } \\
\left(m^{2}\right)\end{array}$ & Peroent \\
\hline WT-WP-WSC2 & $\begin{array}{r}1,360 \\
-\quad r \\
\end{array}$ & $88 \%$ \\
\hline Organte........................ & 110 & $7 \%$ \\
\hline Metals wo $\mathrm{Hg}$ & 40 & $3 \%$ \\
\hline Corrosive - Meta wo Hg + Drganio + WT-WP-WSC2 & 30 & $2 \%$ \\
\hline Conosive & 5 & $<\$$ \\
\hline Tory & I.550 & reas \\
\hline
\end{tabular}

Sum of totals may nor add due to rounding: numbers over $10 \mathrm{~m}^{3}$ are rounded to the nearest $10 \mathrm{~m}^{3}$, numbers less than $10 \mathrm{~m}^{3}$ are rounded to integers, non-zero numbers less than $I$ are rounded to $I$.

\section{RH_TRU(M) Waste Life-Cycle Baseline Volumes by Hazardous Constituent Volumes $\left(\mathrm{m}^{\mathbf{3}}\right)$}

(in descending order by Hazardous Constituent volumes)

\begin{tabular}{|c|c|c|c|c|c|c|}
\hline $\begin{array}{l}\text { PH_TRU(M) } \\
\text { Hazardous Constituents: } \\
\text { Program }\end{array}$ & $\begin{array}{l}\text { YT-YP- } \\
\text { Ysc2 }\end{array}$ & Orgenic & Metals vo Hy & $\begin{array}{l}\text { Corrosive * } \\
\text { Metal wo Hg- } \\
\text { Drgonic. } \\
\text { YT-YP-VSC2 }\end{array}$ & Corrostive & rorer \\
\hline TWRS & 1360 & 80 & 9 & 0 & 0 & 8.458 \\
\hline PNNL & 0 & 10. & 10 & 30 & 5 & $x$ \\
\hline Solid Waste & 0 & 10. & 10 & 0 & 0 & $x$ \\
\hline Facility Transitions & of & 0 & 5 & 0 & 0 & 5 \\
\hline Tord & 1,300 & 110 & 10 & $x$ & $s$ & 1,550 \\
\hline
\end{tabular}

Sum of totals may not add due to rounding: numbers over $10 \mathrm{~m}^{3}$ are rounded to the nearest $10 \mathrm{~m}^{3}$, numbers less than $10 \mathrm{~m}^{3}$ are rounded to integers, non-zero numbers less than 1 are rounded to 1.

\section{Comparison to Previous Baseline(s)}

The FY97.1 forecast of $1,670 \mathrm{~m}^{3}$ of $\mathrm{RH}$ _TRU(M) shows an $87 \%$ decrease from the FY96 forecast of $13,350 \mathrm{~m}^{3}$ due almost entirely to forecast reductions from TWRS. The FY97.1 forecast is $0.60 \%$ higher than the FY 97.0 forecast of $1,660 \mathrm{~m}^{3}$.

\section{RH_TRU(M) Waste Comparison to Previous Baseline(s) by Physical Waste Form}

The FY97.1 forecast shows $89 \%$ debris waste and $6 \%$ shielding. This is about the same as the FY96 forecast of $92 \%$ debris waste and $6 \%$ shielding. 


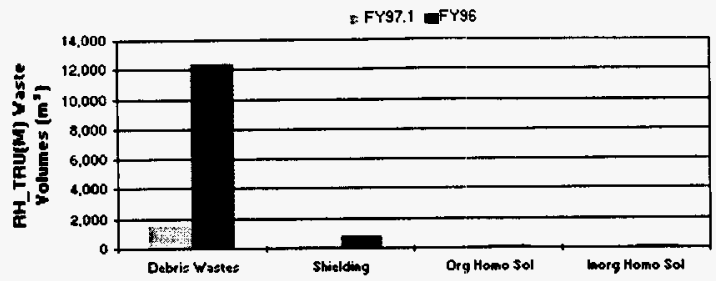

(in descending order by Physical Waste Form volumes)

\begin{tabular}{|c|c|c|}
\hline $\begin{array}{l}\text { RH_tPU(M) Vaste Comparison: } \\
\text { Phosioal Vaste Form }\end{array}$ & $\begin{array}{c}\text { FYg7.1 Foreeast } \\
\left(m^{*}\right)\end{array}$ & $\begin{array}{l}\text { FY96 Forecast } \\
\text { (m) }\end{array}$ \\
\hline Depuis Wastes & 1480 & 12,340 \\
\hline Shiolding. & 100 & 820 \\
\hline OrgHomo Sol & 50 & 800 \\
\hline Inorg Homo Sol & 40 & 110 \\
\hline Torts & 1,079 & 12,25 \\
\hline
\end{tabular}

Sum of totals may not add due to rounding: numbers over $10 \mathrm{~m}^{3}$ are rounded to the nearest $10 \mathrm{~m}^{3}$, numbers less than $10 \mathrm{~m}^{3}$ are rounded to integers, non-zero numbers less than 1 are rounded to 1 .

\section{RH_TRU(M) Waste Comparison to Previous Baseline(s) by Hazardous Constituent}

The FY97.1 forecast of $1,550 \mathrm{~m}^{3}$ of RH_TRUM hazardous constituent volume shows an $87 \%$ decrease from the FY96 forecast of $11,770 \mathrm{~m}^{3}$, due almost entirely to forecast reductions from TWRS. The FY97.1 forecast shows $88 \%$ Washington State regulated waste and $7 \%$ toxic organics in contrast to the FY96 forecast of $89 \%$ toxic organics and $7 \%$ metals without mercury.

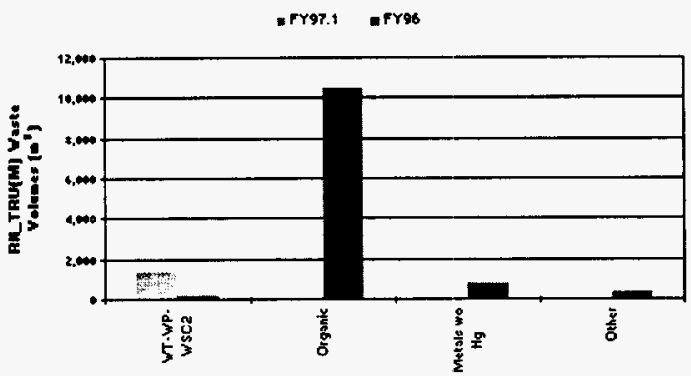

(in descending order by Hazardous Constituent volumes)

\begin{tabular}{|c|c|c|}
\hline $\begin{array}{l}\text { RH_TRU[M] Vaste Comparison } \\
\text { Hazardous Constituent }\end{array}$ & $\begin{array}{c}\text { FYs7.1 } \\
\text { Forecast }\left(\mathrm{m}^{2}\right) \\
\end{array}$ & $\begin{array}{c}\text { FYst Forecast } \\
\left(\mathrm{fin}^{*}\right)\end{array}$ \\
\hline WT.WP.WSC2 & $\begin{array}{r}1,360 \\
\end{array}$ & 190 \\
\hline Organic & 110 & 10,440 \\
\hline Metals woltg & 40 & 810 \\
\hline Other & 35 & 330 \\
\hline Tory & $4.5 \mathrm{~F}$ & MLTH \\
\hline
\end{tabular}

Sum of totals may not add due to rounding: numbers over $10 \mathrm{~m}^{3}$ are rounded to the nearest $10 \mathrm{~m}^{3}$, numbers less 
than $10 \mathrm{~m}^{3}$ are rounded to integers, non-zero numbers less than 1 are rounded to 1.

\begin{tabular}{|c|c|}
\hline $\begin{array}{c}\text { CHARACTERISTICS: } \\
\text { CH_LLMW } \cdot \text { RH_LLMW } \cdot \text { CH_TRU(M) } \cdot R H \_T R U(M) \cdot \\
\text { GTC III } \cdot \text { LLW } \cdot \text { HAZ }\end{array}$ & $\begin{array}{c}\text { CONTAINERS: } \\
\text { CH_LLMW } \cdot \text { RH_LLMW } \cdot \text { CH_TRU(M) } \\
\text { RH_TRU(M) } \cdot \text { GTC HI } \cdot \text { LLW } \cdot \text { HAZ }\end{array}$ \\
\hline \multicolumn{2}{|c|}{$\begin{array}{l}\text { WASTE CLASSES: } \\
\text { CH_LLMW } \cdot \text { RH_LLMW } \cdot \text { CH_TRU(M) } \cdot \text { RH_TRU(M) } \cdot \text { GTC III } \cdot \text { LLW } \cdot \text { HAZ }\end{array}$} \\
\hline \multicolumn{2}{|c|}{$\begin{array}{l}\text { PROGRAMS: } \\
\text { Analytical Services · EM-40 - Facility Transitions - Landlord - Liquid Effluent - NP · Offsite - PNNL - RCRA - Solid } \\
\text { Waste - SNF - TWRS }\end{array}$} \\
\hline
\end{tabular}

NOTICE: This page is provided subject to our disclaimer. Contact: Oscar Valero at (509) 373-4752.

HNF-EP-0918 rev. 1 Approved for public release; distribution is unlimited. 


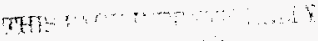

….... 


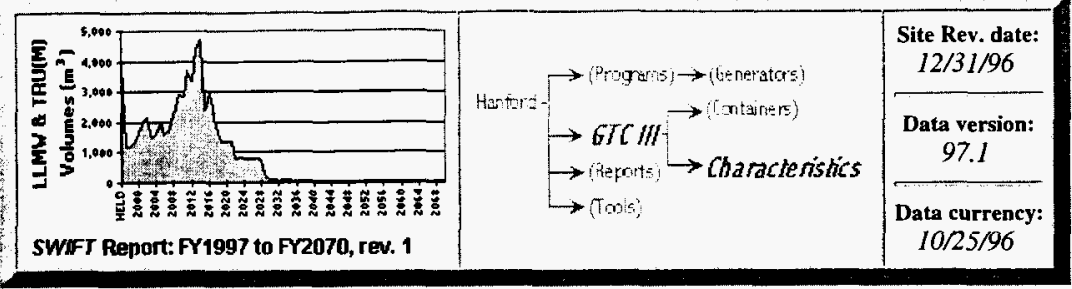

\section{GTC III Characteristics}

\section{Contents}
» Highlights
»Comparison to Previous Baseline(s)
»Summary Table
"» Characteristics Definitions

\section{Highlights}

- No LLW or LIMW greater-than-class III (GTCIII) is forecast for shipment to the Hanford SW Project by onsite and offsite generators.

- This forecast shows a significant reduction from the FY96 forecast of $990 \mathrm{~m}^{3}\left(640 \mathrm{~m}^{3}\right.$ of LLMW_GTCIII and $350 \mathrm{~m}^{3}$ of LLW_GTCIII).

\section{Summary Table (Volumes in $\mathbf{m}^{3}$ )}

[Not applicable]

\section{Comparison to Previous Baseline(s)}

The FY97 forecast of no GTCIII waste shows a significant reduction from the FY96 forecast of $990 \mathrm{~m}^{3}$. This reduction arises because the 2 generators that reported GTCIII waste last year - DST Retrieval and PNNL - have both changed their planning assumptions for the current year's forecast. DST Retrieval is using a new baseline for waste forecasts based on the experience of Project W-151. PNNL has determined that they would include in their forecast only waste for which a disposal pathway exists. As a result, no GTCIII waste has been forecast for that program. No GTC III was reported for FY97.1.

Physical Waste Forms (PWFs)

(In descending order, by Physical Waste Form volume) 


\begin{tabular}{|c|c|c|}
\hline $\begin{array}{l}\text { GTCIII Yaste Comparison: } \\
\text { Phrical Yaste Form }\end{array}$ & $\begin{array}{l}\text { FYS7.1 Forecast } \\
\left(m^{x}\right)\end{array}$ & $\begin{array}{c}\text { FY96 Foreeast } \\
\left(\mathrm{m}^{2}\right)\end{array}$ \\
\hline InglgHomo Sol & 0 & 368 \\
\hline Debris Wastes. & 0 & 360 \\
\hline Shielding & 0 & 90 \\
\hline Special Wastes & ㅇ․ & 160 \\
\hline Otg Homo Sol & 0 & 6 \\
\hline Tory & $\theta$ & $\operatorname{sen}$ \\
\hline
\end{tabular}

Sum of totals may not add due to rounding: numbers over $10 \mathrm{~m}^{3}$ are rounded to the nearest $10 \mathrm{~m}^{3}$, numbers less than $10 \mathrm{~m}^{3}$ are rounded to integers, non-zero numbers less than $I$ are rounded to $I$.

Hazardous Constituents (HCs)

(In descending order, by Hazardous Constituent volume)

\begin{tabular}{|c|c|c|}
\hline $\begin{array}{l}\text { GTCMI Comparison } \\
\text { Hazardous Constituent }\end{array}$ & $\begin{array}{c}\text { FY97.1 } \\
\text { Forecast }\left(\mathrm{m}^{2}\right)\end{array}$ & $\begin{array}{c}\text { FYss Forecast } \\
\left(\mathrm{m}^{2}\right)\end{array}$ \\
\hline Metals wo Hg * WT-WP.WSC2 & 0 & 368 \\
\hline Metals woHg & $\underline{0}$ & 158 \\
\hline Organic & 0 & 112 \\
\hline Toty & 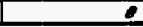 & ape \\
\hline
\end{tabular}

Sum of totals may not add due to rounding: numbers over $10 \mathrm{~m}^{3}$ are rounded to the nearest $10 \mathrm{~m}^{3}$, numbers less than $10 \mathrm{~m}^{3}$ are rounded to integers, non-zero numbers less than 1 are rounded to 1.

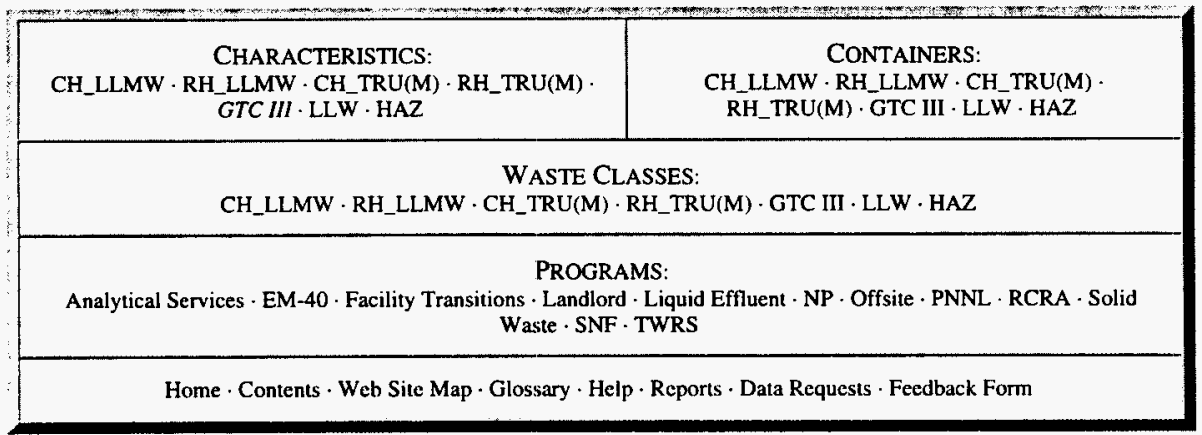

NOTICE: This page is provided subject to our disclaimer. Contact: Oscar Valero at (509) 373-4752.

HNF-EP-0918 rev. 1 Approved for public release; distribution is unlimited. 


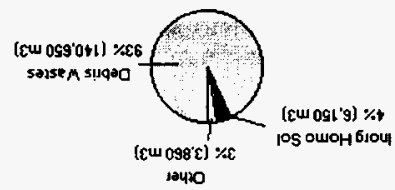

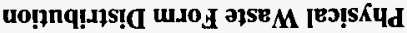

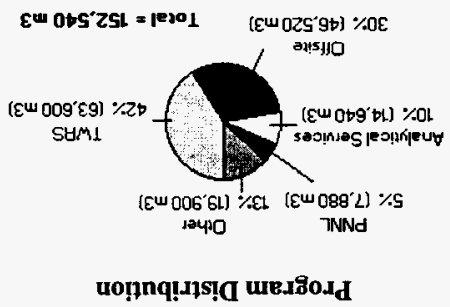

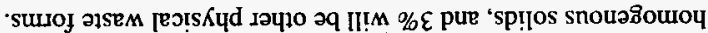

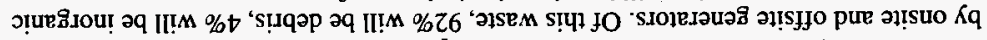

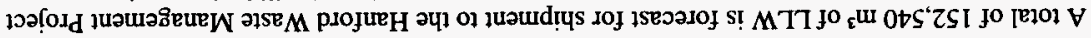

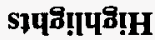

$$
\text { sə9е L Krewuins « }
$$

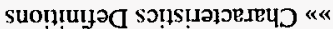

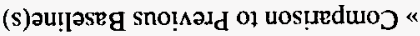

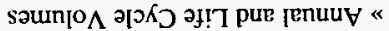

งฺบริ!!บชิ!H «

รานวุน⿰冫

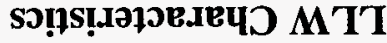

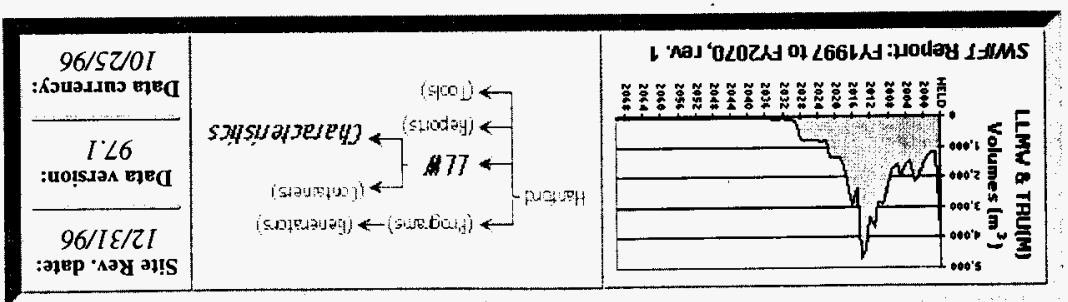




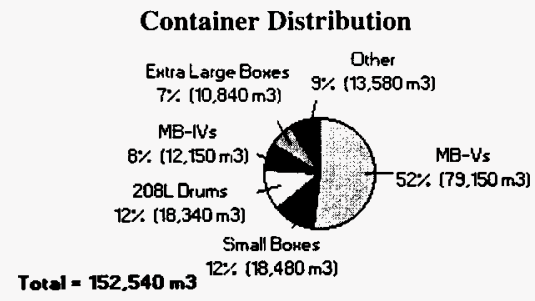

Sum of totals may not add due to rounding: numbers over $10 \mathrm{~m}^{3}$ are rounded to the nearest $10 \mathrm{~m}^{3}$, numbers less than $10 \mathrm{~m}^{\mathrm{J}}$ are rounded to integers, non-zero numbers less than I are rounded to I.

\section{Annual LLW Characteristics}

Physical Waste Forms (PWFs)

\section{LLW Life Cycle Volumes by Physical Waste Form}

The total baseline volume of waste is approximately $152,540 \mathrm{~m}^{3}$. The minimum expected volume is approximately $71,220 \mathrm{~m}^{3}$, and the maximum expected volume is $361,960 \mathrm{~m}^{3}$. The minimum, baseline, and maximum waste forecast volumes are distributed as follows:

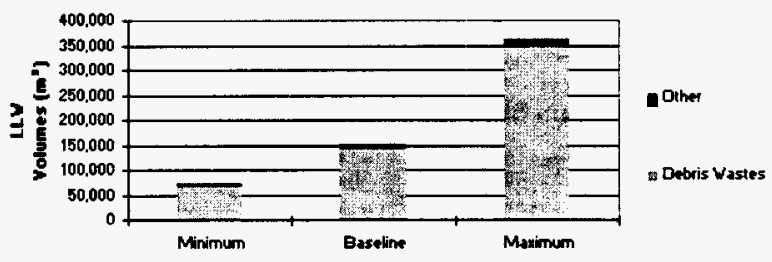

(In descending order, by Physical Waste Form volume)

\begin{tabular}{|c|c|c|c|}
\hline $\begin{array}{l}\text { LUY Life Cgele: } \\
\text { Phrsical Yaste Form }\end{array}$ & Mininem & Baseline & Marimum \\
\hline Depois Wastes & 64,820 & 140,650 & 343,410 \\
\hline Other & 6.400 & 11,890 & 18.550 \\
\hline Totel & 7,22 & 123.518 & 351.009 \\
\hline
\end{tabular}

Sum of totals may not add due to rounding: numbers over $10 \mathrm{~m}^{3}$ are rounded to the nearest $10 \mathrm{~m}^{3}$, numbers less than $10 \mathrm{~m}^{3}$ are rounded to integers, non-zero numbers less than $I$ are rounded to $I$.

\section{LLW Annual Baseline Volumes by Physical Waste Form}

The graph shows the LLW volume for 1997 through 2070. TWRS (1997 - 2002) accounts for $42 \%$ of the LLW; more than 99\% of TWRS waste is debris waste. Offsite (1997 - 2070) contributes $30 \%$ of the LLW; $91 \%$ of Offsite waste is debris waste. The third major contributor to LLW is Analytical Laboratories (1997-2070), which contributes $10 \%$ of the LLW volume. The remaining contributors, comprising $18 \%$ of the LLW volume, include Liquid Effluents, Non-programmatic, RCRA, SNF, Solid Waste, and Facilities Transistions. 


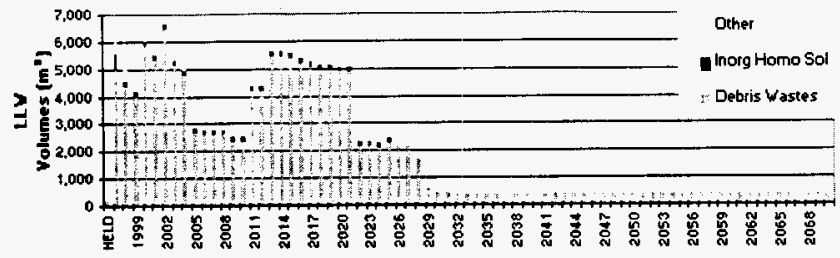

\section{Hazardous Constituents (HCs)}

\section{LLW Life-Cycle Volumes by Hazardous Constituent}

Not Applicable.

\section{LLW Annual Baseline Volumes by Hazardous Constituent}

Not Applicable.

\section{Summary Tables (Volumes in $\mathbf{m}^{3}$ )}

\section{Physical Waste Forms (PWFs)}

\section{LLW Forecast by Physical Waste Form}

(In descending order, by Physical Waste Form volume)

\begin{tabular}{|c|c|c|}
\hline $\begin{array}{l}\text { LLY Forecast: } \\
\text { Phosical Yaste Form }\end{array}$ & $\begin{array}{c}\text { FYs7.1 Foreeast } \\
\text { (m) }\end{array}$ & Pereent \\
\hline Debris Wastes & 140,650 & $92 \%$ \\
\hline ho:g Homo Sol & 6.150 & $4 x$ \\
\hline Soll Giavel & 3.860 & $3 \%$ \\
\hline Shielding & 900 & $1 \%$ \\
\hline Org Homo Sol & 800 & 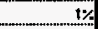 \\
\hline Lab Packs & 190 & $\times 1 \%$ \\
\hline Tores & 152,510 & rees \\
\hline
\end{tabular}

Sum of totals may not add due to rounding: numbers over $10 \mathrm{~m}^{3}$ are rounded to the nearest $10 \mathrm{~m}^{3}$, numbers less than $10 \mathrm{~m}^{3}$ are rounded to integers, non-zero numbers less than 1 are rounded to $\mathrm{l}$.

LLW Life-Cycle Baseline Volumes by Physical Waste Form ( $\left.\mathbf{m}^{3}\right)$

(In descending order, by Physical Waste Form volume) 


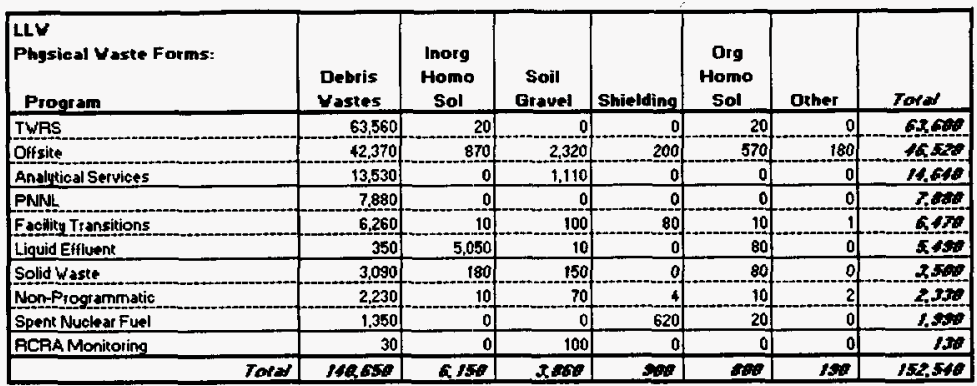

Sum of totals may not add due to rounding: numbers over $10 \mathrm{~m}^{3}$ are rounded to the nearest $10 \mathrm{~m}^{3}$, numbers less than $10 \mathrm{~m}^{3}$ are rounded to integers, non-zero numbers less than 1 are rounded to 1 .

\section{Hazardous Constituents (HCs)}

LLW Forecast by Hazardous Constituent Volumes ( $\left.\mathbf{m}^{3}\right)$

Not Applicable.

LLW Life-Cycle Baseline Volumes by Hazardous Constituent Volumes ( $\left.\mathrm{m}^{3}\right)$

Not Applicable.

\section{Comparison to Previous Baseline(s)}

The FY97.1 forecast of $152,540 \mathrm{~m}^{3}$ shows a $57 \%$ decrease from the FY96 forecast of 353,160 $\mathrm{m}^{3}$. This decrease reflects the significant waste volume reductions from Offsite, Pacific Northwest National Laboratory, and RCRA programs. The LLW volume reductions from these 3 programs account for almost the entire reduction of LLW volume for Hanford. The FY97.1 forecast $\left(152,540 \mathrm{~m}^{3}\right)$ shows a $0.24 \%$ increase from the FY 97.0 forecast of 152,180 $\mathrm{m}^{3}$.

\section{LLW Comparison to Previous Baseline(s) by Physical Waste Form}

The percentage composition for FY97.1 shows that $92 \%$ will be debris waste and $4 \%$ will be inorganic homogeneous solids. By comparison, the FY96 forecast shows $81 \%$ debris waste, $10 \%$ soil and gravel, and $4 \%$ inorganic homogeneous solids.

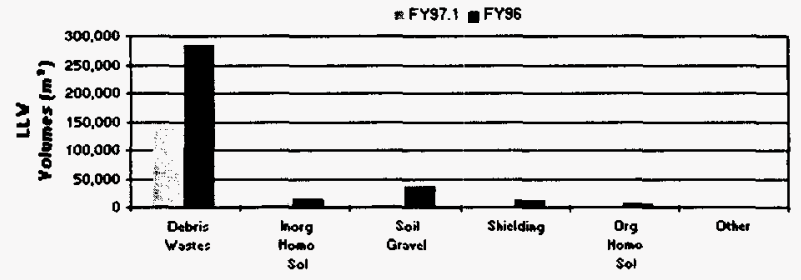

(In descending order, by Physical Waste Form volume) 


\begin{tabular}{|c|c|c|}
\hline $\begin{array}{l}\text { LLV Comparison: } \\
\text { Phosieal Yaste Form }\end{array}$ & $\begin{array}{c}\text { FYg7. } 1 \text { Forecast } \\
\left(m^{2}\right)\end{array}$ & $\begin{array}{c}\text { FYgs Forecast } \\
\left(m^{\prime}\right)\end{array}$ \\
\hline Debris Wastes & 140.650 & 285,670 \\
\hline thorg Homo Sol & 6.150 & 13.850 \\
\hline Soil Gravel & 3.860 & 37,470 \\
\hline Shielding & 900 & $\$ 1,290$ \\
\hline OrgHomo Sol & 800 & 5,160 \\
\hline Other & 190 & 380 \\
\hline Toref & 85,010 & $15+100$ \\
\hline
\end{tabular}

Sum of totals may not add due to rounding: numbers over $10 \mathrm{~m}^{3}$ are rounded to the nearest $10 \mathrm{~m}^{3}$, numbers less than $10 \mathrm{~m}^{3}$ are rounded to integers, non-zero numbers less than 1 are rounded to 1.

\section{LLW Comparison to Previous Baseline(s) by Hazardous Constituent}

Not Applicable.

\begin{tabular}{|c|c|}
\hline $\begin{array}{l}\text { CHARACTERISTICS: } \\
\text { CH_LLMW } \cdot \text { RH_LLMW } \cdot \text { CH_TRU(M) } \cdot \text { RH_TRU(M) } \\
\text { GTC III } \cdot L L W \cdot H A Z\end{array}$ & $\begin{array}{l}\text { CONTAINERS: } \\
\text { CH_LLMW } \cdot \text { RH_LLMW } \cdot \text { CH_TRU(M) } \\
\text { RH_TRU(M) } \cdot \text { GTC III } \cdot \text { LLW } \cdot \text { HAZ }\end{array}$ \\
\hline \multicolumn{2}{|c|}{$\begin{array}{c}\text { WASTE CLASSES: } \\
\text { CH_LLMW } \cdot \text { RH_LLMW } \cdot \text { CH_TRU(M) } \cdot \text { RH_TRU(M) } \cdot \text { GTC III } \cdot \text { LLW } \cdot \text { HAZ }\end{array}$} \\
\hline \multicolumn{2}{|c|}{$\begin{array}{l}\text { PROGRAMS: } \\
\text { Analytical Services } \cdot \text { EM-40 } \cdot \text { Facility Transitions } \cdot \text { Landlord } \cdot \text { Liquid Effluent } \cdot \text { NP } \cdot \text { Offsite } \cdot \text { PNNL } \cdot \text { RCRA } \cdot \text { Solid } \\
\text { Waste } \cdot \text { SNF } \cdot \text { TWRS }\end{array}$} \\
\hline
\end{tabular}

NOTICE: This page is provided subject to our disclaimer. Contact: Oscar Valero at (509) 373-4752. HNF-EP-0918 rev. 1 Approved for public release; distribution is unlimited. 
THT :AC : $\therefore$

ix $\quad \therefore$ 


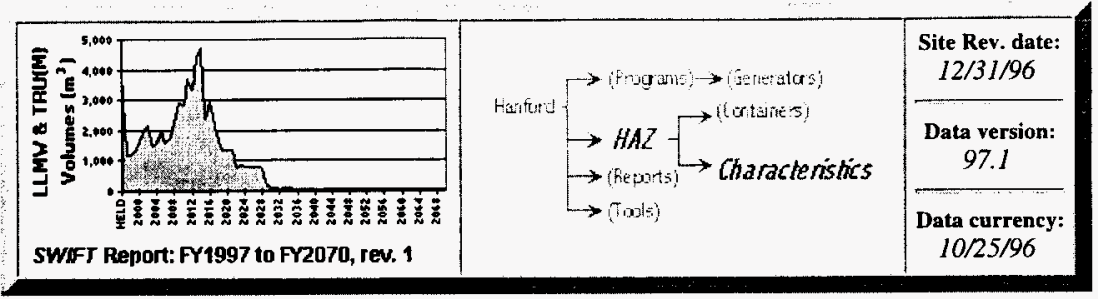

\section{Hazardous Waste (HAZ) Characteristics}

\section{Contents}

» Highlights

» Annual and Life Cycle Volumes

»Summary Tables
" Comparison to Previous Baseline(s)

"» Characteristics Definitions

\section{Highlights}

- A total of $2,770 \mathrm{~m}^{3}$ of hazardous waste is forecast for shipment to the Hanford Waste Management Project by onsite and offsite generators. Of this waste, $81 \%$ will be debris wastes, $8 \%$ will be lab packs, $4 \%$ will be soil and gravel, $3 \%$ will be organic homogeneous solids, and $4 \%$ will be other physical waste forms.

- The hazardous constituent volume will consist of containers holding state regulated material ( $80 \%)$; toxic organic compounds $(11 \%)$; combinations of ignitable, corrosive, and reactive compounds, metals without mercury, toxic organic compounds, and state regulated materials (3\%); metals without mercury $(2 \%)$; and other hazardous constituents $(4 \%)$.

\section{Program Distribution}

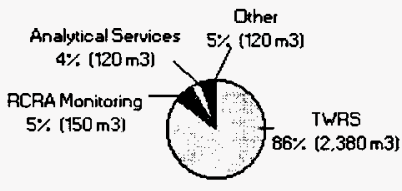

Total $=2.770 \mathrm{m3}$ 


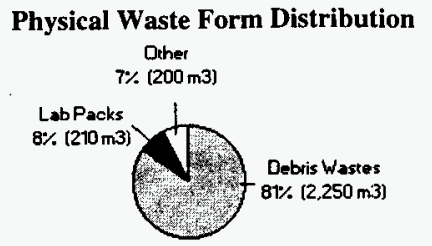

Total $=2,770 \mathrm{~m} 3$

\section{Hazardous Constituent Distribution}

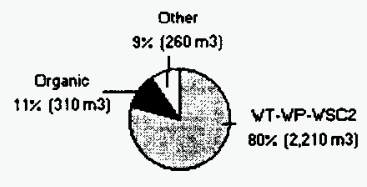

Total $=2.770 \mathrm{m3}$

\section{Container Distribution}

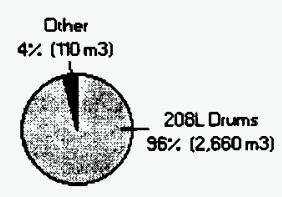

Total $=2,770 \mathrm{m3}$

Sum of totals may not add due to rounding: numbers over $10 \mathrm{~m}^{3}$ are rounded to the nearest $10 \mathrm{~m}^{3}$, numbers less than $10 \mathrm{~m}^{3}$ are rounded to integers, non-zero numbers less than 1 are rounded 101 .

\section{Annual HAZ Waste Characteristics}

\section{Physical Waste Forms (PWFs)}

\section{HAZ Waste Life Cycle Volumes by Physical Waste Form}

The total baseline volume of waste is approximately $2,770 \mathrm{~m}^{3}$. The minimum expected volume is approximately $1,430 \mathrm{~m}^{3}$, and the maximum expected volume is $5,300 \mathrm{~m}^{3}$. The minimum, baseline, and maximum waste forecast volumes are distributed as follows:

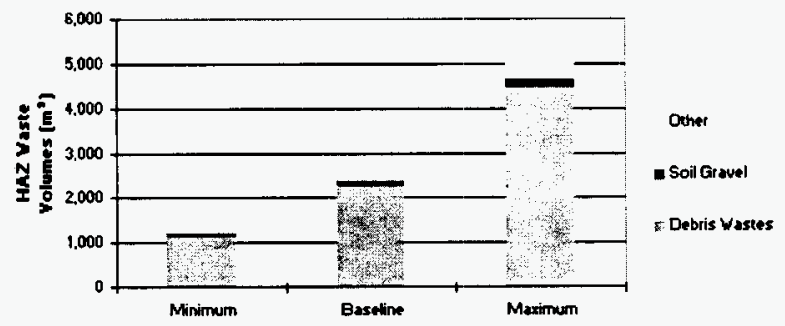

(in descending order by Physical Waste Form volumes) 


\begin{tabular}{|l|r|r|r|}
\hline HAZ Waste Life Cgcle: & & & \\
Phgsical Vaste Form & Minimum & Baseline & Marimum \\
\hline Oebris Wastes & 11,130 & 2,250 & 4.460 \\
\hline LabPacks & 130 & 210 & 330 \\
\hline Other & 170 & 320 & 510 \\
\hline
\end{tabular}

Sum of totals may not add due to rounding: numbers over $10 \mathrm{~m}^{3}$ are rounded to the nearest $10 \mathrm{~m}^{3}$, numbers less than $10 \mathrm{~m}^{3}$ are rounded to integers, non-zero numbers less than 1 are rounded to 1.

\section{HAZ Waste Annual Baseline Volumes by Physical Waste Form}

The graph shows the hazardous volume for 1997 through 2034. About $86 \%$ of the waste is generated by TWRS, $5 \%$ by RCRA and $4 \%$ by Analytical Laboratories. Waste generation will peak in 2013-2021, due to waste (98\% debris waste) associated with the retrieval of the long-length contaminated equipment from TWRS.

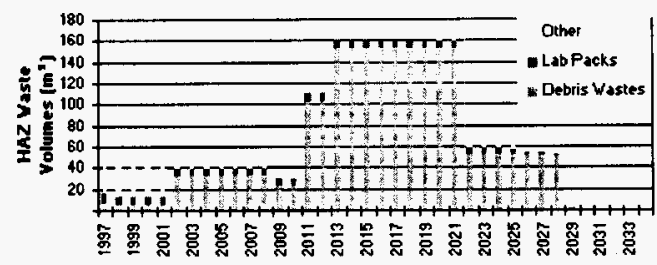

\section{Hazardous Constituents (HCs)}

\section{HAZ Waste Life-Cycle Volumes by Hazardous Constituent}

The total baseline volume of waste is approximately $2,770 \mathrm{~m}^{3}$. The minimum expected volume is approximately $1,430 \mathrm{~m}^{3}$, and the maximum expected volume is $5,300 \mathrm{~m}^{3}$. The minimum, baseline, and maximum waste forecast volumes are distributed as follows:

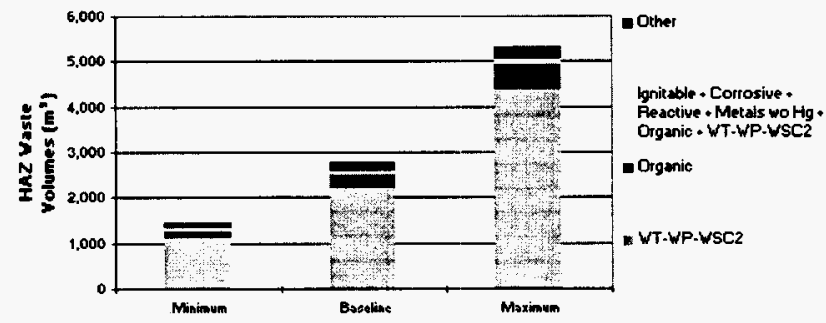

(in descending order by Hazardous Constituent volumes) 


\begin{tabular}{|l|r|r|r|}
\hline HAZ Waste Life Cycle: & & \\
Hazardous Constituents & Minimum & Baseline & Maximum \\
\hline WT.WP.WSC2 & 1,110 & 2,210 & 4.380 \\
\hline Organic & 140 & 310 & 560 \\
\hline Ignituble + Corrosive + Reactive + Metals wo Hg - & & & \\
Orgunic -WT-WP.WSC2 & 80 & 80 & 100 \\
\hline Other & 100 & 170 & 270 \\
\hline
\end{tabular}

Sum of totals may not add due to rounding: numbers over $10 \mathrm{~m}^{3}$ are rounded to the nearest $10 \mathrm{~m}^{3}$, numbers less than $10 \mathrm{~m}^{3}$ are rounded to integers, non-zero numbers less than 1 are rounded to 1.

\section{HAZ Waste Annual Baseline Volumes by Hazardous Constituent}

The graph shows the hazardous waste volume for 1997 through 2034 . About $86 \%$ of the waste is generated by TWRS, $5 \%$ by RCRA and $4 \%$ by Analytical Laboratories. Waste generation will peak in 2013-2021, due to waste (90\% Washington State regulated waste) associated with the retrieval of the long-length contaminated equipment from TWRS.

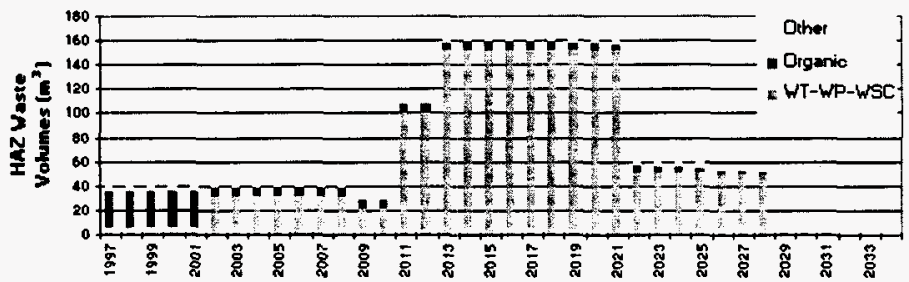

\section{Summary Tables (Volumes in $\mathbf{m}^{3}$ )}

Physical Waste Forms (PWFs)

\section{HAZ Waste Forecast by Physical Waste Form Volumes}

(in descending order by Physical Waste Form volumes)

\begin{tabular}{|c|c|c|}
\hline $\begin{array}{l}\text { HAZ Vaste Forecast: } \\
\text { Physical Vaske Form }\end{array}$ & $\begin{array}{c}\text { Fra7.1 Forecast } \\
\text { (m") }\end{array}$ & Percent \\
\hline Debris Wasles & 2.250 & $81 \%$ \\
\hline Labpiaks & 210 & $8 *$ \\
\hline Soil Gravel & 110 & $4 \%$ \\
\hline OrgHorno Sol & 90 & $3 \%$ \\
\hline horgHomo Sol & 50 & 2 \\
\hline Other & 60 & $2 \%$ \\
\hline Torel & $27 \pi$ & $1020 x$ \\
\hline
\end{tabular}

Sum of totals may not add due to rounding: numbers over $10 \mathrm{~m}^{3}$ are rounded to the nearest $10 \mathrm{~m}^{3}$, numbers less than $10 \mathrm{~m}^{3}$ are rounded to integers, non-zero numbers less than 1 are rounded to 1.

\section{HAZ Waste Life-Cycle Baseline Physical Waste Form Volumes ( $\left.\mathrm{m}^{3}\right)$}

(in descending order by Physical Waste Form volumes) 


\begin{tabular}{|c|c|c|c|c|c|c|c|}
\hline $\begin{array}{l}\text { HAZ Waste } \\
\text { Physical Waste Forms: } \\
\text { Program }\end{array}$ & $\begin{array}{l}\text { Debris } \\
\text { Wastes }\end{array}$ & $\begin{array}{c}\text { Lab } \\
\text { Paoks }\end{array}$ & $\begin{array}{c}\text { Soil } \\
\text { Gravel }\end{array}$ & $\begin{array}{l}\text { Org } \\
\text { Homo } \\
\text { Sol }\end{array}$ & $\begin{array}{c}\text { Inorg } \\
\text { Homo Sol }\end{array}$ & Other & Fotal \\
\hline TWRS & 2,200 & 80 & 0 & 60 & 20 & 20 & 2300 \\
\hline RCRA Monitoring & 10 & 3 & 110 & 10 & 0 & ... & sot. \\
\hline Analytical Services & 0 & 110 & 0 & 0 & of & 6 & 200 \\
\hline Liguid Effluent...... & 10 & 10 & 1 & 20 & 20 & 10 & $Q Q$ \\
\hline F-eility Transikions & 1 & 3 & 0 & 0 & 0 & 10 & $\theta$ \\
\hline Solid Waste & 20 & o & 2 & 0 & 6 & 2 & 30 \\
\hline Tokd & 2250 & 20 & $m$ & $\$ 0$ & 50 & $Q 2$ & 2770 \\
\hline
\end{tabular}

Sum of totals may not add due to rounding: numbers over $10 \mathrm{~m}^{3}$ are rounded to the nearest $10 \mathrm{~m}^{3}$, numbers less than $10 \mathrm{~m}^{3}$ are rounded to integers, non-zero numbers less than I are rounded to $I$.

Hazardous Constituents (HCs)

\section{HAZ Waste Forecast by Hazardous Constituent Volumes}

(in descending order by Hazardous Constituent volumes)

\begin{tabular}{|c|c|c|}
\hline $\begin{array}{l}\text { HAZ Waste Forecast: } \\
\text { Hazardous Constituent }\end{array}$ & $\begin{array}{c}\text { FY97.1 } \\
\text { Forecesst }\left(\mathrm{m}^{3}\right)\end{array}$ & Percent \\
\hline$W T-W P-W S C 2$ & 2,210 & $80 \%$ \\
\hline Dranio & 310 & $11 \%$ \\
\hline gnitable + Corrosive + Reactive + Metals woHg + Organic + wT-WP- & 80 & $3 \%$ \\
\hline Metals woHg & 50 & $2 \%$ \\
\hline Corrosive + WT-WP-WSC2 & 40 & 1 \\
\hline Qthes & 119 & $4 \%$ \\
\hline Tard & 2770 & $M O E$ \\
\hline
\end{tabular}

Sum of totals may not add due to rounding: numbers over $10 \mathrm{~m}^{3}$ are rounded to the nearest $10 \mathrm{~m}^{3}$, numbers less than $10 \mathrm{~m}^{3}$ are rounded to integers, non-zero numbers less than 1 are rounded to $I$.

\section{HAZ Waste Life-Cycle Baseline Hazardous Constituent Volumes $\left(\mathbf{m}^{3}\right)$}

(in descending order by Hazardous Constituent volumes)

\begin{tabular}{|c|c|c|c|c|c|c|c|}
\hline $\begin{array}{l}\text { HAZ Waste } \\
\text { Physical Yaste Forms: } \\
\text { Program }\end{array}$ & $\begin{array}{c}\text { WT-WP- } \\
\text { WSC2 }\end{array}$ & Drganic & $\begin{array}{c}\text { Ignitable + Corrosive } \\
+ \text { Reactive + Metal } \\
\text { to Hg + WT-WP- } \\
\text { WSC2 }\end{array}$ & $\begin{array}{c}\text { Metals } \\
\text { vo Ho }\end{array}$ & $\begin{array}{c}\text { Corrosive + } \\
\text { WT-WP- } \\
\text { WSC2 }\end{array}$ & Dihet & roes \\
\hline TWRS & 2,150 & 190 & 의 & 30 & . & 99 & 2,300 \\
\hline RCRA Monitoring & .... & 20 & of & 7 & 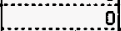 & 0 & 550 \\
\hline Analutical Services & 30 & i & of & 0 & 40 & 40 & 20 \\
\hline Liquid Effluent & 0 & 是 & 80 & 0 & 0 & 0 & 80 \\
\hline Solid Waste & 4 & 1 & 0 & 10 & o & 20 & 30 \\
\hline Facility Transitions & 0 & 1 & o & 2 & o & 10 & 0 \\
\hline Tord & 220 & 320 & $\theta 0$ & 50 & $\infty$ & 800 & 2770 \\
\hline
\end{tabular}

Sum of totals may not add due to rounding: numbers over $10 \mathrm{~m}^{3}$ are rounded to the nearest $10 \mathrm{~m}^{3}$, numbers less than $10 \mathrm{~m}^{3}$ are rounded to integers, non-zero numbers less than $I$ are rounded to $I$.

\section{Comparison to Previous Baseline(s)}

- The FY97.1 forecast of $2,770 \mathrm{~m}^{3}$ of hazardous waste shows a $91.8 \%$ decrease from the FY96 forecast of $33,830 \mathrm{~m}^{3}$. The reason for the enormous change between the two forecasts is that the Waste Management Program is no longer the central collection point for hazardous waste generated on the Hanford Site. Many generators have elected to send their hazardous waste directly to other vendors for waste management. Only those generators who plan to have the Waste Management Program manage their waste are included in the FY 97 forecast. 
There was no change between the FY97.1 forecast and the FY97.0 forecast.

\section{HAZ Waste Comparison to Previous Baseline(s) by Physical Waste Form}

For the FY97.1 forecast the volume percent of the three most significant physical waste forms are: debris waste $(81 \%)$, lab packs $(8 \%)$ and soil and gravel $(4 \%)$. For the FY 96 forecast the percentages are: soil and gravel (53\%), debris waste (16\%), and lab packs (14\%).

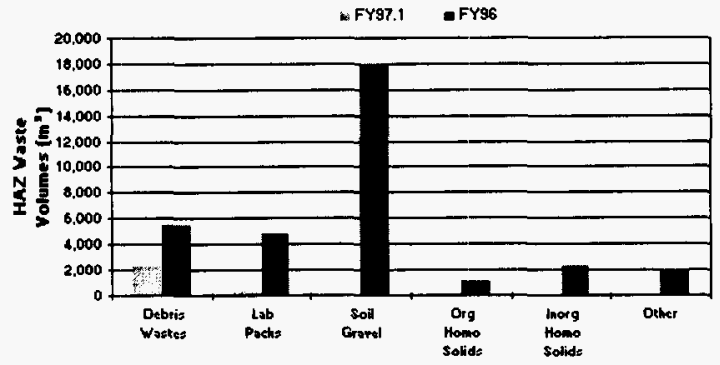

(in descending order by Physical Waste Form volumes)

\begin{tabular}{|c|c|c|}
\hline $\begin{array}{l}\text { HAZ Comparison: } \\
\text { PLrsieal Vaste Form }\end{array}$ & $\begin{array}{c}\text { FYs7.I forecese } \\
\left(m^{\prime \prime}\right)\end{array}$ & $\begin{array}{c}\text { FYas Foreeast } \\
\left(m^{2}\right)\end{array}$ \\
\hline Depris Wastes & $\begin{array}{r}2,250 \\
\end{array}$ & 5.510 \\
\hline LabPuaks & 210 & 4840 \\
\hline Soll Giovel & 110 & 18,020 \\
\hline Dorgomo Solids & 30 & 1.080 \\
\hline Inorg Homo Solids & 50 & 2,310 \\
\hline Quher & 60 & 2,070 \\
\hline Tater & 2,370 & sxtest \\
\hline
\end{tabular}

Sum of totals may not add due to rounding: numbers over $10 \mathrm{~m}^{3}$ are rounded to the nearest $10 \mathrm{~m}^{3}$, numbers less than $10 \mathrm{~m}^{3}$ are rounded to integers, non-zero numbers less than $l$ are rounded to $l$.

\section{HAZ Waste Comparison to Previous Baseline(s) by Hazardous Constituent}

For the FY 97.1 forecast the volume percent of the three most significant hazardous waste constituents are: Washington State regulated $(80 \%)$, toxic organics $(11 \%)$, and combinations of ignitable, corrosive, and reactive compounds, metals without mercury, toxic organic compounds, and state regulated materials (3\%). For the FY96 forecast the percentages are: Washington State regulated waste $(51 \%)$, toxic organics $(21 \%)$, and metals without mercury (7\%). 


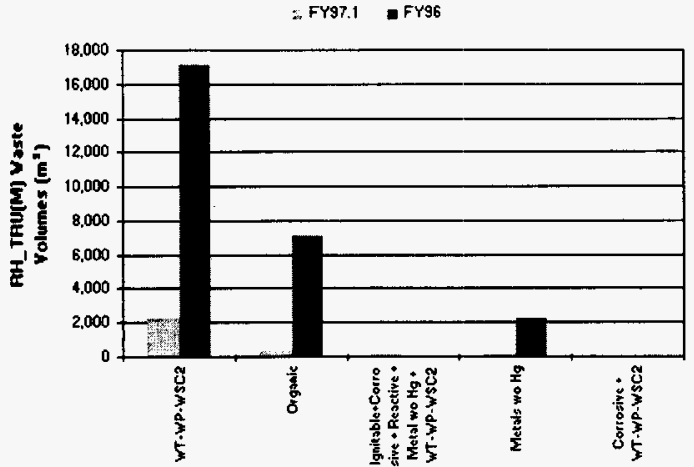

(in descending order by Hazardous Constituent volumes)

\begin{tabular}{|c|c|c|}
\hline $\begin{array}{l}\text { Hazadous Vaste Comparison } \\
\text { Harardous Constituent }\end{array}$ & $\begin{array}{c}\text { Fre7.1 } \\
\text { Forecest (m') }\end{array}$ & $\begin{array}{c}\text { FY96 Foreeast } \\
\left(m^{2}\right)\end{array}$ \\
\hline WT:WP.WSC2 & ............2210 & .................17,10 \\
\hline 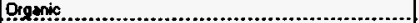 & ...310 &. .7060 \\
\hline $\begin{array}{l}\text { Ignitable - Corrosiwe * Reactive a Melals wo Hg • Organic } \\
\text { +WT-WP-WSC2 }\end{array}$ & 80 & 0 \\
\hline Metals wo $\mathrm{Hg}$ & 50 & 2,270 \\
\hline Corrosiue WT.WP WSCL & 40 & 130 \\
\hline Other & B0 & 7,270 \\
\hline Toref & 2,77 & 32000 \\
\hline
\end{tabular}

Sum of totals may not add due to rounding: numbers over $10 \mathrm{~m}^{3}$ are rounded to the nearest $10 \mathrm{~m}^{3}$, numbers less than $10 \mathrm{~m}^{3}$ are rounded to integers, non-zero numbers less than $I$ are rounded to $I$.

\begin{tabular}{|c|c|}
\hline $\begin{array}{l}\text { CHARACTERISTICS: } \\
\text { CH_LLMW } \cdot \text { RH_LLMW } \cdot \text { CH_TRU(M) } \cdot \text { RH_TRU(M) } \cdot \\
\text { GTC III } \cdot \text { LLW } \cdot H A Z\end{array}$ & $\begin{array}{c}\text { CONTAINERS: } \\
\text { CH_LLMW } \cdot \text { RH_LLMW } \cdot \text { CH_TRU(M) } \\
\text { RH_TRU(M) } \cdot \text { GTC III } \cdot \text { LLWW } \cdot \text { HAZ }\end{array}$ \\
\hline \multicolumn{2}{|c|}{$\begin{array}{l}\text { WASTE CLASSES: } \\
\text { CH_LLMW } \cdot \text { RH_LLMW } \cdot \text { CH_TRU(M) } \cdot \text { RH_TRU(M) } \cdot \text { GTC III } \cdot \text { LLW } \cdot \text { HAZ }\end{array}$} \\
\hline $\begin{array}{r}\text { PROG } \\
\text { Analytical Services } \cdot \text { EM-40 - Facility Transitions } \cdot \text { Landlc } \\
\text { Waste } \cdot \text { SN }\end{array}$ & Effluent $\cdot$ NP $\cdot$ Offsite $\cdot$ PNNL $\cdot$ RCRA $\cdot$ Solid \\
\hline
\end{tabular}

NOTICE: This page is provided subject to our disclaimer. Contact: Oscar Valero at (509) 373-4752.

HNF-EP-0918 rev. 1 Approved for public release; distribution is unlimited. 


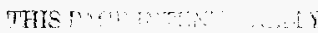

1. A 


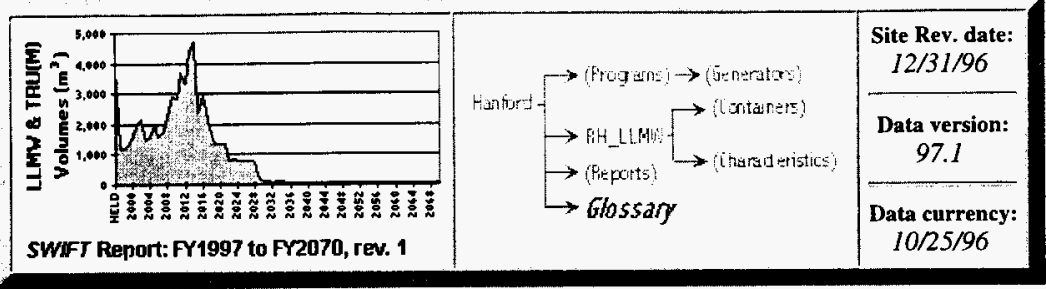

\section{Glossary}
" Abbreviations
»Characteristics Definitions
»Waste Class Naming Conventions
»Container Definitions

\section{Abbreviations}

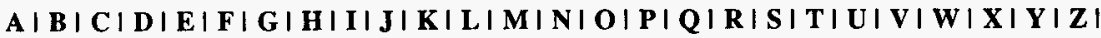

- B -

BEMR Baseline Environmental Management Report

BHI Bechtel Hanford Incorporated

BWHC Babcock \& Wilcox Hanford Company

- C -

CERCLA Comprehensive Environmental Response, Compensation, and Liability Act

CDR

$\mathrm{CH}$ Conceptual Design Report

Cs contact-handled

CWC cesium

Central Waste Complex

- D -

D\&D decontamination and decommissioning

DESH Duke Engineering \& Services Hanford

DOE U.S. Department of Energy

DST double-shell tank

- E .

EM

EM-40

ER Environmental Restoration Program

ERC environmental restoration (also refers to the Environmental Restoration program) ERDF Environmental Restoration Contractor Environmental Restoration Disposal Facility 
- F -

FFTF

FMEF

FY

FY96

FY97.0

FY97.1

- G -

GTCIII

- H -

$\mathrm{HAZ}$

$\mathrm{HC}$

HELD

HEPA

$\mathrm{Hg}$

HLVP

HLW

Homo

Inorg

- I -

IX

- L .

LBL

LEC

LERF

LLBG

LLE

LLMW

LLVP

LLW

LMHC

- M -

M\&I

MB-

mrem
Fast Flux Test Facility

Fuels Material and Examination Facility

fiscal year

Dataset collected 6/30/95

Dataset collected 6/30/96

Dataset revisions collected 10/30/96

greater than Category III

Hazardous Waste

Hazardous Constituent

waste that is expected to be shipped to CWC, but that does not have a shipping schedule High Efficiency Particulate Air (filter)

Mercury

High-Level Vitrification Project

high-level waste

homogeneous

inorganic

ion exchange

Lawrence Berkeley Laboratory

long-length equipment container

Liquid Effluent Retention Facility

Low-Level Burial Ground

long-length contaminated equipment

low-level mixed waste

Low-Level Vitrification Project

low-level waste

Lockheed Martin Hanford Company

maintenance and integration

metal box

milli-rem 
MUSTs miscellaneous underground storage tanks

MYPP

Multi-Year Program Plan

MYWP

Multi-Year Work Plan

$-\mathbf{N}$.

$\mathrm{nCi}$

nanocurie

NA

Not Available

$\mathrm{NHC}$

Numatec Hanford Company

NP

Non Programmatic

- $\mathbf{O}$ -

Org

organic

- P -

PCB

polychlorinated biphenyl

PFP

Plutonium Finishing Plant

PHMC

Project Hanford Management Contract

PNNL

Pacific Northwest National Laboratories

PPE

Personal Protective Equipment

PRTR Plutonium Recycle Test Reactor

PUREX

Plutonium Uranium Extraction Facility

PWF

Physical Waste Form

- R -

$\mathrm{R} \& \mathrm{D}$

research and development

RCRA

Resource Conservation and Recovery Act

RFSH

Rust Federal Services of Hanford

RH

remote-handled

- S -

SNF

spent nuclear fuel (also refers to the Spent Nuclear Fuel program)

Sol

solid

$\mathrm{Sr}$

strontium

SST

single-shell tank

STP

Site Treatment Plan; Stabilization Treatment Program

SWB

standard waste box

SWF

Solid Waste Forecast

SWIFT

Solid Waste Integrated Forecast Technical Report; Solid Waste Information Forecasting Tool

SWITS Solid Waste Inventory Tracking System

- T -

TC\&S

Terminal Cleanout and Stabilization 


$\begin{array}{ll}\text { TEDF } & \text { Treated Effluent Disposal Facility } \\ \text { TFTR } & \text { Tokamak Fusion Test Reactor } \\ \text { TRU(M) } & \text { transuranic waste (both non-mixed and mixed) } \\ \text { TRUSAF } & \text { TRU Storage and Assay Facility } \\ \text { TSD } & \text { treatment, storage, and disposal } \\ \text { TWRS } & \text { Tank Waste Remediation System } \\ \text { - W - } & \\ \text { w } & \text { with (i.e., w Hg means with Mercury) } \\ \text { WAC } & \text { Washington Administrative Code } \\ \text { WATS } & \text { Waste Acid Treatment System } \\ \text { WESF } & \text { Waste Encapsulation and Storage Facility } \\ \text { WHC } & \text { Westinghouse Hanford Company } \\ \text { WIPP } & \text { Waste Isolation Pilot Plant } \\ \text { WM } & \text { Waste Management Project } \\ \text { wo } & \text { without (i.e., wo Hg means without Mercury) } \\ \text { WRAP I } & \text { Waste Receiving and Processing Facility } \\ \text { WSCF } & \text { Waste Sampling and Characterization Facility } \\ \text { WT-WP-WSC2 } & \text { Washington State Regulated hazardous constituents }\end{array}$

\section{Waste Class Naming Conventions}

Solid waste can be characterized into five classes, excluding LLW and HAZ. These classes are briefly described in the following Table. These definitions are applicable specifically to forecast waste, and are based on WHC-EP-0063.4.

Table 1 Waste Category Definitions

\begin{tabular}{|l|c|c|c|c|c|}
\hline & $\begin{array}{c}\text { CH_ } \\
\text { LLMW }\end{array}$ & $\begin{array}{c}\text { RH_ } \\
\text { LLMW }\end{array}$ & $\begin{array}{c}\text { CH } \\
\text { TRU(M) }\end{array}$ & $\begin{array}{c}\text { RH_- } \\
\text { TRU(M) }\end{array}$ & $\begin{array}{c}\text { LLMW } \\
\text { GTCIII }\end{array}$ \\
\hline Dose rate & $\begin{array}{c}<=200 \\
\mathrm{mrem} / \mathrm{h}\end{array}$ & $\begin{array}{c}>200 \\
\mathrm{mrem} / \mathrm{h}\end{array}$ & $\begin{array}{c}<=200 \\
\mathrm{mrem} / \mathrm{h}\end{array}$ & $\begin{array}{c}>200 \\
\mathrm{mrem} / \mathrm{h}\end{array}$ & Varies \\
\hline $\begin{array}{l}\text { Dangerous per WAC } \\
\text { 173-303 }\end{array}$ & Yes & Yes & $\begin{array}{c}\text { Yes (TRU(M)) } \\
\text { No (TRU) }\end{array}$ & $\begin{array}{c}\text { Yes (TRU(M)) } \\
\text { No (TRU) }\end{array}$ & Yes \\
\hline $\begin{array}{l}>100 \text { nCi/g(b) alpha-emitting } \\
\text { isotopes } \\
\text { (atomic numbers }>92 \text { \& half-lives } \\
>20 \text { years) }\end{array}$ & No & No & Yes & Yes & No \\
\hline
\end{tabular}

$$
(<\ldots \text { less than }>\ldots \text { greater than }=\ldots \text { equal })
$$

Contact-handled low-level mixed waste (CH_LLMW) 
This waste has a dose rate equal to or less than $200 \mathrm{mrem} / \mathrm{h}$ and contains radioactivity not classified as spent nuclear fuel or transuranic waste (concentrations of transuranic radionuclides less than or equal to $100 \mathrm{nCi} / \mathrm{g}$ of the waste matrix). The waste is also defined as dangerous (hazardous) waste in the Washington Administrative Code (WAC) 173-303.

\section{Remote-handled low-level mixed waste (RH_LLMW)}

This waste has a dose rate greater than $200 \mathrm{mrem} / \mathrm{h}$ and meets the definition for LLW. This waste is also defined as dangerous (hazardous) waste in WAC 173-303.

\section{Contact-handled transuranic or transuranic mixed waste (CH_TRU(M))}

This radioactive waste has a dose rate equal to or less than $200 \mathrm{mrem} / \mathrm{h}$ at contact with the waste container. At the time of assay, this waste contains more than $100 \mathrm{nCi} / \mathrm{g}$ of alpha-emitting isotopes with atomic numbers greater than 92 and half-lives greater than 20 years. TRUM waste is TRU waste that is also dangerous (hazardous) waste as defined in WAC 173-303.

\section{Remote-handled transuranic or transuranic mixed waste (RH_TRU(M))}

This waste has a dose rate greater than $200 \mathrm{mrem} / \mathrm{h}$ at contact with the waste container. At the time of assay, this waste contains more than $100 \mathrm{nCi} / \mathrm{g}$ of alpha-emitting isotopes with atomic numbers greater than 92 and half-lives greater than 20 years. TRUM waste is TRU waste that is also dangerous (hazardous) waste as defined in WAC 173-303.

\section{Low-level mixed waste greater than Class III (LLMW_GTCIII)}

This waste meets the definition for LLW and is also defined as dangerous (hazardous) waste in WAC 173-303. Greater-than-Class III (GTCIII) designation is determined when the sum of the fractions of the radionuclides' Class III concentration limits are greater than one, as defined in the Hanford Site Solid Waste Acceptance Criteria, WHC-EP-0063 Rev. 4, November 1993.

Contact-handled $(\mathrm{CH})$ and remote-handled $(\mathrm{RH})$ waste are considered distinct categories, based on the inherent characteristics of the waste. However, in a few instances, generators have reported $\mathrm{RH}$ waste that is shielded to $\mathrm{CH}$ levels as $\mathrm{CH}$ waste.

In addition to the above waste categories, another key definition concems Held waste. Held waste is existing generated waste with no current shipping schedule.

\section{Characteristics Definitions}

\section{Physical Waste Forms (PWFs)}

The primary physical waste forms of most waste volumes can be delineated in the following categories, based on the DOE Waste Treatability Group Guidance Document (DOE/LLW-217 Revision 0):

Debris Wastes: Wastes that meet the U.S. Environmental Protection Agency (EPA) criteria for "debris." Debris materials are divided into four groups as either metal (inorganic), 
inorganic non-metal, combustible (organic), or mixtures of materials (heterogeneous). If the waste is dominated by one type of material it should be classified as that material; otherwise it is classified as heterogeneous.

Inorganic Homogeneous Solids: Material that has an inorganic matrix or content, and does not meet the criteria for debris.

Organic Homogeneous Solids: Material that has an organic matrix or content (i.e., material that includes chemical compounds based on carbon, hydrogen, and oxygen), and does not meet the criteria for debris.

Labpacks: Various quantities of compatible waste within the same Department of Transportation hazard class, packaged in vessels such as cans or bottles.

Soils/Gravel: Soil or gravel contaminated with hazardous and/or radioactive materials.

Shielding: Three types of shielding include steel, lead, and concrete. It is assumed that, if shielding is required, then the shielding material is handled as solid waste. A fourth type of shielding is also included: void space, which is space within a container that is not occupied by waste.

Special Wastes: waste containing one or more of the following: elemental mercury, elemental lead, beryllium waste, batteries, reactive metals, explosives/propellants, and aerosols/compressed gases.

\section{Hazardous Constituents (HCs)}

Hazardous constituents as defined by the Resource Conservation and Recovery Act (RCRA) are an important characteristic of the waste that will be generated. These hazardous constituents can be grouped into eight main categories that may be individual or mixed. Several hazardous constituents might be present in a particular waste form and require definition by waste volume percentages as mixed hazardous constituents (e.g., if a 208-liter drum contains both ignitables and corrosives, then the package is $100 \%$ ignitables and corrosives). The relevant hazardous constituent groups are:

Ignitables (RCRA code: D001): Waste that can cause a fire through friction, absorption of moisture, or spontaneous chemical action.

Corrosives (RCRA code: D002): Any liquid or solid that causes destruction of human skin tissue or that has a severe corrosion rate on steel.

Reactive Metals (RCRA code: D003): Typically sodium metal or alkali metal alloys but can also be particulate fines of aluminum, uranium, zirconium, or other pyrophoric materials, and may be mixed with stabilizing materials.

Metals Without Mercury (RCRA codes: D004-D011): Toxic metals that are not contaminated with mercury.

Metals With Mercury (RCRA codes: D009, P065, P092, and U151): Toxic metals that are specifically contaminated with mercury. 
Toxic Organics (RCRA codes: D018-D043): Toxic organic compounds.

State Regulated (Washington State codes: WT, WP, WSC2): Waste that is defined as hazardous only under Washington State regulations.

PCBs: Polychlorinated biphenyl-contaminated materials (designated in 40 CFR 761 or WAC 173-303-071) where PCB concentration is further divided into two categories: less than 50 parts per million (ppm), and greater than or equal to $50 \mathrm{ppm}$.

\section{Container Definitions}

For the 1997 forecast, 12 different container types have been reported for solid waste shipment to Waste Management during its life cycle. The following is a brief description of these containers:

\section{Drums}

114-liter drum: This is a small standard drum equivalent to 30 U.S. gallons.

208-liter drum: This is a standard-size drum equal to 55 U.S. gallons.

322-liter drum: Often used as an overpack for 208 liter drums, this is a large standard-size drum equivalent to 85 U.S. gallons.

Other drums: This category represents various container sizes used less often than the standard drums, such as 57-liter drums, 76-liter drums, or 416-liter drums.

\section{Boxes}

Extra-large box: This shipping container is defined by an external volume greater than $28.3 \mathrm{~m}^{3}$ $\left(1,000 \mathrm{ft}^{3}\right)$. Boxes of this size are too big to be accepted at the STP treatment facility.

Large box: The size of this container is defined as greater than $16.3 \mathrm{~m}^{3}$ and less than $28.3 \mathrm{~m}^{3}$ in external volume $\left(576-1,000 \mathrm{ft}^{3}\right)$. This size is too large to be accepted at the STP facility.

Long-length equipment container (LEC): These containers vary in size, but are used only for equipment retrieved from the Hanford Tank Farms. The waste in these containers will be almost all RH_LLMW.

MB-IV: This metal box measures $1.95 \mathrm{~m}$ long by $1.32 \mathrm{~m}$ wide by $1.11 \mathrm{~m}$ high.

MB-V: Made of either metal or plywood, this box measures $2.43 \mathrm{~m}$ long by $1.22 \mathrm{~m}$ wide by $1.33 \mathrm{~m}$ high.

Medium box: Any size in between an external volume of 3.6 and $16.3 \mathrm{~m}^{3}\left(128-576 \mathrm{ft}^{3}\right)$ classifies as a medium box. All Medium boxes can be handled by STP treatment facility.

Small box: A small box has an external volume less than $3.6 \mathrm{~m}^{3}\left(128 \mathrm{ft}^{3}\right)$. 
Standard waste box (SWB): This container is used only for TRU(M) waste and is constructed of carbon steel for the Waste Isolation Pilot Plant (WIPP).

PROGRAMS:

Analytical Services · EM-40 - Landlord · Facility Transitions · Liquid Effluent · NP · Offsite · PNNL · RCRA - Solid Waste $\cdot$ SNF $\cdot$ TWRS

CHARACTERISTICS:

CH_LLMW $\cdot$ RH_LLMW $\cdot$ CH_TRU(M) $\cdot$ RH_TRL(M) . GTC III $\cdot$ LLW $\cdot$ HAZ

\section{CONTAINERS:}

CH_LLMW $\cdot$ RH_LLMW $\cdot$ CH_TRU(M) . RH_TRU(M) $\cdot$ GTC III $\cdot$ LLW $\cdot$ HAZ

\section{WASTE CLASSES:}

CH_LLMW $\cdot$ RH_LLMW $\cdot$ CH_TRU(M) $\cdot$ RH_TRU(M) $\cdot$ GTC III $\cdot$ LLW $\cdot$ HAZ

Home · Contents - Web Site Map · Glossary · Help · Reports · Data Requests - Feedback Form

NOTICE: This page is provided subject to our disclaimer. Contact: Oscar Valero at (509) 373-4752.

HNF-EP-0918 rev. 1 Approved for public release; distribution is unlimited. 

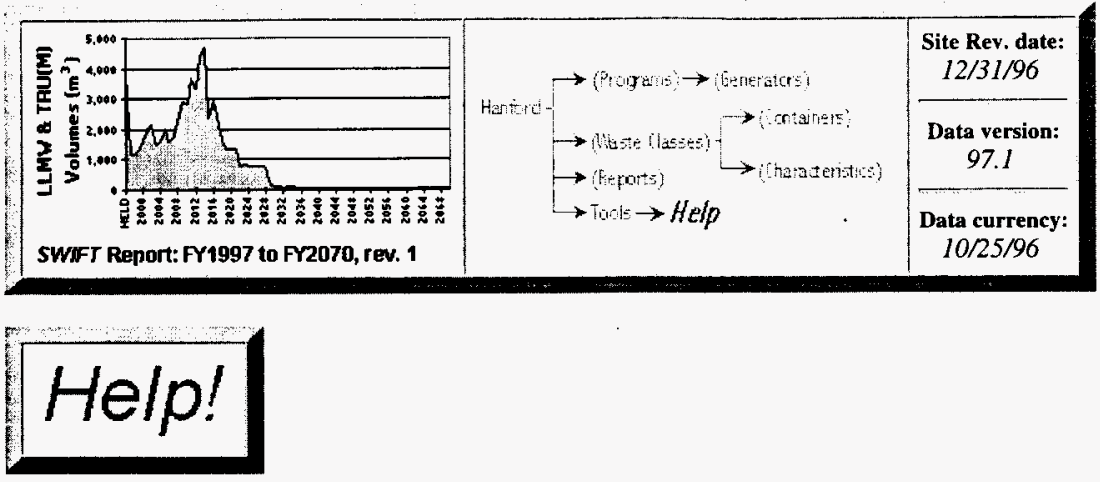

\section{Help Contents}

This section provides some general information about how the site is organized and how to use Netscape, as well as important details about how some calculations were performed.

\section{Overview}

- SWIFT Report Web Site Overview

- Forecasting process

\section{How to ...}

- Using Netscape

- Netscape bookmarks

\section{Data issues}

- Increase/decrease percentages

- Rounding

- Min/max ranges

- Waste class naming conventions

- Waste categories

- Container specifications

- Generator life cycle phases 


\section{HELP:}

Help Home - SWIFT Report Web Site Overview - Forecasting Process - Using Netscape - Netscape Bookmarks · Percentages - Rounding · Min/Max - Waste Class Naming - Waste Categories - Container Specifications - Generator Life Cycles

PROGRAMS:

Analytical Services - EM-40 - Facility Transitions - Landlord - Liquid Effluent - NP - Offsite - PNNL - RCRA - Solid Waste - SNF - TWRS

\begin{tabular}{|c|c|}
\hline $\begin{array}{c}\text { CHARACTERISTICS: } \\
\text { CH_LLMW } \cdot \text { RH_LLMW } \cdot \text { CH_TRU(M) } \\
\text { GTC III } \cdot \text { RLW } \cdot \text { RHAZ }\end{array}$ & $\begin{array}{c}\text { CONTAINERS: } \\
\text { CH_LLMW } \cdot \text { RH_LLMW } \cdot \text { CH_TRU(M) } \\
\text { RH_TRU(M) } \cdot \text { GTC III } \cdot \text { LLW } \cdot \text { HAZ }\end{array}$ \\
\hline CH_LLMW $\cdot$ RH_LLMW $\cdot$ CH_TRU(M) $\cdot$ RH_TRU(M) $\cdot$ GTC III $\cdot$ LLW $\cdot$ HAZ \\
\hline Home $\cdot$ Contents $\cdot$ Web Site Map $\cdot$ Glossary $\cdot$ Help $\cdot$ Reports $\cdot$ Data Requests $\cdot$ Feedback Form
\end{tabular}

NOTICE: This page is provided subject to our disclaimer. Contact: Oscar Valero at (509) 373-4752.

HNF-EP-0918 rev. 1 Approved for public release; distribution is unlimited. 

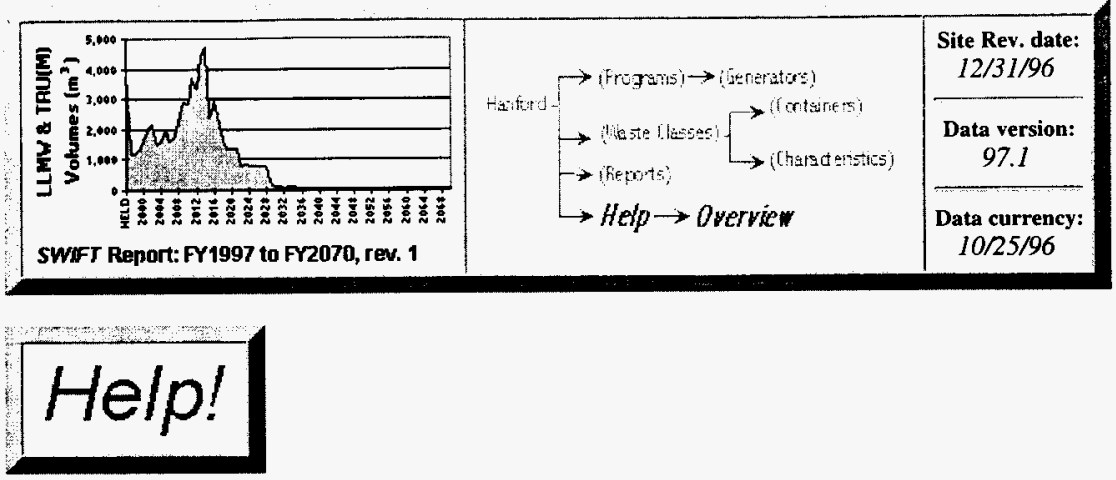

\section{SWIFT Report Web Site Overview}

This site has 3 levels of information about forecast LLMW and TRU(M) solid waste to be managed at the Central Waste Complex (CWC). Each level is successively more detailed. The block diagram shows the logical construction of the site, starting with the least detailed (broadest) view of the data:

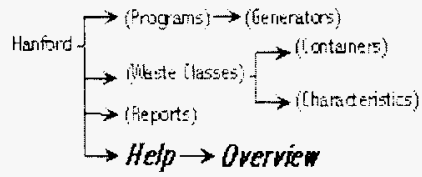

The Site Map shows more details about this organization.

The general format for each section is:

- Header (Logo, locator, time stamp)

- Contents

- Highlights

- Comparison to previous baseline(s)

- Background

- Forecast assumptions and comments

- Other Forecast

- Tool bars

- Footer

The Header has three pieces of useful information:

- SWIFT logo-a time series line graph showing volumes for LLMW and TRU(M) waste in the current forecast 
- Locator-a graphical view of your current location in the web site

- Time stamp-a display of the currency of the site, the version of the data included in the site, and the date of the data collection and analysis

The Contents section provides 1) an overview of what's at the current location, and 2) links to specific information in the location.

The Highlights section is a brief, bulleted, overview of key LLMW and TRU(M) waste issues, and typically includes the forecast life cycle, current forecast volumes, and comparison to previous baseline.

The Comparison to previous baseline(s) section provides expanded discussion of changes from previous forecasts of LLMW and TRU(M) waste.

The Background section describes the mission of the program or generator, and may also provide details about how that mission is being met.

The Forecast assumptions and comments section describes the key programmatic assumptions on which the forecast is based. These may include the life cycle end date, assumptions about budgets, treatment, or other issues that affect the amount and types of expected wastes.

The Other Forecast Data section discusses LLW and HAZ waste in the current forecast. Differences in current and baseline LLW forecasts are identified and described.

The Tool bars provide easy movement between and among Programs, waste class summary data, and Generator information. The bottom bar provides quick access to the site's tools, which include:

- Home-takes you back to the Home Page.

- Contents-loads a list of the site's contents, all of which are linked for easy access.

- Web Site Map-provides a graphical overview of the main structure and contents of the site.

- Glossary - provides definitions for acronyms used in the site.

- Help—gets you to the Help contents list.

- Reports-moves to the list of reports available on the site; click on the report name to load it.

- Data Requests_-loads a form for requesting filtered or sorted views of the data in the forecast.

- Feedback Form-is your chance to tell us what you'd like to have included in the site, and any comments or suggestions you have.

Program areas include a Summary Table of the totals for LLMW and TRU(M) waste reported by each of the generators in their program, and bar chart showing Annual Waste Class Volume for each forecast year.

Generator areas have a link to Detailed Forecast Data in the Contents section at the top of the page. A word-to-the-wise: tables with data for long life cycles can take quite a while to load (as much as a minute or two). They have a note mentioning this under the Data link. 
HELP:

Help Home - SWIFT Report Web Site Overview - Forecasting Process - Using Netscape - Netscape Bookmarks · Percentages - Rounding · Min/Max - Waste Class Naming - Waste Categories · Container Specifications - Generator Life Cycles

\section{PROGRAMS:}

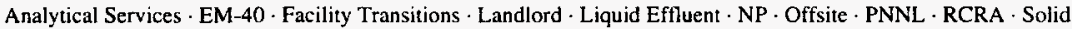
Waste $\cdot$ SNF $\cdot$ TWRS

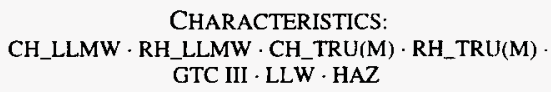

CHARACTERISTICS:

CH_LLMW $\cdot$ RH_LLMW $\cdot$ CH_TRU(M) $\cdot$ RH_TRU(M) . GTC III $\cdot$ LLW $\cdot$ HAZ

CONTAINERS:

CH_LLMW $\cdot \mathrm{RH}_{-} L L M W \cdot \mathrm{CH}_{m} \mathrm{TRU}(\mathrm{M}) \cdot$ RH_TRU(M) $\cdot$ GTC III $\cdot$ LLW $\cdot$ HAZ

\section{WASTE Classes:}

CH_LLMW $\cdot$ RH_LLMW $\cdot$ CH_TRU(M) $\cdot$ RH_TRU(M) $\cdot$ GTC III $\cdot$ LLW $\cdot$ HAZ

Home - Contents - Web Site Map - Glossary - Help · Reports · Data Requests - Feedback Form

NOTICE: This page is provided subject to our disclaimer. Contact: Oscar Valero at (509) 373-4752.

HNF-EP-0918 rev. 1 Approved for public release; distribution is unlimited. 


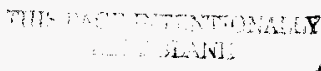


-әретाене әпе

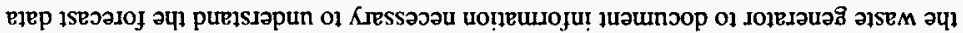

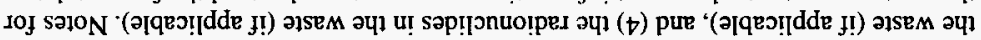

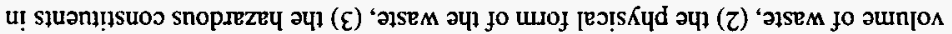

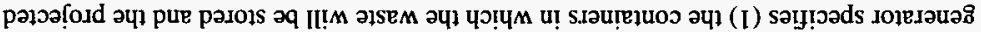

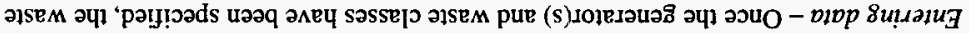

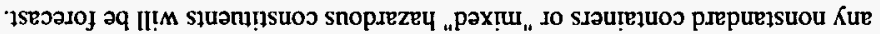

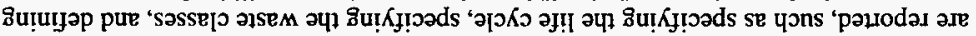

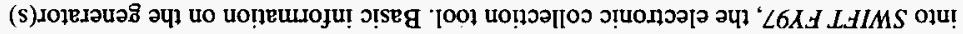

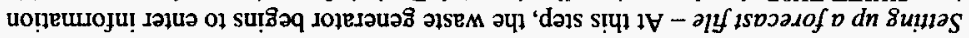

'suo!̣dunsse әsou sిu!sn piep

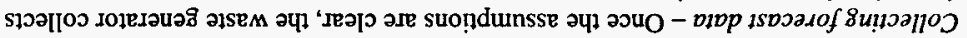

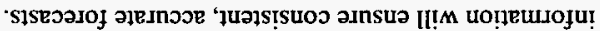

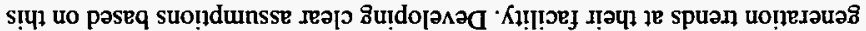

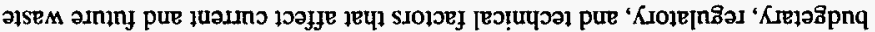

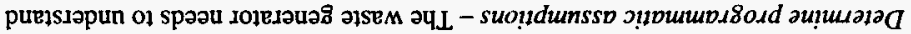

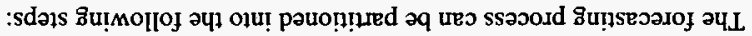

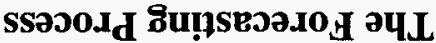
ssasosd bugsesarof $\leftarrow$ doH

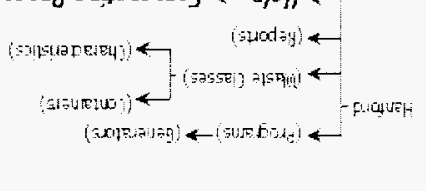

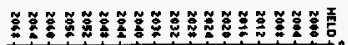

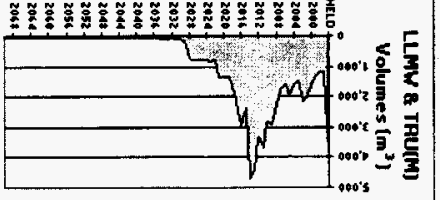




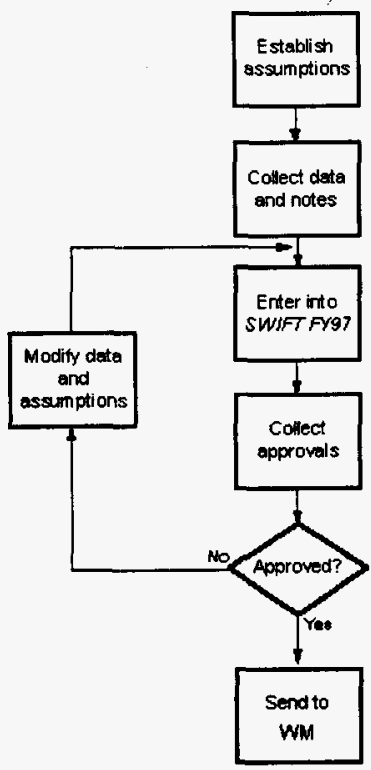

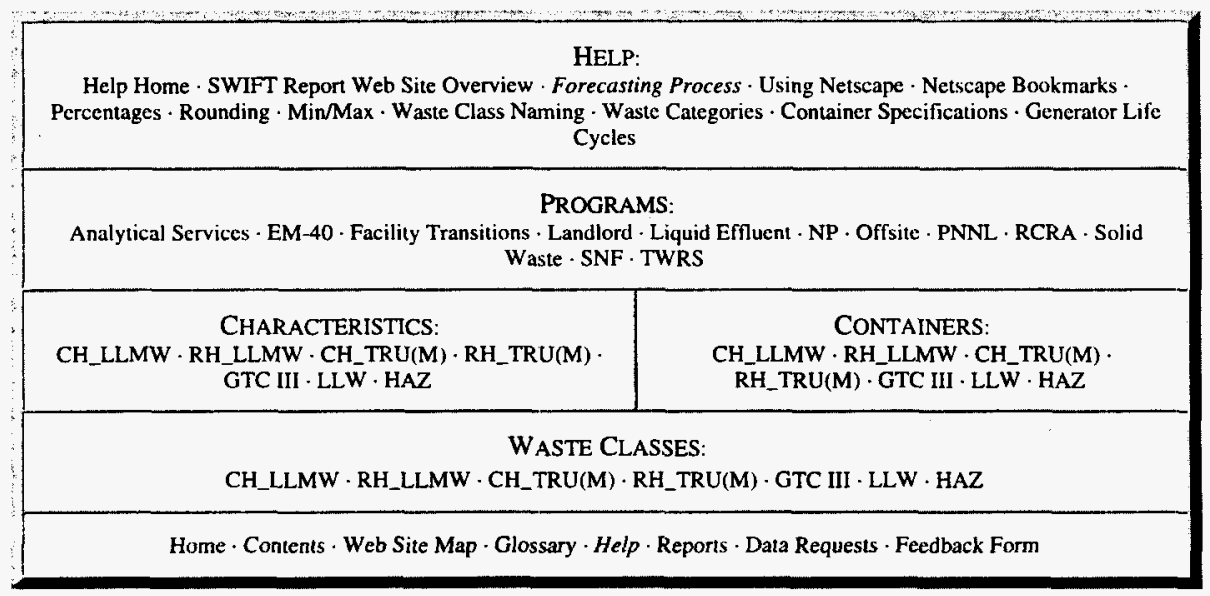

NOTICE: This page is provided subject to our disclaimer. Contact: Oscar Valero at (509) 373-4752.

HNF-EP-0918 rev. 1 Approved for public release; distribution is unlimited. 

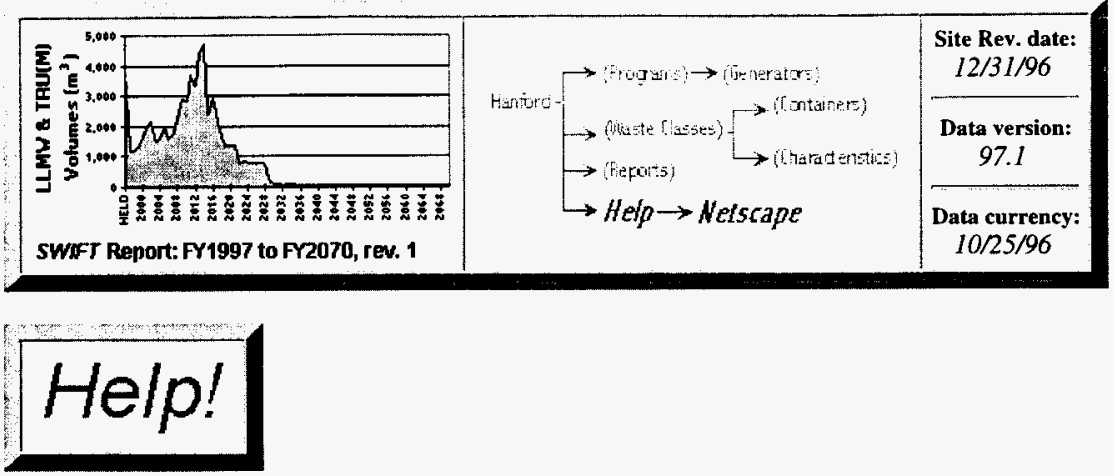

\section{Using Netscape}

\section{Up to our Knees in Solid Waste}

The Internet - is it scary? You bet it is. No one even knows how big it is, or what's in it. And why would you want to go there? For those of you who are still Internet-impaired, this page will help you navigate your way through this website and, incidentially, through the World Wide Web in general.

For this website, we've found it is best viewed with Netscape rather than Microsoft Browser, which skews the tables. Speaking of tables, if you print out a page and the table has the right edge missing, there's a way to fix that:

Step 1: While in Netscape, go to Options. Choose General Preferences. Click on the Fonts tab. You'll see two boxes with Choose Font... on each one. Click on the top one, and make sure the font size selected is 10. Click OK. Now go back to Options, and select Save Options.

Step 2: When you print a page in Netscape, tell your printer to scale down to $90 \%$. You normally do that by clicking on Setup, Options, looking for a place which will allow you to scale your print job. There's more on printing in Netscape below.

\section{Have Mouse, Will Travel}

Navigating around a website or around the Web is very simple. At the top of the screen is the comfortingly familiar Menu bar, some buttons, a Location bar, and then more buttons. Let's start in the middle, with Location:. Web site addresses start with http, followed by colons, slashes, double slashes, whistles, bells, and periods (a period is called a "dot"). If anything is out of place, you'll go nowhere. If someone tells you of a cool site, you simply highlight the location address (by clicking and dragging over it with the cursor), then type in the new site (or paste it in if you've copied it from somewhere), and enter. Sometimes when you're trying to get to a new website you'll get a terse message saying it can't be found, or it's too busy for you or something. Don't take the Web at its word; it may be lying to you. Try again. If it still 
says the same thing, wait a while before retrying. If it's still down, perhaps the site you're aiming at is having server problems. In that case, there's nothing you can do but try again later.

When you see text in some other color (often blue), that means that text is a link to another, related site. If you slide your mouse cursor arrow over that text, it will turn into a hand. Just click once. In this web site you'll find a toolbar at the bottom of every "page" you visit, with links to every other page. Just position your cursor over the name of one you want to visit, and when the cursor tums into the hand, click. [Linked text is often underlined as well, a Netscape default. If you wish to get rid of the underline, you can go to Options, General Preferences, and click on Appearance. At the bottom of this dialog box, you'll see Link Styles. You can deselect underline (or select it if it's off).]

\section{What If I Get Lost?}

Sometimes as you surf the Web, you click on links until you have no idea where you are. If you just want to get back home, there's a Home button above the Locations bar that will bring you home faster than Dorothy clicking her heels together. If you pass a spot, and want to get back to it, click on Back. To then return in a forward direction (you guessed it) click on Forward. This is easy!

\section{This is Cool! How Can I Save It?}

Now you've come to a site that has some text you'd like to keep. Go to File, and Save As, and do it in the good old fashioned Windows way.

If you want to print, you can just go to File and Print, and it will print the whole website out for you. But what if you just want to print one page? While viewing in Netscape, you can't tell where one page ends and another beings. Don't worry. Here's the best way I've found to print a specific page in a long Netscape document:

1. Go to File

2. Go to Print Preview

3. After the document loads, click on Next Page to scroll through and find which pages you wish to print.

4. Click on Print

5. Deselect All, and select Pages

6. Type in numbers at From: and To: (for instance, From: 3 To: 3)

7. Make any Setup changes you need to

8. Click on Print

\section{Gotta Remember This Site!}

Don't worry, you don't have to have a good memory to return to your favorite sites. When you find yourself someplace where you think you'll want to return, simply click on Bookmarks in the Menu bar. Click on Add Bookmark. That's all there is to it. Now to return to that site later, just go to Bookmarks, and click on the one you want. If you find you have a zillion bookmarks, there are ways to make headings and arrange them. To read more about bookmarks, click here. 


\section{It's Fun... Really It Is!}

At the beginning of this epic, the question was raised "why would you want to go there?" The Web has sites of interest for just about everyone. If you're interested in a particular area of the government, want to check up on the competition, enjoy strolling through a museum, or just want a good belly laugh, the Web has something for you. Wherever you go, click on links and see where they take you. (Often not where you originally intended to go!)

\section{Give It a Try!}

\begin{tabular}{|c|c|}
\hline $\begin{array}{r}\text { HEL } \\
\text { Help Home } \cdot \text { Help Home }- \text { SWIFT Repon Web Site Over } \\
\text { Bookmarks } \cdot \text { Percentages } \cdot \text { Rounding } \cdot \text { Min/Max } \cdot \text { Waste Cla } \\
\text { Generator L }\end{array}$ & $\begin{array}{l}\text { oceasting Process } \cdot \text { Using Netscape } \cdot \text { Netscape } \\
\mathrm{sg} \cdot \text { Waste Categories } \cdot \text { Container Specifications } \text { - }\end{array}$ \\
\hline $\begin{array}{r}\text { PROGR } \\
\text { Analytical Services } \cdot \text { EM-40 - Facility Transitions } \cdot \text { Landlor } \\
\text { Waste } \cdot \text { SNF }\end{array}$ & Id Effluent - NP - Offsite $\cdot$ PNNL $\cdot$ RCRA $\cdot$ Solid \\
\hline $\begin{array}{c}\text { CHARACTERISTICS: } \\
\text { CH_LLMW } \cdot \text { RH_LLMW } \cdot \text { CH_TRU(M) } \\
\text { GTC III } \cdot \text { LLW_TRU(M) } \cdot \text { HAZ }\end{array}$ & $\begin{array}{c}\text { CONTAINERS: } \\
\text { CH_LLMW } \cdot \text { RH_LLMW } \cdot \text { CH_TRU(M) } \\
\text { RH_TRU(M) } \cdot \text { GTC III } \cdot \text { LLW } \cdot \text { HAZ }\end{array}$ \\
\hline \multicolumn{2}{|c|}{$\begin{array}{l}\text { WASTE CLASSES: } \\
\text { CH_LLMW } \cdot \text { RH_LLMW } \cdot \text { CH_TRU(M) } \cdot \text { RH_TRU(M) } \cdot \text { GTC III } \cdot \text { LLW } \cdot \text { HAZ }\end{array}$} \\
\hline \multicolumn{2}{|c|}{ Home - Contents - Web Site Map - Glossary - Help · Reponts - Data Requests - Feedback Form } \\
\hline
\end{tabular}

NOTICE: This page is provided subject to our disclaimer. Contact: Oscar Valero at (509) 373-4752.

HNF-EP-0918 rev. 1 Approved for public release; distribution is unlimited. 
THS ${ }_{1} \ldots \ldots+\ldots$ 

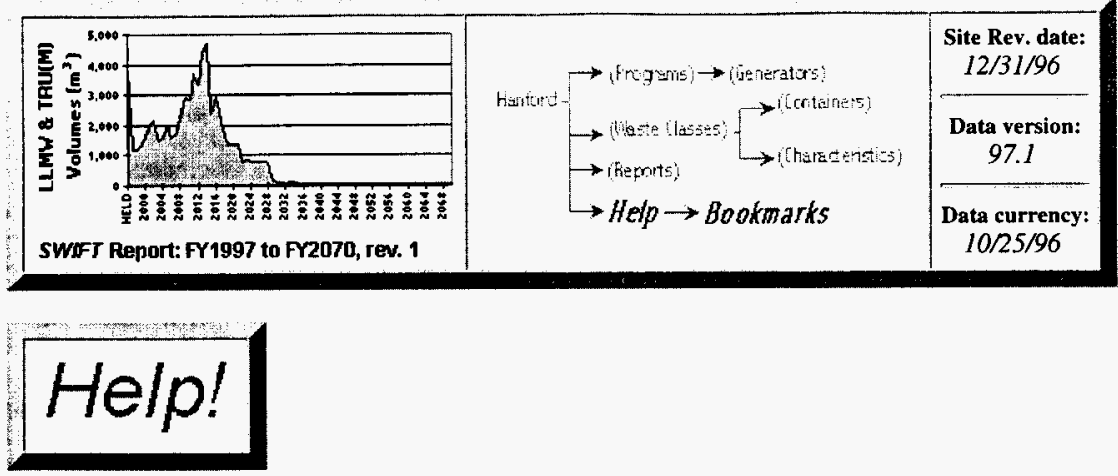

\section{Netscape - Bookmarks}

\section{What's a Bookmark?}

When you're in Netscape, one of the menu items at the top of the screen is Bookmarks. When you're surfin' the Net, and come to a really cool site you know you'll want to visit again, making a bookmark is how you can do so (without writing down those ridiculous site addresses, or having a phenomenal memory). It's easy!

\section{How To}

When you get to a site you like, click on Bookmarks. Then click on Add Bookmark. Then at some unforeseen future date, you can click on Bookmarks, click on the name of the site, and it will take you there! What could be simpler?

\section{Going Overboard}

Okay, so now you have eight billion bookmarks - so many you can't see them all, much less find the one you want. What to do? Divide them up into categories, with headers. It's easy, too.

\section{How To II}

Click on Window, and Bookmarks. Click on one of your bookmarks. Now click on Item, and select New Folder This is actually a folder for a group of bookmarks. In the dialog box, where it says "Name", it says New Folder. Type in the name you want. Click $\mathrm{OK}$. You can now click on it and drag it up or down. Now click on the bookmarks you want to be in this folder, and drag them "into" it. Close the Bookmarks Window.

Now when you want to find a bookmark, click on Bookmarks, and you'll just see a list of the folders. Click on the proper one, and a list of that folder's bookmarks 
appear. Click on one, and voila!

Handy Tip: When you make a bookmark, Netscape uses whatever is on the title bar for the name it gives the bookmark. Sometimes these titles are quite long, and can be unwieldy when you click on Bookmark to find one to open. The solution is simple. Go to Window, then Bookmarks. Click once on the offending bookmark title, click on Item, and click on Properties.... In the Name section, just delete part of the name, or give it a whole new descriptive name. Be sure not to accidently do this in the location section! (Like I did.) Go through your bookmarks and give them short names you find useful.

You see, I told you it was easy!

\begin{tabular}{|c|c|}
\hline \multicolumn{2}{|c|}{$\begin{array}{l}\text { HELP: } \\
\text { Help Home - SWIFT Report Web Site Overview - Forecasting Process - Using Netscape · Netscape Bookmarks } \cdot \\
\text { Percentages - Rounding - Min/Max - Waste Class Naming · Waste Categories - Container Specifications - Generator Life } \\
\text { Cycles }\end{array}$} \\
\hline \multicolumn{2}{|c|}{$\begin{array}{l}\text { PROGRAMS: } \\
\text { Analytical Services } \cdot \text { EM-40 } \cdot \text { Facility Transitions " Landlord - Liquid Effluent } \cdot \text { NP } \cdot \text { Offsite } \cdot \text { PNNL } \cdot \text { RCRA } \cdot \text { Solid } \\
\text { Waste } \cdot \text { SNF } \cdot \text { TWRS }\end{array}$} \\
\hline $\begin{array}{l}\text { CHARACTERISTICS: } \\
\text { CH_LLMW } \cdot \text { RH_LLMW } \cdot \text { CH_TRU(M) } \cdot \text { RH_TRU(M) } \\
\text { GTC III } \cdot \text { LLWW } \cdot \text { HAZ }\end{array}$ & $\begin{array}{l}\text { CONTAINERS: } \\
\text { CH_LLMW } \cdot \text { RH_LLMW } \cdot \text { CH_TRU(M) } \\
\text { RH_TRU(M) } \cdot \text { GTCIII } \cdot \text { LLW } \cdot \text { HAZ }\end{array}$ \\
\hline Home - Contents - Web Site Map - Glossary - $H$ & ts - Data Requests - Feedback Form \\
\hline
\end{tabular}

NOTICE: This page is provided subject to our disclaimer. Contact: Oscar Valero at (509) 373-4752.

HNF-EP-0918 rev. 1 Approved for public release; distribution is unlimited. 

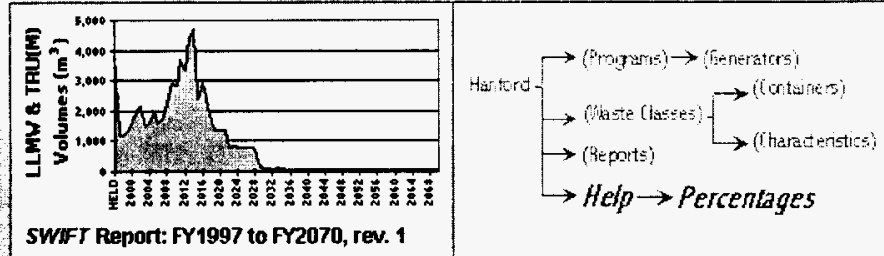

Site Rev, date: $12 / 31 / 96$

Data version:

97.1

Data currency: $10 / 25 / 96$

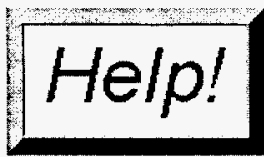

\section{Increase/Decrease Percentages}

The magnitude of changes in forecast data are described in terms of their percentage increase or decrease from the baseline. In this instance, the baseline is the FY96 Forecast. The formula is:

Change $=100 *($ FY97 volume - Baseline volume $/$ Baseline volume $)$

If the change is positive $(>0)$ then there is an increase in the particular waste class forecast; if the change is negative, there is a decrease.

For example:

Baseline forecast of LLMW: $340 \mathrm{~m}^{3}$

FY97 forecast of LLMW: $500 \mathrm{~m}^{3}$

Change $=100 *(500-340) / 340$ or $+47 \% \ldots$ a $47 \%$ increase, which seems reasonable.

If the FY97 forecast of LLMW is $200 \mathrm{~m}^{3}$, the change is:

Change $=100 *(200-340) / 340$ or $-41.1 \ldots$ a $41 \%$ decrease.

If the FY97 forecast of LLMW is $20 \mathrm{~m}^{3}$, the change is:

Change $=100 *(20-340) / 340$ or $-94.1 \ldots$ a $94 \%$ decrease.

This can be disconcerting if the changes are major:

Baseline forecast of LLMW: $2 \mathrm{~m}^{3}$

FY97 forecast of LLMW: $4,000 \mathrm{~m}^{3}$

Change $=100 *(4000-2) / 2=+199,900 \ldots$ a $199,900 \%$ increase .

But switching the situation doesn't yield what most of us expect:

Baseline forecast of LLMW: $4,000 \mathrm{~m}^{3}$

FY97 forecast of LLMW: $2 \mathrm{~m}^{3}$ 
Change $=100 *(2-4000) / 4000$ or $-99.95 \ldots$ or nearly $100 \%$ decrease

HELP:

Help Home - SWIFT Report Web Site Overview - Forecasting Process - Using Netscape - Netscape Bookmarks . Percentages - Rounding - Min/Max - Waste Class Naming - Waste Categories - Container Specifications . Generator Life Cycles

PROGRAMS:

Analytical Services - EM-40 - Facility Transitions - Landlord - Liquid Effluent - NP - Offsite - PNNL - RCRA . Solid Waste $\cdot$ SNF . TWRS

CHARACTERISTICS:

CH_LLMW $\cdot$ RH_LLMW $\cdot$ CH_TRU(M) $\cdot$ RH_TRU(M)

- GTC III - LLW - HAZ

\section{CONTAINERS:}

CH_LLMW $\cdot$ RH_LLMW $\cdot \mathrm{CH}_{-}$TRU(M) . RH_TRU(M) $\cdot$ GTC III $\cdot$ LLW $\cdot$ HAZ

\section{WASTE Classes:}

CH_LLMW $\cdot$ RH_LLMW $\cdot$ CH_TRU(M) $\cdot$ RH_TRU(M) $\cdot$ GTC III $\cdot$ LLW $\cdot$ HAZ

Home · Contents - Web Site Map · Glossary · Help · Reports - Data Requests · Feedback Form

NOTICE: This page is provided subject to our disclaimer. Contact: Oscar Valero at (509) 373-4752.

HNF-EP-0918 rev. 1 Approved for public release; distribution is unlimited. 

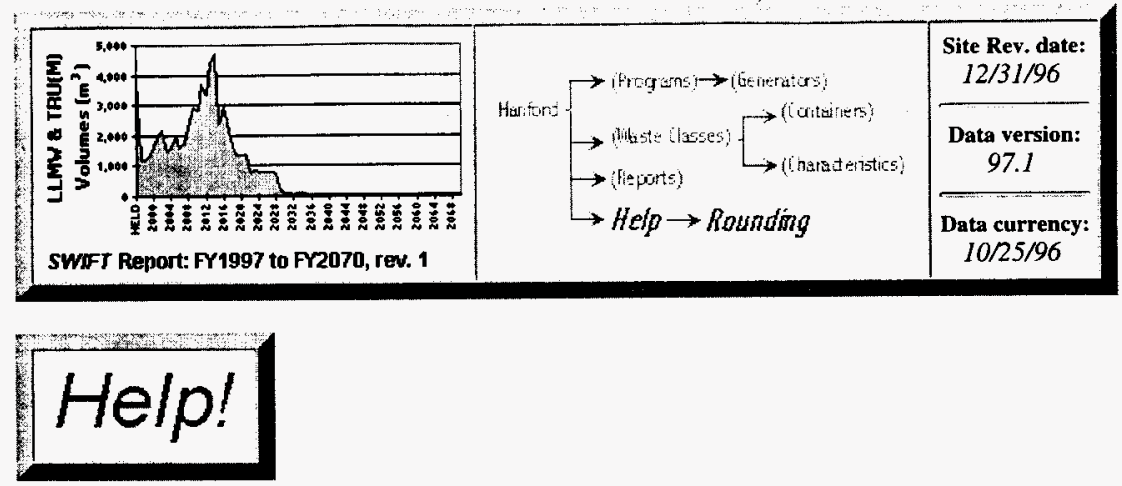

\section{Rounding}

Generators provide a great deal of highly detailed data, which are then rolled into summary data that can be meaningful for planning and performing comparisons. The following formula was used for rounding:

\section{Detailed Generator Data}

Data $>1 \mathrm{~m}^{3}$ Detailed generator data are rounded to the nearest cubic meter of waste, except where $<1 \mathrm{~m}^{3}$ was forecast.

Data $<1 \mathbf{m}^{3}$ Data between 0 and 1 show the integer 1 in tables to serve as a place holder; totals are calculated by summing the actual values and then rounding. For example, if a generator has $0.0026 \mathrm{~m}^{3}$ of $\mathrm{CH}$ _TRUM waste every year for 5 years, each of the five years on a table will show a 1 in the CH_TRUM column, and the total for the five years will also be 1 .

\section{Summary Generator and Program Data}

Summary data are always calculated by summing the detailed values, and then roundingComparison numbers (i.e., percent increases, percent decreases, minimum ranges, maximum ranges) are always made on the unrounded numbers. Summary values between 0 and 1 are shown as $1 \mathrm{~m}^{3}$; summary values between 1 and 9 are shown rounded to the nearest integer; and summary values greater than $10 \mathrm{~m}^{3}$ are rounded to the nearest $10 \mathrm{~m}^{3}$. 
HELP:

Help Home - SWIFT Report Web Site Overview - Forecasting Process - Using Netscape - Netscape Bookmarks · Percentages - Rounding - Min/Max - Waste Class Naming - Waste Categories - Container Specifications - Generator Life Cycles

\section{PROGRAMS:}

Analytical Services · EM-40 - Facility Transitions · Landlord · Liquid Effluent · NP · Offsite - PNNL · RCRA · Solid Waste $\cdot$ SNF $\cdot$ TWRS

CHARACTERISTICS:

CH_LLMW $\cdot$ RH_LLMW $\cdot$ CH_TRU(M) $\cdot$ RH_TRU(M) . GTC III $\cdot$ LLW $\cdot$ HAZ

\section{CONTAINERS:}

CH_LLMW $\cdot$ RH_LLMW $\cdot$ CH_TRU(M) RH_TRU $(M) \cdot$ GTC III $\cdot$ LLW $\cdot$ HAZ

\section{WASTE CLASSES:}

CH_LLMW $\cdot$ RH_LLMW $\cdot$ CH_TRU(M) $\cdot$ RH_TRU(M) $\cdot$ GTC III $\cdot$ LLW $\cdot$ HAZ

Home - Contents · Web Site Map · Glossary $\cdot$ Help $\cdot$ Reports $\cdot$ Data Requests $\cdot$ Feedback Form

NOTICE: This page is provided subject to our disclaimer. Contact: Oscar Valero at (509) 373-4752.

HNF-EP-0918 rev. 1 Approved for public release; distribution is unlimited. 

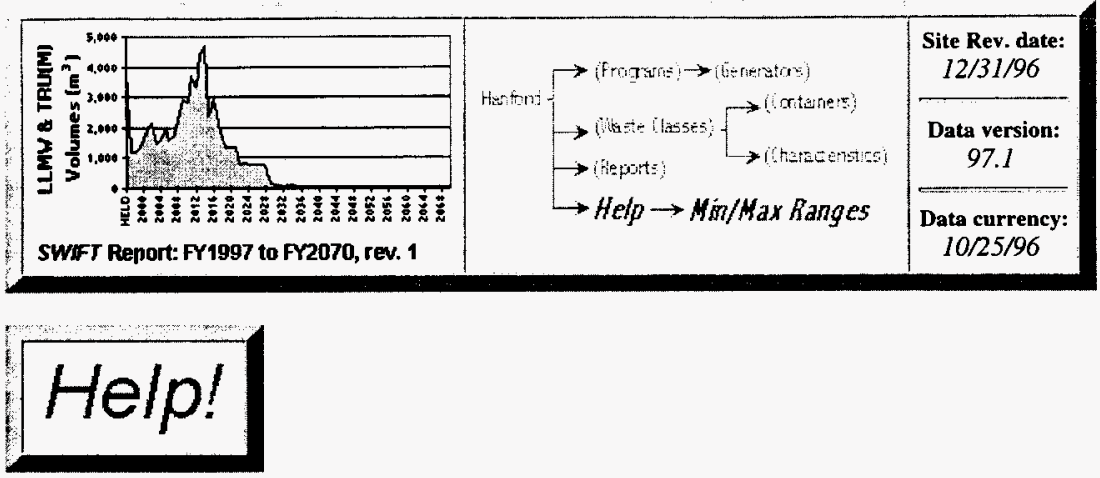

\section{Min/Max Ranges}

Because of the uncertainties inherent in long-term forecasts, SWIFT FY97 allows the waste generator to specify a range for the volume estimate by providing minimum and maximum percents. The table below shows how these percents are calculated. Ranges apply only to the total volume for a forecast year and are entered in the minimum and maximum rows, without the percent sign.

Range calculation examples

\begin{tabular}{llll} 
If you think you will ship... & then enter... & because... \\
\hline min & $18 \mathrm{~m}^{3}$ & $90 \%$ & 18 is $90 \%$ of 20 \\
best estimate & $20 \mathrm{~m}^{3}$ & $20 \mathrm{~m}^{3}$ & \\
$\max$ & $25 \mathrm{~m}^{3}$ & $125 \%$ & 25 is $125 \%$ of 20 \\
\hline $\min$ & $20 \mathrm{~m}^{3}$ & $100 \%$ & 20 is $100 \%$ of 20 \\
best estimate & $20 \mathrm{~m}^{3}$ & $20 \mathrm{~m}^{3}$ & \\
$\max$ & $25 \mathrm{~m}^{3}$ & $125 \%$ & 25 is $125 \%$ of 20 \\
\hline
\end{tabular}

The use of waste reduction techniques prior to shipping waste to Hanford's Treatment, Storage, and Disposal (TSD) Facility is highly recommended. The volumes reported in the SWIFT FY97 forecast should reflect the projected shipment volumes after these reduction techniques are used.

Many generators provided different minimum and maximum ranges for each waste class in the forecast. The minimum and maximum ranges reported in this forecast are actually weighted averages for LLMW and TRU(M) waste, using the following formulas:

Minimum $\%=100 *$ (Sum of minimum L.LMW and TRU(M) volumes) / (Sum of LLMW and TRU(M) volumes)

Maximum \% $=100 *$ (Sum of maximum LLMW and TRU(M) volumes) / (Sum of LLMW and TRU(M) volumes) 
HELP:

Help Home - SWIFT Report Web Site Overview - Forecasting Process - Using Netscape - Netscape Bookmarks · Percentages · Rounding - Min/Max - Waste Class Naming - Waste Calegories · Container Specifications - Generator Life Cycles

\title{
PROGRAMS:
}

Analytical Services - EM-40 - Facility Transitions - Landlord - Liquid Efluent - NP - Offsite - PNNL - RCRA - Solid Waste - SNF - TWRS

\section{CHARACTERISTICS:}

CH_LLMW $\cdot$ RH_LLMW $\cdot$ CH_TRU(M) $\cdot$ RH_TRU(M) GTC III $\cdot$ LLW $\cdot$ HAZ

\section{CONTAINERS:}

CH_LLMW $\cdot$ RH_LLMW $\cdot$ CH_TRU(M) . RH_TRU(M) $\cdot$ GTC IIJ $\cdot$ LLW $\cdot$ HAZ

\section{WASTE CLASSES:}

CH_LLMW $\cdot$ RH_LLMW $\cdot$ CH_TRU(M) $\cdot$ RH_TRU(M) $\cdot$ GTC III $\cdot$ LLW $\cdot$ HAZ

\author{
Home · Contents · Web Site Map · Glossary · Help · Reports · Data Requests · Feedback Form
}

NOTICE: This page is provided subject to our disclaimer. Contact: Oscar Valero at (509) 373-4752.

HNF-EP-0918 rev. 1 Approved for public release; distribution is unlimited. 

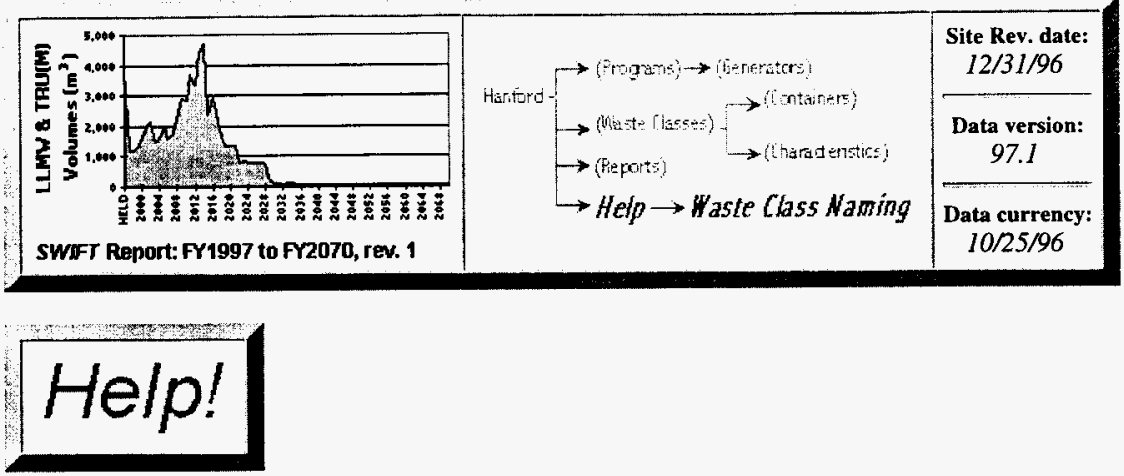

\section{Waste Class Naming Conventions}

Solid waste can be characterized into five classes, excluding LLW and HAZ. These classes are briefly described in the following Table. These definitions are applicable specifically to forecast waste, and are based on WHC-EP-0063.4.

Table 1.1: Waste Category Definitions

\begin{tabular}{|c|c|c|c|c|c|}
\hline & ${ }_{\text {LLMW }}^{\text {LHW }_{-}}$ & $\frac{\mathrm{RH}_{\mathbf{L}}}{\mathbf{L M W}}$ & $\underset{\text { TRU(M) }}{\mathrm{CH}_{-}}$ & $\underset{\text { TRU(M) }}{\text { RH_- }}$ & $\begin{array}{l}\text { LLMW }_{-} \\
\text {GTCIII }\end{array}$ \\
\hline Dose rate & $\begin{array}{l}<=200 \\
\mathrm{mrem} / \mathrm{h}\end{array}$ & $\begin{array}{l}>200 \\
\text { mrem/h }\end{array}$ & $\begin{array}{l}<=200 \\
\text { mrem } / \mathrm{h}\end{array}$ & $\begin{array}{l}>200 \\
\mathrm{mrem} / \mathrm{h}\end{array}$ & Varies \\
\hline $\begin{array}{l}\text { Dangerous per WAC } \\
173-303\end{array}$ & Yes & Yes & $\begin{array}{l}\text { Yes (TRU(M)) } \\
\text { No (TRU) }\end{array}$ & $\begin{array}{l}\text { Yes (TRU(M)) } \\
\text { No (TRU) }\end{array}$ & Yes \\
\hline $\begin{array}{l}>100 \mathrm{nCi} / \mathrm{g}(\mathrm{b}) \text { alpha-emitting } \\
\text { isotopes } \\
\text { (atomic numbers }>92 \& \text { half-lives } \\
>20 \text { years) }\end{array}$ & No & No & Yes & Yes & No \\
\hline
\end{tabular}

$$
(<\ldots \text { less than }>\text {... greater than } \quad=\ldots \text { equal })
$$

\section{Contact-handled low-level mixed waste (CH_LLMW)}

This waste has a dose rate equal to or less than $200 \mathrm{mrem} / \mathrm{h}$ and contains radioactivity not classified as spent nuclear fuel or transuranic waste (concentrations of transuranic radionuclides less than or equal to $100 \mathrm{nCi} / \mathrm{g}$ of the waste matrix). The waste is also defined as dangerous (hazardous) waste in the Washington Administrative Code (WAC) 173-303.

Remote-handled low-level mixed waste (RH_LLMW) 
This waste has a dose rate greater than $200 \mathrm{mrem} / \mathrm{h}$ and meets the definition for LLW. This waste is also defined as dangerous (hazardous) waste in WAC 173-303.

Contact-handled transuranic or transuranic mixed waste (CH_TRU(M))

This radioactive waste has a dose rate equal to or less than $200 \mathrm{mrem} / \mathrm{h}$ at contact with the waste container. At the time of assay, this waste contains more than 100 $\mathrm{nCi} / \mathrm{g}$ of alpha-emitting isotopes with atomic numbers greater than 92 and half-lives greater than 20 years. TRUM waste is TRU waste that is also dangerous (hazardous) waste as defined in WAC 173-303.

\section{Remote-handled transuranic or transuranic mixed waste (RH_TRU(M))}

This waste has a dose rate greater than $200 \mathrm{mrem} / \mathrm{h}$ at contact with the waste container. At the time of assay, this waste contains more than $100 \mathrm{nCi} / \mathrm{g}$ of alpha-emitting isotopes with atomic numbers greater than 92 and half-lives greater than 20 years. TRUM waste is TRU waste that is also dangerous (hazardous) waste as defined in WAC 173-303.

\section{Low-level mixed waste greater than Class III (LLMW_GTCIII)}

This waste meets the definition for LLW and is also defined as dangerous (hazardous) waste in WAC 173-303. Greater-than-Class III (GTCIII) designation is determined when the sum of the fractions of the radionuclides' Class III concentration limits are greater than one, as defined in the Hanford Site Solid Waste Acceptance Criteria, WHC-EP-0063 Rev. 4, November 1993.

Contact-handled $(\mathrm{CH})$ and remote-handled $(\mathrm{RH})$ waste are considered distinct categories, based on the inherent characteristics of the waste. However, in a few instances, generators have reported $\mathrm{RH}$ waste that is shielded to $\mathrm{CH}$ levels as $\mathrm{CH}$ waste.

In addition to the above waste categories, another key definition concerns Held waste. Held waste is existing generated waste with no current shipping schedule. 


\section{HELP:}

Help Home - SWIFT Report Web Site Overview - Forecasting Process - Using Netscape - Netscape Bookmarks · Percentages - Rounding - Min/Max - Waste Class Naming - Waste Categories - Container Specifications · Generator Life Cycles

\section{PROGRAMS:}

Analytical Services - EM-40 - Facility Transitions - Landlord - Liquid Effluent - NP · Offsite - PNNL - RCRA · Solid Waste $\cdot$ SNF $\cdot$ TWRS

\begin{tabular}{|c|c|}
\hline $\begin{array}{c}\text { CHARACTERISTICS: } \\
\text { CH_LLMW } \cdot \text { RH_LLMW } \cdot \text { CH_TRU(M) } \cdot \text { RH_TRU(M) } \\
\text { GTC III } \cdot \text { LLW } \cdot \text { HAZ }\end{array}$ & $\begin{array}{c}\text { CONTAINERS: } \\
\text { CH_LLMW } \cdot \text { RH_LLMW } \cdot \text { CH_TRU(M) } \\
\text { RH_TRU(M) } \cdot \text { GTC III } \cdot \text { LLW } \cdot \text { HAZ }\end{array}$ \\
\hline \multicolumn{2}{|c|}{$\begin{array}{l}\text { WASTE CLASSES: } \\
\text { CH_LLMW } \cdot \text { RH_LLMW } \cdot \text { CH_TRU(M) } \cdot \text { RH_TRU(M) }_{2} \cdot \text { GTC III } \cdot \text { LLW } \cdot \text { HAZ }\end{array}$} \\
\hline
\end{tabular}

NOTICE: This page is provided subject to our disclaimer. Contact: Oscar Valero at (509) 373-4752.

HNF-EP-0918 rev. 1 Approved for public release; distribution is unlimited. 


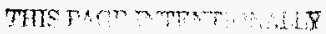

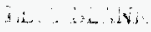


III киобедер-иеиі-гареалб

III kobales

| גіобอุe

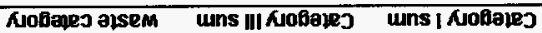

$\therefore I T q D_{L}$

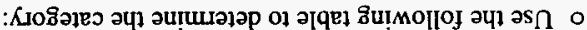
'sanjes su!̣!nsas aul ppV ०

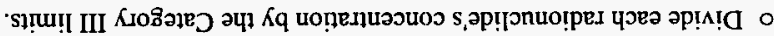

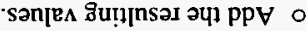

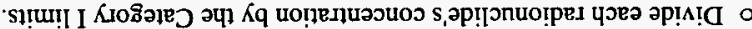

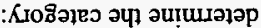

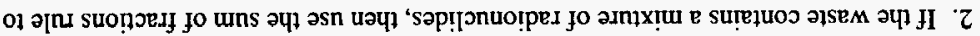

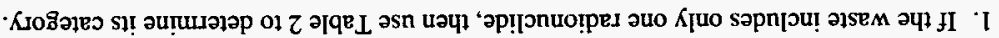

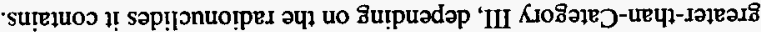

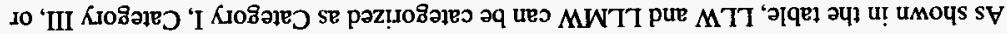

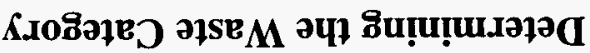

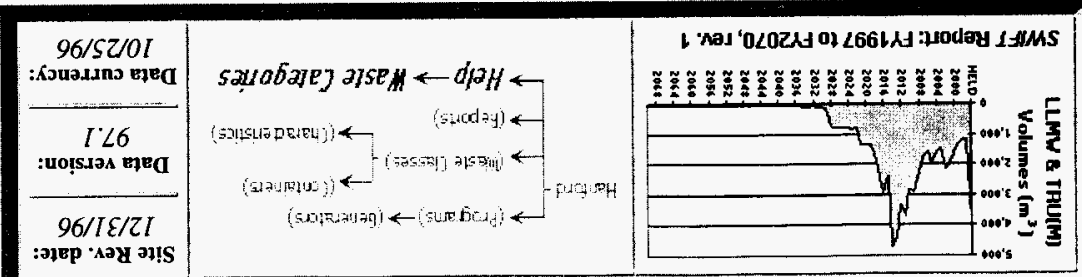


Radionuclide concentration limits

\begin{tabular}{|c|c|c|c|}
\hline symbol & radionuclide & $\begin{array}{c}\text { Category I limit } \\
\text { Cikm }\end{array}$ & $\begin{array}{c}\text { Category lll limit } \\
\text { Cism }\end{array}$ \\
\hline${ }^{3} \mathrm{H}$ & TRITIUM & $5.0 \mathrm{EG}$ & nla \\
\hline${ }^{\mathrm{m}} \mathrm{C}$ & CARBON14 & $4.0 \mathrm{E}-2$ & $9.1 \mathrm{EO}$ \\
\hline${ }^{k} \mathrm{C}$ & $\begin{array}{l}\text { CARBON14 } \\
\text { (activeted metal) }\end{array}$ & $4.0 \mathrm{E}-1$ & $9.1 \mathrm{E} 1$ \\
\hline$n_{p}$ & PHOSPHORUS32 & $n / a^{*}$ & $n / a^{*}$ \\
\hline$x_{5}$ & SULFUR35 & $n / a *$ & $n / a^{*}$ \\
\hline${ }^{x_{\mathrm{Cl}}}$ & CHLORINE36 & $4.0 \mathrm{E}-4$ & $8.3 \mathrm{E}-2$ \\
\hline${ }^{\omega_{\mathrm{Co}}}$ & COEALTGO & $7.7 \mathrm{E} 1$ & n/a \\
\hline${ }^{79} \mathrm{Se}$ & SELENIUM79 & $3.8 \mathrm{E}-1$ & 8.3 E1 \\
\hline $\boldsymbol{D}_{\mathrm{Sr}}$ & STRONTIUM9O & $4.3 \mathrm{E}-3$ & $1.5 \mathrm{E} 4$ \\
\hline${ }^{n_{T C}}$ & TECHNETIUM 99 & $5.6 \mathrm{E}-3$ & $12 \mathrm{EO}$ \\
\hline 299 & IODINE129 & $2.9 \mathrm{E}-3$ & $5.9 \mathrm{E}-1$ \\
\hline$\omega y_{1}$ & IODINE131 & $n / a^{x}$ & $n / a^{*}$ \\
\hline${ }^{407} \mathrm{Cs}$ & CESIUM137 & $6.3 \mathrm{E}-3$ & 1.3 E4 \\
\hline${ }^{210} \mathrm{~Pb}$ & LEAD210 & $1.0 \mathrm{E}-2$ & $5.6 \mathrm{ES}$ \\
\hline${ }^{208} \mathrm{Ra}$ & RADIUM226 & 1.4 E-4 & $3.6 \mathrm{E}-2$ \\
\hline $20 y$ & URANIUM 233 & 7.7 E-3 & lower of 1.1 EO or 100 nCiggn \\
\hline $20 x$ & URANIUM 234 & $9.1 \mathrm{E}-3$ & $2.1 \mathrm{EO}$ \\
\hline 205 & URANIUM235 & $3.2 \mathrm{E}-3$ & $5.9 E-1$ \\
\hline $207 \mathrm{~Np}$ & NEPTUNIUM237 & $1.9 \mathrm{E}-4$ & lower of $4.0 \mathrm{E}-2$ or $100 \mathrm{nCigm}$ \\
\hline $20 \mathrm{Pu}_{\mathrm{u}}$ & PLUTONIUM238 & $9.1 \mathrm{E}-3$ & lower of $4.5 \mathrm{E} 1$ or $100 \mathrm{nCu}$ gm \\
\hline 20 & URANIUM238 & $6.3 \mathrm{E}-3$ & $1.4 \mathrm{EO}$ \\
\hline $29 p u$ & PLUTONIUM239 & $3.6 \mathrm{E}-3$ & lower of 7.7 E-1 or $100 \mathrm{nCigm}$ \\
\hline $200 \mathrm{Pu}$ & PLUTONIUM240 & $3.6 \mathrm{E}-3$ & lower of $7.7 \mathrm{E}-1$ or $100 \mathrm{nCigm}$ \\
\hline${ }^{221} \mathrm{Pu}$ & PLUTONIUM241 & $7.7 \mathrm{E}-2$ & $3.1 \mathrm{E} 1$ \\
\hline $2 \times 1 \mathrm{Am}$ & AMERICIUM241 & $2.6 \mathrm{E}-3$ & lower of $1.1 \mathrm{EO}$ or $100 \mathrm{nCi} / \mathrm{gm}$ \\
\hline $203_{\mathrm{Am}}$ & AMERICIUM243 & $1.3 E-3$ & lower of $2.8 \mathrm{E} 1$ or $100 \mathrm{nCl} / \mathrm{gm}$ \\
\hline
\end{tabular}

"half-hite is less than 5 years 


\section{HELP:}

Help Home - SWIFT Report Web Site Overview - Forecasting Process - Using Netscape - Netscape Bookmarks Percentages - Rounding - Min/Max - Waste Class Naming - Waste Categories - Container Specifications - Generator Life Cycles

\section{PROGRAMS:}

Analytical Services - EM-40 - Facility Transitions - Landlord - Liquid Effluent - NP · Offsite · PNNL - RCRA - Solid Waste . SNF . TWRS

\begin{tabular}{c|c}
$\begin{array}{c}\text { CHARACTERISTICS: } \\
\text { CH_LLMW } \cdot \text { RH_LLMW } \cdot \text { CH_TRU(M) } \\
\text { GTC III } \cdot \text { LLW_TRU(M) } \cdot \text { HAZ }\end{array}$ & $\begin{array}{c}\text { CONTAINERS: } \\
\text { CH_LLMW } \cdot \text { RH_LLMW } \cdot \text { CH_TRU(M) } \\
\text { RH_TRU(M) } \cdot \text { GTC III } \cdot \text { LLW } \cdot \text { HAZ }\end{array}$ \\
\hline CH_LLMW $\cdot$ RH_LLMW $\cdot$ CH_TRU(M) $\cdot$ RH_TRU(M) $\cdot$ GTC III $\cdot$ LLW $\cdot$ HAZ
\end{tabular}

Home · Contents - Web Site Map · Glossary · Help $\cdot$ Reports · Data Requests · Feedback Form

NOTICE: This page is provided subject to our disclaimer. Contact: Oscar Valero at (509) 373-4752.

HNF-EP-0918 rev. 1 Approved for public release; distribution is unlimited. 


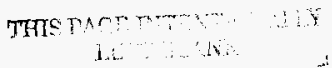



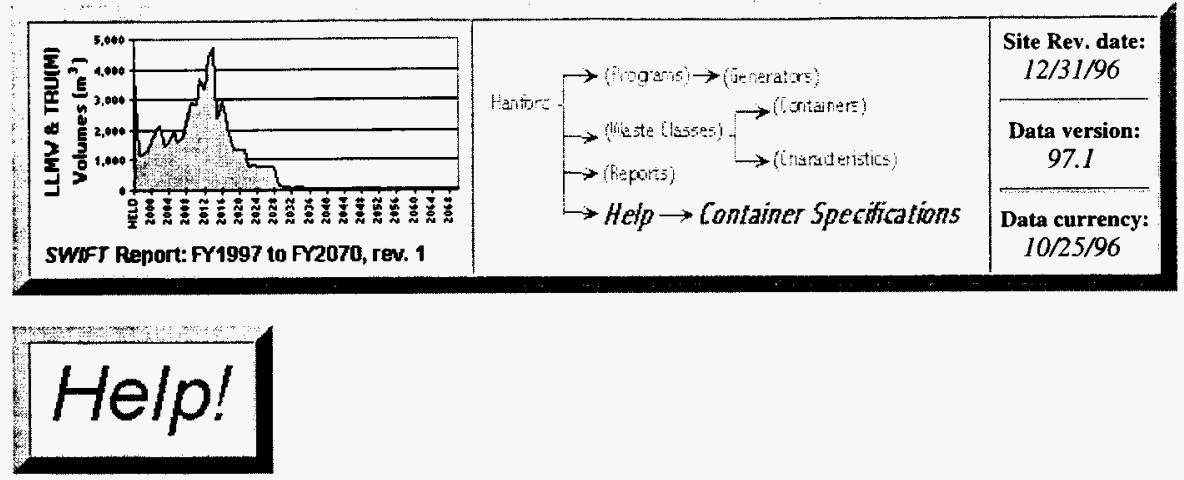

\section{Container Specifications}

The Following tables were provided to the waste generator for calculating external volumes of waste.

\begin{tabular}{|c|c|c|c|c|}
\hline $\begin{array}{l}\text { Standard drums } \\
\text { designation* }\end{array}$ & $\begin{array}{c}\text { dilameter } \\
\text { (m) }\end{array}$ & $\begin{array}{c}\text { external } \\
\text { height } \\
\text { (m) }\end{array}$ & $\begin{array}{c}\text { volume } \\
\left(\mathrm{m}^{3}\right)\end{array}$ & $\begin{array}{l}\text { internal } \\
\text { volume } \\
\left(\mathrm{m}^{3}\right)\end{array}$ \\
\hline 30 Liter 1 A2 & 0.378 & 0.378 & 0.042 & 0.036 \\
\hline 61 Liter $1 A 2$ & 0.378 & 0.683 & 0.077 & 0.063 \\
\hline 114 Liter $1 \mathrm{~A} 1$ & 0.487 & 0.733 & 0.137 & 0.121 \\
\hline 114 Liter 1 A2 & 0.500 & 0.740 & 0.145 & 0.120 \\
\hline 208 Liter $1 \mathrm{~A} 1$ & 0.595 & 0.873 & 0.242 & 0.220 \\
\hline 208 Liter $1 A 2$ & 0.608 & 0.886 & 0.257 & 0.220 \\
\hline 322 Liter 1 A2 & 0.701 & 0.991 & 0.382 & 0.329 \\
\hline 416 Liter 1 A2 & 0.807 & 1.080 & 0.552 & 0.472 \\
\hline $\begin{array}{l}208 \text { Liter lead- } \\
\text { lined }\end{array}$ & 0.608 & 0.886 & 0.257 & 0.021 \\
\hline $\begin{array}{l}208 \text { Liter } \\
\text { concrete-lined }\end{array}$ & 0.608 & 0.886 & 0.257 & 0.058 \\
\hline
\end{tabular}


Standard boxes

\begin{tabular}{|c|c|c|c|c|c|c|}
\hline \multirow[b]{2}{*}{ name } & & \multicolumn{4}{|c|}{ _ external } & \multirow{2}{*}{$\begin{array}{c}\text { internal } \\
\text { volume } \\
\left(m^{3}\right)\end{array}$} \\
\hline & & $\begin{array}{c}\text { length } \\
\text { (m) }\end{array}$ & $\begin{array}{c}\text { width } \\
\text { (m) }\end{array}$ & $\begin{array}{c}\text { height } \\
\text { (m) }\end{array}$ & $\begin{array}{c}\text { volume } \\
\left(\mathrm{m}^{3}\right)\end{array}$ & \\
\hline$M B-I^{*}$ & $2 \times 2 \times 6$ & 1.82 & 0.61 & 0.67 & 0.74 & 0.65 \\
\hline$M B-\|^{*}$ & $3 \times 3 \times 6$ & 1.82 & 0.92 & 1.00 & 1.67 & 1.46 \\
\hline$M B-\| I^{*}$ & $2 \times 4 \times 8$ & 1.82 & 1.22 & 0.67 & 1.48 & 1.73 \\
\hline ME-IV" & $\begin{array}{l}3.3 \times 4.3 \times \\
6.3\end{array}$ & 1.95 & 1.32 & 1.11 & 2.87 & 2.51 \\
\hline$M Q-V^{*}$ & $4 \times 4 \times 8$ & 2.43 & 1.22 & 1.33 & 3.95 & 3.46 \\
\hline$M B-\left.V\right|^{*}$ & $5 \times 5 \times 9$ & 2.83 & 1.53 & 1.67 & 7.20 & 6.30 \\
\hline$H-2-42701$ & $\begin{array}{l}4 \times 4 \times 8 \\
\text { wood }\end{array}$ & 2.44 & 1.22 & 1.36 & 4.05 & 3.29 \\
\hline CPC's B-25 & $4 \times 4 \times 6$ & 1.85 & 1.19 & 1.32 & 2.92 & 2.55 \\
\hline SWE & & 1.80 & 1.38 & 0.94 & 2.09 & 1.80 \\
\hline Sea Land" & $4 \times 8 \times 20$ & 6.10 & 2.50 & 1.20 & 18.30 & 16.01 \\
\hline
\end{tabular}

Cylindrical LECs

\begin{tabular}{lcccc} 
designation & alias & $\begin{array}{c}\text { diameter } \\
(\mathbf{m})\end{array}$ & $\begin{array}{c}\text { external } \\
\text { length } \\
(\mathbf{m})\end{array}$ & $\begin{array}{c}\text { volume } \\
\left(\mathbf{m}^{3}\right)\end{array}$ \\
\hline LEC-1 & $26^{\prime \prime} D \times 52^{\prime}$ LG & 0.66 & 15.85 & 5.43 \\
LEC-2 & $26^{\prime \prime} D \times 70^{\prime}$ LG & 0.66 & 21.34 & 7.31 \\
LEC-3 & $36^{\prime \prime} D \times 52^{\prime}$ LG & 0.91 & 15.85 & 10.41 \\
LEC-4 & $36^{\prime \prime} D \times 70^{\prime}$ LG & 0.91 & 21.34 & 14.01 \\
LEC-5 & $54^{\prime \prime} D \times 70^{\prime}$ LG & 1.37 & 21.34 & 31.53 \\
LEC-6 & $63^{\prime \prime} D \times 52^{\prime}$ LG & 1.60 & 15.85 & 31.88 \\
LEC-7 & $63^{\prime \prime} D \times 70^{\circ}$ LG & 1.60 & 21.34 & 42.91 \\
LEC-8 & $67^{\prime \prime} D \times 70^{\prime}$ LG & 1.70 & 21.34 & 48.53 \\
LEC-9 & $83^{\prime \prime} D \times 48^{\prime}$ LG & 2.11 & 14.63 & 51.07 \\
\hline
\end{tabular}

Square LECs

\begin{tabular}{|c|c|c|c|c|}
\hline \multicolumn{2}{|l|}{ te- } & \multicolumn{3}{|c|}{ external } \\
\hline designation & alias & $\begin{array}{l}\text { length } \\
\text { (m) }\end{array}$ & $\begin{array}{l}\text { width a height } \\
\text { (m) }\end{array}$ & $\begin{array}{c}\text { volume } \\
\left(\mathrm{m}^{3}\right)\end{array}$ \\
\hline LEC-10 & $26^{\prime \prime} S Q \times 52^{\prime}$ & 15.85 & 0.66 & 6.91 \\
\hline LEC-11 & $26^{\prime \prime} 5 Q \times 70^{\circ}$ & 21.34 & 0.66 & 9.31 \\
\hline LEC-12 & $36^{\prime \prime} \mathrm{SQ} \times 52^{\prime}$ & 15.85 & 0.91 & 13.25 \\
\hline LEC-13 & $36^{\prime \prime} \mathrm{SQ} \times 70^{\prime}$ & 21.34 & 0.91 & 17.84 \\
\hline LEC-14 & $54^{\prime \prime} \mathrm{SQ} \times 70^{\prime}$ & 21.34 & 1.37 & 40.14 \\
\hline LEC-15 & $63^{\prime \prime} 50 \times 52^{\prime}$ & 15.85 & 1.60 & 40.59 \\
\hline LEC-16 & $63^{\prime \prime} S Q \times 70^{\prime}$ & 21.34 & 1.60 & 54.63 \\
\hline LEC-17 & $67^{\prime \prime} \mathrm{SQ} \times 70^{\prime}$ & 21.34 & 1.70 & 61.79 \\
\hline LEC-18 & $83^{\prime \prime} 50 \times 48^{\prime}$ & 14.63 & 2.11 & 65.02 \\
\hline
\end{tabular}


Other containers

\begin{tabular}{|c|c|c|c|c|c|c|}
\hline \multirow[b]{2}{*}{ designation } & \multirow[b]{2}{*}{$\begin{array}{l}\text { diameter } \\
\text { (m) }\end{array}$} & & \multirow{2}{*}{$\begin{array}{c}\text { external } \\
\text { width } \\
\text { (m) }\end{array}$} & \multicolumn{2}{|c|}{ 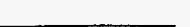 } & \multirow{2}{*}{$\begin{array}{l}\text { internal } \\
\text { volume } \\
\left(\mathrm{m}^{3}\right)\end{array}$} \\
\hline & & $\begin{array}{c}\text { length } \\
\text { (m) }\end{array}$ & & $\begin{array}{c}\text { height } \\
\text { (m) }\end{array}$ & $\begin{array}{c}\text { volume } \\
\left(\mathrm{m}^{3}\right)\end{array}$ & \\
\hline $\begin{array}{l}\text { lon exchange } \\
\text { module }\end{array}$ & & 2.18 & 1.77 & 2.27 & 8.76 & 8.76 \\
\hline $\begin{array}{l}\text { lon exchange } \\
\text { column }\end{array}$ & 0.46 & 1.76 & & & 0.29 & 0.21 \\
\hline Cartridge & 1.54 & & & 1.52 & 3.60 & \\
\hline $\begin{array}{l}\text { Disposable solid } \\
\text { waste cask }\end{array}$ & 2.15 & & & 4.36 & 15.77 & 0.93 \\
\hline Hittman liner & 1.34 & & & 1.48 & 2.09 & 1.63 \\
\hline Enduropak & 0.89 & & & 1.25 & 0.78 & 0.55 \\
\hline Concrete plug & & 1.83 & 1.83 & 1.83 & 6.12 & \\
\hline Concrete vault & & 1.30 & 1.30 & 1.27 & 2.13 & \\
\hline Compactor TK & & 2.74 & 2.13 & 2.13 & 12.49 & \\
\hline FI-10-1 & 0.61 & 1.83 & & & 0.53 & \\
\hline FSV-1 liner & 0.45 & 4.80 & & & 0.75 & \\
\hline HIC dewatering & 1.22 & 1.83 & & & 2.14 & \\
\hline HN-200 liner & 1.33 & 1.57 & & & 2.17 & \\
\hline Shielding bloc & & 6.10 & 2.44 & 0.61 & 9.06 & \\
\hline
\end{tabular}

\begin{tabular}{|c|c|}
\hline \multicolumn{2}{|c|}{$\begin{array}{l}\text { HELP: } \\
\text { Help Home } \cdot \text { SWIFT Report Web Site Overview } \cdot \text { Forecasting Process }- \text { Using Netscape } \cdot \text { Netscape Bookmarks } \cdot \\
\text { Percentages } \cdot \text { Rounding } \cdot \text { Min/Max } \cdot \text { Waste Class Naming } \cdot \text { Waste Categories } \cdot \text { Container Specifications } \cdot \text { Gencrator Life } \\
\text { Cycles }\end{array}$} \\
\hline \multicolumn{2}{|c|}{$\begin{array}{l}\text { PROGRAMS: } \\
\text { Analytical Services } \cdot \text { EM-40 } \cdot \text { Facility Transitions } \cdot \text { Landlord } \cdot \text { Liquid Effluent } \cdot \text { NP } \cdot \text { Offsite } \cdot \text { PNNL } \cdot \text { RCRA } \cdot \text { Solid } \\
\text { Waste } \cdot \text { SNF } \cdot \text { TWRS }\end{array}$} \\
\hline $\begin{array}{l}\text { CHARACTERISTICS: } \\
\text { CH_LLMW } \cdot \text { RH_LLMW } \cdot \text { CH_TRU(M) } \cdot \text { RH_TRU(M) } \\
\text { GTC III } \cdot \text { LLW } \cdot \text { HAZ }\end{array}$ & $\begin{array}{l}\text { CONTAINERS: } \\
\text { CH_LLMW } \cdot \text { RH_LLMW } \cdot \text { CH_TRU(M) } \\
\text { RH_TRU(M) } \cdot \text { GTC III } \cdot \text { LLW } \cdot \text { HAZ }\end{array}$ \\
\hline \multicolumn{2}{|c|}{$\begin{array}{l}\text { WASTE CLASSES: } \\
\text { CH_LLMW } \cdot \text { RH_LLMW } \cdot \text { CH_TRU(M) } \cdot \text { RH_TRU(M) } \cdot \text { GTC III } \cdot \text { LLW } \cdot \text { HAZ }\end{array}$} \\
\hline Homc $\cdot$ Contents - Web Site Map - Glossary $\cdot H$ & Is - Data Requests - Feedback Form \\
\hline
\end{tabular}

NOTICE: This page is provided subject to our disclaimer. Contact: Oscar Valero at (509) 373-4752.

HNF-EP-0918 rev. 1 Approved for public release; distribution is unlimited. 


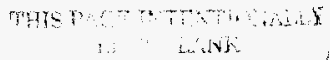



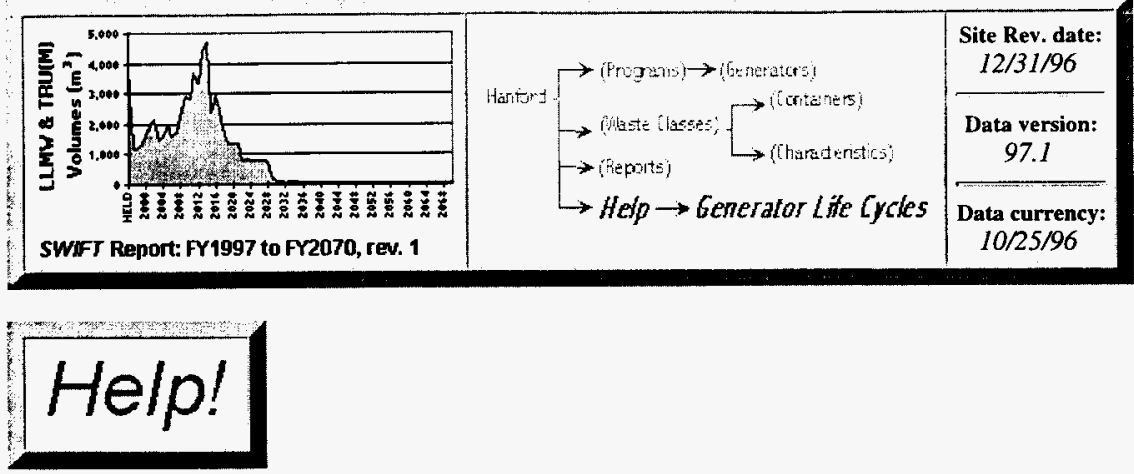

\section{Generator Life Cycles}

Most waste generators within the major Hanford programs undergo four life-cycle phases.

As illustrated in Figure 1.1, the four life cycle phases are important in that each phase may determine the program that is responsible for the waste generator. For example, if a facility within Liquid Effluents transitions into a deactivation mode, then responsibility for the facility would generally be transferred from Liquid Effluents to the Facility Transitions program.

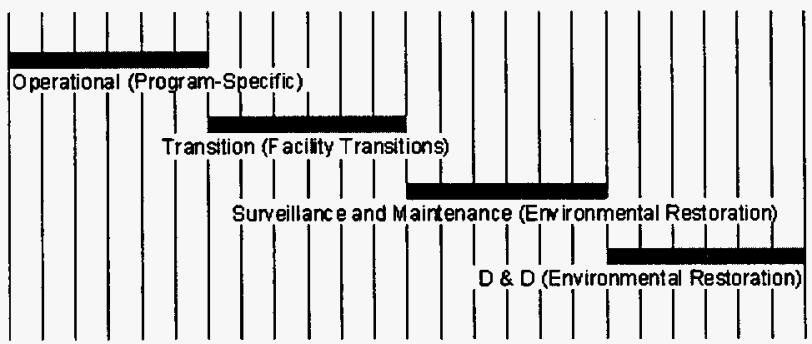

Figure 1.1: Waste Generater Life-Cycle Phases

\section{Operational}

This phase is defined as that period of time in which a waste generator's activities are targeted toward a certain plan, project, end-product, or service. Often the type of operational activity can allow a waste generator to be categorized into a specific program area.

\section{Transition (deactivation)}

This phase is distinguished by specific deactivation activities to eventually turn over the facility to the D\&D program. Facilities in the deactivation phase are generally the 
responsibility of the Facility Transitions program.

\section{Surveillance \& Maintenance}

This phase is defined as that period of time between the completion of transition (deactivation) and the commencement of D\&D. Programmatic responsibility for waste generated in this phase is currently the responsibility of the Environmental Restoration program.

\section{Decontamination and decommissioning (D\&D)}

This phase is defined as that period in which the facility and affected environment is completely remediated after deactivation has occurred. Facilities in this phase are the responsibility of the Environmental Restoration (ER) program (managed by Bechtel).

\begin{tabular}{|c|c|}
\hline $\begin{array}{r}\text { Help Home }- \text { SWIFT Report Web Site Overview } \cdot \text { Forec } \\
\text { Percentages · Rounding } \cdot \text { Min/Max - Waste Class Naming } ~\end{array}$ & $\begin{array}{l}\text { cess - Using Netscape - Netscape Bookmarks - } \\
\text { gories - Container Specifications - Generator Life }\end{array}$ \\
\hline $\begin{array}{r}\text { PROG } \\
\text { Analytical Scrvices - EM-40 - Facility Transitions } \cdot \text { Landlo } \\
\text { Waste } \cdot \text { SN }\end{array}$ & Effluent $\cdot$ NP - Offsite $\cdot$ PNNL $\cdot$ RCRA $\cdot$ Solid \\
\hline $\begin{array}{l}\text { CHARACTERISTICS: } \\
\text { CH_LLMW } \cdot \text { RH_LLMW } \cdot \text { CH_TRU(M) } \cdot \text { RH_TRU(M) } \cdot \\
\text { GTC III } \cdot \text { LLW } \cdot \text { HAZ }\end{array}$ & $\begin{array}{c}\text { CONTAINERS: } \\
\text { CH_LLMW } \cdot \text { RH_LLMW } \cdot \text { CH_TRU(M) } \\
\text { RH_TRU }(M) \cdot \text { GTC III } \cdot \text { LLW } \cdot \text { HAZ }\end{array}$ \\
\hline \multicolumn{2}{|c|}{$\begin{array}{l}\text { WASTE CLASSES: } \\
\text { CH_LLMW } \cdot \text { RH_LLMW } \cdot \text { CH_TRU(M) } \cdot \text { RH_TRU(M) } \cdot \text { GTC III } \cdot \text { LLW } \cdot \text { HAZ }\end{array}$} \\
\hline \multicolumn{2}{|c|}{ Home - Contents - Web Site Map - Glossary - Help - Reports - Data Requests - Feedback Form } \\
\hline
\end{tabular}

NOTICE: This page is provided subject to our disclaimer. Contact: Oscar Valero at (509) 373-4752.

HNF-EP-0918 rev. 1 Approved for public release; distribution is unlimited. 


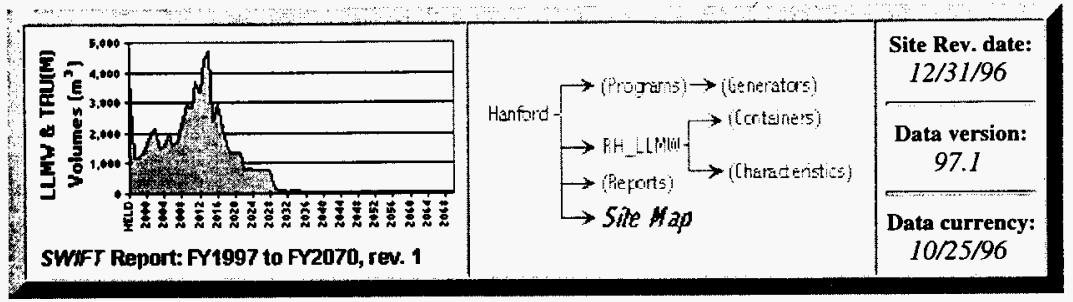

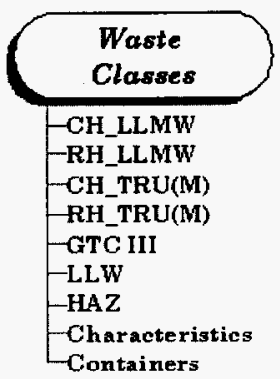

"Generator detail pages are binked to thair progrems. The top ber on the Toolber at the battom of a pragrem page lists all gevenators for that prosen.

Home

Contents

-Site Map

-Gloss ary

-Help

-Reports

-Data Requests

Feedback Form

\section{Welcome}

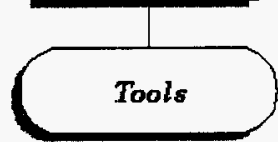

Programs*

-Analytieal Services

-EM-40

Facility Transitions

-Landlord

-Liquid Effluent

-NP

Offsite

-PNNL

-RCRA

-Solid Waste

-SNF

LTWRS

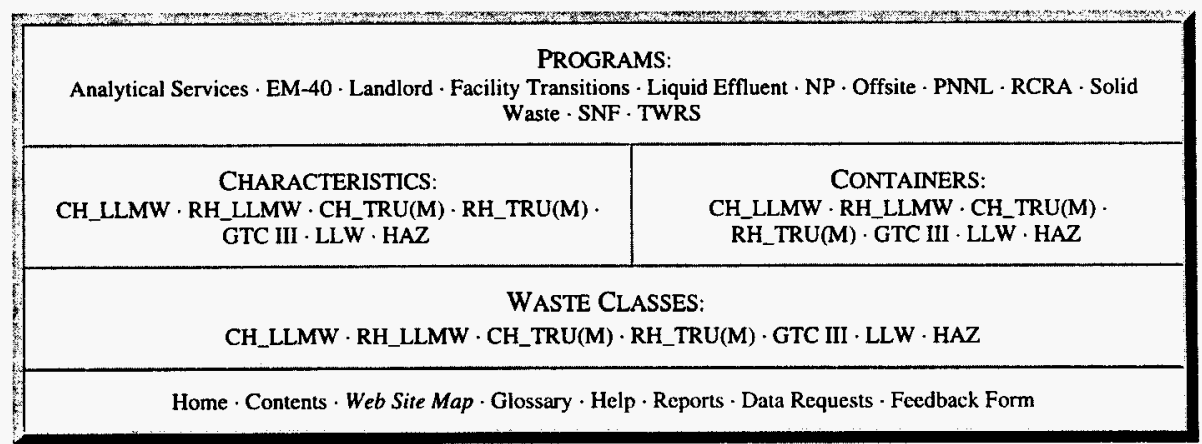

NOTICE: This page is provided subject to our disclaimer. Contact: Oscar Valero at (509) 373-4752. 
HNF-EP-0918 rev. 1 Approved for public release; distribution is unlimited. 


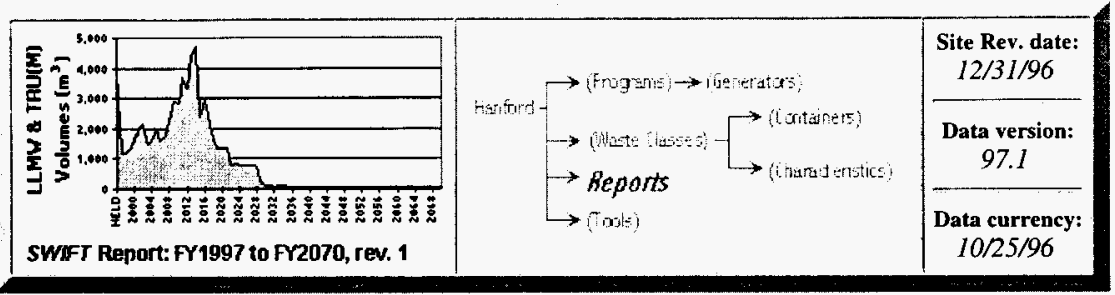

\section{Reports}

- LLMW and TRU(M) Solid Waste Generators: by Volume

- LLMW and TRU(M) Solid Waste Generators: by Program and Volume

- FY97 Waste Generator List by Hanford Program Area

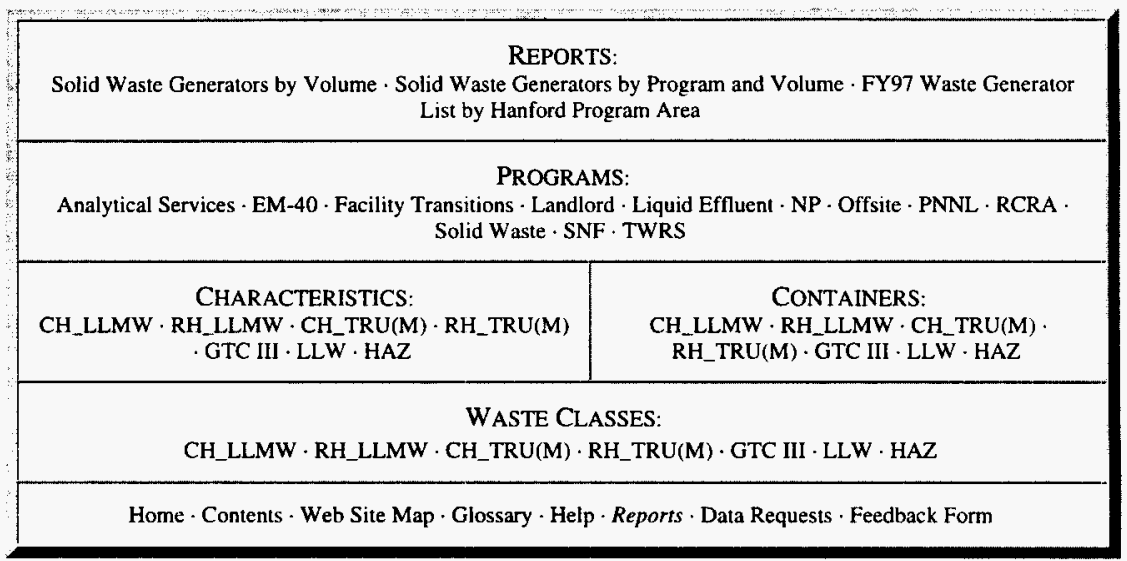

NOTICE: This page is provided subject to our disclaimer. Contact: Oscar Valero at (509) 373-4752.

HNF-EP-0918 rev. 1 Approved for public release; distribution is unlimited. 


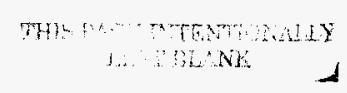




\begin{tabular}{|c|c|c|c|c|c|c|c|}
\hline$\overline{\mathrm{DE}}$ & - & $F$ & F & $\overline{D E}$ & LOOZ & 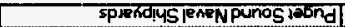 & ays]0 \\
\hline $0 \varepsilon$ & $=$ & $0 \varepsilon$ & $=$ & - & IEOZ & 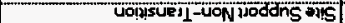 & Jpeureisos $d-U O N$ \\
\hline oE & $=$ & - & $=$ & oE & SZZOZ & 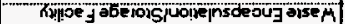 & süonjsue II Kugloed \\
\hline$\overline{D E}$ & - & - & - & $0 \varepsilon$ & SzOZ & 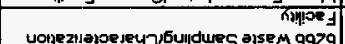 & 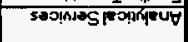 \\
\hline $0 p$ & $=$ & $=$ & $=$ & $0 t$ & 2661 & 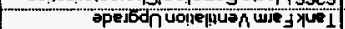 & $S \mathrm{H}$ \\
\hline ob & - & 06 & - & - & EEOZ & 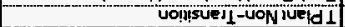 & opeutue \\
\hline 05 & - & - & - & OS & $\angle 66^{\circ} \mathrm{L}$ & 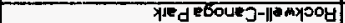 & 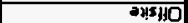 \\
\hline 09 & $=$ & 109 & $=$ & b & $600 z$ & Büping $22 \varepsilon$ & suoj!sule \\
\hline 09 & - & - & - & 09 & LOOZ & EunuglpM & БUIOJIUOW $\mathrm{VHC}$ \\
\hline 09 & - & - & - & 09 & SZOZ & 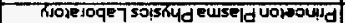 & $\$(3)$ \\
\hline 09 & - & 09 & $=$ & - & S202 & 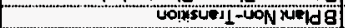 & 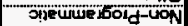 \\
\hline $0 L$ & 09 & - & F & 5 & 0002 & süọjeido 0 uiseg- & ang JejonN xus \\
\hline $0 L$ & - & OL & - & - & $\varepsilon 20 Z$ & 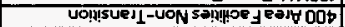 & 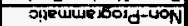 \\
\hline $0 L$ & - & - & 02 & - & 8661 & 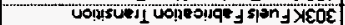 & 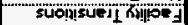 \\
\hline 08 & $=$ & $=$ & - & 08 & $0 L O Z$ & 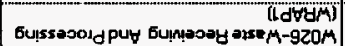 & ajseMP: \\
\hline OEI & - & 09 & - & $\overline{08}$ & LEOZ & UO!!ISUPI-LON d Jd & 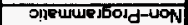 \\
\hline OSI & - & OLI & - & OS & $\angle Z O Z$ & UopjsueII-UONXJ日กd & 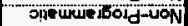 \\
\hline 012 & - & olz & - & 2 & 6ZOZ & 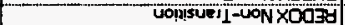 & oneume \\
\hline 0 obz & - & OEZ & - & Ot. & LOOZ & samply sniding & 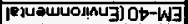 \\
\hline OOE. & oE & $=$ & 09 & 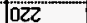 & $\angle z O z$ & sLo!jelodo JuEd I 190LZIIIZZ & ajsempyos \\
\hline OSL & $\begin{array}{llll}- & & & \\
0\end{array}$ & $0 \varepsilon 1$ & - & 09 & SLOZ & 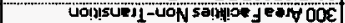 & शpewweibold-Uo \\
\hline 006 & $\widehat{\text { OLL }}$ & $0+2$ & $\widehat{D S}$ & 06 & OLOZ & 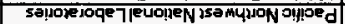 & TNNd \\
\hline $09 Z^{\prime}$ & - & - & OBg & 088 & SODZ & 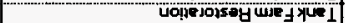 & SUMI \\
\hline $08 Z 1$ & $=$ & 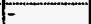 & OSE & 068 & 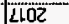 & [sश्रण 6 t] & SOMI \\
\hline $0 \triangleright S^{\prime} 2$ & - & - & - & $0 \triangleright S^{\prime} 2$ & bEOZ & 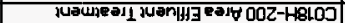 & JUen|yj P!nb!] \\
\hline $0 t Z \varepsilon$ & $=$ & $=$ & 0921 & oopt & $\mathrm{LZOZ}$ & (s) & $58 M$ \\
\hline OSSE & - & OzZ & - & OLSE & 0202 & 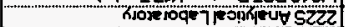 & soọnas \\
\hline $09 L^{\prime} \varepsilon$ & F & $00^{\circ} \varepsilon$ & - & $\mathrm{OLL}$ & $D E O Z$ & 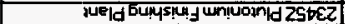 & 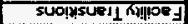 \\
\hline $000^{\circ} 6$ & F- & $=$ & $=$ & $000^{2} \mathrm{~b}$ & व7ت & jueding gporos & 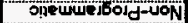 \\
\hline 010 t & 06 & - & $\operatorname{os} 0^{\prime} \varepsilon$ & 028 & 8202 & 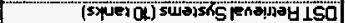 & $\operatorname{sen} 1$ \\
\hline $00 L$ & - & - & 006 & OSLE & ZEOZ & suolved W & $58 M 1$ \\
\hline $0 \mathrm{Zls}$ & 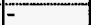 & - & - & $0 \mathrm{CIS}$ & 1202 & 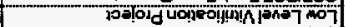 & SHMi \\
\hline 0969 & 0.8 & 028 & $=$ & $0 Z 25$ & BZZOZ & 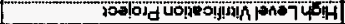 & SAMI \\
\hline $00 s^{\circ} \varepsilon z$ & $06 b$ & $06 t$ & 02522 & - & $\angle L O Z$ & 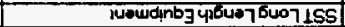 & SEM I \\
\hline $0 E 929$ & 0291 & OLE' & $027 \mathrm{GZ}$ & opoos & 0202 & spejol pjojueh & \\
\hline For & ${ }_{7 \text { Hy }}^{\text {(w) }}$ & $\begin{array}{c}\text { (w)ח女1 } \\
\text { Нכ }\end{array}$ & Awt1 & คพาา & $\begin{array}{c}\text { कारु } \\
\text { 2y? } \\
\text { jo } \\
\text { pug }\end{array}$ & Jojearueg msen & werosd \\
\hline
\end{tabular}

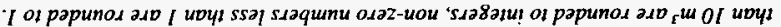

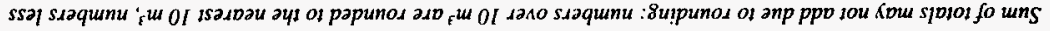

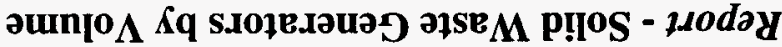

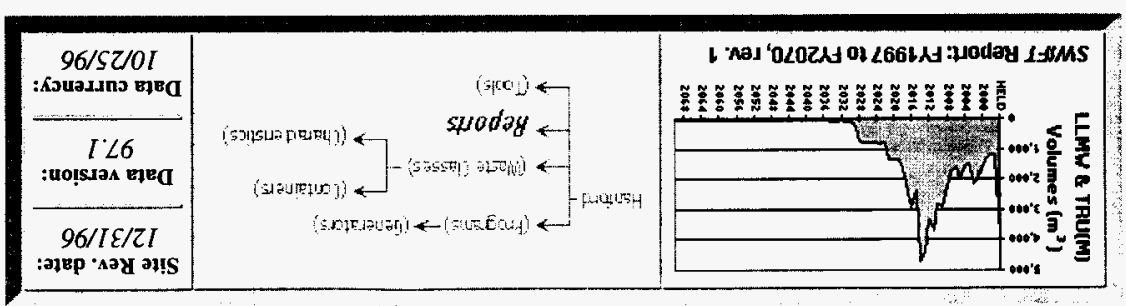




\begin{tabular}{|c|c|c|c|c|c|c|c|}
\hline F acitity Transitions & 324 Building & 2001 & 20 & -1 & 4 & to. & 30 \\
\hline Qffsite & Knolls Atomie Power-Laboratory & 2001 & 10 & 5 & -7 & - & 20 \\
\hline Offsite & Paducah Energy Systems & 1,998 & 20 & - & -1 & - & 20 \\
\hline Solid Waste & Central Waste Comples & 2070 & 20 & - & -7 & 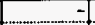 & 20 \\
\hline Spent Nuclear Fuel & K-Basin Fuel Sampling Proiect & 2000 & - & 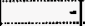 & 20 & - & 20 \\
\hline Fucility Transitions & $202 \mathrm{APures}$ Qperations & 1997 & 10 & - & - & - & 10 \\
\hline Won-Programmatic & UPlant Non-Transition & 2035 & 2 & $=$ & 10 & $=$ & 10 \\
\hline Ollsite & General Atomics & 1999 & 7 & - & 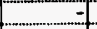 & $=$ & \\
\hline Ollsike & University of Ultah & 1997 & 7 & - & - & - & \\
\hline OHsite & Battelle Columbus Laborstories & 2003 & 8 & - & - & - & 8 \\
\hline Oflsite & Pearl Harboi Naval Shipyards & 2001 & 5 & - & $=$ & - & 5 \\
\hline TWAS & Cross-Sile Transier System & 1997 & 5 & -1 & - & - & 5 \\
\hline Facitiny Trensitions. & 2259 BPlant & 1998 & 2 & $=$ & $=$ & $=$ & 2 \\
\hline Solid Waste & $224 T$ TRU Srorage \& Assay F acillity & 1998 & 2 & - & - & $=$ & 2 \\
\hline Facility Iransitions & 309 PRTA Vault weste llon Exchange & 1998 & 1 & - & 7 & - & \\
\hline Fecility Transitions & 335 Sodium Test Facility & 1999 & 1 & - & $=$ & - & \\
\hline Faciliky Transicions & FFTF Transition Project & 2001 & 1 & - & - & $=$ & \\
\hline Qfisite & Ames Laborasory-Ames, lowa & 2070 & - & - & 1 & - & \\
\hline Offrite & Lowrenoe Berkeley Laboratory & 2030 & $=$ & $=$ & 1 & - & \\
\hline Offrite & Porsmoukh Naval Shipyards & 2001 & 1 & - & - & - & 1 \\
\hline Liquid Effluent & $\begin{array}{l}300 \text { AreadTreated Effluent Disposal } \\
\text { Facillkies }\end{array}$ & 2025 & -1 & & $=$ & - & \\
\hline Offsite & Argonne National Laboratory-East' & 2070 & $=$ & - & - & - & \\
\hline Offrine & Bates Accelerator-Massachusetts & 2030 & - & - & - & $=$ & \\
\hline Offrite & Bettis Atomio Powel-Laboratory" & 2009 & - & - & $\because$ & -1 & \\
\hline Offrite & Bextis Atomio Power-Shipyards" & 2012 & - & - & $=$ & - & \\
\hline Offste & Brookhaven Netiongl Laboratory & 2016 & $=$ & $=$ & - & - & \\
\hline Offsite & Fermi Nexional Acceter etor L uboratooy & 2027 & -1 & - & -1 & $=$ & \\
\hline Ofisine & Knolls Akomic Pow en-Shipyards" & 2004 & - & -1 & - & - & \\
\hline Oflgite & Portsmouth Energy Systems & 1997 & - & $=$ & - & $=$ & \\
\hline Offsike & Rooky Flass & 2000 & - & - & - & $=$ & \\
\hline Ofisile & Stanford Lines Accelerator Cencer" & 2070 & - & $=$ & - & - & \\
\hline Offsine & University of Californie-Davis & 2003 & - & $=$ & - & - & \\
\hline Solid Waste & 278EP Low LevelBurial Grounds" & 2070 & -1 & & -1 & - & \\
\hline
\end{tabular}

* Forecast only LLW and/or HAZ waste

\section{REPORTS:}

Solid Waste Generators by Volume . Solid Waste Generators by Program and Volume - FY97 Waste Generator List by Hanford Program Area

\section{PROGRAMS:}

Analytical Services · EM-40 - Facility Transitions · Landlord - Liquid Effluent - NP · Offsite - PNNL - RCRA - Solid Waste $\cdot$ SNF $\cdot$ TWRS

CHARACTERISTICS:
CH_LLMW $\cdot$ RH_LLMW $\cdot$ CH_TRU(M) $\cdot$ RH_TRU(M)
GTC III $\cdot$ LLW $\cdot$ HAZ

WASTE CLASSES:

CH_LLMW $\cdot$ RH_LLMW $\cdot$ CH_TRU(M) $\cdot$ RH_TRU(M) $\cdot$ GTC III $\cdot$ LLW $\cdot$ HAZ

Home · Contents - Web Site Map · Glossary · Help · Reports · Data Requests · Feedback Form

NOTICE: This page is provided subject to our disclaimer. Contact: Oscar Valero at (509) 373-4752.

HNF-EP-0918 rev. 1 Approved for public release; distribution is unlimited. 

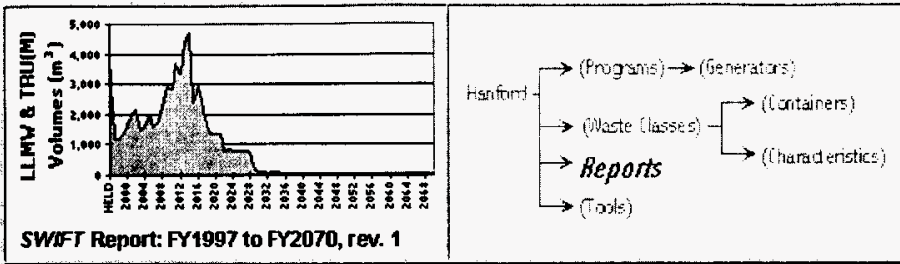

Site Rev. date:

I2/3I/96

Data version:

97.1

Data currency:

10/25/96

\section{Report - Solid Waste Generators by Program and Volume}

Sum of totals may not add due to rounding: numbers over $10 \mathrm{~m}^{3}$ are rounded to the nearest $10 \mathrm{~m}^{3}$, numbers less than $10 \mathrm{~m}^{3}$ are rounded to integers, non-zero numbers less than 1 are rounded to $J$.

\begin{tabular}{|c|c|c|c|c|c|}
\hline Hanford & $\begin{array}{c}\text { CH는 } \\
\text { ㄴMㅂ }\end{array}$ & $\begin{array}{l}\text { PHL } \\
\text { LLMY }\end{array}$ & $\underset{\text { TAU(M) }}{\text { CHL }}$ & $\begin{array}{c}\text { AHL } \\
\text { TAU(M) }\end{array}$ & $\begin{array}{l}\text { Totel } \\
\text { LLMH_a } \\
\text { TRU[M] }\end{array}$ \\
\hline Torar & 30.40 & 29.320 & $6.3 \times$ & $16 \pi$ & 67.600 \\
\hline Anafytical Services & $\begin{array}{l}\text { CHL } \\
\text { 느N }\end{array}$ & $\begin{array}{l}\text { RHL } \\
\text { LLMU }\end{array}$ & $\begin{array}{c}\text { CHL } \\
\text { TAU(M) }\end{array}$ & $\begin{array}{c}\text { RHL } \\
\text { TRU(M) }\end{array}$ & $\begin{array}{l}\text { Totel } \\
\text { LLPMY- } \\
\text { TRU[M] }\end{array}$ \\
\hline Torat & 3.000 & - & 20 & - & 3.60 \\
\hline 2225 Andytioal Labor atory & 3,570 & - & 20 & - & 3,530 \\
\hline 6266 Waste SamplingIChur acterization F aciliky & 30 & - & - & - & 30 \\
\hline EM-40 (Enwironmental Restoration) & $\begin{array}{l}\text { CHL } \\
\text { LMY }\end{array}$ & $\begin{array}{l}\text { PHL } \\
\text { LLMM }\end{array}$ & $\underset{\text { TRu[M] }}{\text { CHL }}$ & $\begin{array}{c}\text { RHL } \\
\text { TRUIM) }\end{array}$ & $\begin{array}{l}\text { Toral } \\
\text { LAMY_- } \\
\text { TRUL] }\end{array}$ \\
\hline Taror & $D$ & - & 230 & - & 240 \\
\hline Facility Iransitions & $\begin{array}{l}\text { CHL } \\
\text { LLMW }\end{array}$ & $\begin{array}{l}\text { AHL } \\
\text { LLMH }\end{array}$ & $\begin{array}{c}\mathrm{CH}_{\mathrm{M}} \\
\text { TRU(M) }\end{array}$ & $\begin{array}{c}\text { PHL } \\
\text { TRU(M) } \\
\end{array}$ & $\begin{array}{l}\text { Total } \\
\text { LLMH_- } \\
\text { TRU[M] }\end{array}$ \\
\hline Tord & 90 & $M$ & 3.10 & $\boldsymbol{t}$ & 3.970 \\
\hline 23452 Plutonium Finishing Plant & 710 & & 3,050 & - & 3,760 \\
\hline 303K Fuels Fabriostion Transition & - & 70 & - & - & 70 \\
\hline 327 Building & 4 & - & 60 & - & 60 \\
\hline 324 Building & 20 & & 4 & 10 & 30 \\
\hline Waste Encapsulation' Storege Facitity & 30 & - & - & - & 30 \\
\hline 202A Puren Qperacions & 10 & - & - & - & 10 \\
\hline 225BBPlant & 2 & & - & - & 2 \\
\hline FFTF Trensinion Project & 1 & $=$ & - & - & \\
\hline 335 Sodium Test Facility & 1 & & - & - & \\
\hline 309 PRTR Vaulk Waste (lon Ekchange Mod) & 1 & & 1 & - & \\
\hline Liquid Efinent & $\begin{array}{l}\text { CHL } \\
\text { LLMH }\end{array}$ & $\begin{array}{l}\text { RHL } \\
\text { LLMH }\end{array}$ & $\frac{\mathrm{CH}}{\text { TAUTM) }}$ & $\underset{\text { TRU(M) }}{R H}$ & $\begin{array}{l}\text { Total } \\
\text { LLMH_- } \\
\text { TRU(M) }\end{array}$ \\
\hline Tarat & 2.540 & - & - & - & 2.540 \\
\hline Co18H-200 Area Effluent Trearment F acility & 2,540 & $=$ & $=$ & - & 2.540 \\
\hline 300 Ave alTue ated Effluent Disposal F acilities" & & & - & $\because$ & \\
\hline Nonfrogrammatic & 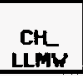 & $\begin{array}{l}\text { PHL } \\
\text { LLMMY }\end{array}$ & $\underset{\text { TRU[M] }}{\text { CHL }}$ & $\begin{array}{c}\text { PHL } \\
\text { TRU[M] }\end{array}$ & 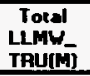 \\
\hline
\end{tabular}




\begin{tabular}{|c|c|c|c|c|c|}
\hline Tarar & 4100 & - & 1.320 & - & 5.50 \\
\hline Stored Equipment & 4,000 & - & - & - & 4,000 \\
\hline 300 Are a F acilities Non-Transition & 60 & - & 730 & $=$ & 790 \\
\hline REDOXNon-Transition & 2 & $=$ & 210 & $=$ & 210 \\
\hline PUAEXNon-Transition & 50 & - & 110 & -1 & 150 \\
\hline PFPNon-Transition & 照 & - & 60 & - & 130 \\
\hline 400 Area $F$ acilities Non-Transition & $=$ & - & 70 & $=$ & 70 \\
\hline BPlant Non-Transition & - & $=$ & 60 & $=$ & 60 \\
\hline T Plant Non-Tuansition & - & $=$ & 40 & $=$ & 40 \\
\hline Sile Support Non-Iransition & $=$ & $=$ & 30 & $=$ & 30 \\
\hline UPlent Non-Transition & 3 & - & 10 & - & 10 \\
\hline Orisile & $\begin{array}{c}\text { CH } \\
\text { LLMM }\end{array}$ & $\begin{array}{c}\text { AHL } \\
\text { LLMH }\end{array}$ & $\begin{array}{c}\text { CHL } \\
\text { TRU[M] }\end{array}$ & $\begin{array}{c}\text { PHL } \\
\text { IRu(M) }\end{array}$ & $\begin{array}{l}\text { Total } \\
\text { LLMY_- } \\
\text { TRU(M) }\end{array}$ \\
\hline Toxed & 2000 & 5 & 2 & - & 20 \\
\hline PrinestonPlasmaPhysics Laboratory & 60 & - & - & $=$ & 60 \\
\hline Rookwell-Conoga Park & 50 & $=$ & $=$ & - & 50 \\
\hline Pugst Sound Neval Shipyards & 30 & $=$ & $=$ & - & 30 \\
\hline Paducah Energy Systems & 20 & - & $=$ & $=$ & 20 \\
\hline Knolls Atornic Power-Laboratory & 10 & 5 & - & - & 20 \\
\hline Bautelle Columbus Laboravories & 8 & - & - & - & 8 \\
\hline University of Utah & 7 & $=$ & - & $=$ & 7 \\
\hline General Aromios & 7 & $=$ & - & - & 7 \\
\hline Pearl Habor Noval Shipyerds & 5 & + & - & $=$ & 5 \\
\hline Ames Laboratory - Ames, lowa & - & - & $<1$ & - & $<1$ \\
\hline Portsmouth Nowei Shipyzods & 1 & - & - & $=$ & 1 \\
\hline Levrence Barketey Labor atory & -1 & $=$ & 1 & $\Rightarrow$ & 1 \\
\hline Fermi Nationd Acoelerator L Looratory" & $=$ & $=$ & $=$ & $=$ & - \\
\hline University of C Afornia- Dawis & - & - & - & - & $=$ \\
\hline Asgonne National Leboratory-East & - & -1 & - & - & $=$ \\
\hline Eetes Acoeleratol-Massachusetts" & 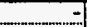 & $=$ & 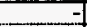 & $=$ & $=$ \\
\hline Betis Axomic Power-Laboratory & $=$ & - & - & - & - \\
\hline Bettis Atomic Power-Shipyards" & - & - & - & $=$ & $=$ \\
\hline Knolls Aromic Pow er-Shipyards" & $=$ & $=$ & - & - & $=$ \\
\hline Brookhuven Nation al Laboratory & $=$ & $=$ & $=$ & $=$ & $=$ \\
\hline Stenford Liner Acocter ator Center & - & - & - & - & \\
\hline Rocky Flats Remediation Serviess & $=$ & $\Rightarrow$ & $=$ & - & \\
\hline Pottsmouth Energy Systems & & - & & - & \\
\hline
\end{tabular}




\begin{tabular}{|c|c|c|c|c|c|}
\hline PNNL & $\begin{array}{l}\text { CHL } \\
\text { LLMY }\end{array}$ & $\begin{array}{c}\text { RH } \\
\text { 느냅 }\end{array}$ & $\begin{array}{c}\mathrm{CH} \\
\text { TRU(M) }\end{array}$ & $\begin{array}{c}\text { AHL } \\
\text { TRLf(-1) }\end{array}$ & $\begin{array}{l}\text { Total } \\
\text { LLMW_- } \\
\text { TRU[A] }\end{array}$ \\
\hline Toxat & 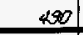 & 50 & 240 & 70 & 300 \\
\hline RCRA Monitoring & $\begin{array}{l}\text { CHL } \\
\text { LLMH }\end{array}$ & $\begin{array}{l}\text { RHL } \\
\text { LLAH }\end{array}$ & $\underset{\text { TRU(M) }}{\text { CHL }}$ & $\begin{array}{c}\text { RHL } \\
\text { TAบ(M) }\end{array}$ & $\begin{array}{l}\text { Total } \\
\text { LLMW_- } \\
\text { TRU(M) }\end{array}$ \\
\hline $\operatorname{tax} x$ & $\infty$ & - & - & - & $\mathscr{O O}$ \\
\hline Solid Waste & $\begin{array}{c}\text { CHL } \\
\text { LLMH }\end{array}$ & $\begin{array}{l}\text { AHL } \\
\text { 느넌 }\end{array}$ & $\begin{array}{c}\text { CHL } \\
\text { TRU[M] }\end{array}$ & $\begin{array}{c}\text { AHL } \\
\text { TAU(H) }\end{array}$ & $\begin{array}{l}\text { Total } \\
\text { LLMYY_- } \\
\text { TRL(M) }\end{array}$ \\
\hline rover & 30 & $\mathscr{O O}$ & - & 30 & 400 \\
\hline 221T12706T TPlant Operations & 220 & 60 & - & 30 & 300 \\
\hline W026-Waste Receining And Processing & 80 & & - & - & 80 \\
\hline Central Waste Complex & 20 & & - & - & 20 \\
\hline 224T TRUS Storage \& Assay F acility & 2 & - & 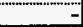 & - & 2 \\
\hline 218EN'Low Level BurialGrounds" & - & - & - & - & \\
\hline Spent Nuclear Fuel & $\begin{array}{l}\text { CHL } \\
\text { LLMU }\end{array}$ & $\begin{array}{l}\text { PHL } \\
\text { LLAMH }\end{array}$ & $\begin{array}{c}\text { CHL } \\
\text { TRU(M) }\end{array}$ & $\begin{array}{l}\text { AHL } \\
\text { TAU(M) }\end{array}$ & $\begin{array}{l}\text { Total } \\
\text { LLinY_- } \\
\text { TRU(M) }\end{array}$ \\
\hline Toxer & 5 & - & 30 & $\infty 0$ & $\$$ \\
\hline 10OKK-Basin Operations & 5 & $=$ & - & 60 & 70 \\
\hline $\mathrm{K}-\mathrm{B}$ asin Fuel Sampling Project & - & - & 20 & - & 20 \\
\hline IMRS & $\begin{array}{c}\text { CHL } \\
\text { LLMY }\end{array}$ & $\begin{array}{c}\text { PHL } \\
\text { 느냅 }\end{array}$ & $\begin{array}{c}\text { CHL } \\
\text { IRU[M] }\end{array}$ & $\begin{array}{l}\text { PHL } \\
\text { TAU[M] }\end{array}$ & $\begin{array}{l}\text { Total } \\
\text { LLMY_- } \\
\text { TRU(M) }\end{array}$ \\
\hline Toxar & 18.230 & 29.040 & 1.300 & 1.850 & 50.teo \\
\hline SST Long Lengh Equipmmt & & 22.520 & 490 & 490 & 23,500 \\
\hline High L evel Vicrification Proieck & 5,220 & - & 870 & 870 & 6,950 \\
\hline Low Level Vitrificetion Project & 5,120 & - & - & - & 5,120 \\
\hline SSTRST T ank Farm Operations & 3,760 & 940 & - & - & 4,700 \\
\hline OST Retrieval Systems (10 tanks) & 870 & 3,050 & $=$ & 90 & 4010 \\
\hline W3430ST Retrieval (17 Tenks) & 1,480 & 1,760 & $=$ & - & 3,240 \\
\hline SST Retrieval (149 tanks) & 890 & 390 & $=$ & - & 1,280 \\
\hline Tank Fom Restoration & 880 & 380 & - & - & 1,260 \\
\hline Tank Fam Ventilation Upgrade & 40 & - & $=$ & $=$ & 40 \\
\hline Cross-Site Transfer System & & & $=$ & - & 5 \\
\hline
\end{tabular}

\section{* Forecast only LLW and/or HAZ waste}

\begin{tabular}{|c|c|}
\hline \multicolumn{2}{|c|}{$\begin{array}{c}\text { REPORTS: } \\
\text { Solid Waste Generators by Volume } \cdot \text { Solid Waste Generators by Program and Volume } \cdot \text { FY97 Waste Generator List by } \\
\text { Hanford Program Area }\end{array}$} \\
\hline \multicolumn{2}{|c|}{$\begin{array}{l}\text { PROGRAMS: } \\
\text { Analytical Services } \cdot \text { EM-40 } \cdot \text { Facility Transitions } \cdot \text { Landlord } \cdot \text { Liquid Effluent } \cdot \text { NP } \cdot \text { Offsite } \cdot \text { PNNL } \cdot \text { RCRA } \cdot \text { Solid } \\
\text { Waste } \cdot \text { SNF } \cdot \text { TWRS }\end{array}$} \\
\hline $\begin{array}{l}\text { CHARACTERISTICS: } \\
\text { CH_LLMW } \cdot \text { RH_LLMW } \cdot \text { CH_TRU(M) } \cdot \text { RH_TRU(M) } \\
\text { GTC III } \cdot \text { LIW } \cdot \text { HAZ }\end{array}$ & $\begin{array}{l}\text { CONTAINERS: } \\
\text { CH_LLMW } \cdot \text { RH_LLMW } \cdot \text { CH_TRU(M) } \\
\text { RH_TRU(M) } \cdot \text { GTC III } \cdot \text { LLW } \cdot \text { HAZ }\end{array}$ \\
\hline \multicolumn{2}{|c|}{$\begin{array}{l}\text { WASTE CLASSES: } \\
\text { CH_LLMW } \cdot \text { RH_LLMW } \cdot \text { CH_TRU(M) } \cdot \text { RH_TRU(M) } \cdot \text { GTC III } \cdot \text { LLW } \cdot \text { HAZ }\end{array}$} \\
\hline
\end{tabular}


NOTICE: This page is provided subject to our disclaimer. Contact: Oscar Valero at (509) 373-4752. HNF-EP-0918 rev. 1 Approved for public release; distribution is unlimited. 


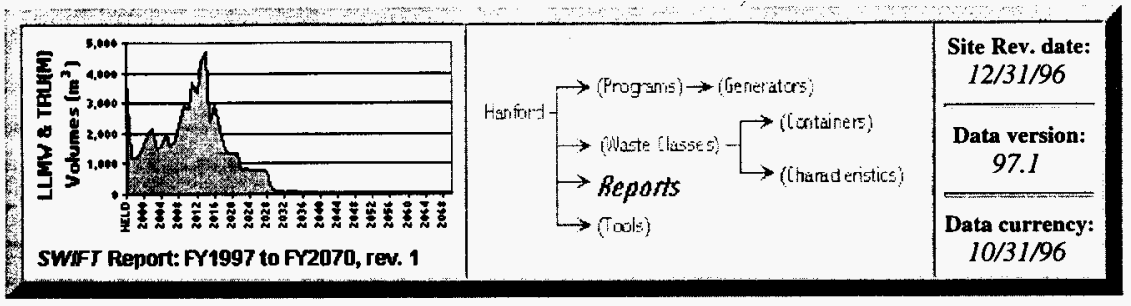

\section{FY97 Waste Generator List by Hanford Program Area}

\section{Programs, Waste Generators, and Old and New Abbreviations}

\begin{tabular}{|c|c|c|c|c|c|c|}
\hline Progten. & Mate Fennetor & $\begin{array}{l}\text { FY 1997.1 Report } \\
\text { Ablewizing }\end{array}$ & $\begin{array}{l}\text { FY } 1997 \text { Report } \\
\text { Abprevition }\end{array}$ & $\begin{array}{l}\text { FYtoss Report } \\
\text { Abbreviation }\end{array}$ & $\begin{array}{l}\text { FY1sses Report } \\
\text { Abbrevilaion }\end{array}$ & $\begin{array}{l}94 \text { Report } \\
\text { cevilion }\end{array}$ \\
\hline \multirow[t]{2}{*}{$\begin{array}{l}\text { Antingiod } \\
\text { Servideas }\end{array}$} & 222 S Anstict L bor sory. & RFSH ANALYT LAB & WHC AMALYT LAB & WHCANALYT LAB & YHC ANALYT LAB & WHE_222S \\
\hline & $\begin{array}{l}6266 \text { waste sumpling } \& \\
\text { Churpoterizution Faciliky }\end{array}$ & RFSH WS & WHC WSCF & WHC WSCF & 1 & [nal \\
\hline \multirow{8}{*}{ 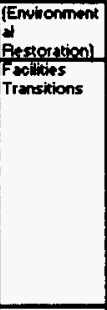 } & Surolus Fagilities & BHI SURPLS FAC & BHII SUAPLS FAC & BH SURPLS FAC & WHC SURPLS FAC & WHC SURPLS FAC \\
\hline & $\begin{array}{l}\text { 202A Purex Operations } \\
202 \text { B Plant } \\
2315 \mathrm{Clutonium} \mathrm{Finishing} \\
303 \mathrm{~K} \text { Fueis Fabrication }\end{array}$ & $\begin{array}{l}\text { BWHC PUAEX } \\
\text { BWHCEPLANT } \\
\text { BWHCPFP } \\
\text { BWHCFUEL TRAN }\end{array}$ & $\begin{array}{l}\text { WHC PUAEX } \\
\text { WHC B PLANT } \\
\text { WHC PFP } \\
\text { WHE FUEL HRANS }\end{array}$ & $\begin{array}{l}\text { WHC PUREX } \\
\text { WHC B PLANT } \\
\text { WHEPFP } \\
\text { WHEFUEL TAANS }\end{array}$ & $\begin{array}{l}\text { WHC FUPEX } \\
\text { WHC } \text { PLANI } \\
\text { WHC PFP } \\
\text { WHC FUL TAANS }\end{array}$ & $\begin{array}{l}W H C 202 A \\
W H C 223 B \\
W H C-2345 \\
W H=303 K\end{array}$ \\
\hline & $\begin{array}{l}309 \text { PRTR Vaut Wastefion } \\
\text { Exchange Mod) }\end{array}$ & 1 & WHC PRTR & WHC FFTF & 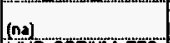 & (ne). \\
\hline & 335 Sodium Test Froility & $\begin{array}{l}\text { BWHC_SOOIU } \\
\text { ST }\end{array}$ & WHC_SODUM_TES & Whe & WHC_SODIUM_TES & WHC_335 \\
\hline & 324 Sulding (FNM) & BWIC.324 & (FromPNNL) & (nj) & ina] & (na) \\
\hline & 327 Buldong (PNN) & $B W H C=327$ & [From PNAL] & (n) & (n) & (na) \\
\hline & FF fF Transtion Project & BWHC FFTF & $W H C F F$ & WHEFFTF & WHCFFTF MAIN & WHCFFT'MANY \\
\hline & Facility & IBWHC WESF & WHC WESF & (na) & [na] & fnal \\
\hline \multirow[t]{3}{*}{ Liquid Effluent } & $\begin{array}{l}300 \text { Ared Treated Effuent } \\
\text { Cisposal Focility (Project }\end{array}$ & RFSH 300 TEDF & WHC 300 TEDF & WHC 300 TEDF & YHC 300 TEDF & $\forall H C \quad L 045$ \\
\hline & 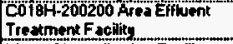 & RFSH 200 ETF & WHC 200 ETF & WHC_200_ETF & WHE_200_ETF & WHE PX CO18H \\
\hline & $\begin{array}{l}\text { Waste Neutralization F acility } \\
\text { [3401307 Buildings] }\end{array}$ & $\begin{array}{l}\text { (P) of } \\
\text { PFSH 300 TEDEI }\end{array}$ & $\begin{array}{l}\text { Port of } \\
\text { WHC } 300 \text { TEOF }\end{array}$ & ASTE NEUT: & WASTE NEUT & $\mathrm{W} / \mathrm{HC}$ \\
\hline \multirow[t]{10}{*}{$\begin{array}{l}\text { Non- } \\
\text { Programmaxi }\end{array}$} & $\begin{array}{l}300 \text { Area F acilities Non- } \\
\text { Transition }\end{array}$ & $N P$ SO0 TR & NP $300 \mathrm{TA}$ & NP $300 \mathrm{TR}$ & (na) & (na) \\
\hline & Hóp Area Facilites Non: & $\mathrm{NP} 400 \mathrm{TH}$ & NP $\$ 00 \mathrm{HA}$ & NPPOOOH & {$[n a]$} & $(n a)$ \\
\hline & BPint Non-fiension & NPBPLANTIA & NPEPLANY TA & NP B PLANT IR & (ns) & (n) \\
\hline & PFPNon-I tansition & NPPFP TR & $N \beta P \beta T R$ & NPPFPTR & $(n)$ & (n) \\
\hline & PUREXNon-Tynstion & NPPUPEX Th & NP'PUEX TR & NPFUPEX TR & (na) & $(n)$ \\
\hline & REE ${ }^{2} \times$ Non-Transition & NPABDDX If & APPEDOX TR & NPAEDOX TA & [nd & (nd) \\
\hline & Sile Support Non-Transition & NPSIFESIP IR & NPSSESUP TA & NPSITE_SUP TR & (n) & (na) \\
\hline & $\begin{array}{l}\text { Stored Equipment (was Buried } \\
\text { Equipment) }\end{array}$ & WHC EQUIP & WHE BQUP & WHC BPLP & WHC. & WHC BQUP \\
\hline & TPInk Mon-Trensition & NP"TPLANA YA & NPTPANIIIR & NP'TPLANI HA & [nd & (ind \\
\hline & UPlent Non Trensition & TNP U PLANT TR & NP UPLANT IA & NP U PLANT TR & Inal & lnal \\
\hline \multirow[t]{16}{*}{ Difsite } & Ames Laborotory - Ameg, lowa & ANYES & AMES & AVES & AMES & ARES \\
\hline & Argonne Notiona Loboratory. & $A N L E$ & ANi E & ANit $E$ & ANiLE & ANL E \\
\hline & Bates Acceierator. & MITEATES & MAT EATES & MITBATES & MIT BATES & MTEATES \\
\hline & Battelle Columbus & BATCLBSLAB & TEATCLSSLAB & BATCLBSLAB & BA ICLBS LAB & BAT CLBS LAB \\
\hline & Eottis Atomic Power: & $B A P L$ & $B A P L$ & BAPL & $\mathrm{BAPL}$ & $B A P$ \\
\hline & Betetis Atomic Power : & BAPL SHPYOS & BAPL SHPYOCS & BAPL SHPYOS & BAPL SHIPYOCS & BAPL SHPYOS \\
\hline & Brookhw ven Nationsi & BRKHVN & BAMHVN & BAKHYN & EPKHVN & BRKHVN \\
\hline & Ferm National Acoelerator & FEPMI & FEFM & $F E B M$ & FEAMT & 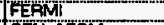 \\
\hline & Gonera Atomios & CN ATOM & CON ATOM & GENIOM & CEN ATM & GENAIOM \\
\hline & Knolis Atomic Power: & KAPL & $\mathrm{KAPL}$ & KAPL & KAPL & $(n a)$ \\
\hline & Knols Atomic Power. & KAPL SHPYDS & KAPL SHPYOS & KAPL SHPYOS & KAPLSHIPYDS & KAPL SHFYOS \\
\hline & Lewence Berkele L Lborstory & $\mathrm{LBE}$ & $L B L$ & $\mathrm{LBL}$ & LEL & $16 \bar{B}$ \\
\hline & Paduosh Energs Systems & PADLCAHES & PADUCAHES & PADUCAHES & PADICAHES & PADUCAHES \\
\hline & Peorlitabor Novalshipyards & $\begin{array}{l}\text { PEAP HARBOA } \\
\text { POAT SOTHAS }\end{array}$ & $\begin{array}{l}\text { PEAAL HAPBOA } \\
\text { POATS }\end{array}$ & $\begin{array}{l}\text { PEAPL HAPBOA } \\
\text { POATSMDATHES }\end{array}$ & (na) & PQR \\
\hline & Portsmouth Enigy Systems & FOATSMOUTHLS & POFTSADUTH & POH SMOUIH NS & $(n))^{2}$ & (nd) \\
\hline & 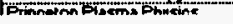 & & & 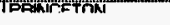 & & tophiritrol \\
\hline
\end{tabular}




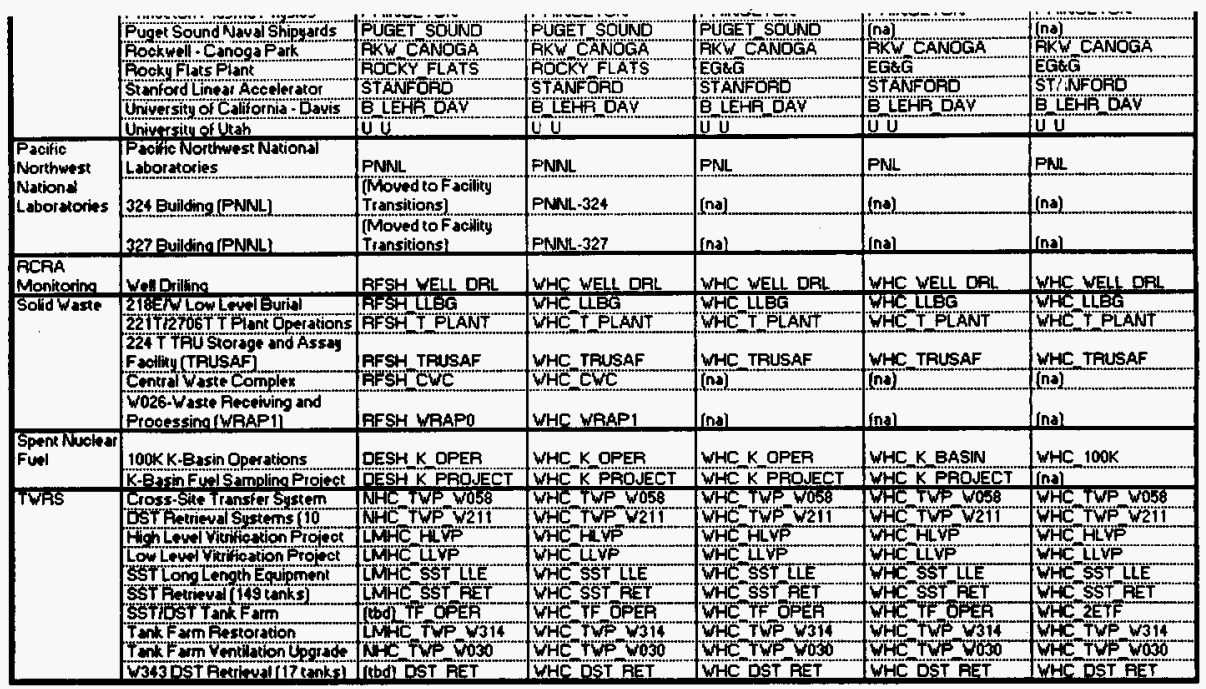

Legeret

BWHC Babcook \& Whoon Haniord

PFSH Rust Federal Servioes of

DESH Duke Engineering * Services

NHC Numatec Hanford Company

LMHC Lockheed Martin Hanford

(tbd) to be determined

WHC Vestinghouse Hanford

BHH Bectel Hanford

NP Non Programmatic

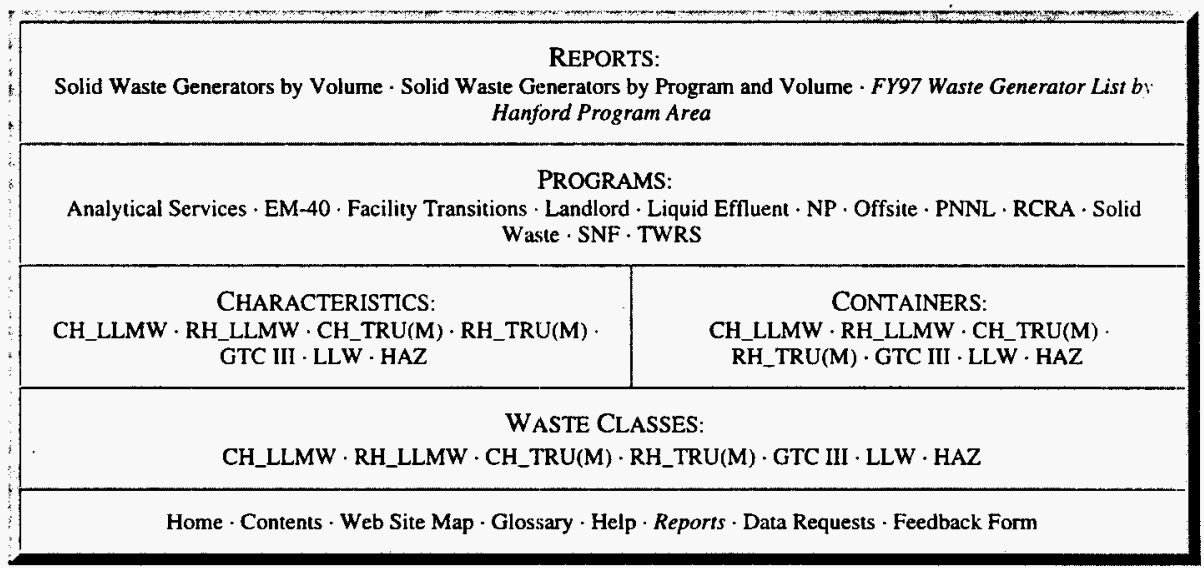

NOTICE: This page is provided subject to our disclaimer. Contact: Oscar Valero at (509) 373-4752.

HNF-EP-0918 rev. 1 Approved for public release; distribution is unlimited. 


$$
\begin{aligned}
& \text { HNF-EP-0918, REV. } 1 \text { Page } 1 \text { of } 1 \\
& \text { DISTRIBUTION }
\end{aligned}
$$

U.S. Department of Energy, Richland Operations office (9 Copies)

R. F. Guercia (6)

Public Reading Room

Document Processing Center

Centeral Files
S7-55

Al-65

A3-94

A3-88

Pacific Northwest National Laboratories (2 Copies)

T. J. DeForest

K7-97

Technical Files

$\mathrm{K} 1-11$

RUST FederaT Services of Hanford Inc. (2 Copies)

K. L. H1adek

0 . J. Valero

H6-06

H6-06 


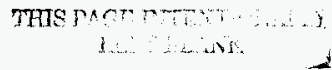

